

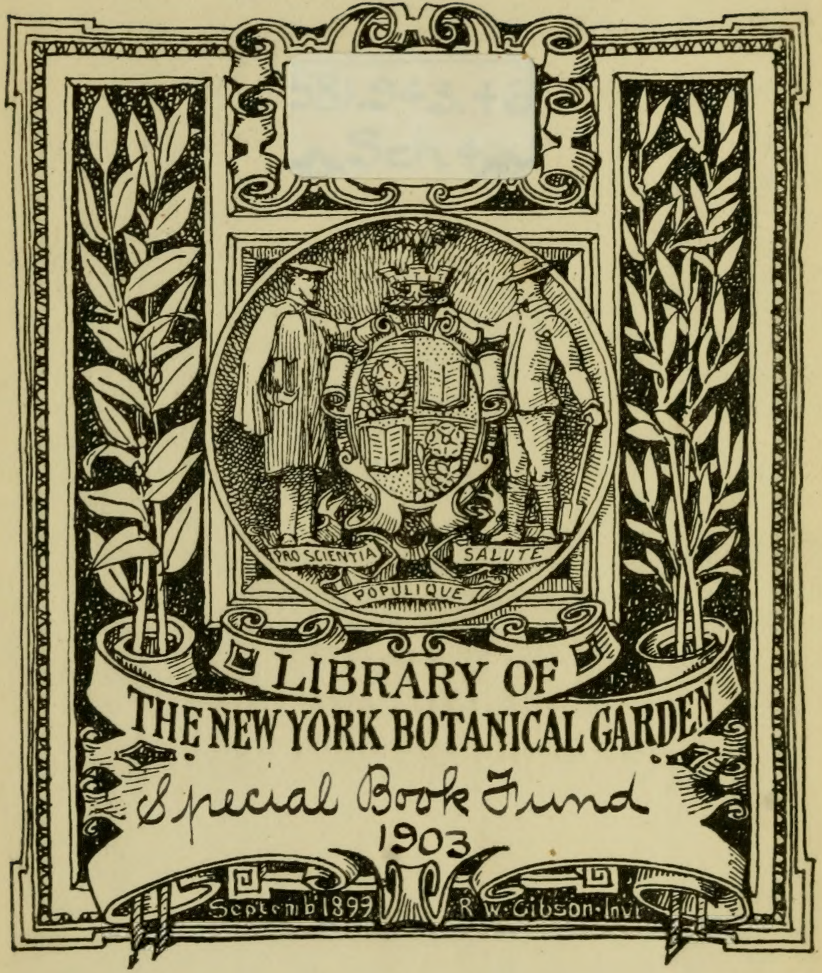








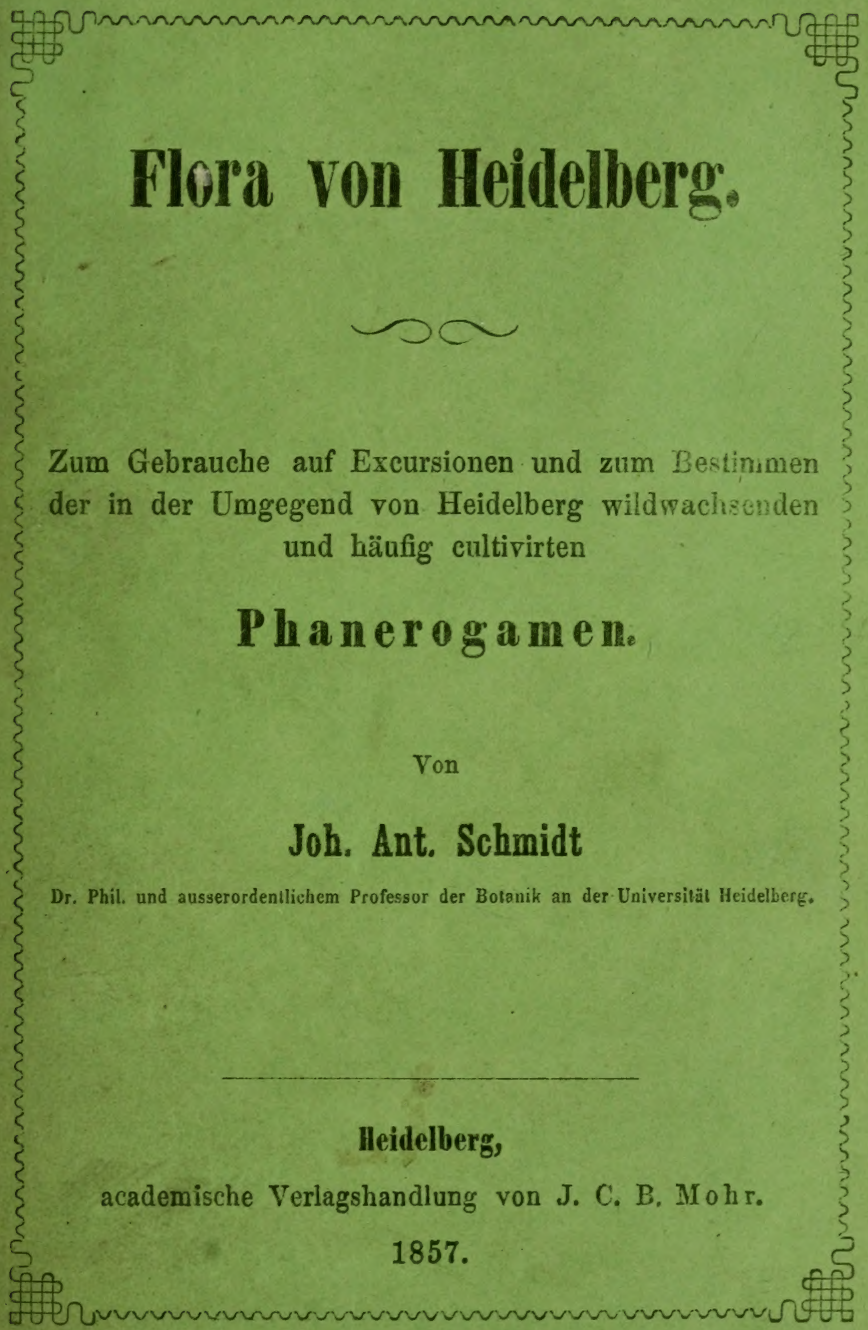





\section{Flora von Heidelberg.}

Zum Gebrauche auf Excursionen und zum Bestimmen der in der Umgegend von Heidelberg wildwachsenden und häufig cultivirten

\section{Phanerogamen.}

Von

\section{Joh. Ant. Schmidt}

LIBRARY

NEW YORK BOTANICAL GARDEN

Dr. Phil. und ausserordentlichem Professor der Boianik an der Universität Heidelberg.

\section{Heidelberg,}

academische Verlagshandlung von J. C. B. Mohr. 


$$
.5243
$$

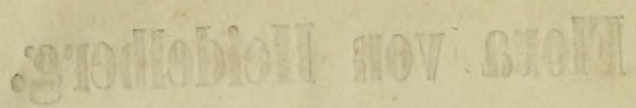

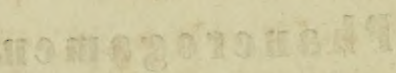




\section{LIVR:ARY \\ NEW YORK \\ Vorrede. \\ BOTANICAL \\ OARDEN}

Wenngleich die Gegend um ITeidelberg scit Jahren vielfach von Botanikern durchforscht worden, auch die Erfahrungen der letzteren, wenigstens theilweise, wiederholt veröffentlicht sind, so blieb doch bisher der oft ausgesprochene Wunsch nach einer neueren Specialflora dieser Gegend unerfïllt. - Nachdem die im Jahre 1819 von Dierbach verfasste, früher häufig benutzte "Flora Heidelbergensis " gegenwärtig, nach einer so langen Zeit aus leicht zu begreifenden Gründen nicht mehr ganz ausreichend und entsprechend gefunden werden kann, mag die Erneuerung eines solchen Buches nicht unzweckmässig erscheinen, um so weniger, als bekanntlich die Umgegend von Heidelberg alljährlich vielfach, und öfters auch naturhistorischer Zwecke wegen, durchwandert wird.

Daher habe ich, ermuntert durch dic Bereitwilligkeit der bekannten Verlagshandlung, zunächst für Alle, welche die Absicht haben die Flora von Heidelberg kennen zu lernen, den vorliegenden Leitfaden entworfen, in der Hoflnung, dass durch denselben auch hier das Interesse für die vaterländischen Pflanzen immer mehr geweckt werde. 
Dả ich dås Material fiir eine geordnete CryptogamenFlora noch nicht hinlänglich kenne, so sind in dieser Schrift nur die Phanerogamen abgehandelt worden. Aber freilich fehlt es auch in der Reihe der letzteren nicht an Gattungen und Arten, iiber welche ein bestimmtes Urtheil wohl erst nach Jahrelang fortgesetzten Beobachtungen und Studien wird gegeben werden können!

Die möglichst ausfïhrlichen Angaben über das Vorkommen der Pflanzen habe ich theils selbst, während meines hiesigen 6jährigen Aufenthaltes in Erfahrung gebracht, theils verdanke ich sie den mïndlichen Belehrungen (auch schriftlichen Ueberlieferungen) des vor einigen Jahren hier verstorbenen Prof. G. W. B is choff, theils den freundlichen Mittheilungen des Hrn. Dr. K. Schimper in Schwetzingen, welcher bekanntlich seit langen Jahren die hiesige Gegend allseitig durchforscht hat, theils den Erfahrungen einzelner Freunde der Botanik, besonders dem regen Eifer einiger Studirenden. Ausserdem verdanke ich für den vorliegenden Zweck mancherlei Belehrung nachstehend genannten Werken, besonders der erst kürzlich erschienenen "Flora des Grossherzogth. Baden," von J. Ch. Döll, einem Werke, welches für das weitere und specielle Studium der vaterländischen Pflanzen so manche erwünschte und neue Aufschlüsse gewährt.

Die Flora der hiesigen Gegend hat in folgenden älteren und neueren Schriften, welche ich öfters verglichen und nicht selten citirt habe, mehr oder weniger Berücksichtigung gefunden:

G.M. Gattenhof, „Stirpes agri et horti Heidelbergensis. "Heidlbg. 1782.") 
J. H. Dierbach, „Flora Ifeidelbergensis." Heidelberg 1819 u. 20. F. G. L. Succow, "Flora Mannhemiensis." Mannheim 1821 u. 22. J. Ch. Döll, „Rheinische Flora." Frankfurt a/M. 1843.

K. König, „Der botanische Führer durch die Rheinpfalz." Mannheim 1843.

F. Schultz, „Flora der Pfalz." Speyer 1846.

G. F. Schnittspahn, "Flora des Grossherzogth. Hessen." (3. Aufl.) Darmstadt 1854.

J. Ch. Döll, „Flora des Grossherzogth. Baden." Bd.I. Carlsruhe 1857. Endlich : Jahresberichte des naturwissenschaftlichen Vereins „Pollichia."

Die Einrichtung des Buches betreffend, habe ich nur Weniges zu bemerken. In Uebereinstimmung mit dem in ganz Deutschland bekannten Taschenbuch von Koch ist das natürliche System von De Candolle mit wenigen Abänderungen zu Grunde gelegt. Die deutsche Sprache musste schon desshalb gewählt werden, weil Mancher gar lebhaftes Interesse für die Pflanzenwelt besitzt, ohne schon die lateinischen Kunstausdriicke hinlänglich zu kennen.

Ausser den Arten des eigentlichen Floragebietes, welche fortlaufende Nummern erhalten haben, sind die häufig vorkommenden Culturpflanzen und eine Anzahl Arten aus den benachbarten Gegenden aufgenommen, dabei aber vorziiglich solche Excursionen berücksichtigt, welche von hier jenseits des Rheines unternommen werden, um die Kenntnisse der Vegetations-Verhältnisse diesseits des Rheines nicht unwesentlich zu erweitern. Freilich

*) Trühere Schriften über die Heidelberger Ilora kenne ich aus eigener Anschauung nicht. Nach Gattenhof praef. p. 3, finden sich die ältesten speciellen Nachrichten über hier wildwachsende Pflanzen in: P. S. Sprenger "Horti medici Heidelbergensis Catalogus arborum, fruticum ac plantarum, tam indigenarum, quam exoticarum. Francof, ad Moen 1597. 
mussten, als schon zu fernliegend, die interessânten Gegenden des Donnersberges und Rheinhessens fast ganz unberiicksichtigt bleiben, und verweise ich in dieser Beziehung auf dic lehrreichen Werke von F. Schultz und F. G. Schnittspahn.

Bei solchen Pflanzen, welche im Gebiet der Flora seltener auftreten, habe ich das Vorkommen derselben in den benachbarten Gebieten, besonders die zunächst anzutreffenden Standorte, möglichst anzugeben gesucht. Nur bei Fundorten, welche ich selbst aus eigener Erfahrung nicht kenne, sind die Namen Derjenigen beigefügt, welche in den erwähnten Werken oder mïndlich Mitthcilungen dariiber gemacht haben. Die eigene Wabrnehmung der betreffenden Fundorte ist mit ! bezeichnet.

Ein sog. Schlüssel zum Bestimmen der Gattungen ist vorausgeschickt, und wird hie und da die nur kurz gegebenen Gattungs-Charaktere noch etwas vervollständigen. Ein Verzeichniss der zahlreichen nüthig gewordenen Abkürzungen, nebst Erklïrungen, findet sich nachstehend. Uebrigens habe ich, da es mein Wunsch ist, dass dieser Leitfaden besonders auf Excursionen gebraucht werde, soweit als irgend möglich, in allen Dingen nach Kürze zu streben gesucht, und hoffe, dass nicht allein dic getroffene Auswahl, sondern auch die Anordnung des Ganzen als zweckmässig sich bewähren und recht Vielen die gewiinschte Belehrung verschaffen möge.

Ileidelberg, im Februar 1857.

\section{Der Verfasser.}




\section{Einleitnng.}

Die Gegend, deren Flora hier abgehandelt ist, erstreckt sich von der Stadt Heidelberg aus ungleichmässig nach verschiedenen Richtungen, und wird begrenzt im Westen durch den Rhein, im Norden durch die Grenzlinie des Grossherzogthums Baden, im Osten durch die Ortschaften Birkenau, Ober-Flockenbach, Wilhelmsfeld, Schönau, Wiesenbach, Schatthausen und endlich im Süden durch die Ortschaften Ravenberg, Malsch, Kirrlach, Waghäusel, Wiesenthal. - Diese localen Grenzen haben gewissermassen ihre botanischen Eigenthümlichkeiten. Der Rhein erscheint uns als Verbreitungsgrenze einer Anzahl weiter unten noch näher zu bezeichnenden Arten. Mit der nürdlichen Grenzlinie fallen die botanisch bemerkenswerthen Standorte: Sandtorfer Moor und Käferthaler Wald fast völlig zusammen, und mit dem hessischen Ort Lampertheim beginnt das häufige Vorkommen der in Baden schon bei Mannheim aufhörenden Sclerochloa dura. Die Grenzen an der Bergstrasse: Nesterbach und Sulzbach sind bezcichnet durch den einzigen Standort der Globularia vulgaris, sowie die bei Hemsbach durch den einzigen Standort des Cypripedium Calceolus. Mit dem Vorkommen der Cineraria spathulaefolia, Vicia pisiformis, Nardus stricta und anderen Pflanzen des Odenwaldes erscheint unsere Flora gegen den leizteren gleichsam begrenzt, wie auch das häufige Auftreten der Ilex Aquifolium bei Schönau eine gewisse östliche Grenze des Gebietes zeigt. Schatthausen ist bemerkenswerth durch den 
einzigen Standort der Aceras anthropophora. Bei Wiesenbach und Angelloch bildet das durch geognost. Verhältnisse hervorgerufene plötzlich so sporadische Auftreten der in der Nähe von Heidelberg verbreiteten Digitalis purpurea eine natürliche Grenze, und bei Rauenberg kann dasselbe von dem Auftreten der (uns sonst fehlenden) Achillea nobilis behauptet werden. Endlich erscheint das Gebiet in der Ebene gegen Süden abgeschlossen mit dem pflanzengeographisch interessanten Torfmoor von Waghäusel und mit einer Verbreitungsgrenze der Jurinea Pollichii. - Das so eingeschlossene Floragebiet ist theils vollständig Ebene und bildet die in unmittelbarer Nähe von Heidelberg beginnende, weithin sich erstreckende Rheinfläche, theils ist es Hügelland (gegen Südost), theils ist es durchaus gebirgig (gegen Osten).

Die geognostischen Verhältnisse dieser Gegend haben ihre specielle und ausführliche Erörterung in den Werken von Bronn ${ }^{1}$ ) und Leonhard ${ }^{2}$ ) gefunden, aut welche ich hier verweisen muss. Das Vorherrschen des bunten Sandsteines und des Granites ist, besonders im Neckarthal, wenig geeignet einen Wechsel in der Vegetation hervorzurufen, welche noch einförmiger erscheinen würde, wenn nicht schon in unserer Nähe (Haarlass, längs der Bergstrasse und an zahlreichen Orten zerstreut) Ablagerungen von Löss beobachtet würden, welche bald mehr, bald weniger eine Anzahl kalkholder Pflanzen zeigen und zur Abwechselung der einförmigen Sandsteinvegetation beitragen; z. B. Hippocrepis comosa, Chrysanthemum corymbosum, Crepis praemorsa, Inula salicina, Prunella grandiflora, Orchis militaris, Carex montana, C. ornithopoda, Phleum phalarioides, Brachypodium pinnatum etc.). Weniger

1) H. G. Bronn. Gaea Heidelbergensis. Heidelbg. u. Leipzig 1830.

2) G. Leonhard. Geognostische Skizze des Grossherzogthums Baden. Stuttgart 1846.

G. L $\theta 0 \mathrm{nh}$ ard. Beiträge zur mineralogischen und geognostischen Kenntniss des Grossherzogthums Baden. Heft 1 u. 2. Stuttgart 1853. 
der Gneiss, als der verwitterte Syenit und Porphyr scheinen hie und da an der Bergstrasse einige botanisch wichtige Standorte zu bedingen, z. B. Sulzbach und Nesterbach (Syenit), Oelberg bei Schriesheim, Weinheim, Dossenheim (Porphyr). An den wenigen Standorten, wo der Muschelkalk zu Tage tritt, nämlich zunïchst bei Wiesloch, Alt-Wiesloch, Baierthal, Maischbach, auch sporadisch unterhalb Leimen erhält die Vegetation, wenn auch keinen üppigen, doch den eigenthümlichen Charakter der Kalkflora. Einen sehr auffallenden Wechsel durch geognostische Verhültnisse hervorgerufen zeigt die Keuperformation, wie solche die Hügelkette in der Wieslocher Gegend, besonders von Dielheim bis Rauenberg und Malsch darbietet. Hier ist die Vegetation eine von Pflanzen des Sand - und Kalkbodens gemengte, und zwar bald vorherrschend aus Kalkpflanzen, bald mehr aus Sandpflanzen bestehend, je nachdem die geognostisch schwankenden Verbältnisse des Keupers die Verschiedenheit bedingen. Durch die Verwitterung der bald aus Sandsteinen; bald aus thonigem und kalkigem Mergel bestehenden Schichten wird ein aus vielen Bestandtheilen gemengter Boden gebildet, und erscheint die Flora daselbst als eine eigenthümlich zusammengewürfelte. Als kalkholde Pflanzen der Keuperformation sind zu nennen: Anemone sylvestris, Linum tenuifolium, Peucedanum Cervaria, Anthemis tinctoria, Teucrium Botrys, Ajuga Chamaepitys, Herminium Monorchis, Ophrys muscifera, Aristolochia Clematitis, Tragopogon major, Passerina annua; als sandholde: Lepigonum rubrum, Euphorbia Gerardiana, Jasione montana, Åira flexuosa, Hypericum humifusum, Polycnemum arvense, Sarothamnus vulgaris.

Einförmig und wenig mannigfaltig an Phanerogamen sind die Höhen unserer Berge, welche, wenn sie auch hie und da nicht ganz unbeträchtlich sind *), doch ausser der

*) Die beträchtlichsten Höhen des Florengebietes (nach Angabe der Karte des Grossh. bad. Generalstabs sind die folgenden: 
geognostischen Einfürmigkeit, auch stellenweise, besonders àn den wärmer gelegenen Standorten grossen Mangel an Feuchtigkeit zeigen. Zum Theil aus diesen Gründen entbehrt unsere Gebirgsflora manche interessante Verhältnisse der benachbarten Gegenden, denn wir vermissen eine Anzahl Pflanzen des hessischen Odenwaldes und des Taunus (Trollius europaeus, Lunaria rediviva, Circaea alpina, intermedia, Trifolium spadiceum).*)

Die besonders in der Nähe von $H_{\text {. }}$, diesseits und jenseits des Neckars stets wiederkehrenden und oft schaarenweise auftretenden krautartigen Pflanzen der bewaldeten Gebirgshöhen sind die folgenden: Digitalis purpurea, Calamintha officinalis, Prenanthes purpurea, Centaurea nigra, Senecio sylvaticus, Hypericum pulchrum, Epilobium angustifolium, Spiraea Aruncus, Sarothamnus vulgaris, Luzula maxima, Molinia caerulea $\beta$ sylvatica etc.

Mannigfaltiger gestaltet sich die Flora der Ebene. Wie die ganze Rheinfliiche besteht die Ebene des Gebietes aus dem sog. Schuttland, dessen verschiedenartige Zusammensetzung nicht allein dem Vorkommen vieler Pflanzen günstig ist, sondern welche auch durch das theils wasserreiche, theils wasserarme, theils kultivirte, theils unkultivirte Land eine grössere Abwechselung der Vegetation darbietet.

Von botanischen Standorten sind folgende besonders hervorzuheben:

Königstuhl 1879 Fuss, Heiligenberg 1458 Fuss, Oelberg 1323 Fuss, Wagenberg 1297 Fuss, Geisberg 1232 Fuss (über dem Meere).

*) Auch fehlt unseren Bergen (beiläufig bemerkt) manche Pflanze, durch welche die Flora des Donnersberges so ausgezeichnet ist, deren. Fehlen bei uns freilich zunächst aus den ganz verschiedenen Verbreitungsverhältnissen abgeleitet werden müsste : Aconitum Ljcoctonum, Arabis brassicaeformis, A. Turrita, Geranium lucidum, Cotoneaster vulgaris, Laserpitium latifolium, Cynoglossum montanum etc. 
Wasser, Sümpfe und Flussufer. Sowohl der Neckar, als besonders der Rhein liefern uns wesentliche Standorte für solche Pflanzen, welche ciner anhaltenden Feuchtigkcit des Bodens nothwendig bedürfen. Wir haben daher in der Ebene sowohl stellenweise ausgebreitete Wasserfliichen, welche für eigentliche Wasserpflanzen sich eignen, als auch eine grüssere Anzahl von Sumpfgegenden, welche vielfach Gelegenheit darbieten, die Feuchtigkeit des Bodens schwankend zu sehen und die Amphibien-Natur mancher Pflanzen zu prüfen. Die Wasserflora weist 54 eigentliche Wasserkrïuter d. h. theils untergetauchte Pflanzen, theils solche mit schwimmenden Blättern nach. Von diesen gehört gerarle die Hälfte, nämlich $27 \mathrm{zu}$ den Monocotyledonen, und zwar meist zu solchen Familien, bei welchen die Ausbildung der Blüthendecken sehr zurïcktritt, inilem nur 4 mit ansehnlichen Blumen sich finden. Während von diesen Nonocotyledonen manche nur sporadisch auftreten, erreichen die dicotyledonischen Wasserpflanzen eine grössere Verbreitung, bedecken häufiger die Gewïsser, und tragen mit ihren oft ansehnlichen Bluthendecken dazu hei, den allerdings meist recht einförmigen landschaftlichen Charaliter der Rheinsumpfgegenden zu belelsen. Ausser dieser Wasserflora sind die bald mehr, bald weniger ausgetrockneten Sümpfe dem Gedeihen einer grossen Anzahl Pflanzen günstig, wie die in dieser Schrift so oft genannten Flussufer, die Sümpfe des Friedrichsfelder Waldes, die Standorte beim Rohrhof, bei Neckarau, Sandtorf, Wagliüusel, Roth, auch selbst in der Nähe von Heidelberg, die ausgebreiteten Sümpfe von Kirchheim und St. Ilgen, von Handschuchsheim beweisen. Die bemerkenswerthesten Erscheinungen dieser Sumpfflora gehören ebenfalls zu den MIonocotyledonen (besonders Cyperaceen), doch herrschen in den Niederungen zuweilen auch einzelne dicotyledone Familien, wie z. B. die Umbelliferen.

Torfmoore von grösserem Umfange zeigen sich im Florengebiet nur bei Waghäusel und Sandtorf. Ausserdem. 
lrommen zerstreut torfhaltige Wiesen vor, welche im Gebirge, z. B. oberhalb Dossenheim, Wilhelmsfeld, bei Schönau, Weinheim, einige bemerkenswerthe Pflanzen, sonst aber den Charakter der Sumpfwiesenflora besitzen. Die geographische Lage dieser ebengenannten Moore bedingt einen von norddeutschen und Hochgebirgs Torfmooren durchgehends verschiedenen Vegetations-Charakter, welcher sich zunächst besonders im fast völligen Mangel der Ericeen, überhaupt in dem nur geringen Vorkommen halbstrauchartiger Bildungen ausspricht. In beiden Torfmooren nehmen die Cyperaceae eine sehr vorragende Stelle ein (bei Waghäusel 35, bei Sandtorf 30 Arten), doch dürfen einige wesentliche Torf-Cyperaceen, z. B. Eriophorum vaginatum, Scirpus caespitosus, Rhynchospora alba nicht erwartet werden. Es fehlt diesen Mooren nicht an Sphagnum reiche Flächen, welche zwar Vaccinium Oxycoccus niemals, aber Drosera longifolia und rotundifolia, Utricularia minor, selbst Sturmia Loeselii (letztere besonders bei Sandtorf) ziemlich vorherrschend enthalten. Nicht uninteressant ist die Verschiedenheit, welche die Flora der beiden Torfmoore in Einzelnheiten darbictet. Bei Waghäusel finden sich, und zwar für unsere Flora nur dort allein: Pinguicula vulgaris, Orchis palustris, Potamogeton plantaginea, Scirpus pauciflorus, Schoenus nigricans, Cladium Mariscus, Carex pulicaris, C. paradoxa, während bei Sandtorf nur allein: Comarum palustre, Sparganium minimum, Potamogeton rufescens, Carex filiformis beobachtet sind. Letzteres Moor, welches durch das Eingreifen der Cultur in neuerer Zeit für den Botaniker an Werth verloren hat, besitzt daher weniger Eigenthümlichkeiten, aber es ist reich an Sumpfpflanzen, die Vegetation ist üppiger und manche nicht gemeine Pflanzen ( . B. Cicuta virosa, Carex PseudoCyperus) erreichen einen hohen Grad von Geselligkeit.

Wiesen. Die Flora derselben erscheint sehr abhängig von der Feuchtigkeit des Bodens. In der Nähe der Ufer und Sümpfe herrschen Carices und Junceae zum Nachtheil 
der gesammten Vegetation vor, dagegen licfern die ausgedehnteren trockenen Wiesen der Rheinfläche eine grosse Fülle von botanisch bemerkenswerthen Pflanzen. Die meisten der aufgeführten Wiesengräser (s. Gramineae p. 353) finden sich auch in der niichsten Umgegend Heidelberg's, hier aber freilich oft in Begleitang des sehr vorherrschenden Colchicum auctumnale, welches immer eine beträchtliche Feuchtigkcit des Bodens, und damit übereinstimmend eine gewisse Einfürmigkeit der Flora anzeigt. Grüssere Beachtung verdienen in der Nähe von Heidelberg die Bergwiesen, z. B. Engelswiese, bei Handschuchsheim, Bergstrasse, welche ebensowohl, wie jene in der Gegend von Gaiberg und Nussloch ihre Eigenthümlichkeiten besitzen. Von den Wiesen sind die sog. Triften als Standort unterschieden worden. Diese bilden eine mehr unterbrochene, bald trockene, bald feuchte Grasdecke, zeichnen sich zwar nie durch Ueppigkeit, aber stellenweise durch Mannigfaltigkeit der Vegetation aus.

Hügel und Abhänge, auch sog. Raine, theils bewaldet, theils mit wenigem Gebüsch bewachsen, theils ohne alle Holzbildungen, pflegen an wärmeren, geschützteren Lagen, besonders an der Süidseite der Berge pflanzenreich zu sein, wie die oft aufgeführten Bezeichnungen: Haarlass, Geisberg, Handschuchshcim, Dossenheim, Philosophenweg etc. schon für die nähere Umgegend Heidelberg's beweisen. Hier werden die sonst günstigen Verhältnisse, wenigstens theilweise durch grösseren Wechsel der geognostischen Verhältnisse erhüht.

Thäler und Schluchten sind für die Flora bemer kenswerth, weil sie eine grössere Feuchtigkeit als die Höhen der Gebirge darbieten. Die Thäler in der Nähe von $H$. jenseits des Neckars, weniger diesseits (Dreitröge Thal) besonders aber Birkenauer-, Gorxheimer-Thal bei Weinheim, Ludwigsthal bei Schriesheim, Mühlenthal bei Handschuchsheim, Leimen (bei der sog. Baiermühle) u. s. wi dienen als Bestätigung.

- Wälder und Waldgebüsche der Hügel- und 
Gelirgsgegend bestehen grösstentheils aus Laubholz, stellenweise wechselnd mit kleinen Beständen ron Nadelholz, z. B. Vogelheerd bei Schatthausen, bei Birkenau, Rauenberg u. s. w. Niederwald ist uberall so vorherrschend, dass selbst einzelne wirklich alte und hohe Stämme von Forstbüumen schon zu den Seltenheiten gehören. Diese Wülder bestehen grösstentheils aus Quercus, Fagus, Carpinus,") im Ganzen aus 25 Bäumen, 35 Sträuchern und 6 Halbstrüuchern. Es wird aber ausserdem nicht selten die holzartige Vegetation durch nicht einheimische angepflanzte Arten vervollständigt, von welchen jedlenfalls Castanca vulgaris und Juglans regia eine hervorragendere Bedeutung einnelımen. Da die lirautartige Waldvegetation auf fast allen Höhen unserer Berge eine meist gleichförmige ist, so liefern für die Flora der Gebirgswälder die bewaldeten und feuchteren Bergabhänge, die bewaldeten Hügel, z. B. bei H. jenseits des Neckars, Gaiberger Wald, Leimen, Nussloch, Wiesloch, Teufelskopf bei Dielheim, Weinheim, Schriesheim u. s, w. bei Weitem günstigere Verhältnisse. - Laubwälder der Ebene sind ron geringerer Ausdelnnung, meist von Sümpfen begleitet, daher etwas feucht, durch stellenweises Vorherrschen der Alnus Arten und einiger Salices, auch durch manche Schattenliebende Sumpfkräuter bezeichnet. Bemerkenswerth in botanischer Hinsicht sind: der obere Wald bei Wiesloch, die Wälder bei Kirrlach, Waghäusel, Wiesenthal, der Friedrichsfelder, Neckaraucr, Seckenheimer Wald. (Letztgenannte Wald-Standorte sind aber theilweise neuerdings verschwunden, indem der Boden in Ackerland verwandelt worden.) - Beträchtlichere Ausdehnung nehmen die aus Pinus sylvestris bestehenden Nadelwälder der Ebene ein, welche zuweilen mit niederem Laubholz gemischt sind. Diese

") Die lichtbedürftige Hainbuche (Carpinus) herrscht bei H. besonders jenseits des Neckars; die schattenliebendo Buche (Fagus) wird häufiger diesseits des Neckars gefunden. 
oft genannten Waldstrecken: Käferthaler Wald, Friedrichsfeld, Sandhausen, Walldorf, verdienen besondere Beachtung. Die Flora ist zwar stellenweise sehr einfürmig, aber reich an Eigenthümlichkeiten, und erhält durch die Vegetation der Sandlä̈chen und der Sümpfe, von welchen diese Nadelwaldungen stets umgeben zu sein pflegen, docn auch einige Abwechselung. Dex Boden ist aber vorherrschend ein trockener, daher Pflanzen, wie die bei Darmstadt und bei Graben vorkommende Goodyera repens im Gebiet der Flora gar nicht, andere, wie Pyrola uniflora, P. secunda, Aceras anthropophora sehr selten auftreten.

Sandflächen. Die eigenthümliche Flora derselben pflegt, wenn die äussercn Bedingungen überhaupt eine Vegetation gestatten, durch Geselligkeit der zahlreichen Arten sehr ausgezeichnct zu sein. Die Zahl der auf Sandflïchen vorzugsweise verbreiteten Arten beträgt etwa 200. Das Vorherrschen einzelner Familien, z. B. Compositae, Chenopodeae, Euphorbiaceac, Liliaceae ist unverkennbar. Uebrigens ist die Flora dieser Flächen lieineswegs immer als sandstet zu bezeiclnen, denn es sind dem Sandboden nicht selten Kalktheilchen beigemengt, welche wenigstens das Vorkommen mancher kalkholder Pflanzen gestatten. So finden sich z. B. Silene conica, Lithospermum officinale, Euphrasia lutea, Helianthemum Fumana, Alyssum montanum in Gesellschaft von Helichrysum arenarium, Kochia arenaria, Euphorbia Cyparissias, Artemisia campestris, Silene Otites. Stellenweise erscheinen aber diese ausgedehnten Flächen sehr vegetationsarm. Die charakteristischen Gräser des unfruchtbaren Flugsandes: Elymus arenarius, Psamma arenaria sind zwar sehr seltene Erscheinungen, doch giebt es Strecken, welche ausser Corynephorus canescens und Koelcria cristata $\beta$ glauca, kaum eine andere Spur der Vegetation oder höchstens noch: Thymus Serpyllum, Helichrysum arenarium, Jurinea Pollichii, Eryngium campestre darbieten. - Obwohl die Flora dieser Sandflächen, welche die Ebene des Geb. von Norden 
nach Süden gleichsam durchschneiden, in ihren Hauptbestandtheilen viel Uebereinstimmendes zeigt, so giebt es doch hie und da manche Eigenthunlichkeiten, welche gewisse Standorte zu den botanisch bevorzugten machen, wie $z$. B. die Gegend unfern des sog. Relaishauses (zwischen Mannheim und Schwetzingen), die des Rohrhofes, die Flächen zwischen Friedrichsfeld, Schwetzingen u. Oftersheim, auch Sandhausen, Käferthal u. s. w.

Das cultivirte Land: A ecker, Wein berge etc. Es ist nicht der Zweck dieser Schrift die Bedeutung, welche die zahlreichen Culturpflanzen für hiesige Gegend haben, weiter hervorzuheben, als gelegentlich bei der Aufzählung der Arten. Es ergiebt sich für das Gebiet der Flora eine Anzahl von 29 krautartigen Pflanzen, welche in grösserer Ausdehnung gebaut werden, nämlich: Papaveraceae 1, Cruciferae 4, Papilionaceae 9, Solaneae 3, Chenopodeae 1, Urticeae 2, Gramineae 9. Von diesen sind zugleich wildwachsend: Camelina sativa, Onobrychis sativa, Vicia sativa, Medicago sativa, Trifolium pratense, Humulus Lupulus. Die Flora zählt ausserdem acht Arten auf, welche nur sehr selten als Cultur- oder Handelspflanzen angetroffen werden, nämlich : Linum usitatissimum, Sinapis alba, Rubia tinctorum, Scorzonera hispanica, Nicotiana rustica, Polygonum Fagopyrum, tataricum, Avena orientalis; 1 zuweilen im Grossen ausgesïetes Gras: Lolium multiflorum; 24 Kräuter, welche meist in Gärten cultivirt werden und hic und da verwildern, aber nicht als einheimisch oder eingebürgert betrachtet werden können; 19 Bïume und Sträucher, welche an Wegen, an den Anpflanzungen häufig angetroffen werden (wobei jedoch die in den Schlossanlagen und an sonstigen Spaziergängen bei Heidelberg angepflanzten ausländischen Straucharten keine Berücksichtigung gefunden haben.) - Wenn durch den Anbau mancher Culturpflanzen von Jahr zu Jahr mehr der ursprüngliche Character der Vegetation zu schwinden droht, so kann doch versichert werden, dass es nicht so leicht 
gelingt, einheimische Pflanzen gänzlich zu verdrängen und es mag zuletzt auch darin ein Interesse gefunden werden, die allmählig immer enger werdende Verbreitungsgrenze einer Pflanze zu verfolgen! Wie überall, pflegen auch hier die Culturpflanzen ihre Begleiter zu haben, besonders sind die Getreide-Aecker auf kalkhaltigem Boden botanisch mannigfaltig. Bekanntlich hält die Sorgfalt des Landmannes in manchen Fällen diese Begleiter fern, und es sind daher die in hiesiger Gegend schr reichlichen Tabaks-Pflanzungen eben so arm an "Unkrïuter," wic die Kartoffel-, Rüben- und Mais-Aecker. Aus diesem Grunde ist die Flora des cultivirten Landes, wenigstens stellenweise, sehr einförmig. Auch die Weinberge bieten dem Botaniker hier elsen keine Mannigfaltigleit. Manche (im Rheingau) charakteristische Begleiter derselben scheinen (selbst auf kalkhaltigem Boden) völlig zu fehlen, z. B. Calendula arvensis. Dagegen ist freilich eine der interessantesten Pflanzen der Flora: Symphytum luulbosum Schimp. gerade aus den Weinbergen durch Cultur allmählig ganz oder fast ganz verdrängt worden. - Auch hier siud in neuerer Zeit manche 1jährige südeuropäische (auch amerikanische) Pflanzen mit ausländischen Sämereien verbreitet. Einige derselben haben sich eingebürgert, z. B.: Galinsogea parriflora, Geranium pyrenaicum, Centaurea solstitialis u. s. w., andere sind dagegen nur in einzelnen oder vorübergehenden Erscheinungen beobachtet: Glaucium corniculatum, Silene gallica, Sisymbrium pannonicum, Helminthia echioides, Crepis nicaeensis etc.

Das Gebict der Flora enthält 1114 Arten wildwachsende Phanerogamen, welche in 448 Gattungen und 107 Familien vertheilt sind. Von diesen gehören 846 zu den Dicotyledonen (197 Thalamifl., 383 Calycill., 169 Corollifl., 97 Monochlamyd.) und 268 zu den Monocotyledonen. Dic nachstehend nach der Artenzahl geordneten Familien zeigen übersichtlich, welche von densell,en am stärksten in der Flora vertreten sind.

SCHMIDT, Flora vo H. 
Compositae 118.

Gramineae 94.

Cyperaceae 65.

Papilionaceae 60.

Scrophularineae 52 .

Cruciferae 51.

Labiatae 45.

Umbelliferae 44 .

Ranunculaceae 34 .

Rosaceae 32.

Orchideade 32.

Alsineae 24.

Polygoneae 21.

Liliaceae 21.

Borragineae 20.

Sileneae 19.

Chenopodeae 17.

Salicineae 17.

Juncaceae 16.

Stellatae 15.

Geraniaceae 12.

Campanulaceae 12 ,

Euphorbiaceae 12.

Onagrarieae 11.

Potameae 11.

Ericeae 10.

Gentianeae 10.

Caprifoliaceae 9.

Primulaceae 9.

Violarieae 8.

Dipsaceae 8.

Orobancheae 8 .

Hypericineae 7.

Pomaceae 7.

Amygdaleae 6.
Crāssulaceáe 6 .

Valerianeae 6.

Solaneae 6.

Asparageae 6.

Fumariaceae 5 .

Sanguisorbeae 5 .

Urticeae 5.

Cupuliferae $\mathbf{5}$.

Typhaceae 5 .

Papaveraceae 4.

Polygaleae 4.

Saxifrageae 4 .

Convolvulaceae 4 .

Plantagineae 4 .

Betulineae 4.

Coniferae 4.

Lemnaceae 4.

Elatineae 3 .

Lineae 3.

Malvaceae 3.

Acerineae 3.

Oxalideae 3.

Callitrichineae 3 .

Lythrarieae 3.

Paronychieae 3 ,

Grossularieae 3 .

Lentibularieae $\mathbf{3}$.

Amarantaceae 3.

Nymphaeaceae 2.

Cistineae 2.

Resedaceae 2.

Droseraceae 2.

Tiliaceae 2.

Rhamneae 2.

Halorageae 2. 
Ceratophylleae 2.

Portulaceae 2.

Sclerantheae 2.

Oleaceae 2.

Thymeleae 2.

Santalaceae 2.

Aristolochieae 2.

Ulmaceae 2.

Alismaceae 2.

Najadeae 2.

Aroideae 2.

Irideae 2.

Colchicaceae 2.

Berberideae 1.

Parnassineae 1.

Ampelideae 1.

Balsamineae 1.

Celastrineae 1.
Hippurideae 1.

Tamariscineae 1 .

Cucurbitaceae 1 .

Araliaceae 1.

Corneae 1.

Ambrosiaceae 1.

Monotropeae 1.

Aquifoliaceae 1.

Asclepiadeae 1.

Apocyneae 1.

Verbenaceae 1.

Globularieae 1.

Plumbagineae 1.

Loranthaceae 1.

Hỳdrocharideae 1 .

Butomeae 1.

Juncagineae 1.

Amaryllideae 1.

Von diesen Pflanzen erscheinen als Büume 30, Sträılcher 51 , Halbstrïucher 15 ; als 4 und $\hat{\wp}$ Kräuter 694 , von welchen 438 von $1 \frac{1}{2}-3^{\prime}$ Höhe (einige bis 4 , selbst bis $\left.6^{\prime}\right)$ und 256 theils niederliegend bis $1^{\prime}$.

Als $\odot$ Kräuter: 270 , meist niederliegend oder $1-1 \frac{1}{2}^{\prime}$ hoch, selten $2-4^{\prime}$.

Endlich 54 Wasserkräuter (27 Dicot., 27 Mon.)

Die geographische Lage des Gebietes bringt es mit sich, dass der bei Wuitem grösste Theil diescr Pflanzen eine im mittleren und südlichen Deutschland ziemlich weite Verbreitung findet. Manche sind im ganzen Rheingebiet ein= heimisch, einige aber besitzen eine engere Verbreitung und haben für hiesige Gegend ihr pflanzengeographisches Interesse. Um einige specielle Eigenthümlichkeiten der Flora übersichtlich und mit wenigen Worten näher zu bezeichnen, mögen 
die folgenden Bemerkungen genügen (da Weiteres weder Raum noch Zweck dieser Schrift gestatten).

Es erreichen innerhalb des Geb. eine gewisse Verbreitungsgrenze gegen Süden, sofern die Verbreitung im Grossherzogth. Baden entweder schon im Floragebiet völlig aufhört, oder doch erst südlich von Offenburg wieder beginnt:") Fumaria parviflora, Jurinea Pollichii, Orobanche procera, Chaiturus Marrubiastrum, Globularia vulgaris, Armeria vulgaris, Kochia arenaria, Potamogeton plantaginea, Najas major; N. minor, Schoenus nigricans, Cladium Mariscus, Carex pulicaris, dioica, humilis, supina, Stipa pennata, capillata, Eragrostis poaeoides, Sclerochloa dura.

An der badischen Bergstrasse fehlen die im Grossherzogth, bis gegen Heidelberg verbreiteten Arten: Dentaria bulbifera, Lithosperm. purpurco-coerulcum, Helleborus foetidus, Achillea nobilis, Veronica acinifolia.

Es treten bei uns als Seltenheiten die folgenden Arten auf, welche jenseits des Rheines eine ausgedehntere Verbreitung zeigen: Lepidium Draba, Sinapis Cheiranthus, Tetragonolobus siliquosus, Trifolium rubens, Orlaya grandiflora, Helosciadium repens, Peucedanum alsaticum, Comarum palustre, Rosa pimpinellifolia, Viburnum Lantana. Dipsacus laciniatus, Podospermum laciniatum, Hypochoeris maculata, Chrysocoma Linosyris, Centaurea maculosa, Arctostaphylos officinalis, Samolus Valerandi, Chlora perfoliata, serotina, Globularia vulgaris, Atriplex oblongifolia, Carex hunilis, Carex paradoxa, Bromus patulus, Stipa pennata, St. capillata.

Ausserdem sind zahlreiche Pflanzen, wie in der speciellen Darstellung öfters hervorgehoben, jenseits des Rheines häufiger auftretend als diesseits.

Ueberhaupt zeigt die Flora jenseits des Rheines, in der Nähe unseres Gebietes grosse und auffallende Verschieden-

") Vgl. d. einzelnen Angaben über d. Verbreitung im spez. Theil. 
heiten, wie einerseits die beispielsweise aus der Gegend von Dürkheim aufgeführten 48 Arten, welche bei uns durchaus nicht vorkommen, andererseits aber auch etwa 35 andere Pflanzen zeigen, welche, wenigstens in der Nähe des Gebietes jenseits des Rheines vermisst werden. Einige der letzteren sind bei uns häufig, z. B. Calamintha officinalis, Euphorbia dulcis, Kochia arenaria, Carex maxima, C. strigosa, die meisten aber gehören auch bei uns zu den Seltenheiten, z. B. Sisymbrium strictissimum, Myagrum perfoliatum, Pyrola uniflora, Geranium palustre, Sedum villosum, Lindernia pyxidaria, Elatineae, Veronica acinifolia, Pinguicula vulgaris, Leersia oryzoides etc.

Folgende Sumpf- und Torfmoorpflanzen fehlen jenseits des Rheins, sind aber in den Torfsümpfen in Hessen, bei Carlsruhe und Frankfurt a. Mr. nachgewiesen: Elatineae, Lindernia pyxidaria, Pinguicula vulgaris, Scirpus pauciflorus.

Folgende Arten haben bei uns ihre Verbreitung aus dem Odenwalde erhalten und erscheinen grösstentheils als seltene Gebirgepflanzen: Polygala depressa, Geranium palustre, Vicia pisiformis, Sedum villosum, Galium saxatile, Dipsacus pilosus, Cineraria spathulaefolia, Crepis paludosa, Arnica montana, Pyrola uniflora, Lathraea Squamaria, Digitalis grandiflora, Veronica montana, Leucojum vernum, Cypripedium Calceolus, Rhynchospora alba, R. fusca, Festuca sylvatica, Nardus stricta.

Aus dem Mainthal hat sich Sisymbrium strictissimum, und aus dem nordöstlichen Deutschland (vielleicht mit Getreidesame) Chaiturus Marrubiastrum verbreitet.

Aus dem würtembergischen Neckargebiet sind: Myagrum perfoliatum, Lathyrus Nissolia zu uns gelangt.

Als in neuerer Zeit eingewandert müssen die folgenden eingebürgerten Arten betrachtet werden, indem es grösstentheils erwiesen ist, dass sie durch den Einfluss der Menschen sich verbreitet haben, oder wie die mit * bezeichneten mit dem Rhein aus dem Oberlande herbeigeschwemmt sind: Ca- 
melina dentata, Melilotus parviflora, Medicago denticulata, Lathyrus hirsutus, Myricaria germanica *, Polycarpum tetraphyllum, Chrysanthemum segetum, Galinsogea parviflora, Centaurea solstitialis, Crepis setosa, Crepis taraxacifolia, Corispermum Marshallii, Salix daphnoides *, S. nigricans ${ }^{*}$ ), Leersia oryzoides, Lolium linicola, Elymus arenarius.

Endlich sind noch die folgenden Arten besonders hervorzuheben, von welchen entweder nur ein einziges Vorkommen oder wenige Standorte bekannt sind, deren Verbreitung nicht genau verfolgt werden kạnn und wovon die mit * bezeichneten in der Nähe unseres Gebietes fehlen. Die letzteren verdienen als Eigenthümlichkeiten unserer Flora ganz besondere Beachtung: Ranunculus aconitifolius*, Ran. lanuginosus, Trifolium scabrum*, Potentilla alba, Symphytum bulbosum $^{*}$. Potamogeton plantaginea ${ }^{*}$, Sparganium minimum, Lilium Martagon, Orchis sambucina, Aceras anthropophora*, Cladium Mariscus *, Carex filiformis, Car. dioica *, Psamma arenaria, Eragrostis poacoides, Calamagrostis lanceolata. 


\section{Anordnung der Gattungen (und Familien) nach dem Linné'schen Systeme.}

(Die eingeklammerten Gattungen und Arten nehmen ausnahmswoise die betreffende Stelle des Systemes ein.)

\section{Class. 1. Monandria.}

1 freies Staubgefäss in einer Zwitterblüthe.

Ord. 1. Monogynia. 1 Griff.

II ippuris. Fruchtknoten unterständig, von einem unscheinbaren Kelche gekrönt; Blïthen achsel- und quirlständig. (Wasserpflanze). p. 106.")

(Alchemilla arvensis Scop.) p. 98 .

\section{Ord. 2. Digynia. 2. Griff.}

Callitricho. Blüthen achselst.; Blthendecken fehlen; Frucht in 4 Nüsschen zerfallend. Wasserpfl. p. 107.

Coris p erm u m. Blth. achselst.; Nuss zusammengedrückt (schwankt auch diandrisch). (Sandpfl.) p. 259.

$\left.\begin{array}{l}\text { (Festuca Pseudo-Nyuros) } \\ \text { (Festuca sciuroides) }\end{array}\right\}$ Graminoao p. 376.

Class. 2. Di andria.

2 freio Staubgefässe in einer Zwitterblüthe. Ord. 1. Monogynia. 1. Griff.

a) Blüthendecken sehr unscheinbar, verkümmert.

Lemna. Wasserpfl. p. 301.

C la di u m. (C y p er a c e a $\theta$.) (Blattscheiden vollständig geschlossen, Antheren an beiden Enden stumpf.) p. 335.

(Fraxinus) †. p. 197.

b) Blthd. unterständig, Blkr. verwachsenbl., regelmässig.

Oleaceae. Blkr. 4zählig. (Fraxinus zuweilen olne Blkrone, häufig polygamisch). †. p. 197.

*) p. mit der boigefügten Zahl zeigt dio Seitenzahl an, wo dio betreffendo Familio od. Gattung nobst vorkommenden Arten zu finden ist. 
c) Blthd. unterständig, Blkr, verwachsenbl., unregelmässig oder ungleich; Kapsel. (Fruchtknoten vieleiig).

Pinguicula. K. 5spalt.; Blkr. rachenförmig, gespornt. Kapsel 1fächerig. p. 249.

Utricularia. K. 2blätt., Blkr. rachenf,, gespornt, Kaps, 1fïcherig. p. 249.

Veron ica. Blkr. 4zählig, radfürmig, wonig ungleich, Kaps. 2fächcrig, verkehrt-herzförmig. p. 214.

Gratiola. Blkr. röhrig, unregelm., Staubgef. 4, aber 2 unfruchtbar; Kapsel 2fächerig, eiförmig. p. 214.

d) Blthd. unterständig, Blkr. verwachsenbl, unregelmässig;

Nüsschen 4. (Fruchtknoten 4eiig).

Salvia. Antheren-Mittelband fadenartig und wagerecht verlaufend,

1 Antherenfach unfruchtbar. Blkr. lippenf. (Labiatac). p. 232.

L y c op us. Antheren 2fächerig mit fruchtbaren Fächern und schwach entwickeltem Mittelbande. Blkr. röhrig, wenig lippenf. (Labiatae). p. 232 .

e) Blthd, oberständig, Blkr. getrenntbl.

Circaea. K. und Blkr, 2zählig. p. 102.

Ord. 2. Digynia. 2 Griff.

Anthoxanthum (Gramineae). p. 355 .

Class. 3. Triandria.

3 freie Staubgef. in einer Zwitterblüthe.

Ord. 1. Monogynia, 1 Griff.

a) Fruchtknoten oberständig, Blthd. unvollständig.

Cyperacoa e (ausser Carex u. Cladium). Blattscheiden vollständig geschlossen, Antheren an beiden Enden stumpf, aufrecht. p. 335. Nardus. (Gramineae). Blattscheiden gespalten, Antheren an beiden Enden gleichsam ausgeschnitten, aufliegend. p. 358.

b) Fruchtknoten oberständig. Pcrigon Ggliederig, grasähnlich. (Junous conglomeratus)

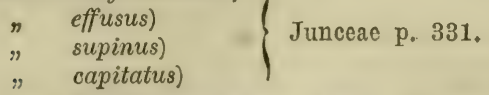

c) Fruchtknoten unterständig. Perigon gefärbt.

Irideae. p. 317 .

d) Fruchtknoten unterständig. K. u. Blkr. vorhanden, K. oft undeutlich, Blkr. verwachsenbl.

Valorianoae. p. 144. (ausgenommen die dioecische Valeriana dioica L.). 


\section{Ord. 2. Digynia, 2 Griff.}

Pol y cnemum. Blth. achselst.; Perig. trockenhäutig, 5zählig; Fruchtkn. oberständig; Kapsel ringsum aufspringend, 1samig. (Amarantaceae). p. 259.

Gram in eae (ausser Zea, Anthosanthum, Nardus, Festuca PseudoMyuros und sciuroides). Blattscheiden gespalten; Antheren an den Enden gleichsam ausgeschnitten, aufliegend. p. 353.

\section{Ord. 3. Trigynia. 3- Griff.}

Montia. K. 2blättr.; Kapsel 3klappig, 3samig (Portulaceae). p. 111. Polycarpon. K. 5́blättr.; Kapsel 3klappig, vielsamig. (Paronychieae). p. 112.

If olosteum. K. 5blättr.; Kapsel an der Spitze mit 6 Zähnen aufspringend, vielsamig (schwankt auch mit $4-5$ Stbgef.). (Alsineae), p. 45 .

\section{Ord. 4. Tetragynia. 4 Griff.}

(Elatine triandria Sclikr.) p. 52.

\section{Class. 4. Tetrandria.}

4 freio Stbgef. von gleicher Länge in einer Z $\mathrm{Z}$ witterblüthe.

Ord. 1. Monogynia. 1 Griff.

a) Blüthendecke einfach: Kelch od. Perigon; eigentl. Blumenkrono fehlend.

Majanthemum. Perig. blumenartig, 4theilig, meiss, unterständig. p. 320 .

Parietaria. Perig. kelchartig, grünlich, 4theilig, unterständig; Stbgef. in der Knospe eingebogen (schwankt aber polsgamisch). p. 278. Isnardia. Kelch oberst., 4theilig, grün. Wasserpn,! p. 105.

S a u g u i s orba. Kr. unterst., 4kantig, 4theilig, rothgefärbt, mit 1-3 Deckblättchen, p. 98.

Alchemilla. K. unterst. glockig, 4theilig, grün, mit $4 \mathrm{kl}$. Deckblättchen (ausser Alch. arvensis, welche monandr. ist). p. 98.")

b) Kelch und getrenntbl. Blumenkrone.

Cornus. K. und Blkr. 4zählig, Steinfrucht. ち. p. 137.

Trapa. K. u. Blkr. 4zählig. Falsche Nuss. Wasserpfl. p. 102.

H урес оum. K. 2bl.; Blbl. 4 unregelmässig! Gliederschote. p. 12.

*) Hier sucht der Anfänger auch gewöhnlich Galium und Asperula (Stellatae), weil er den unscheinbaren Kelch für fehlend hält. : 
(Rhammus cathartica L. Stbgef. den Blumenblättern gegenüberstehend. Beere. ち. (Ist aher häufig dioecisch.) p. 67. (Evonymus) häufiger pentandr.

c) Kelch einfach, Blumenkrone verwachsenblättr., oberständig. Stellatae. Blkr, fast immer 4zählig; Blätter quirlständig. p. 140.

d) Kelch einfach, Blumenkrone verwachsenbl, unterständig.

Centunculus. Blth, sehr klein, achselständig; Blkr. regelmässig, 4spaltig, glockig-lkugelig; Stbgef. sehr kurz; Kapsel ringsum aufspringend, p. 251.

Plantago. Blkr. röhrig, regelmässig, trockenhäutig, 4spaltig, mit zurückgeschlagenen Zipfeln; Stbgef. sehr lang; Kapsel ringsum aufspringend. p. 255.

Globularia. Blkr. trichterförmig, unregelmässig (blau), 5spaltig; Nuss, p. 254.

c) K. doppelt, der innere mit den Fruchtknoten verwachsen, Blkr. verwachsenblättr., oberständig.

Dipsaceae. Tïpfchenartige Blthstd.; Antheren frei, p. 146.

$$
\text { Ord. 2. Tetragynià. } 4 \text { Griff. }
$$

P ot a mogeton. Perig. 4zählig, grünlich od.häutig; Blthstd, ährenf. Wasserpfl.! p. 298.

Ilex. K. 4zähnig; Blkr. radfürmig, 4 gliedr.; Beere 4samig (schwankt aber 5zählig. Strauch mit lederartigen Blättern. p. 196.

R adiola. K. 4spaltig; Blbl. 4; Kapsel 8fächerig. - Sehr klein. p. 52.

S a gin a (ausser S. nodosa). K. 4bl.; Blbl. 4; Kaps. 1fächerig. Kleine meist niederliegende Kräuter. (Zahlenverhältniss sehr schwankend). p. 45 .

\section{Class. 5. Pentandria.}

5 freie Stbgef, in einer Zwitterblüthe. Ord. 1. Monogynia. 1 Griff.

a) Blkr. 0 .

Gla ux. Kelch unterständig, gefärbt. p. 251.

Thesium. Kelch oberständig, aussen grün. p. 271.

b) Blkr. getrenntbl,, oberständig.

Ribes. K. glockig, 5spaltig; Blbl, und Stbgef. vom Kelche entspringend. (Zahl der Stbgef. schwankend). (Griff. eigentlich 2, aber meist mit einander verwachsen). p. 116.

Hedera. Ksaum sehr kurz, 5zähnig; Blbl. und Stbgef, vom Kelche entspringend. p. 136. 
c) Blkr. getrenntblätterig, unterständig.

Viola. K. bleibend, grün; Blkr. unregelmässig; Fruchthnoten 1fächr.; Kíaps. 3klappig aufspringend. p. 32.

Impations. K. abfällig, blumenartig gefärbt; Blkr. unregelmässig; Fruchtk. 5fächerig; Kapsel elastisch aufspringend. p. 64.

Vitis. Blbl. regelmässig, am Grunde sich lösend, an der Spitze zusammenhängend (grün). Beere. ţ. p. 60.

Evon jmus. Blkr. regelmässig, ausgebreitet, (grün); Stbgef. 5, mit den Blbl. abrrechselnd; Kapsel. - $\$$ mit gegenst Bl. p. 67.

(Rhamnus Frangula L. Blkr. regelmässig, ausgebreitet (grün);

Stbgef. den Blbl. gegenüberstehend; Beere. - t mit abwechselnden $\mathrm{Bl}$.) p. 68.

d) Blkr. verwachsenbl., oberständig.

Campanulaceae. Blkr. regelmässig; Stbgef. frei, mit ihrem Grunde den Fruchtknoten deckend; Kapsel. Kräuter. p. 188.

L o nicera. Blkr. unregelmässig; Stbgef, der Blkrrühre angervachsen. Beere. Sträucher. p. 137.

(S a molus. Stbgef. den Blbl, gegenüberstehend; Blkr, glockig, regelmässig, 5 unfruchtbare Stbgef.; Fruchtk. halb oberst.) p. 251.

e) Blkr. verwachsenbl, unterständig; Stbgef, mit d. Blbl. wech-

selnd; Frucht kapsel- od. beerenartig; Fruchtk, einfach, nicht 4lappig.

Vinca. Blkr. tellerförmig, mit 5eckigem Schlund, in der Knospe gedreht; Narbe scheibenförmig. p. 199.

Convolvulus. Blkr. trichterförmig-glockig, 5faltig; Blth, einzeln oder paarweise; Fruchtkn. 2fächerig, armsamig. p. 203.

Cuscuta. Blkr. röhrig oder glockig; Blth. lnäuelartig; Bl. fehlen; schmarotzt mittelst Saugwarzen. p. 203.

Verbascum. Blkr. radförmig, etwas ungleich; einige oder alle Stbfäden mit Wolle besetzt, ungleich; Antheren 1fächerig; Fruchtknoten 2fächerig, vielsamig. p. 214.

Solaneae. Blkr. verschieden; Stbgef. ohne Wolle, gleich; Antheren 2 fächerig; Fruchtkn. 2-4fächerig, vielsamig. p. 211.

Menjanthes. Blkr. trichterförmig, innen bärtig; Bl. 3zählig, abwechselnd; Fruchtkn. 1fächerig. Sumpf- u. Wasserpfl. p. 200.

Limnanthemum. Blkr. radförmig, gewimpert; Bl. kreisrund, schwimmend, abwechselnd; Fruchtkn. 1fächerig. Wasserpfl. p. 200.

Erythraea. Blkr, röhrig; Antheren nach dem Verblühen schraubenförmig gedreht; Blth. in Trugdolden; Bl, gegenständig; Fruchtknoten Ifächerig. p. 200.

f) Blkr. verwachsenbl, unterständig; Stbgef. den Blbl. gegenüberstehend; Kapsel 1 fächerig, mit centralem Samenträger.

Primulacea $\theta$ (ausser den schon orwähnten: Centunculus, Glaux, Samolus). p. 250. 
g) Blkr. verwachsenbl., unterständig; Stbgef. mit den Blbl. wechselnd; Fruchtln. Alappig; Frucht 4 Nüsschen.

Borragineae. p. 204.

$$
\begin{aligned}
& \text { Ord. 2. Digynia. } 2 \text { Griff. } \\
& \text { Blthdecke einfach, grünlich. }
\end{aligned}
$$

Ulmus. Flügelfrucht. 万. Bl. mit Nebenbl. p. 280.

Chenopodeae. Perig. die nussartige Frucht umhüllend; Blth. knäuelartig; Kräuter ohne Nebenbl. (Jedoch ausser Corispermum und Atriplex.) Zahlenverhältniss der Stbgef. schwankt. p. 259.

Herniaria. Perig. 5theilig; 5 Stbgef. nebst 5 borstenf. Nebenstaubgef, Kleine niederliegende Kräuter mit trockenhäutigen Nebenbl. p. 112.

b) Blkr. verwachsenbl., unterständig.

Gentiana. K. 4-5spaltig; Blkr. röhrig-glockig, 4-5spaltig, welkend, bleibend, ohne Nebenkr.; Kapsel 1fächerig. p. 199.

Cynanchum. K. 5theilig; Blkr. fast radförmig, mit 5lappiger Nebenkrone; Frucht 2 zusammenhängende Balgkapseln, p. 198.

(Cusouta.) s. Pent. Mon.

c) Blkr. getrenntbl., oberständig; Kelchsaum oft sehr unscheinbar.

Umbolliferae. Blth, in Dolden oder Köpfchen. Diachenium!

p. 119.

(Ribes) s. Pent. Mon.

Ord. 3. Trigy nia. 3 Griff.

$\mathrm{S}$ a $\mathrm{mbucus.} \mathrm{Blkr}$. verwachsenbl., radfürmig, oberständig; Beere 3samig. p. 137.

Viburnum. Blkr. verwachsenbl., radfürmig, oberständig; Beere 1samig. p. 137.

(Stellaria media schwankt decandrisch. Niederliegende krautartige Alsineae mit 2spalt. weissen Blbl.) p. 46.

\section{Ord. 4. Tetragynia. 4 Griff.}

Parnassia. Drüsige grüne Nebenkr.; Blkr. weiss, ansehnlich. p. 37. Spergula. Nebenkr. fehlt; Blkr. klein, weiss. Einige Arten sind decandr. p. 45.

\section{Ord. 5. Pentagynia. 5 Griff.}

Linum. Blkr. sehr zart, hinfällig; Fruchtkn. 10fächerig, 10eiig. p. 52 .

Drosera. Fruchtk. 1fächerig, mehreiig; drüsige Oberfläche d. Bl. - Sumpfpfl. p. 35.

Armeria. Fruchtk. 1eiig; Kelch mit trockenhäutigem Anhängsel; Bltstand kopfö̈rmig; grasähnl. Bl. - Sandpfl. p. 254. 
(Sagina nodosa Bartlg. (auch decandrisch) - Alsineae. p. 45 und 49.

(Cerastium semidecandrum L.) - Alsineae. p. 50. (s. Decandria.)

Ord. 6. Polygynia. Zahlreiche Griff.

M y o surus. Blth. klein; Fruchtboden sehr verlängert. (Ranunculaceae.) p. 3.

Class. 6. Hexandria.

6 freie, gleich lange Stbgef. in einer $\mathrm{Zw},-\mathrm{B} 1 \mathrm{th}$.

Ord. 1. Monogynia. 1. Griff.

a) Porig. 6gliederig, grasähnlich.

Juncus. Kapsel 3fächerig, 3klappig, vielsamig. Kahle Kräuter. (Mit Ausnahmen s. Triandr.) p. 329.

Luzula. Kapsel 3fächerig, 3klappig, 3samig. Behaarte Kräuter p. 329 .

b) Perig. 6gliedcrig, grünlich-gelb; unterständig.

Acorus. Zahlreiche Blth, einen Kolben vollständig bedeckend. p. 304 .

c) Perig. blumenartig gefärbt, 6blätterig, unterständig.

Liliaceae. (ausser Muscari) Kapsel 3klappig; Bl. entrickelt. Meist Zwiebelpfl. p. 322.

A sparagus. Beere. Perig. röhrig; Bl. verkümmert, schuppenartig (auch dioec.). p. 319.

d) Perig. blumenartig gefärbt, 6spaltig oder -zähnig, unterständig. M u s c ari. Perig. kugelig oder eirund (blau). Kapsel p. 322. Convallaria. Perig. glockig oder rührig (weiss). Beere. p. 320.

e) Perig. blumenartig gefärbt, 6gliederig, oberständig. Amaryllideae. p. 318.

f) Blthdecken vollständig; (K. und Blkr; letztere bei Peplis zuwcilen fehlend.)

Peplis. K. unterständig, 6theilig; Blbl, 6. Kapsel. (Niederliegendes Kraut.) p. 109.

Berberis. K. unterständig, 6blätterig; Blbl. 6. Beere. ち. p. 11. Ord. 2. Trigynia. 3 Griff.

Rumex. Blth. quirlig-aehrig; Perig. 6blätterig; Fruchtk, 1; Griffel 3 ; Narben federig; Trucht nussartig, vom Kelch bedeckt. ( $R$, acetosa, acetosella $u$. scutatus sind dioec.)

Triglochin. Blth. in endständigen, dichtblth. Achren, grünlich;

Perig. 6blätterig; Fruchtk. 3-6, durch einen centralen Fruchtträger zusammengehalten, vom Grunle aus sich lüsend; Griff. 0; Narbon federig. 
Sclieuchzeria. Trauben armblth.; Perig. 6blätterig; Fruchtk. 3, nur am Grunde zusammengewachsen; Griffel 0; Narben warzig. Toficldia. Blth. in endst. Aehren, gelb; Perig. 6blätterig; Fruchtknoten 3 bis zur Mitte verwachsen; Griffel kurz mit kopfförmigen Narben. p. 328.

Colchicum. Perig. 6spaltig, trichterfürmig, mit sehr langer Rühre;

Griffel lang mit verlängerten Narben, p. 328.

$$
\text { Hexa - Polygynia. 6-viele Griffel. }
$$

Alisma. Blth. quirlig-rispig; Perig. 6gliederig, dio äusseren kelchartig, die inneren blumenkronartig. p. 295.

(Triglochin maritimum.) p. 297.

Class. 7. Heptandria.

7 freic Stbgef, in einer Zwitterblth.

Monogynia. 1 Griff.

Esculus (Hippocastaneae). p. 59. (schwankt auch octandr.)

Class. 8. Octandria.

8 freie Stbgef. in einer Zwitterblth.

Órd. 1. Monogynia. 1 Griff.

a) Blthdecken einfach, unterständig.

Daphne. Perig. 4spaltig, abfällig; Narbe 1. Strauch mit rothen Blth. p. 270.

Pass.erina. Perig. 1spaltig, bleibend, welkend; Narbe 1. $\odot$. p. 270 .

Polygonum. Perig. 3-5theilig, bleibend, die 3kantige oder zusammengedrückte Frucht umgebend; Narben 2-3. Kräuter mit scheidenförmigen Nebenbl. p. 264.

b) Blthdecken doppelt; Blkr. verwachsenbl., oberständig. Vaccinium. Halbsträucher. p. 192.

c) Blthdecken doppelt; Blkr. verwachsenbl., unterständig.

Calluna. K. 4blätterig; Blkr. 4spaltig, glockig. Str. mit kurzen, linealen Bl, p. 193.

Chlora. K. 8theilig; Blkr. 8spaltig, tellerförmig. Blaugrüno $\odot$ Kräuter.p. 202.

d) Blthdecken doppelt; Blkr. getrenntbl., oberständig.

O onothera. K. 4theilig; Blbl.4, (gelb), dem Kelch eingefügt; Samon schopflos. p. 102.

Epilobium. K. 4theilig; Blbl. 4, (roth oder weiss), dem Kelch eingefügt; Samen mit Haarschopf. p. 102. 
e) Blthdecken doppelt; K. und Blkr. grünlich, wenig verschieden, getrenntbl., unterständig.

A c er. K. und Blkr. 5zählig; Fruchtk. 2flügelig, (schwankt poljgam. oder dioec.). Baum oder Str. mit handf.-gelappten Bl. p. 58.

Ord. 2. Digynia. 2 Griff.

Chrysosplenium. Perig. 4spaltig, halb oberständig, gelblichgrün; Kapsel vielsamig, 2schnäbelig. p. 118.

Ord. 3. Trigynia. 3 Griff.

(Polygonum) manche Arten. p. 264.

Ord. 4. Tetra-Penta-gynia. 4-5 Griff.

Elatine. K. 3-4spaltig; Blkr. 3-4blätterig, mit achselst. Blth. Kleine Sumpfpflanzen. p. 31.

Adoxa. K. 2spaltig, Blkr. 4spaltig, an den endständigen Blth.; K. 3spaltig, Blkr. 5spaltig an den seitenständigen Blth. des grünlichen Köpfchens. p. $13 \%$.

Paris. Blth. einzeln, endständig; Perig. sblätterig, die äusseren 4 breiter als d. inneren; Stbf. an d. Spitze pfriemlich-zugespitzt. (Zahlonverhältniss schwankt), p. 320.

Class. 9. Enneandria.

9 freio Stbgef. in ciner Zwitterblth.

Ord. 1. Hexagynia. 6 Griff.

Butomus. Perig. bblätterig, gefärbt; 6 vielsamige Balgkapseln. p. 296.

\section{Class. 10. De candria.}

10 freie Stbgef, in einer Zwitterblth.

Ord. 1. Monogynia. 1 Griff.

a) Blkr. getrenntbl.

Dictamnus. K. 5bl.; Blkr. 5bl., unregelmässig; Truchtk. 5lappig, auf einem kurzen Fruchtträger sitzend. p. 65.

Monotropa. K. 5bl.; Blkr. regolmässig, 5theilig, am Grunde des Fruchtk. 5 Drüsen. (Chlorophylllos.) p. 195.

Pyrola. K. 5spaltig; Blkr. regelmässig, 5zählig; Drüsen fehlend; Antheren durch Poren aufspringend; Kapsel vielsamig. (Bci P. uniflora sind die Blbl, am Grundo verwachsen.) p. 193.

b) Blkr. verwachsenbl.

Arctostaphylos. K. 5spaltig; Blkr. glockig, eiförmig; Antheren durch Poren aufspringend; Beere 5samig. p. 192.

(Geraniaceae.) s. Monadelph, und p. 60. 


\section{Ord. 2. Digynia. 2 Griff.}

a) Fruchtk, am Grunde ohne stützenden Fruchtträger.

Saxifraga. K. jzähnig oder כ̇theilig (mehr oder weniger mit d. Fruchthnoten rerwachsen, oberständig); Blbl. 5, weiss; Kapsel 2schnäbelig. p. 118.

(Chrysosplenium.) K. 4spaltig, halb oberständig, gelblich-grün; Blkr. 0; Kapsel 2schnäbelig. p. 118.

Scloranthus. K. 5spaltig unterständig, orhärtend und mit der Frucht abfallend; Blkr. 0. p. 113.

ש) Fruchtk. am Grunde ron einem mehr oder weniger entwickelten Fruchtträger gestützt; K. verwachsenll., röhrig. (Sileneae.)

Gypsophila. K. Jzähnig, am Grunde nackt; Blbl. aus d. Nagel allmählig verbreitert; Kapsel 4 klappig; Samen nierenförmig-kugelig. p. 39.

Saponaria. K. כzähmig, am Grunde nackt; Blbl. plötzlich in den Nagel zusammengezogen. Im Uebrigen wie vor. p. 39.

Dianthus. K. 5zähnig, am Grunde mit Schuppen gestützt; Blbl. plötzlich in den Nagel zusammengezogen; Kapsel 4klappig; Samen schildförmig. p. 39.

\section{Ord. 3. Trigynia. 3, Griff.}

a) Fruchtknoten am Grunde mit Fruchtträger; K. verwachsenbl,, röhrig. (Sileneae.)

Silone. Fruchtlinoten und Kapsel 3fächerig. (S. Otites u. inflata sind dioec.) p. 40.

$\mathrm{Cucubalus.} \mathrm{Fruchtknoten} \mathrm{und} \mathrm{Bcere} \mathrm{1fächerig.} \mathrm{p.} 40$.

b) Fruchtlnoten ohne Fruchtträger; K. getrenntbl. (Alsineae.)

\section{$\alpha$. Ohne Nebenbl.}

Stellaria. Blbl. 5, tief gespalten; Kapsel 6klappig; S. flügellos. (Zahl der Stbgef. schwankend!) p. 45.

Alsine. Blbl. 5, ungetheilt od. etwas ausgerandet; Kapsel 3klappig; S. flügellos, p. 45 .

Arenaria. Blbl. 5, ungetheilt; Kapsel 6klappig; S. flügellos. p. 45. M o ehringia. Blbl. 5, ungetheilt; Kapsel Glklappig; S. mit flügelartiger Anschwellung. p. 45.

$\beta$. Mit trockenhäutigen Nebenbl.

Lepigonum. Blbl. 5, ungetheilt; Kapsel 3klappig; S. geflügelt oder flügellos. p. 45.

\section{Ord. 4. Pentagynia. 5 Griff.}

a) Fruchtknoten am Grunde mit Fruchtträger; K. verwachsenbl.

(Sileneae.)

Lychnis. Blbl. 5; Kapsel; Narben einwärts mit Papillen besetzt, ausserdem kahl, p. 40 . 
Agrostemma. Blbl. 5; Kapsel; Narben einwärts mit Papillen besetzt und überall mit Haaren besetzt. p. 40 .

乙) Fruchtk. ohne Fruchtträger; Kbl. getrennt, 5.

Corastium. Blbl. 5, ausgerandet oder 2spaltig; Kapsel 1fächerig, an der Spitze 10klappig. (C. semidecandrum ist pentandr.) p. $4 \bar{J}$. II a la chium. Blbl. 5, 2spaltig; Kapsel 1fächerig, an der Spitze in 5 2zähnige. Klappen aufspringend. p. 45.

(Spergulr.) Blbl. 5, ungetheilt; Kapsel 1fächerig, 5klappig; S. rundlich, geflügelt. (Einige Arten sind pentandr.) p. 45.

(Sagina.) Blbl. 5, ungetheilt; Kapsel der vor.; Samen nierenf., flügellos. (Einige Arten sind tetandr.) p. 45.

Oxalis. Blbl. 5; Stbfïden meist am Grunde etwas aneinander gewachsen, (daher fast monadelph.); Kapsel 5fächerig, an den Kanten aufspringend; Bl. 3zählig! p. 65 .

Sedum. Blbl. 5; Fruchtknoten 5, getrennt, nur am Grnnde verbunden. Saftreiche Kräuter! p. 114.

Class. 11. D ocecandria.

12-19 freio Stbgef. in einer Zwitterblth.

Ord. 1. Monogynia. 1 Griff.

A sarum. Perig. glockig, 3spaltig, oberständig. p. 273.

Portulaca. K. 2spaltig, von der bleibenden Basis ringsum abspringend; Blkr. 5blätterig. p. 111.

L ythrum. K. röhrig, 8-12zähnig; Blkr. meist 6blätterig. (Zuweilen hexandr.) p. 109.

Ord. 2. Digynia. 2 Griff.

A grimonia. K. kegelfürmig, bleibend, mit hakenförmigen Borsten; Blbl. 5. p. 88 .

Ord. 3. Trigy nia (Hexagynia). 3-6 Griff,

Reseda. Blbl. unregelmässig; Stbgef. einer drüsigen Scheibe eingefügt; Fruchtknoten an der Spitze offen. p. 35.

Ord. 4. Polygynia (Docecagynia). Zahlreiche Griff.

Sempervivum, Blbl. und Griffel 12 odermehrere; Bl. saftreich. p. 114.

Class. 12. Icosandria.

20 od, zalılreiche freie Stbgef. in einer Zwitterblth., d. Kelche eingefügt. Ord. 1. Monogynia. 1 Griff.

Am y gda 1 ea o. Blthdecke vollständig, unterständig. p. 85 . (Crataegus.) Blthdecko vollständig oberständig. p. 99. 


\section{Ord. 2. Di-vel Pentagynia. 2-5 Griff.}

a) Blthdecke unvollständig, unterständig.

Pot er iu m. Ksaum 4theilig, erhärtend, mit 2-3 Deckblttch.; Blkr. 0; Stbgef, hängend; Narbe pinselartig. (Häufig monoec, oder polsgam.) p. 98.

b) Blthdecke vollständig, unterständig.

Spiraea. K. 5spaltig; Blbl. 5; Balgkapseln vielsamig. (Sp. Aruncus ist dioec.; manche Arten sind polygyn.) p. 87.

c) Blthdecke vollständig, oberständig.

Pomaceae. (Crataegus ist zuweilen monogyn.) p. 99.

Ord. 3. Polygynia. Viele Griff.

Rosaceae. Sect.: Dryadeae. p. 87.

Rosa. Kbl. 5; Blbl. 5; Nüsschen sehr viele, von dem becherförmigen Fruchtboden eingeschlossen. p. 88.

\section{Class. 13. Poly andria.}

20 oder zahlreiche Stbgef. in ciner Zwitterblth., dem Fruchtboden eingefügt.

Ord. 1. Monogynia. 1 Griff.

Actaea. Kbl. 4; Blbl. 4. Beere. p. 4.

Papaver. Kbl. 2; Blbl. 4; Kapsol rundlich, kugelig oder keulig. Milchsaft weiss. p. 12.

Chelid onium. Kbl. 2; Blbl. 4; Kapsel schotenartig-langgestreckt. Milchsaft gelblich- roth. p. 12.

N ymphaeaceae. Blbl, zahlireich. (Wasserpflanzen.) p. 12.

Heli anthemum. Kibl. 5, die 3 inneren in der Knospe umeinander gerollt; Blbl. 5, hinfällig; Kapsel 3klappig. Halbstr.; p. 31.

Tilia. Kbl. 5, klappig; Blbl. 5; grosses häutiges Deckbl. mit dem Blthstande verwachsen.

Ord. 2. Di-vel Polygynia. 2-viele Griff.

R anunculaceao (Actaea und Myosurus ausgeschlossen.) - (Fast alle sind polygyn. Dolphinium und $\Lambda$ quilegia moist diund triggn.) p. 3 u. 4.

\section{Class. 14. Didynamia.}

4 freio Stbgef, von welchen 2 Stbfäden länger sind.

Ord. 1. Gymnospermia.

(Fruclitk, tief 4lappig, bei der Reife 4 Nüsschen darstellend.)

Griffel im Grunde des Fruchtknotens.

Labiatae. (ausser den diandr. Gattungen Salvia und Ijcopus,) p. 232. 


\section{Ord. 2. Ang iospermia.}

(Fruchtknoten einfach, nicht 4lappig; Griffel an der Spitze des Fruchtknotens; Kapsel.)

Verben a. Blkr. trichterf.; Fruchtk. 4 fächerig, 2-4eiig. p. 248. Scrophularia. Blkr, kugelig-2lippig; Fruchtk。2fächerig, vieleiig. p. 214.

Scrophu larineae. Sect.: Antirrhineae. Fruchtk. 1-2fächerig, vieleiig; Antheren an der Basis stumpf, (ausser den diandr. Gattungen: Gratiolā und Veronica.) p. 214.

Scrophularineae. Sect.: Rhinanthaceae. Fruchtk. 2fächerig, vieleiig; Antheren an der Basis begrannt. p. 215.

Orobancheae. Fruchtl. 1fächerig. Chlorophyllos. p. 229.

Class. 15. Tetradynamia.

6 freie Stbgef, von welchen 4 länger und 2 kürzer.

Cruciferae. p. 16, 17, 18.

Class. 16. Monadelphia.

Stbgef, einer Zwitterblth, in einen Bündel verwachsen.

Ord. 1. Pentandria. 5 Stbgef.

(Linum. p. 52.) s. Pentandr.

Ord. 2. Octandria. 8 Stbgef.

(Polygala. Blth, unregelmässig. p. 37.)

Ord. 3. Decandria. 10 Stbgef.

(Oxalis. p. 65.) s. Decandr.

Geraniaceae. Griff. 5, an die Blthachse angewachsen; Frucht geschnäbelt. Kräuter mit handf.-gelappten oder getheilten Bl. p. 60 . Einige Papilionaceae. p. 69.

Myricaria. Blkr. regelmässig. $\hbar . p .110$.

Ord. 4. Polyandria, 11-zahlreiche Stbgef. Malvaceae, p. 54 .

\section{Class. 17. Diadelphia.}

Stbgef, einer Zwitterblth, in 2 Bündel verwachsen, oder 9 Stbgef. verwachsen und 1 frei.

Ord. 1. Hexandria. 6 Stbgef. in 2 Bündeln. Fumariacoae. p. 14 .

Ord. 2. Octandria. \& Stbgef, in 2 Bündeln. Polygala, p. 37. 
Ord. 3. Decandria. 10 Stbgef. (Schmetterlingsblth.) 9 verwachsen und 1 frei. Papilionaceae (mit monadelph. Ausnahmen), p. 69 u. 70.

Class. 18. Polyadelphia.

Stbgef, einer $Z$ witterblth, in 3 oder mehr Bündeln rerwachsen. Hypericineae. Stbgef, zahlreich. p. 56.

Class. 19. Syngenesia.

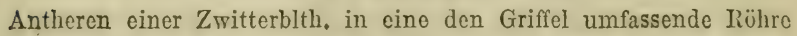
verwachsen. (Compositae.)

Ord. 1. Polygamia a equalis.

Alle Blth, der Blthk, sind zwitterig.

Alle Ligulaeflorae. p. 153 u. Is 4 .

Die Gattungen: Serratula, Jurinea, Lappa, Cirsium, Carduus, Silybum, Onopordon, Carlina, Eupatorium, Chrysocoma. p. 152 u. 153. Zuweilen die Gattungen: Bidens, Tanacetum, Artemisia, Helychrssum, Senecio. Die Art: Centaurea nigra L. p. 168.

Ord. 2. Polyg. superflua.

Randständ. Blth, weibl, ; Scheibenblth. zwitterig, fruchtbar. Die meisten p. 151 u. 152 aufgeführten Gattungen.

Ord. 3. Polyg. frustanea.

Randblth. unfruchtbar; Scheibenblth. zwitterig, fruchtbar. Die Gattungen: Centaurea, Bidens, zuweilen auch Galinsogea. Arten von Anthemis.

Ord. 4. Polyg. necessaria.

Randblth. weibl., fruchtbar; Scheibenblth. zwitterig, unfruchtbar. Cal endula.

Class. 20. Gynandria.

Die Stbgef, einer Zwitterblth. mit dem Griffel zu einer gemeinschaftlichen Säule verwachsen.

Ord. 1. Mo nandria. 1 Stbgef.

Orchideae (ausser Cypripedium). p. 306.

Ord. 2. Diandria. 2 Stbgef.

Cypripedium. p. 308.

Ord. 3. Hexandria. 6 Stbgef.

Aristolochia, p. 273. 


\section{Class. 21. Monoecia.}

Männl. und weibl. Blth, auf derselben Pflanze.

\section{Ord. 1. Monandria. 1 Stbgef.}

Eu phorbia. Hülle becherartig oder glockig, zahlreiche münnl. u. 1 weibl. Blth. einschliessend. Die einzelnen Blth. sind ron sehr kleinen. (zuweilen verkümmerten) fadenartigen Blättch. unterstützt. Perig. 0. p. 274.

A rum. Kolben oben frei von Blth., am Grunde weibl, u. männl. Blth. getrennt, von einer Scheide ganz umhüllt. Perig. 0. p. 304. Zanichellia. Blth. unscheinbar; Antheren 2fächerig, mit schmalem Mittelbande; Fruchtk. 4, von einer zarten Deckblattbildung umgeben. - Wasserpfl. mit linealen, ganzrandigen Bl. p. 298. Iijas (minor). Blth. unscheinbar, von einer scheidenartigen Lmhüllung umgeben; Antheren 4fächerig; Fruchtk. 1. - Wasserpfl. mit linealen, gezähnelten Bl. p. 301 .

\section{Ord. 2. Diándriá. 2 Stbgef.}

Pinus. Blth, in zapfenf. Aehren; Bl, nadelfürmig. ち. p. 292.

(Carex.) s. Monoec. Triandr.

(Betulineae.) s. Monoec. Tetrandr.

\section{Ord. 3. Triandria. 3 Stbgef.}

Typha. Kolben oder Aeliren walzenf, verlängert; Perig. borstenartig. - Wasserpfl. p. 303.

Sparganium. Kolben kugelig; Perig. schuppig. - Wasserpfl. p. 303.

Carex. Aehrch. mehrblth.; Fruchtl. von einem flaschenartigen, oft geschnäbelten Fruchtschlauch umgeben, welcher mit d. Frucht verwächst. (Cyperaceae.) p. 335.

$\mathrm{Z}$ e a. Weibl. Blth. von Scheiden eingehüllt; Karjopsen rundlichniorenfürmig, dicht gedrängt, einer gemeinschaftl. Achse (kolbenartig) eingefügt. (Gramineae.) p. 354.

A marantus. Blth. in aehrenförm. Knäueln; Perig. 3-5̌theilig; Narben 3. p. 257. (schwankt mit 5 Stbgef.)

\section{Ord. 4. Tetrandria. 4 Stbgef.}

Urtica. Perig. 4theilig; Griffel 0; Narben kopfig-pinselartig. Kräuter mit Brennhaaren. p. 278.

(Parietarir. Perig. 4theilig; Griffel fadenfürmig; Narbe kopfigpinselartig.) - Kräuter ohne Brennhaare. p. 278.

Morus. Perig. 4blätterig. Falsche Beere. - Bäume oder Sträucher. p. 280 . 
Botulineac. Perig. fehlend oder sehr unscheinbar; Männl. Kätzchen hängend, verlängert. - Bäume. p. 283.

Ord. 5. Pentandr. - Polyandria. 5-viele Stbgef.

a) Bäume oder Sträucher.

Cupuliferae. Blth. in Kätzchen; Stbgef. 6-15; Frucht nussartig mit Becherhülle; Bl. ganz oder gelappt. p. 282.

Juglans. Männl. Blth. in Kätzchen; Stbgef. zahlreich; Früchte steinfruchtartig; Bl, unpaarig-gefledert. p. 281.

b) Kräuter.

$\alpha$. Blth. ohne Blkr.

(Amiarantus.)

Atriplex. Blth. in aehrenf. Knäueln; männl. Perig. 5blätterig; Schlauchnuss der weibl. Blth. seitlich flach zusammengedrückt, der Zwitterblth. niedergedrückt; weibl. Perig. 2theilig-spaltig, d. Frucht bedeckend. p. 259.

Ianthium. Hüllk. der männl. Blth. vielblätterig; Blthdecke 5zähnig; Hüllk. der weibl. Blth. 1blätterig, 2blth; Blthdecke bei den weibl. Blth. fehlend; falsche Frucht aus dem erhärteten Hüllk. gebildet. p. 187.

Ceratophyllum. Blthdecko der männl. Blth. vielblätterig ; Antheren zahlreich, sitzend; Blthdecke der weibl. Blth. fehlend; Nuss dornartig endigend. - Untergetauchte Wasserpfl. p. 108.

b) Blth, mit Blkr.

Isriophyllum. K. und Blkr. 4zählig; Stbgef. 8; Blth, quirlig. - Wasserpfl, mit fiedertheiligen Bl, p. 106.

Sagittaria. K. 3theilig; Blkr. 3blätterig; Stbgef. zahlreich; Früchtchen zahlreich, auf einem kugelfürmigen Fruchtboden, - Wasserpflanze. p. 295 .

Ord. 6. Monadelphia (Polyadelph.). Stbgef. mit einander verwachsen.

Cucurbitaceae. p. 110.

\section{Class. 22. Di o e cia.}

Männl, und weibl. Blth. auf verschiedenen Pflanzon.

Ord. 1. Monandria.

(Najas major.) s. Monoecia.

Ord. 2. Diandria (-Pentandr.). 2-5 Stbgef.

Salix. Blth, in Kätzchen. ち̋. p. 285.

Ord. 3. Triandr. - Pentand. 3-5 Stbgef.

a) Bäume oder Sträucher.

(Rhamnus.) Stbgef, 4. (s. Pent. oder Tetrandr.) 
Vi s cum. Stbgef, 4. Auf Bäumen schmarotzend. p. 272.

Junip or us. Bl, nadelförmig. Beerenzapfen. p. 292.

b) Kräuter.

(Valeriana dioica.) Stbgef. 3. p. 146.

(Carex dinica und Davalliana.) Stbgef. 3. p. 340.

Spinacia. Perig. der männl. Blth. 4theilig, der weibl. 2-3spaltig, bleibend; Stbgef. 4-5; Griffel 4. p. 259.

H u mulu s. Männl. Perig. כtheil.; weibl. Perig. schuppenf, innerhalb der Schuppen einer zapfenf. Aehre. p. 278,

C a nnabis. Männl. Perig. 5theil, ; weibl, Perig. 1blättr., mit seitlicher Längsspalte. p. 278.

(Urtica dioica L. Stbgef. 4.) p. 279.

Ord. 4. Hexandr. 6 Stbgef.

(Rumex.) p. 264.

(Asparagus.) p. 319.

Ord. 5. Octandria. 8 Stbgef.

Populus. (Salicineae p. 290.)

Ord. 6. Enneandria - Polyandr. 9-viele Stbgef.

Mercurialis. Perig. 3theil.; Stbgef. 9-12; Griffel kurz, mit 2 verlängerten Narben; Kapsel 2knotig. p. 274.

H Jdrochar is. K. 3theil.; Blkr. 3blättr.; Stbgef, 9 und 3 Rudimente; 6 Griff. u. 6 Rudim. - Wasserpfl. p. 294.

(Spiraea. s. Icosandr. Pentagyn.)

(Silene Otites, inflata; Lychnis alba, rubra, s. Decandr.)

(Populus nigra, pyramidalis.) p. 290.

Ord, 7. Mona-Polyadelphia. Stbgef. mit

einander verwachsen,

Bryonia. (Cucurbitaceae.) p. 111. 



\section{Erklärung der Abkürzungen und der gebrauchten Zeichen.}

abf. = abfallend.

bl. = blätterig.

B. wnd Bl., auch Blt. = Blatt oder Blätter.

Blkr, = Blumenkrone.

Blbl. = Blumenblätter.

Blth, = Blüthe.

blth. = blüthig.

Balgkl. = Balgkapsel.

Blthk. = Blthköpfchen.

Blthst. = Blüthenstiel.

Deckbl. = Deckblatt.

f. am Endo eines Wortes = förmig.

Fr. = Frucht.

Frtr. = Fruchtträger.

Fruchtschl。 $=$ Fruchtschläuch $\theta_{0}$

Fruchtb. = Fruchtboden.

Fruchtk. = Fruchtknoten.

Gf. und Griff. = Griffel.

geth. = getheilt.

gesp. = gespalten.

Geb. = Gebiet.

$H_{*}=$ Heidelberg.

h. am Endo eines Ortsnamen = hoim.

Hkb. = Hüllkelchblätter.

$H_{*}$ = Hüllkelch.

K. Kelch. =

Kbl. = Kelchblätter.
Kp. = Kapsel.

$\mathrm{Kl}$. = Klappen.

Knospenl. = Knospenlage.

Kn. = Knollen.

m. am Ende eines Wortes $=$ mäsșig.

Nebenbl. = Nebenblätter.

Nssch. = Nüsschen.

Off. = Officinell.

od. $=$ oder.

$\mathrm{Pfl}_{.}=$Pflanze.

Perig. = Perigon.

sp. und splt. $\Rightarrow$ spaltig.

Stbgef. = Staubgef.

St. = Stengel.

Stbl. = Stengelblätter.

Sch. = Schote oder Schötchen.

Str. = Strauch.

$\mathrm{S} .=$ Samen.

st. am Endo eines Wortes = ständig.

th. = theilig.

$\mathrm{u}_{\mathrm{o}}=$ und.

vor. = vorige oder vorigen.

Var. = Varietät.

Wbl. = Wurzelblätter.

W. = Wurzel.

Wzst. $=$ Wurzelstock.

$\mathrm{Z}_{\mathrm{w}}$ = $\mathrm{Z}_{\text {wiebel }}$.

$\mathrm{zW}_{\mathrm{F}}=\mathrm{zwischen}$. 
Zpfl. = Zipfel.

Dio Zeichon ' (Fuss) oder " (Zoll) mit den beigefügten Zahlon zeigen die Höhe der betreffenden Pflanze an.

$\hbar=$ baum- oder strauchartiges Gewächs.

$2=$ eine ausdauernde Pflanze.

$\hat{\delta}=$ eine sog. 2jährige Pflanze.

$\odot=$ eine 1jährige Pflanze.
N. V.a, d. Geb. = Nächstes Vorkommen ausserhalb des Gebietes.

und $\mathrm{zwar}$ in $\mathrm{B}$. $=\mathrm{im}$ Grossherzogth. Baden.

in Hs. = im Grossherzogthum Hessen.

in $\mathrm{Rhb},=$ in Rheinbaiern.

in Rhh. $=$ in Rheinhessen.

\section{Abkürzungen einiger öfters vorkommenden Namen ron Antoren.}

Bisch. = Bischoff.

DC. = De Candolle.

Desf. = Desfontaines.

Ehrh. = Ehrhart.

Gaud. = Gaudin.

Gmel. = Gmelin.

Good, = Goodenough.

Juss. = Jussieu:

$\mathrm{L}_{\mathbf{0}}=$ Linné.

Lk. $=$ Link.

Lam. = Lamarck.

M. et $K_{\text {. }}=$ Mertens und Koch.

Pers. $=$ Persoon.
Poll. = Pollich.

R.Br. = Robert Brown.

R. et Sch. $=$ Roemer u. Schultes. Rich. = Richard.

Rchb. = Reichenbach.

F.Sch. = F. Schultz.

Schimp: $=$ K. Schimper.

Schlchd. = von Schlechtondal.

Schnttsp. od. Schtsp. $=$ Schnittspahn.

Scop. $=$ Scopoli.

Tournef. $=$ Tournefort.

Willd. = Willdenow. 


\section{PII A NEROGAIIAE.}

(Phanerogamen oder Samenpflanzen.)

Pflanzen mit Blüthen, welche wesentlich aus Staubgefässen und Pistillen bestehen, mit Samen, welche die Anlage zu einer künftigen Pflanze (den Keim, embryo) enthalten, und auf der Mutterpflanze vollständig ausgebildet werden.

Sie bestehen aus Zellgewebe und meist ausgebildeten Gefässbündeln. Der Keim ist (mit wenigen Ausnahmen) mit einem oder mehreren Keimblättern (ootyledones) versehen.

\section{Series $\mathbf{l}$. DICOTYLEDONEAE.}

(Zweikeimblättrige Pflanzen.)

Stämme aus Rinde, Holz und Mark bestehend, im Umfang wachsend durch eine jährliche Ablagerung neuer Schichten zwischen Holz und Rinde, welche concentrisch geordnet und von Markstrahlen durchsetzt sind. Blätter meist netzfürmig geadert. Blüthentheile mit vorherrschender Fünfoder Vierzahl. Keim mit 2 gegenstïndigen, selten mehreren 
wirtclst. Keimbl. (Blüthen meist von einer doppelten (Kelch oder Biumenkrone), seltener von einer einfachen Bluthendecke (Kelch oder Perigon) umgeben, zuweilen völlig deckenlos.)

\section{Class. I. A N GIOSPER II AE. \\ (Bedecktsamige Pflanzen.)}

Pflanzen mit Fruchtknoten, welche im Innern die Samenknospen (Eichen) enthalten und bei der Reife zur wahren Frucht sich ausbilden. Der Blüthenstaub gelangt bei fehlendem oder vorhandenem Griffel durch die Mitwirkung der sog. Narbe zur Befruchtung. Keimbl. 2 (mit wenigen Ausnahmen).

\section{Subclass. 1. T II A L A II I L O R A E.}

Blumenblätter getrennt, nebst den Staubgefässen auf dem Fruchtboden stehend. (Bbl. zuweilen 0.)

\section{RANUNCULACEAE. Juss.}

Ausdauernde oder einjährige Kräuter, selten klimmende Sträucher, mit nebenblattlosen abwechselnden oder selten gegenst. Bl., deren Scheidentheil meist s. entwickelt. Blattfl. gewöhnlich getheilt oder gelappt, in manchen Fällen fein geschlitzt, selten einfach. Blüthen einzeln, oder verschieden gruppirt, regelmässig oder unregelmässig. Kbl. 3-10 oft blumenartig, Bbl. von derselben Zahl, bisweilen aber fehlend. Stbgef. zahlreich (nur bei Myosurus 5), Fruchtkn. mehrere, getrennt, jeder mit 1 Griffel, selten einzeln. Früchte nussoder balgkapselartig, selten beerenartig, 1-mehrsamig. Samen mit grossem Eiweiss und kleinem, geradem Keirn. - Alle 
Arten mehr oder weniger scharfe Säfte enthaltend, daher einige giftig oder verdächtig, häufig durch glänzende Oberfäche ausgezeichnet. Haarbildung, wenn vorhanden, einfach. Meistens im Frühling blühend, sowohl durch Schönheit, als durch Geselligkeit der Arten, eine rorzugsweise Zierde der Flora. Vorkommen meist auf etwas feuchton Wiesen und an Waldrändern; einige im dichtesten Schatten, andere an der Sonne schr ausgesetzten Standorten gedeihend. Eine Section der Gattg. Ranunculus im Wasser und bisweilen geradezu als Amphibien lebend. - Manche zeigen Vorliebe für Kalk - und Lehm-, wenige für Sandboden.

\section{Uebersicht der Gattungen.}

A. Nüsschen 1samig.

a) Clematideae. - Knospenlage klappig. Bl. gegenst.

Clematis. K. blumenartig, 4-5th., weiss; Blkr. 0., N̦üsschen mit bleibendem Gr. federartig geschränzt.

b) Anemoneae. - Knospenlage dachig; Bl. abwechselnd; Blbl. ohne Honigdrüse, bisweilen 0.

Thal ictrum. Fruchtb. wenig entwickelt, flach. K. 4-5th., hinfällig; Blkr. o., Nüsschen ungeschwänzt; Bltst. rispig.

A nem one. Fruchtb. gewölbt oder kegelförmig; K. 5-9th., Blkr. o.; Nüsschen geschwänzt od. nicht geschwänzt; Bltst. 1mehrblüthig.

Ad on is. Fruchtb. gewölbt; K. 5th.; Blbl. 5-10; Nüsschen ungeschwänzt; Bltst. armblth.

c) Ranunculeae. - Knospenl. dachig; Blbl. am Grunde mit einer Honigdrüse.

Ranunculus. Kbl. 3-5; Blbl. 5, selten zahlreich, IIonigdrüse nackt oder von einer Schuppe bedeckt; Fruchtb. kugelig oder elliptisch.

Myosurus. Kbl. 5; Blbl. 5 mit fadenf. Honigdr.; Stgf. 5; Fruchtb. sehr verlängert.

B. Balgkapseln vielsamig; $\mathrm{K}$. blumenartig. (Helleboreae.)

Caltha. Kbl. 5 regelm., abfallend; Blkr. 0.; Balgk, 5-15, getrennt.

Hell e borus. Kbl. 5 regelm., bleibend; Blbl. $5-10$, tutenf.; Balgk. $5-6$ getrennt.

Nigella. Kibl. 5 regelm,, abfallend; Blbl. 5-10, röhrig, 2lippig, an der Basis mit einer schuppig bedeckten Honiggrube; Balgk. 5-10, verwachsen. 
A quilegia. Kbl. regelm., abfallend; Blbl. 5, trichterf., gespornt, Balgk. 5, getrennt.

Delph inium. Kbl. 5, unregelm., gespornt, abf.; Blbl. 4 (bei unserer Art 1), unregelm.; Balgk. 5, getrennt.

C. Balgk, od. Beeren mehrsamig; Blth. regelm. (Paeoniae.)

A ctaea. Kbl. 4; Blbl. 4, schmal, Griff 1, Beere.

\section{Clematis $L$. W a.l d rebe.}

1. C. Vitalba $L$. Gemeine W.; St.kletternd; Bl. gefiedert; Blst. etwas rankend; K. beiderseits filzig behaart, weiss. $\hbar$.

In Wäldern, Gebüschen u. Hecken häufig! In Gebirgswäldern, z. B. bei Weinheim nicht selten ansehnliche, armdicke Stämme bildend. Juli-August.

\section{Thalictrum $L$. Wiesenraute.}

2. Th. galioides Nestl. Labkrautähnl. Wr.; W. kriechend; St. gefurcht; Bl. fiedrig zusammengesetzt; Blättch. linealisch, ungetheilt od. die endst. 3spaltig, glänzend; Rispe längl.-pyramidenf.; Blth. gelb, überhängend; Nüsschen (wio bei d. folg.) sitzend, längsrippig. 4 . $1-2^{\prime}$.

Auf trocknen Wiesen am Rhein, nicht häufig, z. B. auf den Rheininseln bei Ketsch! Juli.

[Jenseits des Rheins bei Ludwigsh.! Mundenh.! Frankenthal!]

3. Th. flavum $L$. Gelbe Wr.; W. kriechend; St. gefurcht; Bl. fiedrig-zusammengesetzt; Blttch. eif-keilartig, meist 3splt., glänzend, Rispe gedrängt; Blth. gelb, aufrecht. 2. $1 \frac{1}{2}-2 \frac{1}{2}{ }^{\prime}$. Die Breite der Blättchen variirt sehr.

Auf feuchten Wiesen, in Weidengebüschen, besonders am Rhein stellenweise nicht selten, z. B. beim Rohrhofe! bei Neckarau! Brühl! Waghäusel! etc. Juni, Juli.

[Th. minus L. Kle in er $\Theta$ Wr.; St. sperrig-ästig: Bl. 3zähligzusammenges.; Blttch. keilf.-verkehrt-eirund od. rundlich, gezähnt od. gespalten, unterseits hellgrün, Rispe locker, weitschweifig-ästig, Blth. gelb, überhängend. 24. 1-2'.

N. V. a. d. G.: Auf trocknen kalkhaltigen Hügeln um Dürkheim! Jun., Juli.]

\section{Anemone $L$. Windröschen.}

4. A. Pulsatilla $L$. Kü ch en s chelle; Bl.u. Blthstdhbl. 3fachfiederspaltig, Zipfel linealisch; Blth. einzeln, aufrecht; Kbl. glockig, von der Mitte an schwach nach Aussen gebogen; Nüsschen bärtiggeschweift. 24. 6-9"; Kbl. blau-violett, selten weiss, aussen, wio d. Hülle, seidenhaarig. (Pulsatilla vulgaris Lob.) 
Auf Haiden, an Bergabhängen bei Schriesheim! Weinheim! Loimen! Nussloch! An lichten Waldstellen, z. B. beim Maischbacher Hofe! Am Rande der Nadelwälder bei Friedrichsfeld! Käferthal! Sandtorf! März-Mai. Die Entwickelung der Bl. orfolgt nach der Blthzeit. Diese bisweilen noch einmal im Sept. (Off.: rad. et herba Pulsatillae vulgaris.)

5. A. nemorosa $L$. I a in -W in d r., Wst. kriech,; Bl.u.Hbl. 3zählig, eingeschnitten gesägt; Blth. einzeln; Kbl. beiderseits kahl; Nüssch. weichhaarig, ungeschweift; Blth. weiss od. röthl. 4. 5-9".

In Wäldern, auf Waldwiesen gemein! April, Mai.

6. A. ranunculoides $L$. Gelbe Windr.; der vor. ähnl., aber Blth. meist $\mathrm{zu} \mathrm{2-3;} \mathrm{Kbl.} \mathrm{unterseits} \mathrm{weichhaarig;} \mathrm{Blth.} \mathrm{gelb.} 4$. $5-9 "$.

Auf Waldwiesen hie und da, z. B. in Menge bei Weinheim! Schriesheim! Seltener in der Nähe von Heidelberg, z. B. an schattigen, feuchten Stellen bei der Stiftsmühle, bei Schlierbach! auch auf den Grasplätzeu beim Schlosse! Mai.

7. A. sylvestris $L$. Wa a d - W in $\mathrm{dr}$.; Wbl. 5theil., Zipfel fast rautenf., 3spalt.; Hüllbl. 3zähl.; Blth, einzeln; Kbl. unters. seidenhaarig, Nüssch. wollig behaart, ungeschweift; Blth. weiss. 4. $\frac{1}{2}-1^{\prime}$.

An sonnigen Standorten, an Waldrändern, in Gebüschen und Hecken sowohl der Gebirge, als der Ebene. Auf Kalk - u. Thonboden sehr vorzugsweise. Zwischen Leimen u. Nussloch! bei Dielheim! Rauenberg! Wiesloch! Schatthausen! Weinheim! auf den Rheininseln bei Ketsch! zwischen Schriesheim u. Dossenheim, einzeln auch bis Handschuhsheim! Im Käferthaler Walde (Dr. Schimp). Mai.

[A. Hepatica L. L e b e rblume; Bl. herzf., 3lappig, Lapp. ganzrandig, Schaft 1blth., zottig; Hüllbl. 3zählig, der Blth. nahegerückt, aussenkelchartig. $4.3-7 "$. Blth. blau. N. V. a. d. G.: Zwischen Dürkheim und Grünstadt: in Laubwaldungen bei Hartenburg, auf bewaldeten felsigen Hügeln $z$ wischen Kallstadt $u$. Herxheim! im Bischofswalde bei Neu-Leiningen (Dr. Kooh). März-Mai.]

\section{Adonis Dill. Adonis.}

8. A. aestivalis $L$. Sommer-A d.; Bl. mehrf.-fiederth.; K. kahl; Nüssch. kahl, mit gleichfarbigem, etwas gebogenem Schnabel; Blkr. mennigroth od. strohgelb. ๑. $\frac{1}{2}-1$ '.

Auf kalkhaltigen Aeckern bei Wiesloch! Rauenberg! Weinheim! beim Relaishause! Hockenheim! Alt-Lussheim! Juni-Juli.

9. A. flammea Jacq. Feurige Ad.; der vorig. ähnl.; Kbl. 
weichhaarig; Nüssch. kahl, mit geradem, schrarzbraunem Schnabel; Blkr. mennigr., selten strolgelb, meist etwas verkümmert. ๑. $\frac{1}{2}-1^{\prime}$. Mit der vorigen, jedoch seltener. In der Gegend von Baierthal und Dielheim! auch bei Weinh. ziemlich verbreitet! Juni-Juli.

[A. vernalis L. Frühlings-Ad.; Bl. mehrfach-fiedertlı.; Kbl. weichhaarig; Bbl. gross, gelb; Nüssch. kurzgeschnäbelt, weichhaarig. 4. $\frac{1}{2}-1^{\prime}$. - N. V. a. d. Geb.: Triften bei Dannstadt (unfern Schifferstadt), in Rhb. (Dr. Walz). April, Mai.]

\section{R a u uculus $L$. Hahnenfuss.}

a) Batrachium Wimm. Wasser- od. Amphibienpfl. Blbl. weiss, Honigdrüse nackt; Nüssch. querrunzelig.

10. R. hederaceus $L$. Épheublät tr. Hhnf.; St. kriechend; Bl. alle gleichgestaltet, nierenf., stumpf, 5lappig; Nüssch. kahl. 4. In Gräben bei Neckarau u. Brühl. Juni, Juli.

11. R. aquatilis $L$. W a s ser-H.; St. schwimmend, untergetauchte Bl. borstenf.-vielspaltig, nach allen Richtungen abstehend, schwimmende Bl. nierenf., gelappt od. gespalten, lederartig; Nssch. steifhaarig od. kahl.

Von dieser Art finden sich folgende Varietäten:

a) tripartitus Godr.; schwimmende Bl. 3theil, mit keilf, eingeschnittenen, gekerbten Zipfeln;

B) sucoulentus $\mathrm{Koch}$ (terrestris $A$ ut.) St. s. verkürzt, BI. gedrängt, vielth. mit schmalen, dicklichen Zipfeln, d. oberen selten 3-5lappig;

$\gamma$ ) capillaceus $\mathrm{K}$ o $\mathrm{h}$ (paucistamineus $\mathrm{T}$ a u $\mathrm{ch}$ ). BI. alle untergetaucht, haarf, gespalten, Stgf, öfters nur 8-12. Erscheint in tieferen Gewässern mit längeren, in seichteren mit kürzeren Zipfeln.

In Gräben und Sümpfen, in Teichen und stehenden Gewässern ist die Hauptform verbreitet, var. $\alpha$ in Menge bei Wagh.! Neckarau! Sandtorf! var. $\beta$ in den ausgetrockneten Sümpfen des Friedrichsf. Waldes und beim Relaishause! auch bei Neckarau! St. Ilgen! var. $\gamma$ mit der Hauptform bisweilen im Neckar! häufiger bei Neckarau! Waghäusel! Walldorf! Mai-Juli.

12. R. divaricatus Schr. Spreitzbl. H.; St. schwimmend, Bl. alle untergetaucht, borstenartig-vielsp. mit kurzen in eine kreisrunde Fläche auseinandertretenden Zipfeln; Nssch. meist steifhaar. 4.

In Gräben und in langsam fliessenden Gewässern, selten im Neckar beim Haarlass und unterhalb der Bergheimer Mühle! im Rh. bei Ketsch! bei Neckarau! Waghäusel! Roth! Juni-Juli.

13. R. fluitans Lam. Fluthend. H.; St. schwimmend, Bl. 
meist alle untergetaucht, borstenartig-vielsp., mit sehr verlängerten, parallel-gestreckten Zipfeln, Nssch. kahl. 2. Blkr. grösser, als bei d. vorigen. Variirt:

$\alpha)$ terrestris; St. u. Blzpfl. verkürzt;

$\beta$ ) heterophyllus; obere Bl. schwimmend, klein, nierenf., 35 spaltig, dünnhäutig.

Die Hauptform in unseren Flüssen, z. B. in der Nähe von II, im N. nicht selten. Var. $\alpha$ erscheint an Stellen, wo das Wasser zurückgetreten, oftmals mit Uebergängen zur Hauptform. Besonders deutlich in trocknen Sommern im Neckar beim Haarlass $u$. bei der Bergheimer Mühle. Var. $\beta$ mit der Hauptform, aber sehr selten im Neckar beim Haarlass! Juni, Juli.

\section{b) Land-oder Sumpfpflanzen.}

๔) Blkr. weiss, Honigdr. nach oben schuppenartig verlaufend.

14. R. aconitifolius $L$. Ei s en hu tbl. H.; kahl, St. steif-aufr.; Bl. handf., 3-7theil., mit zugespitzten Zipfeln. 4. $\frac{1}{2}-2^{\prime}$.

An bewaldeten felsigen Standorten hinter d. Haarlass! Mai.

[N. V. a. d. Geb.: In Baden: Schwarzw. (Döll). In Rheinb.: Annweiler (F.Sch.), Donnersb.! In Hess.: Vogelsberg. Taunus (Schntsp.) ]

$\beta$ ) Blkr. gelb, Honigdrüse von einer Schuppe bedeckt.

$$
\text { -) Blätter ungetheilt. }
$$

15. R. Flammula L. Brennender H.; W. faserig; St. aufsteigend; Bl. elliptisch od. lineal-lanzettl.; Blthstiel kahl; Nüsschen glatt, mit s. kurzem stumpfem Schnabel. 4. $\frac{1}{4}-1 \frac{1}{2}{ }^{\prime}$. Variirt:

$\beta$ ) reptans $\mathrm{L}$; niederliegend, kriechend, Bl. lineal. In allen Theilen kleiner $u$. zarter, als die Hauptform.

Auf feuchten Wiesen, in Gräben, Sümpfen stellenweise häufig: beim Rohrhof! in den Sümpfen des Friedrf. Waldes! beim Maischbacher Hof! Schönau! Waghäusel! Roth! Ketsch! Neckarau! Var. $\beta$ viel seltener, z. B. bei Friedrichsf. u. d. Relaishause! bei Neckarau. Juni-September.

16. R. Lingua $L$. Grosser H.; W. faserig; St. aufrecht; Bl. lanzettl.; Blthst. seidenhaarig; Nssch. glatt, mit starkem sichelförm. Schnabel. 24. 2'. Blkr. goldgelb, ansehnlich.

In Gräben und Sümpfen, nicht häufig. Beim Rohrhof! Wagh.! Brühl! Juli, August.

17. R. Ficaria $L$. F e igwarz en $\mathrm{H}$.; W. mit büschelf. Knollon; Bl. rundl.-herzf., ganzrandig od. etwas kantig, glänzend; Kbl. meist 3. 4. 3-9". Die zarten, sehr hinfälligen, etwas aufstrebenden St., meist in d. Blattwinkeln rundl. Bulbillen tragend. (Fioaria ranunculoides Roth.)

In Wäldern, Hecken, Weinbergen u. Gärten gemein. März-Mai. 
*) Blätter getheilt.

1) Nüsschen meist glatt.

A. Blüthenstiele nicht gefurcht.

18. R. auricomus $L$. Goldgelber H.; Wbl. nierenf., fast ungeth. od. 3-5sp., obere Bl. fingerig-geth.; Nssch. bauchig, sammthaarig. 4. $\frac{1}{2}-1^{\prime}$. Blbl. meist etwas verkümmert, auch wohl fehlend. In Gebüschen, Wäldern, auf Waldwiesen hio u. da, fehlt selten an quellenreichen Standorten! April-Juni.

19. R. acris $L$. Scharfer H.; weichhaarig; Wbl. handf. geth., obere Bl. 3theil.; Nssch. kahl, zusammengedrückt mit kurzem, wenig gekrümmtem Schnabel. 4. 1-1 $\frac{1}{2}^{\prime}$.

Auf Wiesen, in Wäldern, an Wegen gemein! Mai-Sept.

20. R. lanuginosus $L$. Wolliger $\mathrm{H}_{\text {. }}$; von abstehenden dichten Haaren rauhhaarig; Wbl. handf. geth., obere Bl. 3theil.; Nssch. kahl, zusammengedrückt, mit starkem hakenf, gebogenem Schnabel. 4. 1-2'. Von der vorigen Art auch durch kräftigen Habitus und länger gestielte $\mathrm{Wbl}$. leicht $\mathrm{zu}$ unterscheiden.

In feuchten, schattigen Schluchten, z. B. bei Leimen hinter d. Baiermühle! bei Maischbach. Soll auch vereinzelt im Dreitröge Thal bei $H$. gefunden sein, wurde jedoch in neuester Zeit daselbst nicht gesehen! Mai, Juni.

[N. V. a. d. Geb.: In B.: Bruchsal, Mosbach. In Hs. : Darmstadt (Schntsp.).]

\section{B. Blüthenstiele gefurcht.}

a) Fruchtb. borstig-behaart.

21. R. polyanthemos $L$. Vi weichhaarig; Bl. handf.-geth., mit linealen Zipfeln; Kbl. aufrecht; Nssch. kahl, mit hakenf.- gekrümmtem Schnabel. 4. 1'.

Auf Wiesen und an der Sonne ausgesetzten Waldrändern, besonders der Ebene, nicht selten! Mai-Juli.

22. R. nemorosus $D C$. Hain-H.; dem vorigen sehr ähnlich; Bl. mit verkehrt-eiförm. Zipfeln; Nssch. kahl, mit an der Spitze eingerolltem Schnabel. 4. $\frac{3}{4}-1^{\prime}$.

In Gebüschen, Wäldern, vorzugsweise schattige Standorte liebend, mehr im Gebirge verbreitet, besonders in d. Gebirgswäldern und an schattigen Abhängen zw. H. u. Wiesloch! Auch bei Schriesh. u. Weinh.! Ziegelh.! Schönau! Mai-Juli.

b) Fruchtboden kahl.

23. R. repens $L$. Kriechender H.; St. mit kriech. Ausläufern; Bl. 3zählig, mit 3sp. gezähnten Zipfeln; Kbl. aufrecht-abstehend; Nssch. fein eingedrückt punktirt. 4. $\frac{1}{4}-1$ '.

An Wegen, auf Wiesen, in Wäldern sehr häufig! Mai-Sept. 
24. R. bulbosus $L$. Zwiebeltrag. H.; St. an der Basis knollenartig, ohne Ausläufer; Bl. d. vor.; Kbl. zurückgeschlagen; Nssch. völlig glatt. 4. 4-10".

Nưr stellenweise häufig an Wegen, Waldrändern, auf Bergwiesen, vorzugstreise auf Lehm- u. Kalkboden. Die knollenartige Anschwellung ist um so umfangreicher, jo lockerer der Boden. Mai-Juni.

2) Nüsschen warzig oder dornig.

25. R. Philonotis Ehrh. Ra uher H.; St. aufrecht, ohne Anschwellung, meist rauhhaarig; Bl. 3zählig, mit 3sp., gesägten Zipfeln; Blthst. gefurcht; Kbl. zurïckgeschlagen; Nssch. berandet, mehr oder weniger feinwarzig. $\odot . \frac{1}{2}-1^{\prime}$. Blkr. blassgelb.

Auf feuchten, sandigen Aeckern nicht häufig, z. B. zwischen Friedrichsf. u. d. Relaishause! beim Grenzhofe! vor Schönau! $z W$. H. u. Schwetzingen (Döll). Juni-August.

[Auf feuchten, etwas salzhaltigen Aeckern bei der Dürkheimer Saline in Rhb. stellenweise vorherrschend I]

26. R. sceleratus $L$. Gift-H.; steif-aufrecht, glänzend; Bl. etwas fleischig, d. unteren handf.-getheilt, d. oberen 3sp.; Kibl. zurückgeschlagen; Fruchtb. nach dem Verblühen walzenf. verlängert; Nsseh. sehr klein, unberandet, feinwarzig. ๑. $\frac{1}{4}-1 \frac{1}{2}^{\prime}$. Blkr. s. kurz, blassgelb.

In Gräben, an sumpfigen Standorten: Wagh.! Brühl! Neckarau! in den Sümpfen d. Friedrichsf. Waldes! bei Wiesloch! Kirchh.! auch hie u. da am Neckar, z. B. bei Neuenh.! Neckargem.! Juni-Sept. Sehr giftig.

27. R. arvensis $L$. Acker-H.; aufrecht; Wbl, ungeth, oder 3sp.; Stbl. vielsp. mit linealen Zipfeln; Kbl. aufrecht; Nssch. geschnäbelt, dornig-knotig. ๑. $\frac{1}{2}-1^{\prime}$. Blkr. hellgelb.

Auf Aeckern, im Getreide häufig! Mai-Juli.

\section{Myosurus Dill. Mäuseschwanz.}

28. M. minimus $L$. S ehr kleiner M.; Bl. grundständ., lineal, Schaft 1blüthig. $\odot .2-3^{\prime \prime}$. Meist nur wenig rom Boden sich erheb., sehr ausgezeichnet durch den oft beträchtlich sich verlängernden Fruchtb.; Blth. s. klein, gelblich-grün.

Auf etwas feuchten Lehmäckern, z. B. unfern Friedrichsf. in d. Nähe des sog. rothen Loches in Gemeinschaft mit Lindernia pyxidaria! auch auf Aeckern in der Nähe des Wolfsbrunnens bei H.I bei Dossenheim (Döll). Mai-Juli.

\section{Caltha $L$. Dotterblume.}

29. C. palustris $L$. Sumpf-D.; St, aufsteigend; BI, herzfo- 
kreisrund, wie die ganze Pflanze etwas fleischig, stark glänzend. 4. $\frac{1}{2}-\frac{3}{4}{ }^{\prime}$. Blth. gelb.

Auf sumpfigen Wiesen, in Gräben gemein. April, Mai.

\section{Helleborus $L$. Niesswurz.}

30. H. foetidus $L$. Stinkende N.; St. beblättert, vielblüth.; Wbl. fussf.; Stbl. 3splt.; Deckbl. eiförm.; K. kugelig-glockig, grünlich. 4. 1-2'.

An waldigen Abhängen stellenweise, z. B. hinter d. Haarlass! In Menge am Teufelskopf bei Dielheim! bei Rauenberg! Malsch! März-Mai. Giftig.

[N. Y. a. d. Geb.: In B.: Langenbrücken! Bruchsal! In Rhb.: Dürkh.! Grünstadt! In Rhh.: Oppenheim!]

9. Nigella $L$. Schwarzkümmel.

31. N. arvensis $L$. A cker-S.; Bl. 2-3fach flederth.; Blth. ohne besondere Hülle; Balgk..-vom Grunde bis zur Mitte verwachsen, glatt. ๑. $\frac{1}{4}-1^{\prime}$. Kbl. bläulich-weiss, grün-gestreift.

Auf Aeckern, auf trocknen Weiden, besonders auf Kalk - und Lehmboden, in grosser Menge an d. Abhängen zw. Baierthal u. AltWiesloch am sogen. Schlangengrunde! hinter Rauenberg! bei Nesterbach unfern Weinheim! Stellenweise auch in der Ebene nicht selten, z. B. Neckarau! Seckenheim! beim Relaishause! Ladenburg! Juli-Sept.

\section{Aquilegia $L$. A kelei.}

32. A. vulgaris $L$. Gemoine A.; Wbl, doppelt-3zählig; Blttch. 3lappig, gekerbt; Kbl. längl.-eiförm.; Sporn der Blbl. an der Spitze hakenförm. 24. 1-1 1'. Blth. nickend, blau, röthl. od. weiss.

In Wäldern und Gebiischen hie und da. Am Königstuhl bei II. Auf den Felsen vor Schlierbach! Am Oelberge bei Schriesheim! bei Handschuhsheim! Nussloch! Wiesloch! am Teufelskopf bei Dielheim! in d. Wäldern zw. Rauenberg u. Malsch! Mai-Juni.

\section{Delphinium $L$. Rittersporn.}

33. D. Consolida L. Feld-R.; BI. 3theil., mit zerschlitzten linealen Zipfeln; Blk. 1 blättr.; Balgk. kahl. ๑. $1^{\prime}$. Blth. blau. Auf Aeckern, unter der Saat häufig! Juni-Sept.

12. Actaea $L$. Christophskraut.

34. A. spicata $L$. BI. mehrfach gefiedert; Blth. klein in kurzen blattgegenständ. Trauben, Beeren eiförm., glänzend schwarz. 4 . $1-2^{\prime}$. Blk. gelbl,-weiss. 
In Laubwaldungen, zw. Leimen u. Nussloch! Bei Weinheim! Leutershausen! Waghäusel? Mai, Juni.

[N. V.a. d. Geb.: In B.: Eichelberg b. Bruchsal! In Hs.: Eberstadt, Auerbacher Schloss (Schntsp.). In Rhb. Trifels bei Annweiler, Donnersberg.]

\section{BERBERIDEAE. Vent.}

Sträucher oder 4. Kräuter mit abwechselnden, einfachen oder zusammengesetzten Blättern, ohne Nebenblätter. Blüthen in Trauben. Kbl. 3-10 blumenkronartig, hinfällig, in der Knospenlage dachig. Bbl, von gleicher Zahl oder doppelt so viele. Stbgef. den Blumenblättern gegenüberstehend, so viele als diese, Antheren durch aufspring. Klappen elastisch sich öffnend. Fruchtknoten 1 einfächrig. Frucht beeren- oder kapselart. Samen eiweisshaltig mit geradem Keim. - Die Flora hat nur 1 Art. In den Schlossanlagen findet sich ausserdem, gleichsam verwildert das krautartige, zierliche, morphologisch interessante Epimedium alpinum L.

Berberis. Stbgf, 6; Beere. ち.

\section{Berberis $L$. Sauerdorn.}

35. B. vulgaris $L$. Gemeiner S. ; dorniger Str. mit verkehrteiförmigen, wimperig-gesägten, büscheligen $\mathrm{Bl}$., vielblüthigen, hängenden Trauben, längl.-rothen Beeren. ち. 4-9'. Blth. gelb.

In Wäldern und Gebüschen hie u. da. In den Gebirgswäldern bei Nussloch, Rauenberg u. Weinh. oft ansehnl. Stämme bildend! Auch auf den Rheinins. bei Ketsch nicht selten! Mai. (Off. Baccre Berberum.)

\section{NYMPHAEACEAE. De Cand.}

Krautartige Wasserpflanzen mit dickem, kriechendem Wurzelstock, lauggestielten, rundlichen, lederartigen, schwimmenden Blättern, ohne Nebenblätter. Blüthen cinzeln, ansehnlich, auf langen Stielen. Kbl. 4-5. Bbl. und Stbgef. zahlreich, allmählig in einander übergehend, Fruchtknoten vielfächerig, Fächer vieleiig, die Eichen den Wänden der Fücher ange- 
heftet. Narben sitzend, in eine strahlige Scheibe verwachsend, Samen eiweisshaltig, Keim im bleibenden Keimsack eingeschlossen. - Fast nur in der Nähe des Rheines als vorzugsweise Repräsentanten unserer Wasserflora.

N jmphaea. Kbl. abfällig; Blb. so lang als d. Kbl. N u ph a r. Kbl. 5, bleibend; Blb. kürzer als dio Kbl.

\section{Nymphat $L$. Seerose.}

36. N. alba $L$. Weisse S.; Bl. herzf.-rundl., ganzrandig, schwimmend; Narbe 12-20strahlig. 4. Blkr, weiss, zart.

In Gräben, Sümpfen, Teichen : bei Neckarau! Wagh.! Schwetz.! im Rhein bei Ketsch! Juni, Juli.

\section{Nuphar $S m$. Mummel.}

37. N. luteum Sm. Gelbe II. od. S e erose; Bl, herzf.-oval, ganzrandig, schwimm.; Narbe 10-20strahlig, ganzrandig. 4. Blkr. gelb, lederartig.

In stehenden und langsam fliessenden Gewässern hie und da, vorzugsweise in den Sümpfen längs des Rheines! Juni, Juli.

\section{PAPAVERACEAE. De Cand.}

Einjährige oder ausdauernde Kräuter mit weissem oder gelbem, narkotisch scharfem Milchsaft. Bl. meistens getheilt oder zerschnitten, selten einfach. Blüthen einzeln oder doldig. Kbl. 2, sehr hinfällig. Bbl. 4, regelmässig oder etwas ungleich, in der Knospenlage ineinandergefaltet. Stbg. zahlreich od. 4, frei. Fruchtknoten frei, 1fächerig od. scheinbar mehrfächerig, mit kurzem od. fehlendem Griffel. Frucht kapselartig, vielsamig. Samen mit reichlichem, öligem Eiweiss und kleinem, geradem Keim. - Als sog. Unkräuter durch Geselligkeit in den Gärten und Feldem mitunter lästig. Auf Wiesen und in Wäldern fehlend.

a) Stbgef, zahlreich. Blkr. regelmässig.

Papaver. Narbe 4-20strahlig; Kps. rundl., durch Löcher aufspr. Chelidonium. Nb. 2lappig; Kps. schotenartig, 2klappig aufspr.

b) Stbgef. 4. Blbl, ungleich, 2 etwas grösser. H уресоum. Kps. бchotenf., in einsamige Glieder zerfallend. 


\section{Paparer $L$. Mohn.}

38. P. Argemone $L$. Keulenf. M.; St. starr, aufrecht, steifhaarig; Bl. fiedersp.; Stbgf. oberwärts verbreitert; Kps. keulenförm., steifhaarig. ๑. $1-1^{\prime}$. Blkr. klein, blassroth, an der Basis schwarzgeff.

In Kornfeldern, auf Sand- u. Kalkboden häufig: bei Rauenberg! Malsch! Wiesloch! Weinheim! Vereinzelt auch in Weinbergen u. auf Schutt, z. b. bei Handschuhsh, am Klingenteich bei H. Juni, Juli.

39. P. Rhoeas $L$. Klatschros; St. rauhhaarig; B1. fiedersp.; Stbgf. pfriemlich; Kps. eirund-kugelig, kahl, Strahlen der Narbe mit den Rändern sich einander deckend. ๑. 1-2'. Blkr. ansehnlich, dunkelscharlachroth, bisweilen am Grunde schwarz-gefleckt.

Auf Aeckern, unter der Saat stellenweise sehr gemein! Juni, Juli. (Off, Flor. Rhoeados.)

40. P. dubium $L$. Z w e if elh a fter M.; St. steifhaarig; Bl. fiedersp.; Stbf. pfriemlich; Kips. keulenf., kahl; Strahlen der Narbe

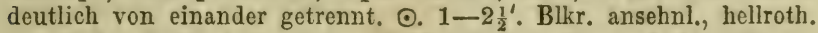

Unter der Saat, besonders auf Sandfeldern hie und da nicht selten, z. B. bei Schwetzingen! Hockenheim! beim Relaishause! Walldorf!' Sandtorf! Juni, Juli.

P. somniferum L. Schlafbringender M.; St. kahl; Bl. längl., stengelumfassend, ungleich-gezähnt, Stbf. oberwärts verbreitert, Kps. kugelig, kahl. $\odot .2-4^{\prime}$. Blk. gross, weiss od. lilla.

Gebaut und hie u. da verwildert. Juli, August. (Off. : Capita et semina Papav.)

\section{1\%. Chelidonium L. Schöllkraut.}

41. Gh. majus $L$. Grösseres S.; St. ästig; Bl. fiedersp. mit

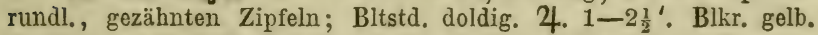
Enthält in allen Theilen einen orangegelben Milchsaft.

An Mauern, auf Schutthaufen, an Wegen überall! Mai-Sept. Eine Spielart mit tiefeingeschnittenen Bl. u. gesp. Blbl. ( $\beta$ laciniatum $\mathrm{K} \mathrm{och}$ ) ist an Mauern beim Haarlass beobachtet. (Off. : rad. et herb. Chelid, maj.)

\section{[II y есошт $L$. Lappenblume.}

H. pendulum L. Hängende L. (Goldäugelein); meergrün; Wbl. 1-2fach-gefiedert; Bltch. schmal-lineal; Blthschäfte gabelsp., etwas ausgebreitet, armblth., äussere Blbl. ganz, innere halb 3sp., Gliederkpsl. hängend, ๑. 4-10". Blth. klein, gelb.

Unter der Saat, auf Moorrübenäckern, Brachfeldern zw. Ellerstadt u. Gönnheim in Rhb.! Mai, Juni. ] 


\section{FUMARIACEAE.}

Einjährige oder ausdauernde, zarte, kahle, meist blaugrüne Kräuter mit einem reichlichen, wässrigen Safte, abwechselnden, vielspaltigen Blättern ohne Nebenblätter. Blth. in Trauben. Kbl. 2 blumenkronartig, hinfällig. Bbl. 4 unregelmässig, kreuzweise gestellt, die 2 äusseren oder 1 derselben gespornt oder sackartig. Stbgf. 6 diadelphisch. Fruchtknoten 1 fächrig, 1-mehreiig. Frucht nuss - oder schotenartig. Samen eiweisshaltig. - Als niedere Krautvegetation durch Geselligkeit hio und da auffallend; die 2 Corgdalis- $\Lambda$ rten durchaus schattenliebende Frühlingspflanzen.

Cor 5 dalis. Fr. schotenartig, vielsamig; S. mit Anhängsel.

F u maria. Fr. nussartig, 1samig; S. ohne Anhängsel.

\section{Corydalis $L$. Lerchensporn.}

42. C. cava Schw. et $K$. Hohler L.; Wzstck. knollig, ausgehöhlt; Bl. doppelt-3zählig, eingeschn.; Deckbl. der vielblüth. Traube oval-ganzrandig. 4. $\frac{1}{2}-1^{\prime}$. Blth. purpurn od. weiss.

In Gebüschen, Wäldern hie und da. Weinheim! Schriesheim! Im Carmeliterwäldehen und in d. Schlossanlagen bei H.! Zwischen Kirrlach u. Waghäusel! Neckarauer Wald! April, Mai.

43. C. solida Sm. Gefingerter L.; Wzstck. knollig, fest; Bl. d. vor. Art; Deckbl. d. vielblüth. Traube fingerartig-getheilt. 4 . Blth. purpurn.

In Gebüschen, Zäunen, Wäldern zuweilen mit der vorigen. In grosser Menge z. B. im Birkenauer Thal b. Weinheim! bei Leutershausen! Schriesheim! auf d. Teufelskopf bei Dielheim! März, April.

\section{Fumaria $L$. Erdrauch.}

44. F. officinalis $L$. Heilkrä ftiger E.; St. niederliegend; Bl. mehrfach-zusammengesetzt; Blzpfl. lanzettl.; Kbl. ei-lanzettl., gezähnt, fast $3 \mathrm{mal}$ kürzer, als die Blkr.; Nssch. rundlich, an der Spitze etwas ausgerandet. $\odot \frac{1}{2}-1^{\prime}$. Grünlich-grau; Blth. purpurroth. Variirt mit bald kürzeren, bald sehr verlängerten Blthtrauben. Auf Aeckern, Schutthaufen, an Wegen häufig! Juni-Septbr. (Off.: Hb. Fumariae.)

45. F. Vaillantil Loisl. V aillant's E.; der vorigen ähnl., 
jedoch mehr blaugrün; Kbl. sehr kurz; Nssch. rundlich, stumpf. ๑: Blth. rosa.

Auf Aeckern, in Weinbergen, besonders auf Kalk - u. Lehmbod. In Menge bei St. Ilgen! Wiesloch! Dielheim! Baierthal! bei Weinheim! einzeln auch bei Leimen! Wieblingen! Schriesheim! Handschuhsheim! Juni-August.

46. F. parviflora Lam. Kle in blumiger E.; St. nicderl.; Bl. mehrf.-zusammengesetzt; Blzipfel lineal, rinnenf., Trauben abgekürzt; Kbl. s. kurz; Nssch. eiförm.-rundl., zugespitzt. ๑. $\frac{1}{2}-1^{\prime}$. Blth. klein, weiss, etwas purpurn. Das ganze Kraut zarter, als bei d. vorigen, weisslich-grüngrau.

Auf kalkhaltigen Aeckern selten. Zwischen Rauenberg u. Rodenberg! Auf der Mühlau bei Mannheim (Döll).

[N. V. a. d. Geb.: In Hs.: Darmstadt, Worms. (Schntsp.) In Rhb.: Grünstadt, Ellerstadt (Dr. Koch). In B. ?]

\section{CRUCIFERAE.}

Einjährige oder ausdauernde Kräuter mit abwechselnden einfachen oder oft sehr zerschnittenen Blättern ohne Nebenblätter, meist deckblattlosen, während des Aufblühens sich verlïngernden Blüthentrauben. Blthn. regelmässig. K. u. Blkr. $4 \mathrm{bl}$, gekreuzt. Stbgf. tetradynamisch. Fruchtkn. frei, 1 bis 2 fächrig, 2 -vieleiig. Narbe 2 lappig od. kopfig. Frucht schotenartig, 2klappig, aufspringend, oder nussartig, nicht aufspringend. Samen eiweisslos mit gekrümmtem Keim. Oberfiäche meist weissgrau od. blassgrün, im ersten Falle fast immer mit gabelästigen od. sternförm. Haaren besetzt, im letzteren kahl. Kraut u. Blthn. durch flüchtige, scharfe Oele, Samen durch fette Oele ausgezeichnet. Eigentliche Giftstoffe fehlen. - Uebrigens im IIabitus u. im Blüthenbau sehr übereinstimmend, daher die Bestimmung der Gattungen, welche mitunter nach geringfüg. Charakteren der Früchte und Samen geschehen muss, nicht immer ganz leicht. ") -

-) Für die Bestimmung der Gattungen ist ein einigermassen entwickelter Zustand der Frïchte durchaus nothwendig, in manchen Fällen selbst die schon ausgebildeten Samen wünschenswerth. Die Zusammenstellung der Gattungen ist übrigens so gewählt, dass auch ohne Berücksichtigung des Koimes das Auffinden einer jeden Gattung möglich sein wird. 
Diese bei uns sehr vorherrschende und besonders im Frühling blühend auftretende Familie ist an fast allen Lokalitäten und auf fast allen Bodonarten vertreten, doch sind die Cruciferen als Wiesenpflanzen verhaltnissmässig selten. Die Neigung mitunter an feuchten Standorten $\mathrm{zu}$ wachsen und ein Amphibienleben $\mathrm{zu}$ führen, findet sich auch hier, und trägt zur Wandelbarkeit mancher Arten (Notsturtium) wesentlich bei. Vorherrschend sind gelbe und weisse Blumenfarben, erstere bei 28 , letztere bei 23 Arten. Um so bemerkenswerther in landschaftlicher Beziehung sind die hell violetten Blumen unserer Wiesen-Crucifere: Cardumine pratensis $I_{\text {. }}$

\section{Uebersicht der Gattungen.}

\section{SILIQUOSAE. Schotentragende.}

Schote, in 2 Klappen aufspringend.

A. Keim seitenwurzelig; Würzelchen an den Ründern der flach aufeinanderliegenden Keimblätter. Same rund.

a) Narbe 2lappig.

Cheiranthus. Narbenlappen abstehend, Sch. zusammengedrückt; $S$. in jedem Tache 1reihig.

b) Narbe kopfig.

$\alpha$ ) Samen in jedem Fache 1reihig.

*) Klappen der Sch. mit deutlichem Mittelnerven.

B a rbarea. Sch. stielrund, 4kantig; Blkr. gelb.

Arabis. Sch. zusammengedrückt; Klappen ausser d. Mittelnerven mit undeutlichen Seitenadern; Blkr. (bei uns. Arten) weiss.

*) Klappen der Sch. ohne Mittelnerven.

Cardamine. Sch. zusammengedrückt, ungeschnäbelt.

Dentaria. Sch. zusammengedrückt, langgeschnäbelt.

ß) Samen in jedem Fache 2reihig.

Turritis. Sch. zusammengedrückt, Klappen 1nervig.

Nasturtium. Sch. verkürzt, etwas cylindrisch, Kl. nervenlos.

$B$. Keim rückenwurzelig. Würzelchen auf dem Rücken der flach aufeinanderliegenden Keimblätter. Same länglich.

Sis y mbrium. Sch. stielrund od. flach-lineal; Kl. 3nervig; S. in jedem Fache 1reihig.

Erysimum. Sch. 4kant.; Klappen 1nervig; S. 1reihig.

C. Keim rückenwurzelig; Würzelchen auf dem Rücken der rinnig ineinandergefalteten Keimblätter.

Brassica. Sch. stielrund od. kantig; Klappen Inervig; S. in jed. Fache 2reihig, kugelig. 
Sinapis. Sch. stielrund od. kantig; Klappen 3-5nervig; S. 1reihig, kugelig.

Diplotaxis. Sch. zusammengedrückt; Klappen 1nervig; S. 2reihig, oval.

Eruca strum. Sch. zusammengedrückt; Klappen 1nervig; S. 1reihig, oval.

\section{SILICULOSAE. Schötchentragende.}

Schötchen in 2 Klappen aufspringend.

A. Latiseptae. Scheidewand der Schötchen breit.

a) Stbfäden alle od. einige mit zahnartiger Hervorragung.

A lyssum. Sch. rundl. od. oval, zusammengedrückt, Fächer $2-4$ eiig.

Farsetia. Sch. oval mit etwas convexen Kl, ; Fächer 6-9eiig.

b) Stbfäden ohne Hervorragung.

Draba. Sch. eirund-längl. mit convexen Kl.; Fächer vieleiig.

Cochlearia. Sch. fast kugelig, gedunsen; Fächer vieleiig; Griffel beim Aufspringen auf d. Scheidewand stehenbleibend.

Camelina. Sch. birnfürm., etwas convex; Fächer vieleiig; Griffel frühzeitig abfallend.

B. Angustiseptae. Scheidewand d. Schötchen schmal.

a) Stbräden ohne Anhängsel.

L e pi di u m. Sch. rundl. od. eiförmig, ungeflügelt od. geflügelt, Fächer 1samig; Blbl. gleich.

Hu tchinsia. Sch. ungeflügelt; Fächer 2samig, sonst wie vor.

Capsella. Sch. fast 3eckig, etwas zusammengedrückt, Fächer vielsamig; Blbl. gleich.

Thlaspi. Sch. rundlich, an d. Spitze gekerbt; Klappen geflügelt ; Fächer 2-vielsamig; Blbl. gleich.

Iberis. Sch. eirund, an d. Spitze gekerbt; Klappen geflügelt; Fächer 1samig; Blbl, ungleich.

b) Stbfäden an d. Basis mit einem kleinen Anlängsel.

Teesdalia. Sch. rundl., an d. Spitze gekerbt; Kl. schmal geflügelt; Fächer 2samig; Blbl. etwas ungleich, sehr klein.

III. NUCAMENTACEAE. Nüsschentragende.

Schötchen nussartig, hart, 1samig, wenig oder gar nicht aufspringend. )

-) Auch im unreifen Zustande sind die Früchte schon etwas pergamentartig, fester, und dadurch von den Früchten der früheren Abth, zu unterscheiden.

SCHNIDT, Flora v. H. 
Senebiera. Sch. von der Seite zusammengedr. od. fast 2knotig, ungeflügelt.

Is a tis. Sch. flach mit kielförmigen Klappen, 1 fächrig, bei d. Reife schwarz.

Neslia. Sch. kugelig, 1fächrig.

My a grum. Sch. birnförmig, 3fächrig, die 2 oberen Fächer nebeneinandergestellt, leer.

IV. LOMENTACEAE. Gliederschotentragende.

Schoten od. Schötchen der Quere nach in meist 1samige Glieder sich trennend.

$\mathrm{R}$ a phan us. Sch. walzenförm., in $2-6$ Glieder zerfallend.

Rapistrum. Schtch. 2gliedrig, das untero Glied stielrund, -1-3samig, das obero eiförmig, 1samig.

\section{Che iranthus $L$. Goldla ck.}

47. Ch. Cheiri L. Gemeiner G.; Bl. lanzettl., spitz, ganzrandig, spärlich mit 2theiligen anliegenden Haaren besetzt. 4. 1-1 $\frac{1}{2}^{\prime}$. Blkr. gelb.

Im Gemäuer der H. Schlossruine! Mai, Juni.

2i. Barbarea $R, B r \cdot B$ arbenkraut.

48. B. vulgaris $R . B r$. Gem $\theta$ in es B.; Bl. leyerf.-fiedersp., d. oberen ungeth., gezähnt; Blth. gedrängt; Sch. aufrecht; Fruchtstiele ein wenig abstehend. $\hat{\odot} \cdot 1-1 \frac{1}{2}^{\prime}$. Bl. mattgrün, kahl od. wenig behaart. Blkr. gelb.

Auf feuchten Aeckern, Wiesen, in Gräben und Gebüschen häufig! April-Juni.

49. B. arcuata Rchb. B ogenförm. B.; Bl. d. vorigen; Blth. locker; Sch. deutl., gebogen; Fruchtstiele fast horizontal abstehend. ๙.. $1-1 \frac{1}{2}^{\prime}$. Die ganze Pfl. schlanker u. zarter; Blkr. gelb.

An älnlichen Standorten wie vorige; im Gebiete der Flora bisher nur nahe bei Rauenberg! Mai-Juli.

[Verbreitung im Rheingebiet zweifelhaft. Im Rhein- u. Mainthale d. Flora v. Nassau (Fuckel).]

50. B. stricta Andr. Steifes B.; Bl. d. vorigen; Blth. gedrängt, pyramidenförm.; Sch. nebst den Fruchtstielen dem Stengel dicht angedrückt. ๑. $2-3$ '.

Hie und da an Flussufern, in Gräben, z. B. am Neckar bei Ziegelhausen! bei Wiesloch! an der Weschnitz bei Weinheim! Mai, Juni. 


\section{Arabis $L$. Gänsekraut.}

a) Traube gerade, gedrängt.

51. A. Gerardi Bess. Gerard's G.; St. aufrecht, angedrücht rauhhaarig, wurzelst. Bl. (wie bei d. folg. Arten) in den Bltstiel verschmälert, rosettig, stengelst. Bl. länglich, herzf.-stengelumfassend mit anliegenden Blattöhrchen; Sch. fast aufrecht, längsaderig; S. fein punktirt, schmalgeflügelt. $\hat{\delta}$. $1 \frac{1}{2}-2 \frac{1}{2}$ '. Blkr. weiss.

Auf feuchten Wiesen und Kiesfächen der Rheinebene: Wagh.! Neu-Lussheim! Mai, Juni.

[A. hirsuta Scop. Rauha ariges G.; St. aufrecht, abstehend steifhaarig, stengelst. Bl. am Grunde herz-pfeilf. mit abstehenden Oehrchen; Sch. fast aufrecht, längsaderig; S. nicht punktirt, schmalgeflügelt. $\hat{\delta}$. $\frac{1}{2}-1^{\prime}$. Blkr. weiss; Sch. mehr zusammengedrückt, etwas kürzer und breiter als die vorigen.

N. V. a. d. Geb.: In Rhb.: Auf Kalkhügeln bei Callstadt und Leistadt! Mai, Juni.]

b) Tr. geschlängelt, locker.

[A. auriculata Lam. Oehrchen-G.; St. und Bl. rauhhaarig, stengelst. Bl. eirund-länglich, herzf.-stengelumfassend; Sch. abstehend, fast 3nervig; S. flügellos. ๑. 4-10". Blkr. weiss.

N. V. a. d. G.: In Rhb.: Auf trockenen Kalkhügeln, Brachäckern, in Weinbergen bei Dürkh.! Callstadt! Leistadt; April, Mai.]

23. C a rdamine $L$. S cha um r raut.

a) Blbl. 3mal länger als d. $K$.

52. C. amara $L$. Bitteres S.; St. kantig, mit Ausläufern; Bl. gefiedert; Fiederläppchen eirund-längl., stumpf, gezähnt; Stbgef. fast so lang als die weisse Blkr.; Antheren violett. 4 . $\frac{1}{2}-1 \frac{1}{2}^{\prime}$.

An Quellen, Gräben, in feuchten Gebüschen, auch in Torfsümpfen und auf nassen Wiesen, jedoch nicht überall. In der Nähe von H., besonders in der sog. Hirschgasse, hinter dem Haarlass u. bei Ziegelhausen in Menge! April, Mai. (Verwechslung mit Nasturt. off.!)

53. C. pratensis $L$. Wi e sen-S.; St. rundl. ohne Ausläufer; Bl. gefiedert; Fiederläppchen lineal, ganzrandig: Stbgef. viel kürzer als die hell-violette (selten weisse) Blkr.; Antheren gelb. 4. $\frac{1}{2}-1$ '. Auf Wiesen, an Gräben, in feuchten Wäldern überall! April, Mai.

b) Blbl. doppelt so lang als d. K., weiss.

54. G. hirsuta $L$. Rauhhariges S.; St, aufrecht, wie d. Bl. steifhaarig; Bl. gefiedert, d. unteren rosettig; Stbgef. 4, fast so lang als die Blkr.; Sch. u. Fruchtstiele aufrecht; Griffel kürzer als d. Breite der Schote. א. 3-9". 
Auf feuchten Wiesen: Waghäusel! an Bächen u. in Gebüschen: hinter der Stiftsmühle! am Graben vor Ziegelhausen! April, Mai.

55. G. sylvatica $L k$. Wald-S.; St. aufsteigend, wie d. Bl. schwach behaart; Bl. gefiedert, d. unteren nicht rosettig; Stbgef. 6, fast so lang als d. Blkr.; Sch. aufrecht; Fruchtstiele abstehend; Griffel von der Länge der Schotenbreite. $\hat{\varsigma} .4-9$ ". Schlanker $u$. zarter, als vorige.

In Waldgebüschen: hie u. da beim Haarlass! Im Birkenauer Thal bei Weinheim! April-Sept.

c) Blbl. sehr klein, den K. wenig überragend, grünlich, mitunter völlig fehlschlagend.

56. C. impatiens $L$. Spring-Sch.; St. aufrecht, reichbeblättert; Bl. vielpaarig gefiedert mit pfeilförm., gewimperten Oehrchen; Stbgef. wenig länger als d. Blkr.; Sch. u. Fruchtstiele abstehend; Sch. elastisch aufspringend. $\odot .1-1 \frac{1}{2}^{\prime}$. Die ganze Pflanze hellgrün, zart.

In Wäldern, besonders auf Gerüll stellenweise gesellig, z. B. in der Nähe von $H$. hinter dem Haarlass! im Carmeliterwäldchen, an den Weinbergen hinter der Schlossterrasse! Bei Wagh.! im oberen Walde bei Wiesloch! am Teufelskopf bei Dielheim! bei Weinheim! Mai-Juli.

\section{Dentaria $L$. Zahnwurz.}

57. D. bulbifera $L$. Kn ollentragender Z.; Wurzelstock fleischig-schuppig; St. aufrecht, in den Blattwinkeln Zwiebelknospen tragend, untere Bl. gefied., obere ungeth. 24. $1-1_{\frac{1}{2}}^{\prime}$. Blkr. blassrth.

In Wäldern. Zwischen Wiesenthal u. Huttenheim, häufiger im Stangenwald bei Noudorf, selten bei Waghäusel (Dölll). Mai, Juni.

[N. V.a. d. Geb.: In B.: bis Graben u. Bruchsal (Forster Wald). In Hs.: Koberstadt bei Langen (Sclentsp.), nur sporadisch. In Rhb. fehlend.]

\section{Turitis $L$. Thurmkraut.}

58. T. glabra L. K a hles Th.; St. starr, aufrecht, blaugrün, kahl, untere Bl. schrotsügeförm., rauhhaarig, obere Bl. pfeilf.-stengelumfassend, ganzrandig, kahl; Sch. aufrecht, schmal lineal. $\hat{\text {. } . ~ 2-4 ' . ~}$ Blkr. gelblich-weiss. Die unteren Blätter frübzeitig absterbend!

Auf sandigen Flächen, z. B. bei Friedrichsfeld! Schwetzingen! Neu-Lussheim! Sandhausen! u. s. w. nicht selten. An Waldrändern und in Gebüschen hie u. da, z. B. an der Hillenbach bei Handschuhsheim! Molkenkur, Heiligen Berg (Stud. Gysser). In den Steinbrüchen zwischen Neckargemünd u. Schlierbach! Juni, Juli. 
26. Nasturtium R. Br. Brunnenkresse.

a) Blkr. weiss.

59. N. officinale R. Br. Gemeine Br.; St. mehr oder weniger niederliegend; Bl. 3-7paarig gefiedert; Fiederläppchen rundl., an der Spitze etwas ausgeschweift; Sch. linealisch, etwas convex. 4. Variirt:

$\alpha)$ siifolium $\mathrm{Ko} \mathrm{ch}$; in allen Theilen grösser $\mathrm{u}$. kräftiger;

ק) microphyllum $\mathrm{Rchb}$; in allen Theilen kleiner, zwergartig.

Die Pflanze kann leicht mit Cardamine amara verwechselt werden, von welcher sie sich durch die ausgeschweiften Fiederläppchen, durch gelbe Antheren und durch kleinere Blkr. unterscheidet. (Sisymbrium Nasturtium L.)

In Gräben, an Flussufern stellenweise häuffg genug, z. B. bei St. Ilgen! Wiesloch! Rauenberg! Brühll am Neckar bei H.! Var. $\alpha$ in den tiefen Moorgräben bei Waghäusel und Sanddorf nicht selten. Var. $\beta$ am Neckar bei Neuenheim! am Rhein bei Ketsch! in trocken gelegten Gräben bei Wiesl.! Juni-Sept. (Off. : Hb. Nasturt. aquatici.)

b) Blkr. gelb.

60. N. amphibium R. Br. Wasser-B.; St. aufrecht, am Grundo wurzelnd; BI. längl.-lanzettl., am Grunde eingeschnittengezähnt, die unteren leyerförm.; Blb. länger als d. K.; Sch. ellipt.länglich, 2-3mal kürzer als das Fruchtstielchen. 24. 1-3'. E6 finden sich folgende Varietäten:

$\alpha)$ indivisum $\mathrm{Rchb.;} \mathrm{Bl.} \mathrm{ganz,} \mathrm{gesägt;}$

$\beta$ ) variifolium $\mathrm{R} \mathrm{chb}$.; untergetauchte Bl. kammartig flederspaltig, obere Bl. ganz.

An Flussufern, an und in Gräben und Teichen, in Sümpfen, Var. $\alpha$ in ausgetrockneten Sümpfen, an Teichrändern, überhaupt in trockneren Jahren öfter auftretend; Var. $\beta$ in den Sumpfgegenden des Gebietes und in tiefern stehenden Gewässern nicht selten! Mai bis Juli.

61. N. sylvestre $R . B r$. W ald-B.; St. aufsteigend, verzweigt; Bl. fiederspaltig, lappig od. gesägt; Blbl. länger als d. K.; Sch. lineal von der Länge des Fruchtstielchens oder länger. 4. $\frac{1}{2}-1 \frac{1}{2}^{\prime}$. Die Einsehnitte der Blattränder sind sehr veränderlich und nicht selten bei einem und demselben Exemplar wechselnd. Ebenso variirt auch die Länge der Griffel, welche jedoch stets kürzer als bei der folgenden Art, oft sehr kurz ist.

An Flussufern, Wegen, Gräben, in feuchten lichten Wäldern überall häufig! Juni-Sept.

62. N, anceps Rchb. $Z$ weischneidiger Br.; St. aufsteig., verzweigt; Bl. leyerförm.-fiedersp.; Blbl. länger als d. K.; Sch. 
lineal-länglich, convex, an beiden Enden zusammongedrückt, kürzer als d. Fruchtstiel; Griffel verlängert. 4. 1-2'.

An sandigen Flussufern. Mit Sicherheit bisher nur am Neckar bei Ladenburg, daher hinsichtlich der Verbreitung weiter zu verfolgen. Juni-August.

63. N. palustre $D C$. S u mpf-B.; St. aufrecht, fast einfach; untere Bl. leyerförmig, obere tief fiedersp.; Blbl. von der Länge d. K.; Sch. längl., gedunsen, an beiden Enden stumpf, von der Länge des Fruchtstieles; Griffel kurz. 4. $\frac{1}{2}-1_{\frac{1}{2}}^{\prime}$.

An Gräben, Teichen, in Sümpfen, nur auf feuchtem Boden! Juni-August.

\section{2\%. Sisymbrium $L$. Rauke.}

a) Blkr. gelb.

64. S. officinale Scop. Heilkräftige R.; St. aufrecht; Bl. schrotsägeförmig-fiederspaltig, die oberen spiessförmig; Sch. pfriemlich, oben verschmälert, der Spindel angedrückt. ๑. $\frac{1}{2}-1^{\prime}$. Blth. klein.

Auf Schutt, an Wegen, besonders in Dörfern sehr häufig. Juli bis November.

65. S. Sophia $L$. Sophien-R.; St. aufrecht, einfach oder verzweigt; Bl. 3fach gefiedert, Zipfel linealisch, weichhaarig; Sch.

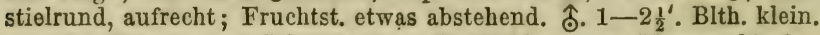

An Wegen, auf Schutthaufen, Sandfeldern, an Mauern häufig; auch in Weinbergen mitunter sehr gesellig! Juli-October.

[S. Loeselii L. Lös el's R.; St. aufrecht; Bl. leyerf.-gefiedert; die unteren nebst St. abstehend behaart; Bbl. länger als d. K.; Sch. abstehend. $\odot$. $\frac{3}{4}-1^{\prime}$.

Auf Sandfeldern beim Relaishause (Dierb.) Juni, Juli. Sporadisches, gegenwärtig unsicheres Auftreten! (In Rhh. Worms und Oppenheim an alten Mauern (Schtsp.) in B. u. Rhb. fehlend.]

66. S. strictissimum $L$. S ehr steife R.; St. aufrecht, steif: BI. länglich-lanzettlich, ungetheilt, weichhaarig; Sch. stielrund, nebst den Stielchen fast aufrecht. 4. 2-4'. Blkr. ansehnlich.

An Flussufern, in Weidengebüschen. Am Neckar bei der Bergheimer Mühle! Juni, Juli. [In Hs.: Darmstadt (Schtsp.). Längs des Mainufers von Schweinfurt bis Frankfurt, Hochheim und Wertheim.]

b) Blkr. weiss.

67. S. Alliaria Scop. Kn o b l a u ch R.; St. aufrecht, einfach; Bl. ungetheilt, buchtig gezähnt, weichhaarig, untere langgestielt nierenförmig, obere herzeiförmig; Sch: stielrund, nebst den Stielchen abstehend. §. $1-2 \frac{1}{2}^{\prime}$. Blätter nach Knoblauch riechend. (Erysimum Alliaria L.)

In Wäldern und Gebüschen häufig! April-Juni. 
68. S. Thalianum Gaud. Thal's R.; St. aufrecht, zart; BI. länglich-lanzettl. gezähnelt, weichhaarig; Sch. flach-lineal, nebst den fast gleichlangen Stielchen aufrecht abstehend. ๑. 3-10". (Arabis Thaliana L.)

Auf Sandflächen, Granitfelsen, Brachäckern häufig genug! März-Juni. *)

\section{Erysimum $L$. Schotend otter.}

69. E. cheiranthoides $L$. Goldlackartiger S.; St. aufrecht, ruthenförmig; BI. längl.-lanzettlich, von gabeligen Haaren etwas rauh; Blthstiele länger als d. K., 2-3mal kürzer als die aufrecht abstehenden Schoten. ๑. 1-2'. Blkr. ansehnlich, gesättigt gelb.

Auf Aeckern, an Schutthaufen, an Ufern häufig! Juli-Sept.

70. E. orientale $R$. Br. Morgenländischer S.; kahl, blaugrün; Bl, tief-herzförmig stengelumfassend, ganzrandig. ๑. $\frac{1}{2}-2^{i}$. Blkr. weissgelb. (Brassica orientalis L.). (Erysimum perfoliatum Crantz.)

Auf Aeckern, besonders auf Kalk- und Lehmboden nicht selten. Weinheim! Ladenburg! Handschuhsheim! Leimen! Wiesloch! beim Relaishause! einzeln auch bei Eppelheim! Wieblingen! Juni-Aug.

\section{Brassica $L$. Kohl.}

a) Schoten aufrecht abstehend; Samen glatt.

B. oleracea L. Gemü se K.; Bl. blaugrün, kahl, untere leyerf., obere länglich; Blthtraube schon vor dem Aufblühen verlängert, schlaff; Kbl. aufrecht; Stbfäden alle aufrecht. $\widehat{\diamond}$. Blkr. weissgelb.

Wird in zahlreichen Varietäten kultivirt.

Br. Rapa L. Rübenkohl. Untere BI. leyerförmig, obere eiförmig-zugespitzt, mit tiefherzförm. Grunde stengelumfassend, Traube gedrängt, doldentraubig, die geöffneten Blüthen die Knospen überragend; Kbl. abstehend; die 2 kürzeren Staubfäden abstehend. ๑. und $\hat{\text { o. }} 2-4^{\prime}$. Blth. gelb; Bl. der jungen Pflanze dunkelgrün, steifhaarig, die später folgenden blaugrün, kahl. Variirt:

$\alpha)$ oleifera; Rübenreps. Wurzel dünn (Oelpflanze);

-) Das in früherer Zeit beobachtete sporadische Auftreten von S. pannonicum (Jacq.) auf Sandfeldern zwischen Schwetzingen und Sanddorf (Dr. Schimp) ist für jetzt zweifelhaft. Die Pflanze würde überdies nur als zufällig eingewrandert betrachtet werden können. 
$\beta$ ) rapiferc $R$ übe; Wurzel dick, länglich oder oval (Gemüsepflanze).

Wird gebaut, kommt auch zuweilen verwildert vor.

B. napus L. Kaps; Bl. der vorigen Art, jedoch jeder Zcit mehr blaugrün; Traube verlängert; die geöffneten Blüthen tiefer stehend als die Knospen; Kbl. abstehend; die 2 kürzeren Staub-

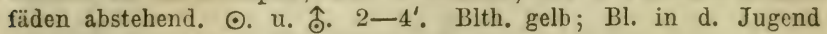
zuweilen feinhaarig. Variirt als:

$\alpha)$ oleifera; Kohlreps; Wurzel dünn (Oelpflanze);

ß) rapifera; Kohlrübe, Stockrübe; Wurzel dick, fleischig (Gemüsepflanze).

Kultivirt und verwildert. Mai, Juni.

b) Schoten der Spindel anliegend; S. netzartig eingestochen punktirt.

71. B. nigra Koch. S chwarzer Kohl (Senf); St. steifaufrecht, unten borstig-behaart; Bl. gestielt, untere leyerf., obere lanzettl., ganzrandig, etwas hängend; Kbl. abstehend; Sch. 4kantig, kurzgeschnäbelt. ๑. 2-4'. Blth. hellgelb; S. schwärzlichbraun. (Sinapis nigra L.).

Am Neckarufer stellenweise sehr verbreitet, besonders bei Ladenburg! Neuenheim! Neckargemünd! bei der Bergheimer Mühle! Auch am Rhein, z. B. beim Relaishause! Juni-Aug. (Off.: Sem. Sinap. nigrae).

\section{Sinapis $L$. S enf.}

a) K. wagerecht-abstehend.

72. S. arvensis $L$. Acker-S.; St. steifhaarig, untere BI. langgestielt, fast leyerförmig, obere eiförmig, buchtig gezähnt; Sch. fast cylindrisch, holperig, kahl oder schwach behaart, länger als d. zusammengedrückte Schnabel, Klappen der Sch. 3nervig. ๑. $\frac{1}{2}-1^{\frac{1}{2}}{ }^{\circ}$. Blth. gelb.

Auf Aeckern, Schutthaufeu, an Wegen gemein! Juni-Sept.

S. alba L. Weisser S.; Borstig behaart; Bl. leyerf.-gefledert, unregelmässig gelappt; Sch. cylindrisch, von weissen Haaren steifhaarig, kürzer als der schwertförmige Schnabel; Klappen 5nervig. ○. $1 \frac{1}{2}-2^{\prime}$. Blth. gelb.

Auf Aeckern, unter dem Getreide, hio und da kultivirt und verwildert. Mai-Juli. (Off.: Sem. Sinap. albae s. Erucae.)

b) K. aufrecht anliegend.

73. S. Cheiranthus Koch. Goldlackblth. S.; St. ästig, fast kahl; alle Bl. tief fiedersp.; Fiederlappen ungleich gezahnt od. fast ganzrandig; Sch. walzig, holperig; Klappen 3nervig. ㅅ. $\frac{1}{2}-1 \frac{1}{2}$ '. Blkr, ansehnlich, gelb. (Brassica Cheiranthus Vill.). 
Auf Sand- und Kiesfl̈̈chen, auf steinigen Hügeln selten, z. B. bei Waghäusel! Oberhausen! Wiesenthal! stellenweise auf der Rheinfläche bis Mannheim! Juni-August.

[In grösserer Verbreitung $\mathrm{zw}$. Graben-Carlsruhe: in Rhb. $\mathrm{zw}$. Ludwigshafen-Dürkheim! Scheint in Hs. zu fehlen, obwohl d. Grenze d. Verbreitung erst in Rhpreussen bei Andernach erreichend!]

\section{Diplotax is $D C$. Doppelsame.}

74. D. tenuifolia $D C$. Schmalbl. D. St. ästig, am Grunde halbstrauchig, beblättert ; Bl. mehr oder weniger fiedersp. ; Blthstielchen doppelt so lang als die Blüthe. 4. $1-2^{\prime}$. Bl. etwas blaugrün, kahl; Blth. ansehnlich, citronengelb. (Sisymbrium tenuifolium L.)

An Flussufern, an Wegen, auf Schutthaufen stellenweise häufig, meist sehr gesellig. Besonders in der Nähe des Rheines verbreitet bei Mannheim! beim Relaishause! Waghäusel! Ketsch! Schwetzingen! Auch am Neckar hie und da nicht selten, z. B. bei Neuenheim! beim Schwabenheimer Hofe! Ladenburg! Mai-October.

75. D. muralis $D C$. M a u e r-D.; St. ästig, meist niederliegend, krautartig, nur am Grunde beblättert; Bl. eirund-lanzettl., buchtiggezähnt oder flederspaltig; Blthstielchen so lang als die Blth. ๑. $\frac{1}{2}-1 \frac{1}{2}^{\prime}$. Blth. citronengelb, kleiner als bei der vorigen. (Sisymbrium murale L.)

Auf Aeckern, Schutthaufen, an Mauern, Wegen häufiger als die vorige. Am Neckarufer von Weinheim bis $\mathrm{H}$. verbreitet. Auch auf Brachäckern bei Baierthal! Alt-Wiesloch! Malsch nicht selten! Juni bis September.

\section{Erucastrum Schimp. H undsrauke.}

76. E. Pollichii Sch.et Sp. Pollich's H.; Bl, tieffiedersp. mit länglichen buchtiggezähnten Zipfeln; Trauben locker, unterwärts mit Deckblättern; Kbl. aufrecht abstehend. ๑. u. ค. $1-2^{\prime}$. Bl. dunkelgrün; Blth. hellgelb. (Sisymbrium Erucastrum Poll.).

An Landstrassen, auf Schutthaufen, Brachfeldern stellenweise ziemlich häufig: Wiesloch! Schatthausen! von Mannh.! bis Schwetzingen! Ketsch! Waghäusel! Auch am Neckar bei Neuenheim! und Neckargemünd! Mai-Juli.

\section{Alyssum $L$. St einkraut.}

77. A. montanum $L$. Berg-St.; niederliegend, sternhaarig grau; Bl. lanzettl., untere verkehrt-eiförmig; Kbl. nach der Blthzeit abfallend; Blbl. länger als der Kelch; längere Stbf. deutlich geflügelt, kürzere nur mit Anschwellungen. 4. 3-9". Blth. goldgelb. 
Auf Sandflächen bei Friedrichsfeld! Schwetzingen! Walldorf! beim Relaishause! u. s. w. in grosser Menge. Auf Felsen und an sandigen od. lehmigen Abhängen weniger verbreitet, z. B. im Ludwigsthal bei Schriesheim! bei Weinheim! Wiesloch! April-Juni, auch August-September.

78. A. calycinum $L$. B ekelchtes $\mathrm{St}$; a afrecht od. niederliegend, meist sternhaariggrau; Bl. länglich-lanzettl.; Kbl. bleibend; Blbl. kaum länger als d. K.; längere Stbfäden ohne Anhängsel, kürzere borstig gezähnt. $\odot .3^{\prime \prime}-1^{\prime}$. Blth. hellgelb, endlich weisslich.

Auf Aeckern, an Mauern, Felsen, auf Sandflächen, auch in trockenen lichten Wäldern hie und da häufig, z. B. in den Sandgegenden der Ebene! bei Weinheim u. a. im Birkenauer Thale in grosser Menge! Auch bei Neuenheim! Wieblingen! an den Felsen beim Haarlass! An lichten Waldstellen zw. Nussloch u. dem Maischbacher Hof findet sich die Pflanze nicht selten fusshoch, grasgrün, fast kahl, als interessante Waldform. Mai-Juli.

34. Farsetia $R$. Br. Farsetia.

79. F. incana $R$. Br. We issgra ue F.; aufrecht, weissgrau;

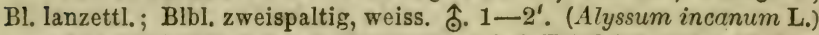

Auf Sandfeldern beim Relaishause! bei Friedrichsfeld und dem Rohrhofe! Sandhausen! in den Kiesgruben vor Schwetzingen! Auch am sog. Winterhafen bei H.l und stellenweise weiter abwärts am Neckar, besonders beim Schwabenheimer Hof und bei Ladenburg! Mai-August.

35. Draba $L$. Hungerblü $\mathrm{m} \mathrm{ch}$ en.

80. D. verna $L$. Frühlings-H.; Bl, alle grundständig, rosettig, lanzettlich; Blbl. 2spaltig, sehr klein, weiss; Schötchen meist elliptisch. ๑. 2-4". Variirt:

B) praecox, Schötchen rundlich.

Auf sandigen Feldern, an sonnigen Anhöhen, Mrauern allgemein verbreitet. Die Varietät besonders an den sonnigen Abhängen des Ludwigsthales bei Schriesheim! März-Mai.

\section{Cochlearia $L$. L ö f e l kraut.}

C. Armoracia L. Mährrettig; St. ästig; untere Bl. länglich, gekerbt, mittlere kammartig fiederspaltig, obere eiförmig-lanzettlich, gesägt oder ganzrandig; Klappen der Sch. nervenlos. 4. 2-4'. Blkr. weiss. Armoracia rusticana Fl, d. W.

Wird cultivirt und verwildert zuweilen. Juni, Juli.

\section{3\%. Camelina Crants. L e ind ot ter.}

81. C. sativa Crantz. G emeiner L.; Bl, längl.-lanzettl., ganz- 
randig oder kaum gezähnt, am Grunde pfeilförmig. ๑. 1-1 $\frac{1}{2}$. Blkr. blassgelb.

ß) microcarpa Andr, mit kleineren Schötchen.

Auf Aeckern, an Wegen nicht selten. Die Var. besonders häufig unter dem Getreide bei Alt-Wiesloch und Dielheim! Wird auch hio und da als Oelpflanze gebaut. Mai-Juli.

82. C. dentata Pers. Gezähnter L.; Bl. lineal-länglich, buchtig gezähnt oder fiederspaltig, am Grunde pfeilförmig. ○. 1-1 $\frac{1}{2}$ '. Blkr. blassgelb; Samen doppelt so gross als bei der vorigen Art.

Auf Aeckern, vorzugsweise auf Leinfeldern selten. Seckenheim. Mai-Juli.

[Häufiges Unkraut in Leinfeldern in Hs.; auch hio und da in Rhb., z. B. bei Grethen unfern Dürkheim].

\section{Lepidium L. Kresse.}

a) Sch. ungeflügelt.

83. L. Draba $L$. Stengelumfas sende $\mathrm{Kr}$.; grauflaumig, untere Bl. länglich, geschweift gezähnt, in den Blattstiel verlaufend, obere pfeilförmig, stengelumfassend; Schötchen herzförmig, kahl; Griffel fadenförmig. 2. 1-1 $\frac{1}{2}^{\prime}$. Blth. weiss klein.

An Ackerrändern und Wegen sehr selten und vereinzelt. Zwischen dem Grenzhofe und Edingen, zw. Feudenheim u. Mannheim (Dr. Schimp.) Mai, Juni.

[In Rhb.: Speier, Grünstadt $(F . S c h$.$) . In Rhh. : Nierstein (Schntsp.)]$

84. L. graminifolium $L$. Grasblättrige Kr.; kahl; St. sperrig-ästig; Wbl.längl., etwas fiederspaltig; obere Bl. lineal, ganzrandig; Schötchen eirund spitz, mit fast fehlendem Griffel. §. 1-2'. Blth. klein, weiss.

An Wegen, auf Schutt, in Weinbergen. Am Neckar bei H.! am Wege nach der Stiftsmühle und nach Neuenheim! zw. Schwetzingen und Mannheim! bei Ketsch! Auf den Rheindämmen stellenweise sehr verbreitet! Juli-October.

\section{b) Sch. geflügelt.}

85. L. campestre $R$. Br. Feld-Kr.; grauflaumig; St. steif, aufrecht, fast einfach: untere Bl. länglich, buchtig gezähnt, obere pfeilförmig, stengelumfassend; Sch. rundlich, von der Mitte an breit abstehend gefiügelt, Griffel kurz. \$. $1-1 \frac{1}{2}^{\prime}$. Blkr. klein, weiss.

Aưf Brachäckern, an Gräben, auf Schutthaufen, an Wegen hie und da, häufiger auf Kalk - und Lehmboden als auf Sand! Mai bis Juli.

L. sativum L. Gartenkresse; kahl, blaugrün; St. aufrecht, einfach; untere Bl. gelappt od. gefledert, obere linealisch; Sch. rund, 
ganz geflügelt, der Spindel angedrückt; Griffel fast fehlend. ๑. $1-1 \frac{1}{2}^{\prime}$. Blth. klein, weiss.

Cultivirt und hie und da rerwildert! Juni-August.

86. L. ruderale $L$. Schutt-Kr.; schärflich behaart; St. aufrecht, ästig; untere Bl. fledersp., obere lineal; Sch. rundlich-eiförmig, schmal geflügelt, abstehend. $\hat{\odot} \frac{1}{4}-1^{\prime}$. Uebelriechend! Blth. klein, weiss diandrisch, gewöhnlich ohne Blumenblätter.

An Wegen, auf Schutt, auf Triften! Nicht überall und in der

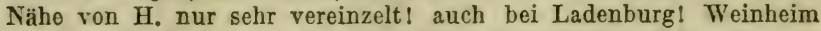
nur sporadisch, dagegen häufiger beim Relaishause! Schwetzingen! Waghäusel! Neckarau! Mannheim! Sandhofen!

[Jenseits des Rheines von Ludwigshafen bis Dürkheim allgemein verbreitet und auffallend gesellig!] Mai-Sept.

\section{[II ut chinsia $R . B r$.]}

[H. petraea R. Br.; ästig; Bl. gefiedert; Schötchen elliptisch, stumpf; Blkr. s. klein, weiss. ๑. $2-3^{\prime \prime}$.

Auf Kalkhügeln bei Dürkheim u. Callstadt in Rhb.! April, Mai.]

\section{Capsella Medic. Hirtentäschel.}

87. G. Bursa pastoris Moench. Gemeines H.; untere Bl. rosettig, fledersp., obere lineal, ganzrandig; Sch. dreieckig-keilförmig in sehr verlängerten Trauben. ๑. $\frac{1}{2}-1 \frac{1}{2}^{\prime}$. Blth. weiss. Variirt mit ganz ungetheilten Blättern und mit blumenkronlosen Blüthen, deren 6-10 Stbgef. unfruchtbar bleiben.

An Wegen, auf Aeckern, in Gärten überall! März-Nov.

\section{Thlaspi $L$. Täschelkraut.}

88. T. arvense $L$. Feld-T.; hellgrün; Stbl. länglich, buchtig gezähnt, am Grunde pfeilförmig; Sch. rundlich, tiefausgerandet, breitgeflügelt, Fächer vielsamig; Samen bogig-runzlich. ๑. $\frac{1}{2}-1^{\prime}$. Blkr. weiss.

Auf Aeckern, an Wegen, in Gärten sehr häufig! Mai-Sept.

89. T. perfoliatum $L$. D u r chwachsenes T.; blaugrün; Stbl. herzförmig, ganzrandig, halbstengelumfassend; Sch. verkehrt herzförmig, schmalgeflügelt, tiefausgerandet; Fächer 4samig; S. glatt; ๑. 4" 1 1'. Bl. weiss.

Auf Aeckern, in Weinbergen, an grasreichen Anhöhen, besonders auf Kalk- und Lehmboden hie und da! Stellenweise in Menge jenseits des Neckars vom Haarlass längs des Philosophenweges! bis Dossenheim! und Weinheim! häufig auch bei Wiesloch! Dielheim: Edingen! Wieblingen! Eppelheim! Waghäusel! etc. April-Juli. 
[Th. montanum L. Berg-T.; St. lockere Rásen bildend, aufsteig.; Wbl. spatelf.; Stbl. herzf. sitzend; Fruchtk, 4eiig; Sch. rundlich verkehrt herzf.; S. glatt. 4. 4-8". Blkr. weiss.

N. V. a. d. Geb.: auf Kalkboden an Bergabhängen bei Kallstadt $u$. Herxheim in Rhb.! April, Mai.]

\section{Iberis $L$. B a uernsenf.}

90 1. amara $L$. Bitterer B.; ästig; Bl. länglich, keilförm., an der Spitze 2-3zähnig, Sch. fast kreisrund, schmal ausgerandet, mit spitzen Lappen. ๑. 3-10". Blkr. weiss. Die ganze Pfl. s. bitter.

Auf Aeckern, kalkhaltigen Boden vorziehend, auf Kiesflächen. Bei Weinheim! Ladenburg! Seckenheim! Eppelheim nicht selten! Einzeln bei Wieblingen! in den Kiesgruben bei Schwetzingen!

[Allgemeiner verbreitet in Rhb. bei Oggersheim und Maxdorf! auch in Rheinhessen!] Juni, Juli.

\section{Te sula li a $R$. Br. Teesdalia.}

91. T. nudicaulis $R$. Br. Naktstengelige T.; Bl. grundständig, rosettig, zahlreich, leyerförm.-fiederspalt. ๑. 2-4". $\mathrm{Blkr}$. klein, weiss; Stengel 1-mehrere.

Auf Sandflächen, Haiden, in trocknen lichten Nadelwäldern hie und da, jedoch in der Nähe von II, ziemlich selten, z. B. am Philosophenwege! bei der sog. Glasshütte! zwischen Schönau u. Neckarsteinach! Stellenweise zwischen Friedrichsfeld u. dem Relaishause! Häufiger im Käferthaler Walde! bei Sandtorf! April-Juni.

\section{Senebiera Pers. Senebiera.}

92. S. Coronopus Poir. Krähenfussartige S.; St. niederliegend, ästig; Bl. tief-flederspaltig; Blthtrauben sehr verkürzt; Sch. knäuelartig beisammenstehend, ungetheilt, nierenförm., netzig-runzelig. ๑. 2-10". Blkr, klein, weiss. Meist im Grase versteckt, wenig vom Boden sich erhebend, daher leicht zu übersehen.

An feuchten, grasreichen Triften, an Gräben, Wegen nicht häufig! In Schwetzingen! Neckarau! In der Nähe von Mannheim am Wege nach Sandhofen! Juni-Sept.

\section{Is atis $L$. W a id.}

93. I. tinctoria $L$. Färber-W.; blaugrün, untere Bl. gestielt, länglich, obere pfeilförm. stengelumfassend; Sch. länglichkeilförm., hängend. ङ. 1-2'. Blkr. gelb.

An Flussufern, Abhängen hie und da. Am ganzen Neckarufer von Ziegelhausen bis gegen Mannheim stellenweise häufig! Auf Kleeäckern zw. Handschuhsh. u. Edingen (Stud. Gysser). Mai, Juni. 


\section{Neslia Desv. Neslie.}

94. N. paniculata Desv. Rispige N.; schärflich behaart; Bl. lanzettl., oben pfeilförm., sitzend; Schötchen klein, etwas runzelig, in verlängerten Trauben. $\odot \frac{1}{2}-1^{\prime}$. Blkr. gelb. (Myagrum paniculatum $\mathbf{L}_{0}$ )

Unter der Saat selten. Zwischen dem Maischbacher Hof und Alt-Wiesloch! bei Nussloch! Weinheim! vereinzelt auch beim Relaishause! Juni-August.

\section{II y g r um Tourn. Hohldotter.}

95. M. perfoliatum $L$. Pfeilblättr. H.; kahl, blaugrün, untere Bl. länglich, buchtig-fiederspalt., stumpf, obere lanzettlich, pfeilfürm., stengelumfassend. $\hat{\delta} \cdot \frac{1}{2}-1 \frac{1}{2}^{\prime}$. Blkr. gelb.

Auf thonhaltigen Aeckern bei Ziegelhausen (Bischoff). Ist in den letzten Jahren nicht wiedergefunden! Juni. Juli.

[Im würtembergischen Neckargebiet einheimisch, von dort sporadisch bis in die Rheinebene verbreitet.]

\section{4\%. Raphanus $L$. Rettig.}

R. sativus $L$. Gemeiner R.; Bl. leyerförm.; Sch. elliptisch, 1-2gliederig, wenig eingeschnürt; S. netzig-runzlich. ๑. $1 \frac{1}{2}-3$ '. Blkr. blass-violett od. weiss. Variirt als :

๔) Radicula DC.; Wzl. klein, spindel- oder rübenförm. mit weisser, rother oder violetter Rinde (Radies);

ß) niger L.; W. gross, rübenf., mit schwarzer Rinde (Rettig). Cultivirt und hie und da verwildert! Juli, August.

96. R. Raphanistrum L. A cker-R.; Bl. Ieyerförm.; Sch. linealisch, 4-6gliedrig, stark eingeschnürt; S. glatt. $\odot .1-2^{\prime}$. Blkr. gelb od. weiss mit dunklen Adern.

Unter der Saat, auf Brachäckern häufig! Juni-Sept.

45. Rapistrum Boerh. Rapsdot ter.

97. R. rugosum All. Runzeliger R.; aufrecht oder niederliegend; Bl. leyerfürm.; Sch. oval, mit pfriemlichem Griffel, kurzhaarig, bei der Reife gerieft-runzelig. ๑. $\frac{1}{2}-1 \frac{1}{2}^{\prime}$. Blkr. gelb. (Myagrum rugosum $\mathbf{L}$.)

An Wegen, auf Brachäckern, unter der Saat in der Ebene hie und da: Schwetzingen! Mannheim! Ladenburg! beim Rohrhofe! besonders häufig bei Waghäusel! Juni-August. 


\section{CISTINEAE. D $\bullet$.}

Halbsträucher mit abwechselnden oder gegenständigen Blättern, mit Nebenblättern oder ohne dieselben. Blthn. in meist armblüthigen Trauben. Kelchbl. 4, die 2 äusseren kleiner, zuweilen fehlend, die 3 inneren umeinandergedreht. Blbl. 5, sehr hinfällig, gedreht, jedoch in einer den Klchbl. entgegengesetzten Richtung. Stbgf. zahlreich. Fruchtkn. frei, 1-mehrfächrig. Griffel 1. Kaps. 3-10klappig, meist viel= samig. Samen eiweisshaltig.

Helianthemum. Kbl. 5; Kps. 3klappig, vielsamig.

\section{He li anthemum Tournef. S onnenröschen.}

98. H. vulgare Gärtn. Ge meines S.; halbstrauchig, niederliegend oder aufsteigend; BI. gegenst., eiförm. oder länglich, gewimpert, mit lineal-lanzettl. Nebenbl. $\hbar$. $\frac{1}{2}-1^{\prime}$. Blkr. gelb. Variirt sehr in Behaarung, bald kahl, bald rauhhaarig oder fast filzig. (Cistus Helianthemum L.)

Auf Sandflächen, an Waldrändern, sonnigen Anhöhen nicht selten, z. B. zwischen Friedrichsf. u. Schwetzingen! bei Schatthausen! Rauenberg! Wiesloch! bei Schriesheim! auch in d. Nähe von H. bei der Molkenkur u. am Haarlass! Juni-August.

99. H. Fumana Mill. D ü nn blättr. S.; halbstrauchig, zwergartig, niederlieg.; $\mathrm{Bl}$. wechselst., lineal., feinstachelspitzig, schwachgewimpert; Nebenbl. fehlend. †. 2-8". Blkr. gelb, klein und sehr hinfällig.

Auf Haiden, Sandfeldern, auf sonnigen Hügcln selten. Beim Relaishause! Zwischen Friedrichsfeld u. dem Relaishause (mit Stipa pennata) und zerstreut auf den Sandfächen der Ebene: Virnheim (Dr. S c h i m p), zw. St. Ilgen u. Sandhsn. (Lehrer Riegel). Juni, Juli.

[Allgemeineres Vorkommen auf Kalkhügeln in Rhb. zw. Dürkheim-Grünstadt 1]

\section{VIOLARIEAE. De Cand.}

Einjährige oder ausdauernde Kräuter mit zuweilen sehr verkürzten Stengelbildungen, einfachen, meist abwechselnden Blättern und oft sehr entwickelten Nebenblättern. Blüthen 
unregelmässig. Klchbl. 5, bleibend, am Grunde etwas verlängert. Blbl. 5, wovon eins (d. untere) sporn - oder sackartig. Stbgef. 5, mit zusammenhängenden Antheren, deren Connective nach oben zu häutigen Fortsätzen sich verlängern. Fruchtkn. 1fächrig, mit 3 wandständigen Samenträgern, Griffel 1, mit kopfförmiger Narbe. Kapsel 3klappig. Samen eiweisshaltig mit geradem Keim. - Der Charakter der einzigen in Deutschland vorkommenden Gattung Violı stimmt mit dem (willkührlich etwas begrenzten) Charakter der Familie überein. Die Hauptmerkmale der sehr formenreichen und wandelbaren Veilchenarten sind von den Blätt. und Nebenblättern der sog. Sommertriebe entnommen. Es muss daher beachtet wcrden, dass die Bl. u. Nebenbl. der Sommertriebe, welche erst nach der Frühlingsblüthe sich entwickeln, meist durch beträchtlichere Grösse, durch ausgebildetere Form und verschiedene Behaarung von der BI. u. Nebenbl. der Frühlingstriebe abweichen. Die Blüthen der Sommertriebe haben gewöhnlich keine Blumenkronen, sind aber nicht selten fruchtbar.

\section{Viola $L$. Veilchen.}

a) St. verkürzt, wurzelstockartig, kaum oberirdisch. Kbl, stumpf.

100. V. palustris $L$. Sump f-V.; Wstck, ohne Ausläufer; B1. nierenherzförmig, kahl; Nebenbl. oval, driisiggesägt; Narbe flach ; Fruchtstiele aufrecht; Kapsel 3kantig, kahl. 4. 3-6". Blkr. klein, blassviolett.

Auf Sumpfwiesen und Torfmooren: St. Ilgen! Brühl! Waghäusel! Sandtorf! Zwischen Schriesheim, Wilhelmsfeld u. Schönau! In der Hillenbach und im Mühlenthale bei Handschuhsheim (Stud. Gysser). Mai, Juni.

101. V. odorata $L$. Wo hlriechendes V.; Wstek. mit langen F̂riechenden Ausläufern; Bl. langgestielt breit-eifürmig, am Grunde herzförmig, nebst Blattstielen feinbehaart; Nebenbl. eilanzettl., kurzgewimpert; Narbe hakig-geschnäbelt; Fruchtstiele niederliegend; Kapsel rundlich, hehaart. 4. Blkr. dunkelblau, selten weiss, wohlriechend.

In Heckøn, Gebüschen, Wäldern überall verbreitet. März, April.

Diese Art bildet mit der folgenden eine auffallende Mittelspecies:

V. hirto-odorata Bogenh.; Ausläufer sehr kurz; Bl. langgestielt, rundlich-herzförmig, weichhaarig; Nebenbl. eilanzettl.; Sporn der Blkr. länger als bei $V$. odorata u. hirta; Blkr. getrübt violett oder weisslichgefleckt, nur schwach wohlriechend. - Die Pflanze hat den Habitus der V. odorata, fällt aber durch die abweichende Behaarung 
und Blumenkr. sogleich auf. - Seit einigen Jahren in der Näho von H. an der südlichen Böschung der Schwotzinger Chaussee, unfern der Eisenbahn.

102. V. hirta $L$. R a uha arigos V.; Wstck. ohne Ausläufer oder seltener mit sehr kurzen Ausl.; Bl. kurzgestielt, eiherzförm. nebst Blattst. rauhhaarig; Nebenbl. eiförm., kurzgewimpert; Narbe hakig geschnäbelt; Fruchtstiele niederliegend; Kapsel rundlich, behaart. 2. Blkr. geruchlos, hellblau. Die Pflanze unterscheidet sich schon durch ihren gedrungenen Habitus ron V. odorata!

In Wäldern, Gebüschen, auf Waldwiesen, vorzugsweise auf Kalkund Lehmboden, sowohl in der Ebene, als im Gebirge verbreitet. März-Mai.

b) St. entwickelt, aufsteigend; Kbl. lanzettl., spitz.

«) Nebenbl. klein, kürzer als der ungeflügelte Bltstiel.

103. V. arenaria $D C$. S and-V.; St. meist wenig entwickelt, schwach aufsteigend; Bl. dicht rosettig, klein rundlich-herzförm. od. nierenfürm., schwach gekerbt, sammtartig-weichhaarig oder kahl; Nebenbl. längl.-eiförmig, wimperig gesägt; Kapsel rundlich-eifürmig, zugespitzt. 4. $1-3^{\prime \prime}$. Blkr. blasslila od. weiss. - Die Pflanze, welche zwar zuweilen cinige Achnlichkeit mit der folgenden zeigt, ist doch durch die Blattform (besonders der Sommertriebe) leicht zu unterscheiden. - Die im hiesigen botanischen Garten kultivirte Pflanze zeigte allerdings sehr entwickelte, verlängerte Stengel und war im Habitus der V. sylvestris sehr ähnlich, aber sio behielt sowohl die charakteristische Herz-Nierenform der Blätter, als auch die sammtartige Behaarung derselben. Die Pflanzo erträgt den kultivirten Zustand niemals lange.

Auf den Sandfeldern und in den Nadelwäldern bei Friedrichsfeld! beim Relaishause! bei Schwetzingen! Sandhausen! Walldorf! April, Mai.

104. V. sylvestris Lam. Wald-V.; St. sehr verlängert, aufstoigend; Bl. tiefherzförm.-rundlich, gesägt-gekerbt, kurzzugespitzt, schwachbehaart; Nebenbl. lanzettl., wimperig gesägt; Kapsel länglich, spitz. 4. Blkr. violett, geruchlos. Variirt:

ß) Riviniana Rchb.; BI. mehr rundlich; Blkr. beträchtlich grüsser, blasslila, Sporn farblos.

Dieso Art unterscheidet sich von der folgonden besonders durch die Blattform. Die Blattnerven treten am Grundo der Fläche sogleich auseinander und verlaufen in beträchtlichen Bogenkrümmungen, so dass das Blatt mehr rundlich erscheinen muss. Bei der folgenden Art bleiben dio Nerven am Grundo der Fläche ein klein wenig bei- 
sammen, und verlaufen in sehr schwachen Krümmungen, daher das Blatt mehr länglich wird.

In feuchten Laubwäldern, auf Lehm - und Kalkboden häufig, in der Nähe von II. z. B. beim Haariass allgemein verbreitet. Var. $\beta$. hie und da, meist an sehr schattigen Standorten, z. B. zwischen Friedrichsfeld und Schwetzingen! zwischen Kirrlach und Waghäusel! beim Maischbacher Hof! bei Weinheim! Leutershausen! April, Mai.

105. V. canina $L$. Hunds-V.; St. verlängert, aufsteigend; Bl. herzförmig-länglich, stumpflich, gesägt-gekerbt, behaart od. kahl, Nebenbl. lanzettl,, wimperig gesägt; Kapsel länglich, kurz zugespitzt, 4. Blkr. hellblau, geruchlos. Variirt:

«) ericetorum Schrad.; zwergartig, 1-2", niederliegend, aufsteigend; BI. klein; Blthssiele kurz mit kleineren Blüthen.

B) lucorum Rchb.; hoch $\left(8^{\prime \prime}-1^{\prime}\right)$ aufsteigend, in allen Theilen grösser.

Auf sandigen Haiden, Hügeln, Triften, an trockenen Waldrändern, in Nadelwäldern nicht so verbreitet wie die vorige Art. Auf den Sandflächen des Gebietes jedoch nicht selten und daselbst auch an sehr sonnigen Standorten die Var. $\alpha$, welche mit $V$. arenaria DC. leicht verwechselt werden kann. Var. $\beta$ an schattigen, feuchten sandigen Standorten hie und da; z. B. zwischen Schwetzingen u. Ketsch! bei Oftersheim! Schönau! im Ludwigsthal bei Schriesheim! April-Juni.

$\beta$ ) mittlere Nebenblätter ansehnlich, wenigstens halb so lang als der geflügelte Blattstiel oder länger.

I06. V. lactea Sm. Milchweisses V.; St. aufrecht; Bl. herzförmig od, eirund-lanzettl., kerbig-gesägt, kahl od. weichhaarig; Nebenbl. lanzettl. gezähnt; Kapsel länglich, abgestumpft, mit kurzer Spitze. 24. Blkr. hellblau oder weiss. Variirt in Grösse aller Theile und zeigt sich selbst an einem und demselben Standort als sehr unbeständig und wandelbar. Es lassen sich 3 Unterarten unterscheiden:

$\alpha)$ elatior Fr. ( $V$. elatior M. et K.) $\frac{1}{2}-1^{1^{\prime}}$; BI. lanzettlich mit eiförmigem Grunde in den Blstiel verlaufend, kurzbehaart; Nebenbl. länger als der Blattst; Blkr. ansehnlich, hellblau od. weiss.

B) pratensis (V. pratensis M. et K.) $3-8^{\prime \prime}$; Bl. lanzettlich, mit keilförmigem Grunde, in den Bltstiel verlaufend, kahl; Nebenbl. v. d. Länge des Bltst.; Blkr. bald grösser, bald kleiner, bläulich od. weiss.

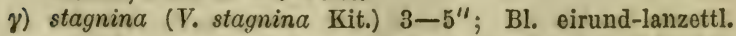
mit abgestutztem od. herzförmigem Grunde, nicht in den 
Blattstiel verlaufend, kahl; Nebenbl. von der Länge des Blattst.; Blkr. klein, weiss.

Auf feuchten Wiesen, in der Ebene hie und da. Var. $\alpha$ auf den Inseln bei Ketsch! bei Otterstadt und längs des Rheins gegen Speyer und Neckarau verbreitet! Var $\beta$ nur sehr stellenweise, z. B. auf den Wiesen zwischen d. Relaishause u. Neckarau! Var. $\gamma$ häufig auf Wiesen beim Strassenheimer Hof unweit Ladenburg! bei Ketsch! Waghäusel! beim Rohrhof, bei Alt-und Neu-Lussheim oft sehr gesellig! Mai.

[Jenseits des Rheins mehr verbreitet. Var. $\alpha$ häufig auf den Rheininseln bei Speier (König). Var. $\beta$ auf trockenen Wiesen am Rhein bei Speier! Var. $\gamma$ sehr gesellig im Igelheimer Walde bei Speier; bei Friesenheim! mit $V$. canina $\beta$ lucorum zusammen im Kiefernwalde bei Maxdorf!]

$\gamma$ ) Nebenbl, anselnnlich flederspaltig.

107. V. tricolor $L$. Dreifarbiges V.; St. aufsteigend, ästig; Bl. grobgekerbt, dio untern herzeiförmig, die oberen lanzettlich. ๑. $4-10^{\prime \prime}$.

«) vulgaris; Blkr. beträchtlich länger als d. Keelch, blau und gelb schattirt.

$\beta$ ) arvensis; Blkr. kaum länger als d. Kelch, vorherrschend gelb.

Auf Aeckern, Sandfeldern, an Wegen, in Gebüschen, an Waldrändern, häufig! Mai-Oct. (Off.: Hb. Jaceae).

\section{RESEDACEAE. DC.}

Irrüuter mit wechselständigen Blättern und meist sehr kleinen drüsenförmigen Nebenblättern. Blüthen unregelmässig in gipfelständigen Trauben, Kelch 4-7theilig. Blb. 4-7 ungleich, ganz oder zerschlitzt. Stbgef. 11-24 einer drüsigen, unregelmässigen, einseitigen Scheibe eingefügt. Fruchtknoten frei, 1fächrig, 3-6lappig, an der Spitze offen, mit 3-6wandständigen, vielsamigen Samenträgern und eben so vielen Narben. Kapsel häutig, sich niemals schliessend. Samen nierenförmig, eiweisslos, mit gekrümmtem Keim.

Reseda. Kelch und Blkrone 4-7zählig, Kapsel häutig, an der Spitze klaffend. 


\section{Reséla $L$. Resede.}

108. R. Iuteola $L$. W a ; St. aufrecht; Bl. lanzettl., ungetheilt; Traube ährenfürmig verlängert; Kelch 4theilig; Bbl. 4. 1-2'. Blkr. gelb.

An Wegen, Flussufern, Ackerrändern, auf steinigen Hügeln nicht selten. Am Neckarufer bei Neuenheim! Ladenburg! bei Waghäusel! St. Ilgen! Nussloch! an den Rheindämmen verbreitet. Juni bis August. (Off.: Hb. Luteolae).

109. R. lutea $L$. Gelbe R,; St. mehr niederliegend; untere B1. doppelt-fiederspaltig, obere tief 3spaltig; Kelch 6theilig; Bbl. 5-7. ๑. Blkr. grünlich blassgelb.

Auf trockenen Aeckern, an Wegen gleichfalls ziemlich häufig. Wiesloch! Schatthausen! Rauenberg! zwischen Mannheim und Schwetzingen! vereinzelt auch bei H., z. B. auf Kleeäckern bèi Handschuhsheim! Juni-August.

\section{$X$. DROSERACEAE. $D C$.}

Kräuter, deren einfache, grundständige, rosettenartige, in der Knospe eingerollte Blätter, bei unsern Arten mit langen, rothen haarähnlichen Drüsenbildungen versehen und besonders an recht warmen Tagen etwas reizbar sind. Blüthen regelmässig, in einseitswendigen Trauben, 5theilig, in der Knospe dachziegelig. Staubgef. 5. Fruchtknoten, 1fächrig, mit 2-5 wandständigen Samenträgern und eben so vielen Narben auf kurzen Griffeln. Kapsel 1fächrig, vielsamig. Samen eiweisshaltig mit geradem Keim.

Drosera. Griffel $3-5$ mit tiefgespaltenen Narben; Kapsel Ifächrig, 3-4klappig.

\section{5\%. Drosera $L$. Sonnenthau.}

110. D. Iongifolia $L$. Langblätteriger S.; Bl. länglich, allmählig in den Blattstiel verlaufend; Blüthenschaft aufrecht, doppelt so lang wie die Blätter. 4.

In Torfsümpfen bei Waghäusel! Juli, August.

111. D. rotundifolia $L$. Rundblät teriger S.; Bl. kreisrund, langgestielt; Blüthenschaft aufrecht, 3-4mal so lang, wie die Bl. 24.

In Torfsümpfen, auf feuchten Wiesen: Waghäusel! Sandtorf! In der Hillenbach und im Mühlenthale bei Handschuhsheim (Stud. Gysser). Zwischen Schönau und Wilhelmsfeld (Dierb.). Juli, Aug. 


\section{PARNASSINAE. E. Meyer.}

Kräuter mit einfachen, kahlen, in der Knospe gefalteten Blïttern. Blüthen einzeln, langgestielt, regelmässig, 5theilig, in der Knospe dachziegelig. Den Blumenblättern gegenüberstehend, 5blattartige, etwas fleischige, fingerförmig zerschlizte, drüsige Nebenblumblätter. Stbgef. 5. Fruchtknoten 1fächrig, mit 3-4 wandständigen Samenträgern und sitzenden Narben. Kapsel vielsamig. Samen eiweisslos mit geradem Keim.

Parnassia. (Einzige Gattung.)

53. Paruassia. $L$. Parnassie.

112. P. palustris $L$. (Ein blatt); St. einfach, 1blüthig, grundständige Bl. langgestielt, herzförmig; das einzige Stengelbl. sitzend, stengelumfassend. 4. $\frac{1^{\prime}}{2}$. Blkr. weiss, gestreift, Nebenkr. grünlichgelb.

Aụf nassen Wiesen, in Torfsümpfen der Ebene u. d. Gebirge: Neckarau! Waghäusel! Sandtorf! St. Ilgen! Schatthausen! Handschuhsheim! auf der Engelswiese bei H.! August, September.

\section{POLYGALEAE. Juss.}

(Mit Begrenzung für "die einzige Gattung unserer Flora.)

Kräuter mit abwechselnden ganzrandigen Blättern ohne Nebenblätter, zuweilen von sehr bitterem Geschmack. Blüthen in meist gipfelständigen Trauben, unregelmässig. Kelchbl. 5, die zwei innern um Vieles grösser, flügelartig, gefärbt. Blbl. $3-5$, das vordere unpaare kielförmig, häufig 3lappig mit kammförmigem Mittellappen. Stbgf. 8, am Grunde mit den Blumenblättern in eine Röhre verwachsen, welche oben oder auch schon am Grunde gespalten ist (monadelphisch oder diadelphisch). Antheren 8. einfächrig, an der Spitze aufspringend. Fruchtkn. 2fächrig, 2eiig. Kapsel 2 fächrig, 2 klappig, 2samig. Samen hängend, eiwcisshaltig mit sehr entwickeltem wulstartigem Samenmantel. - Die vorkommenden Arten sind im Habitus ziemlich übereinstimmend 
und bilden oine häufig auftretende Gräser liebendo niedere Krautvegetation,

\section{Polygala. L. Kreuzblume.}

a) Seitennerven der flügelartigen Kelchblätter ästig geadert und an der Spitze durch Queeradern vérbunden.

113. P. vulgaris $L$. Gemein $\mathrm{K}$. ; St. aufsteigend; grundst. Bl. wechselst., elliptisch; Trauben endständig, locker, vielblüthig; Deckblätter halb so lang als das Blthstielchen. 4. 6-9". Die flügelartigen Klchbl. bald breiter, bald schmäler; Blth. blau, roth oder weiss. - Das Kraut wenig oder gar nicht bitter.

Auf Wiesen, trocknen Kiesflächen, Haiden häufig. Boi Nesterbach, unfern Weinheim, eine ungewöhnlich reichblüthige Form, welche in grosser Menge und mit rosa Blth. die Anhöhen bedeckt. Mai-Juli. (Off.: Rad. Polygalae vulg.)

114. P. comosa. Schkr. Schopfförmige K.; St. aufsteigend; Bl. d. vor.; Trauben endständig, gedrängt, vielblüthig; Deckblätter von der Länge der Blthstielchen; vor dem Aufblühen die Knospo schopfartig überragend. 4. 6-9". Blth. meist blassroth, scltener blau oder weiss; das Kraut wenig oder gar nicht bitter.

An sonnigen Anhöhen, an Waldrändern hie und da häufig, z. B. in der Wolfsschlucht und beim Riesensteine in der Nähe von H. Auch beim Haarlass! bei Leimen! in der Hessel bei Wiesloch! Weinheim! u. s. w. Mai-Juli.

115. P. depressa. Wender. Niederlieg onde K.; St. niederliegend, weitschweifig, zart; grundst. Bl. gegenst. eirund-elliptisch ; Trauben 3-5blthg, scheinbar seitenständig; Deckblätter um dio Hälfte kürzer als der Blthst. 4. Blth. hellblau. Kraut ohne Bitterkeit. (P. serpyllacea Weihe.)

Auf freien, grasigen Waldstellen zwischen dem Speyrer Hof und Gaiberg! an grasreichen, etwas schattigen Abhängen im Mühlenthale bei Handschuhsheim! Mai, Juni. [Durch den Odenwald hio und da verbreitet; jenseits des Rheins erst auf den Torfflächen und Haiden bei Kaiserslautern auftretend !]

b) Seitennerven der Kelchflügel nicht durch Queeradern verbunden.

116. P. amara. $L$. Bittere K.; St. verkürzt, wenig aufsteigend; grundständ. BI. rosettig, verkehrt-eiförmig, anschnlich ; Trauben endständ., vielblüthig; Deckbl. so lang als das Blthstielchen. 4. 4-6". Blth. blau, selten weiss oder röthlich. Sehr bitterschmeckend. Man kann unterscheiden: 
«) grandiflora (gonuina Koch), Blth. grösser; Kelchflügel länger als d. Kapsel.

ß) parviflora (austriaca Koch), Blth. klein; Kelchflügel schmäler und kürzer als d. Kapsel. Diese bald abgerundet, bald mehr keilförmig.

Auf feuchten Wiesen, Triften, an grasigen Abhängen, lichten Waldstellen. Var. $\beta$ hie und da, z. B. Waghäusel! Leimen! Wiesloch! Maischbacher Hof! Schatthausen (mit Botrychium Lunaria)! Neu-Lussheim! Var. $\alpha$ ist seltener, z. B. auf Wiesen bei St. Ilgen! auf Triften zwischen Nussloch und Wiesloch! Mai-Juli. (Off.: Hb. Polyg. amarae.)

\section{SILENEAE.}

Kräuter mit knotig-gegliederten Stengeln, gegenständigen, einfachen, nebenblattlosen Blïttern und trugdoldenartigen, reichblüthigen oder sehr armblüthigen Blüthenständen. Blth. regelmässig. Kelch verwachsen-blättrig, röhrig, 5zühnig. Blbl. 5 getrennt, langbenagelt. Stbgef. $10 \mathrm{mit}$ den Blumenblättern aus einem meist kurzen, säulenartigen Fruchtträger entspringend. Frchtk. 1- selten mehrfächrig, mit mittelständigem Samenträger und 2-5 Griffeln. Frucht kapselartig oder (nur bei Cucubalus) beerenartig. Samen eiweisshaltig mit peripherischem Keim. - Die Sileneen gehören, als meistens stattliche, geselligwachsende Pflanzen, zu den hervorragenden Erscheinungen unserer Flora. Obwohl hinsichtlich ihrer Blüthen auffallend übereinstimmend, sind sie doch im Habitus ziemlich verschieden. Fast an allen Standorten und auf allen Bodenarten vorkommend. Die Blüthezeit der Sileneen beginnt mit der zweiten Hälfte des Frühlings. Keine gehört zu den ersten blühenden Frühlingspfl., wie so manche aus der verwandten folgenden Familio.

a) Griffol 2.

Gypsophila. Kelch ohne Aussenkelch; Blbl. allmählig in den Nagel verschmälert; Samen nierenförmig-kugelig.

Saponaria. Wie vorige, aber Blbl, plötzlich in den Nagel zusammengezogen.

Dianthus. Kolch am Grunde mit einem aus 2 oder mehreren schuppenartigen Blättern bestehenden Aussenkelch; Blbl. plötzlich in den Nagel zusammengezogen; Samen schildförmig. 


\section{b) Griffel 3.}

Cucubalus. Frucht eine kugelförmige, 1fächrige Becro.

Sileno. Frucht eine mehr oder weniger 3füchrige Kapsel.

c) Griffel 5 .

Lychnis. Bbl. mit nebenkronartigen Anhängscln; Narben einwärts mit Papillen besetzt, ausserdem kahl.

Agrostemma. Wie die vorige, aber die Narbon einwärts mit Papillen und überall mit langen Haaren besetzt.

\section{Gypsophila $L$. Gypskraut.}

117. G. muralis $L$. M a u $\theta \mathrm{r}$ G.; St. gabelästig; Bl. lineal ; Blth. einzeln langgestielt; Blbl. ausgerandet, rosa. ๑. 2-6".

Auf Sandflächen, Brachaeckern, auf Mauern, an Wegen oft sehr gesellig, jedoch nicht überall. In Menge bei Friedrichsfeld! Schwetzingen! in Weinbergen bei Handschuhsheim und Dossenheim! auch einzeln im Dreitröge - Thal, am Philosophen-Wege! u. s. w. Juli, August.

\section{S a pon a ria $L$. S e ifenkraut.}

118. S. Vaccaria $L$. $\mathrm{Kuh-S.;} \mathrm{kahl,} \mathrm{graugrün;} \mathrm{Bl,} \mathrm{lanzettl.}$ am Grunde verwachsen; Blth. locker, trugdoldenartig; Kelch krugförmig, geflügelt-5kantig. $\odot .1-2^{\prime}$. Blbl. ohne Anhängsel, hellrosa. (Vaocaria pyramidata Med.)

Unter der Saat, besonders auf Kalk- und Lehmboden, auch in der näheren Umgebung von H. nicht selten! Juni, Juli.

119. S. officinalis $L$. Heilkräftiges S.; kahl, grasgrün; BI. länglich-elliptisch, am Grunde schmal zusammenhängend; Blth. büschelig; Kelch walzenförmig, flügellos. 24. 1-2'. Wrzlst. kriechend. Blbl. am Grunde mit 2 spitzen Anhängseln, hellroth.

An Flussufern, in Weinbergen, in Hecken, auf Sandfeldern verbreitet, zuweilen in Menge, z. B. am Neckar-Ufer von H. bis Ladenburg! bei der Bergheimer Mühle; Philosophen-Weg! Molkenkur! u. s. w. Juli, August. (Off. Rad. Saponariae.)

\section{5\%. Dianthus $L$. Nelke.}

a) Blth. in endständigen, büscheligen Köpfchen.

120. D. prolifer $L$. Kopf-N.; St. meist einfach, kahl; BI. linealisch; Blthköpfchen von elliptischen, durchscheinend-häutigen Deckschuppen umgeben. $\odot \frac{1}{2}-1^{\prime}{ }^{\prime}$. An sehr trocknen Standorten zuweilen 1 blüthig. Blkr. blassroth, klein. 
Auf sonnigen Irügeln, auf Sand- und Kalkboden, auf Sandfeldern oft häufig: Friedrichsfeld! Schwetzingen! Sandhausen! NeuLussheim! bei Wiesloch! Malsch! Schriesheim! beim Haarlass. Juni - August.

121. D. Armeria $L$. $\mathrm{R}$ a uhe N.; St. ästig, wio die lineallanzettl. Bl. weichhaarig; Blthstand locker, vielblth.; Deckbl. und Aussenkelchschuppon lanzettl., krautig, rauhhaarig. $\widehat{~}$. $4^{\prime \prime}-1^{\prime}$. Blkr. klein, hellroth, dunkelpunktirt.

An Waldrändern, in Gebüschen, auf Geröll nicht selten, besonders auf den Bergen um H. diesseits und jenseits des Neckars verbreitet! Juni-August.

122. D. Carthusianorum $L$. Karthäuser-N.; kahl; BI. linealisch; Blthköpfchen büschelig. meist $6 \mathrm{blth.,} \mathrm{gedrängt;} \mathrm{Deckbl.}$ und Aussenkelchschuppen verkehrt-eiförm., pfriemlich-begrannt, trockenhäutig, braun. 4. $\frac{1}{2}-1^{\prime}{ }^{\prime}$. Blkr. roth, ansehnlich.

An grasreichen Bergabhängen, auf Felsen, auf Sandflächen und in lichten Nadelwäldern nicht selten. In der Nähe von $\mathbf{H}$. diesseits und jenseits des Neckars auf Felsen häufig genug! Stellenweise auch in Menge bei Weinheim! Rauenberg! Schatthausen! Wiesloch! Nussloch! Verbreitet in den Nadelwäldern der Sandebenen, woselbst aber zuweilen sehr verkümmert. Mai-Juli.

b) Blth, einzeln oder rispig.

123. D. deltoides $L$. Delt ablumige N.; St. aufsteigend, schärflich, 1blüthig; Bl. lineal-lanzettl., am Rande scharf; Aussenkelchschuppen 2, eirund, begrannt, halb so lang wie die Kelchröhre; Blbl. gezähnt. 4. $\frac{1}{2}-1^{\prime}$. Blbl. rosa, mit dunklerem Ringe.

Auf trocknen Hügeln, in sandigen Wäldern selten. Zwischen Friedrichsfeld und Schwetzingen! Zwischen Schwetzingen und Ketsch! Im Kiiferthaler Walde! Juni-September.

124. D. superbus $L$. Pracht-N.; St. aufsteigend, kahl, 2mehrblth.; Bl. lineal-lanzettl., am Rande scharf; Aussenkelchschuppen 4, begrannt, dreimal kürzer als d. Kelch; Blbl. fiedersp.-zerschlitzt am Schlunde behaart. 4. $\frac{1}{2}-1 \frac{1^{\prime}}{2}$. Blkr. ansehnlich, blassviolett, wohlriechend.

Auf feuchten Wiesen bei Brühl! Neckarau! Auf d. Inseln bei Ketsch! An lichten Waldstellen auf dem Teufelskopf bei Dielheim! Im Friedrichsfelder Walde! Im Kastanienwalde hinter dem H. Schlosse ! Auf dem westlichen bewaldeten Abhango des Oelberges bei Schriesheim (Stud. Gysser). Juli-Sept. 


\section{Cucubalus $L$. Traubenkropf.}

125. C. baccifer $L$. Beerentr. T.; St, kletternd mit abstehenden Zweigen; Bl. kurzgestielt, länglich-eiförmig, spitz, gewimpert; Blth. blattwinkelständig; Kelch bauchig-glockig; Beeren kugelig, glänzend schwarz. 4. 2-4'. Blth. grünlichweiss.

An Bächen und Flussufern, in Gebüschen selten: bei Schönau; am Rheinufer bei Mannheim (Suceow). Juni-August.

\section{Silene $L$. Leim kraut.}

a) Blbl. am Schlunde ohnø Krönchen.

126. S. Otites Sm. Ohrlöffel-L.; St. aufrecht; untere BI. spatelförmig, obere linealisch, fein behaart; Blthrispo wirtelförmig verzweigt, kahl; Kelch röhrig-glockig mit stumpfen Zähnen; Blbl. ungetheilt. 4. 1-2'. Blth. klein, gelblichweiss, moist dioecisch, seltener polygamisch.

Auf Sandflächen, sandigen Hügeln häuflg: Friedrichsfeld! Schwetzingen! Hockenheim! Sandhausen! u. s. w. Juni-August.

127. S. inflata $S m$. A u fgeblasenes L.; kahl, graugrün; St. aufsteigend, gabelästig; Bl. elliptisch-lanzettl., feingesägt; Blth. fast einseitswendig, nickend; Kelch krugförmig, aufgeblasen, netzigaderig, glatt; Blbl. gespalten. 4. $\frac{1}{2}-1_{\frac{1}{2}}^{\prime}$. Blkr. weiss. - Variirt sehr in der Grösse aller Theile, bald mehr, bald weniger graugrün. Blth. häufig dioecisch. Stbgef.-Blth. grösser als die Pistillblth. (Cucubalus Behen L.)

An Wegen, in Gebüschen, auf Felsen und trocknen Wiesen häufig! Mai-August.
b) Blbl. am Schlunde mit Nebenkrünchen.

128. S. nutans $L$. Nickendes L.; St. aufrecht, weichhaarig, oberwärts drüsig-klebrig; untere BI. lanzettl.-elliptisch, in den Blt.stiel verlaufend; Blth. in einseitigen Rispen, überhängend; Kelch röhrig-glockig, 10streif. 4. 1-2'. Blbl. weiss.

An Mauern, Wegen, in Nadelwäldern, an sandigen Abhängen häufig! Mai-Juli.

129. S. noctifiora $L$. Nach t-L.; klebrig-zottig; St. aufrecht, gabelspalt.; Bl. länglich, die unteren spatelförm.; Blth. langgestielt, einzeln, aufrecht; Kelch röhrig-bauchig, 10streif. ๑. 4"-1'. Blkr. fleischroth, bei Tage halbgeschlossen, gegen Abend sich öffnend. wohlriechend.

Unter der Saat, besonders auf lehmigen Aeckern: Zwischen Ladenburg, Dossenheim und Handschuhsheim! Bei Wiesloch! Schatthausen! Rohrbach! Wieblingen! Juni-September. 
130. S. conica $L$. Kegelförmiges L.; weichhaarig, grau; St. aufrecht; Bl. lineal-pfriemlich; Blth. trugdoldig-rispig; Kelch eirund-kegelig, 30streifig. ๑. Blkr. klein, rosa (nur Vormittags geöffnet).

Auf Sandflächen und sandigen Hügeln stellenweise. Beim Relaishause! In den Kiesgruben bei Schwetzingen! Boi Walldorf! Sandhausen! An der Rheinziegelhütte bei Mannheim! Mai, Juni. [Auch jenseits des Rheins, z. B. auf den Sandflächen bei Maxdorf verbreitet!]

60. Iychnis $L$. Lichtnelke.

131. L. Viscaria $L$. Pechnelke; St. kahl, oberwärts, besonders unter den Gelenken sehr klebrig; Bl. lanzettl., kahl, am Grunde etwas wollig; Blth. traubig-rispig; Blbl. ungetheilt. 4. 1-1 $\frac{1}{2}^{\prime}$. Blkr, rosa.

An grasreichen Abhängen, in Nadelwäldern, in Steinbrüchen durch das Gebiet verbreitet, besonders häufig an sonnigen Bergabhängen vom Haarlass bis Weinheim! Mai-Juli.

132. L. flos Guculi $L$. Kukuksblume; St. aufrecht, etwas rauh, oberwärts klebrig; Bl. lanzettl., kahl; Blth. gabelästig-rispig; Blbl. tief 4spalt. 4. 1-2'. Blkr. fleischroth.

Auf Wiesen, an Flussufern, in feuchten, sumpflgen Gebüschen gemein. Mai-Juli.

133. L. alba Mill. Weisse L.; St. aufrecht, zottig; Bl. eirund-lanzettl., die oberen, nebst Blthstielen und Kelchen drüsig behaart; Blth. gabelästig-rispig, dioecisch; Blbl. 2spalt.; Zähne der Kapseln nach dem Aufspringen gerade. 4. $1 \frac{1}{2}-2 \frac{1}{2}^{\prime}$. Blth. weiss, gegen Abend geöffnet, wohlriechend. ( $L$. dioioa var. $b \mathrm{~L}$; Lychn. vespertina Sibth.) Staubgefblth. etwas grösser, die Kelche derselben länglich, die kleineren Pistillblth. mit mehr ovalen Kelchen.

In Gebüschen, an Wegen und Waldrändern, auch auf Feldern überall häufig! Juni-September.

134. L. rubra M. E. u. P. p. 384. R o th $\theta$ L., zottig aber drüsenlos, St. aufrecht, Bl, eiförmig, spitz, Blthn. gabelästig, dioecisch, Blbl. 2spaltig, Zähne der Kapseln nach dem Aufspringen zurückgerollt. 4 Blth. rosa, stets kleiner als bei der vorigen, geruchlos, am Tage geöffnet. $1-2 \frac{1}{2}$ ' (Lych. dioica L. var.; L. diurna Sbth.)

Auf Wiesen, in feuchten Laubwäldern, an Bächen und Flussufern häufig. Juli-Sept.

61. Agrostemma $L$. Rade.

135. A. Githago $L$. Kornrade; rauhhaarig, grau; Bl. lineal-lan- 
zettl.; Blthen einzeln, endständig; Kolchzipfel länger als Kelchröhro u. Blkr. ๑. $1 \frac{1}{2}-3^{\prime}$. Blkr. violettroth. (Lychnis Githago Lam) Unter dem Getreide stellenweise sehr häufig. Juni, Juli.

\section{ALSINEAE.}

Einjährige oder ausdauernde, häufig unscheinhare, niederliegende Kräuter mit meist zarten, knotig gegliederten Stengeln, ganzen, gegenständigen Blättern, selten mit Nebenblättern, häufiger ohne dieselven. Blthsde. meist trugdoldig, mehr oder weniger gabeltheilig. K. 4-5blättrig, Blbl. 4-5 kurzbenagelt (zuweilen fehlend), mit den 3-10 Stbgef. einem unterständigen, drüsigen Ringe eingefügt, Fruchtknnten frei mit 2-5 Griffeln. Kapsel 1 füchrig, an der Spitze klappig anfspringend, mit mittelstïndigem vielsamigen Samentrüger. Samen eiweisshaltig, meist mit peripherischem Keim. Die Alsineen zeigen im Habitus eine grosse Uebereinstimmung, und sind daher oft nur durch feinere Merkmale zu unterscheiden. Für die Charaktere der Gattungen sind Früchte und Samen wohl zu berücksichtigen. - Diese Pflanzen sind durch Geselligkeit sehr ausgezeichnet, und liefern, obwohl einige Seltenheiten vorkommon, für die niedere Krautregetation die bekanntesten Repräsentanten. Eine unverhältnissmässig grosse Zahl der 24 Arten ist $\odot$, nämlich 16 . Die Blüthezeit ist vorzugsweise die erste Hälfte des Frühlings, 8 Arten eröffnen die Flora. Die wenigen, welche in den eigentlichen Sommermonaten zur Blüthe kommen, werden an kalten, feuchten, schattigen Plätzen wahrgenommen. Culturland und Waldränder sind die gewöhnlichen Standorte. Dio meisten sind sandhold, einige sandstet. Bei manchen ist die Oberfläche leicht geneigt Drüsen zu bilden, wenn die Pflanze unverhältnissmässig stark der Sonne ausgesetzt ist, denn für eine normale Entwicklung scheint allen eine etwas feuchte, kühle Umgebung nöthig zu sein. Die weisse Blumenfarbe ist fast allgemein, und erleidet im Floragebiet nur einmal eine Ausnahme.

\section{a) Griffel 3.}

d) Ohne Nebenblätter.

Alsine. Blbl, ungetheilt oder schwach ausgerandet, Stbgef. 10, Kapsel dreiklappig, Samen nierenförmig, flügellos.

Arenaria. Blbl. ungetheilt; Stbg. 10; Kaps. 6klappig; S. nierenf., flügellos. 
Moehringia. Blbl. ungeth.; Stbg. 10; Kapsel (bei unserer Art) 6klappig; S. nierenf., mit einer flügelartigen Anschwellung am Nabel.

Stellaria. Blbl. 2theil. od. 2spalt.; Stbg. 3, 5-10; Kp. 6klappig; S. nierenf., flügellos.

Holosteum. Blbl. gezähnt; Stbg. $3-5$; Kp. 6klappig; S. schildförmig.

ß) Mit dünnhäutigen Nebenblättern.

Lepigonum. Blbl. ungetheilt; Stbg. 10; Kp. 3klappig; S. 3eckig od. rundlich, geflügelt od. flügellos.

b) Griffel $4-5$.

a) mit trockenhäutigen Nebenbl.

Spergula. Blbl. ungetheilt; Stbg. 5-10; Kp. 3klappig; S. kreisrund, geflügelt.

\section{B) Ohne Nebenbl.}

Sagina. Blbl, ungetheilt; Stbg. 4-10; Kp. 4-5klappig; S. nierenf., flügellos.

Cerastium. Blbl. ausgerandet od. gespalten; Stbg. 5-10; Kp. 10klappig; S. rundlich, flügellos.

M a l a chium. Blbl. tief 2 spaltig; Stbg. $5-10$; Kp. in 5 zweizähnige Klappen aufspringend.

\section{Als ine. Wahlbq. Alsine.}

136. A. tenuifolla Wahlbg. Schmalblättr. A.; St. aufrecht ästig; Bl. lineal-pfriemlich, 3nervig, kahl; Klchbl. lanzettl,, länger als die elliptischen Blbl. ○. 2-4". Variirt:

B) viscida, feinhaarig-drüsig an allen Theilen, besonders an den Kelchen.

Unter der Saat, auf Brachäckern, auf Kalk- und Sandboden nicht selten: Wiesloch! Schatthausen! Dielheim! Ladenburg! Seckenheim! Var. $\beta$ auf Sandfächen beim Relaishause! Mai-Juli.

[A. Jacquini Koch; St. steif aufrecht, etwas ästig; Bl. pfriemlich-borstig, am Grunde 3nervig; Blth. büschelig-trugdoldig; Kbl. lanzettl.-pfriemlich, spitz, weissknorpelig; Blb. weiss, kürzer als der K. ๑. 4-10".

N. V. a. d. Geb: in Rhb. auf Kalkhügeln zwischen Dürkheim und Leistadt! 6-8].

\section{Arenaria $L$. Sandkraut.}

137. A. serpyllifolia $L$. $Q u \in$ ndelblättr. S.; St. niederliegend od. aufsteigend; BI. sitzend, eiförmig, zugespitzt; Klchbl. 
lanzettlich, 3nervig, länger als die weissen Blbl. §. 2-4". Variirt mit grösseren und kleineren Blättern und

$\beta$ ) glutinosa, klebrig, überall drüsig behaart.

Unter der Saat, an Wegen, in Wäldern überall sehr häufig! Var. $\beta$ auf Sandfeldern bei Schwetzingen! beim Relaishause! Walldorf! u. s. w. Mai-Juli.

\section{Ilochringia $L$. Moehringie.}

138. M. trinervia Clairv. Dreinervige M.; St. aufsteigend, schwach, weichhaarig; Bl. kurzgestielt, eiförmig, spitz, 3-5nervig; KIlchbl. lanzettlich, 3nervig, länger als die weisse Blbl, ๑. $\frac{1}{2}-2^{\prime \prime}$. (Arenaria trinervia L.).

In Wäldern, Gebüschen häufig! April-Juni.

\section{Stellaria $L$. Sternmiere.}

a) St. stielrund.

139. St. nemorum $L$. Hain $-\mathrm{Stm}$; St. aufrecht, zottig; Bl. gestielt, herzförmig, zugespitzt, gewimpert; Blbl. weiss, noch einmal so lang als d. Kelch. 24. $1-1_{\frac{1}{2}}^{\prime}$.

In Wäldern, an feuchten, schattigen Standorten nicht selten! Mai, Juni.

140. St. media Vill. Gemeine Stm.; St. niederliegend, einzeilig behaart; Bl. gestielt, eiförmig, zugespitzt; Blattstiele gewimpert; Blbl. weiss, kürzer als der Kelch. ๑. - Die häufig pentandr. Pflanze wird, wenn sie auf fettem, etwas schattig feuchtem Boden wächst, um Vieles kräftiger, und erhält dann grössere decandrische Blüthen. (St. neglecta Weihe) Zuweilen fehlen dio Blbl. völlig. - (Alsine media $\mathrm{I}_{\text {s.) }}$.

Auf Culturland, an Wegen überall sehr gemein: Blüht das ganze Jahr.

b) St. kantig; Kelch von der Länge der Kapsel.

141. St. Holostea $L$. Grossblumige Stm.; grasgrün, St. aufsteigend, schwach, starr; Bl. sitzend, lanzettlich, zugespitzt, am Rando und Kiele scharf; Deckbl. krautig; Klchbl, nervenlos, halb so lang als die Blbl.; Kapsel kugelartig. 4. 6-10". Blbl. ansehnlich, weiss.

In Wäldern, Gebüschen, Hecken häufg! April, Mai.

142. St. glauca With. Meorgrüne Stm.; grasgrün; St. aufrecht, schwach; Bl. sitzend, lineal-lanzettlich, kahl; Deckbl. trockenhäutig-kahl; Klchbl. 3nervig, etwas kürzer als d. Blbl.; Kapsel elliptisch. 4. 4-10". Blbl. woiss. (S. palustris Retz). 
Auf Sumpfwiesen, in Torfsümpfen nicht häuffg: Waghäusel: Sandtorf! Auf der Engelswiese bei II.: auf den Wiesen beim Strassenheimer Hof unfern Ladenburg! Mai-Juli.

143. St. uliginosa Murr. S u mpf-Stm.; etwas grasgrün, St. niederliegend, ausgebreitet, kahl; Bl. sitzend, länglich-lanzettlich, am Grunde etwas gewimpert; Deckbl. trockenhäutig, kahl; Klchbl. 3nervig, fast doppelt länger als die Blbl.; Kapsel eifürmig. ๑. Blkr. klein, weiss.

Auf feuchten Waldwiesen, in Torfsümpfen, an Quellen hie und da. In der Hirschgasse und auf der Engelswiese bei H.! beim Maischbacher Hof! am Teufelskopf bei Dielheim! In den Sümpfen bei Waghäusel! Brühl! Roth u. s. w. Juni-August.

\section{c) St. kantig; Kelch länger als dio Kapsel.}

144. St. graminea $L$. Gras $-\mathrm{St}$.; St. verlängert, ausgebreitet, ästig, kahl; Bl. sitzend, lineal-lanzettlich, am Grunde gewimpert; Deckbl. trockenhäutig gewimpert; Kelchbl. 3nervig, so lang als d. Blbl,; Kapsel länglich. ๑. $\frac{1}{2}-2^{\prime}$. Bllir. klein, weiss.

In Gräben, an Waldrändern, auf feuchten Wiesen, überall häufig! Juni-August.

\section{Holosteum $L$. Spurre.}

145. H. umbellatum $L$. Doldenart. Sp.; graugrün, kahl; St. aufsteigend; Bl, elliptisch; Blthstiele doldig, nach dem Verblühen zuerst zurückgeschlagen, dann wieder gerade. ๑. 2-10". Blkr. weiss, gewöhnlich triandrisch. Die am Grunde gegliederten Blthstiele sind meist drüsig behaart.

Auf Sandfeldern, Aeckern, an Wegen, auf Mauern häufig! April, Mai.

\section{6\%. Lepigoum $L$. S chuppenmiere.}

146. L. rubrum Wahlb. Rothe Sch.; meist drüsig behaart; St. niederliegend, ästig; BI. lineal, flach, stachelspitzig, etwas fleischig; Klchbl. stumpf, randhäutig, nervenlos; Samen keilförmig, flügellos. ๑. 3-5". Blkr. klein, rosa. (Arenaria rubra L. Spergularia rubra Presl).

An Wegen, auf Triften, an lichten Waldstellen, auf feuchtem, sandigem Boden. In der Nähe v. H. auf den Bergen diesseits und jenseits des Neckars nicht selten! Bei Sandhausen! Beim Relaishause! Schwetzingen! Auf den sandigen Aeckern bei Malsch! Juli -August.

[L. medium Wahlbg.; dem vorigen ähnlich; Bl. lineal, fleischig, beiderseits gewülbt, stumpf; KKbl. randhäutig, nervenlos, 
stumpf, Samen verkehrt-cifürmig zusammengedriickt, flïgellos oder schwach geflügelt. ๑. 4-9". Blkr. blassroth. (Arenaria mrrina Roth).

N. V. a. d. Geb.: in Rhb, an den Salinen von Dürkheim! Mai-Sept.]

\section{Spergula L. Spark.}

147. S. pentandra $L$. Fün fmänniger Sp.; St. aufrecht, fadenförmig, oberwärts schwach behaart; Bl. lineal-pfriemlich, büschelig, stumpf, unterseits ohne Furche; Nebenbl. sehr klein, Blth.stiele aufrecht, armblüthig; Blbl. lanzettl., etwas länger als $d$. K.; Stbgef. 5-10; Samen flach, linsenfürmig, schwärzlich, glatt, breitgefliigelt; Flïgelsaum silberweiss, feinstrahlig-gerieft. ๑. 2-4". Blkr. weiss.

Auf Sandfeldern, sandigen Hügeln, in Nadelwäldern. Bisher im Gebiet der Flora nur beim Relaishause! Jenseits des Rheins auch auf den Sandflächen bei Maxdorf und daher wahrscheinlich in unseren Sandgegenden nur übersehen und mit der folgenden Art verwechselt! April, Mai.

148. S. Morisonii Boreau. St., BI. und Blthstiel der vor. Art; Blbl. oval, kürzer als der Kelch; Stbgef. 5-10; Same flach, bräunl., am Rando feinwarzig, schmalgeflügelt; Flügclsaum gelblichweiss, feinstrahlig gerieft. ○. 2-5". Blkr. weiss.

Auf Sandflächen, in Nadelwäldern hie und da: Beim Relaishause! Bei Walldorf! Sandtorf! April, Mai.

149. Sp. arvensis $L$. A cker-Sp.; St. aufstrebend; Bl. büschelig, lineal-pfriemlich, unterseits mit einer Längsfurche; Nebenbl. gross; Blthstiele aufrecht; Blbl. oval, kürzor als d. K; Stbgef. 5-10; Samen fast kugelig, warzig, sehr schmal oder kaum gefiigelt. $\odot$. $\frac{1}{2}-2^{\prime}$. Blkr. weiss. Variirt:

a) sativa Bönningh; Samon schwarz, feinwarzig.

$\beta$ ) vulgaris $B$.; Samen mit verlängerten, weissen, später bräunlichen Warzen.

$\gamma)$ maxima Weihe, in allen Theilen grösser; S. noch einmal so gross wie bei $\alpha$ und $\beta$, auch deutlicher warzig.

Auf sandigen Aeckern, an Wegen nicht selten! Var. $\gamma$ nur sehr stellenweise, z. B. bei Hockenheim! Neu-Lussheim! Var. $\alpha$ als Futterkraut hie und da gebaut! Juni-August.

\section{Sagina $L$. Sagine.}

a) Blüthentheile \&zählig.

150. S. procumbens $L$. Niederliegende S.; St. nieder- 
liegend, kriechend; Bl. lineal stachelspitzig, kahl; Blthstiele nach dem Verblïhen an der Spitze zurückgebogen, bei der Fruchtreife gerade; Klchbl. stumpf; Blbl. weiss, kürzer als d. Kelch. $\odot$.

ß) subciliata Bisch.; Blätter, besonders die der Frühlingspflanze fein gezähnelt wimperig.

Auf Aeckern, an Wegen, in Gärten die Hauptform sehr häufig. Var. $\beta$ am Wege rom Schloss nach dem Wolfsbrunnen (Bisch.). Auf dem Königstuhl bei H., daselbst neben dem Wirthshause auf einer Mauer. Juni-Sept.

151. S. patula Jord. Abstehende S.; St. dünn, aufsteigend oder ausgebreitet, starr, ästig; Bl. lineal, stachelspitzig, kahl; Blthstiele drüsig behaart, nach dem Verblühen immer aufrecht; Klchbl. eirund-lanzettlich, drüsig, der reifen Kapsel anliegend und von fast gleicher Länge, an der Spitze etwas zurückgekrümmt; Kapsel eirund-länglich. $\odot .2-4^{\prime \prime}$. Blbl. klein, weiss, wie bei der folgenden meist fehlend. Variirt:

$\beta$ ) glaberrima Bisch.; Blüthenstiele und Kelchbl. völlig kahl. (S. apetala-patula Schultz).

Auf Aeckern und an Wegen. Hauptform.: an Ackerrändern bei der Baiermühle unfern Leimen! Var. $\beta$ im Dreitrögethal bei H., daselbst am obern Lärchenbestande! Mai-Juli.

Diese Art ward bisher wohl nur übersehen und ist mit der folgenden verwechselt.

152. S. apetala $L$. Blumenblattlose S.; St. dünn, borstenförmig, aufsteigend oder fast niederliegend; Bl. lineal, stachelspitzig, kahl, drüsigbehaart oder gewimpert; Blthstiele kahl, nach dem Verblühen aufrecht oder etwas gekrümmt; Klchbl. eirund, kahl, kürzer als die Kapsel, bei der Reife weitabstehend; Kapsel kugeligeirund. ○. 2-4". Blbl. gewöhnlich fehlend, selten klein weiss.

Auf Triften, an feuchten lichten Waldstellen, auf Aeckern hie und da: im Mühlenthal bei Handschuhsheim! beim Speyerer Hof! im Dreitrögethal! häufig auf feuchten lehmigen Aeckern unfern Friedrichsfeld! Juni-September.

Diese Art ist von der vorigen besonders durch die Form der Kelche und der Kapseln wohl zu unterscheiden. Die Behaarung ist übrigens bei beiden Arten schwankend. Auch diese variirt als:

ß) glanduloso-ciliata Schultz (apetala var. ambigua Bisch.) Blüthenstiele drüsig behaart.

Auf Brachäckern bei dem Speyerer Hof, gegen Rohrbach. (Bisch.).

b) Blththeile 5zählig.

153. S. nodosa Bartl. Knotige S.; St. niederliegend oder aufsteigend, Bl. lineal-fadenfürmig, kurzstachelspitzig, am Grunde SCHMDT, Flora v. H. 
büschelig vorbunden; Blthsticlo aufrecht; Kelchbl. stumpf; Blbl. länger als d. Kelch, weiss. 4. 2-8". Fast immer ganz kahl, seltener drüsig behaart. (Spergula nodosa L.).

Auf nassen sandigen IIaiden, auf sumpfigen Torfwiesen: Waghäusel! Sandtorf! Juli, August.

70. Cerastium $L$. Hornkraut.

a) Blbl. so lang oder kürzer als der Kelch.

154. C. glomeratum Thuill. Goknäuoltes H.; gelblich grün, meist drüsenhaarig; St. fast aufrecht; Bl. eiförmig; Blth. knäuelartig gedrängt; Deckbl. u. Kelchzipfol krautig, an der Spitzo bärtig; Fruchtstiele fast von der länge des Kelches ๑. 3-6". Blkr. weiss (fehlen auch bisweilen (apetalum). (C. vulgatum L.).

Auf Aeckern, Grasplätzen, an Wegen häufig! Mai-Juli.

155. C. brachypetalum Desp. Kurzblumiges H.; abstehend behaart, graugrün (zuweilen etwas drüsig); St. aufsteigond; Bl. länglich-eiförmig; Blth. gabelrispig; Deckbl. und Kelchzipfel krautig, an der Spitze bärtig; Fruchtstiele 2-3mal länger als der Kelch. ๑. 4-8". Blbl, klein, weiss.

Auf Felsen, auf Mauern, in Weinbergen hio und da. Beim IIaarlass! Im Birkenauer Thal und bei Nesterbach unfern Weinheim! In Ludwigsthal bei Schriesheim! Dossenheim! Mai, Juni.

156. C. semidecandrum $L$. Halbzehnmänniges H.; St. aufrecht od. aufsteigend, weichhaarig, meist etwas drüsig; Bl. oirund stumpf; Blth. gabelästig; Deckbl. und Kelchzipfel halbtrockenhäutig, an der Spitze kahl; Fruchtstiele 2-3mal länger als die an der Spitze ausgebissen gezähnelten Kelchzipfel. ๑. 1-3". Blkr. weiss; Stbgefässe oft nur 5.

Auf Sandflächen, trockenen Hügeln, z. B. bei Schriesheim! Friedrichsfeld und in den Sandgegenden der Ebene häufig! März bis Mai.

157. C. triviale $L k$. Gemeines $H_{\text {. }}$; rauhhaarig; St. aufsteigend; Bl. eirundlänglich, spitz; Blth. mehr od. weniger gedrängt; Deckbl. und Kelchbl. am Rande trockenhäutig, an der Spitze kahl; Fruchtstiele 2-3mal länger als die ganzrandigen Kelchbl. ) ๑$5^{\prime \prime}-1^{\prime}$. Blkr. weiss, etwas grösser als bei den vorigen Arten. $(C$. vulgatum L.). Variirt:

B) pumilum; (C. pumilum Curt.), in allen Theilen kleiner,

-) Die Fruchtstiele sind sowohl bei dieser Art, als bei der vorigen bald mehr niedergebogen, bald wagerecht abstehend. 
2-6"; drüsig-behaart, klebrig; Deckbl. u. Kelchbl mit sehr schmalem, trockenhäutigem Rande; Fruchtstiele kürzer.

Dio Hauptform auf Triften, Wiesen, Aeckern, an Wegen, in Wäldern häufig! Die Varietät auf trockenen sandigen Hügeln und Sandflächen ziemlich selten, z. B. beim Relaishause! an den Felsen im Ludwigsthale bei Schriesheim! April-August.

b) Blbl, doppelt so lang als der Kelch.

158. C. arvense $L$. A cker-H.; rasenbildend, weichhaarig; St. niederliegend, kriechend, dann aufsteigend, an der Spitze etwas gabelästig, 7-15blüthig; Bl. lineal-lanzettlich; Deckbl. u. Kelchbl. am Rande breit trockenhäutig; Blüthenstiele aufrecht mit glockigem Kelche. 4. 4-10". Blkr. weiss. Meist hellgrün, mehr oder weniger bchaart, wechselt mit breiteren und schmäleren Blättern.

An Wegen, auf Mauern, an Ackerrändern häufig! April-Juni.

\section{\%1. II a la chi un Fries. We ichling.}

159. N. aquaticum Fr. Wasser-W.; St. aufsteigend, gestreckt, kantig, oberwärts drüsigbehaart; Bl. eirund-herzförmig, spitz; Rispo gabelästig, armblüthig; Fruchtstiele zurückgeschlagen; Blbl. weiss, noch einmal so lang als d. Kelch. 4. 1-3'. (Cerastium aquatioum $L_{\text {..). }}$

An Gräben, Flussufern, auf feuchten Waldwiesen hio und da: z. B. am Neckarufer sehr verbreitet! auch bei Rohrbach! Handschuhsheim! St. Ilgen! Waghäusel! u. s. w., übrigens hier nicht so häufig, als in manchen andern Gegenden Deutschland's. Juni-Sept.

\section{ELATINEAE. Camb.}

Kleine meist niederliegende $\odot$ Sumpfpflanzen mit gegenständigen oder quirligen Blättern, ohne Nebenblätter, und mit sehr unscheinbaren Blüthen. $K$. und Blkr. 2-5theilig, in der Knospenlage dachig. Staubgefässe ebensoviele oder $2 \mathrm{mal}$ so viele als Blumenbläiter. Fruchtknoten frei, 2-5fächrig mit 2-6 kurzen Griffeln und einem mittelständigen Samentrïger. Kapsel meist niedergedrückt kugelig. Samen zahlreich, eiweisslos, mit geradem oder gekrümmtem Keim.

Elatine. K. u. Blkr. 2-4zählig; Stbgef. 2-8; Griff. 2-4; Kapsel 2-4fächrig, vielsamig. 


\section{Elatine $L$. Tännel.}

160. E. triandra Schkr. Dreimänniger T.; Bl. gegenst., längl.-lanzettlich, fast sitzend; Blthen sitzend; Blbl. u. Stbgef. 3; Samen bogenförmig gekrümmt. ๑. Blkr. blassroth.

Wurde in früheren Jahren von Dr. Schimper in Sümpfen beim sog. rothen Loch, zwischen Friedrichsfeld and Schwetzingen aufgefunden, scheint aber jetzt verschwunden! Juni-August.

16l. E. Hydropiper $L$, Pf f f fer-T.; Bl. gegenständig, länglich-elliptisch, langgestielt; Blth. fast sitzend; Blbl. 4; Stbgef. 8; Samen hufeis enförmig. ๑. Blth. blassroth.

An Teichufern, an überschwemmten Plätzen. In Sümpfen im Friedrichsfelder Walde (Schimp). Juni-August.

162. E. Alsinastrum L. Quirlblättriger T.; Bl. quirlig, elliptisch; Blth. fast sitzend; Blbl. 4; Stbgef. 8; Samen fast gerade; $\odot$. Blth. grünlich weiss; St. 2-10" glatt, gegliedert, hohl. - Grös- sere Exemplare haben einige Aehnlichkeit mit Hippuris vulgaris.

In Sümpfen und an fast ausgetrockneten lehmigen Stellen in der Nähe des sog. rothen Loches zwischen Friedrichsfeld u. Schwetzingen stellenweise häufig! Juni-August.

\section{LINEAE. $D C$.}

Kräuter mit ganzen, meist abwechselnden, seltener gegenständigen Blättern ohne Nebenblätter. Blthstände gabelästig; Klchbl. 4-5, bleibend, in der Knospe dachig; Blbl. 4-5, in der Knospe gedreht, sehr hinfällig; Stbgef. 4-5, am Grunde in einen hypogynischen Ring verbunden, meist abwechselnd mit $4-5$ Rudimenten von Staubgefässen. Fruchtknoten mit $4-5$ votsständigen und eben so vielen unvollständigen Scheidewänden. Griffel 4-5. Kapsel 8-10fächrig. Fächer 1samig. Samen hängend, eiweisshaltig, mit geradem Keim.

Li num. K., Blkr., Stbg., Gr. 5zählig, Kps. 10fächrig, 10klappig. Radi ol a. K., Blkr., Stbg., Gr. 4zählig, Kps. 8fächrig, 8klappig.

73. Lin um $L$. L e in.

a) Bl. gegenständig.

163. L. catharticum L. Purgir-L.; kahl; St. aufsteigend, fadenförmig, oben gabelästig; Bl. verkehrt-eiförmig, obere lanzettlich; 
Klchbl. elliptisch, zugespitzt, gewimpert, ๑. 3-10". Blth. klein, weiss.

Auf Wiesen, Waldtriften, sowohl auf trocknem, als recht fouchtem Boden häufig! Juni-August.

b) Bl, abwechselnd.

164. L. tenuifolium $L$. Schmalblättr. L.; St. zahlreich, aufrecht, ruthenförmig; Bl. lineal-pfriemlich, am Rande gewimpert; starr; Klchbl. elliptisch zugespitzt, drüsig gewimpert, dio Kapsel überragend. 4. $\frac{1}{2}-1^{\prime}$. Blkr. ansehnlich, hellroth.

Auf trockenen Hügeln, waldigen Anhöhen, sowohl auf Kalk und Lüss, als auf Sand hie und da. Beim Maischbacher Hof! Am Schlangengrunde $\mathrm{zwischen}$ Baierthal und Alt-Wiesloch! am Teufelskopf bei Dielheim! zwischen Rauenberg und Rodenberg! Stellenweilen auch an den Bergabhängen zwischen Rohrbach und Leimen! An der Hillenbach bei Handschuhsheim! beim Schriesheimer Vitriolbergwerk (Stud. Gysser) und besonders häufig bei Nesterbach unfern Weinheim! Juni-August.

L. usitatissimum L. Flachs; St. einzeln, aufrecht; Bl. lineallanzettlich, kahl; Kelchbl. oval, zugespitzt, feingewimpert, drüsenlos, fast so lang wie die Kapsel. ๑. 1-2'. Blkr. hellblau.

Wird hie und da gebaut. Juni, Juli. (Off,: Semen Lini).

\section{Radiola Dill. Zwerglein.}

165. R. linoides Gmel. Gemeiner Z.; St. zart, wiederholt gabeltheilig; Bl. sehr klein gegenst., eiförmig; Blth. sehr unscheinbar knäuelartig, weiss. ๑. 1-2". (Linum Radiola L. Rad. Millegrana $\mathrm{Sm}$.$) .$

Auf feuchten sandigen Triften und Haiden nicht häufig. Zwischen Waghäusel und Wiesenthal; bei Sandtorf. Uebrigens hinsichtlich der Verbreitung im Gebiete der Flora unsicher! Juli, August.

\section{MALVACEAE. $R$. $B r$.}

Sträucher oder (bei uns immer) Kräuter mit abwechselnden handnervigen meist gelappten oder getheilten, seltener ganzen Blättern, mit Nebenblättern. Blth. achselständig oder in gipfelst. Rispen. Kelch 3-5gliecirig, mit klappiger Knospenlage, in den meisten Fällen von einer aussenkelchartigen Deckblattbildung umgeben. Blkr. meist 5gliedrig, regelmässig, in der Knospe gedreht. Stbgef. viele, monadelphisch, 
mit nierenförmigen, 1fächrigen, der Qucere nach sich öffnenden Antheren. Fruchtknoten (bei deutschen Gattangen) kreisförmig, durch die Vereinigung von zahlreichen Fruchtblättern um eine gemeinschaftliche Axe gebildet. Griffel zahlreich, säulenförmig verwachsen. Früchte in einsamige Nüsschen zerfallend, oder (bei ausländischen Gattungen) kapselartig Same nierenförmig oder oval, mehr oder weniger eiweisshaltig. Keim gerade. - Die durch Schleimgehalt ausgezeichneto sehr natürlicho Familie zeigt im Gebiete der Flora nur die Gattung Malva. Jenseits des Rh. tritt unfern unseres Geb. die Gattung Althaea hinzu.

Malva. K. 5spalt; Aussenkelch 3blättr.; kreisförmig gestellte Nüsschen mehr als 5 .

Althaea. Wie vorige, aber Aussenk. 6-9spaltig.

75. Mli alva $L$. Malve.

I66. M. alcea $L$. Alceen-M.; St. aufrecht, wie d. Bl. und Kelche sternhaarig graugrün; BI. handförmig 5theilig; Blthsticlo einzeln 1-3blüthig; Früchtchen kahl, querrunzelig. 4. 2-3' Blth. ansehnlich, rosa.

An Wegen, Hecken, auf trockenen Anhöhen. Am Neckarufer stellenweise recht gesellig, z. B. bei Ladenburg! Feudenheim! beim Schwabenheimer Hof! Neckargemünd! In Menge bei Wiesloch, Schatthausen! Rauenberg! Friedrichsfeld! Neckarau! Auch auf dem heiligen Berge bei H.! Juni-August.

167. M. sylvestris $L$. W ald-M.; St. aufsteigend, rauhhaarig; Bl. herzförmig-rundlich 5-7lappig; Blthstiele büschelig, nach dem Verblühen aufrecht; Blbl. 3-4mal länger als d. Kelch; Früchtchen kahl, netzig-runzelig. $\hat{~} .1-3^{\prime}$. Blkr, rosa, mit dunkleren Streifen.

An Wegen, auf Mauern, Triften, Schutt, besonders in Dörfern häufig! Juni-Sept. (Off.: Flor. Malvae).

168. M. rotundifolia Aut. Rundblättr. M.; St. niederliegend, rauhhaarig; Bl. herzförmig kreisrund mit $4-7$ sehr kurzen Lappen; Blthstiele büschelig, nach dem Verblühen abwärts gekrümmt; Blbl. 2mal so lang als d. Kelch; Früchtchen weichhaarig, glatt. $\odot$. Blth. lila od. weiss. (M. vulgaris Fries).

An Wegen, auf Schutt, ebenfalls besonders in Dörfern, noch häuffger als vorige! Juni-Sept. (Off.: Hb. et Flor. Malv. vulg.).

[Althaea $L$. Eibisch.]

[A. officinalis L. Heilkräft. E.; sammtartig-grauflzig; Bl. 
eirund-rautenf., 3-5lappig, grobgesägt; Blthstiole achsolst., reichblüth., kürzer als d. Bl. 4. 2-3'. Blkr. weiss od. blass rosa.

Auf feuchten Wiesen, an Gräben, salzhaltigen Boden liebend.

N. V. a. d. Geb. in Rhb. bei Lambsheim! und zwischen Lambsh. u. Frankenthal, woselbst nicht selten! Vereinzelt auch in der Nähe der Dürkheimer Saline (Dr. Koch). Juli, August. (Off.: rad. hb. et flores Altheae).

A. hirsuta L. Rauhhaar. E. ; stoifhaarig; unt. Bl, nierenförmig 5lappig, mittlere handförmig, obere tief 3spaltig; Blthstiele acliselst, 1blth., länger als d. Bl. 24. $\frac{1}{2}-2^{\prime}$. Blkr. rosa.

N. V. a. d. Geb. in Rhb, auf Kalkhügeln bei Dürkheim! Juli bis September.]

\section{TILIACEAE. Juss.}

(Mit alleiniger Berücksichtigung der Gattung Tilia.)

Büume mit abwechselnden, zweizeiligen, einfachen Blïttern, hinfälligen Nehenblättern und Trugdolden, deren gemeinschaftlicher Stiel in der Mitte mit einem grossen, häutigen, etwas gefärbten Deckblatte versehen ist. Kelchbl. 4-5 mit klappiger Knospenlage. Blbl. 4-5 mit dachiger Knospenlage. Stbgef. zahlreich, frei (bei ausländischen Arten oft polyadelphisch). Antheren 2fächrig, der Länge nach aufspringend. Frucntknoten 5fächrig. Fächer 2-mehreiig, Griffel 1 mit 5lappiger Narbe. Frucht kapselartig, durch Fehlschlagen 1 fächrig, 1-2samig. Samen eiweisshaltig mit geradem Keim.

Tilia. Als einzige deutsche Gattung.

\section{Tilia $L$. Linde.}

169. T. parvifolia Ehrh. Kleinblättr. L., Winterlinde; Bl. schiefherzförmig, oberseits kahl, unterseits blaugrün. und in den Aderwinkeln dicht behaart; Trugdolde 5-9blüthig; Lappen der Narben horizontal abstehend; Kapsel abgerundet stumpfkantig; Blth. gelblichweiss. †. $60^{\prime}$ Höhe. Blüht 14 Tage später als die folgende Art.

In Vorhölzern, Waldungen, besonders im Gebirge nicht selten; hie und da, z. B. bei Nussloch und Weinheim in grösseren Gruppon. Juli. (Off.: Flores Tiliae).

170. T. grandifolia Ehrh. Grossblättr. L, Früh-od, Som- 
merlinde); Bl. schief herzförmig, beiderseits grïn, unterseits weichhaarig; Trugdolde 2-3blüthig; Lappen der Narben aufrecht; Kapsel 5kantig; Blth. gelblich. $\hbar$. von der Höhe der vorigen; Blitter um die Hälfte grösser.

In den Laubwäldern hinter dem Haarlass und am Oelberge zwischen Dossenheim und Schriesheim ziemlich häufig! Ausserdem wie die vorige angepflanzt. Juni, Juli.

\section{HYPERICINEAE. DC.}

Halbsträucher oder (bei uns immer) Kräuter mit einfachen gegenständigen oder wirtelständigen Blättern ohne Nebenblätter. Blüthen in endständigen Trugdolden. Kelch 4-5theilig, in der Knospe dachig. Blbl. 4-5 regelmässig, stets gelb, in der Knospe gedreht. Sthgefässe zahlreich, polyadelphisch, gewöhnlich am Grunde in $3-4$ Bündeln verwachsen. Fruchtknoten frei, 3-5fächrig, vieleiig, mit 3-5 Griffeln. Frucht cine mehrfächrige Kapsel mit einwärts gcschlagenen Klappen, selten eine Beere. Samen klein, an einer mittelständigen Axe oder an den Rändern der einwärts geschlagenen Klappen. Samen eiweisslos mit geradem Keim. Die Hypericineen sind durch Harzreichthum ausgezeichnet. Die Blätter der meisten Arten und häufig auch die Kelche sind mehr oder weniger mit Drüsen versehen. Die vorkommenden Arten der Gattung Hypericum bilden einen nicht unwesentlichen Bestandtheil der Flora in den Gebirgswäldern um H., und können geradezu als charakteristisch für die höhere Krautvegetation daselbst betrachtet werden.

Нурегісum. K. und Blkr. 5zählig; Kapsel 3-5fächrig.

\section{7\%. IIypericum $L$. Johanniskraut, Hartheu.}

a) St. 2-4kantig.

171. H. perforatum $L$. Gemeines J.; St. aufrecht, 2kantig; Bl. eilänglich, durchscheinend punktirt; Klchbl. lanzettl., spitz, meist drüsenlos. 24. $1-2^{\prime}$. Die gelben Blüthen enthalten einen rothen harzigen Farbestoff, welcher sich beim Zerreiben der Blüthen leicht wahrnehmen lässt.

An Waldrändern. in Gebüschen, auf Haiden, an Wegen häuffg ! Juni, Juli. (Off.: Hb. Hyperioi). 
172. H. quadrangulare $L$. Vierkantiges J.; St. aufrecht, 4 kantig; Bl. eiförmig, wenig punktirt; Klchbl. elliptisch, stumpf, zuweilen etwas drüsig. 4. $1-1 \frac{1^{\prime}}{2}$. (II. dubium Leers).

Auf Wald-Wiesen, in Gebüschen, in Wäldern, vorzugsweiso im Gebirge, jedoch nur zerstreut. Beim Maischbacher Hof! am Teufelskopf bei Dielheim! zwischen Ziegelhausen und Schönau! bei Neckarsteinach! Wilhelmsfeld! Juli, August.

173. H. tetrapterum Fries. Vierflügeliges J.; St. aufrecht, geflügelt, 4 kantig; Bl. eiförmig, durchscheinend punktirt; Klchbl. lanzettl., kurz zugespitzt, drüsenlos. 24. $\frac{1}{2}-1^{1}{ }^{\prime}$. Blüthenstand gedrängter und Blthen kleiner, als bei den vorhergehenden Arten.

An und in Gräben, an feuchten Waldstellen, auf Sumpfwiesen nicht selten, viel verbreiteter als vorige Art. Häufig bei Wiesloch! Rauenberg! St. Ilgen! Waghäusel! Auch stellenweise in den Sümpfen im Friedrichsfelder Walde! Bei Kirchheim! Ziegelhausen!'Beim Haarlass und am Neckarufer! Juli; August.

174. H. humifusum $L$. Niederliegendes J.; St. niederliegend, fadenförmig, 2kantig; $\mathrm{Bl}$. eilänglich, durchscheinend punktirt; Klchbl. länglich, stumpf, ganzrandig oder drüsig-gewimpert. $\odot-4$. Blkr. sehr klein.

Auf sandigen und lehmigen Aeckern, Triften, in trocknen Wäldern, stellenweise häuffg, z. B. in der Nähe von H. beim Speyrer Hof, beim Riesenstein, am heiligen Berge! Auch bei Schwetzingen! Nou-Lussheim! u. s. w. Juni-September.

b) St. rund; Kelchbl, stets am Rando drüsig gewimpert.

175. H. pulchrum $L$. S chönes J.; St. aufrecht, kahl; Bl. sitzend, herzförmig-eirund, stumpf, kahl, unterseits graugrün, punktirt; Kelchbl. verkehrt-eirund, sehr stumpf, mit sitzenden Driisen. 4. $1-1 \frac{1}{2}^{\prime}$.

An waldigen, sonnigen Abhängen, auf Bergwiesen, in lichten Wäldern auf Sandboden. Auf den Bergen bei H. diesseits und jenseits des Neckars häuffg! Auch bei Schriesheim!' Weinheim (z. B. auf dem Wagenberge) stellenweise verbreitet. In der Ebene seltener, auf Kalkboden fehlend oder nur vereinzelt, z. B. bei Nussloch! Juni -August.

176. H. montanum $L$. Berg-J.; St. aufrecht, kahl; Bl. sitzend, herzförmig-eirund oder elliptisch, am Rande schwarzpunktirt; Kelchbl. lanzettl., mit gestielten Drüsen. 4. 1-2'. Trugdolden armblüthig, kopfig-gedrängt. Variirt

$\beta$ ) scabrum; Bl. unterseits durch kurze, dichtstehende Haare sehr rauh, weissgrau. 
In lichten Wäldern sowohl der Gebirge, als dor Ebene, in Nadelwäldern, auf Haiden, jedoch immer nur zerstreut und einzeln. In der Nähe von II. nicht selten, z. B. am Haarlass, am PhilosophenWege, im Klingenthal, auf dem Königsstuhl! Auch bei Schönau und durch das Gebirge bis Schriesheim und Weinheim! Bei Schatthausen! Seltener, bei Nussloch und Wiesloch! Im Friedrichsfelder Walde verbreitet, und daselbst, nicht fern vom Relaishause, die Var. $\beta$. Juli, August.

177. H. hirsutum $L$. R a $u$ h hariges J.; St, aufrecht, nobst den Blättern weichhaarig; Bl. eiförmig-länglich, kurz gestielt, punktirt; Kelchbl. lanzettl., mit gestielten Drüsøn. 2. $1 \frac{1}{2}-2^{\prime}$. Trugdolden in langgestreckten Trauben.

In Wäldern, Gebüschen, vorzugsweise Schatten liebend. In den Gebirgswäldern des Odenwaldes verbreitet, und daher auch häufig in der Nähe von H., sowohl jenseits des Neckars, als diesseits, besonders im Dreitröge-Thal! am Königsstuhl! bis Gaiberg u. Schatthausen! Fehlt nicht in den Wäldern der Ebene, z. B. bei Schwetzingen! Friedrichsfeld! Im oberen Wald bei Wiesloch! Juli-August.

\section{ACERINEAE DC.}

Bäume oder Sträucher mit reichlichem zuckerhaltigem Safte, gegenständigen, handförmig-gelappten, - seltener dreitheiligen oder gefiederten Blättern, ohne Nebenblätter. Blth. meist vielehig, seltener zwitterig in Trauben oder Doldentrauben. K. und Blkr. 4-5-9theilig, in der Knospe dachig. Blkr. bisweilen fehlend. Sthgef. meist 8, seltener 4, einer hypogynischen Scheibe eingefügt. Frchtk. 2lappig. 2fächrig mit 1 Griffel und 2 Narben. Frucht geflügelt, bei der Reife in 2 einsamige Nüsschen zerfallend. Samen eiweisslos. Keim gekrümmt.

A cor. Blth. vielehig; K. u. Blkr. meist 5zählig; Stbgef. 8.

78. Acer $L$. A horn.

a) Stbgef. der männl. Blth. so lang, als dio Blkr.

178. A. campestre $L$. Feld-A.; Bl. handförmig-5lappig, mit ganzrandigen oder schwaeh gekerbten Lappen; Doldentrauben aufrecht; Flügel der Frucht wagerecht abstehend. - Blth. grünlich. $8-10^{\prime}$ hoher Strauch oder $20-25^{\prime}$ hoher Baum, mit oft ansehnlicher Korkentwickelung an den $Z_{\text {weigen. }}$ 
In Wäldern, Gebüschen nicht selten. Ansehnliche, sehr alto Stämme in den Bergwäldern hinter Schriesheim: Mai.

179. A. platanoides $L$. Spitzblättriger A.; Bl. buchtiggelappt, mit feinzugespitzten, gezähnten Lappen; Doldentrauben aufrecht; Flügel der Frucht wagerecht abstehend. Blth. grünlich. Ansehnlicher Baum mit glatter Rinde.

In den Gebirgswäldern um H., z. B. in zahlreichen und schönen Stämmen auf dem Oelberge bei Schriesheim! Häuflg angepfianzt. April, 'Mai.

b) Stbgef, der männl. Blth. doppelt so lang als die Blkr.

180. A. Pseado-Platanas $L$. Platanen-A.; Bl. 5lappig, ungleich gesägt; Trauben hängend; Flügel der Frucht wenig abstehend. Blth. grün. Ansehnlicher Baum mit glatter Rinde.

In Wäldern der Ebene und der Gebirge hie und da. Häufig angepflanzt. Mai, Juni.

(Ausser diesen bei uns einheimischen Arten findet sich zuweilen angepflanzt und mitunter in Gebüschen und Wäldern verwildert der aus Nord-Amerika stammende, durch hellgrüne Zweige und meist 3theilige Bl, auffallende Acer Negundo L.)

\section{HIPPOCASTANEAE. DC.}

Bäume oder Sträucher mit gegenständigen, handförmig zusammengesetzten Blättern ohne Nebenbl. Blth. in gipfelständigen Rispen. Kelch 5zähnig. Blkr. unregelmässig, $4-5$ blättrig, nebst den $7-8$ Stbgef. einer unterständigen, dem Kelche angewachsenen Scheibe eingefügt. Frchtk. frei, 3fächrig, Fächer 2eiig. Griffel 1. Kapsel 1-3fächrig, 1-6samig. Samen kugelig, mit grossem, kreisrundem, grundständigem Nabel, eiweisslos. Keim gekrümmt.

Escul u s. K. glockig; Blbl. 4-5; Stbgef. 7-8; Kapsel lederartig, mehr oder weniger stachelig.

\section{[Esculus L. Rosskastanie.]}

E. Hipnocastanum $L$. Gemeine R.; Bl. 5-7fingerig; Blättchen keilförmig, stark gerippt; Blbl. 5, weiss, roth u. gelb gefleckt; Stbgef. 7. $30-70^{\prime}$ hoher Baum aus den nürdlichen Theilen Ostindiens stammend.

Häuffg angepflanzt, Mai. 
In der nächsten Umgebung von II. findet sich häuffg cultivirt: E. rubiounda Lois, rothblühende $\mathrm{R}$.

\section{AMPELIDEAE H.B.K.}

Klimmende, rankende Sträucher mit gegenständigen, handförmig gelappten oder fingerförmig getheilten Blättern. Blth. in Rispen oder Trugdolden. Kelch 4-6gliedrig, unscheinbar. Blbl. 4-5, einer unterständigen Scheibe eingefügt, in der Knospenlage klappig. Stbgef. 4-5, den Blumenblättern gegenüberstehend. Frchtk. frei, 2-3fächrig. Fächer 1-2eiig. Griffel kurz oder fehlend. Beeren 2-3fächrig. Fächer 1-2samig. Samen mit knöcherner Schaale und knorpeligem Eiweiss. Keim gerade.

Vitis. K. 5zähnig; Blbl. 5, am Grunde sich ablösend, an der Spitze zusammenhängend; Stbgef. 5; Beere 4-6samig.

79. Vitis $L$. Weinstock.

181. V. vinifera $L$. Gemeiner W.; Bl. herzförmig, meist buchtig 5lappig. grobgezähnt; Ranken blattgegenständig. $\hbar$. Blth. grünlich-gelb. Cultivirt.

In den Waldungen hie und da, z. B. bei Wiesloch völlig verwildert. Juni, Juli.

Hieher auch Ampelopsis hederacea Michx. (sogenannt. wilder Wein), aus Nord-Amerika stammend, häufig zu Lauben und Mauerbekleidung verwendet.

\section{GERANIACEAE $D C$.}

Kräuter oder Halbsträucher mit gegenständigen oder abwechselnden handförmigen Blättern und Nebenblättern. Blth. meist doldig, seltener einzeln. Kelchbl. 5, in der Knospe dachig, bleibend. Blbl. 5. in der Knospe gedreht. Stbgef. meist 10, monadelphisch, bisweilen einige unfruchtbar. Frchtk. 5, nebst den 5 Griffeln an die verlängerte Blüthenaxe angewachsen. Früchtchen 1samig, bei der Reife mit den Griffeln vom Grunde bis zur Spitze von der Axe sich 
klappenartig ablösend. Same eiweisslos mit gekrümmtem Keim. - Meist bodenvage Pflanzen ohne entschiedene Vorliebe für bestimmte Lokalverhältnisse. Im Allgemeinen zwar häufig, aber wenig gesellig auftretend.

Geranium. Stbgef. 10, meist*) alle fruchtbar; Griffel mit den Fruchtklappen sich bogenförmig von der Fruchtaxe ablösend.

Erodium. Stbgef. 5 fruchtbar, 5 unfruchtbar; Griffel mit den Frchtk. sich spiralförmig von der Fruchtaxe ablösend.

80. Geranium $L$. St or ch schnabel.

a) Perennirend; Wrzlst. horizontal mit den Blattresten des vor. Jahres besetzt. St. ausgebreitet, ästig. Blkr. gross. $\alpha$. Stbgef, niedergebogen.

182. G. macrorhizum $L$. Grosswurzeliger St.; Bl. handförmig-7lappig, eingeschnitten-gezähnt, weichhaarig; Blthstiele 2blüthig, nach dem Verblühen zurückgeschlagen; Stbgef. abwärtsgebogen; Fruchtklappen kahl, queerrunzelig. 4. 1-2'. Blkr. blutroth. Wrzlst. stark, etwas ästig. Kraut wohlriechend.

Auf einer verfallenen Mauer unterhalb der Engelswiese bei H.l (Die Pflanze stammt aus dem südlichen Europa, wurde ehemals in Weinbergen häufig kultivirt und ist jetzt in manchen Gegenden der Rheinischen Flora eingebürgert). Juni, Juli.

\section{$\beta$. Stbgef. aufrecht.}

183. G. pratense $L$. Wiesen-St.; St. oberwärts drüsenhaarig; Bl. handf.-5-7theilig, eingeschnitten gesägt; Blthstiele 2blüthig, nach dem Verblühen zurückgeschlagen; Fruchtklappen glatt, mit abstehenden Drüsenhaaren: Stbfäden am Grunde breitgeflügelt. 4. 1-2'. Blkr. hellblau.

Auf Wiesen stellenweise häufig, z. B. am Neckar bei Ziegelhausen! Schlierbach! Bei Handschuhsheim! Iadenburg! Schatthausen! Wiesloch! u. s. w. Juli, August.

184. G. palustre $L$. Su mp f-St.; oberwärts mit rückwärtsgekehrten drüsenlosen Haaren; Bl. handf.-5spaltig, eingeschnitten-gezähnt; Blthstiele 2blüthig, nach dem Verblühen niedergebogen; Stbgef. lanzettl., kaum geflügelt; Fruchtklappen glatt, mit abstehenden drüsenlosen Haaren. 2. 1-2'. Blkr. purpurroth.

Auf sumpfigen Wiesen, an schattigen Gräben, in feuchten Wäldern nicht häuff. Bei Alt-Wiesloch! Rauenberg! Schatthausen!

") Bei G. pusillum sind 5 Stbgef. unfruchtbar. 
Nussloch! Gaiberg! und von dort stellenweise bis Neckargemuind! Juni-August. [Verbreitet von hier durch don Odenwald ins Mainthal! In Rhb. fehlend. (F. Sch.)]

185. G. sanguineum $L$. Blutrother St.; St. mohr oder weniger ausgebreitet-ästig, überall mit abstehenden, drüsenlosen Haaren besetzt; Bl. tief-7theilig mit linealischen Zipfeln; Blthstiele meist 1blüthig, nach dem Verblühen etwas abwärtsgeneigt; Fruchtklappen glatt, weichhaarig. 4. $\frac{1}{2}-2^{\prime}$. Blkr. ausgerandet, purpurroth. St. und häufig auch die Bl. rothgefärbt.

Auf sonnigen Hügeln, an Folsen, auf trocknen Waldwiesen. An den Abhängen der Bergstrasse von $H$. bis Weinheim stellenweiso häufig! u. A. auf den Felsen beim IIaarlass! Am Geisberge bei II. und gegen Rohrbach! In der sog. Hessel bei Wiesloch! bei Maischbach! Dielheim! Schatthausen! Rauenberg! Baierthal verbreitet! Mai-August.

186. G. pyrenaicum L. Pyrenäen-St.; St. weichhaarig, drüsenlos; Bl. nierenförmig-7-9lappig, mit stumpfen Lappen; Blth.stiele 2blüthig, nach dem Verblühen etwas abwärtsgeneigt; Fruchtklappen glatt, weichhaarig, drüsenlos. $4 \cdot \frac{1}{2}-1^{\prime}$. Blbl. 2spaltig, lillapurpurroth. - Die Blüthen um die Hälfte kleiner als bei den vorigen Arten.

Auf Waldwiesen, in Gebüschen, z. B. bei Weinheim, am Fusswege nach Nesterbach! In Menge auf den Grasplätzen des Mannheimer Schlossgartens! Juni-August. (Wie in manchen andern Gegenden Doutschlands eingewandert und nun eingebürgert.)

b) Einjährig. Blthstiele meist 2blüthig, nach dem Verblühen niedergebogen. Blkr. klein.

$\alpha$. Fruchtklappen glatt; Samen wabig-punktirt.

187. G. dissectum $L$. Zerschlitzter St.; St. ausgebreitet, rauhhaarig; Bl. handf.-5-7theilig; Bltlıst. kurz; Blbl. 2spaltig, kaum länger als d. K.; Fruchtklappen drüsig-behaart. ๑. 3-8". Blkr. purpurroth, am Grunde gewimpert.

Auf Aeckern, an Wegen häuff. Mai-August.

188. G. columbinum $L$. T a u ben-St.: St. niederliegend, ausgebreitet, weichhaarig; Bl. handf. -5 -6theilig; Blthstiele lang; Blbl. ausgerandet, kaum länger als d. K.; Fruchtklappen kahl. ๑. 3-10". Blkr. rosa.

In Weinbergen, an Wegen, auf Sandfeldern und Geröll hio und da; z. B. am Philosophen-Wege! InWeinbergen zwischen Handschuhsheim und Dossenheim! Beim Relaishause! Im Steinbruch hinter Nussloch! Im Birkenauer Thal bei Weinhoim! Juni-August. 
189. G. rotundifolium $L$. Rundblätteriger St.; St. ausgebreitet, weichhaarig (zuweilen etwas klebrig); Bl. rundlich-nierenf. 5-7spaltig; Blthstiele kurz; Blbl. ungetheilt, wenig länger als d. Kolch; Fruchtklappen abstehend, drüsenlos, weichhaarig. ๑. 310". Blkr, hellroth.

In Weinbergen, an Wogen, auf Schutt stellenweise, z. B. in der Nähe von H. an den Felsen beim Haarlass! Am PhilosophenWeg! In Weinbergen beim Dreitrögo-Thal! Auch bei Weinheim an mehreren Standorten, z. B. auf Felsen im Birkenauer Thal! In Weinbergen unterhalb der Burg Windeck! Bei Nesterbach! Mai -Juli.

B. Fruchtklappen und Same glatt.

190. G. pusillum $L$. K leinor St.; St. aufrecht oder wonig niederliegend, weichhaarig; Bl. fast kreisrund 7-9spaltig; Blbl. verkehrt-herzförmig, ausgerandet-2spaltig, am Grunde schwach gewimpert; Fruchtklappen weichhaarig. ๑. 4-- $8^{\prime \prime}$. Blkr. blassviolett. 5 Stbgef. unfruchtbar.

An Wegen, auf Aeckern, Schutt häufig! Juni-August.

$\gamma$. Fruchtklappen runzelig; Samen glatt.

191. G. molle $L$. Weicher St.; St. ausgebreitet, weichhaarigzottig; Bl. rundlich-nierenförmig 7-9spaltig; Blbl. länglich, tief 2spaltig, am Grunde deutlich gewimpert; Fruchtklappen queerrunzelig; kahl. ๑. 5-10". Blkr. purpurroth.

Auf Aeckern, Triften, an Wegen, überhaupt an sandigen, trocknen Plätzen hie und da, z. B. bei Friedrichsfeld, Schwetzingen u. 8. w. nicht selten. Mai-August.

192. G. Robertianum $L$. Ruprechtskraut; St. aufrecht; Bl. 3-5zählig; Blättchen gestielt, 3spaltig, eingeschnitton-flederspaltig; Blbl. verkehrt-eiförmig, ungetheilt, länger als d. K.; Fruchtklappen netzig-runzlig, weichhaarig. $\odot$. $\frac{1}{2}-1^{\prime}$. Blkr. getrübt-hellroth. St. und oft auch dio Bl. blutroth angelaufen. Das ganze Kraut widerlich riechend.

In feuchten Gebüschen, an Gräben, Mauern, in Wäldern sehr häufig! Mai-September.

\section{Erodium l'Herit. Reiherschnabel}

193. E. cicutarium l'Herit. Schierlingsbl. R.; St. niederliegend, rauhhaarig; Bl. gefledert-fiederspaltig; Blthstiele melrblüthig. $\odot$. Blth. purpurroth oder hellroth. Die Blätter bald grösser, bald kleiner, mehr oder weniger gespalten. Hinsichtlich der Behaarung wechselnd. (E. pimpinellaefolium Rchb.)

An Wegen, auf Sandfeldern, Schutthaufen, Aeckern gemein. April-October. 


\section{BALSAMINEAE Rich.}

Meist einjührige Krïuter, mit zarten, saftigen Stengeln, einfachen, abwechselnden gegenständigen Blättern ohne Nebenblatter. Blth. unregelnässig in achselstïndigen Trauben. Kelch gefärbt 4-5blätterig, das untere Kelchblatt gross und gespornt, die zwei seitlichen kleiner. Blbl. 4-5, das obere gross, concav, die 4 seitlichen mehr oder weniger mit einander verwachsen. Stbgef. 5 mit kurzen Staubfäden. Antheren mit den Rändern zusammenhängend. Frchtk. 5fächrig mit 5 sitzenden Narben. Fächer vieleiig. Samenträger central. Kapsel 5 fächrig, 5klappig. Klappen bei der Reife von der Mittelsäule sich elastisch ablösend und spiralig zusammenrollend. Samen eiweisslos. Keim gerade.

Impatiens. Als einzige Gattung.

\section{Impatieus $L$. Springkraut.}

194. I. Noli tangere $L$. Gemeine Balsamine; Bl. kurzgestielt, eiförmig, grobgezähnt; Blth. hängend, mit an der Spitze zurückgebogenem Sporn. ๑. 1-2'. Blth. gelb. Das Kraut äusserst zart und hellgrün.

In schattigen, feuchten Waldungen, an schattigen Gräben, Zäunen hie und da. Im Carmeliterwäldchen bei H.! Bei Handschuhsheim! Zwischen Ziegelhausen und der sog. Glashütte! Waghäusel! u. s. w. Juni-August.

I. parviflora $D C$. Verschieden durch aufrechte, viel kleinere Blüthen mit geradem Sporn. Stammt aus der Mongolei, füngt aber an in verschiedenen Gegenden Deutschlands zu verwildern. - Bei H. zeigt sie sich vorzugsweise in der näheren Umgebung des bot. Gartens! Juni-August.

\section{OXALIDEAE $D C$.}

Kräuter mit abwechselnden, zusammengesetzten Blättern, mit Nebenblättern oder ohne dieselben. Blth. regelmässig, Kelch 5theilig, in der Knospenlage dachig. Blbl. 5, in der Knospe gedreht. Stbgef. 10, meist am Grunde etwas ver- 
bunden, die inneren lïnger als die iusseren. Fruchtlinoten 5 fächerig, vieleiig, mit 5 Grifieln und centralem Samenträger. Kapsel 5klappig. Samen eiweisshaltig, von einem fleischigen, elastisch abspringenden Samenmantel umgeben. Keim gerade.

Oxalis. Hieher die einzige Gattung.

\section{Oxalis $L$. Sauerklee.}

195. 0. acetosella $L$. Gemeiner S.; Wrzlst. kriechend, schuppig; Bl. 3zählig, Blättchen verkehrt herzförmig; Nebenblt. o Schaft 1blüthig. 4. $3-6^{\prime \prime}$. Blth, rüthlich-weiss (zuweilen violett).

In schattigen, feuchten Laubwäldern, an Zäunen häufig! April, Mai. (Off. Hb. Acetosellae.)

196. 0. stricta L. Steifer S.; St. aufrecht; BI. 3zählig, Blättchen verkehrt-herzförmig; Nebenbl. 0 ; Blthstiele 2-5blüthig, bei der Fruchtreife aufrecht. Die Pfl, treibt unterirdische Ausläufer, welche ausdauern, während Hauptwurzel und das ganze Kraut $\odot$ sind.: $\frac{1}{3}-1^{\prime}$. Blth. gelb, klein.

An Wegen, auf Aeckern und Grasplätzen hie und da, z. B. in Menge hinter dem Stift Neuburg und im Klingenthal bei II.! Stammt wie die folgende aus Nordamerika, ist aber bei uns völlig eingebürgert. Juni-August.

197. 0. corniculata $L$. Gehürnter S., meist grauhaarig; St. ausgebreitet, ästig; Bl. 3zählig; Blättch. verkehrt-herzf.; Nebenbl. lineal., dem Blattstiel angewachsen; Blthstiele 2-5blïthig, bei der Fruchtreife zurückgeschlagen. $\frac{1}{3}-1^{\prime}$. Ausläufer fehlen. Blth, gelb.

Auf Sandfeldern, an Wegen viel seltener als vorige, z. B. bei Schwetzingen. Juni-August.

\section{[RUTACEAE Juss.]}

Kräuter oder Sträucher mit abwechselnden, durchscheinend-punktirten Blättern ohne Nebenblätter. Kelch 3-5spalt. oder theil,, in der Knospe dachig. Blumenblïtter von derselben Zahl, einer drüsigen Scheibe eingefügt. Stbgef. meist 5-10, ebenfalls der Scheibe eingefügt. Frchtk. mehrfächerig, gelappt. Griffel 1. Frucht kapselartig. Samen eiweisshaltig. Keim gekrümmt.

a) Di osmeae. Innere Kapselschicht pergamentartig, elastisch von der Mittelschicht abspringend.

Dictamnus. K. 5theilig; Blkr. ungleich; Stbgef. 10, abwärtsgebogen; Käpsel 5fächerig.

SCHMIDT, Flora v. H. 


\section{Dictamnus $L$. Diptam.}

D. Fraxinella Pers. Eschen blättr. D.; Bl. einfach gefiedert; Blttch. elliptisch, feingesägt; Traube reichblth., nebst Blth. drüsigbehaart; Blbl. elliptisch-lanzettl. $1 \frac{1}{2}-2 \frac{1}{2}^{\prime}$. Blkr. rosa oder weiss.

In lichten Bergwäldern, an bewaldeten Abhängen vorzugsweiso auf Löss, Kalk oder Porphyr. N. V. a. d. Geb. in B.: Eichelberg, bei Bruchsal! In Rhb.: Schlammberg bei Dürkheim! Kalkhügel bei Callstadt! Mai, Juni. - Die ganze Pflanze stark balsamisch riechend. Das in beträchtlicher. Menge vom Blthstande ausgehende aetherische Oel lässt sich bei warmem, trocknem Wetter durch einen in die Nähe gebrachten brennenden Spahn entzünden, und veranlasst bei hinlänglicher Dunkelheit eine rasch vorübergehende phosphorähnliche Lichterscheinung. (Das Vorkommen im Floragebiet ist unsicher. Der von Gattenhof angegebene Standort: oberhalb Ziegelhausen, ist verloren, indem die Pflanze daselbst wahrscheinlich schon längst ausgerottet worden. Der Standort im Walde bei Reilingen, zwischen Walldorf und Neu-Lussheim, ist ebenfalls in neuerer Zeit als nicht mehr vorhanden zu betrachten.) [Off. Rad. Dictamni albi.

\section{Subclass. 2. \\ CALYCTFLORAE.}

Kelchbl. am Grunde mehr oder weniger verbunden. Blbl. und Stbgef. im Grunde des Kelches eingefügt, oder der mit dem Fruchtk. verwachsene Kelch trägt die getrenntoder verwachsen-blätterige Blkr. mit den Stbgef.

\section{CELASTRINEAE R.Br.}

Sträucher mit einfachen oder zusammengesetzten Blättern und kleinen hinfälligen Nebenblättern. Blth. regelmässig. Kelch 4-5theilig, in der Knospenlage dachig. Blbl. 4-5, am Rande einer hypogynischen fleischigen Scheibe eingefügt. Stbgef. 4-6, mit den Blbl, wechselnd, der Scheibe auf- 
sitzend. Frchtk. 2-5fächerig. Fücher 1-vieleiig. Griffel 1-5. Frucht meist kapselartig. Samen mit fleischigem Samenmantel und reichlichem Eiweiss oder ohne Mantel und Eiweiss. Keim gerade.

Ev onymus. K., Bl., Stbgef. 4-5zählig; Griffel 1; Kapsel 3-5fächerig; Fächer 1samig; Samen eiweisshaltig, von einem fleischigen Mantel umgeben.

\section{E r ou yu us $L$. Spindelbaum.}

198. B. europaeus $L$. Spillbaum, P faffenhütchen; Str. 4-12', mit 4kantigen, glatten Zweigen; Bl. elliptisch; Kapsel 3lappig, flügellos, roth; Blüthen grünlich.

In Wäldern, Gebüschen, Hecken häufig! Mai, Juni.

\section{RHAMNEAE. $R$. Br.}

Sträucher mit zuweilen dornigen Zweigen, abwechselnden oder gegenst. Blättern und Nebenblättern. Blüthen regelmässig, hermaphroditisch, polygamisch oder dioecisch. Kelch 4-5spaltig, in der Knospenlage klappig; Blbl. 4-5 einer hypogynischen oder epigynischen Scheibe eingefügt, zuweilen auch völlig fehlend. Staubgef. $4-5$ den Blumenblättern gegenüberstehend, Fruchtknoten frei oder etwas mit dem Kelch verwachsen, 2-4fächerig, Fächer 1eig, Griffel 1, Steinfrucht 1-3samig, Samen mit wenigem Eiweiss, ohne Mantel; Keim gerade.

Rhamnus. K., Blkr., Stbgef. 4-5zählig. Kelchsaum abfallend. Steinfrucht fleischig oder lederartig. Same mit tiefer Längsfurche.

\section{Rhamuus $L$. Wegdorn.}

199. R. cathartica $L$. Purgir-W.; Kreuzdorn; Zweige gegenst. mit endständigen Dornen; Bl. rundlich-oval, feingesägt; Bltstiele länger als die Nebenbl; Blth. 4zählig, meist dioecisch; Früchto schwarz 4samig. Blth. grün. Strauch 4-5'.

In Gebüschen, lichten Waldungen, auf Felsen, in Torfsümpfen hie und da. Beim Haarlass! an den felsigen Abhängen bei Schriesheim und Weinheim! Beim Relaishause und von dort bis zum Rohr- 
hofe stellenwcise nicht selten! Bei Neckarau und Waghäusel mitunter ansehnliche Gebüsche bildend! (Weibliche Stämme sind vorherrschend, männliche seltener). Mai-Juli. (Off.: Baccae Spinae cervinae).

200. R. Frangula $L$. Glatter W.; Faulbaum; Zweige wechselnd, dornenlos; Bl. elliptisch, zugespitzt, ganzrandig; Blth. 5zählig, zwitterig; Früchte 2samig, zuerst roth, dann schwarz. Blth, grünlich weiss. Str. 6-12'.

In Wäldern und Gebüschen häufig! Mai-Juli. (Off.: Cort. et Baccae Frangulae.

\section{PAPILIONACEAE. $L$.}

Meist 4 oder $\odot$ Kräuter, zuweilen Sträucher, selten Büume mit abwechselnden, gewöhnlich 3 - oder mehrzähligen gefiederten, seltener einfachen Blättern und meistens mit sehr entwickelten, für die Charakteristik der Arten nicht selten sehr wesentlichen Nebenblättern. Blüthen in Trauben oder Aehren, zuweilen einzeln. Kelch 5theilig oder 2lippig, die Oberlippe 2gliedrig, die Unterlippe 3gliedrig. Blkrone 5blättrig, schmetterlingartig; das obere grösste Bbl. (Fahne) in der Knospe die übrigen deckend, die 2seitlichen entgegengesetzt (Flügel), die 2 unteren mehr oder weniger miteinander verwachsend, und eine die Staubgefässe und den Fruchtknoten umschliessende Rinne bildend (Kiel oder Schiffchen). Staubgefässe 10, seltener monadelphisch, häufiger diadelphisch, indem 9 mehr oder weniger mit einander verwachsen, der 10. Staubfaden aber völlig frei bleibt. Fruchtknoten frei mit 1 Griffel und seitenständigem Samenträger. Frucht eine 1fächerige oder seltener eine scheinbar 2fächerige, mehrsamige oder seltener 1samige Hülse. zuweilen in Querglieder zerfallend. Same eiweisslos mit gekrümmtem Keim. Da die meisten dieser Pflanzen gesellig sind, so flndet sich die Familie nächst Compositae und Gramineae am häufigsten. Auf dem verschiedensten Boden und fast überall auftretend, lieben die Papilionaceae vorzugsweise einen trockenen, freien, etwas warmen Standort und gedeihen selten in Sümpfen und auf nassen Wiesen. Einigo haben Vorliebe für kalkartigen Boden und das Wachsthum mancher wird durch geeignete Hinzuführung desselben wesentlich befürdert. - 
Habitus ziemlich übereinstimmend, besonders bei den zahlreichen Arten mit 3zähligen Blättern. Die Blumenkronen sind fast bei der Hälfte aller Arten gelb, bei den übrigen roth oder blau. Die weisse Schmetterlingsblüthe, welche bei den bekannten kultivirten Arten vorherrscht, zeigt sich bei den einheimischen nur selten. - Durch Gehalt an eigenthümliche Stoffe wenig ausgezeichnet, werden die meisten unserer einheimischen Papilionaceen bemerkenswerth durch grössere oder geringe Menge von stickstoffhaltigen Bestandtheilen, welche nicht nur, nebst viel Stärkmehl im Samen, sondern auch in der Frucht und im Kraute sich finden. Aus diesem Grunde und durch oft reichlichen Gehalt des Krautes an Zucker, Gummi, Schleim sind die Papilionaceen als Wiesenpflanzen sehr geschätzt und verdienen die Verbreitung, zu welcher sie durch das reichliche Ausstreuen ihrer keimfähigen Samen gelangen. - Das Vorkommen von ätherischem Oele in den Blüthen bei einigen, von Bitterstoff in der Wurzel, im Kraut und in den Samen bei anderen, macht sie auch in pharmazeutischer Beziehung, jedoch verhältnissmässig wenig beachtenswerth.

Trib. 1. Loteae. Staubgef. monadelph. oder diadelph. Hülse ohne Querscheidewände, 1 fächerig oder (in unserer Flora jedoch nur bei Astragalus) scheinbar 2fächerig. - Blätter unpaarig gefiedert od. 3zählig, selten einzeln. - Samenlappen bei der Keimung sich über die Erde erhebend, blattähnlich.

a) Stbgef. monadelphisch.

«) Kelch 2lippig, Flügel am Grunde oberwärts faltig-runzelig.

S a r o th a mnus. Griffel verlängert, oberwärts etwas verbreitert, spiralig eingerollt. Narbe kopfig.

Genista. Gr. pfriemlich, aufsteigend; Narbe schief, nach innen gebogen.

Cytisus. Gr. pfriemlich aufsteigend; Narbe schief, nach aussen gebogen.

$\beta)$ Kelch 5zähnig, Flügel nicht faltig.

Ononis. K. zur Fruchtzeit offen; Schiffchen geschnäbelt, B1. 3zählig.

Anthyllis. K. zur Fruchtzeit geschlossen, aufgeblasen, Schiffchen fast stumpf, Bl. gefledert.

b) Stbgef. diadelphisch.

ж) Bl. 3zählig.

Lotus. Schiffchen geschnäbelt; Hülse lineal, ungeflügelt; Griffel an der Spitze verschmälert.

Tetragonolobus. Schf. geschnäbelt; Hülse 4flügelig; Gr. an der Spitze verdickt. 
Medicag 0. Schf. stumpf; Fruchtknoton gekrümmt; IIülse sichel- od. schneckenförmig gewunden, 1-vielsamig.

Melil otus. Schf. stumpf; Fruchtknoten gerade; Hülse kurz, 1-3samig; Stbgef, nicht mit d. Blbl. verwachsen.

Trifolium. Schf. stumpf; Stbgef. ein wenig mit dem Blbl. verwachsen, sonst wie Melilotus.

ß) Bl. gefiedert.

Astragalus. Schiffehen stumpf; Griffel kahl; Ir̈̈lse der Länge nach scheinbar 2fächerig. - Kräuter.

Robinia. Schf. stumpf; Griff. bärtig; Hülse völlig 1fächerig, zusammengedrückt. - Baum.

Trib. 2. Hedysareae. Stbgef. diadelphisch. Hülse durch Querscheidewände aufspringend, $d . h$. in einsamige Glieder getheilt; Bl. unpaarig-gefiedert. Samenlappen bei der Keimung blattähnlich.

Coronilla. Schiffchen geschnäbelt; Hülse lineal, etwas gcbogen, an den Gelenken zusammengezogen.

Hippocrepis. Schf. geschnäbelt; Hülso zusammengedrückt, an der oberen Naht buchtig ausgeschnitten.

Ornithopus. Schf. abgerundet, stumpf; Hülse sichelförmig, zusammengedrückt, an den Gelenken zusammengezogen.

Onobrychis. Schf. schief abgestutzt; Hülso 1gliedrig, verkehrt-eiförmig, knochenhart, bekielt, grubig-netzartig.

Trib. 3. Vicieae. Stbgef. diadelphisch. Hülse 1fächerig. BI. paarig gefiedert, meist in eine Ranke ausgehend; Samenlappen fleischig, sich nicht grün färbend, meist unter der Erde bleibend.

Vicia. K. 5zähnig; Griffel fadenförmig, bald behaart, bald kahl; Hülse zusammengedrückt, vielsamig.

Pis um. K: 5spaltig; Gr. 3kantig, nach unten rinnenartig. Hülse zusammengedrückt, vielsamig.

Ervum. K. 5spaltig; Gr. nach oben verbreitert, abgeplattet, überall behaart. Hülse abgekürzt 2samig; Same zusammengedrückt.

Lathyrus (incl. Orobus). K. 5spaltig; Griffel nach oben verbreitert, abgeplattet, nach innen behaart. Hülse zusammengedrückt, vielsamig; Same kugelig oder oval.

Trib. 4. Phaseoleae. Stbgef. diadelphisch. Hülse 1 fächerig, mit schwammigen Anschwellungen zwischen den Samen. Blätter 3zählig; Samenlappen fleischig, sich nicht grün färbend. Bei der Keimung oft rom Boden sich erhebend.

Phaseolus. Griffel mit den Staubgef. und dem Schiffchen schneckenförmig zusammengerollt. 
86. Sarothamus Wimm. Besenpfriemèn.

201. S. scoparius Koch. Gemeiner B.; St. aufrecht mit ruthenförmigen, scharfkantigen Zweigen; Bl. 3zählig, die oberen einfach; Hülse zusammengedrückt, zottig. †. 2-5'. Blth. ansehnlich, gelb. (S. vulgaris Wimm. Spartium soopartum L.).

Auf trockenen Haiden, an Abhängen, in lichten Wäldern besonders auf Sandboden häufig! Mai, Juni.

\section{Genista $L$. Ginster.}

202. G. tinctoria $L$. Färber-G.; St. aufsteigend, dornen1os; Bl. lanzettlich od. elliptisch, am Rande weichhaarig, Trauben endständig; Blkr. und Hülse kahl. ち. 1-2'. Blth. gelb.

Auf trockenen Wiesen, an Abhängen, in Wäldern hio und da häufig, sowohl im Gebirge (schon in der Nähe von H.) als auch besonders auf den Wiesen beim Relaishause! Neckarau! Waghäusel! Juni, Juli.

203. G. pilosa $L$. Behaarter G.; St. niederliegend, dornonlos; Bl. längl.-lanzettlich, unterseits nebst den Zweigen, dem Kelche, der Fahne, dem Schiffchen und der Hülse seidenhaarig; Trauben seitenständig, verkürzt. ந. 4-8". Blth. gelb.

Auf trockenen Haiden, sonnigen Hügeln, in lichten Wäldern, besonders im Gebirge zuweilen sehr häufig, z. B. von Ziegelhausen in der Richtung nach Wilhelmsfeld und Schriesheim! Mai, Juni.

204. G. germanica $L$. Deutscher G.; St. aufrecht, dornig, unten blattlos, oben beblättert, rauhhaarig; Bl. lanzettlich oder elliptisch; Trauben gipfelst. $\hbar$. $\frac{1}{2}-2^{\prime}$. Blth. gelb.

In lichten trockenen Wäldern, an Abhängen, auf Haiden nicht selten. Hie und da im Gebirge in der Nähe von - H., besonders diesseits des Neckars! häuffger aber bei Nussloch! Wiesloch! Auch, wiewohl nicht so verbreitet, in der Ebene bei Schwetzingen! Kirrlach! Walldorf! Mai, Juni.

\section{Cytisus $L$. Geisklèe.}

205. C. sagittalis Koch. Geflügelter G.; St. niederlicgend, 2schneidig geflügelt, gegliedert; Bl. elliptisch; Trauben endständig, kopfförmig. $\hbar$. $\frac{1}{2}-2^{\prime}$. Blth: gelb. (Genista sagittalis L.).

Auf Haiden, an Bergabhängen, auf trockenen Wiesen, in Nadelwäldern hie und da. Auf den Felson vor dem Haarlass! auf der Engelswiese! und gegen Ziegelhausen häuffg! Auch bei der Molkenkur! am Riesenstein! auf dem Königstuhl! bei Schriesheim! Weinheim! Sporadisches Vorkommen auf den Hügeln zwischen Rauenberg und Malsch! - In den Nadel rraldungen bei Friedrichsfeld und 
Walldorf zuweilen mit sehr verlängerten, weithin sich crstreckenden Zweigen und auf dem magern Boden wenig blühend, übrigens auch dort und bei Schwetzingen nicht selten! Mai, Juni.

\section{Ononis $L$, Hauhechel.}

206. 0. spinosa $L$. Dorniger H.; St. aufrecht oder aufsteigend, dornig, 1reihig-zottig, oberwärts drüsenhaarig; Blättchın eiförmig-länglich, gezähnelt, kahl oder weichhaarig; Blth. blattwinkelständig, einzeln; Hülsen eiförmig, etwas länger als d. Kelch. 4. 1-2 $\frac{1}{2}$. Blkr, rosa.

An Wegen, auf Triften und Aeckern, besonders am Neckarufer häufig! Juni-August. (Off.: Rad. Ononidis spin.).

207. 0. repens $L$. Krie chender H.; St. fast niederliegend, dornig oder dornenlos, ringsum zottig; Blättchen eiförmig, gezähnelt, meist drüsenhaarig; Blth. blattwinkelständig, einzeln, Hülsen eiförmig, kürzer als der Kelch. 4. 1-2'. Blkr. rosa.

Auf Sandflächen, sandigen Hügeln, in Nadelwäldern der Ebeno stellenweise sehr verbreitet! Juni-August.

\section{Anthyllis $L$. Wundklee.}

208. A. Vulneraria $L$. Gemeiner W.; St. aufsteigend; untere Bl. langgestielt, einfach, länglich-eirund, obere gefiedert; Blthen in endständigen kugeligen Köpfchen mit fingerig-gespaltenen Deckblättern. 24. $\frac{1}{2}-1$ '. Blkr. gelb; Kelche weiss wollig.

Auf trockenen Wiesen, sonnigen grasreichen Hügeln; in lichten Nadelwäldern und auf sandigen Triften stellenweise häufig, z. B. hinter dem Haarlass! und längs der Bergstrasse! Auch in den Ebenen hie und da, z. B. zwischen Friedrichsfeld und dem Relaishause! bei Schwetzingen! u. s, w. Mai-Juli.

\section{Lotus $L$. Hornklee.}

209. L. corniculatus $L$. Gemeiner H.; ausgebreitet, aufsteigend, kahl od. behaart, Blättchen länglich verkehrt-eirund oder keilig. Köpfchen langgestielt 5-12blüthig. 24. Blth. gelb. Erscheint in 2 Varietäten :

ג) vulgaris; St. fest, Köpfchen wenigblüthig; Kelchzähn $\theta$ vor dem Aufblühen zusammenneigend. $\frac{1}{4}-\frac{3}{4}$.

ß) uliginosus; St. röhrig; Köpfchen vielblüthig; Kelchzähne vor dem Aufblühen zurückgebogen ( $L$. uliginosus Schkr.). In allen Theilen grosser und kräftiger, weil auf feuchtem Boden wachsend. $1-1 \frac{1^{\prime}}{}$. 
Auf Wiesen, an Wegen, an Waldrändern, Gräben häufig! Var. $\beta$ etwas Feuchtigkeit liebend. Juni-August.

92. Tetragouolobus Scop. Spargelerbse.

210. T. siliquosus Roth. Geme in e Sp.; St. niederliegend; Blättchen rautenförmig-verkehrt-eirund, graugrïn; Blth. einzeln, anselnlich, hellgelb. 24. $3-10^{\prime \prime}$.

Auf feuchten Wiesen, an Gräben nicht häufig: Waghäuscl! Brühl! 「Jenseits des Rheines mehr verbreitet, z. B. an den Oggersheimer Sümpfen! bei Ruchheim! Maxdorf! Dürkheim! Juni, Juli.

93. Il edicago $L$. S chneckenklee.

a) Hülsen dornenlos.

211. M. sativa L. Luzernerklee; St. aufrecht, Blättchon länglich, verkehrt-eiförmig; Trauben länglich, vielblüthig; Hülse schneckenförmig, 2-3mal gewunden. 4. 1-2'. Blth. blau oder grünlich violett.

Häufig kultivirt; an Wegen, grasreichen Dämmen, an Waldrändern überall verwildert! Juni-September.

212. H. falcata $L$. Sichelf. Schn.; St. niederliegend oder aufsteigend, länglich keilfürmig; Trauben verkürzt, vielblüthig; IIülse sichelf,, $\frac{1}{2} \mathrm{mal}$ gewunden. 4. 1-1 $\frac{1}{2}$. Blth. gelb. Variirt:

ß) versicolor Aut. (M. media Pers.) Blïthen erst gelblich weiss, dann grüngelb, endlich gelblich-blau.

Auf Aeckern, an Wegen, in Weinbergen, auf trockenen Anhöhen besonders auf kalkhaltigem Boden häufig, z. B. hinter dem Haarlass! in der Gegend von Wiesloch und Baierthal! Juni-Sept.

213. M. Iupulina $L$. $\mathrm{Hop} \mathrm{fen}-\mathrm{Sehn}$.; St. niederliegend; Blättchen verkehrt-eirund; Blth. klein in sehr verkürzten gedrungenen, vielblüth!gen Aehren; Hülse nierenfürmig, an der Spitze gewunden, netzaderig. $\odot$. Blth. hellgelb. Variirt:

ß) Willdenowiana Koch; Hülse abstehend behaart, drüsentragend.

Auf Wiesen, an Wegen, auf Aeckern sehr häufig. Var. $\beta$ auf trockenen Sandflächen; Mai-Sept.

\section{b) Hülsen dornig.}

214. M. minima. Lam. Kleinster Sch.; St. niederliegend od. aufsteigend; Blättchen verkehrt-eiförmig; Nebenbl, eiförmig-spitz, am Grunde kurzgezähnelt; Blthstiele 1-5blüthig; Hülse 5mal gewunden, 2reihig dornig, ohno Adernetz. ๑. 1-6". Blth. gelb. 
Auf trockenen Sandflächen, an felsigen Abhängen, in Weinbergen, an Wegen hie und da. Am Philosophenwege bei H.! Im Birkenauer Thal und bei Nesterbach unfern Weinheim! - Auf Sandflächen $\mathrm{zwischen} \mathrm{Friedrichsfeld!} \mathrm{Schwetzingen} \mathrm{und} \mathrm{Hockenheim!} \mathrm{bei}$ Alt-Lussheim und Sandhausen! am neuen Kirchhofe bei Mannheim oft sehr häufig! Seltener bei Wiesloch! Rauenberg! Mai-Aug.

215. M. denticulata Willd. Gezähnelter Schn.; St. aufrecht, ästig; Blättchen verkehrt-eiförmig; Nebenbl. länglich, borstig gezähnt, fast flederspaltig; Blthstiele 4-8blüthig; Hülse 2-4mal gewunden, 2reihig dornig, netzaderig. ๑. $1 \frac{1}{2}-2^{\prime}$. Blth. gelb.

Im Getreide zwischen Seckenheim und Mannheim (v. Zwackh). Bei Wieblingen, Eppelheim, Friedrichsfeld ( $F$. Schultz). Wie manche sog. Getreide-Unkräuter aus dem südl. Europa eingeführt und daher hinsichtlich des Vorkommens schwankend! Juni-August.

\section{Helilotus Tournef. Steinklee.}

216. M. macrorhiza Pers. Langwurzeliger St.; aufrecht, Blättchen geschweift-sägezähnig; Nebenbl. pfriemlich, ganzrandig; Traube locker; Blbl. gleich lang; Hülse eiförmig, netzig-runzelig, behaart, bei der Reife dunkelbraun. §. 3-4'. Blth. gelb. (M. officinalis Willd.).

Auf Wiesen, an Wegen, besonders an Flussufern häuflg! Juli bis August. (Beim Rohrhofe findet sich eine monströse Ausbildung der Blüthen, bei welchen die 10 Staubgef. frei und die Hülsen von lanzettlichen, an den Rändern eingebogenen Blättchen dargestellt sind). (Off.: Summitates Meliloti).

217. M. officinalis Desr. Heilkräftiger St.; aufsteigend; Bl. und Nebenbl. d. vorig.; Traube locker; Flügel länger als das Schiffchen; Hülse eiförmig, queerrunzelig, kahl, bei der Reife hellbraun. ๑-ઈ. 1-3'. Blth. gelb. (M. diffusa Koch).

An Wegen, auf Aeckern, Triften hie und da, weniger häufig als vorige. Variirt, jedoch hier nur selten mit weisser Blkr. (MI. Petitpierreana Willd.). Juli-Sept. (Off.: Summ. Melil.).

218. M. vulgaris Willd. Gemeiner St.; aufrecht; Bl. und Nebenbl. d. vorig.; Trauben locker; Flügel länger als das Schiffchen, kürzer als die Fahne; Hülse eiförmig, netzig-runzelig, kahl, bei der Reife dunkelbraun. $\hat{\circ}$. 2-4'. Blth, weiss.

Auf Aeckern, Sandfeldern, an Wegen gemein! Juni-August.

219. M. parviflora Desf. Kleinblüthiger St.; aufrecht; Blättchen eiförmig-keilig; Nebenbl. am Grunde feingezähnelt; Traube dicht, verlängert; Flügel so lang wio das Schiffchen, kürzer als dio 
Fahne; Hülsen fast kugelig, netzig-runzelig, kahl. ๑. $\frac{1}{2}-1^{\prime}$. Bltlı. sehr klein, gelb.

Im Getreide zwischen Fricdrichfeld und dem Relaishause, jedoch nicht jeden Sommer! Wurde mit Kleesamen aus dem südlichen Europa eingeführt. Juni, Juli.

\section{Trifolium $L$. Kle e.}

a) Blthen sitzend, in ein rundliches oder elliptisches Küpfchen zusammengestellt.

$\alpha)$ Kelchschlund inwendig mit einem erhabenen, meist behaarten Ringe.

220. T. pratense $L$. Wiesenklee; St. aufsteigend, weichhaarig; Blttch. eiförmig; Nebenbl. eiförmig begrannt; Köpfchen einzeln oder paarig, kugelig, reichblüthig, mit einer Hülle; Kelch 10nervig, zottig. 4. $\frac{1}{2}-2^{i}$. Blkr. purpurroth, selten weiss.

Auf Wiesen, an Wegen überall häufig! und allgemein angebaut. Juni; Juli.

221. T. medium $L$. Mittlerer Kl.; St. aufsteigend, mehr oder weniger hin und her gebogen, weichhaarig; Blttch. elliptisch; Nebenbltt. lanzettlich spitz; Köpfchen einzeln kugelig, etwas armblüthig, ohne Irülle; Kelch 10nervig, kahl. 4. 1-1 $\frac{1^{\prime}}{2}$. Blkr. purpurroth. (Tr. flexuosum Jacq.).

Auf kahlen trockenen Wiesen, an Abhängen, in Wäldern und Gebüschen häufig. Juni-August.

222. T. alpestre $L$. Alpen-Kl.; St. aufrecht, weichhaarig; Blttch. länglich-lanzettlich, feingesägt; Nebenbl. lanzettl., pfriemlich; Köpfehen einzeln od, paarig, kugelig, mit Hülle; Kelch 20nervig, zottig. : 4. $\frac{1}{2}-1^{\prime}$. Blkr. purpurroth.

In trockenen Gebüschen und Wäldern, auf grasreichen Hügeln, an Abhängen der Gebirge und der Ebenen stellenweise. Im Gorxheimer Thal und auf dem Wagenberge bei Weinheim! In der sog. IIessel bei Wiesloch! bei Nussloch! Schatthausen! Rauenberg! beim Maischbacher Hof! An der Hillenbach bei Handschuhsheim und am Oelberge bei Schriesheim (Stud. Gysser). Auch, wiewohl selten, im Friedrichsfelder und Käferthaler Walde! Häufiger zwischen Schwetzingen und Ketsch! zwischen Kirrlach und Waghäusel! Juni-Aug.

223. T. rubens L. Rother Kl.; St. aufrecht, kahl; Blttch. länglich-lanzettl., scharfgezähnt; Nebenbl. lanzettl., gesägt; Aehren walzenf -länglich, sehr gedrängt, mit Hülle; Kelch 20nervig, Röhre kahl, Zähne zottig. 4. 1-1 $\frac{1}{2}^{\prime}$. Blth. purpurroth.

In Gebirgswäldern, an bewaldeten Abhängen. Sehr vereinzelt 
im Gebirge bei Weinheim! Zwischen Waghäusel und Lussheim! (König). Im Käferthaler Walde (Düll). Juni, Juli.

[N. V. a. d. Geb.: In Hs. auf dem Starkenburger Schlossberg, bei Zwingenberg (Schntsp). In Rhb.: Haardtgebirge, z. B. Kastanienwald bei der Callstadter Ziegelhütte, unfern Dürkheim!]

224. T. ochroleucum $L$. Gelblichwe isser Kl.; St. fast bogenförmig aufsteigend, rauhhaarig; Blttch. elliptisch-ganzrandig; Nebenbl, lanzettl.-pfriemlich, Aehren eiförmig, armblüthig, mit Hülle; Kelch 10nervig, rauhhaarig. 4. $\frac{1}{2}-1^{\prime}$. Blkr. gelblich-weiss.

Auf feuchten Wiesen, an lichten Waldstellen nicht verbreitet. Auf der Engelswiese bei H.! Auf Wiesen bei Neckarau! Zwischen Weinheim und Grosssachsen. Juni, Juli.

[Jenseits des Rheins stellenweise häufig, z. B. bei Maxdorf! Forst! hinter der Callstadter Ziegelhütte!]

[Jenseits des Rheines wird zuweilen das südeuropäische T. incarnatum L. gebaut, durch aufrechte, zottige St., eiförmige, zuletzt verlängerto Aehren und purpurrothe Blkr. ausgezeichnet; Mai, Juni!]

225. T. arvense $L$. A cker-Kl.; St. aufrecht oder niederliegend, zottig; Bl. lineal-länglich ; Nebenbl. eiförmig, zugespitzt; Aehre elliptisch, ohne Hülle, dicht zottig; Kelch 10nervig, mit abstehenden Zähnen. ๑. $\frac{1}{4}-1^{\prime}$. Blkr. weissröthlich, sehr klein.

Auf Aeckern, Sandfeldern, in lichten, trocknen Wäldern häufig. Juni-September.

226. T. scabrum $L$. S charfer Kl.; St. niederliegend oder aufstrebend; wie die ganze Pflanze zottig; Blttch. verkehrt-eirund; Nebenbl. eirund zugespitzt; Aehre kugelig, umhüllt; Kelche 10nervig, mit lanzettl., starren, endlich bogig abstehenden Zähnen. ๑. $\frac{1}{4}-\frac{1}{2}{ }^{\prime}$. Blbl. klein, röthlich.

Bisher nur auf Sandfeldern beim Relaishause (Döll). AprilMai. [Auch in der Nähe des Geb. kein anderer bekannter Standort.]

ß) Kelchschlund inwendig kahl, ohne ringf. Anschwellung.

227. T. fragiferum $L$. Erdbeertrag ender Kl.; St. niederliegend, kriechend; Blättch. verkehrt-eiförmig; Nebenbl, lanzettlichpfriemlich; Aehre langgestielt, kugelig, umhüllt; Kelche bei der Fruchtreife kugelig aufgeblasen, häutig, netzig-aderig, behaart. 4 . Blkr. klein, hellroth, abfallend. Aehre bei der Fruchtreife durch die aufgeblasenen Kelche erdbeerähnlich.

Auf feuchten Wiesen, an Flussufern nicht selten und meist gesellig, z. B. hie und da am jenseitigen Neckarufer bei H.! und bei Neuenheim! Auch beim Relaishause! Bei Neckarau! Brühl! Waghäusel! u. s. w. Juli-September. 
b) Blth. mehr oder weniger gestielt; Kelchschlund kahl.

a) Blkr. weiss oder hellroth; Köpfchen rundlich, ohne Hülle.

228. T. montanum $L$. Bergklee; St. aufsteigend, behaart Blttch. längl.-lanzettl., scharf gesägt, unterseits behaart; Nebenbl. eiförmig, zugespitzt; Blthstielchen von der Länge der Kelchröhre. 4. $1-1 \frac{1}{2}^{1}$. Blkr. weiss.

Auf trocknen Wiesen, in Nadelwäldern, auf sandigen Hügeln, zwar vorzugsweise im Gebirge, z. B. auf der Engelswiese bei H.! Schriesheim! Weinheim! Leimen! Wiesloch! Schatthausen! Rauenberg! Beim Maischbacher Hofe! jedoch auch in den Ebenen nicht selten, z. B. bei Walldorf! Kirchheim! beim Relaishauso! Friedrichsfeld! Schwetzingen! Juni, Juli.

229. T. repens $L$. Kriechender Kl.; St. niederliegend, kriechend; Blttch. verkehrt-eirund, feingesägt, kahl; Nebenbl, trockenhäutig, stachelspitzig; Blthstielchen von der Länge der Kelchröhre. 4. Blth. weiss.

An Wegen, auf Wiesen, auf Aeckern überall gemein! JuniAugust.

230. T. hybridum $L$. B a stard-Kl.; St. aufsteigend, rührig; Blttch. verkehrt-eirund, feingesägt, kahl; Nebenbl. lanzettl., spitz; Blthstielchen 2-3mal länger als die Kelchröhre. 4. 1-2'. Blkr. anfangs weiss, dann hellroth.

Auf feuchten Wiesen, an Bächen und Flussufern häufig! Mai - August.

231. T. procumbens $L$. Niederliegender Kl,; St. niederliegend; Blttch. keilförmig, d. mittlere meist kurzgestielt; Nebenbl. eiförmig; Köpfchen locker, 5-10blüthig; Fahne zusammengefaltet, fast glatt; Flügel vorgestreckt. $\odot .4-10^{\prime \prime}$. (T. filiforme Aut.)

Auf feuchten Wiesen, in Sümpfen, auf Triften! Mai-Septbr.

232. T. agrarium $L$. Feld-Kl.; St. niederliegend oder aufsteigend; Blttch. verkehrt-eifürmig, das mittlere länger gestielt als die seitenständigen; Nebenbl. eiförmig; Köpfchen gedrängt, 20-30blüthig; Fahne convex, gefurcht; Flügel auseinandertretend. $\odot$. 2-6". (T. procumbens :Aut.)

B) majus; St. fast aufrecht $6-10^{\prime \prime}$. Blättch. und Köpfchen grösser. (T. campestre Schreb.)

Auf Wiesen, an Wegen, Waldrändern häufig! Mai-August.

233. T. aureum Poll. Goldgelber Kl.; St. aufrecht; Blttch. alle sitzend, länglich-lanzettl.; Nebenbl. lanzettl.; Küpfehen gedrängt 20-30blüthig; Fahne convex, gefurcht; Flügel auseinandertretend. ๑. $\frac{1}{2}-1 \frac{1}{2}^{\prime}$. Blkr. goldgelb, später hellbraun. (T. agrarium Aut.) 
In Wäldern, auf Waldwiesen, an Waldrändern, besonders im Gebirge nicht selten, z. B. sehr verbreitet auf den Bergen um II.! Auch bei Nussloch! beim Maischbacher Hofe! auf dem Teufelskopf bei Dielheim! auf dem Wagenberge bei Weinheim! In den Ebenen seltener, z. B. im Friedrichsfelder Waldo! bei Schwetzingen! Juni -August.

\section{Astragalus $L$. Tragant.}

234. A. Cicer $L$. Kicherartige T.; St. aufsteigend, behaart; B1. 8-12paarig; Blttch. länglich-lanzettl.; Trauben gedrängt-kurz; Irïlsen rundlich-oval, rauhhaarig. 4. 1-2'. Blkr. gelblich-weiss.

An grasigen Abhängen, in Gebüschen selten. An der Chaussec von II. nach Schwetzingen! (von II. kommend links, nicht weit von der Eisenbahn) Zwischen Schriesheim und Ladenburg (Stud, Gysser). Juni, Juli. [N. V. a. d. Geb. in Rhb.: Berghausen bei Speyer; Frankenthal (F. Sch.) in Hs: Darmstadt.]

235. A. glycyphyllos $L$. Süssholzblättr. T.; St. niederliegend, fast kahl; Bl. 5-6paarig; Blttch. ciförmig; Trauben locker; IIülsen 3kantig-lineal., gebogen, kahl. 4. 2-3'. Blkr. gelblichweiss.

In Wäldern, Gebüschen, auf trocknen Waldwiesen nicht selten, z. B. bei H. im Dreitröge-Thal! auf dem heiligen Berge! bei Schriesheim! Weinheim! Wiesloch! Rauenberg! auch im Friedrichsfelder Walde! u: s. w. Juni-August.

236. A. hypoglottis $L$. Wiesen-T.; St. ausgebreitet, behaart; Bl. 8-10paarig; Blttch. länglich-lanzettl.; Blthstiele länger als d. Bl.; Trauben rundl.-eiformig, gedrängt; Hülsen rundl-eiförm. rauhhaarig. 4. 3-8". Blkr. blau. (A. arenarius Dierb. p. 233.)

Auf trocknen Wiesen und Triften selten. Nach Dierb. zwischen Schwetzingen und Ketsch. N. V. a. d. Geb.: auf trocknen Wiesen und Sandflächen in Rhb. bei Maxdorf! in Rhh. zwischen Leeheim und Geisheim (Schntsp.).

Robinia $L$. Robinie.

R. Pseudacacia $L$. Falsche Akazie; Baum mit vielpariggeflederten Bl., dornartigen Nebenbl, hängenden Trauben, kahlen Hïlsen. - Blkr. weiss. Stammt aus Nordamerika. Häufig angepfianzt und zuweilen als niederes Gesträuch verwildert! Juni.

\section{9\%. Coronilla $L$. Kronwicke.}

237. C. varia $L$. Bunte K.; St. niederliegend, hin- und hergebogen, kantig; Bl.10-20paarig; Blttch. lineal-länglich, stachel- 
spitzig; Nebenbl. lanzettl.; Dolden 15-20blüthig. 4. 1-1 $\frac{1}{2}$. Blkr. weiss mit rother Fahne.

An sonnigen Abhängen, auf Sandfeldern, Wiesen, Aeckern häufig! Juni, Juli.

\section{Ornithopus $L$. Vogelfuss.}

238. 0. perpusillus $L$. Kleinster V.; weichhaarig, niederliegend; Bl. 7-20paarig; Blttch. klein, elliptisch; Blthsticlo armblüthig, länger als das Blatt. $\odot$. Blkr. sehr klein, weiss oder blassröthlich.

Auf Sandfeldern, sandigen Hügeln, in trocknen Nadelwäldern der Ebene hie und da, z. B. beim Relaishause! bei. Oftersheim und Käferthal (Schimp.). Juni-September.

\section{Hippocrepis $L$. Hufeisenklee.}

239. H. comosa $L$. S chopfförmiger H.; St. ausgebreitet, niederliegend; BI. 3-vielpaarig; Blttch. verkehrt-eiförmig; Dolde 4-12blüthig; Hülse bogenförmig mit kahlen Gelenken. 4. Blkr. gelb. Auf trocknen Wiesen, an Waldrändern, sonnigen Abhängen stellenweise gesellig, z. B. beim Haarlass! zwischen Leimen und Nussloch! bei Wiesloch! Weinheim! Seltener beim Relaishausel bei Schriesheim! Mai-Juli.

100. Onobrych is Tournef. Esparset te.

240. 0. sativa Lam. Gebräuchliche E.; St. aufsteigend Bl. vielpaarig-gefiedert; Blttch. elliptisch-lanzettlich; Trauben langgestielt; Hülse rundlich, am Rande dornig-gezähnt. 4. 1-2'. Blkr. roth. Variirt:

ß) montana Koch; niederliegend; Blttch. rundlich; IIülsen etwas kleiner und wie die ganze Pflanze graubehaart.

Auf Aeckern, an Bergabhängen, auf Wiesen, vorzugsweise Kalk liebend! Häufig gebaut. Die Var. auf dürren, sonnigen Hügeln, z. B. bei Leimen! am Teufelskopf bei Dielheim! Juni, Juli.

\section{Vicia $L$. Wicke,}

a) Griffel unterhalb der Narbe ringsum behaart, an der Spitze nicht bärtig.

$\alpha$. Trauben langgestielt, armblüthig.

241. V. hirsuta Koch. Rauhhaarige W.; St. zart, aufsteigend; Bl. 6-Spaarig; Blttch. lineal., abgestutzt; Traube 4-6blüthig; Hülsen 2samig, behaart. $\odot \frac{1}{2}-2^{\prime}$. Blkr. bläulich-weiss, klcin. (Ervum hirsutum L.) 
Unter der Saat, auf Sandfeldern, in Hecken sehr häufig! Juni bis August.

242. V. tetrasperma Lois. Viers amige W.; St. zart aufstcigend; BI. 3-4paarig; Blttch. lineal., kurz zugespitzt; Traube 1-3blüthig; Hülsen 4samig, kahl. ๑. $\frac{1}{2}-2^{\prime}$. Blkr. bläulich-weiss. (Ervum tetraspermum L.)

Auf Aeckern, unter der Saat, an Waldrändern häuffg! JuniAugust.

$\beta$. Trauben langgestielt, reichblüthig.

243. V. pisiformis $L$. Erbsen-W., kahl; St. aufsteigenil, kletternd ; B]. kurzgestielt, 3-5paarig, Blttch. lgross, eiförmig, stachelspitzig; Nebenbl. halb pfeilförmig, sägezähnig eingeschnitten; Irülsen länglich-lineal. 4. 4-6'. Blkr. gelblich-weiss:

In Waldgebüschen selten. Am westlichen Abhange des Oelberges bei Schriesheim (Stud. Gysser)! Auf dem Wagenberge bei Weinheim? (nach einer etwas zweifelhaften Angabe) [N. V. a. d. Geb. im hessischien Odenwalde (Schintsp.)]

(Die von Dierbach aufgeführte $V$. sylvatica $\mathrm{L}$. wurde weder am angegebenen Standort (Haarlass), noch sonst im Gebiete der Flora in den letzten Jahren aufgefunden.)

[V. cassubica $L$. St. aufrecht, weichhaarig; Bl. vielpaarig; Blttch. länglich, stumpf, unterseits feinhaarig; Nebenbl. halbpfeilf., ganzrandig; Traube kürzer als d. Bl. 4. 1-2 . Blkr. röthlich-blau.

N. V. a. d. Geb. in Rhb. an den bewaldeten Abhängen bei d. Callstadter Ziegelhütte, unfern Dürkheim! Juli, August.]

ל) Griffel an der Spitze vorn bärtig, ausserdem ringsum kahl oder etwas behaart.

$\alpha$. Trauben langgestielt, reichblüthig; Hülse lineal-länglich.

244. V. dumetorum $L$. Hecken-W.; St. aufsteigend, kletternd, kahl; Bl. 5paarig; Blttch. eiförmig, stumpf; Nebenbl. halbmondförmig, gezähnt; Traube so lang als das Bl. 4. 3-4'. Bllir. violett-roth:

In Wäldern, an Waldrändern, in Gebiischen, durch den Odenwald verbreitet und auch bei H. stellenweiso nicht selten, z. B. im Gebirge diesseits und jenseits des Neckars! Am westlichen Abhange des Oelberges bei Schriesheim! bei Weinheim! Auch bei Waghäusel und Lussheim (F. Schultz). Juli, August.

245. V. Cracca $L$. Vogel-W.; St. schlaff, behaart; Bl. vielpaarig, rankend; Blttch. länglich-elliptisch; Nebenbl. spiessförmig, ganzrandig; Traube so lang als das $\mathrm{Bl}$.; Platte der Falme so lang als ihr Nagel. 4. 1-4'. Blkr. blau. Behaarung veränderlich.

In Gebüschen, Hecken, an Wegen, auf Aeckern und Wiesen häufg: 
246. V. tenuifolia Roth. D'ünnblättr. W.; St. steif-aufrecht; Bl. vielpaarig, rankend; Blttch. linealisch, unterseits behaart; Nebenbl. spiessförmig, ganzrandig; Traube länger als das Bl.; Platte der Fahne noch einmal so lang als ihr Nagel. 4. 2-3'. Blkr. hell-blau.

Auf somnigen Hügèln, an Waldrändern selten. Beim Strassenheimer Hof, unfern Ladenburg! bei Weinheim. Vereinzelt an der Schlossterrasse bei H. (Schimp). Häufiger jenseits des Rheines am Haardtgebirge bei Dürkheim! und auf d. Kalkhügeln zwischen Dürkheim-Grünstadt.] Juni-August.

$\beta$. Trauben kurzgestielt, blattwinkelständig; armblüthig.

") Bl. rankenlos.

V. Faba $L$. Sa u bohne; St. steif, aufrecht; BI. in eine Stachelspitze endigend, 1-2paarig; Blttch. elliptisch, etwas fleischig; Hülse schwammig, dicht behaart. $\odot . ~ 1-3^{\prime}$, Blkr. weiss; Flügel mit schwarzbraunem Fleck.

Im Orient einheimisch; hie und da gebaut. Juni, Juli.

*) Bl. mit verzweigter Ranke endigend.

247. V. sepium $L$. Z a un-W.; St. schlaff; Bl. 4-6parig; Blttch. eifürmig, abgestutzt; Nebenbl. gezähnt; Traube 4-5blüthig; Hülsen linealisch, abstehend, kahl. 4. 1-2'. Blkr. getrübt-blau oder seltener weiss. Hülse schwarz.

In Wäldern, Hecken, Gebüschen, an Wegen sehr häufig! Juni bis August.

248. V. sativa L. F utter-W. St. aufrecht; Bl. 6-7paarig; Blttch. eirund oder länglich, ausgerandet; Nebenbl. gezähnt; Traube 2-3blüthig; Hülse aufrecht, länglich, weichhaarig. ๑. 1-3'. Fahne blau, Flügel purpur, Hülse gelbbraun; Samen rund, zusammengedrückt, glatt.

In Behaarung der St. und Bl., auch hinsichtlich der Breite und Ausrandung der Blttch. sehr veränderlich.

Cultivirt; auf Aeckern, an Wegen überall verwildert und eingebürgert! Juni, Juli.

249. V. angustifolia Roth. Schmalblättr. W.; St. aufrecht; Bl. 4-5paarig; Blttch. der unteren Bl. verkehrt-eiförmig, der oberen lineal-lanzettlich; Nebenbl. gezähnt; Traube 1-2blüthig; IIülsen abstehend, lineal, kahl. $\odot \frac{1}{2}-1^{\prime}$. Blkr. dunkelroth; Hülse schwarz; Samen kugelig, gekörnt.

Auf Aeckern, Sandflächen, an trockenen Waldstellen hie und da, z. B. ziemlich verbreitet zwischen Friedrichsfeld und dem Relaishause! bei Ladenburg! Wiesloch! vereinzelt auch bei Rohrbach! Wieblingen! u. s. w. Mai-Juli. 
**) Nur die oberen Bl, mit kurzer Ranke.

250. V. lathyroides $L$. Platt er bsenartige W.; St. niederliegend, ausgebreitet; BI. 2-3paarig; Blttch. eiförmig-länglich; Nebenbl. ungezähnt; Blth. einzeln; Hülsen aufrecht, lineal., kahl. ๑. 3-9". Blkr. sehr klein, hell-violett. Samen viereckig, gekürnt.

Auf trockenen Hügeln und Sandfächen nicht selten. Beim Relaishause! zwischen dem Rohrhofe und Brühl! bei Schwetzingen: Oftersheim! hie und da im Friedrichsfelder Walde, z. B. unfern Friedrichsfeld beim Jägerhäuschen! häufig an der Rheinziegelhütte bei Mannheim! April, Mai.

\section{Pisum $L$. Erbse.}

P. sativum L. Schoten-E.; Bl. 2-3paarig, rankend; Blttch. eiförmig, ganzrandig; Nebenbl. herz-eiförmig, gross; Blthstiele 26blüthig; Samen kugelig. ๑. 1-2'. Blkr. weiss; Samen hellgelb oder grün.

Stammt aus dem Orient; cultivirt. Mai-Juli.

P. arvense L. Feld-E.; Bl. 2-3paarig, rankend; Blttch. eiförmig, fein gekerbt; Nebenbl. herz-eiförmig, gross; Blthstiele 14 blüthig; Samen rundlich, eingedrückt-kantig. ○. 1-2'. Blkr. blassviolett; Samen grau-grün.

Cultivirt und nicht selten verwildernd! Mai-Juli.

\section{Er ru m $L$. L inse.}

E. Lens $L$. Gemeine L.; St. aufrecht, kantig; Bl.4-6paarig mit kurzer Ranke; Blttch. eirund; Nebenbl. lanzettlich; Blthstiele 2-4blüthig; Hülsen ellipt.-rautenf., kahl. ๑. $\frac{1}{2}-1^{\prime}$. Blkr. weiss.

Cultivirt; hie und da verwildert! Juni, Juli.

\section{Lathyrus $L$. Plat terbse.} (Mit Einschluss von Orobus L.)

a) Blttstiele mit Blattflächen, an der Spitze in Ranken endigend. $\alpha$. St. ungeflügelt, kantig.

251. L. tuberosus $L$. Knollig e Pl.; kahl, etwas graugrün; St. klimmend; Bl. 1paarig; Blttch. elliptisch; Nebenbl. pfeilförmiglanzettlich; Blthstiele reichblüthig; Hülsen kahl. 4. 1-3'. Blkr. rosa. Wrzlst. verlängert, fadenförmig, an der Spitze mit ansehnlichen Knollen.

Im Getreide, an grasigen Abhängen, an Wegen, besonders auf Lehm- und Kalkboden nicht selten, z. B. zwischen Handschuchsheim und Ladenburg! auf Aeckern um H., besonders gegen Wieblingen! 
Papilionaceae.

Eppelheim! Kirchheim! In Menge bei Wiesloch und Rauenberg! Juni-August.

252. L. pratensis $L$. Wiesen-PI.; St. aufrecht, weichhaarig; Bl. 1paarig; Blttch. lanzettlich; Nebenbl. pfeilförmig-lanzettlich; Blthstiele reichblüthig; Hülsen kahl. 4. 1-2'. Blkr. gelb.

Auf Wiesen, an Waldrändern, in Hecken häufig! Juni-August.

$\beta$. St. geflügelt.

L. sativus $L$. Essbare Pl., kahl; St. aufstrebend; Bl, 1paarig; Blttch. lineal-lanzettl.; Nebenbl. halb pfeilfürmig; Blthstiele 1-2blüthig; Hülsen kahl; Samen glatt. ๑. $1-3^{\prime}$. Blkr. weiss od. lilla.

Cultivirt; verwildert hie und da! Juni, Juli.

253. L. hirsutus $L$. Rauhhaarige $\mathrm{Pl}$; St. aufstrebend; Bl. Ipaarig; Blttch. lanzettl.; Nebenbl. halb pfeilförmig; Blthstiele 2blüthig; Hülsen rauhhaarig; Samen kürnig-rauh. ๑. $2^{\prime}$. Blkr. blau.

Unter der Saat selten. Am oberen Wald bei Wiesloch (Schimp, Dierb). Mai, Juni. [Fehlt in der Nähe des Geb.; n. V. Frankf. a/M.]

254. L. sylvestris $L$. Wald-Pl.; St. aufsteigend oder liegend, breitgeflügelt; Bl. 1 paarig; Blttch. lanzettl, ; Nebenbl. Jineallanzettl.; Blthstiele reichblüthig; Hülsen kahl; Samen glatt. 4. $3-5^{\prime}$. Blkr, blass-purpurroth.

In Gebüschen, an Waldrändern, an felsigen Abhängen hie und da, z. B. hinter dem Haarlass und im Dreitröge-Thal bei H.! bei Schriesheim! Weinheim! Leimen! Nussloch! beim Naischbacher Hof! vereinzelt zwischen Rohrbach und Kirchheim! Juni-August.

255. L. palustris $L$. Su $\mathrm{mpf}-\mathrm{PI}$; St, aufrecht, schmal geflügelt; Bl. 2-3paarig; Blttch. lanzettl., stachelspitzig; Nebenbl. pfeilförmig; Blthstiele 3-6blüthig: Hülsen kahl; Samen glatt. 4. 1$2^{\prime}$. Blkr. blau.

Auf sumpfigen Wiesen der Rheinebene beim Rohrhof! bei Brühl! Waghäusel! Juni, Juli.

[Jenseits des Rheins verbreiteter, z. B. Maxdorf! Speyer! etc.]

b) Bltstiele olne Blattfläche, rankend oder blattartig.

256. L. Aphaca $L$. Nebenblätterige Pl.; St. aufsteigend; Bltstiele rankend; Nebenbl, sehr gross, eiförmig, am Grunde spiessförmig; Blthstiele 1blüthig. ๑. $\frac{1}{2}-1^{\prime}$. Blkr. gelb. Samen glatt.")

Unter der Saat, auf Brachä̉ckern stellenweise häufig, z. B. bei Friedrichsfeld! zwischen Handschuchsheim und Dossenheim! von La-

•) Die ersten Blätter der jungen Pflanze zeigen Blattflächen aus $1-2$ Blattpaaren bestehend. 
denburg bis Feudenheim! Seckenheim! Neckarau! Mannheim! Seltener bei Rohrbach! Leimen! Wiesloch! bei Kirrlach! Neu-Lussheim! Juni-August.

257. I. Nissolia L. Blattlose PI.; St. aufrecht; Bltstiele blattförmig, lanzettl., rankenlos; Nebenbl. sehr klein, pfriemlich; Blthstiele $1-2$ blüthig. $\odot . \frac{1}{4}-\frac{3}{4}^{\prime}$. Blkr. hellroth. Samen feinkörnig.

Auf kalkhaltigen Aeckern sehr selten. Am sog. Schlangengrunde zwischen Baierthal und Alt-Wiesloch! Juni-August.

[In der Nähe d. Geb. fehlend oder sporadisch und unsicher. Allgemeineres Vorkommen in der Würtemberg. Flora.]

c) Blattstiele ohne Ranken; Blätter 2-6paarig. (Orobus L.)

258. L. vernus Wimm. Frühlings-Pl.; St. aufrecht, flügellos, kantig; Bl. 2-4paarig; Blttch. eirund, zugespitzt, fein gewimpert, hellgrün; Blthstiele 4-6blüthig. 4. $\frac{1}{2}-1^{\prime}$. Blkr. roth, endlich blau werdend. (Orobus vernus L.)

In Wäldern, feuchten Waldgebüschen, besonders im Gebirge. Hinter dem IIaarlass häufig! Am Oelberge bei Schriesheim! bei Leutershausen und Weinheim nicht selten! hie und da bei Nussloch u. Dielheim! April, Mai.

259. L. niger Wimm. Schwarze Pl.; St. aufrecht, flügellos, kantig; Bl. 5-6paarig; Blttch. länglich-eiförmig, stumpf, blaugrün; Blthstiele 5-8blüthig. 4. 1-2'. Blkr. purpurroth. Beim Trocknen wird die ganze Pflanze schwarzblau. (Orobus niger L.)

An Waldrändern, in lichten Wäldern der Gebirge stellenweise häufig, z. B. bei H. diesseits und jenseits des Neckars! Fehlt auch in der Ebene nicht, z. B. im Friedrichsfelder Walde! bei Kirrlach! Juni-August.

260. L. macrorhizus Wimm. Grosswurzel. Pl.; St. aufrecht, gefiügelt; Bl. 2-3paarig; Blttch. länglich-lanzettl., graugrün, Blthstiele 4-6bliithig. 2. $\frac{1}{2}-1^{\prime}$. Blkr. hell-purpurroth. (Orobus tuberosus L.) Variirt:

ß) tenuifolius Roth; Blttch. linealisch.

In Wäldern, auf Waldtriften häufig! Die Varietät auf trockenen, sonnigen Hügeln, in Nadelwäldern, z. B. zwischen Schriesheim und Leutershausen! zwischen dem Grenzhofe und Friedrichsfeld! April bis Juni.

\section{Phaseolus $L$. Bohne.}

P. vulgaris $L$. Gemeine B.; Bl. 3zählig; Trauben kïrzer als d. Bl.; Hülsen hängend, glatt. ๑. Bald mit windendem Stengel (volubilis), bald niedrigbleibend (nanus). Blkr. weiss oder bläulich.

Stammt aus Ostindien; häufig cultivirt! Juni-August. 


\section{AMYGDALEAE.Juss.}

Bäume oder Strüucher mit abwechselnden einfachen Blättern und sehr hinfälligen Nebenblättern. Blüthen regelmässig. Kelch 5zähnig, abfallend. Blbl. 5, nebst den zahlreichen, freien Staubgefässen aus dem Kelchschlunde entspringend. Fruchtknoten frei, 1fächerig, 2eiig, mit 1 Griffel. Steinfrucht meist 1samig. Same an verlängerter Nabelschnur hängend, eiweisslos. Keim gerade. - Ausgezeichnet durch Gehalt an Blausäure, vorzugsweise in den Samen.

A mygdalus. Steinfrucht saftlos, bei der Reife unregelmässig aufspringend.

Persica. Steinfrucht saftig, nicht aufspringend; Stein mit Furchen unregelmässig durchzogen und mit Löchern durchbohrt.

Prunus. Steinfrucht saftig, nicht aufspringend. Stein glatt oder etwas uneben, aber nicht gefurcht.

\section{Amygdalus $L$. Mandelbaum.}

A. communis L. Ge meiner M.; Bl. lanzettlich, drüsiggesägt. ち. 10-20'. Blbl. eirund-keilförmig, hellrosa. - Variirt mit hartschaaligen und dünnschaaligen Steinen, mit süssen und bitteren Samen.

Cultivirt. März, April. (Off.: Amygdalae.)

\section{Persica Tournef. Pfirsich.}

$P$. vulgaris Mill. Gemeine $\mathrm{Pf}_{\text {. }}$; $\mathrm{Bl}$. schmal lanzettlich, scharf gesägt. Ђ. 8-16'. Blbl. fast kreisrund, hellpurpur.

Cultivirt. April. (Off.: Flor. et nuclei Persicae).

\section{Prun us $L$.}

a) Bl. vor der Entfaltung umeinandergerollt. Steinfrucht sammethaarig.

P. Armeniaca I. A prikose; Bl. eiförmig, zugespitzt, doppeltgesägt; Blthstiele seitlich, einzeln oder paarweise, $\hbar$. Blkr. weiss. Cultivirt. März, April.

b) Bl. vor der Entfaltung umeinandergerollt. Blüthen weiss, vor oder mit den Blättern sich entfaltend. Steinfrucht kahl, mit bläulichem Reife (Pflaumen).

261. P. spinosa $L$. Schlehendorn; Zweige in Dornen en- 
digend, in der Jugend behaart; Bl, elliptisch, doppeltgesägt; Blthknospe 1blüthig; Blthstiele kahl; Früchte kugelig. †. 5-8'.

In Hecken, Gebüschen, an Waldrändern, auf Felsen häufig! April, Mai. (Off.: $F l$. Acaciarum.)

262. P. insititia $L$. Haferschlehen-Pfl.; Zweige sammethaarig, mit oder ohne Dornen; Bl. elliptisch, gesägt, unterseits weichhaarig; Blthknospen 2blüthig; Blthstiele weichhaarig; Früchte kugelig, nickend. †. $8 \div 20^{\prime}$.

Stammt aus dem Orient, häufig kultivirt und in den Gebirgswäldern ziemlich häufig verwildert! April, Mai. (Stammart allcr Pflaumen-Spielarten mit runden Früchten).

263. P. domestica $L$. Zwetsche; Zweige kahl, mit oder ohno Dornen; Bl. elliptisch, gesägt, weichhaarig; Blthknospen 2blüthig; Blthstiele weichhaarig; Früchte länglich, hängend. ち. 8-20'.

Stammt aus dem Orient, wird kultivirt und verwildert häufig! April, Mai. (Stammart aller Pfl.-Spielarten mit länglichen Früchten). c) BI. vor der Entfaltung einfach auf einander gelegt. Blth. weiss, vor oder mit den Blättern sich entfaltend, in mehrblüthigen

Dolden. Steinfrüchte kahl, unbereift (Kirschen).

264. P. avium $L$. Süsse K.; BI. elliptisch, doppeltgesägt, zugespitzt, etwas runzelig, in der Jugend weichhaarig; Bltsticl mit 2 Drüsen. †. $10-40^{\prime}$. Ohne Ausläufer; mit süssen Frïchten.

In Wäldern und Gebüschen nicht selten! Häufiger aber in zahlreichen Spielarten kultivirt. April, Mai.

265. P. Cerasus $L$. S a ure Kir s che; Bl. eilanzettlich, drüsigsägt, zugespitzt, flach, kahl, glänzend, etwas lederartig; Bltstiel fast drüsenlos. ち. 16-30' mit Wurzelausläufern und saueren Früchten.

Ebenfalls in Wäldern und Gebüschen hie und da! Häufig in mehreren Spielarten kultivirt. April, Mai. (Off. : Cerasa acida siccata).

$\alpha)$ Blthen traubig, weiss, nach den Blättern erscheinend. Steinfrüchte kahl, unbereift. (Trauben-Kirschen).

266. P. Padus $L$. Traubenkirsche (Ahlkirsche); BI, elliptisch, zugespitzt, doppeltgesägt, etwas runzelig; Bltstiel mit zwei Drüsen; Trauben hängend. Strauch $10-20^{\prime}$ mit erbsengrossen, schwarzen Früchten.

In feuchten Waldgebüschen, an Bächen und Flussufern hie und da. In den Gebirgswäldern bei Rohrbach! Leimen! Gaiberg! Weinheim! Stellenweise am Rheinufer zwischen dem Relaishause und Neckarau! Zwischen Waghäusel und Kirrlach! Mai. (Off. : Cort. $c t$ flor. Pruni Padi). 


\section{ROSACEAE. Juss.}

Kräuter oder Sträucher mit abwechselnden, häufig zusammengesetzten Blättern and meistens mit Nebenbliittern. Blüthen regelmïssig. Kelch meist 5-10spaltig. Bbl. 4-5, nebst den zahlreichen in der Knospenlage einwärts gekrümmten Staubgefässen kelchständig. Fruchtknoten viele, frei, 2 -vieleiig mit seitenständigen, seltener (z. B. Geum) endständigen Griffeln. Früchtchen zahlreich, trocken oder saftig, 1 fächerig, 1-mehrsamig. Same eiweisslos. Keim gerade. Fine zwar in den Blüthen sehr übereinstimmende, im Habitus jedoch sehr verschiedengestaltige Familie, deren Arten grösstentheils bodenvag. Viele lieben kühle, etwas schattige Standorte. In den meisten Gattungen erscheint die Entwickelung der Oberhaut sehr ausgezeichnet. Haare, Drüsen und Stacheln bedingen daher nicht selten den spez. Charakter. - Adstringirende Stoffe in den Rinden, Blättern und Wurzeln; aetherische Oele in den Blüthen und Erüchten sind vorherrschend.

a) Spiraeaceae. Stbgef. icosandr; Früchtchen balgkapselartig 2-6samig.

Spiraea. Kelch 5spaltig; Blbl.6. Icos. Pentagynia.

b) Dryadeae. Stbgef. icosandr.; Griffel zahlreich; Früchtchen 1samig, trocken (nussartig) oder von einer saftigen Hülle umgeben

(steinfruchtartig) auf trockenem oder fleischigem Fruchtboden.

Ge um. K. 10spaltig; Zipfel abwechselnd kleiner; Nüsschen mit dem erhärteten Griffel besetzt, auf walzigem, trockenem Fruchtboden.

Fragaria. K. 10spaltig; Zipfel abwechselnd kleiner; Griffel abfallend; Nüsschen auf dem nach der Blthzeit sich vergrössernden fleischig-saftigen Fruchtboden.

Comarum. K. und Gr. wio Fragaria; Nüsschen auf dem anschwellenden, schwammig bleibenden Fruchtboden.

Potentilla. K. 10spaltig; Zipfel abwechselnd kleiner; Griffel abfallend; Nüsschen auf dem trockenen, gewölbten oder kegelförmigen Fruchtboden.

R u b u s. K. 5spaltig; Steinfrüchtchen auf dem trockenen, halbkugeligen oder kegelförmigen Fruchtboden.

c) Roseae. Stbgef. dodecandr. oder icosandr. Nehrere nussartige Früchtchen von dem krugfürmigen, bei der Reife saftig oder hart werdenden Fruchtboden umschlossen. 
A grimonia. K. 5blättr. Dodec. Digyn.; Fruchtboden kreiselförmig, bei der Reife erhartend, 2 Nüsschen einschliessend, aussen mit hakigen Borsten besetzt.

Rosa. K. 5blaittr. Icosand. Polyg. Fruchtboden becherförmig, nach Oben sich verengernd, bei der Reife fleischig werdend, viele Nïsschen einschliessend.

104. Spiraea $L$. Spierstaude.

a) ohne Nebenbl.

Sp. salicifolia L. Weidenblättr. Sp.; Strauch $3-5^{\prime}$; BI. lanzettl. gesägt, kahl; Rispen endständig. Blkr. weiss oder rosa.

An Hecken, Wegen, in Gebüschen hie und da rerwildert. (Im südöstlichen Europa einheimisch). Juni, August.

267. Sp. Aruncus $L$. Wald-Sp.; St. aufrecht, verzweigt; Bl. fiederig-mehrfach zusammengesetzt; Blttch. eiförmig, zugespitzt, gesägt; Rispen endständig; Blth. dioecisch. 4. 2-4'. Blkr. gelblichweiss, die weiblichen etwas kleiner.

In feuchten Wäldern, an schattigen Bächen, auf Waldwiesen im Gebirge. Bei H., sowohl jenseits, als besonders diesseits des Neckars nicht selten. Am Geisberge und am Künigsstuhl sehr verbreitet! Stellenweise bei Schatthausen! Lcimen! Nussloch! im Mühlenthale bei Handschuchsheim! bei Schriesheim! Weinheim! Juni, Juli.

b) Bltt. mit Nebenblättern.

268. Sp. Ulmaria $L$. Ulmen-Sp.; St. aufrecht, einfach; Bl. unterbrochen gefiedert, unterseits weissfilzig; Blttch. eiförmig, gesägt, das endständige 3lappig; Blth. doldentraubig; Balgkapseln gewunden, kahl. 4. 2-4t. Blkr. weiss. Variirt:

$\beta$ ) concolor; Blätter unterseits grün, ohne Filzbelleidung.

An Gräben, Flussufern, auf feuchten Wiesen, in Sümpfen häufig, wenn gleich nicht ïberall. In der Nähe ron H. z. B. unterhalb der Molkenkur! bei Handschuchsheim! Die Varietät in feuchten Waldgebüschen, z. B. bei Waghäusel! beim Relaishause! Juni, Juli. (Off, : Flor: Ulmariae).

269. Sp. Filipendula $L$. Knollige Sp.; St. steif aufrecht; BI. unterbrochen gefiedert; Blättch. fiederspaltig eingeschnitten, gesägt; Blth.' doldentraubig; Balgkapseln aufrecht, behaart. 4. 1-2'. Blkr. weiss. Wurzelfasern mit mehreren knollenartigen Anschwellungen.

Auf feuchten Wiesen der Ebene nicht häufig, z. B. zwischen Neckarau und dem Relaishause! bei Waghäusel! Auf den Inseln bei Ketsch! Juni, Juli. 
häufig!]

[Jenseits des Rheines, z. B. bei Maxdorf, Forst, Spejer u. s. w.

105. Geum $L$. Nelkenwùrz.

270. G. urbanum $L$. Benediktenkraut; St. aufrecht, untere Bl. unterbrochen leyerförmig gefiedert, obere 3zählig; Blthen einzeln, aufrecht; Kelch (nach der Blüthe) zurückgeschlagen; Blbl. fast unbenagelt; Nüsschen behaart; Griffel .2gliederig, das untere Glied $4 \mathrm{mal}$ länger als das obere. 24. $1 \frac{1}{2}-2^{\prime}$. Blkr. gelb, klein.

An Zäunen, auf Schutt, in feuchten Gebüschen und Wäldern häufig! Juni, Juli. (Off.: Rad, Carynphyllatae.)

271. G. rivale $L$. Ufer-N.; St. u. Bl. d. vor.; Blth. nickend; Kelch (nach der Blïthe) aufrecht; Bbl. langbenagelt; Nüsschen zottig; Griffel 2gliederig, das obere Glied fast so lang wie das untere. 4. $\frac{1}{2}-1^{\prime}$. Blkr. ansehnlich, gelbroth.

In feuchten Gebüschen, auf feuchten Wiesen, an Bachufern hie und da. Im Mïhlenthale bei Itandschuchsheim! zwischen Handschuchsheim und Ladenburg! bei Waghäusel! Alt-Wiesloch! Mai, Juni.

106. Fragaria $L$. Erdbeere.

272. F. vesca $L$. W ald-E.; Ausläufer treibend; untere Bl. langgestielt, 3zählig; Blttch. scharfsägezähnig, unterseits seidenhaarig; Kelchzipfel von dem Fruchtboden abstehend; St. und Blattstiele mit abstehenden, Blthstiele mit angedrïckten Haaren. 4. 3-6". Blkr. weiss.

Auf Triften, an Rainen, in Wäldern und Gebüschen häufig! April, Mai.

273. F. elatior Ehrh. Zimmt-E.; der vorigen ähnlich, aber in allen Theilen grösser. St., Blatt- und Blthstiele mit abstehenden Haaren. 24. $\frac{3}{4}-1 \frac{1}{2}^{\prime}$.

In Wäldern, Waldgebüschen, auf Gestein selten und hinsichtlich der Verbreitung unsicher. Im Gorxheimer Thal bei Weinheim? Bei Wiesloch und längs der Bergstrasse (Döll). Mai.

274. F. collina Ehrh. Hügel-E.; der F. vesca sehr ähnlich; Kelchzipfel dem Fruchtboden anliegend; St. und Bltstiele mit abstehenden; Blthstiele mit aufrechten Haaren. 4. 3-4". Blkr. weiss.

Auf kalk- oder lehmhaltigem Boden an Waldrändern, auf sonnigen Hügeln nicht selten, z. B. in der Nähe von H.: hinter dem Haarlass! am Philosophenwege, am Geisberge! Häufiger bei Leimen! Nussloch! Weinheim! April, Mai. 


\section{0\%. Comarum L. Blutauge.}

275. C. palustre $L$; St. aufsteigend, mit kriechendem Wstock; Bl. 5-7zählig fiedertheilig; Blttch. länglich-lanzettlich, gesägt, unterseits seidenhaarig, graugrün; Kelch länger als d. kleine dunkelpurpurrothe Blkrone. 4. $1-3^{\prime}$.

In Torfsümpfen und torfhaltigen Gräben selten. Bei Sandtorf!

[N. V. a. d. Geb. : in Rhb. Sumpfgräben b. Maxdorf, jedoch nur noch vereinzelt! In Hs.: Neunkircher Höhe im Odenwald; Griesheim b. Darmstadt (Schntsp.). In B.: Knielingen b. Carlsruhe (Bausch).

\section{Potentilla $L$. Fingerkraut.}

a) Bl. gefiedert.

$\alpha)$ Blumenkr, weiss.

276. P. Fragariastrum Ehrh. Erdbeer-F.; St. niederliegend, verlängert, zottig; Bl. 3zählig, Blttch. rundlich-eiförmig. abgestutzt, tiefgesägt, oberseits fast kahl, unterseits etwas zottig; Blthstiele 1-2blüthig; Nüsschen fein queerrunzelig. 24. Blbl. schwach ausgerandet, klein; Bl. dunkelgrün. Der Fruchtboden ist bei der Reife der einer ächten Potentilla. Uebrigens d. Fragaria vesca sehr ähnlich. (Fragaria sterilis. L.).

An Waldrändern und in Gebüschen der Gebirge, an bewaldeten Abhängen, auf Bergwiesen oft sehr gesellig. In der Nähe bei $H_{\text {., }}$ diesseits und jenseits des Neckars weit verbreitet, z. B. beim Haarlass! auf dem Könıgstuhl! In lichten Waldungen der Ebene etwas seltener, z. B. im Friedrichsfelder Walde! bei Schwetzingen! Kirrlach : April, Mai.

277. P. alba $L$. Weisses F.; St. aufsteigend, weichhaarig, armblüthig; Bl. langgestielt, 3-5zählig; Blttch. länglich, an der Spitze gesägt, oberseits kahl, unterseits seidenhaarig glänzend; Nüsschen glatt. 4. 3-8". Blbl. schwach ausgerandet, grösser als bei der vorigen.

In trockenen sandigen Wäldern der Ebene selten. In Nadelwäldern unfern Schwetzingen (Schimp.). Im Käferthaler Walde (Schimp.) Mai, Juni.

[N. v. a. d. Geb: Rhb.: Speyer (F. Schultz). Hs.: Griesheim bei Darmstadt (Schntsp.).]

$$
\text { B) Blkr. gelb; Nüsschen kahl. }
$$

278. P. verna $L$. Frühling $s-F$; ausgebreitet-mehrstengelig, vielblüthig; St. niederliegend oder etwas aufsteigend, wie die Bltstiele und Bl. mit aufrechtabstehenden Haaren; Bl. 5-7zählig; Blttch, keilförmig, an der Spitze gesägt. 4. Variirt mit bald kür- 
zeren, bald längeren Haaren. Auf dürrem Boden bleibt die Pflanze oft ganz niederliegend, polsterartig, an grasigen etwas feuchten Standorten sind die Stengel dagegen mehr verlängert und aufsteigend.

An Waldrändern, auf Haiden, Hügeln, Felsen, Mauern häufig! April-Juni.

279. P. opaca $L$. Glanzloses F.; ausgebreitet-mehrstengelig, vielblüthig; St. aufsteigend wie die Bl. zottig abstehend behaart; Bl. 5-7zählig; Blttch. lanzettlich-keilförmig, bis zum Grunde eingeschnitten gesägt. 24. 3-6'. Der vorigen $\mathrm{zwar}$ sehr ähnlich, aber im Ganzen zarter; St. und Bltstiele oft purpurroth gefärbt.

An sonnigen, grasreichen Abhängen, auf sandigen Flächen ziemlich selten. Zwischen Leimen und Nussloch! im Birkenauer Thal bei Weinheim! beim Relaishause! Mai, Juni.

280. P. cinerea Chaix. Gra u es F.; ausgebreitet-mehrstengelig, vielblïthig, graufilzig-sammethaarig; St. niederliegend oder etwas aufsteigend; Bl. 3-5zählig; Blttch. verkehrt-eifürmig-keilig, an der Spitze gesägt. 2. Behaarung bald dichter, bald dünner. Die Nerven auf der Unterseite der Blätter sehr hervortretend, was besonders, nebst der charakteristischen Behaarung im Spätsommer zu beobachten ist. Blkronen hellgelb, etwas grüsser als bei den zwei vorigen.

Auf Sandflächen, besonders an und in trockenen Nadelwäldern, auf sandigen Hügeln. Zwischen Friedrichsfeld und dem Relaishause! bei Schwetzingen! Sandhausen! Walldorf oft sehr gesellig! An den Felsen im Ludwigsthal bei Schriesheim! April, Mai.

281. P. argentea $L$. Silberweisses F.; St. aufsteigend, filzig, an der Spitze trugdoldig verzweigt; Bl. 5zählig; Blttch. verkehrt-eiförmig, eingeschnitten gesägt, am Rande umgerollt, unterseits weissfilzig; Blthstiele gerade. 24. $\frac{1}{2}-1^{\prime}$. Behaarung bald dichter, bald dünner. An schattigen Standorten sind die Bl. unterseits grünlich weissfilzig.

An Wegen, auf Haiden, an Sandflächen häufig! Juni, Juli.

282. P. collina Wib.; Ḧ̈ gel-F.; St. aufsteigend, rom Grunde an rispig-ästig, zottig-filzig; Bl. 5̌zählig; Blttch. keilförmig-länglich, tiefgesägt und am Rande flach, unterseits dünn graufilzig; Blthstiele nach dem Verblühen zurückgekrümmt. 24. $\frac{1}{2}-\frac{3}{4}{ }^{\prime}$. (P. Güntheri $\mathrm{Pohl}$ ).

Am Rheindamm und auf Grasplätzen des Schlossgartens bei Mannheim! Auf Sandflächen zwischen Friedrichsfeld und dem Relaishause: (Hinsichtlich der weiteren Verbreitung noch zu verfolgen). Mai-Juli.

283. P. reptans $L$. Kriechendes F.; St. peitschenförmig- 
verlängert, kriechend; Bl. 5zählig, gestielt; Blttch. länglich verkehrt eiförmig, gesägt, schwachbehaart; Nebenbl. lanzettlich, ungetheilt oder 2-3zähnig, Bltstiele 1blüthig verlängert. 4 .

An Wegen, Gräben, auf Schutthaufen gemein! Juni-August.

284. P. Tormentilla Sibth. Blutwurz; St. niederliegend oder aufstrebend; Bl. 3zählig, sitzend oder kurzgestielt; Blttch. Iänglich-lanzettlich, an der Spitze tiefgesägt; Nebenbl. vielspaltig; Blthstiele 1blüthig, verlängert; Kelch und Blbl. meist 4. - 4. $\frac{1}{2}-2^{\prime}$. Wstock knotig, innen gelblich-roth. (Tormentilla erecta L.).

In trockenen Wäldern, auf Haiden, Sandflächen häufig! (Selten mit gefüllten Blkr., z. B. bei Handschuchsheim.) Juni-August. (Off,: Rad. Tormentillae).

\section{b) Blätter gefiedert; Nüsschen kahl.}

$\alpha)$ Blkr. weiss.

285. P. rupestris $L$. F els en-F.; St. aufrecht, gabelästig, unt. Blätter gefiedert, obere 3zählig; Blttch. eiförmig-rundlich, weichhaarig, gesägt; Nebenbl. ungetheilt; Blth. doldentraubig; Fruchtstiele aufrecht. $4 . \frac{3}{4}-1^{\prime}$.

In Gebüschen, an trockenen Abhängen sehr selten. Zwischen Waghäusel und Lussheim (Dr. Loudet). Mai-Juli.

[N. V. a. d. Geb.: in Rhb.: Kalkhügel bei Forst (Dr. Koch)]. B) Blkr. gelb.

286. P. supina $L$. Kleines F.; St. niederliegend oder aufsteigend, gabelspaltig; Bl. 5zählig gefiedert; Blttch. länglich, eingeschnitten gesägt; Nebenbl. ungetheilt; Blth. einzeln; Fruchtstiele zurückgekrümmt. ๑. $\frac{1}{4}-1$ '. 'Blkr. klein.

In Dörfern. an Landstrassen, auf Triften hie und da, z. B. am Neckarufer hinter Neuenheim! zwischen Neuenheim und IIandschuchsheim! St. Ilgen! Leimen! Brühl! Schwetzingen! Weinheim! u. s. w. Juni-Sept.

287. P. anserina $L$. Gänse-F.; St. verlängert, kriechend ; Bl. unterbrochen gefiedert, vielpaarig, unterseits silberweiss behaart; Blttch. eingeschnitten gesägt; Nebenbl. vielspaltig; Blthstielo einzeln, verlängert. 2. Blkr. ansehnlich. Variirt:

B) sericea, Bl, beiderseits seidenhaarig.

$\gamma$ ) viridis, Bl. beiderseits schwach behaart oder kahl.

An Wegen, Zäunen, Lfern, auf Triften, besonders in Dörfern sehr häufig! Juni-Sept.

\section{R u b us $L$.}

288. R. Idaeus $L$. Himbeere; St. aufrecht, stielrund; Stacheln gekrümmt; Bl. 3-5zählig gefiedert; Blttch. eifürmig, unter- 
soits meissfilzig; Rispe armblïthig; K. abstehend; Blbl. klein, länglich, aufrecht; Früchte weichhaarig, roth oder gelb. $\hbar$.

In Wäldern. auf Waldtriften häufig. Mai-Juli. (Off.: Fruct. Rubi Idaei.

289. R. fruticosus $L$. Brombecre; Zweige bogig überhängend oder niederliegend, stumpfkantis, unbereift oder selten blaubereift, mit derben und feinen, geraden und gekrümmten Stacheln; obere Bl. 3zählig, untere handförmig-5theilig; Blttch. eiförmigrundlich, zugespitzt, meist doppelt gesägt : Blth.-Rispen gipfelständig; Blbl. ausgebreitet, länger als der abstehende Kelch; Früchte kahl, unbereift, schwarz glänzend. 4. Blkr. weiss oder röthlich.

Sehr veränderlich und formenreich, hauptsächlich in Behaarung und Stachelbildung.") Bemerkenswerthe Formen der hies. Gegend:

1) plicatus W. et N.; St. aufsteigend; Stacheln gekrümmt; Bittch. wellig-gefaltet, obcrscits kahl, unterseits feinhaarig, grün; Rispe ausgebreitet oder verlängert.

2) vulgaris Weihe; aufsteigend; Stacheln gerade oder gekrïmmt, sehr ungleich; Blttch. oberseits grün, unterseits weichhaarig, grün (zuweilen graufilzig, dann discolor Weihe); Rispen meist verlängert, locker.

3) horridus Fl. Frib.; aufsteigend; Blttch. oberseits kahl, unterseits weichhaarig, hellgrün; Rispe ausgebreitet, wie die blüthentragenden ZÆreige schwachdrüsig und mit zahlreichen, starkgekrümmten und kleineren geraden Stacheln besetzt.

4) corylifolius Sm. (nemorosus Hasne); aufsteigend oder niederliegend; St. zuweilen blaubereift; Blttch. beiderseits grün, weichhaarig, seitenständige Blttch. sitzend oder kurz gestielt; Stacheln zerstreut, gerade; Rispe doldentraubig, locker.

-) Wenn ich es vorgezogen habe die zahlreichen von manchen Autoren als eigene Arten aufgestellten liubus hier noch mit der Linné'schen Bezeichnung vorzuführen, so mag dies dadurch gerechtfertigt sein, als es mir zwar müglich gewesen mancherlei Uebergänge $\mathrm{zu}$ beobachten, aber keineswegs Beweise für die möglicho Haltbarkeit einzelner dieser Arten, z. B. tomentosus Borkh, glandulosus Bell, corylifolius Sm. beizubringen. - Uebrigens ist für das specielle Studium der Rubus-Arten sehr zu empfehlen: Dr. Wirtgen, Herbarium Ruborum rhenanorum, Herbar. d. rheinischen Brombeersträuche in sämmtlichen vorkommenden Arten, Varjetïten u. Formen. (3 Lieferungen. Coblenz 1855-56). 
5) tomentosus Borkh. (candicans Weihe); aufsteigend; Stacheln zerstreuet, schwach gekrümmt; Blttch. beiderseits mehr oder weniger sammetartig, weissfilzig; Rispe verlängert, reichblüthig.

6) glandulosus Bell.; niederliegend; Bl.meist 3zählig; Blttch. rundlich, deutlich zugespitzt, grün, blühende $Z$ weige mit Drüsen, feinen Stacheln u. Borsten reichbesetzt; Rispe doldentraubig, armblüthig.

In Wäldern, Gebüschen, Hecken Form 1 u. 2 ziemlich allgemein verbreitet. Form 3 an bewaldeten Abhängen zwischen Dossenheim und Schriesheim! auf dem Geisberge bei H. (Schimp.), bei Schriesheim, Weinheim (Döll), annähernde Formen (?) am Philosophen-Wege: Form 4 an Waldrändern, auf Waldwiesen häufig, besonders im Gebirge bei H:! Form 5 in niederen Gebüschen, und zwar um so weissfilziger, je trockener u. sonniger der Standort, z. B. Philosophen-Weg! Haarlass! Oelberg bei Schriesheim! Uebergangsformen zu Form 2 nicht selten, diese auch bei Wiesloch und Rauenberg! Form 6 in feuchten, schattigen Thälern und Schluchten, z. B. Ludwigsthal bei Schriesheim! bei Leutershausen! Leimen! Mai-Juli. (Off.: Fruct. Rub. frutic.)

290. R. caesius $L$. A c k er - B r o m b e er e; St. meist niederlieg., schwach, stielrund, blaubereift; Stacheln dünn, fast borstig; Bl. meist 3zählig; Blttch. verkehrt-eiförmig, die seitlichen sitzend, zuweilen etwas gelappt; Doldentraube armblüthig; K. der Frucht anliegend; Früchte graublau bereift, glanzlos. †. Blkr. weiss oder blassrosa.

Variirt mehr oder weniger niederliegend, schwächer oder stärker behaart; an schattigen Standorten meist ziemlich kahl und wenig stachelig (umbrosus Rchb.), auf Aeckern mit meist unterseits seidenhaarigen, etwas runzeligen Blättern (agrestis Weihe), an sehr trockenen Standorten sind die Doldentrauben etwas reichblüthiger, schwach drüsig, BI. zuweilen unterseits graufilzig.

Auf Aeckern, steinigen, dürren Triften, Sandfeldern, in Gebüschen, an Ufern überall häufig! Juni-September.

291. R. saxatilis $L$. S t e i n b e e r e ; lrautartig, unfruchtbare St. niederliegend; blüthentragende St. aufrecht; BI. 3zählig; Blttch. verkehrt-eirund, doppelt gesägt, weichhaarig; Doldentraube fast doldig, 3-6blüthig; Kelch zurückgeschlagen. 24. $\frac{1}{2}-1^{\prime}$. Blkr. klein, weiss. Früchte aus wenigen rothen Steinfrüchten bestehend.

In steinigen Gebirgswäldern zwischen Weinheim und Birkenau (Dierb). Mai, Juni.

(Ich kann das Vorkommen aus eigener Erfahrung nicht bestätigen, vermuthe aber das Vorhandensein um so mehr, als die Pflanze im benachbarten Hessen und zwar in nicht grosser Ent- 
fernung [Bickenbacher Tanne (Schnttsp.)] auch neuerdings wahrgenommen wurde.)

\section{Agrimonia $L$. Odermennig.}

292. A. Eupatoria $L$. Gemeiner 0.; rauhhaarig; St. aufrecht; Bl. unterbrochen-gefiedert; Blttch. länglich-lanzettl., gesägt, unterseits drüsenlos; Blth. aehrenförmig; Fruchtboden kreiselförmig, der ganzen Länge nach tief gefurcht. 4. $1 \frac{1}{2}-2^{\prime}$. Blkr. klein, gelb.

An Wegen, Zäunen, in Gebüschen, auf Waldwiesen häufig! Juni-August.

A. Odorata Ait. Hauptsächlich verschieden durch unterseits mit Oeldrüsen versehene Blätter, und durch die nur bis zur Mitte gefurchten Fruchtboden, übrigens der vorigen ähnlich. (Bisher von mir in der hiesigen Gegend noch nicht gesehen!)

\section{Rosa $L$. Rose.}

(Stachelige Sträucher mit unpaarig-gefiederten Blättern.)

๙) Fruchtknoten im Fruchtboden kurzgestielt; Blth. einzeln;

Kelchbl. ganzrandig; Nebenbl. der blüthentragenden Zweige wenig breiter als die übrigen.

293. R. pimpinellifolia De Cand. Bibernellblättr. R.; Stacheln gerade, ungleich; Blttch. 5-9 rundlich oder elliptisch, gesägt, meist kahl; Kielchbl. aufrecht, halb so lang als die Blbl.; Fruchtboden abgeplattet, kugelig. 4-6'. Blkr. weiss-röthlich; Frucht schwarz-roth. - Variirt bald selir stachelig, bald fast stachellos.

Auf sonnigen Hügeln, in Gebüschen selten. Auf dem Wagenberge bei Weinheim ( $F$. Schuttz). Mai, Juni.

[N. V. a. d. G.: auf Kalkhügeln am Haardtgebirge allgemein verbreitet.]

$\beta$ ) Fruchtknoten im Fruchtboden langgestielt; Blthstiele in 3-5-

blüthigen Doldentrauben; Kelchbl. fiederspaltig; Nebenbl, an den blüthentragenden $\mathrm{Zweigen}$ breiter als die übrigen.

294. R. canina $L$. Hundrose; Stacheln stark, sichelförmig, überall fast gleich; Blttch. länglich- elliptisch oder eirund, scharfgesägt, die oberen Sägezähne zusammenneigend; Kelchbl.. so lang als die Blkr., zurückgeschlagen, zuletzt abfallend; Fruchtboden rundlich oder elliptisch. $3-9^{\prime}$. Blkr. rosenroth oder weiss. Juni, Juli. Eine sehr veränderliche Art, von welcher folgende Varietäten $\mathrm{zu}$ beachten sind:

a) vulgaris Koch; Blttch., Blthstiele, Fruchtboden völlig kahl. In Hecken, Gebüschen, Wäldern, überall verbreitet. 
ß) dumetorum Thuill.; Blttch. unterseits, besonders an don Adern, wie auch die Blattstiele, weichhaarig; Blthsticle und Fruchtboden kahl.

In Waldgebiischen, besonders im Gebirge, z. B. am PhilosophenWege bei H.! bei Schriesheim! beim Maischbacher Hof! nicht selten.

$\gamma$ ) collina Koch; Blthstiele, oft auch Fruchtboden, drüsigsteifhaarig; Bltstiele und Blttch. kahl oder behaart.

An Waldrändern, auf etwas bewaldeten IIügeln, an Abhängen hie und da, z. B. zwischen Rauenberg und Malsch! in der Hessel bei Wiesloch! oberhalb des Philosophen-Weges bei II.! Am Wege niach dem Wolisbrunnen!

Von dieser wird unterschieden: forma Jacquiniana Sp. et Schimp.; Blattstiele und Blttch. unterseits zottig; Blthstiele und Fruchtboden etwas borstig.

Auf trockenen, kalkhaltigen Hügeln. Zwischen Rauenberg und Rodenberg! in der Hessel bei Wiesloch (Schimp).

ס) sepium Koch; Blttch. und Blattstiele unterseits oder auch beiderseits drüsig-klebrig; Fruchtboden meist kahl. Blkr. weiss.

In Nadelwäldern, auf Sandfïchen, auf trockenen Hügeln. Bei Friedrichsfeld und zwischen dem Relaishause und Schwetzingen stellenweise! (Off.: Fruct. et semen Cynosbati.)

295. R. rubiginosa $L$. Rostige R.; Stacheln stark, sichelförmig gebogen, etwas ungleich; Blttch, eirund oder elliptisch, unterseits rostbraun, drüsig, feindrüsig-gesägt; Sägezähne etwas abstehend; Kelchbl. von der Länge der Blbl., endlich abfallend; Fruchtboden rundlich-eifürmig, kahl oder drüsenborstig. - Blkr, gesättigt-purpurroth, kleiner als bei der vorigen. 3-5'. Blätter wohlriechend. (R. umbellata Gmel; Dierb.)

An Waldrändern, auf Sandflächen, an Abhängen, besonders bei Weinheim und in der Gegend ron Nussloch und Wiesloch häufig: Auch zwischen dem Relaishause und Schwetzingen! Juni, Juli.

296. R. tomentosa $L$. Filzig o R. Stacheln stark, gerade, ziemlich lang, fast wagerecht abstehend, etwas ungleich; Blttch. elliptisch, doppeltgesägt, beiderseits weissgraufilzig; Kelchbl. von der Länge der Blbl., zurückgeschlagen, meist bleibend; Fruchtboden kugelig, meist drüsenborstig, seltener kahl. 4-7'. Blkr. blassroth. - Variirt:

B) glabriuscula; Blätter weniger filzig, graugrün. (R. villosa Leers; R. mollissima Gmel, Dierb.)

In Waldgebüschen, auf Haiden, an Wegen, besonders im Gebirge ziemlich häufig, die Varietät rorherrschend, z.B, oberhalb des 
Philosophen-Weges gegen Dossenheim und Schriesheim! bei Ziegelhausen! Leimen! Nussloch u. s, w. Juni, Juli.

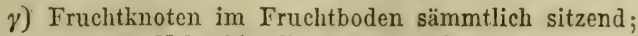

Nebenbl. alle gleichgestaltet.

297. R. arvensis Huds. Feld-R.; Stacheln zerstreut, stark, sichelförmig; Zweige verlängert, meist niederliegend; Blttch. rundlich-eiförmig, grobkerbig-gesägt, unterseits blassgrün; Kelchbl. kurzfiederspaltig, abfallend; Fruchtboden elliptisch-rundlich, kahl. 3-6'. Blkr. weiss. (R. sylvestris Poll; R. repens Scop.) Variirt mit kahlen und feinhaarigen Blttch. Ausserdem als :

$\beta$ ) glauca Dierb.; Zweige aufrecht; Blttch., Blthstiele und Fruchtboden blaugrün.

An Waldrändern, auf Haiden, in trockenen Wäldern ziemlich verbreitet, besonders in der Nähe von H. im Gebirge sowohl diesseits als jenseits des Neckars häufig! Auch in der Ebene bei Friedrichsfeld, Schwetzingen, Ladenburg nicht selten! Die Var. $\beta$ besonders in Steinbrüchen und an Felsen, z. B. bei Neckargemünd! Schriesheim! Weinheim! Juni, Juli.

298. R. gallica $L$. Französische R.; Stacheln ungleich, kurz, etwas sichelförmig; Blttch. elliptisch oder cirund, einfach gesägt, etwas lederartig, oberseits glänzend, unterseits rauh; Kelchbl. tief-fiederspaltig, kürzer als die Blbl., zurückgebogen; Fruchtboden fast kugelig, wie die Blthstiele drïsig-borstig. 2-5i. Variirt mit mehr oder weniger lederartigen Blättern und mit hellrothen oder dunkelrothen Blumenkronen. - Ausserdem:

ж) pumila DC.; St. niedrig, $\frac{1}{2}-1^{\prime}{ }^{\prime}$, steifhaarig-drüsig; Blttch. starrer, glänzender; Blkr. dunkelroth.

ß) Lupodunensis Schimp.; (Ladenburger R.), St. niederliegend, steifhaarig; Blttch. mehr zugespitzt; Blthstiele weichhaarig; Blkr. blassroth.

An Waldrändern, auf Hügeln und Triften nicht häufig. Die Hauptform hie und da zwischen Alt-Wiesloch und Baierthal! zwischen Rauenberg und Malsch! in der Hessel bei Wiesloch (Schimp.) Var. $\alpha$ bei Baierthal! Ladenburg (Stud. Gysser)! bei Eppelheim und beim Grenzhofo (Schimp.). Var. $\beta$ zwischen Ladenburg und Schriesheim. Juni; Juli. (Off.: Flor. Rosae rubrae.)

\section{SANGUISORBEAE Lindl.}

Krïuter mit einfachen oder gefiederten Blättern und Nebenblättern. Blth. einzeln, oder verschieden gruppirt, Zwitter oder einhäusig. Kelch bleibend, 3-5theilig, mit 
klappiger Knnospenlage, im Schlunde zusammengezogen uni durch einen Ring verengert. Blkr. fehlt. Stbgef. 4 oder weniger, oder zahlreich, dem Schlundringe eingefügt. Fruchtknoten 1-4, eineiig. Narbe kopfartig oder pinselartig. Nüsschen vom erhärteten Kelch eingeschlossen. Samen eiweisslos. Keim gerade.

Alchemilla. Kelch glockig, 4theilig, mit 4 kleinen Deckblättchen; Stbgef. 1-4; Narbe kopfig; Nüsschen 1.

S angu is orba. Kelch 4kantig, 4theilig, mit 1-3 Deckblättchen; Stbgef. 4; Narbe kopfig-pinselig; Nüsschen 1-2.

Poterium. Kelch 4kantig, 4theilig, mit 2-3 Deckblättchen; Blth. monoec. oder polsgam,; Stbgef. viele, hängend; Narbe pinselig; Nüsschen 2-3.

\section{Al chemilla Tournef. Frauenmantel.}

299. A. vulgaris $L$. Gemeiner F.; St. aufsteigend; untere B1. langgestielt, nierenförmig, :-9lappig, mit abgerundeten, gesägten Lappen, kahl oder weichhaarig; Blth. in endständigen Doldentrauben, grünlich-gelb; Stbgef. 4. 4. $\frac{1}{3}-1^{\prime}$. Variirt:

B) montana Willd; Bl. seidenhaarig; Blth. gedrängt.

In Wäldern, auf Wiesen, Triften häufig. Die Var. auf höheren Bergen an lichten Waldstellen, z. B. auf dem heiligen Berge und Königstuhle bei H.! auf dem Oelberge bei Schriesheim! Mai bis Juli.

300. A. arvensis Scop. Acker-F.; St. niedrig, ausgebreitet; Bl. gestielt, keilförmig, 3spaltig eingeschnitten, weichhaarig; Blth. achselständig, knäuelartig, grünlich. Stbgef. 1. ๑. 2-4". (Aphanes arvensis $\mathrm{L}$.)

Auf sandigen Aeckern, Triften, an Wegen hio und da häufig! Juni-October.

\section{Sa uguisorba $L$. Wiesenknopf.}

30l. S. officinalis $L$. Heilkräftiger W.; kahl, St, aufrecht, untere Bl. langgestielt, unpaarig gefiedert; Blttch, herzförmi。 länglich, grobgesägt; Blth. in dichten, elliptischen Köpfen, braunroth; Stbgef. kurz. 2. $1 \frac{1}{2}-4^{\prime}$.

Auf feuchten Wiesen der Rheinfläche häufig und meist sehr gesellig. Auch auf Wiesen bei Handschuchsheim! Weinheim! Schönau! Alt-Wiesloch! St. Ilgen! beim Maischbacher Hof nicht selten! Vereinzelt auf der Engelswiese und im Klingenthal bei H.! Juni-August. (Off.: $B b$. Sanguisorbae.) 


\section{Poterium $L$. Becherbiume,}

302. P. Sanguisorba $L$. Gemeine B. (Garten-Biebernell); St. aufsteigend, etwas kantig; Bl. unpaarig gefiedert; Blttch. länglich, grobgesägt; Blth. in ciförmigen Köpfchen mit rothen Narben; Fruchtkelche stumpf-4kantig, netzig-runzelig. $4 \cdot \frac{1}{2}-1 \frac{1}{2}^{\prime}$.

Auf trockenen Hügeln, an Waldrändern, auf Triften, vorzugsweise auf Kalkboden; ziemlich verbreitet in der Näbe von H., z.B. in Menge am Philosophen-Wege, beim Haarlass! Uebrigens vielleicht zuweilen mit der. folgenden verwechselt! Juni-August.

303. P. muricatum Spach. Dem vorigen ähnlich, etwas grösser in allen Theilen; Blttch. mehr oval; Fruchtkelche schwach4llügelig, mit unregelmässig gezähnelten Kanten. 4. 1-2'.

Auf trocknen Triften, auf Esparsettfeldern, an Wegen. Im Gebiet der Flora bisher nur bei Neckarau! Wahrscheinlich weiter verbreitet, da ich die Pflanze auch jenseits des Rheines hie und da antraf, z. B. bei Ludwigshafen! Maxdorf! Ruchheim! Vermuthlich mit Getreidesamen aus dem südlichen Europa eingeführt! JuniAugust.

\section{PONACEAE Lindl.}

Bäume oder Sträucher mit abwechselnden Blättern und Nebenblättern. Blth. regelmässig. K. und Blkr. 5zählig, in der Knospenlage dachig. Kelchröhre dem becherförmigen Fruchtboden angewachsen. Kelchsaum auf der Frucht welkend und bleibend. Stbgefässse viele, dem Kelchschlunde eingefügt. Fruchtk. 1-5, mit eben so vielen Griffeln, unter sich und mit dem fleischig werdenden Fruchtboden und đer Kelchröhre zu einer 2-5fächerigen, beerenartigen oder steinfruchtähnlichen Scheinfrucht (Apfelfrucht) verwachsend. Same eiweisslos, mit geradem Keim.

Crataegus. Griffel 1-5; Frucht steinfruchtähnlich, oben sehr verengert; Steine $1-5$ in das Fruchtfleisch eingesenkt. - Bl. gelappt.

Me spilus. Griffel 2-6; Frucht steinfruchtähnlich, nicht verengert, offen; Steine 5 in das Fruchtfleisch eingesenkt. - Bl. fast ganzrandig.

Pyrus. Griffel 2-5; Frucht beerenartig, 2-5fächerig; Fächer mit pergamentartiger Haut ausgekleidet, 2samig. - Bl. gesägt. 
C ydonia. Wie vorige, aber die Fächer vielsamig; Samen mit Schleimschicht. - Bl. ganzrandig.

Sorbus. Griffel $3-5$; Frucht beerenartig, $3-5$ fächerig, $1-5-$ samig; Fächer mit dünner, zarter Haut ausgekleidet. - Bl. gelappt oder gefiedert.

\section{II5. Crataegus $L$. Weissdorn.}

304. Cr. Oxyacantha $L$. Gemeiner W.; Dorniger Str.; Bl. verkehrt-eiförmig, am Grunde keilig, 3-5lappig, unterseits hellgrün; Lappen vorgestreckt, mehr oder weniger eingeschnitten; Blthstiele kahl; Griffel 1-3 (meist 2). 10-12'. Blkr. weiss; Frucht oval, roth.

In Gebüschen, Wäldern, Hecken häufig! Mai, Juni.

305. Cr. monogyna Jacq. Einweibige W.; dorniger Str.; Bl. verkehrt-eiförmig, am Grunde keilig, tief 3-5lappig; Lappen etwas abstehend, mehr oder weniger, zuweilen fiederspaltig eingeschnitten, unterseits bläulich grün; Blthstiele behaart; Griffel 1-2. Blkr. weiss; Frucht oval, roth.

In Waldgebüschen, Hecken, auf Haiden mit der vorigen häufig! Blüht 14 Tage später.

\section{IIespilus $L$. Mispel.}

M. germanica $L$. Deutsche M.; Bl, länglich-lanzettl., fast ganzrandig, unterseits filzig; Blth. endständig, einzeln, weiss. Strauch oder Baum 6-16'.

Wird kultivirt und verwildert hie und da, z. B. am Philosophen-Wege bei H; im Gebirge zwischen Handschuchsheim und Schriesheim! Mai,

\section{Pyrus $L$.}

306. P. communis $L$. B irn b a um; Bl. eiförmig, zugespitzt, fein gesägt, oberseits glatt; Bltstiele von der Länge der Fläche; Griffel frei. Strauch oder Baum von 10-16'. Blkr. weiss; Antheren roth; Frucht meist länglich. - Im wilden Zustande meist strauchartig, stets mit dornigen Zweigen.

In Wäldern, besonders im Gebirge hie und da! Ausserdem in zahlreichen Spielarten kultivirt und zuweilen gleichsam verwildert. April.

307. P. Malus $L$. A pfelbaum; Bl. eiförmig, zugespitzt, ungleich gesägt, schwach-runzelig, länger als der Blattstiel; Griffel am Grunde unter sich verwachsen. Strauch oder Baum 8-30'. 
Blkr. rosa; Antheren gelb; Frucht meist kugelig. Im wilden $\mathrm{Zu}-$ stande dornig.

In Wäldern, an felsigen Abhängen hio und da. - Ausserdem häufig kultivirt. Mai. (Off.: Poma acidula.)

\section{Cydonia Tournef. Quitte.}

C. vulgaris Pers. Gemeine Q.; Bl. eiförmig, ganzrandig, unterseits, nebst den Kelchen, filzig; Blth. endständig, einzeln, röthlich weiss. (Pyrus Cydonia L.)

Baum oder Strauch aus dem südlichen Europa, bei uns angepflanzt, hie und da verwildert. Variirt mit länglichen und kugeligen Früchten. (Off.: Fruct, et sem. Cydoniae.)

\section{I1\%. Sorbus Tournef.}

308. S. aucuparia L. Gemeine Vogelbeere; BI. unpaarig-gefiedert, in der Jugend flzig, später fast kahl werdend; Knospen filzig; Früchte kugelig, roth. ఫे. 20-30'. Blbl. (wie bei den folgenden) weiss, abstehend.

In Wäldern, besonders im Gebirge stellenweise. In der Nähe ron H., z. B. auf dem heiligen Berge! Königstuhl! am Riesenstein! IÏ̈ufig bei Weinheim! Schriesheim! Mai, Juni.

309. S. domestica $L$. Eberesche; Bl. unpaarig-gefiedert, in der Jugend filzig, später ganz kahl; Knospen kahl, kleberig; Früclite birnfürmig, dunkelgrün. Ђ̆. $20-30^{\prime}$.

In den Weinbergen zwischen Schriesheim und Handschuchsheim hie und da! Mai, Juni.

310. S. torminalis Crantz. Elsbeerbau m; Bl, breit-eiförmig, gelappt, im Alter kahl, Lappen spitz, ungleich gesägt, die unteren abstehend; Früchte eirund, graubraun, weiss-punktirt. Meist strauchartig, selten blühend. (Crataegus torminalis L.)

In Gebirgswäldern, z. B. bei Schriesheim! Weinheim! zwischen Ziegelhausen und Schönau! bei Leimen! Nussloch nicht selten! Mai, Juni.

\section{ONAGRARIEAE Juss.}

Sträucher oder Kräuter mit abwechselnden oder gegenstïndigen, seltener wirtelständigen Blättern ohne Nebenblätter, mit achselständigen oder ansehnlichen gipfelständigen Blüthen. Kielch oberständig, 2-5zählig, in der Knospe klappig. 
Blbl. 2-5 (selten fehlend), nebst den meist 8 , seltener 2 oder 4, sehr selten 10 Staubgefässen dem Kelchschluncle eingefügt. Griffel 1. Narbe kopfig, keulig oder getheilt. Frucht meist vielsamig, 2 - 5fäeherig, kapselartig, seltener beeren- oder nussartig. Samen eiweisslos mit geradem Keim. - Meist bodenvag, Schatten und Feuchtigkeit liebend, einige nur im Wasser auftretend, fast alle durch geselliges Vorkommen auffallend; mit der Blüthe nach Mitte Juni beginnend. - Ohne hervorragende Bestandtheile.

Epilobium. K. und Blkr. 4zählig; Stbgef. 8; Kapsel längl.4fächerig, 4klappig, vielsamig. Samen an der Spitze mit Haarschopf.

O enothera. K. und Blkr. 4zählig; Stbgef. 8; Kapsel längl.4fächerig, 4klappig, vielsamig. Samen ohne Haarschopf.

Isnardia. Kelchsaum kurz, 4theilig, bleibend; Blbl, 4 oder 0 ; Stbgef. 4; Kapsel verkehrt-eiförmig-4fächerig, 4klappig. Samen ohne Haarschopf.

Circaea. K. und Blkr. 2zählig; Stbgef. 2; Nuss 2fächerig 2samig.

Trapa. K. und Blkr.4zählig; Stbgef. 4; Nuss steinhart, durch die vergrösserten und erhärteten Kelchblätter 2-4hörnig, 1fächerig, 1samig.

118. Epilobium $L$. W e idenröschen.

a) Blbl. ganzrandig oder kaum ausgerandet, ausgebreitet; Stbgef. aufsteigend; Bl, alle abwechselnd.

31l. E. angustifolium $L$. Schmalblättr. W.; St. aufrecht, Bl. lanzettlich, ganzrandig oder kaum gezähnelt, kahl; Traube verlängert, gipfelständig. 4. 2-3'. Blkr. purpurroth, ansehnlich. Eigentliche Ausläufer fehlond.

In lichten Wäldern, Gebüschen, an Ufern häufig! Juni-Augst.

b) Blbl. tief ausgerandet, trichterförmig; Stbgef. aufrecht; untere Bl. gegenständig, obere abwechselnd; Blth in gipfelständigen Trauben.

$\alpha$. St. stielrund.

312. E. hirsutum $L$. Rauhhaariges W.; St. aufrecht, ästig, drüsig-zottig; Bl. länglich-lanzettl., scharfgesägt, stengelumfassend, etwas herablaufend, mehr oder weniger behaart; Narben 
4theilig, ausgebreitet. 4. 2-4'. Mit sehr langen Ausläufern;") Blkr. ansehnlich, purpurroth.

B) subglabrum; St. und Bl. mehr oder weniger kahl.

In feuchten Gebüschen und Wäldern, in Torfsümpfen, an Ufern läufig; zuweilen, z. B. bei Waghäusel sehr gesellig! Die Varietät aber selten, z. B. am Neckar bei Ziegelhausen! in feuchten Waldgebüschen hinter Leimen! Juni-August.

313. E. parviflorum Schreb. Kleinblüthiges W.; St. aufrecht, einfach, wie die Bl. weichhaarig oder zottig; Bl. sitzend, lanzettlich, spitz, gezähnelt, die unteren kurzgestielt; Narbon 4theilig, ausgebreitet. 4. $1-2^{\prime}$. Blkr. violett, viel kleiner als bei der vorig. Ausläufer kurz.

B) subglabrum; St. und Bl. fast kahl.

In feuchten Gebüschen, an Gräben, an Ufern häufg! Die Var. am Neckar, unfern Neuenheim! Juni-September.

314. E. montanum $L$. B erg $-W$.; St. aufrecht, meist einfach, weichhaarig; Bl. kurzgestielt, eilänglich, ungleich gesägt, zugespitzt, am Grunde rundlich, wenig behaart; Narbe ausgebreitet. 4 . $\frac{1}{2}-2^{\prime}$. Ausläufer kurz, knospenartig. Blkr. klein, fleischroth. Variirt:

๔) collinum Koch; in allen Theilen kleiner; St. sehr ästig, Bl. gedrängt, eirund, buchtig-gesägt. $3-9^{\prime \prime}$.

B) verticillatum Koch; untere Bl. wirtelständig, zu 3.

In Wäldern, Gebüschen, auf Waldwiesen der Gebirge und der Ebene ist die Hauptform häufig. Varietät $\beta$ in Gebirgswäldern selten, z. B. in der Nähe der Engelswiese! Var. $\alpha$ an feuchten, felsigen Standorten, z. B. in Menge im Dreitröge-Thal, am Fusse der nördlichen Bergseite! auch beim Speyrer Hofe! im Birkenauer Thal bei Weinheim! Juni-September.

315. E. Ianceolatum Seb. et Maur, Lanzettlich. W.; St. aufrecht, ästig, wie die Bl. weichhaarig; Bl. lanzęttlich, ungleichgesägt, stumpflich, am Grunde keilig, ganzrandig, die unteren langgestielt, spatelförmig; Narbe ausgebreitet. 4 . $\frac{1}{2}-1^{\prime}$. Blkr. anfangs weiss, später hellroth. Die ganze Pflanze durch die Behaarung fast weissgrau, Ausläufer kurz.

-) Die bald langen, bald sehr kurzen (knospenartigen) Ausläufer entwickeln sich nach der Blüthezeit, oft erst im Spätherbst. Vgl. F. Schultz. Ueb. Epilobium Arten der Pfalz. 13t. Jahresbericht d. Pollichia, 1855. 
An schattigen Standorten, an felsigen Abhängen. Bisher nur selten. Im Dreitröge-Thal rechts (an und in dem meist ausgetrockneten Bächlein)! Juni-August.

[N. V. a. d. Geb. in Rhb. : Basaltbrüche oberhalb Forst. (F.Schull .)]

316. E. palustre L. Sumpf-W.; St. aufrecht, fast einfach, wie dio Bl. weichhaarig; Bl. sitzend, lanzettlich, beiderseits verschmälert, fast ganzrandig oder undeutlich gezähnelt; Narbe keulenförmig. 24 $\frac{1}{2}-1^{\prime}$. Blkr. klein, blassröthlich; St. zwar rund, aber zuweilen durch sehr feine starre Haare zweizeilig gestreift. Ausläufer kurz.

In Sümpfen, Gräben, an Ufern, auf feuchten Wiesen häufig! Juli, August.

ß) St. mehr oder wenig kantig durch herablaufende, linienförmige Erhabenheiten.

317. E. roseum Schreb. Rosenrothes W.; St. aufrecht, ästig, oberwärts wie die Bl. weichhaarig, schwachkantig; Bl. allo gestielt, eilanzettl., am Grunde keilig, ungleich gesägt; Narbo fast keulig, wenig.ausgebreitet. 4. 1-2'. Blkr. klein, rosa. Ausläuf. kurz.

An Gräben, in feuchten Wäldern hie und da. In der Nähe von H., z. B. sehr verbreitet beim Haarlass! oberhalb der Stiftsmühle! und überhaupt im Gebirge gegen Schönau! auch iu Dreitröge-Thal! beim Speyrer Hof! u. s. w. Juli-September.

318. E. tetragonum $L$. Vierkantiges W.; St. aufrecht, meist ruthenförmig verzweigt, deutlich 4 kantig, wie die $\mathrm{Bl}$. fast kahl; Bl. lineal-lanzettl., ungleich gesägt, meist alle sitzend, nur die unteren kurzgestielt; Narbe keulig. 24. 2-3'. St. oft roth angelaufen; Blth. klein, blassroth; Ausläufer kurz. Variirt:

«) subsessile; obere und untere Bl. mit sehr kurzem, geflügeltem Blattstiel; Zweige mehr abstehend.

$\beta$ ) pallidum; blassgrün; St. schlank $3-4^{\prime} ; \mathrm{Bl}$. sehr dünnhäutig, schwach gesägt.

An Waldrändern, in lichten Wäldern, an Gräben und Bächen ist die Hauptform sowohl im Gebirge, als in den Ebenen verbreitet! Var. $\alpha$ am Waldrande bei der Wiese hinter dem Haarlass! in feuchten Gebüschen im Thale der Hirschgasse! Var. $\beta$ in ausgetrockneten Gräben oberhalb des Stiftes Neuburg, unfern der sog. Brunnenstube! Juli, August.

\section{Oenothera $L$. Nachtkerze.}

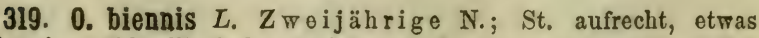
rauhhaarig; Wbl. elliptisch-verkehrt-eirund, etwaș zugespitzt, in den 
Bltstiel verlaufend; Stbl. eilanzettlich; Blth، in endständigen Aehren; Blbl. länger als die Stbgef. §ै. 2-3'. Blkr. anschnlich, gelb. Variirt:

$\beta$ ) parviflora; Blbl. verkürzt, so lang wie die Stbgef.; Bl. schmäler.

In Virginien einheimisch, in Europa verwildert und jetzt überall eingebürgert. An Ufern, Wegen, besonders auf Sand- und Kiesflächen häufig! Die Var. auf feuchtem Sandboden hie und da am Rhein, wie es scheint besonders in feuchten Jahren! Juli-Sept.

\section{[Isuardia $L$.]}

II. palustris $L$., kahl, St. am Grunde kriechend; Bl. gegenständig, eirund-spatelförmig, spitz; Blth. achselst., einzeln, sitzend, blumenblattlos, grün. 4 . $\frac{1}{2}-1^{1}{ }^{\prime}$.

N. V. a. d. Geb. in Rhb.: unfern Speyer auf sumpligen Wiesen, z. B. bei Hasloch und an der Spejerbach bei Speyerdorf. JuliAugust. (Dr. Wals.)]

\section{Circaea $L$. Hexenkraut.}

320. C. Iutetiana $L$. Gemeines H.; St. aufrecht, weichhaarig; Bl. eirund-herzförmig, entfernt gezähnt; Blth. in verlängerten Trauben ohne Deckblätter; Früchte verkehrt-eiförmig, hakenborstig. 4. $\frac{1}{2}-1^{\frac{1}{2}}$. Blkr. röthlich-weiss. August.

In feuchten Laubwäldern der Gebirge und Ebenen häufig! Juli,

\section{Trapa $L$. W assernuss.}

321. Tr. natans $L$. Schwimmende W.; St. verlängert, schwimmend, mit zahlreichen, fadenartigen Wurzelfasern, untergetauchte Bl. sehr klein und hinfällig, schwimmende gestielt, rautenf., gezähnt, etwas lederartig; Bltstiele in der Mitte aufgeblasen; Blth. einzeln, achselständig, unscheinbar, weiss; Früchte mit den erhärteten Kelchen 4hörnig, nussartig, grauschwarz. $\odot$.

In stehenden Gewässern, z. B. in den Gräben bei Neckarau gegen den Rhein hin! Im sog. Altrhein bei Sandhofen! und in der Nähe d, Geb. bei Roxheim! Juli, August.

\section{HALORAGEAE $R$. Br.}

Wasserpflanzen mit fiedertheiligen Blättern ohne Nebenblätter, kleinen, unscheinbaren, aber meist sehr reichlich entwickelten, gewöhnlich diclinischen, seltener hermaphroditischen 
Blüthen. K. u. Blkr. 4theilig oder letztere fehlend. Stbgef. 4-8. Fruchtk. 4fächerig, mit 1eiigen. Fächern, sitzenden Narben. Frucht nussartig. Samen eiweisshaltig, mit geradem Keim.

Myriophyllum. Monoecisch; Stbgef. 8; Blthdecken der weiblichen Blth. unscheinbar; Narben 4, zottig.

\section{II y rio phy 11 um $L$. T a u s end blat t.}

322. M. verticillatum $L$. Quirlförmiges T.; St. kurz, wie die Bl. untergetaucht; BI. quirlig, tief flederspaltig; Blth. quirlig, in endständigen Aehren; Deckbl. alle kammartig-fiederspaltig. 4 . Blkr. weisslich.

In Sümpfen, Teichen, Gräben nicht häufig, aber meist sehr gesellig, z. B. bei Neckarau! Ketsch! Waghäusel! beim Rohrhof! bei Brühl! Sanddorf! Juni-August.

323. M. verticillatam $L$. Aehrenförmiges T.; St. sehr verlängert, wie die $\mathrm{Bl}$. untergetaucht; $\mathrm{Bl}$. quirlig, tief fiederspaltig; Blth. quirlig, in endständigen Aehren; die unteren Deckblätter kammartig eingeschnitten, die oberen ganzrandig, sehr kurz. 4. Blth. weisslich.

In Sümpfen, stehenden Gewässern mit dem vorigen, aber seltener. Hie und da am Rande des Neckars bei H., z. B. gegen Ziegelhausen, unterhalb der Bergheimer Mühle! Stellenweise bei Waghäusel! Neckarau! Juni-August.

\section{HIPPURIDEAE $L k$.}

Wasserpflanzen mit wirtelständigen Blättern. Blth. sehr unscheinbar, wirtelständig. Kelchröhre dem Fruchtknoten angewachsen, mit undeutlich 2lappigem Saume Blkr. 0. Stbgef. 1, mit in 2 Längsritzen aufspringender Anthere. Fruchtk. 1fäch erig, 1eiig, mit fadenförmigem, in der Furche der Anthere liegendem Griffel. Nuss 1samig, von dem bleibenden Kelch gekrönt. Same mit spärlichem Eiweiss.

Hippuris. (Einzige Gattung.)

123. Il i p p uris $L$. Tannenwedel.

324. H. vulgaris $L$. Ge meiner T.; Wrzlst. kriechend, verlängert; St. aufrecht, dichtbeblättert; Bl. lineal, quirlig; Blth. achselständig, quirlig, sitzend; Nüsse oval. 4. 1-2'. Blth. grünlich. 
In stehonden und langsam fliessenden Gewässern, in Sumpfgräben hie und da, z. B. bei St. Ilgen! Brühl! Neckarau! beim Rolir hor! An entsprechenden Standorten in der Nähe des Rheines stellenweise häufig! [Jenseits des Rheines u. A. sehr gesellig in den Oggersheimer Sümpfen!] Mai-August.

\section{CALLITRICHEAE $L k$.}

Kleine, aber meist sehr gesellige, fast ganz untergetauchte Wasserpflanzen, mit fadenförmigen Stengeln, gegenständigen, einfachen Blättern, ohne Nebenblätter und mit sehr unscheinbaren, achselständigen Blüthen. K. und Blkr. fehlend, statt derselben 2 kleine, gegenstïndige, trockenhäutige, durchscheinende Deckblätter. Stbgef. 1 mit nierenförmiger, der Queere nach aufspringender Anthere. Fruchtknoten 4fächerig, mit 1eiigen Fächern und 2 Griffeln. Frucht in 4 Nüsschen zerfallend. Same eiweisshaltig.

Callitriche. (Einzige Gattung.)

\section{Callitriche $L$. Wasserstern.}

325. C. stagnalis Scop. S u m p f-W.; Bl. alle verkehrt-eifürmig; Deckbl. sichelförmig, gerade; Griffel bleibend, zurückgekrümmt; Frucht kreisrund, mit schmalen, flügelig-gekielten, fast glatten Kanten. 4. Bald mit verlängerten $10^{\prime \prime}$ langen, bald mit sehr verkürzten kaum 3 " langen. Stengeln.

In Bächen, Teichen, Gräben, selbst in fast ausgetrockmeten Sümpfen, besonders in der Ebene häufig, z. B. in Menge zwischen Ladenburg und Handschuchsheim! bei St. Mgen! hie und da am Neckar und in den Sumpfgegenden des Gebietes! Mai-September.

326. C. platycarpa Kütz. Breitfrüchtiger W.; untere Bl. lineal, obere verkehrt-eifürmig; Deckbl. sichelfürmig, gerade; Griffel bleibend, zurückgekrümmt; Früchte kreisrund, mit breiten, flügeliggekielten, feinpunktirten Kanten. 4

In Gräben, überhaupt in stehenden und fliessenden Gewässern viel seltener als vorige, z. B. im Neckar, dem Haarlass gegenüber! bei Waghäusel! Juni--September.

327. G. vernalis Kütz. Frühlings-W.; untere Bl. lineal, obere eirund-spatelfürmig; Deckbl. sichelfürmig, an der Spitze etwas gebogen; Griffel gerade, abfallend; Früchte oval, scharf gekielt, kaum flügelrandig. 2. St. $3^{\prime \prime}-1 \frac{1}{2}^{\prime}$. 
In stehenden und fliessenden Gewässern häuflger als die vorigen, vorzugsweise in ausgetrockneten Waldsümpfen, z. B. im Fricdrichsfelder Walde! Mai-September.

\section{CERATOPHYLLEAE Gray.}

Untergetauchte Wasserpflanzen mit quirligen, gabelig-getheilten Blättern. Blth. achselständig, klein, monoecisch, umhüllt von 8-12 länglichen. abgestutzten, 2-3 spitzigen Deckblättern. Blüthendecken fehlen. Stbgefässe von unbestimmter Zahl, mit elliptischen, an der Spitze sich öffnenden Antheren. Fruchtk. 1fächerig, mit einem hängenden Eichen. Griffel 1 bleibend, stachelspitzig. Frucht nussartig. Samen fast eiweisslos. Keim mit 4 Samenlappen.

Ceratophyllum. (Einzige Gattung.)

\section{Ceratophyllum $L$. Hornblatt.}

328. C. demersum $L$. Dreidorniges H.; St. dünn, ästig, aufsteigend; Bl. meist $1-2$ fach gabeltheilig, in 4 lineale Zipfel getheilt; Früchte eiförmig, flügellos, am Grunde mit 2 zurückgekrümmten Dornen, an der Spitze mit 1 geraden Dorn. 4.

In Sumpfgräben, Teichen, auch in Flüssen hie und da, z. B. nicht selten im Neckar! bei Neckarau! Waghäusel! Schwetzingen! Juli, Aúgust.

329. C. submersum L. Eindorniges H., dem vorigen ähnlich; Bl. 3fach gabeltheilig, mit $5-8$ borstenförmigen Zipfeln; Früchte eiförmig, flügellos, an der Spitze mit einem geraden Dorn, am Grunde dornenlos. 4.

In stehenden Gewässern der Rheinfläche stellenweise. Im Geb. der Flora bisher sehr selten und hinsichtlich der Verbreitung sehr unsicher: Schwetzingen (Döll). Juli, August.

\section{LYTHRARIEAE. Juss.}

Kräuter mit einfachen, gegenständigen oder wirtelst. Blättern ohne Nebenbl. Blüthen regelmässig. Kelch unterständig, röhrig oder glockig, bleibend, mit vielzähnigem Saum. Blkrone nebst den 6 oder zahlreichen Staubgefässen dem 
Kelchschlunde eingefügt. Antheren mit 2 Längsspalten aufspringend. Fruchtknoten frei, 2-4fächeris, vieleiig, mit centralem Samenträger und 1 Griffel. Kapsel 1-4fächerig mit eiweisslosen Samen. Keim gerade.

Lythrum. K. röhrig, gezähnt; Blbl. 4-6; Staubgef. meist 12-16; Kapsel länglich, 2-4zähnig aufspringend.

Pe plis. K. glockig, gezähnt; Blbl. 6 (oder fehlend); Stbgef, 6 ; Kapsel kugelig, 2fächerig, unregelmässig aufspringend.

\section{Lyth um $L$. Weiderich.}

330. L. Salicaria L. Geme iner W.; St. aufrecht, 4-6kantig; Bl. gegen- oder wirtelständig, fast sitzend, lanzettlich; Blthen dodecandr. in endständigen quirligen Achren; Kelche mit frühzeitig abfallenden Deckblättchen. 24. 2-3'. Blkr. purpurroth. - Variirt mit fast kahlen oder auch mit graufilzigen Blättern, mit kurzen oder sehr verlängerten Griffeln.

In feuchten Gebüschen, Wäldern, Gräben, an Ufern, Bächen häufig! Juni-Sept.

331. L. Hyssopifolia $L$. Ys sopblätteriger W., St. niederliegend oder wenig aufsteigend, ästig, $4 \mathrm{kantig} ; \mathrm{Bl}$. abwechselnd, lineal; Blthen hexandrisch, einzeln, achselständig; Kelche mit bleibenden Deckblättchen. ๑. 3-9". Blkr. klein, violettroth.

Auf feuchten sandigen od. lehmigen Aeckern stellenweise, z. B. bei Friedrichsfeld! Seckenheim! Ladenburg! zwischen Schwetzingen und Ilockenheim! zwischen Waghäusel und Wiesenthal! Juli-Okt.

\section{2\%. Peplis $L$. Bachburgel.}

332. P. Portula $L$. Portulakähnliche B.; St. niedergestreckt, kriechend; Bl. gegenständig, kurzgestielt, verkehrt-eiförmig, kahl; Blthen fast sitzend, achselständig, sehr klein, röthlichweiss. ๑. $3-8^{\prime \prime}$.

An ausgetrockneten schlammigen und feuchtsandigen Standorten, auf überschwemmt gewesenen Wiesen und Triften nicht selten, z. B. bei Neckarau! Waghäusel! in den Sümpfen zwischen Friedrichsfeld und Schwetzingen! bei Ladenburg! zwischen Dielheim und Rauenberg! vereinzelt auch im Dreitrögethal bei H.! Juni bis August. 


\section{TAMIARISCINEAE. Desv.}

Strïucher mit kleinen schuppig dachziegelförmigen Blättern obne Nebenblittter. Blüthen regelmässig. Kelch 6theilig, mit dachiger Knospenlage. Bbl. 5 am Grunde des Kelches eingefügt. Staubgefässe 5-10, frei oder etwas verwachsen. Fruchtknoten frei, 3 kantig, 1fächerig mit meist 3 Narben. Kapsel 1fächerig, 3klappig, mit wandständigen, vielsamigen Samentrïgern. Samen schopfig, eiweisslos mit geradem Keim.

Myricaria. Stbgefässe 10, bis zur Mitte verwachsen, abwechselnd kürzer. Schopf der Samen langgefiedert.

\section{Myricaria Desv. Myricarie.}

333. M. germanica Desv. Deutsche MI.; Zweige aufrecht, kahl; Bl. schuppig, länglich-lineal, blaugrïn; Blthen in älrenförmigen Trauben; Kiapseln aufrecht abstehend. $\hbar$. 2-5'. Blthen hellroth. (Tamarix germanica L.)

Mit dem Rheine aus dem Oberlande herabgeschwemmt, vereinzelt am Rheinufer und auf den Inseln zwischen Ketsch und Mannheim (Bischoff). Juni, Juli.

\section{CUCURBITACEAE. Juss.}

Kletternde Kräuter mit Wickelranken, und abwechselnden, handnervigen, meist gelappten, rauhen Blättern: Blüthen meist eingeschlechtig. K. oberständig, 5zähnig. Blkr. glockigtrichterförmig, 5 gliederig, dem $\mathrm{K}$. eingefügt. Staubgefässe meist 5, mehr oder weniger verbunden, im Grunde der Blkr. eingefügt. Antheren 1-2 fächerig, unregelmässig gedreht, zuweilen miteinander verwachsen. Fruchtknoten 3-5fächerig, mit mehreiigen Fächern, wandständigen Samenträgern, 1 Griffel und 3-5lappigen Narben; Beere mit mehr oder weniger lederartiger Schaale. Samen eiweisslos mit geradem Keim.

Cucurbita. Monoec. Monadelph. Antheren an der Spitze röhrenartig verbunden; Beere grösser als die Blkrone; Same wulstigberandet. 
Cucumis. Monoec. Monadelph. Antheren zusammenneigend; Beere grösser als die Blkrone; Same scharfberandet.

Bryonia. Monoec. od. Diocc. Monadelph. Antheren frei; Beere kugelig, kleiner als die Blkrone; Same stumpfberandet.

\section{Cuculbita $L$. Kürbis.}

C. Pepo L. Gemeiner K.; steifhaarig, kletternd; Bl. herzförmig, 5lappig, rauh; Ranken ästig; Früchte rundlich oder länglich, glatt. ๑. Blkr. ansehnlich, gelb.

Aus Mittelasien stammend, häufig cultivirt. Juli, August.

\section{Cucum is $L$. Gurke.}

C. sativus I. Gemeine G.; steifharig, kletternd; Bl. herzfürmig, 5eckig, rauh; Ranken einfach; Früchte länglich, höckerig. $\odot$. Blkr. gelb.

Ebenfal!s aus Asien stammend, als Culturpflanze sehr bekannt. Juni-August.

\section{Bryonia $L$. Z a unrübe.}

334. B. dioica $L$. Rothbeerige Z.; St. kletternd; Bl. herzförmig 5lappig, gezähnt, rauh; Blthen dioecisch. Keelch der weibl. Blthe halb so lang als die Blkrone; Narben rauhbarig. 4. 6-10'. Blkr. grünlichweiss. Beeren erbsengross, roth. Wurzel $2^{\prime}$ lang, armsdick, glatt.

In Zäunen, Waldgebüschen, an Ackerrändern allgemein verbreitet! Juni-August. (Off.: Rad. Bryoniae.)

\section{PORTULACEAE. Juss.}

Saftreiche Kräuter mit abwechselnden oder gegenst., ganzrandigen Blättern, meist ohne Nebenblätter. Blüthen klein, achselst. oder endst. Kelch oberständig, 2spaltig. Bbl. 4-6. Stbgefässe 3-15. Fruchtknoten 1 fächerig mit 1 Griffel und centralem Samenträger. Kapsel vielsamig. Samen eiweisshaltig mit ringförmigem Keim.

Portulaca. K. von der bleibenden Basis ringsum abspringend; Blbl. 4-6; Stbgef. 11-15; Kapsel ringsum aufspringend.

Montia. K. bleibend; Blbl. 5; Stbgef. 3; Kapsel 3klappig aufspringend. 
130. Portulaca $L$. Portulack.

335. P. Oleracea $L$. Gemeiner P.; fleischig, saftig; St. niedergestreckt, gabelästig; Bl. länglich-keilförmig: Blthen sitzend; Kbl. stumpfgekielt. ๑. Blkr. gelb.

Auf feuchtem Sandboden, auf Kiesflächen hie und da, z. B. zwischen Mannheim und Neckarau! bei Alt-Lussheim! Waghäusel! u. s. w. Juni-Sept.

\section{I. Il ontia $L$, Montie.}

336. M. fontana $L$. Quell-M.; saftreich, glatt, meist zwergartig, ästig; Bl. gegenst., spatelförmig oder lanzettlich; Blthen in endständigen oder achselständigen Tranben; Blthstiele nach dem Verblühen abwärts geneigt. ๑. 1-3". Blkr. sehr klein, weiss. Var.:

ß) rivularis, mit mehr verlängerten, fluthenden Stengeln.

An Bächen, besonders an sandigen nassen Stellen, an Quellen, die Variet. an den Rändern raschfliessender Bäche selten. Die Yar. z. B. in Ziegelhausen (bei der Mühle)! bei der Glashütte zw. Ziegelhauscn und Wilhelmsfeld (Dierb.). Die gewöhnliche Form. im Ludwigsthal bei Schriesheim. Die Pflanze wird wegen ihrer Kleinheit sehr leicht übersehen, doch scheint sie in der Gegend zwischen Schriesheim und Schönau stellenweise verbreitet. April-Sept.

\section{PARONYCHIEAE. DC.}

Die vorkommenden wenigen Arten sind kleine niederliegende Kräuter mit gegenständigen Blättern und trockenhäutigen Nebenblättern. Blüthen regelmässig, sehr unscheinbar. Kelch 5theilig, bleibend, in der Knospe dachig. Blumenbl. 5, füdlich, oder fehlend. Stbgefässe 4, seltener weniger, dem Kelche eingefügt. Fruchtknoten frei, Ifächerig, mehreiig, mit mittelständigem freiem Samenträger, oder 1eiig; Griffel kurz mit 2-3 Narben; Frucht kapsel- od. nussartig. Samen eiweisshaltig mit peripherischem oder seltener mittelständigem Keim.

Pol y carpum. K. 5theilig; Blbl. 5; Stbgef. 3-5; Griffel 3 Kapsel 1fächerig, 3klappig, vielsamig.

Herniaria. K. 5theilig; Blbl. 0; Stbgef, 5 mit 5 Nebenstbgef.; Narben 2; Nuss 1samig. 
132. Pol ус а трит Löffl. N a g elkraut.

337. P. tetraphyllum Löffl. Vierblätteriges N.; niederliegend oder aufsteigend, gabelspaltig-getheilt, vielästig; $\mathrm{Bl}$. verkehrteiförmig, meist zu 4 quirlständig; Blth. doldentraubig; Stbgef. 3. ๑. $4-6^{\prime \prime}$. Blth. grünlichweiss.

Zwischen Neu- und Alt-Lussheim, neben dem Fahrwege, (von N.-L. kommend, links, ganz in der Nähe des Ortes), und am Wege bei Wiesenthal (Schimp.). (Ist jedoch seit mehreren Jahren an diesen Standorten nicht mehr wahrgenommen worden). Bei Rheinhausen (Döll.) Juni-Sept.

[N. V. a. d. Geb.: jenseits des Rheines bei Speyer und auf Aeckern und an Ackerrändern bei Schifferstadt ( $F$. Schultz).

\section{Il erniaria $L$. B ruchkraut.}

338. H. glabra $L$. Kahles B.; St. niedergestreckt, ästig, wie d. Bl. kahl oder selten etwas weichhaarig; Bl. elliptisch; Kbl. stumpf; Blthen achselständig, knäuelartig, gelbgrün. 4 .

Auf sandigen Aeckern, an Wegrändern, auf Haiden und Triften häufig! Juni-Oktober.

339. H. hirsuta $L$. R a uh hariges Bl.; St. niedergestreckt, ästig, wie die Bl. und Kelche rauhhaarig; Bl. elliptisch; Kbl. stachelspitzig; Blthen achselständig, knäuelartig, gelbgrün. ๑-4.

Auf sandigen Aeckern und Kiesflächen nicht verbreitet, z. B. bei Friedrichsfeld! Schwetzingen! Hockenheim! Alt-Lussheim! in grösserer Menge zwischen Waghäusel und Wiesenthal! Juni-Okt.

\section{SCLERANTHEAE. $L k$.}

Kleine Kräuter mit gegenständigen, am Grunde zusammengewachsenen Blättern ohne Nebenblätter, mit knäuelartigen Trugdolden. Blathen regelmässig, klein. Kelch 4-5theilig, in der Knospe dachig, bleibend, krugförmig, im Grunde mit einem knorpeligen Ringe. Blumenbl. fehlend. Staubgefässe der Kelchröhre eingefügt, meist 10 , selten weniger, die ïusseren unfruchtbar. Fruchtknoten 1fächerig, 1eiig, mit 2 Griffeln und kopfförmigen Narben. Frucht nussartig, von der erhärteten Kelchröhre umgeben, 1samig. Samen eiweisshaltig mit ringförmigem Keim.

Scleranthus als einzige Gattung.

SCHMIDT, Flora v. H. 
134. Seleranthus $L$. Knäuel.

340. S. annuus $L$. Einjähriger K.; hellgrün; St. ausgebreitet verzweigt; Bl. lineal; Klchbl. eirund, spitz, schmal weisshäutigberandet, bei der Fruchtreife abstehend. ๑. 3-8". Blth. grünlichweiss.

Auf Aeckern, Sandflächen, an Wegen sehr häufig! Juni-Okt.

341. S. perennis $L$. A usdauernder K.; bläulichgrün; St. mehr aufsteigend, weniger verzweigt; Bl. lineal; Kbl. länglich, stumpf, breit weisshäutig berandet, bei der Fruchtreife zusammengeneigt. 4. 3-8". Blth. grünlich.

Auf Sandflächen, in Nadelwäldern, in Gebüschen, auf Felsen ebenfalls häufig, wenngleich nicht so verbreitet wie d. vor. Juni bis September.

\section{CRASSULACEAE. $D C$.}

Saftreiche, bei uns immer krautartige Pflanzen mit fleischigen, meist einfachen, abwechselnden oder gegenst. Blätturn ohne Nebenbl., mit endständigen, trugdoldenartigen Blüthenständen. Blüthen regelmässig. Kelch unterständig, bleibend, meist 5 gliederig, seltener überzählig, in der Knospenlage dachig. Blbl. meist 5, seltener zahlreich, dem Kelchgrunde eingefügt und bisweilen an der Basis miteinander verwachsen, in der Knospe dachig. Staubgefässe dem Kelch eingefügt 3-18. Fruchtknoten $3-12$, frei oder seltener verbunden, am Grunde mit Honigschüppchen versehen. Balgkapseln vielsamig. Samen mit geringem Eiweiss und geradem Keim.

Sedum. K. u. Blkr. 5zählig; Stbgef. 10; Fruchtknoten 5 mit 5 rundlichen Honigschuppen.

Sempervivum. K. u. Blkr. 6-20zählig; Stbgef. meist 12 oder mehr; Fruchtknoten und gewimperte Honigschuppen 6-20.

135. Sedum $L$. Steinkraut.

a) Bl. flach, breit.

342. S. Telephium L. Broitblättr. Stkr.; W. knollig; St. eirund-länglich, sitzend, die oberen am Grunde etwas herzförmig, stengelumfassend, ungleich gesägt; Trugdolden endständig, gedrungen. 4. $\frac{3}{4}-1 \frac{1}{2}$ '. Blth. grünlichgelb. Variirt: 
B) purpurascens Koch; Bl. elliptisch, am Grunde abgerundet; Blkr. grünlich purpurroth.

Auf Sandfeldern, Mauern, an Wegen, in Nadelwäldern überall verbreitet, aber meist einzeln, die Varietät etwas seltener, z. B. Neckarufer bei Neuenheim! Haarlass! Dreitrögethal bei H.: Kiesgrube bei Schwetzingen! Juli-Sept.
b) Bl. stielrund sitzend; Bbl, gelb.

343. S. reflexum $L$. Z urückgebogenes Stkr.; St. niederliegend-aufsteigend, wie d. Bl. grasgrün; Bl. lineal-pfriemlich, an dem gelösten Grunde mit einem anliegenden Fortsatz; Trugdolden locker; Kbl. spitz. 2. $\frac{1}{3}-1^{\prime}$. Variirt:

$\beta$ ) rupestre; St. und Bl. blaugrün oder hechtblau.

Die Hauptform auf Nauern, auf grasigen Hügeln nicht so häufig wio die Variet., z. B. bei H. am Philosophenwege! beim Haarlass! auf Weinbergsmauern gegen Rohrbach, Handschuchsheim! u. s. w. Die Varietät sehr verbreitet auf Sandflächen und in trockenen Nadelwäldern der Ebene! auch an Felsen bei Weinheim! Schriesheim! Juli, August.

344. S. acre L. Scharfes Stkr.; St. verkürzt, niederliegend, etwas aufsteigend; Bl. eirund, stumpf, am Grunde wenig verlängert, an den blühenden Trieben lockerstehend, an den unfruchtbaren meist 6reihigdachig; Trugdolden vielblüthig; Kbl. eirund, stumpf, am Grunde etwas verlängert. 4. $2-5^{\prime \prime}$. Bl. von scharf pfefferartigem Geschmack. Variirt:

B) sexangulare L. (acre d. Aut.); Bl. der blühenden Triebe einander sehr genähert, daher genau dachziegelig; Trugdolden armblüthig; Blthen um die Hälfte kleiner.

Auf Mauern, Sandflächen, Haiden, an felsigen steinigen Orten ist die Var. allgemein verbreitet; die Hauptform hingegen bisher mit Sicherheit nur in sehr trockenen lichten Nadelholzwäldern zwischen Friedrichsfeld und dem Relaishause! Juni, Juli.

345. S. boloniense Lois. Bologneser Stkr.; St. büschelig, etwas aufsteigend, dichtbeblättert; Bl. lineal, walzenförmig, stumpf, am Grunde mit kurzem, spitzem Fortsatze, undeutlich 6reihig; Trugdolden vielblüthig; Kbl. walzenförmig, stumpf, am Grunde nicht verlängert. 24. 2-4". S. sexangulare Aut. (nicht L.)

Auf Mauern, an trockenen Abhängen, auf Sandflächen hie und da. In der Nähe von H., z. B. beim Haarlass! am Philosophenwege! in der Wolfsschlucht! u. s. w. In Menge auch an Felsen bei Schriesheim! Weinheim! Rauenberg! auf den Sandflächen bei 
Friedrichsfeld! Schwetzingen! u. s. w. Stellenweise an den Rheindämmen sehr gesellig, z. B. bei Ketsch : Juni, Juli.

o) Bl. stielrund, sitzend; Blkr. weiss od. rosa.

346. S. villosum $L$. Z ottiges Stkr.; St. aufrecht, einfach; Bl. linealisch, stumpf, nebst den Blthstielen drüsenhaarig; Trugdolde armblüthig. $\hat{\delta}$. $3-6^{\prime \prime}$. Blkr. rosa.

An sumpfigen schattigen Abhängen der sog. Hirschgasse bei II. (Bisch. Schimp.). Hinsichtlich der Verbreitung weiter zu verfolgen. Juli, August.

[Verbreitung von hier durch den Odenwald. N. V. a. d. Geb.: Spitze der Neunkircher Höhe, unfern der hessischen Bergstrasse (Schntsp.)],

347. S. album $L$. Woisses Stkr.; St. kriechend, verzweigt, wie die ganze Pflanze kahl; Bl. walzenförmig, stumpf, abstehend; Doldentraube rispig. 4. 4-8". Blkr, weiss.

Auf Mauern, Dächern, auf trockenen Triften, an Felsen, besonders in der Nähe von H. sehr häufig! ausserdem stellenweise, z. B, bei Weinheim! Ladenburg! Leimen! Wiesloch! Juni-Aug.

\section{Sempervirum $L$. Hauslauch.}

S. tectorum L. D a ch-H.; St. verkürzt mit dichten überwinternden Blattrosetten; Bl. verkehrt-ciförmig, am Rande gewimpert; $\mathrm{Kbl}$. und $\mathrm{Bbl}$. sternfürmig ausgebreitet; Blthen rosa in endständigen Trugdolden. 2. 1-1 $\frac{1}{2}^{\prime}$.

Auf Mauern und Dächern hie und da angepflanzt, gleichsam verwildert! Juli-Sept.

\section{XliV. GROSSUlaRIEAE. $D e$ Cand.}

Sträucher, zuweilen mit Dornen, mit abwechselnden und oft büschelartig zusammengedrängten, meist handförmig gelappten Blättern, ohne Nebenblätter, mit traubenartigen Blüthenständen; Blüthen regelmässig, oberständig. Kelch mit 5lappigem gefärbtem Saum. Blbl. 5, meist kürzer als der Kelch. Stbgef. 5, zuweilen auch 4, 6 oder 8. Fruchtknoten 1fächerig mit 2 wandständigen Samenträgern und 2 Griffeln. Beere vielsamig mit dem verwelkten Kelch gekrönt. Samen mit sehr verlängerter Nabelschnur, eiweisshaltig. 
Ribes, als einzige rorkommende Gattung.

\section{Ribes $L$.}

a) dornig; armblüthige Trauben.

348. R. Grossularia L. Stachelbeere; Str. mit einfachen oder 3theiligen Dornen; Bl. 3-5lappig, sägezähnig; K. glockig, mit länglichen zurückgeschlagenen Zipfeln; Beeren eirund, borstig, kurzhaarig oder kahl. Blth. grünlichroth.

In Wäldern, Gebüschen, Hecken häufig! April, Mai.

b) dornenlose Str.; reichblüthige Tràuben.

349. R. rubrum $L$. Rothe Joh annisbeere; BI. 5lappig; Traube kahl mit eiförmigen kurzen Deckblättern; Kelch beckenförmig, kahl; Blbl. spatelförmig; Beeren kugelig, roth. Blkr. gelblichroth.

In Waldgebüschen, auf feuchten Wiesen, an Flussufern hie und da, z. B. hinter dem Haarlass! an der Hillenbach bei Handschuchsheim (Stud. Gysser), bei Rohrbach! beim Relaishause! in den Wäldern zwischen Leimen und dem Maischbacher Hofel April, Mai. (Off.: Baccae Ribium rubrorum.

350. R. nigrum $L$. Schwarze J.; Bl. 5lappig, unterseits drüsig punktirt; Trauben hängend, weichhaarig, mit pfriemlichen, kurzen Deckblättern; K. glockig, drüsenhaarig; Blbl. länglich, grünlichroth; Beeren kugelig, schwarz.

In Waldgebüschen, an Bächen, auf Sumpfwiesen hie und da, z. B. bei Weinheim! Schönau! Dielheim! beim Rohrhofe! u. s. w. April, Mai.

[R. alpinum L.; Bl. 5lappig, kahl; Trauben aufrecht, drüsig behaart; Deckbl. lanzettl., länger als d. Blthstielchen; K. flach, kahl; Blbl. spatelförmig, grünlich. Beeren roth. Meist dioecisch.

Im Geb. d. Flora nur verwildert. N. V. a. d. Geb. in Rhb.: Ilaardtgeb., z. B. bei Dürkheim an den Mauern der Ruine Limburg! Mai].

\section{SAXIFRAGEAE. Vent.}

Saftreiche, bei uns immer $\odot$ oder 4 Kräuter mit abwechselnden oder gegenständigen Blättern ohne Nebenblätter, mit regelmässigen Blüthen. Kelch 4-5spaltig od. theilig, bleibend, in der Knospenlage dachig. Blumenblätter 4-5 (seltener fehlend), nebst den 8-10 Staubgefässen dem Kelche 
eingefügt. Fruchtknoten aus 2 bis gegen die Spitze verwachsenen Fruchtblättern, an deren Rändern die Samentrạ̈cr befestigt sind, oder 1 fächerig mit wandständigen Samentrïgern. Griffel 2, bleibend. Frucht kapselartig mit zahlreichen eiweisshaltigen Samen. Keim gerade.

Saxifraga. K. röhrig, 5spaltig; Bbl. 5; Stbgef. 10; Kapsel 2schnäbelig, 2fächerig.

Chrysosplenium. K. flach, 4-5spaltig; Bbl. 0; Stbgef. 8-10; Kapsel 2schnäbelig, 1 fächerig.

\section{3\%. S a xifraga $L$. St e in brech.}

351. S. tridactylites $L$. Dreifingeriger Stbr.; St. meist ästig, aufrecht, drüsig behaart; untere Bl. spatelf.-3-5lappig, obere 3-5spaltig oder ganzrandig; Blthen blattwinkelst., einzeln; Blbl. weiss, wenig länger als d. Kelch. ๑. 2-6".

Auf trockenen sandigen Aeckern, Sandflächen, auf Mauern, an Wegen häufig. In der Nähe von H., z. B. in Nenge beim Haarlass! am Philosophenwege! Neuenheim! u. s. w. April-Juni.

352. S. granulata $L$. Körniger Stbr.; St. aufrecht, etwas drüsenhaarig, am Grunde kugelige Zwiebelknollen tragend; untere Bl. langgestielt, nierenförmig, lappig-gekerbt; Blth. doldentraubig; Blbl. meist längl.-eirund, doppelt so lang als der K. 24. $\frac{1}{2}-1 \frac{1}{2}^{\prime}$.

Auf Wiesen, an Waldrändern, besonders auf grasigen Hügeln allgemein verbreitet, seltener auf Haiden und Sandfeldern, z. B. zwischen Friedrichsfeld und dem Relaishause! April, Mai.

\section{Chrysosplenium $L$. Gold-Milzkraut.}

353. C. alternifolium $L$. Wechselblättr. G.; St. aufrecht, wie die Bl. hellgrün, glänzend; Bl. wechselst., kreisnierenförmig, gekerbt, behaart; Blth. doldentraubig, grüngelb, von goldgelben Deckblättern unterstützt. 4. 3-6".

In Waldsümpfen, an Quellen, überhaupt in feuchten Wäldern häufig| März-Mai.

354. C. oppositifolium $L$. Gegenblättr. G.; St. rasenbildend, wie die Bl. etwas fleischig, hellgrün; Bl. gegenständig, halbkreisrund, geschweiftgekerbt; Blthen doldentraubig, grüngelb, von gelblichen Deckbl. unterstützt. 4. 2-4". In allen Theilen kleiner; Blthstde armblüthig.

An Quellen, Waldbächen, in feuchten Wäldern seltener als das vorige, z. B. in der Nähe von H. in Menge hinter dem Haarlass! 
in der Hirschgasse: oberhalb des Stiftes Neuburg! boim Wolfsbrunnen! - Hie und da in den Wäldern bei Weinheim, Schriesheim, Leimen, Dielheim recht gesellig! April, Mai.

\section{UMBELLIFERAE. Juss.}

Einjährige, oft zweijährige oder ausdauernde Kräuter, zuwcilen mit starken Wurzelstöcken und rübenförmigen Wurzeln, meist abwechselnden, mehrfach zusammengesetzten oder seltener einfachen Blättern ohne Nebenblätter, mit gewöhnlich sehr entwickelten Scheiden, einfachen oder zusammengesetzten Dolden, vorhandenen oder fehlenden Hüllen und Hüllchen; seltener mit ährenförmigen Blüthenköpfchen, weissen, zuweilen gelben oder rothen, meist kleinen Blumenkronen. Blüthen meist zwitterig und zwar pentandrisch (doch verkümmern zuweilen einige od. alle Stbgef.). Kelch mit dem Fruchtknoten verwachsen, der oberständige Saum 5zähnig od. fast fehlend. Blbl. 5, häufig an der Spitze eingebogen, ausgerandet od. 2lappig erscheinend, zuweilen strahlend, mit den Staubgefässen am Rande der Kelchröhre eingefügt, in der Knospe eingerollt. Fruchtknoten 2 fächerig, oben von einer polsterartigen drüsigen Erhebung (Griffelpolster, stylopodium) bedeckt, aus welcher die 2 fadenförmigen Griffel entspringen. Frucnt aus 2 nussartigen 1samigen Halbfrüchten (mericarpia) bestehend, einem meist 2theiligen oder 2spaltigen Fruchtträger angewachsen, bei der Reife sich von diesem ablösend und zuletzt an dessen Spitze hängend. Jede Halbfrucht in den allermeisten Fällen an der Aussenscite der Länge nach mit 5 Hervorragungen (Joche, Hauptriefen, juga primaria,) (nämlich 3 Mittelriefen. 2 Seitenriefen), aus deren vertieften Zwischenräumen (Thälchen, valleculae) sich zuweilen (aber bei einheimischen Gattungen nur selten) Nebenriefen (j. sesundaria) erheben, und in welchen sich meistens 1-mehrere Oelkanäle (vittae, Striemen) finden. Samenschaale mit der Frucht meist innig verwachsen. Samen mit grossem Eiweiss 
und kleinem Keim. Eiweiss nach Aussen mehr od. weniger gewölbt, auf der inneren Fläche (Fugenfliiche) flach oder seltener an den Rïndern eingerollt, oder endlich halbmondfïrmig ausgehöhlt. - Dio im Habitus mit wenigen Ausnahmen schr übereinstimmenden Doldenpflanzen sind im Gebiet der Flora vorherrschend Wiesenpflanzen der Ebenen und bedürfen theilweise eines durchaus sumpfigen, wasserreichen Bodens. In der Nähe von H. wird die Armuth an Arten auffallend, obwohl eben diese, wie überall in Deutschland, meist sehr gesellig leben. Erst an der Grenze des Gebietes, besonders in den sumpfreichen Umgebungen des Rheines ist die Mannigfaltigkeit grösser, aber abgesehen von einigen gesellig auftretenden Arten. der Verbreitungsbezirk oft nur ein sehr kleiner, das Vorkommen nicht selten sehr isolirt. Obwohl die meisten dieser Pflanzen bodenvag erscheinen, sind doch einige entschieden kalkstet, wenige sandhold. - Die Umbelliferen secerniren allgemein ätherische Oele, die besonders in den Oelgängen der Früchte, seltener in den oft zucker- und schleimhaltigen Wurzeln und Wurzelstöcken vorhanden sind. Ausserdem finden sich bei manchen einheimischen Repräsentanten, sowohl in den Samen und Wurzeln, als auch im Kraut Bitterstoffe, scharfe und narkotische Stoffe, in den Wurzeln zuweilen auch Milchsäfte.

\section{Subord. 1. Orthospermae.}

(Geradsamige.)

Eiweiss auf der Fugenfläche flach oder etwas convex, niemals aber gefurcht.")

-) Für das Studium der Umbelliferen-Gattungen sind reife Früchte fast in allen Fällen durchaus nothwendig. Nur wenn diese vorhanden, wird es gelingen die Charaktere nachzuweisen, und auch die Zahl der Oelstriemen, deren Auffindung für den Anfänger zuweilen einige Schwierigkeit hat, wird um so leichter erkannt werden, wenn man zuvor die reifen Früchte ein wenig in Wasser aufweichen lässt. - Es mag noch bemerkt werden, dass als Rückenfläche der Früchte die äussere Fläche, als Fugenfläche die Berührungsfläche der beiden Halbfrüchte verstanden wird. Um die Bildung des Eiweisses zu sehen, hat man eine Halbfrucht queer durchzuschneiden. Die Früchte sind "vom Rücken her zusammengedrückt". wenn sie von der Rückenfläche aus, „von der Seite her zusam- 
A. Dolden einfach oder unvollständig ährenartig.

Trit. 1. Hydrncotyleae. Uneigentliche Dolde sehr armblüthig, Frucht von der Seite zusammengedrückt.

II y dr oc o tyle. Bbl. eifürmig, spitz; Bl. schildfürmig; Frucht flach zusammengedrückt.

Trib. 2. Saniculeae. Dolde einfach oder kopfförmig; Frucht im Queerschnitte rundlich, von Aussen stachelig oder schuppig.

S a nicula. Bbl, aufrecht, mit einer langen eingebogenen Spitze; Frucht fast kugelig mit hakigen Stacheln, riefenlos, vielstriemig.

Eryngium. Bbl. aufrecht, mit einer langen eingebogenen Spitze, Frucht verkehrteifürmig, schuppig, riefenlos, striemenlos.

B. Dolden zusammengesetzt.

a) Früchte nur mit Hauptriefen, ohne Nebenriefen.

Trib. 3. Amminene. Frucht von der Seite zusammengedrückt.

a) Bl. zusammengesetzt; Riefen (wenn nicht erwähnt), sind fädlich, schwach; Blkr. weiss (selten etwas rosa).

Cicuta. K, deutlich 5zähnig; Bbl. verkehrt herzfürmig, eingebogen, Frucht rundlich; Fruchtträger 2theilig; Riefen unmerklich; H. armbl.; Hch. vielbl.; Thälchen 1striemig.

A pium. K. undeutlich; Bbl. rundlich, ohne Einbiegung; Frucht rundl; Frtr. ungetheilt; Thälchen 1striemig; H. u. Hch. o.

Petroselinum. K. undeutlich; Bbl. rundlich, kaum eingebogen ; Frucht eifürmig ; Frtr. 2theilig; Thälchen 1striem. ; H. armbl.; Hch. vielbl.

Trinia. Dioecisch; K. undeutl.; Bbl. der männl. Blth. lanzettlich, der weiblichen eirund; Fr. rundl.; Frtr. 2theil.; Riefen deutlich, vorstehend; Thälch. 1striemig od. striemenlos; H. o. ; Hch. armblättrig.

I el os ciadium. K. 5zähn.; Bbl. rundlich eingebogen; Fr. eiförm.; Frtr. ungeth.; Thälch. 1striemig; H. 0 od. armbl.; Hch. vielbl.

Falcaria. K. 5zähn.; Bbl. verkehrteirund, eingebogen; Fr. länglich; Frtr. 2theilig; Thälch. 1striem. ; H. und Hch. vielbl.

mengedrückt" dagegen, wenn sie von den Rändern der Halbfrüchte aus zusammengedrückt gedacht werden künnen. Hülle und Irüllchen (abgekürzt H. u. Hch.) können zuweilen zur Unterscheidung der Gattungen dienen, aber keineswegs immer, da das Yorhandensein dieser Blättchen oft schwankend ist. 
A egopodium. K. undeutlich; Bbl. verkehrteirund, eingebogen; Fr. länglich; Frtr. kurz 2spaltig; Griffelpolster kegelf.; Griffel zurückgebogen; Thälch. striemenlos; H. u. Hch. 0.

Carum. K. undeutlich; Bbl. verkehrteirund, eingebogen; Fr. länglich; Frtr. kurz 2spaltig; Griffelpolster niedergedrückt; Griffel zurückgebogen; Thälch. 1striem.; H. u. Hch. 0 oder vielblätterig.

Pimpinella. K. undeutlich; Bbl. verkehrteirund, eingebogen; Fr. eirund-längl.; Frtr. 2spaltig; Griffelpolster flach; Griffel abstehend; Thälch. mehrstriem.; H. u. Hch. 0 .

Sium. K. 5zähnig; Bbl. herzf., eingebogen; Fr. länglich; Griffelpolster gewölbt; Gr. zurückgebogen; Thälchen 3striemig; H. und Hch. vielbl.

Berula. K. 5zähnig; Bbl. herzf., eingebogen; Fr. kugelig; Griffelp. kegelf.; Gr. zurückgebogen; Thälchen mit vielen tiefliegenden Striemen; H. und Hch. vielbl.

$\beta$ ) Bl. einfach; Blkr. gelb.

Bupleurum. K. undeutlich; Bbl. rundlich eingerollt; Fr. länglich; Griffelp. flach; Riefen fädlich oder vorstehend; Thälch. 3striemig oder striemenlos.

Trib. 4. Seselineae. Frucht auf dem Querdurchschnitte fast stielrund.

O en anthe. K. 5zähnig; Bbl. verkehrteirund, eingebogen; Fr. eirund-walzenförmig mit langen, aufrechten Griffeln; Riefen stumpf, Thälch. 1striemig; H. u. Hch, vielbl.

A ethusa. K. undeutlich; Bbl. verkehrteirund, eingebogen; Fr. kugelig-eirund, mit zurückgebogenen Griffeln; Riefen scharfkielig; Thälch. 1striemig; Hch. $3 \mathrm{bl}$., hängend.

Seseli. K. 5zähnig; Bbl. verkehrt-eirund; Fr. ei-länglich, mit zurückgebogenen Griffeln; Riefen vorspringend, etwas korkartig; Thälch. meist 1striemig; Hch. vielbl.

Cnidium. K. undeutlich; Bbl. verkehrt-eirund, eingebogen; Fr. fast kugelig, Riefen dünnhäutig-geflügelt; Thälch. 1striemig; Hch. vielbl.

Silaus. K. undeutlich; Bbl. längl-eirund; Fr. elliptisch; Riefen kurz, scharfgeflügelt; Thälch. vielstriemig.

Trib. 5. Angeliceae. Frucht vom Rücken zusammengedrückt, mit doppelt geflügeltem Rande, die seitenständigen Riefen breitgeflügelt, von den mittleren abstehend.

Selinum. K. undeutl.; Bbl. verkehrt-eirund, eingebogen; Riefen alle häutiggeflügelt; Thälch. 1-2striemig; H. armbl. Hch. vielbl. 
Angelica. K. undeutl.; Bbl. lanzettl,, spitz; die 3 Mittelriefen fadenfürmig; Thälch. 1striem.; H. u. Hch. vielbl.

Trib. 6. Peucedaneae. Frucht linsenähnlich zusammengedrückt, mit einfach gefiügeltem, glattem oder verdicktem Rande.

Peucedanum. K. 5zähnig od. undeutl.; Blbl. verkehrteiförmig, eingebogen; Riefen gleichweit von einander entfernt, mittl. Riefen fadenfürmig, seitenst. breitgeflügelt; Thälch. 1striemig; Hch. vielbl.

An ethum. K. undeutl.; Blbl. rundl. eingerollt mit 4eckigen Zipfeln; Riefen gleichrreit von einander entfernt, mittl. scharfgekielt, seitenst. undeutlich; Thälch. 1striemig; H. u. Hch. o.

Pastinaca. K. undeutl.; Blbl. rundlich, eingerollt, zugespitzt, mittl. Riefen sehr fein, seitenst. breitgeflïgelt, weiter abstehend; Thälch. 1striem.; H. u. Hch. o oder armblätterig.

Heracleum. K. 5zähnig; Striemen der Thälch. verkürzt, keulig; sonst wie vorige; $\mathrm{H}$. armbl.; Hch. vielbl.

b) Früchte mit 5 Hauptriefen und 4 stärker hervortretenden Nebenriefen.

Trib. 7. Daucineae. Frucht vom Rücken zusammengedrückt; Haupt- und Nebenriefen borstig-stachelig.

D a u cu s. K. 5zähnig; Bbl. verkehrtherzf. eingebogen. Hauptriefen borstig; Nebenriefen geflügelt, 1reihig stachelig; H. u. Hch. fiedertheilig.

Subord. 2. Campylospermae.

(Gekrümmtsamige.)

Eiweiss auf der Fugenfläche tief gefurcht oder an den Rändern eingerollt. - Dolden zusammengesetzt oder etwas verkümmert.

Trib. 8. Caucalineae. Frucht zusammengezogen od. fast stielrund, mit 5 borstigen od. stacheligen Hauptriefen und 4 sehr hervorspringenden stacheligen Nebenriefen.

Ca ucalis. K. ózähnig; Blbl. verkehrt herzf., eingebogen; Nebenriefen mit 1 einfachen Reihe Stacheln: H. armbl, Hch. vielbl.

Turgenia. Wie vorige, aber Nebenriefen mit 2-3 Reihen Stacheln; H. u. Hch. 3-5blättr.

Torilis. Wie vorige, aber Nebenriefen ganz bedeckt ron zahlreichen feinen Stacheln in den Thälchen.

Trib. 9. Scandicineae. Früchte länglich, von der Seite zusammengedriickt, oft geschnäbelt; Hauptriefen 5 oder fehlend, Nebenriefen 0 .

Scandix. K. undeutl.; Bbl. verkehrt-eiförmig, eingebogen; 
Frucht langgeschnäbelt, mit 5 stumpfen Riefen; H. armbl, Hch. vielbl.

Anthriscus. Wie Scandix; aber Früchte riefenlos mit kurzem 5rippigem Schnabel; H. o, Hch. vielbl.

Chaerophyllum. Wie Scandix, aber Früchte schnabellos, mit 5 stumpfen Riefen; H. o oder armbl., Hch. vielbl.

Trib. 10. Smyrneae. Früchte etwas eiförmig, gedunsen, von der Seite zusammengedrückt, Frïchte mit 5 IIauptriefen. Nebenriefen 0 .

Conium. K. undeutl.; Blbl. verkehrt-herzförmig, eingebogen ; Früchte eiförmig mit 5 wellig gekerbten Riefen; H. 3-5bl., Hch. $3 \mathrm{bl}$, einseitig.

\section{Subord. 3. Coelospermae.}

(Hohlsamige.)

Eiweiss ausgehöhlt, halbkugelig.

Trib. 11. Coriandreae. Früchte kugelig, mit 5 schwachen Hauptriefen und 4 mehr vorspringenden Nebenriefen.

Cori a ndrum. K. 5zähnig; Blbl. verkehrt-herzförmig, eingebogen; die äusseren Blkr, der Dolden strahlend; Halbfrüchte innig verbunden; H. fast 0 , Hch. 2-3blättr.

139. Ilydrocotyle $L$. W assernabel.

355. H. vulgaris $L$. Gemeiner W.; kriechend; Bl. langgestielt, schildförmig-kreisrund, gekerbt; Blthen sehr klein, sitzend, $3-5$ fast knäuelartig, röthlich. 4 . $3-8^{\prime \prime}$.

In Torfsümpfen, auf Moorwiesen, in sumpfigen Waldgebüschen nicht verbreitet. In Menge bei Waghäusel! Sandtorf! zwischen Walldorf und Roth! seltener bei Brühl. Juli-Sept.

\section{I40. S a nicula $L$. S a n i ckel.}

356. S. europaea L. Europäis cher S.; St. aufrecht, kahl; Wbl. langgestielt, handförmig-getheilt mit 3spaltigen Lappen; Dolde kopfförmig. 4. 1'. Blth. klein, meist polygamisch, weiss.

In schattigen Laubwäldern stellenweise häufig, z. B. zwischen Leimen und Nussloch! bei Dielheim! Weinheim! Leutershausen! in der Hillenbach bei Handschuchsheim! auch bei Neckarau! Seckenheim! u. s. w. Zuweilen übrigens nur sehr vereinzelt, wie z. B. in den Wäldern hinter dem Haarlass und zwischen Ziegelhausen und Schönau! Selten in feuchten Nadelwäldern, z. B. zwischen Schwetzingen und Friedrichsfeld! Mai, Juni. 
141. Eryngium $L$. Mannstreu.

357. E. campestre $L$. Feld-M.; ausgebreitet verzweigt, starr, graugrün, untere Bl. 3theilig, doppelt fiederspaltig, dornigsägezähnig, obere stengelumfassend, einfach fiederspaltig; Blthküpfchen rundlich. 24. 1-1 $\frac{1}{2}^{\prime}$. Blthen blaugrün.

Auf Sandflächen, an Ackerrändern, auf Steingeröll besonders in den Ebenen häufig und bisweilen, z. B. an den Rheindämmen heerdenweise! Juli-Sept.

\section{Cicuta $L$. Was serschierling.}

358. C. virosa $L$. Giftiger W.; Wurzelst. rübenartig, fleischig, im Ininern queerfächerig, milchend; St. aufrecht, wie die Bltstiele röhrig; Bl. 3fach gefiedert; Zipfel lineal-lanzettlich, scharfgesägt; Dolden gewölbt. 4. 3-4'. Blkr. weiss. - Sehr giftig.

In Torfsümpfen, Gräben, Teichen hie und da. In grosser Menge bei Sandtorf! Weniger verbreitet bei Waghäusel! Neckarau! Vereinzelt zwischen Kirchheim und St. Ilgen! Juli-Sept.

\section{A pium $L$. Sellerie.}

A. graveolens L. Gemeiner S.; St. aufrecht, ästig; Bl. glänzend, fiedertheilig mit keilfürmigen gezähnten Lappen; Dolde kurz gestielt, armblüthig; Hülle fehlend. 4. 1-3'. W. bei der wilden Pflanze spindelförmig, bei der kultivirten fleischig. Blkr. weiss.

[Wild wachsend in Menge jenseits des Rheines bei der Dürkheimer Saline! Juli-Sept.]

Hie und da kultivirt.

\section{Petroselinum Hoffm. Petersilie.}

P. sativum Hoffm. Gebräuchl. P.; St. ästig, stielrund, gestreift; Bl. glänzend, die unteren 3fach gefiedert, mit eiförmigkeiligen Lappen, die oberen 3theilig; Dolden langgestielt; Hüllo 1-2blätterig; Hüllch. 6-8blätterig. คิ. 2-3'. Blkr. grünlich-gelb.

Cultivirt, zuweilen verwildert. Juni, Juli. (Off.: Rad., $h b$. et sem. Petroselini.)

\section{[Trinia Hoffm. Trinie.]}

[T. vulgaris De Cand. Ge me in e Tr.; aufrecht, ästig, kahl, blaugrün; Bl. 2-3fach gefiedert, fiederspaltig; Dolden reichblüthig, klein; Hülle und Hüllch. armbl. oder fehlend; Riefen der Frucht stumpf. $\hat{~} . \frac{1}{4}-1^{\prime}$. Blkr. weiss. Die männl. Pflanze weniger ästig, die weibl. mehr ausgebreitet. (T. glauca Dum.) 
N. V. a. d. Geb. auf trockenen Kalkhügeln zwischen Dürkheim und Leistadt häufig! April-Juni.]

143. Il elosciadium Koch. Sumpfschirm.

359. H. nodiflorum Koch. Knoten blüth. S.; St. am Grundo niederliegend und wurzelnd, wie die gefiederten Bl. kahl; Blttch. eilanzettl., gesägt; Dolden kurzgestielt, vielstrahlig; Hülle 1-2blättr. Hüllch. vielbl. 4. $\frac{1}{2}-1 \frac{1}{2}^{\prime}$. Blkr, grünlichweiss. (Sium nodiflorum L.)

In Gräben, an Teichen, in Torfsümpfen. Bei Waghäusel und Sandtorf häufig! bei Brühl! dem Rohrhofe! Neckarau hie und da! Juli-September.

360. H. repens Koch. Kriechender S.; St. niederliegend, kriechend, mit Ausläufern, wie die gefiederten Bl. kahl; Blttch. rundlich-eiförmig, gelappt; Dolden wie die vorige. 4. $3-6^{\prime \prime}$. (Sium repens L.)

In und an Sumpfgräben, auf nassem, überschwemmtem Moorboden der Rheinfläche, aber seltener diesseits des Rheins, z. B. beim Rohrhof. (Dierb., Schimp.) [Jenseits des Rheines verbreiteter, z. B bei Friesenheim; in den Oggersheimer Sümpfen!] Juli-Septbr.

\section{Falcaria Host. Si cheldold e.}

361. F. Rivini Host. Ge me in e S.; St, ästig, sperrig, wie die Bl. kahl, graugrün; untere Bl. 1-3fach fiedertheilig, obere lineallanzettlich, etwas sichelförmig, scharf gesägt; Hülle und Hüllch. vielblätterig. 4. 1-1 $\frac{1}{2}^{\prime}$. Blkr. weiss. (Sium Falcaria L.)

Auf Aeckern, an Wegen, in Weinbergen, auf kalk- und lehmhaltigem Boden nicht selten. In grosser Menge zwischen Weinheim! Ladenburg und Handschuchsheim! einzeln auch bei Neuenheim! Wieblingen! Heerdenweise zwischen Wiesloch! Dielheim! Rauenberg!

\section{A egopodium $L$. Ge iss fuss.}

362. A. Podagraria L. Gemeiner G.; St. aufrecht, tiefgefurcht; untere Bl. doppelt 3zählig-gefiedert; Blttch. eilanzettlich, gezähnt, meist kahl; Hülle und Hüllchen fehlend. 4. 2-3'. Blkr. weiss.

An Bächen, Gräben, Wegen, in Wäldern und auf Wiesen überall häufig! Juni-August.

\section{Carum $L$. Kümmel.}

363. C. Carvi $L$. Ge meiner K.; W. spindelförmig; St. ästig, kantig-gefurcht; Bl. doppelt gefiedert; Blttch. flederspaltig, viel- 
theilig, die untersten Blttch. am gemeinschaftl. Bltstiel anhängselartig kreuzweise gestellt; Hülle 0 ; Hüllch. sehr armblätterig oder 0 . ๙. 1-2'. Blkr. weiss.

Auf Wiesen, Triften, an Wegen häufig! April, Mai. (Off.: Sem. Carvi.)

364. C. Bulbocastanum Koch. Knolliger K.; W. knollenartig, fast kugelig; St. aufrecht (etwas gebogen), stielrund; Bl. 2-3fach gefiedert, mit linealen Zipfeln; Hülle und Hüllch. vielblätterig. 4. $1 \frac{1}{2}-2^{\prime}$. Blkr. weiss.

Auf Aeckern, an Wegen, auf Kalk- und Lehmboden nicht verbreitet. Zwischen Weinheim und Ladenburg! einzeln bis Schriesheim! In Menge bei Nesterbach! Vereinzelt zwischen Schwetzingen und Ketsch (Schimp.). [Jenseits des Rheines hie und da häuflg, z. B. zwischen Frankenthal und Grünstadt! bei Leistadt!] Juni, Juli.

\section{4\%. Pimpinella $L$. Bibernell.}

365. P. magna $L$. Grosse B.: St. kantig-gefurcht; Bl. gefiedert; Blttch. eirund, spitz, grobgesägt, gelappt oder zerschlitzt; Griffel länger als der Fruchtk.; Früchte länglich-eiförmig, kahl. 4 . 2-3'. Blkr. weiss.

Auf Wiesen, in Waldgebüschen, auf Triften, an Wegen häufig ! Juli-September.

366. P. Saxifraga $L$. Gemeine B.; St. stielrund, schwach gefurcht; Bl. gefiedert; Blttch. eirund, stumpf gezähnt, gelappt oder zertheilt; Griffel länger als der Fruchtknoten; Früchte eirund, kahl. 4. $\frac{1}{2}-1^{\prime}$. Blkx. weiss oder röthlich. Variirt:

¿) poteriifotia Wallr.; Blttch. gekerbt.

$\beta$ ) dissectifolia Wallr.; Bltttch. vielfach zerschlitzt.

An Wegen, auf Wiesen, Triften, an Waldrändern häufig! Die Var. $\alpha$ auf trockenem, unfruchtbarem Boden nicht selten. JuliSeptember. (Off. : Rad. Pimpinellae albae.)

\section{Si um $L$. Wassermerk.}

367. S. latifolium $L$. Breitblättr. W.: St. aufrecht, kantig; Bl. gefiedert; Blttch. länglich oder lanzettlich, gesägt; Dolden endständig, etwas convex; Hülle und Hüllch. vielblätterig. 4. 2m4'. Blkr. weiss. Die im Wasser untergetauchten Bl, zerschlitzt.

In Sümpfen, Gräben, Teichen, an Flussufern hio und da! Juli bis September. 
149. Beruì Koch. B erle.

368. B. angustifolia $K$. Schmalblättr. B.; St. aufsteigend, stielrund, gestreift; Bl. gefiedert; Blttch, eirund-lïnglich oder lanzettlich, eingeschnitten gesägt; Dolden flach, blattgegenständig. 4. 2-3'. Blkr. weiss.

In Gräben, Sümpfen, an sumpfigen Waldstellen nicht selten, aber weniger verbreitet als das vorige, z. B. in der Iirschgasse bei II.! bei Handschuchsheim! zwischen Kirchheim und St. Ilgen! in den Sümpfen der Rheinfläche! Juli-September.

150. B up leurum $L$. Has en ohr.

369. B. falcatum $L$. Sichelblättr. H.; St. sperrig-ästig, etras niederliegend; Bl. lanzettl., etwas sichelartig, untere spatelfürmig; Dolden klein; Hüllchbl. lanzettlich, fein zugespitzt; Thälchen 3striemig. 4. 1-3'. Blkr. gelb.

Aur trocknen IIügeln, an Waldrändern, in Gebüschen. In Menge linter Neuenheim, am Damme längs des Neckars! Bei Wieblingen! Iadenburg! Feudenheim ebenfalls am Neckar! [Auf den Kalkhiigeln bei Dürkheim, Kallstadt u. s. w., und besonders weiter abwärts am Rhein bei Oppenheim, Nierstein, sehr allgemein verbreitet! Juli bis October.

370. B. rotundifolium $L$. Rundblättr. H.; St. aufrecht, einfach oder ästig; obere und mittlere Bl. durchwachsen oder stengelumfassend, glatt; Dolden ansehnlich; Hü̈lle 0; Hüllch. 3-5blätterig; die Döldchen überragend; Thälchen striemenlos. ๑. $\frac{1}{3}-1 \frac{1}{2}^{\prime}$. Blkr. gelb.

Unter der Saat, auch auf Brachaeckern, in Weinbergen, vorzugsweise auf Kalk- und Lehmboden: Wiesloch! Weinheim! Ladenburg! zwischen Wieblingen und Edingen! bei Seckenheim! einzeln auch beim Relaishauso! und bei Handschuchsheim (Stud, Gysser). Juli-September.

\section{Oenanthe $L$. Re bend olde.}

371. 0. fistulosa $L$ 。 Rührige R.; W. büschelig, mit rübenförmig verdickten Fasern; St. und Bltstiele röhrig: Bl. meist doppelt gefiedert, mit linealischen einfachen oder 3spaltigen Blttch; Dolden meist $3-7$ strahlig; Hülle 0 ; Hüllch. vielblätterig ; Frücht 4. 1-2'. Blkr. weiss, strahlend, vielehig.

In Gräben, auf nassen Wiesen, in Sümpfen hie und da, besonders häufig in den Sumpfgräben der Ebene, z. B. bei Waghäusel! Sandtorf! Brühl! Neckarau! stellenweise auch bei St. Ilgen! zwischen Handschuchsheim und Ladenburg! u. s. w. Juni-August. 
[0. peucedanifolia Poll. Haarstrangblättr. R.; unterscheidet sich durch nicht röhrige, kürzere Bltstiele, flache, linealische Blttch, längliche, an beiden Enden verschmälerte Früchte. $1-3^{\prime}$.

Auf fruchtbaren Wiesen jenseits des Rheines, z. B. bei Speyer und auf den sog. Bischofswiesen zwischen Forst und Friedelsheim in Menge! Juni, Juli.]

372. 0. Phellandrium Lam. Was serfenchel; W. spindelförmig, faserig; St. aufrecht, dick, hohl, sehr ästig; Bl. 2-3fach-fiederspaltig, mit linealen Zipfeln; Dolden blattgegenständ., vielstrahlig; Hülle 0; Hch. vielbl; Früehte eirund-länglich. 4. 2-4'. Blkr. weiss, regelmässig, zwitterig. (Phellandrium aquaticum L.)

In Sümpfen, Gräben, Teichen, an Flussufern hie und da, besonders in der Nähe des Rheines sehr gesellig! Juli-September. (Off.: Semen Phellandrii.)

\section{Aethusa $L$. Gleisse.}

373. A. Cynapium $L$. Gartengleisse; St. aufrecht, etwas bereift; Bl. 2-3fach gefiedert, glänzend, dunkelgrün; Hüllch. 3blättr. länger als die Döldchen, hängend. ๑. $\frac{1}{4}-2^{\prime}$. Blkr. weiss. - Giftig!

Auf Gartenland, Aeckern, auf Schutthaufen, an Wegen überall verbreitet, stellenweise ein lästiges Unkraut, hie und da weniger häufig! Juni-October.

Die schädliche Pflanze wird im nichtblühenden Zustande häufig mit der Petersilie verwechselt, unterscheidet sich aber von der letzteren durch den bereiften St., schmälere Blattzipfel und durch den Mangel des gewürzhaften Geruches. - Die hängenden Hüllblättchen unterscheiden diese Art zugleich von allen anderen einheimischen Doldenpflanzen.

\section{Seseli $L$. Sesel.}

374. S. coloratum Ehrh. Gefär b ter S.; St. aufrecht, blaugrün; Bl. 2-3fach gefledert, mit linealen Zipfeln; Dolden 20-30strahlig; Hülle o oder armblättrig; Hchbl. lineal-lanzettlich, weissberandet, gewimpert. $\widehat{0}$. $1-1 \frac{1}{2}^{\prime}$. Blkr. röthlich-weiss. (S. annuum L.)

Auf trocknen Wiesen, am Rande trockner. Waldgebüsche, in Nadelwäldern, auf sonnigen Hügeln hie und da. Zwischen Friedrichsfeld u. Schwetzingen! beim Relaishause! bei Neckarau! Weinheim! Leutershausen! zwischen Dielheim und Rauenberg! Bei Waghäusel (Dierb.). Im Käferthaler Nadelwalde $(F$. Soh.) JulimSeptbr.

SCIHDIDT, Flora v. H. 


\section{Cnidium Cuss. Brenndolde.}

375. C. Venosum Koch. Aderige Br.; St, aufrecht, gestreift; Bl. doppelt gefledert, mit linealischen, queeraderigen Zipfeln, die oberen Bltscheiden sehr verlängert, den St. umhüllend; Dolde flachkugelig; Blttch, der Hülle und Hüllch. borstenfürmig, 4. 1-2'. Blkr. weiss.

Auf feuchten Wiesen zwischen Gebüsch selten. Zwischen dem Relaishause und dem Rohrhofe ( $D$ öll). [In der Nähe des Gebietes. in grüsserer Menge, z, B, in feuchten Gebüschen bei Maxdorf!] Juli bis September.

\section{Silaus Bess. Silau.}

376. S. pratensis Bess. Wi es en-S.; St. aufrecht, ästig, kantig; B1. 3-4fach gefiedert mit linealischen, stachelspitzigen Zipfeln; Bltscheiden kurz; Dolden ansehnlich, etwas concav; Hülle armbl.; Hüllch. vielbl. 2. 2-3'. Blkr. blassgelb.

Auf Wiesen, Triften, an Rainen häufig! Auf den Wiesen der Rheinfläche fast nirgends fehlend! Juli-September.

\section{Selinu m $L$. Silge.}

377. S. Carvifolia $L$. Kümmelblättr. S.; St. aufrecht, kantig-gefurcht; Bl. 3fach gefiedert, mit eirund-lanzettl. tief flederspaltigen Zipfeln; Dolden flach; Hülle 0 ; Hüllchen vielbl. 24. 1 $\frac{1}{2}-3^{\prime}$ ' Blkr. weiss.

In Waldgebüschen, auf Wald- und Torfwiesen der Rheinflächo hie und da, z. B. beim Rohrhof (Schimp.)! bei Sandtorf! Waghäusel! Juli, August.

\section{5\%. Angelica $L$. Angelike.}

378. A. sylvestris $L$. Wald-A.; St. stark, röhrig, stielrund, oberwärts weissgrau behaart; Bl. 2-4fach gefledert; Blttch. eiförmig, scharf gesägt, obere Bltscheiden bauchig-aufgeblasen; Dolden gross, gewölbt, vielstrahlig. 24. 2-4'. Blkr. weiss-röthlich.

An sumpfigen Waldstellen stellenweise häuflg, besonders an den Ufern des Neckars und des Rheines. Juli-October.

\section{P euced a u um $L$. Haarstrang.}

a) Die Striemen der Fugenfläche von Aussen sichtbar; die seitlichen Riefen vom Rande etwas abstehend; Hüllch. vielbl.

379. P. offlcinale L. Heilkräftiger H.; St. aufrecht, stielrund, gestreift; Bl. 3-5fach dreitheilig, glänzend; Blttch. linealisch; 
Strahlen der ansehnlichen Dolde kahl; Hülle armblätterig. 4. 2-4'. Blkr. gelb.

Auf den Wiesen der Rheinfläche verbreitet, z. B. häufig bei Neckarau! beim Relaishause! Auch in den Ebenen bei Weinheim! Wiesloch! St. Ilgen! aber seltener. Juli-September.

380. P. Cervaria Lap. Hirsch-H.; St. steif, aufrecht, stielrund, gestreift; BI. 2-3fach gefiedert; Blttch. eirund, scharf gesägt, blau-grün; Strahlen der ansehnlichen Dolde innen (d. h. einseitig) rauh; Hülle reichblätterig, zurückgeschlagen. 4. 2-3'. Blkr. weiss. (Athamanta Cervaria L)

In Gebirgswäldern hie und da, z. B. oberhalb des Haarlass! am westlichen Abhange des Oelberges bei Schriesheim! bei Weinheim und Nesterbach! am Teufelskopf bei Dielheim! in der sog. Hessel bei Wiesloch! Nussloch! Seltener in Nadelwäldern der Ebene, z。 B. zwischen Friedrichsfeld und Schwetzingen! August, September.

381. P. Oreoselinum Moench. Bergpetersilien-H.; St. aufrecht, stielrund, gestreift; Bl. 3fach gefiedert, die Verzweigungen der Bl. zurückgebogen-auseinandergesperrt; Blttch. eingeschnitten; Strahlen der flachen, lockeren Dolde innen rauh; Hülle reichbl, zurückgeschlagen. 4. 2-3'. Blkr, weiss-gelblich.

Auf Sandflächen, in trocknen Nadelwäldern, auf sonnigen Hügeln und Triften häufig, z. B. zwischen Friedrichsfeld! Schwetzingen und dem Relaishause! stellenweise auf der ganzen Sandfläche d. Gebietes! Auch bei Wiesloch! Nussloch! Schatthausen! Malsch! Seltener im Gebirge bei Weinheim! Schriosheim! Dossenheim! Augst., Septbr.

382. P. alsaticum $L$. Elsässischer H.; St. aufrecht, kantiggefurcht; Bl. 3fach gefiedert, mit linealen spitzen, am Rande etwas rauhen Zipfeln; Strahlen der etwas gewölbten Dolde fast glatt; Hüllo mehrbl., abstehend. 4. 2-4'. Blkr. gelblich. Die ganze Pflanze fast pyramidenförmig, durch den Habitus sehr ausgezeichnet!

Auf sonnigen, steinigen Hügeln, an Wegen, in lichten Gebüschen. Auf den Rheindämmen stellenweise, aber im Geb d. Fl. nur vereinzelt bei Alt-Lussheim und Rheinhausen. [Jenseits des Rheines hie und da, z. B. bei Speyer, Frankenthal, Roxheim, aber allgemeiner verbreitet und als wesentlicher, hervorragender Bestandtheil der Vegetation in Rhh. bei Oppenheim! Juli-September.

b) Striemen der Fugenfläche von Aussen nicht sichtbar; die seitlichen Riefen unmittelbar in den Rand übergehend;

Hüllchen armblätterig.

383. P. palustre Moench. Sump f-H.; St. aufrecht, gefurcht; Bl. 3fach gefiedert mit fiederspaltigen, am Rande schärflichen Zipfeln; Dolde ansehnlich, gewölbt; Hüllblttch. häutig-berandet. 犬. 2-4'. Blkr. weiss. (Thysselinum palustre Hoffm.; Selinum palustre L.) 
Auf sumpfigen Wiesen nur stellenweise, z. B. zwischen Ketsch u. Waghäusel (Bisch.), kommt vielleicht auch jetzt noch vor in der Nähe von H., bei der Glashütte (Dierb.) und bei Rohrbach (F.Schultz). Juli, August.

\section{Anethum $L_{\text {. Dill. }}$.}

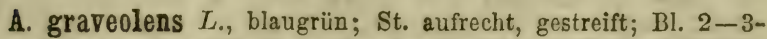
fach gefiedert, mit vieltheiligen linealen Zipfeln; Hülle und Hüllch. fehlend. ๑. 2-3'. Blkr. gelb.

Aus Süd-Europa. Cultivirt; hie und da verwildert. Juli, August. (Off.: Semen Anethi.)

\section{Pastinaca $L$. Pastinak.}

384. P. sativa L. Gemeine P.; St. aufrecht, kantig gefurcht; Bl. gefiedert, oberseits etwas glänzend, unterseits weichhaarig.; Blttch. eiförmig, stumpf, gekerbt; Dolde flach; Hülle o; Hüllch. arm-

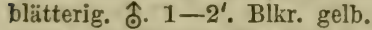

Auf Wiesen, Triften, an Wegen überall! Juli-September.

160. Ileracleum $L$ 。 Bärenklau.

385. H. Sphondylium $L$. Gemeine B.; St. aufrecht, gefurcht, wie die Bl. rauhhaarig; Bl. gefledert oder tief fiederspaltig, mit gelappten oder handförmig getheilten Zipfeln, und aufgeblasenen Scheiden; Dolde ansehnlich; Hülle fast 0 ; Hüllch. vielbl.; Fruchtknoten weichhaarig; Frucht kahl. 4. 2-4'. Blkr. weiss, strahlend. - Variirt;

$\beta$. elegans Jacq.; Blttch. verlängert, eingeschnitten gesägt oder fiederspaltig.

Auf Wiesen, Grasplätzen, an Waldrändern und Wegen häufig! Die Var. seltener, z. B. auf den Bergwiesen zwischen dem Haarlass und dem Stift Neuburg! Juni-September.

\section{Orlaya Hoffm. Breitsame.}

386. 0. grandiflora Hoff $m$. Grossblüthiger Br.; St. gabelspaltig-ästig, kahl; Bl. doppelt gefiedert; Blttch. tief fiederspaltig mit linealen Zipfeln; Dolde ansehnlich, flach; Hülle und Hüllchen mehrblättr., trockenhäutig-berandet. ๑. $5-10^{\prime \prime}$. Blkr. gross, weiss, strahlend.

Auf kalkhaltigen Aeckern selten. Unfern Mannheim, zwischen Heddesheim und Wallstadt. Juni-August. [N. V. a. d. Geb. in Rhb. stellenweise zwischen Dürkheim und Grünstadt! (Döll, König.) 


\section{D a ucus $L$. IIöre (Moorrübe).}

387. D. Carota L. Gemeine M.; St. aufrecht, wio dio Bl. rauhhaarig; Bl. 2-3fach gefiedert; Doldo vielstrahlig, nach der Blüthe vogelnestartig vertieft; Blttch. der ansehnlichen Hülle fleder-

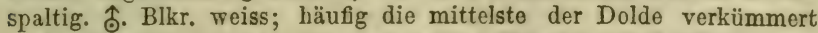
und dunkelpurpurroth; W. der wilden Pflanze spindelförmig, der cultivirten fleischig, gelbroth.

Auf Triften, Wiesen, in lichten Wäldern, an Wegen allgemein verbreitet! Juni-September.

\section{Ca ucal is Hoffm. Ha ftdolde.}

388. C. daucoides $L$. Moorrübenartige $H_{\text {.; }}$ St. gefurcht BI. 2-3fach gefiedert; Blttch. flederspaltig; Dolden klein, armstrahlig; Hülle 0; Hllch. 2-6blättrig; Stacheln der Nebenriefen glatt, hakig. ๑. 4-10". Blkr. klein, weiss.

Unter der Saat, auf Brachaeckern, besonders auf Kalk- und Lelimboden. In der Nähe von H., z. B. bei Wieblingen, Handschuchsheim und Dossenheim rereinzelt! häufiger bei Ladenburg! Seckenheim! Weinheim! Wiesloch! Baierthal! Dielheim! Juni, Juli.

\section{Turgeni a Hoffm. Turgenie.}

389. T. Iatifolia Hoffm. Breitblättr. T.; St. abstehend ästig, wie die Bl. meist kurz-steifhaarig; Bl. einfach gefledert; Blttch. lineal-länglich, eingeschnitten-gezähnt oder gespalten; Doldo 2-3strahlig; Hülle und Hllch. mehrbl.; Stacheln der Riefen feinhakig. $\odot$. $\frac{3}{4}-1 \frac{1}{2}^{\prime}$. Blkr. weiss oder purpurroth. (Caucalis latifolia $\mathbf{L}_{\text {, }}$ )

Auf kalkhaltigen Aeckern. Zwischen Alt-Wiesloch, Dielheim und Rauenberg stellenweise in Menge! Auch hinter Rauenberg, gegen Meckesheim! (und wahrscheinlich weiter gegen Sinsheim mehr verbreitet.) Nach Dierb. auch bei Handschuchsheim, woselbst aber wohl nur sporadisch.

\section{Torilis Adans. Klettenkerbel.}

390. T. Anthriscus Gmel. Gemeiner Kl., graugrün; St. aufrecht, abstehend-ästig; Bl. doppelt geffedert; Blttch. tief gesägt, wie die St. von abwärts gerichteten Haaren steifhaarig; Dolden langgestielt; Hülle meist 5blätterig: Stacheln der Früchte an der Spitze verdickt oder hakig. ๑. $1 \frac{1}{2}-2^{i}$. Blkr. weiss oder blassroth.

An Wegen, Waldrändern, Zäunen, in Steinbrüchen häufig, meist gesellig! Juli-September.

391. T. helvetica Gmel. Schw eizer Kl. ; St. sperrig-ïstig, niedrig; Bl. u. Behaarung der vor.; Dolden kürzer gestielt; Hülle 0 . 
oder Iblätterig; Stacheln der Früchte an der Spitzo widerhalig. $\delta$. $5-10^{\prime \prime}$. Blkr. weiss.

Hinsichtlich der Verbreitung unsicher; wurde früher bei Leimen boobachtet (Döll, Schultz, Bischoff), woselbst aber in den letzten Jahren nur die vorige Art von mir gesehen worden ist.

\section{Seandix $L$. N a d elkerbel.}

392. S. Pecten Veneris $L$. Kammf. N.; St. aufrecht, ästig, rauh; Bl. 2-3fach fiederspaltig; Dolden 2-3strahlig; Hülle o oder 1blättrig; Hllch. mehrblätt.; Fruchtschnabel 2reihig-steifhaarig. ๑. $5-10^{\prime \prime}$. Blkr. klein, weiss.

Auf Aeckern, besonders im Sommergetreide auf Kalk- und Lehmboden nicht selten. Bei Weinheim! Ladenburg, stellenweise bis Handschuchsheim verbreitet! Auch beim Relaishause! bei Seckenheim! Edingen! In grösserer Menge bei Wiesloch! Baierthal! u. s. w. Mai-Juli.

\section{6\%. Anthriscus Hoffm. Kerbel.}

393. A. sylvestris Hoffm. Wilder K.; St. aufrecht, unten rauhhaarig, oben kahl; Bl. 2-3fach gefiedert, glänzend, unterseits an den Nerven behaart; Blttch. lanzettl., fiederspaltig; Hülle fast 0 ; Hllch. 5-6blätterig, gewimpert; Dolden vielstrahlig; Frucht länglich, glatt oder etwas warzig, 4-5mal länger als der Schnabel. 24. 2-4'. Blkr. weiss. (Chaerophyllum sylvestre L.) - Wird von Anfängern leicht mit dem häuffg gemeinschaftlich vorkommenden Carum Carvi verwechselt, unterscheidet sich aber sogleich durch die gewimperten Hllchbl. und durch den Mangel der Anhängsel am Grunde d. Bl.

Auf Wiesen, an Gräben, Zäunen häufig! Mai, Juni.

A. Cerefolium Hoffm. Garten-K.; St. aufrecht, über den Gelenken feinhaarig; Bl. 3fach gefledert, zart; Dolden 3-5strahlig; Hlllch. einseitswendig 2-4blätterig; Frucht lineal, kahl, doppelt so lang als der Schnabel. $\odot$. 1-1 $\frac{1}{2}^{\prime}$. Geruch und Geschmack aromatisch. (Soandix Cerefolium L.)

Aus Süd-Europa. Cultivirt. Hie und da verwildert. Juni, Juli.

394. A. vulgaris Pers. Gemeiner K.; St. sehr verzweigt, oft otwas niederliegend, kahl; Bl. 2-3fach gefledert; Blttch. fiederspaltig, unterseits sehwach behaart; Hllch. 2-4blätterig, einseitswendig; Dolden 3-5strahlig; Frucht eiförmig, mit an der Spitze gebogenen Stacheln, 3mal länger als der Schnabel. ○. $\frac{1}{2}-1^{\prime}$. Blkr. weiss. (Soandix Anthrisous L.)

An Wegen, auf Schutthaufen, Mauern, besonders in Dörfern, jedoch nur stellenweise! In Menge am Rheindamm bei Ketsch! In 
manchen Dörforn der Ebeno verbreitet, z. B. in Brühl! Käforthal! Neu-Lussheim! Sandhausen! seltener bei Schwetzingen! Sanddorf! Malsch! Neuenheim! Mai-Juli.

\section{Cha erophyllum $L$. Kälberkropf.}

395. Ch. temulum $L$. Taumel-K., dunkelgrün; St. aufrecht, violett gefleckt, unter den Gelenken verdickt, unten steifhaarig, oben kurzhaarig; Bl. 2fach gefiedert, mit flederspaltigen, stumpflappigen Blttch.; Hllchbl: gewimpert; Griffel von der Länge

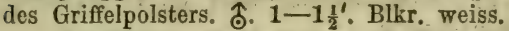

An Wegen, Waldrändern, in Gebüschen häufig! Juni-August.

396. Ch. bulbosum $L$. Knolliger K.; St. aufrecht, unter den Gelenken angeschwollen, unten steifhaarig, oben kahl und glatt; Bl. 3-4fach gefledert, mit tief fiederspaltigen, lanzettl.-linealen zugespitzten Blttchn.; Hllchbl. lanzettl, kahl; Griffel etwas länger als das Griffelpolster. $\hat{~} .2-4^{\prime}$. Blkr. weiss. W. knollenartig, verdickt.

In feuchten Gebüschen, an Ufern, besonders am Neckar stellenweise häuflg, z. B. bei der Bergheimer Mühle! Wieblingen! Neuenheim! Feudenheim! Auch am Rhein nicht selten, z. B. beim Rohrhof! Ketsch! Neckarau! Vereinzelt bei Leimen! St. Ilgen! Weinheim. Juni-August.

397. Ch. aureum $L$. Gelbfrüchtiger K.; St. aufrecht, an den Gelenken sehwach verdickt, unten meist rauhhaarig, seltener kahl; Bl. 3fach gefiedert; Blttch. eiförmig-lanzettl., am Grunde fiederspaltig, an der sehr verlängerten Spitze einfach gesägt; Hllchbl. gewimpert; Griffel länger als das Griffelpolster. 4. 2-4 $4^{\prime}$. Blkr. weiss; Frucht gelb-grün.

Auf Wiesen, an Waldrändern, in feuchten Gebüschen hie und da. Am Neckarufer stellenweise in Menge, z. B. bei der Bergheimer Mühle! Wieblingen! Neuenheim! Ladenburg! Häufig zwischen dem Relaishause und dem Rohrhofe! Juni-August.

\section{Conium $L$. Schierling.}

398. C. maculatum $L$. Gefleckter Sch.; St. aufrecht, unten gefleckt, wie die Bl. völlig kahl; $\mathrm{Bl}$. 3fach gefledert, die unteren mit stielrunden, hohlen Bltstielen; Blttch. tief fiederspaltig; Hllch. 3-4blätterig, einseitswendig, kürzer als die Döldchen, §.. $3-5^{\prime}$. Blkr. weiss. Giftig! [Von den zahlreichen ähnlichen Doldenpflanzen durch die hohlen Blattstiele und durch die wellig gekerbten Riefen (selbst auch bei ganz jungen Früchten wahrzunehmen) leicht $\mathrm{zu}$ unterscheiden.] 
Auf Aeckern, an Wegen, Hecken zwar stellenweise häufig genug, aber nicht überall; seltener im Gebirge als in der Ebene, wo hie und da, z. B. bei Neckarau! beim Relaishause! bei Sandhofen! bei der Rheinziegelhütte unfern Mannheim! heerdenweise. Juni-August. (Off.: Hb, et sem. Conii maculati.)

\section{Coriandrum $L$. Coriander.}

C. sativum $L$. Gemeiner C.; St. kahl, untere Bl. gefiedert, wenig eingeschnitten, die oberen mehr oder weniger feingetheilt; Dolden 3-5strahlig; Hch. 3blätterig, einseitswendig. ๑. 1-2'. Blkr. weiss, strahlend. Riecht wanzenartig.

Stammt aus Süd-Europa, wird in Gärten cultivirt und verwildert hio und da. Juni-August. (Off.: Sem. Coriandri.)

\section{ARALIACEAE Juss.}

Sträucher oder ausdavernde Kräuter mit abwechselnden Blättern ohne Nebenblätter. Blüthen meist in Dolden, regelmässig. Kelchröhre mit dem Fruchtknoten verwachsen. Blbl. 5-10, in der Knospe klappig. Stbgef. von der Zahi der Blbl., mit diesen vom Kelch entspringend. Fruchtknoten 2-vielfächerig, mit 1eiigen Fächern. Griffel 1-viele. Frucht beerenartig. Samen mit reichlichem, festem Eiweiss.

Hedera. K. 5zähnig; Blbl., Stbgef. u. Griffel 5-10; Beeren $5-10$ fächerig.

170. Hedera $L$. E pheu.

399. H. Helix $L$. Gemeiner E.; St. kletternd und kriechend; Bl. eckig-gelappt (an den blühenden $\mathrm{Z}$ weigen eirund), lederartig, glänzend, immer grün; Dolden einfach. Ђ̆. Blkr. grünlich; Beeren blauschwarz.

An Mauern, Felsen, Bäumen sehr häuflg! September, October. (Nur ältere Stämme gelangen zur Blüthe.)

\section{CORNEAE DC.}

Sträucher mit gegenständigen Blättern ohne Nebenblätter. Blüthen meist trugdoldig, regelmässig. K. mit dem Fruchtknoten verwachsen. Blbl. 4, der Kelchröhro eingefügt, in 
der Knospe klappig. Stbgef. 4. Fruchtknoten 2fächerig, mit 1eiigen Fächern. Griffel 1, mit kopfiger Narbe. Frucht steinfruchtartig. Samen mit reichlichem, festem Eiweiss.

Cornus. K. 4zähnig; Steinfrucht 2steinig.

171. Cornus $L$. Hornstrauch.

400. C. sanguinea $L$. Rother H.; Bl. elliptisch, spitz; Trugdolden flach, ohne Hülle. Ђ. 6-16'. Blkr. weiss; Steinfrucht schwärzlich; Zweige im Herbst blutroth werdend.

In Wäldern, Gebüschen, Hecken häufig! Mai, Juni.

\section{CAPRIFOLIACEAE · Juss.}

Sträucher oder Halbsträucher, seltener Kräuter mit gegenständigen Blättern, mit Nebenblättern oder ohne dieselben, mit einzelnen oder traubig gestellten Blüthen. Kelch mit dem Fruchtknoten verwachsen, meist mit kurzem Saum. Blkr. verwachsenblätterig, regelmässig oder unregelmässig, 4-5 gliedrig. Sthgef. 4-5, der Blkr. eingefügt. Fruchtknoten 2-5ficherig, mit 1-mehreren Griffeln und 1 oder mehreiigen Fächern. Frucht beerenartig. Samen eiweisshaltig. - Charakteristisches Auftreten in Vorhölzern und an Waldrändern.

A doxa. Ksaum 2-5lappig; Blkr. radfürmig, nur am Grunde verwachsen, 4-5gliedrig; Stbgef. 5 oder in der Gipfelblüthe des kugeligen Köpfchens 4, alle tiefgespalten (daher scheinbar 10 oder 8); Griffel $4-5$.

S a mbucus. K. 5zähnig; Blkr. radförmig; Stbgef. 5; Narben 3 ; Beere 3-5samig.

Viburnum. K. 5zähnig; Blkr. radförmig; Stbgef. 5 ; Narben 3 ; Beere 1samig.

Lonicera. K. 5zähnig; Blkr. röhrig oder trichterförmig, etwas unregelmässig; Stbgef. 5; Griffel 1; Beere 2-5̌samig.

\section{A loxa $L$. Bis a mkraut.}

401. A. Moschatellina $L$. Gemeines B., kahl, blassgrün; Wrzlst. schuppig, mit unterirdischen Ausläufern; Bl. 3zählig-gefledert, die grundständigen langgestielt, die oberen gegenständig, kleiner; Blthköpfchen endständig. 4. 2-5". Blth. grün; Gipfelblüthen grüsser, 4zählig. - Nach Moschus riechend. 
In Wäldern, feuchten Gebüschen, an Hecken und Zäunen hie und da. Am Haarlass und im Carmeliterwäldchen bei H.! bei Rohrbach! häuffger bei Schriesheim! Leutershausen und besonders bei Weinheim, z. B. im Gorxheimer Thall In Menge bei Dielheim, sowohl im Dorfe an Zäunen, als in den angrenzenden Laubwäldern! März-Mai.

\section{I73. S a mbu cus $L$. II ollunder.}

402. S. nigra $L$. Schwarzer H. (Flieder); Strauch oder Baum 10-20 ; Bl. gefledert; Blttch. eiförmig; Nebenbl. warzenartig oder 0 ; Trugdolden 5zählig-verzweigt. Blkr. weiss; Antheren gelb; Beeren kugelig, schwarz; Mark der Zweige weiss.

In Wäldern, an Zäunen, an Ufern häufig! Juni, Juli. (Off': Flor. et Baccae Sambuci.)

403. S. racemosa $L$. Trauben-H.; Str. 5-12'. BI, geficdert; Blttch. eiförmig-länglich, zugespitzt; Nebenbl. stielartig, warzig; Rispen eiförmig. - Blkr. weiss; Antheren gelb; Beeren eirund, dunkelroth; Mark gelbbraun.

In Wäldern, besonders im Gebirge verbreitet! April, Mai.

404. S. Ebulus $L$. Attich-H., krautartig; Bl. gefledert; Blttch. eilanzettlich; Nebenbl. eiförmig; Trugdolden 3zählig verzweigt. 4. 2-4'. Blkr. weiss; Antheren roth; Beeren kugelig, schwarz. Widerlich riechend.

An Wegen, Ackerrändern, Ufern, in Waldgebüschen, besonders in der Ebene nicht selten und stellenweise gesellig, z. B. am Neckar zwischen $\mathrm{H}$. und Wieblingen! bei Neckarau! Mannheim! Dielheim! Rauenberg! u. s. w. Juli, August. (Off. : Bacoae Ebuli.)

\section{Viburu um $L$. S chlingsirauch.}

405. V. Opulus L. Gemeiner S. (Schneeball); Str. 6-12'; Bl. 3-5lappig; Lappen zugespitzt, gezähnt; Bltstiele drüsig; Trugdolden mit strahlenden, geschlechtslosen Randblumen. - Blth. weiss.

In Wäldern, feuehten Gebüschen, an Ufern, häufig! (Bei der in Gürten oft kultivirten Varietät ( $V$. Opul. $\beta$ roseum) sind alle Blth. strahlend und geschlechtslos und bilden kugelige Trugdolden.) Mai, Juni.

406. V. Lantana $L$. Wolliger S.; Str. 4-10' ; Bl, eiförmig, fein gesägt, besonders unterseits (wie auch an den $\mathrm{Z}$ weigen) sternhaarig-fllzig; Trugdolden etwas convex. - Blkr, weiss.

In Wäldern, an steinigen Bergabhängen, besonders auf Lehmund Kalkhügeln. Im Gebiet der Flora selten; hio und da bei Weinhoim und Nesterbach! im Neckarauer Walde! [Jenseits des Rheines z. B. auf den Kalkhügeln bei Dürkheim sehr verbreitet!] Mai. 
175. Lon icera $L$. Lo nicere.

(c) St. windond; Blthen in quirligen Köpfchen.

407. L. Periclymenum L. Geisblatt; Bl. eirund-länglich, am Grunde frei; Blthküpfchen endständig, gestielt. - Blkr. rothgelb, wohlriechend. t. Variirt kahl und behaart, wio auch:

ß) quercifolia Meyer; mit buchtig eingeschnittenen Blättern.

In Wäldern, Gebüschen, Hecken, besonders im Gebirge an der Bergstrasse! Die Varietät seltener, z. B. im Gorxheimer Thale bei Weinheim. (Bisoh.) Juni-Sept.

408. L. Caprifolium $L$. Ge isblatt; Bl. eirund-länglich, die oberen am Grunde mit einander verwachsen; Blthköpfchen endständig, sitzend; Blkr. weiss oder gelblich roth. ち.

In Wäldern, Hecken. Aus dem südöstl. Europa stammend, aber in den Gebirgswäldern um H. gleichsam eingebürgert, hie und da nicht selten, z. B. oberhalb der Engelswiese! in der Hirschgasso bei H.! am heiligen Berge! bei Weinheim! Schwetzingen (Döll). Juni-Sept.

B) St. nicht windend; Blthen gezweiet.

409. L. Xylosteum $L$. Heckenkirsche; Strauch $4-6^{\prime}$; Bl. elliptisch, weichhaarig; Blthenstiele zottig, die zwei Fruchtknoten am Grunde mit einander verwachsen. Blkr. gelblichweiss.

In Wäldern, Zäunen, an Felsen nicht selten, jedoch nicht allgemein verbreitet. In der Nähe von $H$. nur vereinzelt, etwas häuflger in den Bergwäldern zwischen Dossenheim und Weinheim! bei Nussloch! Mai, Juni.

\section{STELLATAE. $L$.}

Kräuter mit knotig gegliederten, häufig 4 kantigen Stengeln, einfachen, gegenständigen oder wirtelständigen Blättern ohne Nebenblätter, mit vielblüthigen meist sehr zusammengesetzten Blüthenständen. Blüthen meist zwitterig, regelmässig. Kelchröhre mit dem Fruchtknoten verwachsen, mit 4-6ziihnigem oder undeutlichem Saum. Blkr. verwachsenblätterig, meist 4 gliederig. Staubgefässe 4 (selten 3 oder 6 ) der Blumenkrone eingefügt. Fruchtknoten 2fächerigg mit 2 meist etwas verbundenen Griffeln, eineiigen Fächern, aufrechten Eichen. Früchte nussartig oder etwas beerenartig, 2 knotig. Samen 
mit hornartigem Eiweiss und geradem Keim. - Die einheimischen im Habitus sehr übereinstimmenden Arten sind im Florengebiet weit verbreitet, grüsstentheils bodenvag und lieben die mannigfaltigsten Standorte. Die Wurzeln mancher Arten enthalten zuweilen sehr auffallende rothfärbende Stoffe.

Sherardia. Kelchsaum 4-6zähnig; Blkr. trichterförmig, zwei verbundene Nüsse von dem Kelch gekrönt.

Asperula. K. undeutlich; Blkr. trichterförmig, 2 verbundene Nüsse ohne Kelchsaum.

Ga li u m. Blkr. radförmig, sonst wie vorige.

$\mathrm{Rubia.}$ K. undeutlich; Blkr. trichterförmig; 2 verbundene Früchte beerenartig.

I76. Sherardia $L$. Sherardie.

410. S. arvensis $L$. Acker-S.; St. niederliegend od. aufsteigend, vielästig, wie die $\mathrm{Bl}$. meist etwas rauh; Bl. lanzettlich, Blthen in endständigen 4-6blüthigen Köpfchen, mit meist 8blättr. Iülle. ๑. 2-8". Blkr. lila.

Auf Aeckern häuflg! Mai-Okt. Wird von Anfängern leicht mit Asperula arvensis L. verwechselt, unterscheidet sich aber sogleich durch den stets deutlich gezähnten Kelch.

\section{7\%. Asperula $L$. Waldmeister.}

A. arvensis L. Acker-W.; St. aufrecht; Bl. 4-8ständig, lineal-lanzettlich, am Rande scharf; BIthen in endständigen Köpfehen mit gewimperten Deckblättern; Früchte kahl. ๑. $\frac{1}{2}-1^{\prime}$. Blkr. hellblau.

Auf kalkhaltigen Aeckern. - Zwar nach Dierbach's Angabe p. 39 häuflg, aber wahrscheinlich nicht im Florengebiet, sondern auf Kialkboden jenseits Baierthal und Meckesheim.

[N. V. a. d. Geb. mit Sicherheit in Rhb.: zwischen Callstadt und Herxheim; in B.: bei Heidelsheim und Bretten.]

411. A. cynanchica $L$. H üg el-W.; St. niederliegend oder aufsteigend, sehr verzweigt; Bl. 4ständig, lineal; Blthen in Trugdolden mit lanzettlichen zugespitzten Deckbl.; Früchte körnig-rauh. 4. 4-10". Blkr. blassroth.

Auf trockenen, sonnigen Hügeln, Haiden und Sandflächen, in Nadelwäldern verbreitet; stellenweise sehr gesellig, z. B. bei Friedrichsfeld auf Sand! bei Rauenberg auf kalkhaltigem Boden! Auch in der Nähe von H. hinter dem Haarlass! Mai-August.

412. A. galioides Bbrst. Labkrautähnlicher W., graugrün; St. aufsteigend; Bl. 8ständig, lineal, kahl. 4. 1-2'. 
Blkr. weiss, mit sehr kurzer Röhre, den Uebergang zu Galium bildend. (Galium glaucum L.)

Auf sonnigen Hügeln, in lichten Gebirgswäldern nicht häufig. Auf Felsen vor dem Ilaarlass! Im Birkenauer Thal und am Wagenberg bei Weinheim! bei Hemsbach. Einzeln auch am Vitriolberge bei Schriesheim! Juni, Juli.

[Sehr verbreitet jenseits des Rh. auf den Kalkhügeln zwischen Dürkheim und Grünstadt!]

4I3. A. odorata $L$. Wohlriechender (eigentl.) W.; St. aufrecht; Bl. 6-8ständig, eirund-lanzettlich, kahl, am Kiel und an den Rändern borstig scharf; Blthen in Trugdolden; Früchte hakigsteifhaarig. 4. Blkr. weiss, wohlriechend.

In schattigen Laubwäldern, Waldgebüschen sowohl der Ebene als der Gebirge häufig, stets gesellig! Mai. (Off.: Hb. Matrisylvae).

178. Galium $L$. Labkraut.

a) Blïthen in achselständigen Rispen, vielehig, die Gipfelblthe der

Verzweigungen zwitterig, die seitlichen Blthen männlich.

414. G. Cruciata $S c \wedge p$. Kreuz-L.; St. aufstrebend, schwach, 4 kantig, behaart; Bl. 4ständig, elliptisch-länglich, meist 3nervig; Blthstiele nach dem Verblühen zurückgeschlagen; Früchte kahl. 4 . 1-2'. Blkr. grünlichgelb.

Auf Waldwiesen, in Gebüschen, Hecken hie und da. Am Neckarufer zwischen Neuenheim und Ladenburg! bei St. Ilgen! Nussloch! Friedrichsfeld! Weinheim! Schönau! u. s. w. Mai-Juli. b) Blüthen achselständig-rispig, zwitterig; St. rückwärts stacheligscharf; Blkr. weiss.

415. G. tricorne With. Dreihörniges L.; St. etwas niederliegend; Bl. 6-8ständig, lineal-lanzettlich, stachelspitzig, 1nervig, am Rande stachelig-scharf; Blthstiele meist 3 blüthig, nach dem Verblühen zurückgekrümmt; Früchte warzig-körnig. ๑. $1-1_{\frac{1}{2}}^{\prime}$.

Auf kalkhaltigen Aeckern hie und da: Nussloch! Wiesloch! Baierthal! Zwischen Weinheim und Ladenburg! Einzeln bei Handschuchsheim! Mai-Juli.

416. G. Aparine L. Klebkraut; St. aufstrebend, schwach, gleichsam kletternd (mit den scharfen Stacheln anhakend); BI. 6-8ständig, am Rande und Kiel rauh, lineal-lanzettlich, 1nervig; Blthstiele nach dem Verblühen gerade, Früchte hakig-borstig oder kahl. ○. 2-4'. Variirt:

ß) Vaillantii Lois; St. dünner, feinstachelig, an den Kanten kahl; Friichte kleiner. 
Die Hauptform in Zäunen, Gebüschen, an Waldrändern, auch auf Aeckern überall verbreitet! Die Variet. auf kalkhaltigen und lchmigen Aeckern bei Alt-Wiesloch! Baierthal! Rauenberg! Ladenburg u. s. w. Juni-Sept.

417. G. uliginosum L. Morast-L.; St. aufsteigend, schwach; B1. meist 6ständig, lineal-lanzettl.; stachelspitzig, am Rande und Kiele feinstachelig; Blthstiele nach dem Verblühen gerade; Früchte warzigrauh. 4. $\frac{1}{2}-1^{\prime}$. Variirt:

B) glabratum Döll, ; St. und Bl. kahl.

In Gräben, auf sumpfigen Wiesen, an Teichrändern häufig, z. B. am Neckar bei Neuenheim! auf der Engelswiese! beim Rohrhof! Neckarau! Die Var. zwischen Ziegelhausen und der Glashütte (Döll). Juni-Sept.

418. G. palustre L. Sumpf-L.; St. fast niederliegend, endlich aufsteigend; Bl. meist 4ständig, verkehrt-eiförmig, stumpf, am Rande wenig scharf; Blthstiele nach dem Verblühen gerade oder aufrecht-abstehend; Frïchte kahl und glatt. 24. $\frac{1}{2}-\mathbf{1}^{\frac{1}{2}}$.

Auf feuchten Wiesen, in Gräben, Sümpfen, feuchten Gebüschen allgemein verbreitet! Mai-August.

c) Blthen endständig-rispig, zwitterig; St. kahl od. behaart, aber nicht hakig-borstig.

419. G. boreale $L$. Nördliches L.; St. steif aufrecht, 4kantig, kahl oder weichhaarig; Bl.4ständig, lanzettl., 3nervig, am Rande scharf; Blthstiele nach dem Verblühen aufrecht-abstehend; Rispe pyramidal, gedrängt; Früchte steifhaarig oder (bei der Pflanze unserer Gegend häufiger) kahl. 4. 1-1 $\frac{1}{2}^{\prime}$. Blkr. weiss.

Auf Wiesen, Waldtriften hie und da. Beim Relaishause! bei Neckarau! Waghäusel! Ketsch! Handschuchsheim! Zwischen Kirchheim und St. Ilgen (Stud, Gysser).

[Auf den Wiesen der Rheinfläche, auch in der Nähe des Gebietes stellenweise in grosser Menge, z. B. bei Maxdorf 1] Juni-Aug.

420. G. verum $L$. W a hres L.; St. aufrecht, fast stielrund, etwas rauh; Bl. 8-12ständig, lineal ; stachelspitzig, unterseits weichhaarig, am Rande umgerollt; Rispe gedrängt; Bbl. stumpf od. kurz zugespitzt, gelb; Blthstiele nach dem Verblühen wagerecht-abstehend, Früchte glatt. 2. 1-2'.

Auf Wiesen, an Wegen, Waldrändern, besonders der Ebene oft recht gesellig, aber selbst im Gebirge nicht völlig fehlend! Juli, Aug.

421. G. Mollugo L. Weisses I.; St. niederliegend od. aufsteigend, 4kantig, wie die Bl. kahl od. kurzhaarig, Bl. meist 8ständig, lanzettl., oder eiförmig-lanzettlich, stachelspitzig; Rispo reich- 
blüthig, verlängert; Bbl. fein zugespitzt, weiss; Früchte kahl, etw2s runzelig. $4.1-3^{\prime}$.

An Wegen, Hecken, auf Wiesen und in Wäldern häufig! Juni bis August.

Diese Art bildet mit der vorigen eine hybride Pflanze:

G. ochroleucum Wolff (G. vero-Mollugo Schiede), ausgezeichnet durch kantige St., lanzettl., eirunde Bl., weissgelbliche Rispen.

Auf Wiesen beim Relaishause! auf bewaldeten Hügeln bei Rauenberg und Dielheim! Juni, Juli.

422. G. sylvaticum $L$. W ald-L.; St. aufrecht, fast stielrund, wie die Bl. kahl und blaugrün: Bl. meist 8ständig, elliptisch-lanzettl., stumpflich, am Rande wenig rauh; Rispe sehr ausgebreitet; Blthstiele haarfein, vor dem Aufblühen nickend; Früchte kahl, etwas runzelig. 2. 3-4'. Blkr. weiss. Variirt:

B) pubescens DC. St. und Bl. unterseits an den Adern feinhaarig.

In Wäldern und Gebüsclien, sowohl im Gebirge, als in der Ebene häufig! Variet. in trockenen Waldungen, z. B. bei Friedrichsfeld! auf dem Oelberge bei Schriesheim! Juli-Sept.

423. G. saxatile $L$. Felsen-L.; St. niederliegend od. wenig aufstrebend, 4 kantig, kahl, oft dichte Rasen bildend; Bl. 6 ständig, verkehrt-eifürmig, lanzettl., flach, meist kahl; Rispen trugdol-. denartig; Blbl. spitz, weiss; Früchte zugespitzt, dicht kürnig-rauh. 4. 4-10". (G. hercynicum Weig.).

Nur im Gebirge in der Nähe von II., z. B. auf dem Königsstuhl! zwischen Handschuchsheim und Wilhelmsfeld! Juli-Sept.

[N. V. a. d. Geb.: In Hs. : an einzelnen höher gelegenen Punkten des Odenwaldes. - In Rhb.: Haideflächo bei Kaiserslautern!]

424. G. sylvestre Poll. Wildes L.; St. aufsteigend, kahl od. kurzhaarig; Bl. 8ständig, die oberen lineal-keilf., zugespitzt, die unteren verkehrteif.-lanzettlich, am Rande scharf, etwas umgerollt; Rispen trugdoldig; Blbl. spitz, weiss; Früchte stumpf, schwach warzig-runzelig. 24. $3-10^{\prime \prime}$.

In trockenen Wäldern, besonders in Nadelwäldern, auf Haiden, Triften häufg! Juni-Sept.

\section{Rubia $L$. Röthe.}

R. tinotorum L. Färber-R. (Krapp); Bl. 4-6ständig, kurzgestielt, lanzettl., am Rande und Kiele scharf; Blth. achselst, gelb. 4. $2-3$ '. 
Aus dem Orient stammend, hie und da, jedoch im Ganzen ziemalich selten cultivirt! Juli, August. (Off. Rad. Rubiae tinctorum.

\section{VALERIANEAE. D. C.}

Einjährige oder ausdauernde Kräuter mit gegenst. Bl. ohne Nebenbl., und trugdoldigen zwitterigen oder eingeschlechtigen Blthen.Kelch mit dem Fruchtkn. verwachsen, 3-5spaltig, entweder während der Blthezeit eingerollt und später in ein federartiges Krönchen sich ausbreitend, oder kurz und meist unregelmässig gezähnt. Blkrone verwachsenbl., 3-5spaltig, regelm oder unregelm., in der Knospe dachig; Stb.gef. $1-5$, in d. Blkrröhre eingefügt, mit durchaus freien Antheren; Fruchtkn. 3fächerig; 2 Fächer verkümmert und leer; 1 Fach mit 1 hängenden Eichen. Gr. 1. Frucht eine 1samige Nuss (achenium). Same eiweisslos mit geradem Keim. - Vorliebe für theils feuchte und schattige, theils trockene und sonnige Standorte. Ausgezeichnet durch ein flüchtiges Oel, in Verbindung mit einer eigenthümlichen Säure, am reichhaltigsten im Wurzelstock, weniger in den Blth. und Bl. der Valeriana-Arten. Stbgef. 3.

Valerianella. Ksaum gezähnt; Blkr. trichterf., regelmässig;

Valeriana. Ksaum zur Blthzeit eingerollt, später federkronartig; Blkr. trichterf., am Grunde höckerartig; Stbgef. 3.

\section{Valerianella Poll. Feldsalat.}

a) Ksaum undeutlich; Trugdolden gedrängt.

425. V. olitoria Poll. Gemeiner F.; St. aufrecht, kantig, gabelästig; Bl. lanzettlo, die unteren spatelf, ganzrandig oder etwas gezähnt; Früchte kugelig-eirund, etwas zusammengedrückt, kahl od. weichhạarig; Ksaum 3zähnig. ๑. 4-6". Blkr. klein, hellblau.

Auf Feldern, an Wegen, auf Mauern häufig! April, Mai.

426. V. carinata Lois. Gekielter F.; St. aufrecht, rundl., gabelästig; Bl. d. vor.; Frucht fast $4 \mathrm{kantig}$, auf einer Seite mit tiefer Furche; Ksaum 1zähnig. ๑. 4-6". Blkr. d. vor.

Auf Aeckern, an Rainen, in Weinbergen stellenweise sehr verbreitet, besonders in der Nähe von H. beim Haarlass! am Philosophenwege, meist häufger als die vor.! April, Mai. 
乙) Ksaum schiefabgestutzt, unregelmässig gezähnt; Trugdolden mehr ausgebreitet.

427. V. Auricula $D C$. Geöhrter F.; St. aufrecht, kahl od. etwas rauh, unt. Bl. spatelf., obere lanzettl.-lineal, am Grunde ungleich gezähnt od. gelappt; Früchte rundl.-eiförmig, einerseits convex, andererseits gefurcht, d. leeren Fächer grüsser als d. fruchtbare; Ksaum 4-5zähnig. ○. $\frac{3}{4}-1^{\prime}$. Blkr. hellblau.

Auf kalkhaltigen und lehmigen Aeckern, Brachfeldern der Ebene nicht selten; besonders häufig zwischen Handschuchsheim und Ladenburg! beim Relaishause! bei Nussloch! Wiesloch! Juni, Juli.

428. V. dentata Poll. Gozähnter F.; St, aufrecht, fast 4 kantig, schärflich; Bl. d. vor., die oberen am Grunde eingeschnitten sägezähnig, Früchto eiförmig, meist kahl, vorn convex, hinten fast flach, die leeren Fächer kleiner als das fruchtbare; Ksaum feingezähnelt. ๑. $\frac{3}{4}-\mathbf{1}^{\prime}$. Blkr. hellblau.

B) lasiocarpa; Früchte rauhhaarig (V. Morisonii Koch).

Unter dem Getreide, auf Aeckern ziomlich allgemein verbreitet! Die Variet. sehr selten auf trockenen, kalkhaltigen Acckern, z. B. bei Baierthal. Juni-August.

\section{Valeriana $L$. Baldrian.}

a) Blthen alle zwitterig.

429. V. officinalis $L$. Heilkräftiger B.; St. aufrecht, gefurcht, BI. 4-11 paarig gefiedert; Blttch. lanzettl., gezähnt od. ganzrandig; Früchte kahl. 2. Blkr. weisslichroth. - Variirt:

c) minor Koch. Wstck. mit kurzen unterirdischen Ausläufern; Wfasern rübenartig verdickt; Blttch. linealisch. Pfl. in allen Theilen kleiner. St. 1-2'.

B) major Koch. Wstck. d. vor.; Wfasern wenig verdickt; Blttch. lanzettl. - Pfl. in allen Theilen grösser. St. 3-4'.

$\gamma$ ) exaltata Mik. Wstck. ohne Ausläufer; Wfasern wenig verdickt; Blttch. lanzettl; St. 5-6'.

In feuchten Wäldern, auf feuchten Wiesen Var. $\beta$ häuflg! Auf trockenen Wiesen, an Rainen, Gräben Var. $\alpha$ ebenfalls, besonders in der Ebeno verbreitet. - Dio Var. $\gamma$ nur vereinzelt an sumpfigen Waldstellen, in feuchten Gebüschen, z. B. hinter Ziegelhausen am Neckarufer! bei der Bergheimer Mühle! Juni bis August. Var $\boldsymbol{\alpha}$ blüht 14 Tage früher als $\beta$ und $\gamma$. (Off. Rad. Valerianae minoris). 
b) Blthen dioecisch.

430. V. dioica $L$. Kleiner B.; St. einfach, mit kurzen Auslïufern; Wbl. eirund, langgestielt; Stbl. leyerf.-flederspaltig. 4. Blkr. blassroth; Stbgefblthen beträchtlich grösser, in lockeren Trauben; Pistillblth. in sehr gedrängten Trugdolden. $\frac{1}{2}-1^{\prime}$.

In und an Gräben, auf feuchten Wiesen, an sumpfigen Waldstellen häufig! April, Mai.

\section{DIPSACEAE. DC.}

Kräuter mit gegenständigen ganzen oder fiedertheiligen Blättern ohne Nebenbl. Blthen auf einem gemeinschaftlichen Bltithenboden, meist durch besondere Deckbl. (Spreubltt.) getrennt, in endständigen, von einer mehrbl. Hülle umgebenen Köpfchen, K. gleichsam doppelt, bleibend; der äussere als Hülle die Frucht innig umschlıessend, der innere (eigentliche K.) mit dem Fruchtknoten verwachsend und sich nach Oben $\mathrm{zu}$ einem häutigen oder borstigen Saum entwickelnd. Blkr. verwachsenbl., dem Saume des inneren Kelches eingesetzt, 4-5gliederig, regelmässig oder unregelm., an den Randblth. meist strahlend. Stbgef. 4 mit freien Antheren. Fruchtkn. 1 fächerig mit 1 hängenden Eichen und 1 Griffel. Frucht nussartig (achenium). Same eiweisshaltig mit geradem Keim. - Im Habitus der folg. Familie sehr nahestehend.

Dipsacus. Blthboden mit Spreubl.; Hüllbl. das Köpfchen meist überragend; äusserer Kelch $4 \mathrm{kantig}$, innerer mit beckenf., gezähntem od. ganzrandigem Saum.

Knautia. Blthboden rauhhaarig; Hüllbl. kürzer als das Küpfchen; äusserer K. glatt, innerer pfriemlich, 8zähnig.

Scabiosa. Blthboden spreubl, ; Hüllbl, kürzer als das Köpfchen; äusserer K. 8furchig, mit krautigem Saum; innerer K. 5borstig.

Succisa. Blthboden spreubl.; Hüllbl. kürzer als das Köpfchen; äusserer K. 8furchig, mit krautigem Saum; innerer K. 5borstig.

181. D ipsacus $L$. Karde.

431. D. sylvestris $L$. Wilde K. (Eselsdistel); St. stachelig; B1. sitzend, am Grunde verwachsen, gezähnt oder fiederspaltig, am Rande mehr oder weniger stachelig; Blthk. gross, eiförmig, mit ge- 
raden, grannenartigen die Blthen überragenden Spreubl. 犬. 2-4'. Blkr. blass violett.

An Wegen, Gräben, Waldrändern, auf Triften häufig, bald einzeln, bald heerdenweise! Juli-Sept.

432. D. laciniatus $L$. Geschlitzte K.; St. stachelig; Bl. sitzend, am Grunde verwachsen, tief-fiederspaltig, am Rando borstig-gewimpert; Blthk. gross, eiförmig, mit geraden grannenartigen die Blthen überragenden Spreubl. $\hat{\delta}$. 2-4'. Blkr. weisslich.

An Wegen, Rainen, auf Triften, selten und vereinzelt, z. B. sporadisch bei Ketsch! hie und da beim Kirschgartshäuser Hof zwischen Mannheim und Sandhofen! (Der von Dierb. angegebene Standort (Neckarsteinach) sehr zweifelhaft. Juli-Sept.

[Jenseits des Rheins häufiger, in Rhb. bei Altripp, Frankenthal und Roxheim! in Rhh. bei Oppenheim die Nordgrenze für das Rheingebiet erreichend.]

433. D. pilosus $L$. B eli a a r to K.; St. steifhaarig-stachelig; Bl. gestielt, elliptisch-rundlich, am Grunde mit Anhängseln; Blthk. kugelig, mit borstig-gewimperten, geraden Spreubl. §. 2-3'. Blkr. weisslich.

In Wäldern, Gebüschen, an Zäunen hio und da! Auf dem Heiligenberge bei H.! bei Schatthausen! am Rhein zw. Neckarau und Mannheim! Waghäusel (König). Juli, August.

$[N$. V. a. d. Geb. In B.: Bretten, Carlsruhe (Döll), in Hs.: Auerbacher Schlossruine (Schntsp.), in Rhb.: in der Nähe des Geb. fehlend. - Zweibrücken $(F$. Soh. .).

\section{Kn a uti a Coult. In a uti e.}

434. K. arvensis Coult. A cker-K.; St. rauhhaarig; unt. BI. länglich-verkebrteirund, spitz, ganzrandig oder eingeschnitten, obero fiederspaltig-leyerf.; Blthk. schwachgewölbt. 4. 1 $^{\frac{1}{2}}$. Blkr. hellblau. (Scabiosa arvensis L.)

Auf Wiesen, auf Aeekern, an Wegen häufig! Juni-Sept.

435. K. sylvatica Dub. Wald-K.; St. unten steifhaarig, oben weichlaarig, alle BI, ungetheilt, elliptisch-lanzettl, gekerbt od. am Grunde eingeschnitten gesägt; Blthk. schwachgewölbt. 4. 2'. Blkr. hellblau. (Scabiosa sylvatica. L.).

In Gebirgswäldern hie und $\mathrm{da}$, besonders bei $\mathrm{H}$. diesseits und jenseits des Neckars! Längs der Bergstrasse stellenweise häufg, z. B. bei Weinheim! Juli-Sept.

153. S cabiosa $R$. et $S$. $S \mathrm{kab}$ ios e.

436. S. Columbarla $L$. Gemeine S.; St. oberwärts fein- 
haarig; untere $\mathrm{Bl}$. ungetheilt, lejerf., obere tief eingeschnitten; Borsten des inneren K. 3-4länger als der Saum des äusseren, schwärzlich; Blthk. flachgewölbt. 4. $\frac{1}{2}-2$ '. Blkr. blau.

Auf Wiesen, Haiden, Sandflächen, an Wegen häufig! Juni bis August.

437. S. suaveolens Desf. Wohlriechonde S.; St. und Bl. meist grauhaarig, selten fast kahl, grundst. Bl. lanzettl.-spatelf., ganzrandig, obere fiederspaltig; Borsten des inneren K. fast $2 \mathrm{mal}$ so lang als d. Saum des äusseren, gelblich; Blthk. d. vor., aber kleiner. 4. 1-1 $\frac{1}{2}$. Blkr. hellblau, wohlriechend. Variirt:

ß) subpinnatifida Döll; grundst. Bl. eingeschnitten-gesägt oder fiederspaltig.

Auf Sandflächen, am Rande von Nadelwäldern zwischen Friedrichsfeld-Waghäusel! bei Walldorf! Sandhausen nicht selten! Hie und da auch auf trockenen Hügeln, z. B. bei Wiesloch! Rauenberg! Nussloch! Die Variet. beim Relaishause (Döll). Juli-Okt.

184. Suc e is a $M$. et $K$. Te u fel s a b b iss.

438. S. pratensis Mönch. Wiesen-T.; St. kahl; Bl. länglich-lanzettlich, in den Bltstiel verschmälert, ganzrandig oder gezähnt; Blthk. halbkugelig. 4. 1-2'. Wstck. abgebissen. Blkr. blau, seltener weiss. (Scabiosa Succisa L.).

Auf feuchten Wiesen, Haiden, an Gräben häufig! Aug.-Okt.

\section{COMPOSITAE. Adans.}

Einjährige oder ausdauernde Kräuter (bei uns niemals Sträucher), mit meist abwechselnden, selten gegenstïndigen, einfachen od. häufiger mannigfach zusammengesetzten Blättern ohne Nebenblätter. Blüthen zwitterig, eingeschlechtig oder völlig geschlechtslos, meist in grösserer Zahl einem mehr oder weniger flachen, gewölbten oder kegelförmigen Blüthenboden (anthoclinium) eingefügt, von einer gemeinsamen, meist dachigen Hülle (Hüllkelch) umgeben (Blüthenköpfchen od. Blüthenkörbchen) (calathidium). Blüthenboden entweder mit borstlichen, lanzettlichen oder zerschlitzten Deckblättchen (Spreublätter) besetzt, oder ohne dieselben. (Im ersteren Falle heisst d. Blthboden spreublätterig, im letzteren nackt), Blthköpfchen 
einzeln oder verschieden gruppirt. Kelch oberständig mit dem Frucktknoten verwachsen, der Saum (sog. Pappus) verschieden, häufig aus einfachen oder gefiederten Haaren bestehend (P. haarig od. fiederig), seltener aus kurzen Schuppen gebildet (P. spreuig oder randhäutig), sehr selten ganz fehlend. Blkrone verwachsenblätterig, 5gliederig, röhrenförmig oder zungenförmig, seltener unregelmässig lippenartig. Stbgefässe 5, Stbf. meist frei, seltener verbunden. Antheren miteinander zu einer den Griffel umschliessenden Röhre verwachsen, am Grunde stumpf od. verlängert (geschwänzt), gelb oder violett. Fruchtknoten 1 fächerig, 1eiig, mit meist 2 gabeligem Griffel. Frucht eine 1samige Nuss (Achene). Samen eiweisslos mit geradem Keim. - Die vom ersten Frühlinge bis zum Spätherbst blühend auftretende Familie nimmt nicht nur hinsichtlich ihrer zahlreichen Arten, sondern auch durch das häufig sehr gesellige Auftreten einen grossen Theil der krautartigen Vegetation ein. Die Compositae sind artenreicher in den Ebenen, herrschen aber an Individuen auch im Gebirge stellenweise sehr vor. Wenige lieben beständige Feuchtigkeit des Bodens, daher die eigentlichen Sumpfgegenden des Gebietes verhältnissmässig arm an Compositae sind, was noch auffallender sein würde, wenn jene Gegenden nicht fast immer mit sandigen und kieshaltigen Triften abwechseln, woselbst wenigstens manche Arten einen hohen Grad von Geselligkeit erreichen. Die meisten sind bodenvag oder sandhold, wenige kalk- oder sandstet. - Es herrschen bittere Extractivstoffe vor, welche nicht sselten, besonders bei den Tubulifl, in Verbindung mit äthorischen Oelen und manchen eigenthümlichen Stoffen auch mehrere der einheimischen Arten pharmaceutisch bemerkenswerth machen. Das Vorhandensein eines harzigen, zuweilen giftigen Milchsaftes ist für die Abtheilung der Cichoriaceae bezeichnend.*)

\section{A. Tubuliflorae.}

(Blüthen des Blthköpfchens meist verschieden, die der Scheibe [od. des Mittelfeldes] röhrig, zwitterig, des Randes zungenförmig, weiblich oder geschlechtslos; seltener alle Blthen röhrig.)

Trib. 1. Eupatoriaceae. Griffelgabeln stumpf od, keulenf., ge-

-) Obwohl die vorherrschend gelb blühenden Compositae durch die Eigenthümlichkeit ihres Blüthenstandes, durch die ver- 
wöhnlich vorlängert, an der Aussenseite weichhaarig. Papp. unserer Gattungen haarig.

Eupatorium. Hk. dachig; Köpfchen armblth; Blth, alle röhrig, zwitterig.

Tussilago. Hk. 1reihig; Randblth. mehrreihig, zungenf.; Scheibenbl, röhrig, zwitterig.

Petasites. Hk. 1reihig; Blthk. fast dioecisch, bald mehr männl., bald mehr weibl.; Randblth. zungenf., in d. männl. Blthk. 1reihig, in d. weibl. mehrreihig.

Trib. 2. Asteroideae. Griffelgabeln in den Zwitterblth flachlineal, oberwärts gleichförmig fein behaart, zur Blthezeit gegeneinander geneigt. Pappus unserer Gattungen (mit Ausnahme von Bellis) haarig. Randblth. (wenn vorhanden) zungenf., weibl.; Scheibenbl. zwitterig.

wachsenen Antheren eine auffallende Uebereinstimmung zeigen, werden sie doch zuweilen mit äusserlich ähnlichen Pflanzen, z. B. Dipsaceae, Jasione, Eryngium u. s. w. verwechselt. Die Schwierigkeit beim Aufsuchen der Gattungen besteht besonders darin, dass die meistens sehr zusammengedrängten Blüthen oft äusserst klein erscheinen, und die Charaktere der Gattungen von scheinbar sehr geringfügigen Merkmalen hergenommen werden mussten. - Es orfordert daher das Studium dieser Pflanzen einige Uebung, und wird jedenfalls dadurch sehr erleichtert, wenn für die ersten Untersuchungen grössere, ausgebildetere Blthk. gewählt werden, wie sich solche z. B. im Frühling in Taraxaoum, Arnica, Tragopogon, später in Cirsium, Carduus u. s. w. darbieten. Auch ist vor allen Dingen zunächst die praktische Anwendung der Linné'schen Classifikation (Syngenesia) sehr zu empfehlen. Der Anfänger wird für seine Untersuchung zweckmässig solche Blthk. auswählen, deren Blüthen vollständig geöfinet sind, um sich von dem Vorhandensein oder Fehlen der Antheren, von der Bedeutung der röhren- oder zungenförmigen Blkrone zu überzeugen. Die geschwänzten Antheren (häufig sehr kurz und undeutlich) werden $u$. A. recht deutlich bei Inula beobachtet. Für die Bestimmung des Pappus wähle man Blthk., deren Blkronen schon verwelkt sind, und um zu sehen, ob derselbe flederig oder haarig, lasse man einige Augenblicke die Feuchtigkeit der Luft darauf einwirken. Das Vorhandensein oder Fehlen der Spreublättchen ist leicht nachzuweisen, wenn nur mit einiger Vorsicht die Blüthen durch Auszupfen entfernt werden. 
a) Antheren am Grunde ungeschwänzt.

nen zusammengedrückt.

Chry s o coma. Hk. dachig; Blth. alle röhrig, zwitterig; Ache-

A ster. Hk. dachig; Randblth. 1reihig, zungenf., weibl. verschiedenfarbig (nie gelb); Scheibenblth. röhrig, zwitterig, Achenen zusammengedrückt.

Sten actis. Hk. 2reihig; Randblth. 1reihig, zungenf., weibl., weiss; Scheibenblth. u. Achen. d. vor. Papp. d. Randblth. kurzhaarig, d. Scheibe von verschiedener Länge.

Erigeron. Hk. dachig; Randblth. mehrreihig, zungenf., weibl.; Scheibenblth. röhrig, zwitterig; Achen. zusammengedrückt.

Solidag o. Wie Aster, aber alle Blth. gelb und Achen. walzenf. Bellis. Hk. 2reihig; Randblth. 1reihig, weibl.; Scheibenblth. röhrig, zwitterig; Papp. 0. Achen. zusammengedrückt.

b) Antheren am Grunde geschwänzt, d. h. mit sehr feinen Anhängseln.

In ula. Hk. dachig; Randblth. zungenf., weibl. (bei J. Conjza fast röhrig); Scheibenblth. röhrig, zwitterig ; Papp. gleichartig, haarig.

Pulicaria. Wie Inula, aber Papp. ungleichartig, d. innere langhaarig, d. äussere ein kurzes gezähntes Krönchen.

Trib. 3. Senecionideae. Griffelgabeln der $\mathrm{Z}$ witterblüthen lineal, pinselig-behaart, an der Spitze abgestutzt oder in einen kegelf. Fortsatz ausgehend.

\section{a) Pappus haarig.}

๙) Hk. dachig; Antheren geschwänzt.

Filag 0. Blthk. 5kantig; Randblth. mehrreihig, weibl., fädlich; Scheibenblth. zwitterig, 4zähnig; Blthboden șpreubl.

Gn a pha li um. Blthk. halbkugelig od. walzig; Hk. trockenliäutig; Randblth. d. vor.; Scheibenblth. 5zähnig; Blthboden kahl.

Helichrysum. Wie Gnaphalium, aber Randblth. 1reihig, spärlich.

$\beta$ ) Hk, 1-2reihig; Antheren ungeschwänzt; Randblth. zungenf,, weibl.; Scheibenblth. röhrig, zwitterig.

D o r on i cum. Blthk. flach od. halbkugelig; Hk. 2reihig; Griffel gabeln an der Spitze abgestutzt.

A rnica. Blthk. walzig; Hk. 2reihig; Griffelgabeln an der Spitze kegelig verdickt.

Cineraria. Blthk, halbkugelig; Hk, 1reihig; Griffelgabeln an d. Spitze abgestutzt-kopfförmig.

S e necio. Blthk. walzig od. eiförmig; Hk. 1reihig, am Grunde mit aussenkelchartigen kürzeren Hüllbl, G Griffelgabeln wie vor. 
b) Pappus nicht haarig; Antheren immer ungeschwänzt.

a) Blthboden spreublätterig.

Galinsoga. Blthk. halbkugelig, armblth.; IIk. 2reihig; Papp. gefranzt-spreublättefig; Randbth. unfruchtbar.

Bidens. Blthk. walzig; Hk. 2reihig; Papp. aus $2-5$ widerhakigen Grannen gebildet (Blth. meist alle röhrig, zwitterig, seltener d. Randblth. zungenf., geschlechtslos).

Achillea. Blthk. eiförmig; Randblth. verkehrteiförmig, weiblich; Hk. dachig; Papp. sehr kurz, randhäutig, dio zusammengedrückten Achenen bekrönend.

Anthemis. Blthk. halbkugelig od. flach; Randblth. länglich, weiblich; Papp. sehr kurz, randhäutig, die walzenf. Achenen bekrönend.

B) Blthboden nackt.

a) Weibl. Randblth. deutlich zungenf.

Matricaria. Hk. dachig; Blthboden innen hohl, kegelf.; Pappus kurz, randhäutig.

Chrysanthemum. Wio Matricaria; aber Blthboden flach od. schwach convex (innen nicht hohl).

b) Weibl. Randblth. fädlich od, völlig fehlend.

Artemisia. Blthk. kugelig od. eiförmig, in Rispen; Hk. dachig; Papp. sehr kurz, kaum vortretend.

Tanacetum. Blthk. halbkugelig, in Doldentrauben; Hk. dachig; Papp. kurz, randhäutig.

Trib. 4. Cynareac. Griffel der Zwitterblüthen unterhalb der Gabeltheilung knotenartig verdickt, behaart.

a) Randblüthen zungenförmig, weibl., fruchtbar; Scheibenblth. röhrig, zwitterig, aber unfruchtbar. (Polygam. necessaria)

Calendula. Achenen sehr verschieden gestaltet, gebogen oder lineal.

b) Randblüthen trichterförmig, geschlechtslos; Scheibenblüthen röhrig, zwitterig. (Polygam. frustranea)

Centaurea. Hk. dachig; Blthboden spreuig-borstig; Pappus haarig. Achenen am Grunde mit einer seitlichen Schwiele.

c) Blüthen alle röhrig, zwitterig (auch bei Centaurea nigra L.)

$\alpha$. Blthboden spreuig-borstig; Hk. dachig.

Serratula. Antheren ungeschwänzt; Pappus haarig, am Grundo nicht verbunden; Achenen zusammengedrückt.

Jurinea. Antheren kurz geschwänzt; Pappus haarig, am Grunde durch einen Ring verbunden; Achenen 4kantig. 
L a p a. Hkbl. an der Spitze hakig-gekrümmt; Antheren kurz geschwänzt; Pappus haarig, am Grunde nicht verbunden.

Cirsium. Antheren kurz geschwänzt; Pappus gefledert, durch einen Ring verbunden; Achenen länglich-zusammengedrückt.

Carduus. Wie Cirsium, aber Pappus harig, am Grunde durch einen Ring verbunden.

Silybum. Antheren ungeschwänzt; Stbfäden 1brüderig, übrigens wie Carduus.

$\beta$. Blthboden bienenwabig; Hk. dachig.

Onopordon. Uebrigens wie Cirsium.

$\boldsymbol{\gamma}$. Blthboden spreublätterig; Hk. dachig.

Carlina. Die inneren $\mathrm{Hkbl}$. strahlbildend und trockenhäutig; Pappus gefledert, ästig, am Grunde verbunden.

B) Ligulaeflorae.

(Blth. alle zungenförmig, zwitterig.)

Trib. 5. Cichoriaceae. Griffelgabeln fädlich, etwas zurückgebogen, weichhaarig. Alle Milchsaft führend.

a) Pappus schuppenförmig, undeutlich oder fehlend.

Lapsana. Hk. 1reihig, am Grunde mit sog. Aussenhülle; Blthk. walzig; Achenen zusammengedrückt; ohne Pappus.

Arnoseris. Hk. 1reihig, mit Aussenhülle; Blthk. kugelig; Achenen etwas kantig, mit sehr verkürztem, randförmigem Pappus.

Cichorium. Hk. 2reihig; Pappus kurz, schuppig.

b) Pappus federig, entweder bei allen oder nur bei den Blth. der Scheibe.

1) Hk. dachig; Blthboden nackt; Pappus-Strahlen frei.

Picris. Pap. abfällig; P. d. Scheibblth. federig, der Randblth. haarförmig; Achenen kurz geschnäbelt.

Thrincia. Pap. bleibend; P.d. Scheibblth. federig; der Randblth. kurz, kronenförmig; Achenen langgeschnäbelt.

Leontodon. Pap. bleibend; entweder alle federig oder an d. Randblth. haarförmig, kürzer; Achenen kurz geschnäbelt.

2) Blthboden etwas schuppig; Pappus-Strahlen verwebt.

Tragop ogon. Hk. 1reihig; Achenen langgeschnäbelt.

Scorzonera. Hk. dachig; Achenen länglich, kurz geschnäbelt, am Grunde mit einer kurzen Schwiele.

Podospermum. Hk. dachig; Achenen eiförmig, abgestutzt, kurz geschnäbelt, am Grunde mit einer stark verdickten Schwiele.

3) Blthboden mit abfälligen Spreublättchen.

H y pochaeris. Hk, dachig; Achenen alle oder nur die der Scheibe geschnäbelt. 
o) Pappus haarig; Blthboden nackt.

1) Achenen am Grunde des Schnabels schuppig.

Taraxacum. Blthk. reichblüthig; Hk. doppelt, der äussero zurückgebogen; Achenen stumpf $4 \mathrm{kantig}$, langgeschnäbelt, am Grundo des Schnabels knorpelig-schuppig.

Chondrilla. Blthk. 7-12blth.; Hk. doppelt, der äussere kurzblätterig; Achenen stielrund, langgeschnäbelt, am Grunde des Schnabels kurzstachelig und mit 5 knorpeligen Schüppchen besetzt.

2) Achenen ohne Schuppen.

$\alpha$. Achenen zusammengedrückt.

Lactuca: Hk. dachig; Blthk. 5-vielblüthig; Achenen geschnäbelt.

Sonchus. Hk, dachig; Blthk. vielblüthig; Achenen ungeschnäbelt.

Prenanthes. Hk. 8blätterig, fast dachig; Blthk. 2-5blüthig; Achenen ungeschnäbelt.

$\beta$. Achenen stielrund.

Crepis. Blthk. reichblth.; Hk. mit kurzem Aussenkelch; Achenen ungeschnäbelt oder geschnäbelt, immer nach oben etwas verschmälert; Pappus meist rein weiss und biegsam.

Hieracium. Blthk, reichblth.; Hk. meist ohne Aussenkelch; Achenen ungeschnäbelt und fast üborall gleich breit; Pappus zerbrechlich, schmutzig-weiss.

\section{E u p a tori um $L$. W a s serh a nf.}

439. B. cannabinum $L$. Gemeiner W.; St. aufrecht; BI. gestielt, 3-6theilig, mit lanzettl.-gesägten Zipfeln; Blth. klein, in dichten Doldentrauben. 4. 2-3'. Blth. fleischroth.

An Bächen, Teichen, in Gräben und Sümpfen häuflg, hie und da, z. B. bei Waghäusel ungemein gesellig! Juli-September.

\section{Tussilago $L$. Huflat ig.}

440. T. Farfara $L$. Gemeiner H.; Bl. grundständig, herzförmig-rundl., buchtig-gezähnt, unterseits weissfilz.; Blthstiel schuppig; Blthk. walzig, einzeln. 4. $\frac{1}{2}-1^{\prime}$. Wzst. verlängert, kriechend; Blth. gelb (früher als d. Bl. erscheinend).

An Wegen, Ufern, auf Aeckern, besonders auf Lehmboden sehr verbreitet! März, April. (Off.: Rad. et hb. Farfarae.) 


\section{8\%. Petasites Gaertn. Pestwurzel.}

441. P. officinalis Moench. Gemeine P.; Bl. grundst., herzförmig, ungleich gezähnt, unterseits graufilzig; Blthst. schuppig; Blthk. walzig, zahlreich, einen eiförmig-länglichen Strauss bildend. 4. Blth. blassröthlich; Wzst. stark, fast knollenartig. - Bl. durch Grösse auffallend, entwickeln sich nach der Blth.

Man kann unterscheiden:

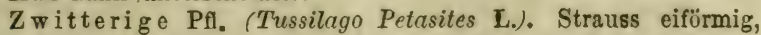
gedrängt; Blth. meist Zwitter, aber unfruchtbar.

Weibliche Pfl. (Tussilago hybrida L.). Strauss länger, locker, fast alle Blth. weiblich.

An Flussufern, Gräben, auf feuchten Wiesen, in beiderlei Formen nicht selten. In der Nähe v. H., z. B. beim Stift Neuburg! am Neckar bei der Bergheimer Mühle! Schlierbach! u.s. w. März, April.

185. Chrysocoma $L$. Goldhaar.

442. Ch. Linosyris $L$. Deutsches G.; St. einfach, dichtbeblättert; Bl. linealisch, scharf gezähnt, kahl; Hkbl. sperrig-abstehend; Blthk. doldentraubig. 4. $1 \frac{1}{2}-2^{\prime}$. Blth. gelb. (Linosyris vulgaris Cass.)

Auf sonnigen Hügeln, an steinigen, trockenen Abhängen sehr selten und vereinzelt an der Grenze des Geb. zwischen Weinheim und Hemsbach. Nach Dierb. auch zwischen Neckarau und dem Rohrhofe. August-October.

[N. V. a. d. Geb. in Hs.: Heppenheim, Zwingenberg (Schntsp.) In B. fehlend bis Offenburg (Döll). In Rhb. Haardtgebirge : Deidesheim, Dürkheim! sporadisch bei Ellerstadt $(F$. Sch ).]

\section{Aster $L$. Sternblume.}

443. A. Amellus L. Virgil's St.; Bl. elliptisch-lanzettlich, etwas gesägt, schärflich-kurzhaarig, 3nervig; Blthk. doldentraubig; Hkbl. länglich, etwas abstehend. 4. 1-1 $1_{\frac{1}{2}}$. Randblth. violett.

Auf sonnigen Hügeln, Bergwiesen, Triften hie und da. In der Nähe von $\mathbf{H}$. stellenweise an den Abhängen vom Haarlass bis gegen d. Stift Neuburg! Häufig bei Weinheim! Leutershausen! einzeln in d. Hillenbach bei Handschuchsheim (Stud. Gysser) verbreitet auch bei Rauenberg! Dielheim! seltener bei Schatthausen (im sog. Vogelheerd)! Nussloch! Leimen! August-October.

444. A. salignus Willd. Weidenbl. S.; St. fast kahl; Bl. lanzettlich, am Grunde verschmälert, fast ganzrandig, oberseits rauh; Blthk. doldentraubig-rispig; Hkbl. lanzettlich, abstehend. 4. 2-4', Randblth. weisslich lilla. 
Hie und da am Neckarufer auf Steingeröll und zwischen Weiden, z. B. auf der Insel bei der Bergheimer Mühle! bei Schlierbach! August, September.

445. A. parviflorus Nees. Kleinblth S.; St. weichharig; Bl. lanzettlich, halb stengelumfassend, gesägt, scharf; Blthk. klein, doldentraubig-rispig; Hkbl. linealisch, angedrückt. 4. 1-2 $\frac{1}{2}^{\prime}$. Randblüthen weiss-röthlich.

Stammt aus Nord-Amerika, hat sich abcr schon seit langer Zeit an den Ufern des Nechars und des Rheines gleichsam eingebürgert. Am Neckar bei der Bergheimer Mühle, bei Feudenheim, Neuenheim, Neckargemünd nicht selten! August-October.

[Es sind noch einige andere nordamerikanische Arten am Neckarufer, unfern $\mathrm{H}$. gefunden, aber immer vereinzelt und unter Umständen, welche die Abstammung aus dem benachbarten botanischen Garten als sicher betrachten lassen. Die Aufzählung dieser keineswegs eingebürgerten Pfl, kann unterbleiben.]

\section{Stenact is Cass. Schmalstrahl.}

446. S. bellidiflora $A l$. $B r$. Gänseblth. S.; untere Bl. verkehrt-eiförmig, obere lanzettf., etwas rauh; Blthk. doldentraubig; Ilkbl. rauhhaarig. 犬. $1 \frac{1}{2}-2^{\prime}$. Randblth. weiss. (Aster annuus L.)

Ursprïnglich aus Nord-Amerika eingewandert, jetzt völlig eingebürgert und an Wegen, Waldrändern, in Steinbrüchen, auf Sandflächen und Triften häufig, jedoch nicht überall. Hinter dem Haarlass! bei Neuenheim! Ziegelhausen! bei Handschuchsheim! auf dem Geisberge! am Wege nach dem Speyrer Hof! bei Nussloch! Schatthausen! Weit verbreiteter und meist gesellig in der Ebene bei Friedrichsfeld! Schwetzingen! Sandhausen! zwischen Mannheim und Sandtorf! Juni-August.

\section{Erigeron $L$. Berufkraut.}

447. E. canadensis $L$. C a na di s $\mathrm{ch}$ es B.; St. aufrecht, dicht beblättert; Bl. lineal-lanzettl., kurzhaarig, borstig-gewimpert, die unteren gesägt; Blthk, klein in verlängerten Rispen. ๑. $1-2 \frac{1{ }^{\prime}}{}$. Sehr kurze Randblth. gelblich-weiss.

Auf Sandfeldern, Mauern, Triften, an Wegen, Waldrändern, ursprünglich aus Canada stammend, jetzt eingebürgert und überall, besonders in der Friedrichsfelder Gegend häufig! Juli-Oktober.

448. E. acris $L$. S charfes B.; St, aufrecht oder aufsteigend; Bl. spatelf. oder lineal-lanzettl., rauhhaarig, borstig gewimpert; Blthk. doldentraubig. $\hat{\delta}-4$. $\frac{1}{2}-1^{\prime}$. Randblth. deutlich, röthlich. Die sehr auffallenden Pappushaare bald röthlich-braun, bald schmutzig weiss. 
- Variirt mit schwächerer oder stärkerer Behaarung, schmäleren oder breiteren Bl., grösseren oder kleineren Blthk.

An Flussufern, Wegen, in Nadelwäldern, auf Sandflächen häufig! Mai-September.

\section{Solidago $L$. Gold $\mathrm{r}$ u the.}

449. S. Virga aurea $L$. Ge meine G.; Bl. eirund-lanzettl., in den geflügelten Blstiel verschmälert, behaart; Blthk, rispig-traubig. 4. $\frac{1}{4}-1 \frac{1}{2}^{\prime}$. Blkr. gelb.

An Waldrändern, auf Waldwiesen, in Gebüschen allgemein verbreitet! August-October.

\section{Bellis $L$. Gänseblü $\mathrm{mchen}$.}

450. B. perennis $L$. A usdauerndes G.; St. verkürzt; B1. grundst., rosettenartig, verkehrt-eirund-spatelförmig, gekerbt, behaart ; Blthk. einzeln; Hbl. lanzettl., stumpf. 4. Randblth. weiss od. roth. Auf Wiesen, Grasplätzen, an Wegen überall sehr häufig! Februar-November.

\section{In ula $L$. Al ant.}

a) Achenen kahl.

451. I. salicina $L$. Weidenbl. A.; St. einfach, 1- oder seltener mehrküpfig, wie die Bl. meist kahl; Bl. länglich-lanzettlich, kurz zugespitzt, fein gezähnt, die mittleren und oberen halbstengelumfassend, etwas bogig zurückgekrümmt; Hkbl. gewimpert. 4. 1$1 \frac{1}{2}^{\prime}$. Blth. gelb.

In feuchten Gebüschen, auf Wiesen, in Wäldern. Vom Haarlass hie und da durch das Gebirge bis Schriesheim und Weinheim! z. B. am Oelberge bei S. und in der Hillenbach bei Handschuchsheim! diesseits des Neckars im Dreitröge-Thal! und durch das Gebirge bis Leimen! Maischbach! Schatthausen! Wiesloch! Dielheim! jedoch immer nur stellenweise. - In grösserer Verbreitung auf den Wiesen der Rheinebene, z. B. beim Relaishause, bei Neckarau! Juli, August.

[I. hirta $L$. B $\ominus$ haarter A. St. einfach, 1köpfig, wie die BI. rauhhaarig; Bl. länglich-lanzettl., kaum gezähnelt; Hkbl. steifhaarig. 4. $\frac{1}{2}-1^{\prime}$. Blth. gelb.

N. V. a. d. Geb. in Rhb. auf trockenen Hügeln bei Leistadt und Kallstadt! In Hs. an der Bergstrasse von Jugenheim bis Hepponheim (Schntsp.). Juni, Juli.]

[I. germanica $L$. Deutscher A.; Bl. länglich, spitz, fast ganzrandig, unterseits wollig-feinhaarig, die mittleren und oberen 
mit herzförmigem Grunde; Blthk, doldentraubig, gedrängt. 4. 11!2'. Randblth. gelb, kaum länger als d. Scheibenblth.

N. V. a. d. Geb, an Abhängen, in Gebtischen in Rhb. hie und da zwischen Dürkheim und Callstadt! - Grünstadt ( $F$. Sch.). In Rhh.: Oppenheim - Bingen (Schntsp.) Juni, Juli.]

b) Achenen rauhhaarig.

452. I. britannica $L$. Brit tischer A.; St. 1-mehrköpfig, wie die Bl. seidenartig-zottig; Bl. länglich-lanzettl., entfernt gezähnt, die unteren in den Blstiel verschmälert, dio oberen halb stengelumfassend; Hkbl. lineal-lanzettl. 4. 1-1 $\frac{1}{2}^{\prime}$. Randblth. gelb, bisweilen theilweise verkümmert.

An Flussufern, Gräben, auf feuchten Wiesen hie und da, z. B. häufig am Neckarufer von Neuenheim bis Ladenburg und Feudenheim! Stellenweise auf feuchten Wiesen der Rheinfläche: Neckarau! Brühl! Alt-Lussheim! Waghäusel! Viel seltener oder fehlend in der Gegend von Weinheim und Wiesloch. Juli-September.

453. 1. Conyza I.C. Ge meiner A.; St. ästig; Bl. elliptischlanzettl., gezähnelt, unterseits weichhaarig, die unteren in d. Blstiel verschmälert, dic oberen sitzend; Blthk. doldentraubig-gedrängt; Randblth. fast röhrig, sehr kurz, die Scheibe kaum überragend, weissgelblich. 4. 2-3'. (Conyza squarrosa L.)

In lichten Wäldern, an Rainen und Waldrändern sowohl im Gebirge als in der Ebene nicht selten! August-October.

[Die Bl. werden zuweilen mit den Bl. der Digitalis purpurea verwechselt, welche aber am Rande gekerbt und unterseits graufllzig sind.]

\section{Pulicaria Gaertn. Flöhkraut.}

454. P. vulgaris Gaertn, Gemeines F.; St. wie die Bl. zottig; Bl. länglich, stengelumfassend, wellig; Blthk. klein, fast kugelig, rispig-doldentraubig; Randblth. sehr kurz, gelb; äusserer Pappus zerschlitzt. 4. $\frac{1}{3}-1^{\prime}$. (Inula Pulicaria L.)

An Ufern, auf feuchten Triften, in Sümpfen hie und da, z. B. stellenweise in Menge längs des Neckars von Neuenheim bis Ladenburg! seltener bei Ziegelhausen und Schlierbach! In manchen Dörfern sehr gesellig, z. B. Kirchheim! Neckarau! In der Nähe des Rheines verbreitet! Juli-September.

455. P. dysenterica Gaertn. Ruhr-F.; St. wie d. Bl. unterseits weissflzig; Bl. länglich mit herzf. Grunde stengelumfassend, entfernt gezähnelt; Blthk. doldentraubig, seltener einzeln; Randblth. die Scheibe beträchtlich überragend, gelb; äusserer Pappus feingekerbt. 4. $1-1 \frac{1}{2}^{\prime}$. (Inula dysenterica L.) 
An Gräben, in feuchten Gebüschen und Sümpfen fast überall verbreitet! Juli-September.

\section{Vilago $L$. Filzkraut.}

456. F. germanica $L$. Deu ts ch es F., filzig-wollig; St. niederliegend oder aufrecht, mehr oder weniger gabeltheilig-ästig; Bl. lanzettlich oder lanzettl.-spatelf.; Blthk. zahlreich, gabel- oder endständig geknäuelt; Hkbl. mit langer, kahler Stachelspitze. ๑. $\frac{1}{4}-3_{4}^{\prime \prime}$. Blthk. klein, gelblich oder röthlich. - Variirt:

$\beta$ ) pyramidata; mit einfachen, steif-aufrechten, an der Spitze wenig gabeltheil. St.

Auf Aeckern, trockenen Hügeln, an Wegen, auch im Vorgebirge nicht selten. In der Nähe von II. besonders häufig im DreitrögeThal! auf Aeckern zwischen Stift Neuburg und Ziegelhausen! In grösserer Verbreitung auf Sandfeldern und Brachaeckern der Ebene, woselbst auch hio und da die Varietät! Juli-September.

457. F. arvensis $L$. A cker-F., wollig-zottig; St. aufrecht, rispig; Bl. länglich-lanzettl.; Blthk. ziemlich locker, knäuelartig, endund gabelst.; Hkbl. lanzettl., stumpf, ganz wollig. ๑. $\frac{1}{2}-1^{\prime}$.

Auf Sandfeldern, trockenen Hügeln, an Wegen besonders in der Ebene häufig, doch auch im Gebirge hie und da, z. B. oft recht gesellig gegen Dossenheim und Schönau!

458. F. minima Fries. Kleinstes F., grauflzig; St. aufrecht, gabeltheilig-ästig; Bl. lineal-lanzettl., angedrückt; Blthk. endund gabelständig, einzeln oder zu 2-3; Hkbl. lanzettlich, stumpf,

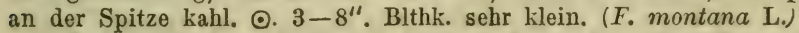

Auf Sandfeldern, Haiden, an Wegen sowohl in der Ebene als im Gebirge häufig, hie und da ganze Strecken heerdenweise überziehend. (Bei Malsch zeigt die sandstete Pflanze den Beginn des rothen Sandsteines!) Juli-September.

\section{9\%. Guaphalium $L$. Ruhrkraut.}

459. G. sylvaticum $L$. Wald-R.; St. einfach, steif-aufrecht, weissfilzig; Bl. lineal-lanzettl., unterseits weissfilzig, oberseits fast kahl; Blthk, zahlreich, aehrenf.; Hkbl. grün, an der Spitze und am Rande trockenhäutig, braun. 24. ${ }_{4}^{3}-1 \frac{1}{2}$. Blth. weiss. (G.rectum Sm.)

In lichten Wäldern, auf Waldtriften, Haiden und Sandfeldern im Gebirge und in der Ebene verbreitet! Juli-September.

460. G. uliginosum $L$. Schla mm-R.; St. ausgebreitet-ästig, seltener einfach, weisswollig; Bl. lineal. oder spatelf.-lineal., weissgrau; Blthk. knäuelartig, beblättert; Hkbl. bräunlich, an der Spitze trockenhäutig, kahl. $0.4-8^{\prime \prime}$. 
Auf etwas feuchten Aeckern, an Teichrändern, in Sümpfen, häufig! Juli-September.

461. G. luteo-album $I$. Gelblich-weisses R.; St, einfach oder etwas ästig, wie d. Bl. grauwollig; Bl. lineal-lanzettl., halb stengelumfassend, die unteren spatelf.; Blthk. in endständigen, nicht beblätterten Knäueln; Hkbl. glänzend, gelblich-weiss; Blth. röthlich. ๑. $\frac{3}{4}-1^{\prime}$.

Auf Sandfächen, feuchten Haiden stellenweise und vereinzeit, nicht nur in den Ebenen, z. B. bei Friedrichsfeld! Sandtorf! sondern auch im Gebirge, z. B. oberhalb Rohrbach! zwischen Ziegelhausen und Schönau! zwischen Handschuchsheim und Dossenheim! beim Speyrer Hof (Stud. Gysser). Juli-September.

462. G. dioicum $L$. $Z$ weihäusiges R.; St. einfach, mit briechenden Ausläufern; grundst. Bl. spatelf., oberseits fast kahl, unterseits weissfilzig; Blthköpfchen endst., doldentraubig, dioecisch, die männlichen länger $u$. dünner; Hkbl. und Blth. weiss oder rosa. 4-8". (Antennaria dioica $\mathrm{R} . \mathrm{Br}$ )

Auf Haiden, Sandfeldern, in trockenen Wäldern der Ebene und der Gebirge häufig! Mai, Juni.

\section{Il e li chry s um Gaertn. S on nengold.}

463. H. arenarium De Cand. S and-S.; St. einfach, wie die Bl. weissfllzig; Bl. eiförmig-lanzettl.; Blthk. kugelig, doldentraubig; Hkbl. und Blth. citronengelb, seltener orange oder purpurroth. 4 . $\mathbf{1}^{\prime}$. (Gnaphalium arenarium L.)

Auf Sandflächen des Gebietes stellenweise in Mengo! JuliSeptember.

\section{[Doronicum $L$. Gemswurz.]}

[D. Pardalianches $L$. Gemeine G.; St. und Bl. rauhhaarig, B1. eirund, gezähnt, grundst. tief herzf., obere stengelumfassend, 4. $1-1 \frac{1^{\prime}}{2}$. Wzst. kriechend, knollig. Blth. gelb.

In Gebirgswäldern. N. V. a. d. Geb. in Hs.: Nordwestseite des Melibocus (Schntsp.). In Rhb. Haardtgebirge: auf dem Drachenfels zwischen Wachenheim und Frankenstein (Dr. Koch). Mai, Juni.

\section{Arnica $L$. Wohlverleih.}

464. A. montana $L$. Berg-W.; St. aufrecht 1-3küpfig, etwas drüsenhaarig; grundst. Bl. längl.-verkehrt-eirund, ganzrandig, etwas lederartig, obere gegenst., lanzettl.; Hk, drüsig-behaart. 4 . $1-1 \frac{1}{2}^{\prime}$. Blthk, ansehnlich; Blth, pomeranzengelb oder hellgelb. 
Auf Triften und Wiesen im Gebirge hie und da; auch in der Ebene auf torfhaltigen Haiden und Waldwiesen. In Menge bei $\mathrm{H}$. in der Wolfsschlucht und am Geisberge! weniger häufig im Mühlenthale und in der Hillenbach bei Handschuchsheim! stellenweise zwischen Dossenheim und Wilhelmsfeld! (und durch den Odenwald). In der Ebene des Geb.: Schwetzingen (Döll), Ketsch ( $F$. Sch.) [Auch jenseits des Rheines hie und da in der Ebene, z. B. Speyer, Hasloch (Dr. Walæ); zwischen Dürkheim u. Lambsheim! jedoch vorherrschend erst bei Kaiserslautern! Im Haardtgebirge ähnlich verbreitet wie im diesseitigen Gebirge, d. h. nur stellenweise, z. B. im Odinsthale bei Wachenheim!] Mai, Juni. (Off.: Rad. hb. et flores Arnicae.)

\section{Cineraria $L$. Aschenpflanze.}

465. C. spathulaefolia Gmel. Spatelbl. A.; St. aufrecht, weissflockig behaart; Bl. oberseits spinnwebig-flockig, unterseits weisswollig, untere eiförmig in den breitgeflügelten Blttst, verlaufend, obere lanzettl.; Blthk. locker doldentraubig; Hk. wollig; Achenen steifhaarig. 4. 1-2'. Blth. gelb. (Senecio spathulaefolius Less.).

Auf Bergtriften, in liohten Gebirgswäldern selten. Am Oelberge, daselbst am Abhange gegen Schriesheim ziemlich verbreitet! Bei Leutershausen und Weinheim ( Wal $)$. Ehemals auch oberhalb des Riesensteins ( $D \ddot{b l l}$ ), woselbst gegenwärtig verschwunden oder nur sehr vereinzelt. Mai.

[Westl. Grenze einer Verbreitungslinie rom Mainthal durch den Odenwald z. B. Mosbach. In Rhh. O. In Rhb. n. V. bei Forst (hinter der Almel auf Pechstein) (C. H. Schultz)].

\section{Senecio $L$. Kreuzkraut.}

a) Randblth. meist fehlend.

466. S. vulgaris $L$. Gemeines K.; flockig behaart oder kahl; Bl. buchtig-fiederspaltig, d. oberen stengelumfassend; Blthk. in endst. Doldentrauben, äussere Hkschuppen sehr kurz, an der Spitze schwarz; Achenen seidenhaarig. ๑. $\frac{1}{2}-1^{\prime}$. Blth. gelb.

Auf Acckern, in Gärten, an Wegen überall sehr gemein! April bis Novembor.

B) Randblth. zungenf., kurz, etwas zurückgerollt, gelb.

467. S. viscosus L. Klebriges K.; St. oberwärts, nebst Bl. und Hk. drüsig-klebrig-behaart; Bl. buchtig-flederspaltig, halb stengel-umfassend; Doldentraube endst.; äussere Hkschuppen lineal., an der Spitze schwarz; Achenen kahl. ○. $\frac{3}{4}-1^{\prime}$.

Auf Sandfeldern, Triften, an Waldrändern in der Ebeno und im Gebirge stellenweise häufig! Juni-September. 
468. S. sylvaticus $L$. Wald-K.; St. schlank; Bl. buchtiggezähnt oder fiederspaltig; Bl. spinnwebig-behaart; Doldentrauben endst., locker; äussere Hkschuppen sehr kurz, grün; Achenen graubehaart. $\odot .1-2^{\prime}$.

Auf Sandboden in lichten Wäldern, an Waldrändern meist sehr gesellig, z. B. im Friedrichsfelder Walde! im Gebirge diesseits und jenseits des Neckars um H.! Juli, August.

$\gamma$ ) Randblth. zungenf., flach ausgebreitet, gelb; Bl. fiederartig eingeschnitten, kahl oder mit abfälliger Wolle.

469. S. erucifolius $L$. Senfblättr. K.; Br. flederspaltig, am Grunde mit stengelumfassenden, ganzrandigen Läppchen, kahl werdend; Blthk. in doldentraubigen Rispen; äussere Hkschuppen zahlreich, halb so lang als die inneren; Achenen scharfhaarig. 4. $2-4^{\prime}$. Wzst. kriechend.

An Wegen, Gräben, in Gebüschen, an Ufern häufig! JuniSeptember.

470. S. Jacobaea $L$. Jakobs K, ; untere Bl. gestielt, leyerförmig-fiederspaltig, obere fiedertheilig, am Grunde mit stengelumfassenden, vieltheiligen Iäppchen, meist kahl; Blthk. in doldentr. Rispen; äussere Hkschuppen wenige, sehr kurz; Achenen der Scheibo scharfhaarig, des Randes kahl;") Wzst. abgebissen. 4. 1-2'.

An Wegen, auf Wiesen, Schutthaufen verbreitet! Juni-Septbr.

471. S. aquaticus Huds. Wasser-K.; untere Bl. gestielt, ungetheilt oder leyerf.-gezähnt, obere leyerfo-eingeschnitten, am Grunde mit stengelumfassenden, vieltheiligen Läppchen, meist kahl; Blthk, in ausgebreiteten, abstehenden, lockeren Doldentrauben; äussere Hkschuppen sehr kurz; Achenen des vor. 4. 1-2'. Wzst. abgebissen. (S. Jacobaea variet. Poll; S. barbareaefolius Krock; S. erraticus Bert.)

Auf feuchten Wiesen der Ebene, z. B. läufig in der Nähe des Rheines! stellenweise auch bei St. Ilgen! Wiesloch! Kirchheim! Roth! Handschuchsheim! Juli-September.

ס) Randblth. zungenf., flach ausgebreitet, gelb; Bl. ungetheilt.

472. S. nemorensis $I_{s}$. Hain-K.; Bl. elliptisch-lanzettlich, ungleich gesägt; Sägezähne mit gerader Spitze, unterseits kahl oder weichhaarig; Blthk. zahlreich in endst. Doldentrauben; Hkschuppen 3-5, so lang als der Hk.; Randblth. 5-8; Achenen kahl. 4. $1 \frac{1}{2}-3^{\prime}$. Sehr veränderlich, Variirt $u$. A. als :

$\beta$. Fuchsii Gmel.; Bl. schmäler, mit sehr ungleichen Sägezähnen; Randblth. stets 5 .

•) Variirt mit fehlenden Randblth. 
In Wäldern der Gebirge und der Ebene stellenweise. Im Gebiete der Fl., sowie in der Näho desselben tritt nur die Var, auf. Häufig zwischen Ziegelhausen und Schönạu! und durch das Gebirge hie und da, z. B. an der Engelswiese! auf dem heiligen Berge! bis Schriesheim und Weinheim! Verbreitet auch auf dem Königsstuhl! und gegen Neckargemünd! Gaiberg! Schatthausen! Vereinzelt bei Rauenberg! Seltener im Friedrichsfelder Walde! Juli-September.

473. S. paludosus $L$. Sump f-K.; Bl. sitzend, verlängertlanzettf., zugespitzt, scharf gesägt, unterseits weissfilzig, seltener fast kahl ; Blthk. ansehnlich in doldentraubigen Rispen; Randblth. 12-14; Achenen feinhaarig. 2. $3-6^{\prime}$.

Auf nassen Wiesen, in feuchten Gebüschen dor Rheinebene, z. B. in Nenge bei Neckarau! und längs des Rheines beim Relaishause! beim Rohrhofe! Ketsch! Mannheim! [Häufig jenseits des Rheines bei Speyer! und zwischen Oggersheim und Maxdorf!] Juni bis August.

\section{Galinsogea $R$. et $P$. Galinsoge.}

474. G. parviflora Cav. Kleinblumige G., fast kahl; St. aufrecht, 3theilig-ästig; Bl. gegenst., eirund, gezähnt-gesägt; Blthk. kaum erlosengross; Randblth. weiss. $\odot: \frac{3}{4}-1^{\prime}$.

Aus Peru stammend. Auch bei uns, wio in manchen andern Floragebieten Deutschlands verwildert und in schneller Verbreitung begriffen. Auf Aeckern und an Wegen zwischen Schriesheim und Leutershausen völlig eingebürgert! Juli-August.

\section{Bi llens $L$. Z $\mathrm{z}$ eizahn.}

475. B. tripartita $L$. D Deitheiliger Z., fast kahl, dunkelgrün; Bl. gegenst., 3-5theilig, mit lanzettl., gesägten Zipfeln; Blthk. aufrecht; Achenen verkehrt-ciförmig, rückwärtsstachelig. ๑. $\frac{1}{3}-1 \frac{1}{2}$. Blth. gelb; meist olıne Randblth.

In Sümpfen, an Gräben, Ufern nicht selten, besonders am Nockarufer und in den Sumpfgegenden des Geb. verbreitet! Juli September.

476. B. cernua $L_{\text {. }}$ Ni ckender Z., fast kahl, lebhaft grün; 13l. gegenst, ungetheilt, lanzettl, gesägt, am Grunde etwas verbunden; 13lthk. nickend; Achenen verkehrt-eiförmig-keilig, rückwärtsstachelig. $\odot . ~ \frac{1}{2}-1 \frac{1}{2}^{\prime}$. Blth. gelb, meist mit, selton ohne Randblth. Variirt:

a) Coreopsis; St. 2-3', mit grösseren Blthk, und verlängerten Randblth. (Coreopsis Bidens L.)

ß) minima; St. 2-4", einfach, mit 1 kloinen Blthk, (Bid. minima L.) 
In Sümpfen und torfhaltigen Gräben, an Teichrändern, weniger verbreitet als vor., z. B. in den Sumpfgegenden des Geb. I ziemlich häufig $\mathrm{zwischen} \mathrm{Ladenburg} \mathrm{und} \mathrm{Weinheim;} \mathrm{bei} \mathrm{Kirchheim!} \mathrm{u.} \mathrm{s.} \mathrm{w.}$ Die Var. $\alpha$ (eine der ansehnlichsten Pflanzen unserer Flora) beim Rohrhofe! bei Sandtorf! Var. $\beta$ meist mit der gewöhnlichen Form zusammen in den Torfgräben bei Waghäusel! Sandtorf! bei Neckarau! beim sog. rothen Loch, unfern Friedrichsfeld! Juli-October.

\section{A chillea $L$. Scha a garbe.}

477. A. Ptarmica $L$. Wiesen-Bertram; St. einfach, steif aufrecht, dichtbeblättert; Bl. lineal-lanzettl, scharfgesägt, kahl; Blthk.

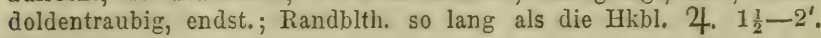
Blth. weiss.

Auf Wiesen, feuchten Triften, in Gräben, an Ufern hie und da, besonders am Neckarufer! Auch im Klingenthal bei H.l bei Handschuchsheim! St. Ilgen! u. s. w. An den Rheindämmen zuweilen heerdenweise! Juni-August. (Off.: Rad. Ptarmicae.)

478. A. Millefolium $L$. Ge me ine S.; St. aufrecht; Bl. lanzettlich, 2fach-fiederspaltig, mit 2-5spaltigen Zipfeln, Mittelrippe (Spindel) breit, fast ungezähnt oder nur an der Spitze gezähnt; Blthk. zahlreich, klein, doldentraubig; Randblth. halb so lang als der Hk. 4. 5" $-3^{\prime}$. Blth. weiss oder röthlich.

$\mathrm{BI}$. in Zertheilung und Behaarung sehr veränderlich. Besondere Beachtung verdient:

$\beta$. setacea Koch, wollig-rauhhaarig; St. 5-6" ; Blttzipfel lineal-borstenförmig; Blthk. sehr gedrängt, etwas kleiner; Randblth. gelblich-weiss.

(Diese Var. kann leicht mit der folg. Art verwechselt werden!)

Auf Wiesen, an Waldrändern, Wegen, auf Triften die Hauptform sehr häufig! Die Var. auf sehr trocknen Sandnächen, z. B. beim Relaishause! bei Sandhausen! auf dürren, trockenen oder steinigen Hügeln, z. B. im Ludwigsthal bei Schricsheim! bei Alt-Wiesloch! Juni-September.

479. A. nobilis $L$. Edle S.; St. aufrecht; Bl. im Umfange eiförmig, doppelt-fiederspaltig, mit linealen, gesägten Zipfeln; Spindel schmal, von der Mitte bis zur Spitze gezähnt; Blthküpfchen gedrängt, doldentraubig; Randblth, so lang als die Irülle, weiss-gelblich. 2. $\frac{1}{2}-\frac{3}{4}$. Wohlriechend.

Auf sonnigen, trockenen IIïgeln, im Gebiet der Flora nur zwischen Rauenberg und Rodenberg auf Keuper-Mergel! Juni; Juli. - $[\mathrm{N}$. V. a. d. Geb. in B.: Bruchsal! Ober-Grombach. Jenseits des Rheines von Neustadt-Dürkheim! - Grünstadt, und durch Rhl. verbreitet!] 


\section{Anthemis $L$. Kamille.}

480. A: tinctoria $L$. $\mathrm{F}$ ärber-K.; St. aufrecht, ästig, wie die Bl. weichhaarig; Bl. doppelt fiederspaltig, Zipfel gesägt; Blth.hoden schwach gewölbt; Spreublttch. lanzettl., stachelspitzig; Achenen 4 kantig-zusammengedrückt, gestreift. 4. Randblth. gelb.

Auf Sandfeldern, trockenen Kalkhügeln, auf Mauern und Brachaeckern stellenweise häufig, z. B. zwischen If. und Schwetzíngen! Friedrichsfeld! Hockenheim! am Neckar bei Neuenheim! Ladenburg! längs der Bergstrasse nicht selten, z. B. Dossenheim! unterhalb der Strahlenburg bei Schriesheim! Weinheim! In grösserer Verbreitung bei Rauenberg! Wiesloch! Maischbach! Juni-August.

481. A. arvensis L. Acker-K.; St. niederliegend oder aufsteigend, ästig, wie die Bl. graufllzig; Bl. doppelt fiederspaltig: Zipfel lineal-lanzettl., weichstachelig; Blthboden verlängert-kegelförmig; Spreublttch. lanzettl., stachelspitzig; Achenen stumpf, 4-kantig, glatt. $\odot . \frac{1}{2}-1^{\prime}$. Hkschuppen bräunlich-berandet; Randblth. weiss. Aromatischer Geruch.

Auf Aeckern, Triften, an Wegen überall häufig! Juni-Septbr.

482. A. Cotula L. Hunds-K. ; St. aufsteigend, ästig, wio die Bl. kahl oder schwach behaart, hellgrün; Bl. doppelt fiedersp.; Zipfel lineal, pfriemlich; Blthboden verlängert-kegelförmig: Spreublttch. lineal, borstlich; Achenen walzenf., körnig-gestreift. $\odot . \frac{1}{2}-1^{\prime}$. IIkschuppen weiss-berandet; Randblth. Weiss. Widerlicher Geruch.

Auf Brachaeckern, Schutthaufen, Triften hic und da, aber seltoner als vorige. In der Nähe v. H., z. B. bei der Bergheimer Mühle! bei Neuenheim! Wieblingen! hie und da am Neckar! Juli-August.

A. nobilis $L$. Edle oder $\mathrm{r} \ddot{\mathrm{m}}$ is $\mathrm{che} \mathrm{K}$; St. aufsteigend, wie die Bl. meist weichhaarig; Bl. gefiedert; Fiederchen vielspaltig; Blthboden verlängert-kegelförmig; Spreubl. länglich, an der Spitze trockenhäutig, ausgebissen-gezähnelt. $4 \cdot \frac{1}{2}-1^{\prime}$.

Stammt aus dem südlichen Europa; in Gärten auch mit gefüllter Blthk. cultivirt; verwildert bisweilen. Juli-September. (Off.: Flores Chamomillae romanae.)

\section{Matricaria $L$. Mutterkraut.}

483. M. Chamomilla $L$. A ech te Kamille; St. doldentr.-ästig; Bi. doppelt-fiedertheilig, mit fädlichen Zipfeln, kahl; Blthboden kegelförmig, innen hohl. ๑. 1'. Randblth, weiss, zuletzt zurückgeschlagen. Aromatischer Geruch. (Chamomilla vulgaris Trag.

Auf Aeckern, Brachfeldern, an Wegen häuffg! Mai - August. (Off, : Flores Chamomillae.) 
20\%. Chrysanthemum $L$. Wu cherblume.

a) Randblth. weiss.

484. Ch. Leucanthemum $L$. Wo is se W.; St. einfach, untere Bl. langgestielt, verkehrt-ei-spatelf, obere sitzend lineal-länglich, gesägt; Blthk. einzeln, ansehnlich; Achenen walzenf., ungeflïgelt. 4. $1-1 \frac{1}{2}^{\prime}$. Variirt kahl und behaart.

Âu Wiesen, an Waldrändern, Wegen sehr verbreitet! Juni,Juli.

485. Ch. corymbosum $L$. Doldentraubige W.; St. ästig, meist behaart; Bl. gefiedert: Fiedern der unteren Bl. fiederspaltig, mit scharfgesägten Zipfeln; Blthküpfchen doldentraubig; Ranłlblth. elliptisch; Achenen kantig, ungeflügelt. 4. 2-3'. (Pyretlırum e, (1)rymbosum Willd.)

In Gebirgswäldern hio und da. Im Dreitröge Thal! hinter dem Haarlass! oberhalb der Engelswiese! Längs der Bergstrasse verbreitet, z. B. bei Weinheim! Oelberg bei Schriesheim! Hillenbach boi Handschuchsheim! Auch auf dem Königsstuhl und von dort bis Schatthausen! Dielheim! Rauenberg! Nussloch! Juni, Juli.

486. Ch. Parthenium Pers. Mutterkraut-W.; St. ästig; Bl. weichhaarig, gefiedert; Fiederchen länglich, flederspaltig, stumpf; Blthk. doldentraubig; Randblth. verkehrt-eiförmig; Achenen kantig, ungeflügelt. 4. 1-2'. (Matricaria Parthenium L.)

Stammt aus dem südlichen Europa, wird häufig in Gärten angepflanzt und findet sich zuweilen verwildert, z. B. am Neckarufer: auf dem Riesenstein bei H.I bei Neckarsteinach! Neuenheim! Ladenburg! u. s. w. Juni, Juli. (Off,: Hb. et Flor. Matricariae.)

487. Ch. inodorum $L$. Geruchlose W.; St. meist ausgebreitet, ästig, mit wenigen Blthk., wie die Bl. kahl; Bl. 2-3fachflederspaltig, mit linealen, fädlichen Zipfeln; Randblth. lineal-längl.; Achenen $4 \mathrm{kantig}$, ungeflügelt. $\odot . \frac{1}{2}-1 \frac{1}{4}^{\prime}$. Geruchlos. Blthboden halbkugelig, aber innen nicht hohl! Uebrigens äusserlich der Matricaria Chamomilla L. sehr ähnlich. (Pyrethrum inodorum Sm.; Tripleurospermum inodorum C. H. Sch. Bip.)

Auf Aeckern, Schutthaufen, an Wegen häufig, oft sehr gescllig: Juli-September.

\section{b) Randblth. gelb.}

488. Ch. segetum L. Saat-W.; St. ästig, wie die Bl. kahl; etwas blaugrün; Bl. länglich, eingeschnitten-gezähnt, vorn breiter, die oberen stengelumfassend; Blthköpfchen einzeln; Hkschuppen trockenhäutig; Achenen der Randblth. 3kantig, der Scheibenblth fast stielrund, $\odot .1-2^{\prime}$. 
Auf Acckern, an Wegen. Das in manchen Gegenden Doutschlands so lästige Unkraut findet sich im Gebiete der Flora nur sehr vereinzelt. Zwischen Schwetzingen und dem Relaishause wurde im September 1855 oin Exemplar von Dr. Schimper gefunden. Es scheint ausserdem die Pfl, auch in früheren Jahren in unserer Gegend nur sporadisch und sehr selten wahrgenommen zu sein. Juli bis August.

[In der Nähe des Gebietes entweder fehlend, wio in B., oder schr selten, wie in Rhb., z. B. bei Speier ( $F$. Sch.), Dürkheim, Maxdorf! und in Hs. bei Darmstadt (Schnttsp.). Allgemeine und lästige Verbreitung zunächst in Nassau (Fuckel), und in Oberhessen!]

\section{Artemisia $L$. Be if uss.}

489. A. Absinthium $L$. Wermuth; St. oben rispig-ästig; Bl. 2-3fach- fiederspaltig, mit lanzettl., stumpfen Zipfeln, seidenhaarig-grau; Blthköpfchen fast kugelig, nickend; Blthboden zottig. 4. $1-2^{\prime}$. Blth. hellgelb.

Auf trockenen Triften, in Dörfern nicht häufig, z. B. in Schwetzingen! Neckarau! Ketsch! Malsch! Juli-September. (Off.: Hb. et Summitates Absinthii.)

490. A. campestris $L$. Feld-B.; St, aufsteigend, ruthenfürmig-rispig; Bl. 2-3fach fiederspaltig, mit linealen, stachelspitzigen Zipfeln, kahl oder weissgrau-seidenhaarig; Blthk. eiförmig, aufrecht, später nickend, kahl; Blthboden kahl. 24. 1-1 $\frac{1}{2}$.

Auf Sandflächen, Haiden, trockenen Hügeln häuflg. Die seidenhaarige Form auf sehr dürren Sandfeldern und Hügeln, z. B. bei Friedrichsfeld! Schwetzingen! Sandhausen! bei Schriesheim! August bis October.

491. A. vulgaris $L$. Gemeiner B.; St. oben rispig-ästig; Bl. fiederspaltig, mit lanzettl., eingeschnittenen, zugespitzten Zipfeln, unterseits weissfilzig, nben kahl; Blthk. eiförmig, aufrecht-abstehend, graufilzig, Blthboden kahl. 24. 2-4'. Blth. braunroth.

An Wegen, Ufern, in Waldgebüschen, Hecken liberall verbreitet! Juli-September. (Off.: Rad. hb. et flor. Artemisiae.)

\section{Ta nacetum $L$. R a infarn.}

492. T. vulgare $L$. Wurm-R.; St. steif-aufrecht; Bl. doppelt fiederspaltig, mit gesägten Zipfeln, kahl; Blthk. doldentraubig. 4. $1 \frac{1}{2}-2 \frac{1}{2}^{\prime}$. Blth, gelb.

An Wegen, Ufern, Waldrändern, auf Triften häufig! Juli-September. (Off.: Hb. Tanaceti.) 


\section{Calendula $L$. Ringel blume.}

C. officinalis $L$. Gebrä u chl. R.; Bl. länglich verkehrt-eifürmig, entfernt gezähnelt, etwas klebrig, weichhaarig; Blthk. cinzeln, ansehnlich; Achenen meistens kahnfürmig, geflügelt, auf dem Rüchen glatt oder weichstachelig. $\odot .1-1 \frac{1}{2}^{\prime}$. Randblth. safrangelb.

Aus Süd-Europa stammend, häufig in Gärten cultivirt, und auf Schutthaufen, an Wegen verwildernd! Juli - September, /Off.: Hb. et flor. Calendulae.)

[C. arvensis $L$. Acker-R., aufsteigend, ästig; Bl. länglichlanzettl., entfernt gezähnelt, otwas klebrig weichlıarig; Blthk, einzeln, um die Hälfte kleiner als bei d. vor.; Achenen meist lineal., die inneren auf dem Rücken weichstachelig. ๑. Randblth. hellgelb.

Auf Aeckern und in Weinbergen jenseits des Rheines b. Forst! Dürkheim! Ungstein etc. häufig! Im Gebiet der Flora fehlend! Juni-August.]

\section{Centaurea $L$. Flockenblume.}

a) Hkbl. dornenlos, mit einem mehr oder weniger trockenhäutigen, ganzrandigen oder wimperig zertheilten Anhängsel; Blthk. meist einzeln, kugelig-eiförmig.

493. C. Jacea $L$. Gemeine Fl.; St. aufsteigend, einfach oder ästig; Bl. länglich, die oberen lineal, ungetheilt, buchtig oder flederspaltig; Anhängsel der Hkbl. gewölbt, rundlich, ganzrandig od. zerschlitzt; Pappus fehlt. 4. 1-2 $\frac{1^{\prime}}{2}$. Blth. hellruth. Variirt bald kahl, bald dünnfilzig weissgrau, mit breiteren und schmäleren Bl., mit dunkler oder heller braungefärbten Hkbl. - Besonders auffallend sind:

๔) lacera Koch; Anhängsel der Hkbl. meistens zerschlitzt und gewimpert, nur die oberen fast ganzrandig.

$\beta$ ) pratensis Koch; äussere Anhängsel der Hkbl. spitz, verlängert, kammartig gewimpert, etwas zurückgekrümmt.

Auf Wiesen, an Wegen, Waldrändern, auf Triften häufig! Die Var. $\alpha$ nicht selten mit der gewöhnlichen Form, die Var. $\beta$ selten auf trockenen Triften, z. B. Nussloch u. Maischbach! Juni-Septbr.

494. C. nigra $L$. S $\mathrm{Shw}$ a rze Fl.; rauh, untere Bl. länglichelliptisch, buchtig-flederspaltig od. gesägt, die oberen lanzettlich, fast ganzrandig; Anhängsel der Hkbl. lanzettl., aufrecht, gefiedert-gervimpert, Wimpern borstig, schwarz; geschlechtslose Randblth. fehlen; Papp. sehr kurz. 4. $1 \frac{1}{2}-2 \frac{1^{\prime}}{2}$.

In Wäldern der Gebirge und der Ebene, auf feuchtem thonhaltigem Boden. Aut den Bergen diesseits und jeuseits des Neckars, 
bei II. nicht selten! Gegen Wilhelmsfeld und Schönau häuffger als gegen Schriesheim und Weinheim! Verbreitet in den Wäldern zwischen Dielheim! Schatthausen und Maischbach! - Häufig im Friedrichsfelder Walde, bei Schwetzingen! Ketsch! Walldorf! im Käferthaler Walde! Juli, August.

495. C. montana $L$. Berg-Fl.; St. wie d. Bl. meist spinnwebig-grau behaart; Bl. längl.-lanzettlich, fast ganzrandig, die oberen herablaufend; Hkbl. breit schwarzberandet, wimperig-gesägt; Papp. kurz. 4. $1-1_{\frac{1}{2}}{ }^{\prime}$. Randblth. gross, blau, Scheibenblth. violett.

In Gebirgswäldern nicht häufig. Hie und da am Königsstuhl bei II., z. B. 'gegen den Kohlhof und Neckargemünd! vereinzelt auch in der Nähe der Molkenkur! bei Rohrbach! Auf dem Gipfel des Oelberges bei Schriesheim (Stud. Gysser). Auf dem Wagenberg bei Weinheim! Mai, Juni.

496. C. Cyanus $L$. Kornblume; St. schlank, ästig wie d. Bl. dünnwollig behaart; Bl. lineal-lanzettl., die unteren am Grundo fiederspaltig; Hkb. schmal schwarzberandet, wimperig-gesägt. Papp. kurz. ๑. 2-3'. Randblth. blau.

Unter dem Getreide, besonders unter Roggen sehr verbreitet! Juni-August. (Off.: Flores Cyani).

497. C. Scabiosa $I_{\text {. }}$ Sk a bio s e n-Fl.; St. ästig, fast kahl; Bl. schärflich, 1-2fach fiedersp. mit lanzettl. Zipfeln; Hkb. rundlich, mit schwarzem, dreieckigem, gewimpertem Anhängsel; Papp. von der Länge der Achenen. 2. 2'. - Variirt mit dichterer od. dïnnerer Behaarung der Blätter und Irülkelchbl; Blthk, kugelig, doppelt so gross als an der folgenden. - Beachtenswerthe Variet.:

$\beta$ ) coriacea; Bl. fast kahl und glänzend, etwas lederartig; Blthk. etwas kleiner; Hkbl. sehr gedrängt, kahl.

Auf Wiesen, trockenen Hügeln, an Wegen häufig! Die Variet. auf trockenen Kalkhügeln bei Baierthal! Maischbach! Juni-Sept.

498. C. maculosa Lam. Gefleckte Fl.; St. rispig-ästig, wie die Bl. etwas filzig; Bl. schärflich 1-2fach fiederspaltig, mit linealen Zipfeln; Hkb, rundlich, mit braunem, dreieckigem, gewimpertem Anhängsel; Papp. von der Länge der Achenen. $\hat{\text {. }}$ Blthk. zahlreich; Blthen rosa. (C. paniculata Aut.).

An Bergabhängen, an Wegen und Rainen. Nur vereinzelt an der Grenze des Gebietes zwischen Weinheim und Hemsbach. Juli August. [Jenseits des Rheins in Rhh. auf Kalkhügeln bei Oppenheim sehr verbreitet! Seltener bei Worms! und hio und da in Rhb. (F. Sch.)]. 
b) IIkbl. an der Spitze in handförmig getheilte Dornon auslaufend. 499. C. Calcitrapa $L$. Sternd istel; St. aufrecht od. etwas niederliegend, gabelästig; nntere Bl. tief fiederspaltig, obere lanzettl.; Blthk. seitenständig einzeln; Hkbl. kahl, glänzend; Papp. fehlt. $\odot$. $\frac{1}{2}-1 \frac{1}{2}^{\prime}$. Blth. hellroth.

* An Wegen, auf Triften, Schutthaufen, an dürren steinigen Orten nicht selten. Sehr verbreitet längs des Neckars von Neuenheim bis Ladenburg und Feudenheim! An den Rheindämmen hie und da, z. B. bei Ketsch! Neckarau! Auch bei Schwetzingen! Brühl! Weinheim! u. s. w. Juli-Sept.

500. C. solstitialis $L$. S o m mer-Fl.; St. sperrig-ästig, wio die Bl. grauwollig; Bl. herablaufend, untere fiedertheil,, obere lineallanzettl., ganzranuig; Hkb. wollig; Papp. etwas länger als die Achenen.. ค. $1 \frac{1}{2} \div 3^{\prime}$. Blth. gelb.

In Weinbergen, Luzerne-Aeckern, an Wegen sehr vereinzelt. Aus dem südlichen Europa stammend, bei uns gleichsam eingebürgert, hinsichtlich der Standorte sehr wechselnd, z. B. am Philosophenwege! auf Aeckern bei Wieblingen! Wiesloch! Mannheim! Juli-Sept.

\section{Serratula $L$. Färberdistel.}

501. S. tinctoria $L$. Gemeine F.; St. doldentraubig verzweigt; Bl. schärflich, eilanzettförmig, leyerf. od. fiederspaltig, selten alle ungetheilt; Hkb. eirund-lanzettl., wie d. Blth. purpurroth. 4. 1-2'. W. enthält einen gelben Farbstoff.

Auf Wiesen, in Waldgebüschen der Ebene verbreitet, besonders in der Nähe des Rheins! In Menge auch bei St. Ilgen! Nussloch! Auf feuchten Wiesen im Gebirge hie und da, z. B. bei Dielheim auf d. sog. Teufelskopf! bei Schriesheim! im Kastanienwalde linter dem Schlosse bei H.! Juli-Sept.

\section{Jurinea Cass. Jurinea.}

502. J. Pollichii Koch. Pollich's J.; St. wie die Bl., unterseits grauflzig; Bl. tieffederspaltig, mit linealen, ganzrandigen Zipfeln; Blthk. einzeln, kugelig, Hkbl. lineal-lanzettl., filzig. 4. 1'. (J. cyanoides Rehb.; Serratula Pollichii DC.).

Auf Sandflächen, in trockenen Nadelwäldern d. Ebene v. Walldorf und Sandhausen bis Hockenheim! Schwetzingen! Friedrichsfeld! verbreitet. Stellenweise auch bei Feudenheim! Käforthal, Sandhofen I Juli-September.

[Jenseits des_Rheins in Rhb. hie und da zwischen Spejer- 
Dürkheim, besonders bei Maxdorf! Durch Hs. verbroitet bis Bingen! In Baden die Grenze der Verbreitung mit dem Gebiet der Flora erreichond.]

\section{I a p a Tournef. Klette.}

503. L. major Gürtn. Grosse Kl.: St. ästig; Bl. rundlichherzf., unterseits schwach weissfilzig; Blthk. trugdoldenartig; Hkbl. pfriemlich, an der Spitze hakenförmig, fast kahl, grün. $\hat{\jmath}^{\circ} 3-6^{\prime}$. Blth. purpurroth. (Arctium Lappa L.).

In Waldgebüschen, auf Triften, an Wegen, an Ufern hie und da, stellenweise häufig in feuchten Gebüschen am Rhein und am Neckar! Juli, August, (Off.: Rad, Bardanae).

504. L. minor $D C$. Kleinere $\mathrm{Kl}$; in allen Theilen kleiner; Bl. fast eirund; Blthk. traubig; Hkbl. hakig, schwach spinnwebig behaart, die inneren gefärbt. $\hat{\circ}$. $1 \frac{1}{2}-3^{\prime}$. Blth, roth. (Arctium Lappa var. L.).

An Wegen, auf Schutthaufen, Triften meist vereinzelt, aber nicht selten. Hie und da am Neckarufer! Juli, August.

505. L. tomentosa Lam. Filzige Kl.; St. ästig; Bl, rundl.herzf., unterseits graufilzig; Blthk, trugdoldenartig; Hkbl. spinnwebig-wollig, lanzettl., die äusseren hakig, die inneren gefärbt mit gerader Spitze. §. 2-4'. Blth. roth. (Arctium Bardana Willd.).

Auf Triften, Sandfeldern, an Wegen, in Gebüschen, an Ufern hie und da, z. B. längs des Neckars von Neuenheim bis Ladenburg stellenweise! Bei Friedrichsfeld! Schwetzingen! beim Rohrhofe! Juli, August.

\section{Cirsium Tournef. Kratzdistel.}

a) Bl. oberseits dornig-steifhaarig; Hkbl. lanzettl., in einen : abstehenden Dorn auslaufend.

506. C. Ianceolatum Scop. Lanzettblättr. K.; St. ästig; Bl. sitzend, herablaufend, tief-fiederspaltig, dorniggezähnt, unterseits spinnwebig behaart; Blthk. einzeln, eiförmig, etwas wollig. §. 2-3'. Blth. hellroth. (Carduus lanceolatus L.).

An Wegen, auf Aeckern, Triften häufig! Juni-Sept.

507. C. eriophorum Scop. Wollköpfige K.; St. ästig; Bl. stengelumfassend, nicht herablaufend, tieffiederspaltig, dornig gezähnt; unterseits filzig; Blthk. einzeln, kugelig, dicht spinnwebig-wollig. $\hat{\wp}$. 2-4'. Blth. purpurroth. (Carduus eriophorus L.).

An Ackerrändern, Dämmen, auf Sandflächen der Ebeno hio und (a, aber meist vereinzelt, z. B. am Neckar bei Ladenburg! Neckar- 
hausen! Edingen! am Rhein bei-Neckarau! Ketsch! Oberhausen! überhaupt auf den Rheindämmen, auch jenseits des Rheins verbreitet: Am Neckarufer in der Nähe ron II. nur sporadisch und ohne sicheren Standort! Juli-September.

b) Bl. oberseits nicht dornig, melir oder weniger herablaufend.

508. C. palustre $S c o p$. S u m p f-K.; St. steifaufrecht, einfach, durch die völlig herablaufenden $\mathrm{Bl}$. schwach geflügelt; Bl. tieffiederspaltig, behaart, mit 2-3lappigen, dornspitzigen Zipfeln; Blthk. endständig, knäuelartig; Hkbl. anliegend, dornigzugespitzt. $ో .2-3$ '. Blth. roth. (Carduus palustris L.).

Auf nassen Wiesen, in Sümpfen, feuchten Wäldern der Ebene und der Gebirge verbreitet! Juni-Sept.

509. C. arvense Scop. A cker-K.; St. oben ästig; Bl. etwas herablaufend, längl.-lanzettlich, ganz oder fiederspaltig, dorniggezähnt, meist kahl; Blthk. eirund, in doldentraubigen Rispen; Hkbl. anliegend, weichstachelig. §. $2-3^{\prime}$. Blthk. 2häusig; Blth. hellroth; W. kriechend. Variirt mehr oder weniger dornig gezähnt. (Serratula arvensis $\mathrm{L}_{0}$ ).

Auf Aeckern und Triften, an Wegen häufig, oft sehr gesellig, z. B. in Haferfeldern lästig! Juni-August.

c) Bl. oberseits nicht dornig und nicht herablaufend.

510. F. acaule All. Stengellose K.; St. sehr verkürzt; Bl. rosettenartig ausgebreitet, kahl, lanzettl., buchtig-fiederspaltig, mit 3spaltigen, dorniggewimperten Zipfeln; Blthk. einzeln; Hkb. angedrückt weichstachelig. 24. Blth. roth. Variirt, wenngleich selten:

B) caulescens; St. $2-4^{\prime \prime}$ beblättert, mit $2-3$ Blthk.

Auf Waldtriften, an Waldrändern, Sandfl̈̈chen nur stellenweise und vereinzelt, z. B hio und da auf dem Königsstuhl! zwischen d. sog. Glashütte und Schönau! bei Käferthal ( $F$. Sch). Juli-Sept.

5Il. C. bulbosum $D C$. Knollige K.; St. steifaufrecht, spinnwebigwollig, mit wenigen 1köpfigen Zweigen; Bl. unterseits dünnwollig, dornig gewimpert, tieffiederspaltig; Hkb. abstehend, weichstachelig. 4. 2-3'. Blth. purpurroth. Wfasern länglich, knollig verdickt. (Carduus tuberosus L.).

Auf feuchten Wiesen und Triften der Ebene hie und da, z. B. zwischen Leimen und St. Ilgen! bei Wiesloch! Roth! einzeln auch bei Rohrbach! Handschuchsheim! Ladenburg! in Menge bei Waghäusel! und stellenwcise auf den Wiesen längs des Rheins! Juni bis August.

512. C. oleraceum scop. Kohl-K.; St. einfach; Bl. kahl od. schwach behaart, dorniggewimpert, stengelumfassend, die unteren 
fiederspaltig, die oberen ungetheilt; Blthk. endständig, gedränğt, ron eirunden gelblichen Blättern umhüllt; Hkbl. lanzettl., abstehend, stachelspitzig. 24. 2-3'. Blth. Teissgelb. Die ganze Pfl, aullallend gelbgrün. (Cnicus oleraceus L.).

Auf feuchten Wiesen, in Waldsümpfen, an Lfern und Gräben häufig! Juli-September.

Die Arten dieser Gattung bilden gern unter sich hybride Mittelformen, deren Vorkommen und Verbreitung in unserer Flora noch weiter zu verfolgen sein wird. Mit Sicherheit kann das Auftreten der folgenden angegeben werden :

C. palustri-oleraceum Näg. ( $($ : hybridum Koch); Bl, schwach behaart, fiederspaltig, dorniggezähnt, stengelumfassend, die unteren etwas herablaufend; Blthk. knäuelartig, von kurzen lanzettl. Hüllbl. umgeben. Blth. meist gelblich, seltener röthlich.

Aur feuchten Wiesen, in Gebüschen in Gesellschaft der Stammpflanzen) bei Neckarau! Waghäusel! Juli.

C.palustri-bulbosum Näg. (C. semidecurrens Richt.; C. Iochinnum Lühr); Bl. wenig herablaufend, buchtig-fiederspaltig, etwas dorniggezähnt, oberseits schwach behaart, unterseits dünnwollig; Blthk, zahlreich, geknäuelt od. mehr od. weniger entfernt; Wurzelfasern etwas verdickt;'Blth, röthlich.

Auf feuchten Wiesen bei Waghäusel gegen Rheinhausen! Juli. *)

\section{Cardus $L$. D is tel.}

513. C. acanthoides $L$. Vieldornige D.; St. ästig; Bl. herablaufend, kahl od. unterseits zottig, tieffiederspaltig mit 3lappigen, dorniggezähnten Zipfeln; Blthk. meist einzeln, aufrecht auf kur-

-) Die folgenden in unserer Nähe jenseits des Rheins bcobachteten Bastarde (vergl. F. Schultz, Flora d. Pfalz und dio lchrreichen Mitthcilungen von Dr. C., II. Schullz, Bip. in den Jahresberichten der Pollichia, 1844, 1849, 1852 und besonders d. 14. Jahresbericht (1856) sind im Gebiete unserer Flora viclleicht noch nachzuweisen:

r. eriophorn-lanceolatum (C. Gerhardi) C. II. Schultz; IIeiligenstein bei Speier; Neuhofen a. Rh. Zw. Ludwigshafen und Mundenbeim (Pollichia 1849, 1852).

C. bulboso-acaule Näg. (C. Zizianum Koch). Auf Wiesen bei Maxdorf!

C. bulboso-oleraceum Näg. (C. Braınii F. Sch.). Deidesheim (C. H. Sch.). 
zen, krausgeflïgelten und dornigen Stielen; Hkb. abstehend. 今. $2-3^{\prime}$. Blth, roth.

An Wegen, Ackerrändern, auf trocknen Triften und Hügeln, besonders auf Lehm - und Kalkboden, z. B. häufig bei Wiesloch! Kirrlach! Ladenburg! beim Relaishause! auch im Neckarthale bei H. hie und da! Juli-Sept.

514. C. crispus $I$. K ra us e D.; St. ästig; Bl. herablaufend, oberseits dünnharig, unterseits filzig, buchtig-fiederspaltig, mit krausgelappten, dorniggezähnten Zipfeln; 13lthk, aufrecht, einzeln od. gehäuft auf kurzen filzigen dornigen Stielen; IIkb. etwas abstehend. ङ. 2-4'. Blth, roth.

An Wegen, Waldrändern, Gräben häufig! Juli, August.

515. C. nutans $L$. Nickende D.; St. meist einfach; Bl. herablaufend, tieffiederspaltig, dorniggezähnt, unterseits etwas zottig; Blthk. einzeln, kugelig, anschnlich, nickend auf filzigen Stielen; äussere IIkbl. zurückgebrochen abstehend. §. 2-3'. Blth. hellroth.

Auf 'Triften, an Wegen, Ufern überall verbreitet! Juli-Okt.

Diese Art bildet mit C. crispus cine hybride Form:

C. nutanli-crispus (C. polyanthcmos Schleich); St. oben ästig mit 2-6 langgestielten, nickenden Blthk. Dịese fast um die Hälfte kleiner als bei C. nutans, mit kaum zurückgebrochenen Hkbl.; Blthstiole fllzig, meist schwachdornig gestreift; Bl. mehr od. weniger fiederspaltig, unterseits schwach behaart. $1 \frac{1}{2}-2^{\prime}$. Blth. roth.

Hie und da am Neckarufer zwischen Neuenheim und dem Schwabenheimer Hof! auch ganz in der Nähe der Neckarbrücke, am Wege nach Ziegelhausen! Juli-Okt.

\section{Silybu m Vaill. Ma riend ist el.}

S. Marianum Gärtn. Gemein o M.; Bl. stengelumfassend, herzförmig, buchtigdornig-gezähnt, kahl, glänzend, weissgefleckt;

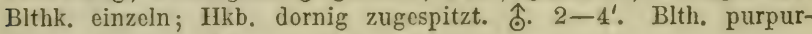
roth. (Carduus Narianus L.).

Aus Sïdeuropa stammend, hie und da verwildert! Aug., Sept.

21\%. On oporilon $L$. Es elsulistei.

516. 0. Acanthium $L$. St. steif aufrecht; Bl. herablaufend eirundlängl., buchtig, dorniggezähnt, spinnwebig-wollig; Blthk, ansehnlich, einzeln, auf geflügelten Stielen; Hkbl. abstehend. $\hat{\odot} .1-5^{\prime}$. Blth. rosa,

An Wegen, auf Sandflächen, Schutthaufon hie und da, in manchen Dörfern der Ebene häufig, z. B. Friedrichsfeld! Brühl! bei 
Neckarhausen! Sandhofen! beim Relaishause! in den Tijesgruben bei Schwetzingen! Juli-Okt.

\section{Carlina $L$. Eberwurz.}

517. C. vulgaris $L$. Gemeine E.; St. einfach oder ästig, dichtbeblättert, 1-mehrköpfig; Bl. steif, längl.-lanzettl., dorniggezähnt, unterseits etwas filzig, strahlenbildende Hüllen strohartig,

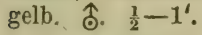

Auf Sandfächen der Ebene verbreitet, auch im Gebirge auf Sandboden häufig! Juli-Sept.

\section{I a psana $L$. Ra inkolhl.}

518. L. communis $L$. Gemeiner R.; St. einfach od. ästig, Bl. gezähnt, die unteren leierförmig, die oberen lanzettl., ganzrandig; Blthk. klein, armblüthig, in Rispen; Irk. kantig. ๑. Blth gelb. Variirt kahl und rauhhaarig.

An Wegen, auf Aeckern, in lichten Wäldern, in Gebüschen häufig! Juni-August.

220. A ruoseris Gaerln. Lämmersal a t.

519. A pusilla Gärtn. Kleiner L.; St, selir verkürzt; BI. rosettig, verkehrteirund-länglich, gezähnt, kahl; Schäfte $1-3 \mathrm{köpfig,}$ an der Spitze keulig rerdickt; Blthk. einzeln, kugelig, armblüthig, klein. $\odot . ~ \frac{1}{4}-\frac{1}{2}^{\prime}$. Blth. gelb. (Hyoseris minima L.),

Auf sandigen Aeckern, Sandtriften hie und da, z. B. bei Schönau! Wilhelmsfeld! Schriesheim! Auf den Sandflächen bei Friedrichsfeld: Oftersheim! beim Relaishause nur stellenweise und keineswegs allgemein! IHäufiger und meist heerdenweise zwischen Waghäusel und Wiesenthal! Juli-Sept.

\section{I. Cichorium $L$. Wegwarte.}

520. C. Intybus. L. Gemeine W. (Cichorie); St. sperrigästig, steifhaarig; untere Bl. schrotsägeförmig, unterseits am Kiel rauh, obere lanzettl., stengelumfassend; Blthk. seitenständig, $2-5$ gehäuft. $\hat{~}$. $2-4^{\prime}$. W. spindelf,; Blth. himmelblau, seltener rüthlich oder weiss.

An Wegen, auf 'Triften, Acckern überall verbreitet! Juli, Aug. (Off.: Rad. Cichorii).

\section{Picris $L$. Bitterkraut.}

521. P. hieracioides $L$. Habichtskrautähnl. B.; ästig, 
steifhaarig; Bl. etwas stengelumfassend, längl.-lanzettl., buchtig gezähnt; Blthk. doldentraubig; äussere Ilkbl. abstehend. $\hat{o} .2-3^{\prime}$. Blth. gelb. An sehr schattigen Standorten zuweilen mit einfachem St. und ganzrandigen Bl.

An Wegen, Rainen, Waldrändern, auf Wiesen häufig, stellenweise sehr gesellig! Juni-Sept.

\section{Thriucia Roth. Hunds a t $\mathrm{t} i \mathrm{ch}$.}

522. Th. hirta Roth. Steifha ariger H.; Wstock abgebissen, am Grunde mit starken Wfasern; Bl. alle grundständig, lanzettl., buchtig-fiederspaltig, steifhaarig; Schaft 1köpfig, allmählig in den IH. übergehend. 24. 3-10". Blth. gelb. (Leontodon hirtum L.).

Auf Haiden, Sandfächen, auch auf lehmigen Triften, an Wegen häufig! Juli-Sept.

\section{L e on todon $L$. Löwenzahn.}

523. L. autumnalis $I_{\text {. }}$. Herbst-L.; Bl.. alle grundständig, lanzettl., buchtig gezähnt od. fiederspaltig, kahl od. behaart; Schaft an der Spitze allmählig verdickt, mit zahlreichen schuppigen Blttch. besetzt, gabelig-ästig, 2-4köpfig; Blthk, vor dem Aufblühen aufrecht; Pappus Strahlen alle gefiedert. 24. $\frac{1}{2}-1_{\frac{1}{2}}^{\prime}$. Wstock abgebissen. Blth. gelb; Randblth, aussen röthlich.

Auf Wiesen, Triften, an Wegen überall schr häufig! Juli-Okt.

524. L. hispidus $I$. Steifh a riger L.; Bl. alle grundständig, längl.-lanzettl., buchtig gezähnt od. flederspaltig, kahl od. ästig behaart; Schaft 1liöpfig, allmählig verdickt mit 1-2 Blttch. besetzt; Blthk. vor dem Aufblühen nickend; die äusseren Strahlen des Pappus kurz, nicht gefiedert. 4. $\frac{1}{2}-1^{\prime}$. Blth. gelb. Variirt:

«) vulgaris Koch (Apargia hispida Willd.); Bl., oft auch Blthköpfchen steifhaarig.

ß) glabratus Koch (Leontodon hastile L.) hahl oder spärlich behaart.

Auf Wiesen, Triften, Sandflächen häufig, besonders Var. $\beta$ auf feuchten Wiesen verbreitet! Var. $\alpha$ auf den Sandflächen der Ebene, auch auf trockenen Hügeln bei Wiesloch! Rauenberg: nicht selten. Juni-September.

\section{T i a gopogo in $L$. B ock s b a t.}

525. T. pratensis $L$. Wiesen-B.; Bl. schmal lineal, ganzrandig, zugespitzt, kahl od. etwas wollig; Stiele der Blthk. wenig 
verdickt; Hkbl. 8, so lang oder kürzer als die gelben Blth. $\hat{\varsigma} .1-3^{\prime}$. Erscheint in 2 Varietäten:

a) vulgaris Döll; Randblth. von der Länge des Hk.; Randachenen so lang als ihr Schnabel, an der Spitze knotig-rauh.

ß) grandiflorus Düll; Randblth. länger als der Hk.; Randachenen länger als ihr Schnabel, an der Spitze schuppigweichstachelig ( $T$. orientalis L.).

Diese 2 Varietäten zeigen zuwcilen Uebergänge. Die Länge der Randblth, bei Var. $\beta$ ist sehr wechselnd, auch die Länge der Fruchtschnäbel sehr veränderlich.

Auf Wiesen, Triften, an Gräben Var. $\alpha$ sehr verbreitet, Var. $\beta$ auf Wiesen hie und da, z. B. oberhalb d. Haarlass! bei Nesterbach unfern Weinheim! bei Neckarhausen (Döll). Mai, Juni.

526. T. major Jacq. grösserer B.; Bl. lanzettlich, zugespitzt; Stiele der Blthk. an der Spitze keulig verdickt, hohl; Hkb. 10-12, länger als die Blthen; Achenen körnig-rauh. $\hat{\odot} .1-3^{\prime}$. Blthen hellgelb.

Auf trockenen sonnigen Hügeln, steinigen Triften, rorzugsweise auf kalkhaltigem Boden, selten. An den Anhöhen hinter Rauenberg lie und dal In grösserer Menge an Abhängen und Weinbergen in der Nähe von Nesterbach (gegen Sulzbach)! Im Birkenauer Thal bei Weinheim (Dierb.). Mai-Juli.

[Jenseits des Rheins nicht selten, z. B. auf den Kallhügeln um Dürkheim verbreitet!]

226. Scorzenera $L$. Schwarzwurzel.

S. hispanica L. Span ische S.; St. oben ästig; Aeste 1küpfig; Bl. stengelumfassend, lanzettl; Hkb. eirund-lanzettl., kahl; Achenen kantig-höckerig-raul. 2. 2-4'. Blth. gelb.

IIäufig als Küchengewächs kultivirt und hie und da verwildert, z. B. auf grasreichen Anhöhen oberhalb Handschuchsheim. Juli, Aug.

[S. purpurea L. Purpurblth. S.; St. 1-3köpflg, schlank; Bl. lineal-lanzettlich; IIk. eirund-lanzettl., meist weissfilzig; Achenen feingerieft mit glatten Riefen. 2. $\frac{3}{4}-1^{\prime}$. Blth. lila od, rosa.

N. V. a. d. Geb, auf den Kalkhügeln zwischen Dürkheim und Loistadt! Mai.]

\section{2\%. Podospermum DC. Stielsame.}

527. P. laciniatum DC. Zerschlitztes St.; St. aufsteigend od. aufrecht, ästig; Bl. fiederspaltig mit linealen zugespitzten Zipfeln; Blthk. einzeln; Hkb. so lang als die kurzen randständigen 
gelben Blth. Variirt selten mit vüllig ungetheilten eifürmig-lanzettl. Bl. क. $\frac{1}{4}-1^{\prime}$. (Scorronera laciniata L.)

Auf trockenen Hügeln, Triften, an Wegen auf Kalk- und Lehmboden sehr selten. Vereinzelt an den Rheindämmen bei Mannheim. [Auf den Kalkhügeln in Rhb. und Rhh. in grosser Verbreitung!] Juni-August.

\section{Il y pochoeris $L$. Ferkelkraut.}

a) Die äusseren Pappus Strahlen kurz, borstig, nicht federig.

528. H. glabra L. Kahles F.; Bl. grundst., verkehrteiförmig, buchtiggezähnt, kahl od. am Rande wimperig; Schaft ästig, fast blattlos; Randblth. so lang wio der Hk.; Achenen derselben ungeschnäbelt, der Scheibenblth. langgeschnäbelt. ๑. $\frac{1}{2}-1^{\prime}$. Blth. gelb; Randblth, nach Aussen grünlich.

Auf sandigen Aeckern, Haiden, Triften hie und da, jedoch selbst in den Sandgegenden des Gebietes nicht allgemein. Häufig bei Sandtorf! zwischen Friedrichsfeld und Schwetzingen! bei Oftersheim! Wiesenthal! bei Schönau! Stellenweise auch in der Nähe von H., z. B. beim Speyerer Ifof! am Philosophenwege! Juli-Sept.

529. H. radicata $L$. L ang w urzeliges F.; Bl. grundständig, schrotsägeförmig-fiederspaltig, rauhhaarig; Schaft ästig, fast blattlos; Randblth. Iänger als d. Hk.; Achenen alle langgeschnäbelt. 2 . 1-2'. Blth. gelb; Randblth. nach Aussen grün.

Auf Wiesen, Triften, an Waldrändern, Wegen allgemein verbreitet! Juni-Sept.

\section{b) Alle Pappus Strahlen federig.}

530. H. maculata L. Geflecktes F.; Bl. grundst., länglich, stumpflich, buchtiggezähnt, meist braunrothgefleckt; Schaft einfach 1-3köpfig, armblättr., steifhaarig; Randblth. länger als d. Hk.; Achenen alle langgeschnäbelt. 24. 1-2'. Blth. gelb. (Achyrophorus máculatus Scop.).

Auf trockenen Wiesen, Triften, Haiden, in Nadelwäldern sehr selten. Im Käferthaler Nadelwalde (Döll). Juni, Juli.

[In Rhb.: Wiesen bei Hanhofen, unfern Speyer! bei Dürkheim (F. Sch.). In B. in der Nähe des Geb. fehlend. In Hs. sporadisch von Niederbeerbach bis zum Taunus, dort allgemein (Schntsp.).]

\section{Taraxacum Juss. Kuhblume.}

531. T. officinale Wigg. Heilkräftig e K. (Löwenzahn); Bl. grundst., schrotsägeförmig, flederspaltig, kahl od. etwas behaart; Schaft rührig 1 köpfig; Hkb. lanzettl., dio äusseron abwärtsgebogen. 
4. $\frac{1}{4}-1$ '. Blth. gelb. (Leontodon Taraxacum L.). Variirt sehr in Blattform und Habitus. Auffallend ist besonders:

$\beta$ ) palustre DC.; kahl; Bl. buchtig-gezähnt, zuweilen lineal und ganzrandig.

Auf Wiesen, Triften, an Wegen überall verbreitet, die Variet. auf Sumpfboden, in Torfsümpfen; z. B. sehr zwergartig und schmalblätterig bei Sandtorf und Brühl! Mai-Okt. (mit Unterbrechungen). (Off, : Rad, et Fol, Taraxaci).

\section{Choudrilla $L$. Knorpelsalat.}

532. Ch. juncea $L$. Bin senartiger Ko; St. sperrig ästig, am Grunde meist borstig; Aeste ruthenf.; grundst. Bl. schrotsägef., obere spärlich, lineal-lanzettl.; Blthk. einzeln od. 2-4 achsel- oder endständig, klein. §. 2-4'. Blth. gelb. Variirt:

$\beta$ ) latifolia; in allen Theilen etwas grösser, die oberen $\mathrm{Bl}$. fast elliptisch.

An Wegen, Rainen, auf trockenen Hügeln, Sandfeldern hie und da, z. B. verbreitet am Neckar beim Schwabenheimer Hof! zwischen Maischbach, Baierthal und Rauenberg! vereinzelt bei Käferthal! Brühl! Waghäusel! in den Kiesgruben bei Schwetzingen (Dr. Schimp). Die Variet. mit der Hauptform z. B. beim Rohrhofe! Juli, August.

\section{Lactuca $L$. Lattich.}

a) Blthk. 5blth.; Achenen ungeflügelt, beiderseits melrrippig.

533. L. muralis Fres. Ma a er-L.; aufrecht; Bl. gestielt, zart, unterseits blaugrün, leyerf.-fiederspaltig mit eirunden, eckig gezähnten Lappen; Blthk. rispig; Achenen sehr kurz geschnäbelt. ๑. $1-2 \frac{1}{2}$ '. Blth. gelb. (Prenanthes muralis : $\mathbf{L}_{\text {. }}$ ).

In schattigen Wäldern, Gebüschen, auf Mauern, Schutt häufig! Juni-September.

b) Blthk. vielblth.; Achenen mehrrippig; Blth. gelb.

534. L. saligna $L$. Weidenblättr. L.; aufsteigend oder etwas niederliegend; Bl. lineal, pfeilfürmig-stengelumfassend, ganzrandig, die unteren schrotsägeförmig-fiederspaltig; Blthk. in verlängerten Rispen; Achenen braun, halb so lang als der Schnabel. ๙. $1-2$ !

Auf Triften, an Ackerrändern, Wegen selten. Mannheim (Dölt). Am Landgraben bei Weinheim (Dierb.). Juli, August.

[Zerstreutes Vorkommen in den benachbarten Gebieten von Rhb. u. Rhh. - N. V. a. d. Geb.: Oggersheim, Forst, Dürkheimer Saline $\left.(F \text {. Sohult } z)_{.}\right]$ 
535. L. Scariola L. Wilder L.; St. aufrecht; Bl. vertikalgestellt, eilänglich, buchtig-fiederspaltig, pfeilförmig, stengelumfassend, am Kiel stachelig; Rispen pyramidenförmig, vor dem Aufblühen überhängend; Achenen schmalberandet, oben borstig-behaart, hellgrau; Schnabel von der Länge der Achenen. $\hat{\odot} .1-5^{\prime}$.

An Wegen, auf Mauern, in Weinbergen hie und da, bei $H$. häufig, z. B. am jenseitigen Neckarufer von Ziegelhausen-Neuenheim! am Winterhafen! bei der Bergheimer Mühle! Stellenweise in grosser Verbreitung an den Rheindämmen! Juli-Sept. (Off.: $H b$. Lactucae sylvestris).

L. sativa I.; Gebräuchl. L. (Salat); St. aufrecht; Bl. horizontal, ungetheilt od. buchtig-fiederspaltig, herzförmig-stengelumfassend, meist kahl od. am Kiel etwas stachelig; Blthk. rispig doldentraubig, stets aufrecht; Achenen schmalberandet, braun, von der Lünge des Schnabels. ๑. Vielleicht Varietät der vorigen (s. Bisch. Beitr. zur Flora Deutschland's p. 190).

In Gärten als bekannte Culturpflanze, hie und da verwildert! Jùli, August. (Off.: Lactucarium v. Tridax).

[L. virosa L. Gift-L.; St. aufrecht; Bl. horizontal, länglicheiförmig, pfeilf.-stengelumfassend, ungetheilt od. buchtig; am Kiel stachelig; Blthk, in pyramidenf. Rispen, vor dem Aufblühen aufrecht; Achenen schwarz, breitberandet, oben kahl, von der Länge des Schnabels. 犬. 2-4'. Widerlich betäubender Geruch. Giftig.

An steinigen, etwas bewaldeten Bergabhängen. N. V. in Rhb.: Haardtgeb., daselbst Schlammberg bei Dürkheim.] (Off.: Hb. Lac-. tuoae virosae.)

c) Blthk. vielblth.; Achenen beiderseits 1rippig; Blth. blau.

[L. perennis L. A usdauernder L. ; St. ästig; Bl. fiederspaltig, mit lineal-lanzettlichen Zipfeln, kahl; Blthk, in doldentraubigen Rispen. 24. 1-2 $\frac{1^{\prime}}{}{ }^{\prime}$. Blth. blau.

Auf trockenen Kalkhügeln, an bewaldeten Abhängen. N. V. in Rhb.: Haardtgeb., stellenweise von Neustadt-Grünstadt, z. B. Dürkheim! Ungstein! Callstadt! Juni, Juli.]

\section{Souchus $L$. Gänsedistel.}

536. S. olèraceus $L$. Gemü se-G.; kahl; St. ästig; Bl. länglich, ungetheilt od. flederspaltig, mit zugespitztem Grunde stengelumfassend, blaugrün; Blthk. doldentraubig; Achenen queerrunzelig. ๑. $\frac{1}{2}-2^{\prime}$. Blth. hellgelb.

An Wegen, auf Schutt, Aeckern, in Gärten sehr allgemein verbreitet, Juni-October. 
537. S. asper Vill. Rauhe G.; dem vorigen äbnlich, aber die Bl. elliptisch-lanzettlich, mit abgerundetem Grunde stengelumfassend, oberseits glänzend; Achenen glatt. ๑. $\frac{1}{4}-2^{\prime}$. Blth, hellgelb.

An Wegen, auf Aeckern, an Zäunen häufig, doch nicht so allgemein wie d. vorige. Vorherrschend auf Sandflächen des Gebietes,

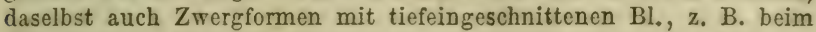
Relaishause! Juni-October.

538. S. arvensis L. A cker-G.; Wurzelst. kriechend; St. einfach, kahl, an der Spitze doldentraubig und nebst Hk. drüsigbehaart; Bl. kahl, starr, glänzend, schrotsägeförmig, die oberen ungetheilt; Achenen queerrunzelig. 4. 2-4'. Blth. gelb.

Auf Aeckern, Triften, an Wegen häufig und im Getreide mitunter sehr lästig! Juni-August.

\section{Prenanthes $L$. H a sensalat.}

539. P. purpurea $L$. Purpurrother H.; St. einfach; BI. kahl, unterseits blaugrün, längl.-lanzettl., buchtig-lejerförmig, stengelumfassend, die oberen ganzrandig; Blthk, zahlreich, nickend, in Rispen. 4. 1-4'. Blth. bläulichroth.

In Gebirgswäldern, besonders häufig in der Nähe von H., diesseits und jenseits des Neckars! auch bei Weinheim! z. B. auf dem Wagenberge: Seltener im Gebirge bei Nussloch und Wiesloch! Juli-September.

\section{Crepis $L$. Pippau.}

a) Pappus schneeweiss, weich; Blth, gelb.

1) Achenen der Scheibe oder alle langgeschnäbelt.

540. C. foetida $L$. Uebelrie chender P.; kurzhaarig, grau; St. aufrecht, ästig; Bl. schrotsägeförmig-fiederspaltig, obere lanzettl.; Blthk. einzeln od. wenige, vor dem Aufblühen nickend; Hk, zottig, drüsenhaarig; Achenen der Scheibo langgeschnäbelt. ๑. $\frac{1}{2}-1^{\prime}$. (Barkhausia foetida DC.).

Auf Brachäckern, an trockenen Rainen, in Steinbrüchen, auf trockenen Hügeln, kalkhold. Hie und da am Philosophenwege! bei Dossenheim! im Birkenauer Thal bei Weinheim! bei Nesterbach! in grösserer Verbreitung bei Ladenburg! und besonders auf Kalkhügeln bei Baierthal! Rauenberg! Dielheim! Nussloch! woselbst oft heerdenweise! Seltener bei Leimen und oberhalb Rohrbach! Vereinzelt bei Friedrichsfeld! Schwetzingen! Mannheim! Juni-August.

541. C. taraxacifolia Thuill. Löwenzahnblättr. P.; St. aufrecht, an der Spitze doldentraubig; Bl. schrotsägeförmig-gezähnt 
oder flederspaltig, graubehaart; Blthk. vor dem Aufblühen aufrecht; Hk. graubehaart, kuirzer als die Pappus-Strahlen; Achenen alle langgeschnäbelt. $\delta$. $1-2 \frac{1}{2}^{\prime}$.

Auf trockenen Wiesen, Aockern, an Wegen, kalkhold. Nur sporadisches Auftreten bei Mannheim (Schimper), Waghäusel (Lafnret). Mai-Juli. [Zerstreutes Vorkommen durch B. längs des Rheines.]

542. C. setosa Hall. fil. Borstiger P., steifhaarig; St. aufrecht, ästig, an der Spitze locker doldentraubig; Bl. schrotsägeförmigflederspaltig; Blthk. vor dem Aufblühen aufrecht; Hk. hellgrün, steifborstig, wenig kürzer als die Pappusstrahlen; alle Achenen langgeschnäbelt. $\odot, \frac{1}{2}-1^{\prime}$.

Auf Triften, an Waldrändern. Aus dem südlichen Europa stammend, mit Getreidesamen eingeschleppt. Auf der Rheininsel Koller zwischen Otterstadt und Brühl (C. H. Schultz, Bip.) JuniAugust. [In Rhb. bei Ludwigshafen, ganz in der Nähe des Ortes an der alten Strasse nach Oggersheim in grosser Menge!]

2) Achenen kurzgeschnäbelt; St. beblättert, an der Spitze doldentraubig-vielköpflg.

543. C. biennis $L$. Zweijähriger P.; St. steif-aufrecht, gefurcht, wie die Bl. scharfhaarig; Bl. schrotsägefürmig-fiederspaltig, obere lineal, ganzrandig; Hkbl. aussen grauhaarig, innen seidenhaarig; Aussenk. abstehend; Achenen 13rippig. 今. 2-4'.

Auf Wiesen, an Wegen, in feuchten Gebüschen häufig! Mai-Sept.

(Die mit fremden Sämereien eingeführte südfranzësische $\mathrm{Cr} \cdot n i$ caeensis Balb., welche früher bei Mannheim vorgekommen, ist in neuerer Zeit daselbst nicht wieder gefunden, hingegen noch kürzlich in $\mathrm{Rhb}$. bei Speyer wahrgenommen.)

544. C. Virens Vill. Grüner P.; St. aufrecht oder aufsteigend, wie die Bl. kahl; untere Bl. lanzettl., buchtig gezähnt oder schrotsägeförmig-fiederspaltig, obere lineal, pfeilförmig, flach; Hkb. weichhaarig, innen kahl; Aussenk anliegend; Blthboden nackt; Achenen 10rippig. ๑. $\frac{1}{2}-1 \frac{1}{2}^{\prime}$. Sehr veränderlich in der Zertheilung der Bl. (C. pinnatifida Willd.)

An Wegen, auf Wiesen, Triften, Aeckern allgemein verbreitet: Juni-September.

545. C. tectorum $L$. D a ch-P.; St. aufrecht, ästig, grau behaart; untere BI. lanzettl., fiederspaltig oder buchtig-gezähnt, obere lineal, pfeilförmig, am Rando umgerollt; Hkb. grau behaart, innen seidenhaarig; Aussenk. abstehend; Blthboden kurzfaserig; Achenen 10rippig. O. $1 \frac{1}{2}-1^{\prime}$

Auf Sandfächen, Mauern, Dächern, dürren Triften meist sehr verbreitet, besonders in den Sandgegenden des Geb. oft gesellig. Juni-September. 
3) Achenen kurz geschnäbelt; Schaft unleblittert, an der Spitze vielköpfig.

546. C. praemorsa Tausch. A b g ebis sen or P.; Schaft und Bl. kurzhaarig; Bl. grundständig, eiförmig-länglich; Blthk. traubig. 4. $\frac{1}{2}-1 \frac{1}{2}^{\prime}$. Wzst. abgebissen mit büscheliger W. (Hieracium pratmorsum $\mathbf{L}$.)

An Waldrändern, in lichten Wäldern, auf Waldwiesen, vorzüglich im Gebirge auf Kalkboden hie und da, z. B. hinter d. Haarlass! in der Hillenbach bei Handschuchsheim! stellenweise längs d. Bergstrasse, häufig bei Weinheim! Verbreitet zwischen Leimen! Nussloch! Schatthausen und Dielheim! In der Ebene weniger häufig, z. B. im Friedrichsfelder Walde! auf der Rheininsel bei Ketsch! zwischen Kirrlach und Waghäusel! Mai, Juni.

b) Pappus schmutzig-weiss, zerbrechlich (zur folgenden Gattung (len Uebergang bildend); Achenen a. d. Spitze zusammengezogen.

547. C. paludosa Moench. S u mp f-P.; St. beblättert, an d. Spitze doldentraubig; Bl. kahl, längl.-lanzettl., etwas stengelumfassend, buchtig-gezähnt; Hkbl. drüsig-behaart, schwärzlich. 2. $\frac{1}{2}-2^{\prime}$. Blth. gelb. (Hieracium paludosum L.)

Auf feuchten Wiesen, in sumpfigen Wäldern und Gebüschen hie und da. Häufig in der Nähe von H., z. B. in der Hirschgasse! auf der Engelswiese! in feuchten Gebüschen gegen Wilhelmsfeld! Schönau! im Mühlenthale bei Handschuchsheim! bei Schriesheim! Sehr verbreitet bei Gaiberg! beim Maischbacher Hof! hio und da im Friedrichsfelder Walde! bei Waghäusel! Juni, Juli.

[In Rhb. ziemlich selten, im benachbairten Gebiet fast fehlend! In Hs. und B. stellenweise verbreitet.]

\section{Hieracium $L$. Habichtskraut.}

a) St. schaftartig, meist mit Ausläufern; ausser den Wbl. nur unten beblättert oder unbeblättert; $\mathrm{Bl}$. ganzrandig oder schwach gezähnt.

548. H. Pilosella L. Gemeines H.; St. unbeblättert, 1köpfig, filzig oder rauhhaarig; Bl. spatelf. oder verkehrt eiförmig-lanzettl., ganzrandig, borstig-behaart, unterseits weissfilzig; Blthk. eirund-walzig; Hkbl. lanzettl., spitzlich, filzig-drüsig, schwärzlich; Ausläufer beblättert, niedergestreckt oder aufstrebend, gewöhnlich nicht blothend. 4. $\frac{1}{2}-1^{\prime}$. Blth. schwefelgelb; Randblth. aussen purpurroth. Variirt:

ß) Peleterianum Mer.; Bl. zottig-gewimpert; Blthk. etwas grösser; Hkbl. sehr zottig, weissgrau; Ausläufer ziemlich kurz. 
$\gamma$ ) robustius (stoloniflorum) Koch; in allen Theilen kräftiger; Blthk. etwas grösser; Ausläufer aufstrebend, verlängert, Blthk. tragend.

An Wegen, auf Triften, Wiesen, Sandnächen die Hauptform überall verbreitet. Var. $\beta$ auf trockenen Triften beim Relaishause und im Seckenheimer und Käferthaler Walde (Döll.) [Jenseits des Rheines am Haardtgebirge häufig, z. B. an den Bergabhängen bei Dürkheim!] Var. $\gamma$ an Waldrändern nahe vor Gaiberg! zwischen Friedrichsfeld und dem Relaishause! Mai-Juli.

549. H. auricula $L$. A urikel-H., bläulich-grün; Bl. spatelförmig-lanzettl., ganzrandig, etwas wellig, kahl oder schwach gewimpert; St. meist 1 blättrig, mit beblätterten, meist nicht blühenden Ausläufern; Blthst. doldentraubig, 2-5köpfig; Blthk, eirund-walzig; Hkbl. drüsig, schwarzgrün. 24. $\frac{1}{2}-1^{\prime}$. Blth. gelb. Randblth. aussen nicht purpurn. (H. dubium Sm.)

An Rainen, Wegen, auf trockenen Wiesen, an Waldrändern häufg, z. B. in der Nähe von H. bei Handschuchsheim! und sehr vorherrschend bei Gaiberg und Nussloch! Gewöhnlich sind die Köpfchen kurz gestielt; am Rando des Gajberger Waldes findet sich indessen eine sehr auffallende Form mit langgestielten Köpfchen, vielleicht $H$. bifurcum mancher Aut?) Mai-August.

550. H. praealtum Vill. Hohes H.; St. kahl od. weichhaarig, oder borstig, mit Ausläufern oder ohne dieselben; Bl. lineal-lanzettl., meist blaugrün; Blthk. mehr oder weniger locker, in Doldentrauben, klein, ei-walzenförmig, wenige oder zahlreich; Blthstiele aufrecht, weichhaarig; Hkbl. stumpflich, mit schwärzlichem, drüsentragendem Kiel. 4. Blth. gelb. Die formenreiche Art erscheint hier hauptsächlich als :

๔) verum; ohne Ausläufer; Bl. lanzettl., spitz, starr, wenig borstig-behaart; zablreiche Blthk, wenig kürzer als dio Blthstiele; Hkbl. schwach behaart. - St. meist einfach 1-2', zuweilen wiederholt gabeltheilig und dann $3^{\prime}$.

B) stoloniferum (Bauhini Schult.); mit zuweilen blühenden Ausläufern; Bl. verlängert lanzettlich, starr, wenig behaart; Blthk, wie vorige; Hkbl, etwas drüsig-borstig. $1 \frac{1}{2}-2 \frac{1}{2}^{\prime}$.

$\gamma$ ) fallax; mit Ausläufern oder ohne dieselben; Blt. starr oder weich, schmal lanzettl., zugespitzt, mehr oder weniger borstig; Blthk. $3-10$, viel kürzer als die Blthstiele; Hkbl. und Blthstiele drüsig und weichhaarig. 1-1 $\frac{1}{2}^{\prime}$. Auf nassen Torfwiesen sind St. u. Bl. völlig kahl, Bl. weich und wenig bläulich. 


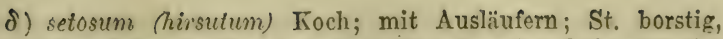
oberwärts sternhaarig-grau; Bl. oberseits dicht borstig, unterseits sternhaarig; Blthk. zahlreich, kurz gestielt.

An Waldrändern, an trockenen Abhängen, auf Bergwiesen nicht selten. Var. $\alpha$ am Philosophen-Wege! bei Dossenheim! Weinheim! Nussloch verbreitet! seltener beim Relaishause und Waghäusel! Die Form mit gabeltheiligem Stengel am Gaiberger Walde! Var. $\beta$ hie und da mit der vorigen, z. B. häufig bei Nesterbach und Weinheim! Var. $\gamma$ am Philosophen-Wege! gegen Ziegelhausen! bei Leimen! Nussloch! Gaiberg! Die kahle Form in Tprfsümpfen bei Sandtorf und Waghäusel! Var. $\delta$ am Philosophen-Wege! bei Weinheim! Leimen! beim Relaishause! Mai-Juli.

551. H. pratense Tausch. Wiesen-H.; St. mit kurzen Ausläufern, armbl., rauhhaarig, oben nebst Hkbl. dicht behaart, schwärzlich; Blthk. zahlreich, doldentraubig, knäuelartig-gedrängt; Bl. länglich-lanzettl., beiderseits grün, etwas behaart; Hlkbl. pfriemlich, spitz. 4. 1-2'. Blth. gelb. (H. cymosum Willd.)

Auf Wiesen, an Waldrändern hie und da, z. B. häufig bei Gaiberg! seltener beim Maischbacher Hof! bei Wiesloch! Juni, Juli.

b) St. ohne Ausläufer, ästig, 1-mehrblätterig; Wbl. bleibend, überwinternd.

552. H. murorum $L$. Mauer-H.; St. aufrecht, fast 1blätterig, oben ästig; Bl. cirund oder fast herzförmig, am Grunde fast eingeschnitten-gezälınt; Zähne abstehend oder zurïckgebogen, meist beiderseits und am Rande rauhhaarig; Rispe doldentraubig, 3-7köpfig; Blthstiele und fein zugespitzte Hkbl. sternhaarig, mit schwärzlichen Drüsenhaaren. 4. 1-2'. Blkr. gelb. Bl. hellgrün od. seltener etwas bläulich, unterseits oft roth, oberseits gefleckt oder ungefleckt. - Variirt:

B) Schmidtii Tsch; Bl. eilanzettlich, mit langen, gerade vorgestreckten Zähnen; blaugrün.

In Wäldern, Gebüschen, auf Mauern häufig. Die Var. seltener, meist an trockenen, bewaldeten Abhängen, z. B. bei Weinheim! Nussloch! Mai-Juli.")

553. H. vulgatum Fries. Gemeines H.; St. aufrecht, 3mehrblätterig, oben ästig; Bl. länglich oder lanzettl., gezähnt, am

-) Hierher gehört auch H. praexox C.H.Schultz, Bip., welches mit $H$. murorum in der Nähe von $H$, besonders an der Sonne sehr ausgesetzten Standorten hie und da auftritt (z. B. auf Mauern der Schlossruine und jenseits des Neckars beim 
Grunde verschmälert, mehr oder weniger rauhhaarig; Rispe doldentraubig, 3-10köpfig; Blthstiele oft sehr ver]ängert. filzig und wio die spitzen Hkbl. mit schwärzlichen Drüsenhaaren. 24. $\frac{1}{2}-2^{\prime}$. Blkr. gelb; Bl. dunkel- oder hellgrün, zuweilen unterseits roth, oberseits gefleckt oder ungefleckt. (H. sylvaticum Gouan.)

An schattigen und sonnigen Standorten, in Wäldern, an trockenen Abhängen, an Wegen häufig! Juni-October.

c) St. ohne Ausläufer, mehrblätterig; Wbl. nicht überwinternd.

554. H. boreale Fr. Nördl. II.; St. starr, oben ästig, mehr oder weniger behaart, dichtbeblättert; Bl. eirund-lanzettl., gezähnt, die oberen sitzend, die unteren fast gestielt; Rispe an der Spitze doldentraubig, reichblth.; Blthstiele grauhaarig; Hk. eirund, fast kahl; Hkbl. angedrückt, lanzettl., stumpf, grün, beim Trocknen schwarz werdend. 24. 2-4'. Blth. gelb. (H. sylvestre Tsch.)

In Wäldern, auf Waldtriften besonders im Gebirge häufig, aber meist einzeln. August-October.

555. H. rigidum Hartm. Steifes $\mathrm{H}$, dem vorigen ähnlich; Bl. weniger zahlreich, etwas steifer, lineal-lanzettl., schwach gezähnt, die unteren sehr kurz gestielt; Rispe der vor.; Hk. kahl oder etwas behaart; Hkb. angedrückt, lanzettl., stumpf, am Rande bleichgrün, fast weisslich, beim Trocknen nicht schwarz werdend. 24. 2-4'. Blth. gelb. (Unterscheidet sich auch von dem vorigen durch frühere Blüthezeit.) (H. laevigatum Koch.)

In lichten Wäldern, an bewaldeten Abhängen auf Sandboden der Gebirge und der Ebene hie und da, z. B. bei H. besonders diesseits des Neckars: beim Riesensteine! am Wege nach dem Speyrer Hof! auch stellenweise zwischen Friedrichsfeld und Schwetzingen! Juni-September.

Haarlass!), und sich hauptsächlich durch den fast blattlosen St., sehr wenige, grössere Blthköpfchen, oberseits fast kahle Bl. und durch frühere Blüthezeit (Anfang Mai) von $H$. $m u$ rorum unterscheidet. Es soll (nach den sehr ausführlichen Mittheilungen des Autors im 9. Jahresbericht der Pollichia 1851) von dieser Pflanze auch eine Herbstform existiren, und es sind auch noch andere (vielleicht schwankende?) Unterscheidungsmerkmale angegeben, worüber aber weitere Beobachtungen und Culturversuche nöthig sein werden, um zugleich die Begrenzung des H. murorum L., vulgatum Fr. und der neuerdings unterschiedenen Arten und Varietäten näher feststellen zu können. 
556. H. umbellatum $L$. Doldiges II.; St, aufrecht, kahl oder behaart, dichtbeblättcrt; Bl. lineal-lanzettlich, gezähnt oder fast ganzrandig; Rispe doldentraubig, an der Spitze fast doldig (zuweilen aber auch mehr verlängert), Blthstiele weissgrau; Hk. kegelförmigeirund; Inkbl. lanzettl., spitz, dunkelgrün, kahl, an der Spitze zurückgebogen, beim Trocknen schwarz werdend. $4 . \frac{1}{2}-3^{\prime}$. Blth. gelb. - Variirt:

ß) angustifolium Koch; Bl. schmal lineal, ganzrandig.

$\gamma$ ) coronopifolium Koch; BI. lineal-lanzettl., beiderseits mit 2-3 verlängerten Zähinen.

Findet sich ausserdem in sehr rerkümmerten Exemplaren mit 2-3 Blthk. und als Spätherbstform mit abgestorbenem Hauptstengel und entwickelten armblätterigen Nebenstengeln, mit meist 1 Blthk.

In Wäldern, Gebüschen, an Wegen, auf Haiden und Sandflächen häufig. Die Var. auf Sandfeldern und in Nadelwäldern zwischen Friedrichsfeld und dem Relaishause! bei Sandhausen u. s. w. nicht selten! Juli-October.

\section{AMBROSIACEAE $L k$.}

Kräuter mit abwechselnden Blättern ohne Nebenblätter. Blth. eingeschlechtig. Männliche Blth. kopflörmig, mit vielblätteriger oder vieltheiliger Hulle. Perigon röhrig, 5zähnig, mit klappiger Knospenlage. Stbgef. 5, dem Perigon eingefügt, mit verwachsenen Stbfäden und freien Antheren. Weibliche Blth. meist paarweise, ohne Perigon, von einer borstlichen Hülle umgeben. Fruchtk. frei, mit 1 Griffel und 2 verlängerten Narben. Frucht nussartig, von der erhärteten zweischnabeligen Hülle eingeschlossen, 1eiig. Same eiweisslos. Keim gerade.

Xanthium. Als einzige europäische Gattung.

\section{Xanthium $L$. Spitzklette.}

557. X. Strumarium L. Gemeine Sp.; St. steif, sperrigästig, dornenlos; Bl. gestielt, herzförmig, 3lappig, kurzhaarig; Blthk. achsel- und endständig, männliche Blth. oben, gelblich, weibl. Blth. unten; Fruchthülle eiförmig, mit hakenförmigen Stacheln. ๑. $\frac{1}{2}-1 \frac{1}{2}^{\prime}$. 
Auf Triften, an Rainen, Wegen hie und ia. Bei Feudenheim, an der Neckar-Ueberfahrt daselbst in grosser Menge! Neckarhausen! Ladenburg! beim Schwabenheimer Hof nicht selten! Iäufig bei Sandtorfl Schwetzingen! Ketsch! Alt-Lussheim! und stellenweise an den Rheindämmen:

\section{CAMPANULACEAE Juss.}

Meist Milchsaft führende Krüuter mit abwechselnden Blättern ohne Nebenblätter, einzelnen oder häufiger traubiggruppirten, bisweilen kopfartig zusammengedrängten Blüthen von vorherrschend blauer Farbe. Kelch ganz oder theilweise mit dem Fruchtknoten verwachsen, meist 5gliederig, in der Knospe klappig. Blkr. regelmässig, verwachsenbl., 5 gliederig, in der Knospe klappig. Stbgef. 5 frei, meist mit etwas verbreiterter Basis, den Fruchtknoten deckend. Antheren vor der Entfaltung der Blkr. aufspringend. Fruchtknoten 2-5fächerig, mit vieleiigen Fächern und centraien Samenträgern, mit 1 Griffel und 2-3theiliger Narbe. Griffel mit Sammethaaren versehen. Kapsel vielsamig. Samen eiweisshaltig. - Meist Wald- und Wiesenpflanzen, manche zwar sehr verbreitet, aber nur selten heerdenweise auftretend.

Jasione. Blkr. 5theilig, mit linealen Zipfeln; Antheren am Grunde innig zusammenhängend; Kapsel 2fächerig, an der Spitze spaltenförmig aufspringend.

Phyte uma. Blkr. 5theilig, mit linealen Zipfeln, diese am Grunde gelöst, an der Spitze zusammenhängend; Antheren frei; Kapsel 2-3fächerig, mit seitlichen Löchern sich öffnend.

Ca mp anula. Blkr. glockig, 5spaltig; Antheren frei; Kapsel ei- oder kreiselförmig, 2-3fächerig, mit seitlichen Löchern aufspringend.

Specularia. Blkr. radförmig; Kapsel prismatisch-länglich, mit Spalten aufspringend; übrigens wie vorige.

\section{3\%. Jasione $L$. J a sione.}

558. J. montana $L$. Berg-J., rauhhaarig; St. einfach oder ästig; Bl. grundständig, rosettig, lineal; Blthstand kopffürmig, langgestielt, von zahlreichen, eiförmigen, spitzen Hbl. umgeben. $\hat{\odot} \cdot \frac{1}{2}-1_{\frac{1}{2}}^{\prime}$. 
Blkr. hellblau; W. einfach. Variirt, wenngleich selten fast ganz kahl, und ausserdem als:

$\beta$ ) major; in allen Theilen grösser.

Auf Sandfeldern, trockenen, sandigen Hügeln, an Wegen ziemlich häufig, jedoch selten gesellig. Auf Felsen vor dem Haarlass! bei Ziegelhausen! diesseits des Neckars hie und da im Gebirge! Verbreitet auf den Sandflächen und Nadelwäldern der Ebene! Bei Rauenberg $u$. Malsch nur sehr vereinzelt! Var. $\beta$ am Vitriolbergwerk bei Schriesheim! Juni-September.

[J. perennis Lam. A usdauernde J.; unterscheidet sich durch längere, keilig-lineale $\mathrm{Bl}$; ; ausläufertreibende $\mathrm{W}$., und durch grössere Blthlöpfe. 24. $1 \frac{1}{2}-2 \frac{1}{2}^{\prime}$. Blkr. hellblau. - N. V. in Rhb. auf den Vorbergen bei Wachenheim in Kiefern Culturen. (Dr.Koch). Juli-September.

\section{Pliyte um a $L$. W a l d rapunzel.}

559. P. spicatum $L$. A ehrenf. W. ; St. einfach; Bl. gekerbtgesägt, die unteren langgestielt, eirund-herzf., die oberen lineal; Aehren walzenf.-länglich. 4. 1-2 $\frac{1}{2}^{\prime}$. Wzst. rübenf. - Variirt:

«) ochroleucum Döll; Bl. meist doppelt gekerbt-gesägt; Blth. gelb.

B) nigrum Schm.; Bl. meist einfach gekerbt-gesägt; Blth blau.

Diese 2 Var. zeigen hie und da, z. B. im Birkenauer Thal bei Weinheim entschieden Uebergänge! In Wäldern, auf Waldwiesen häufig. Im Gebirge Var. $\beta$ vorherrschend, besonders in trockenen Bergwäldern, z. B. beim Haarlass: Stellenweise auch beide Var. beisammen, z. B. im Mïhlenthale bei Handschuchsheim! bei Schönau! Schriesheim! Weinheim! beim Maischbacher Hof! In der Ebene Var. $\alpha$ läufiger, z. B. im Friedrichsfelder Walde! bei Wiesloch! zuweilen ausschliesslich, z. B. Kirrlach! Waghäusel! Mai-Juli.

(Das von Gattenhof und Dierb. auf Wiesen beim Wolfsbrunnen, angegebene $P /$. orbiculare $\mathrm{L}$. ist in neuerer Zeit weder dort, noch sonst im Geb. oder in der Nähe des Geb. wahrgenommen.)

\section{Campanula $L$. Glockenblume.}

a) Blthn. sitzend, in end- oder achselständige Küpfe veroinigt.

560. C. glomerata $L$. Geknäuelte G.; St, aufrecht, einfach, wie die Bl. kurzhaarig, seltener kahl; untere Bl. gestielt, eirund-herzförmig, fein gekerbt, die oberen stengelumfassend; Kzipfel lanzettl. 4. $\frac{1}{2}-1 \frac{1}{2}^{\prime}$. - Variirt mit grösseren und kleineren Blkronen, auch mit weissgrauer Behaarung. 
Auf Wiesen, an Waldrändern, hie und da, Tialkboden liebend, Weinheim! Leutershausen! Hessel bei Wiesloch! Dielheim! Maischbacher Hof! Auf den Wiesen der Rheinfläche, z. B. Neckarau! beim Relaishause! Ketsch! Mai-Juli.

561. C. Cervicaria L. Hirsch-G., steifhaarig; St. aufrecht, einfach; untere Bl. langgestielt, in den Bltstiel verschmälert, lanzettl., feingekerbt, obere Bl. lineal-lanzettl.; Kzipfel eiförmig, stumpf. 4 . $2-3 '$. Blkr. hellblau.

In Gebirgswäldern, auf steinigem, kalkhaltigem Boden nicht häufig. Hie und da bei Weinheim, z. B. im Birkenauer Thal! auf dem Schlossberg daselbst (Düll). In der Hessel bei Wiesloch! auf dem Teufelskopf bei Dielheim! Juli, August.

b) Blthn. gestielt; in Trauben oder Rispen.

$\alpha$. Kapseln nickend, am Grunde aufspringend.

562. G. rotundifolia $L$. Rundbl. G.; St. aufsteigend, grundständige Bl. langgestielt, rundlich-herzf., gekerbt; Stbl, lanzettl.-lineal , fast ganzrandig; Blth. langgestielt, rispig; Kzipfel pfriemlich. 4. $\frac{1}{2}-1^{\prime}$. Blkr. hellblau. - Variirt kahl und behaart, mit etwas breiteren, oder an trockenen felsigen Standorten, mit sehr schmalen linealen Stbl. Bemerkenswerth ist:

ß) hirta Koch; dicht grauhaarig; Kelcho etwas borstig.

Die grundst. Bl., welche zur Blüthezeit meistens schon völlig zerstört sind, müssen im Frühling oder später an den meist immer vorhandenen diesjährigen unfruchtbaren Trieben beachtet werden.

An Mauern, Wegen, auf Haiden, Sandflächen, Wiesen überall verbreitet! Var. $\beta$ an sehr dürren Standorten der Gebirge und der Ebene, z. B. auf dem Oelberge bei Schriesheim! bei Friedrichsfeld! Juni-September.

563. G. rapunculoides $L$, Rap unzelähnliche G.; St, aufrecht, stumpfkantig, steifhaarig; Bl. ungleich gesägt, etwas rauhhaarig, die unteren langgestielt, herzförmig, die oberen fast sitzend, eilanzettl,; Trauben meist einseitswendig; Kzipfel lanzettl., nach d. Verblühen zurückgeschlagen. 4. 1-2'. Wzst. etwas kriochend Blkr. violett.

Auf Aeckern, an Zäunen, in lichten Wäldern und Gebüschen, besonders auf Lehmboden häufig! Im Gebirge seltener, aber auf Aeckern der Ebeno stellenweiso sehr verbreitet! Juni-August.

564. C. Trachelium L. Nesselbl. G.: St. aufrecht, einfach, scharfkantig, wie die $\mathrm{Bl}$. rauhhaarig; BI. grob doppelt-gesägt, untere langgestielt, herzf., obere eilanzettl., fast sitzend; Blth. einzeln oder lockertraubig; Kzipfel eilanzettl., steifhaarig. 24. 1-2'. Blkr, blau, 
grüsser als bei d. vorigen. Ausgezeichnet durch die langen Haare des Blkrsaumes.

An Waldrändern, in Steinbrüchen, an Felsen der Gebirge und der Ebene häufig! Juni-August.

$\beta$. Kapseln aufrecht, seitlich an der Spitze aufspringend.

565. C. persicifolia L. Pfirsich bl. G.; St. steif, aufrecht, einfach, rispig, armblth; Bl. fein gesägt, meist kahl, untere längl.verkehrt-eiförmig, in den Bltstiel verlaufend, obere sitzend, lineallanzettl.; Kzipfel lanzettl. 24. 2-3'. Blkr. gross, hellblau. Meist mit kahlen, seltener mit borstig-behaarten Kelchen.

In Gebirgswäldern häufig! Seltener in Wäldern der Ebene, auf Haiden, z. B. Friedrichsfcld! Schwetzingen! Käferthal! Walldorf! Juni-August.

566. C. Rapunculas L. Rapunzel-G.; St. aufrecht, einfach ; Bl. gekerbt, untere elliptisch, in den Bltstiel verlaufend, obere sitzend, lineal-lanzettl; Rispe zusammengezogen, verlängert, meist einseitswendig; Kzipfel pfriemlich. 4. $1 \frac{1}{2}-2^{\prime}$. W. rübenartig. Blhr. klein, hellblau. - Variirt kahl und behaart.

An Wegen, auf trockenen Wiesen, Sandfächen, in Nadelwäldern der Gebirge und der Ebene häufig! Nai-Juli.

567. C. patula $L$. A usgebreitete G.; St. aufrecht, schwach; Bl. d. vorigen; Blth. in lockeren, ausgebreitet-rerzweigten Rispen;

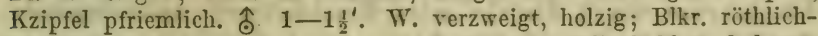
blau, etwas grösser als bei d. vor. Variirt ebenfalls kahl u. behaart.

Auf Wiesen, an Waldrändern, auf Waldtriften hie und da, aber weniger verbreitet als vorige, z. B. ziemlich häuffg bei Handschuchsheim! Schriesheim! Weinheim! beim Haarlass! beim Wolfsbrunnen! auch auf Wiosen um Rohrbach! Leimen! St. Ilgen! im Friedrichsfelder Walde! beim Relaishause nicht selten! Mai-Juli.

\section{Specularia Heist. Venus spiegel.}

568. S. Speculum D.C. A echter V.; St. ausgebreitet ästig; Bl. eiförmig-länglich; Blth. einzeln, achselständig, entfernt; Kzipfel linealisch, so lang als Blkr. und Fruchtknoten. ๑. 5-10". Blkr. violett. (Campanula Speculum L., Prismatncarpus Speoulum l'Herit.)

Unter der Saat, auf Brachaeckern, kalkhold, hie und da, z. B. zwischen Rohrbach und Wiesloch! bei Rauenberg! einzeln zwischen H. und Wieblingen! auf der Insel bei der Bergheimer Mühle, bei Eppelheim und Edingen (Stud. Gysser). Juni, Juli. [In grosser Menge $z$ wischen Bruchsal und Unter Grombach !]

569. S. hybrida D. C. B astard-V.; St. meist einfach; Bl. verkehrt-eiförmig; Blth. einzeln, an der Spitze einander genähert, 
Kzipfel elliptisch, länger als die Blkr. ๑. 5-8". Blkr. hellblau, kleiner als bei der vorigen. (Camprmula hybrida.L., Prismatocarpus hybridus l'Herit.)

Lnter der Saat auf kalkhaltigem Boden nicht häufig, aber gesellig. Zwischen Nussloch und Wiesloch! zwischen Feudenheim und Seckenheim! zwischen Seckenheim u. Mannheim (Schimp.) Mai, Juni.

\section{ERICEAE R. Br.}

Ialbstrüucher oder selten Krïuter mit abwechselnden oder gegenstïndigen, einfachen, zuweilen nadelförmigen, meist lederartigen, immergrünen, selten hinfälligen Blättern olne Nebenblätter. K. bald untenstïnclig, bald theilweise oder ganz oberständig, 4-6zählig. Blkr. verwachsenblätterig oder getrenntblätterig, 4-6zählig. Stbgef. von der Zahl der Blbl. oder doppelt so viele. Antheren 2fächerig, an der Spitze hornartig verlängert, ausserdem oft mit Anhängseln, meist durch Poren aufspringend. Fruchtk. ober- oder unterstiindig, meist mehrfächerig. Samentrïger central. Griffel 1. Frucht eine durch Mittel- oder Randtheilung aufspringende Kapsel oder Beere. Samen klein, eiweisshaltig, mit geradem Keim. - Die meist sehr geselliglebenden Ericeae sind bei uns auffallend schwach vertreten. Ausser Calluna vulgaris und Vaccinium Myrtillus nehmen nur die Pyrolene, besonders als Begleiter der Nadelhölzer, eine hervorragende Bedeutung ein. Unsere Torfnzoore sind (mit Ausnalime von Calluna vulgrris) frei von Ericeae, besitzen daher einen wesentlichen Charaliter der norddeutschen und Hochgebirgs-Torfmoore nicht. - Die einheimischen Arten sind durch adstringirend-bittere Eigenschaften ausgezeichnet.

Trib. 1. Vaccinieae; Bl. flach; Bllir. abfällig; Stbgef. 8-10; Antheren an der Spitze und meist auf dem Rücken 2hörnig; Narbe kugelig; Fruchtk. unterständig; Frucht beerenartig.

V a c cinium. K. und Blkr. 4-5zählig; Beere kugelig.

Trib. 2. Andromedeae; Bl. flach; Blkr. abfällig; Stbgef. 10; Antheren (bei unserer Gattung) an der Spitze mit 2 Grannen; Fruchtk. oberständig; Frucht (bei unserer Gattung) beerenartig.

Arctostaphylos. K. 5spalt.; Blkr. eiförmig, 5zähnig; Beere 5samig. 
Trib. 3. Ericaceae; Bl. (bei uns) nadelfürmig; Blkr. bleibend; Antheren am Grunde mit 2 Anhängseln; Fruchtknoten oberständig; Kapsel.

Calluna. K. 4theilig; Blkr. 4spaltig; Stbgef. 8; Antheren mit Längsspalten aufspringend; Kapsel 4fächerig, 4klappig, die Scheidewände lüsen sich ron den Klappen und bleiben mit der Mittelsäule verbunden.

Trib. 4. Pyroleae; Bl. flach; K. 5spaltig; Blkr. 5bblätterig od. theilig; Stbgef. 10; Antheren am Grunde gehörnt, mit 2 Poren aufspringend; Fruchtknoten oberständig; Kapsel 5fächerig, auf dem liücken der Fächer in Längsritzen aufspringend; Samen sehr klein, mit lockerer Schaale.

Pyrola. Einzige Gattung.

\section{Vaceinium $L$. He idelbeere.}

570. V. Myrtillus $L$. Gemeine H.; Zweige scharfkantig; Bl. eiförmig, feingesägt, kahl, beiderseits grün, abfällig; Blth. einzeln, achselständig; Ksaum fast ganzrandig; Blkr. kugelig, grünlichfleischroth; Beeren blauschwarz, sehr selten weiss. $\hbar$. $1^{\prime}$.

In Wäldern, auf Haiden, besonders im Gebirge häufig! Mai. (Off.: Baccae Myrtillorum.)

571. V. vitis idaea $L$. Preisselbeere; Zweige stielrund; B1. verlielirt-eirund, gekerbt, kahl, immergrün, unterseits dunkel punktirt; Blth. in endständigen kurzen Trauben; Blkr. glockig, röthlich; Beeren roth. ち. 4-8".

Auf Haiden, in trockenen Wäldern, besonders Nadelwäldern selten. Am Abhange des Oelberges gegen Schriesheim in Menge! Im Kiefernwalde oberhalb des Wolfsbrunnens (gegen Osten)! MaiJuli. (Off.: Baccae Vitis idaeae.)

\section{Arctostaphylos Adans. Bärentraube.}

572. A. officinalis W. ct Gr. Heilkräftige B.; Zweige niederliegend, etwas aufsteigend; Bl. länglich verkehrt-eiförmig, ganzrandig, immergrün, lederartig, unterseits netzaderig; Blth. in kurzen endst. Trauben. 支. Blkr. und Beeren roth. (Arbutus uva ursi L.)

Im Nadelwalde zwischen Käferthal und Virnheim nur selten (Dr. Gerlach). Mai, Juni.

[N. V. a. d. Geb. nur in Rhb., z. B. bei Dürkheim auf der Höhe des Schlammberges! im Wachenheimer u. Deidesheimer Walde (F. Schult $)$, als Ausläufer einer Verbreitungslinie von Kaiserslautern.] (Off.: Fol. Uvae ursi.)

SCHMIDT, Flora v. H. 


\section{Callu u Salisb. Haide.}

573. C. vulgaris Salisb. Gemeine H., halbstrauchartig; BI. lineal, 4reihig-dachig, meist kahl; Blthtrauben fast einseitswendig. t. $1-2^{\prime}$. Blkr. blassrosa, seltener weiss. (Erica vulgaris L.)

An Waldrändern, auf Sandflächen, Triften stets gesellig, oft grosse Strecken überziehend. Juli-September.

\section{Pyrola $L$. Wintergrün.}

a) Blth, in gipfelständigen Trauben; Blbl. getrennt.

574. P. rotundifolia $L$. R undbl. W.; Bl. grundst., langgestielt, rurdlich-eifürmig, stumpf; Trauben verlängert; Kbl. lanzettl. zugespitzt; Griffel abrrärts geneigt, an der Spitze bogenförmig. 4. 1'. Blbl. weiss-röthlich, abstehend.

In schattigen Laubwäldern hie und da. In grosser Menge zwischen Leimen, Nussloch und Maischbach! bei Schatthausen! Dielheim! Zwischen Weinheim und Leutershausen! Nur vereinzelt 2 wischen Ziegelhausen und Schönau! Juni.

575. P. chlorantha Sw. Grünblth. W.; der vorigen ähnlich, aber Bl. kleiner, fast kreisrund, am Rande etwas umgebogen, oberseits dunkelgrün, mehr lederartig; Traube locker; Kbl. eirund; Griffel nach abwärts gebogen. 4. 6-10". Bbl, gelbl.-grün, abstehend,

In Kiefernwaldungen stellenweise recht häufig, z. B. im Friedrichsfelder und Käferthaler Walde! bei Sandtorf! Schatthausen! Walldorf! Auch zwischen Nussloch und dem Maischbacher Hof! Juni.

576. P. minor L. Kleineres W.; der ersteren Art sehr älnlich; Bl. rundlich-eiförmig; Traube gedrängt, kürzer; Griffel senkrecht, gerade. 4. 5-10". Blbl. hellrosa oder weiss, kugelig-zusammengeneigt.

In Laubwäldern, auf Waldtriften, in Gebüschen, hie und da, seltener in Nadelwäldern. Vom Haarlass stellenweise durch das Gebirge bis Schönau und Weinheim! häufig in den Kastanienwäldern im Mühlenthale bei IIandschuchsheim! In Menge auf dem Geisberge! vereinzelt in Gebüschen unter dem Riesensteine und bei d. Molkenkur! Bei Gaiberg! Schatthausen! Nussloch! verbreitet. Im Friedrichsfelder Walde, bei Kirrlach, Sandtorf häufig: Mai-Juni.

577. P. secunda $L$. Einseitsblth. W.; Bl. eiförmig, spitz, gesägt; Traube einseitswendig; Griffel wenig gebogen. 4. 4-8". Blbl. grünlich-weiss, zusammenneigend.

In Kiefernwaldungen nicht häufig. Im sog. Vugelheerd bei Schatthausen! Zwischen Friedrichsfeld und dem Relaishause! Im Virnheimer Walde (Schimp.). Oberhalb Birkenau im Nadelwalde (Dierb; woselbst jetzt aber gewiss nur sehr vereinzelt?) Mai, Juni. 


\section{b) Blthen in Dolden; Blbl, getrennt.}

578. P. umbellata $L$. Doldiges W.; Bl. lanzettlo-keilfürmig, gesägt, lederartig, glänzend; Kbl. eiförmig; Griffel sehr kurz. 4. $3-6^{\prime \prime}$. Bllir. hellrosa. (Chimaphila umbellata Nutt.).

In Kiefernwaldungen hie und da, meist gesellig. Zwischen Triedrichsfeld und dem Relaishause! Schwetzingen! Käferthal! Walldorf! Sandhausen! Juni, Juli.

c) Blthschaft 1blüthig; Blkr. verwachsenblittr.

579. P. uniflora $L$. Einblüth. W.; Bl. rundl.-spatelig, gesägt; Kbl. abgerundet, gewimpert; Griffel verlängert. 4. 2-4". Blkr. weiss, ansehnlich.

In moorreichen, etwas feuchten Nadelwäldern bei Naischbach (Dierb. Schimp.) bei Friedrichsfeld und Virnheim (Döll.) Mai, Juni.

[Stellenweise durch den Odenwald verbreitet. N. V. a. d. Geb.: Bickenbacher und Eberstädter Kiefernwaldungen in Hs. (Schnttsp.). In $\mathrm{B}$, und $\mathrm{Rhb}$, zunächst fehlend ]

\section{MONOTROPEAE. Nutt.}

Chlorophyllose strohfarbene saftreiche Pflanzen ohne Spaltöfinungen, mit schuppenförmigen Niederblättern, ohne Laubhätter. K. und Bllir. regelmässig $4-5$ blätterig, unterständig, in der Knospe dachig, Staubgefässe 8-10, am Grunde mit 4-5 Drüsen. Antheren 2 fächerig, durch eine Queerspalte aufspringend. Fruchtknoten $4-5$ fächerig mit 1 Griffel und tricnterförmiger Narbe. Kapsel 4-5klappig, Klappen die am Grunde zusammengewachsenen Scheidewände tragend. Samen zahlreich, klein, eiweisshaltig, von lockerer netzartiger Schaale umgeben.

Monotropa. Bbl. am Grunde höckerartig, innen necktarführend. Endblth. 5zählig; Seitenblth. 4zählig (Stbgef. 8-10, Griffel 1).

\section{II onotropa $L$. Ohnblatt.}

580. M. Hypopitys $L$. Fichtenspargel; St. stielrund, schuppig; Blthtraube endständig, nickend, später gestreckt; Blbl. wachsgelb. 24. Wstock fleischig, mit zahlreichen Wurzelfasern, nicht eigentlich parasitisch lebend. Variirt:

a) glabra Koch; kahl, Fruchtknoten mit kleinen Warzen.

B) hirsuta Koch; St. oben, nebst Blththeilch, behaart. 
In Nadel- und Laubwäldern häufig. Var. $\alpha$ in den Kiefernwäldern der Ebene sehr verbreitet, seltener im Gebirge, z. B. bei Schriesheim! Rauenberg! Var. $\beta$ zuweilen mit der kahlen Form, jedoch vorzugsweise in feuchten Laubwäldern, z. B. bei Wiesloch! Maischbach! Schatthausen! Juni, Juli.

\section{Subclass. 3.}

\section{COROLUFLORAE. $D C$.}

Kelch frei, verwachsenblätterig; Blumenkrone verwachsenblätterig, unterständig; Staubgefüsse der Blkrone (oder wo diese in seltenen Fällen fehlt), dem Kelche eingefügt; Fruchtknoten frei; (sehr selten mit dem Kelche theilweise verwachsen).

\section{AQUIFOLIACEAE. DC.}

Sträucher oder Bäume mit einfachen, immergrünen Blättern ohne Nebenblätter. Blthdecken 4-6gliederig, regelmässig, in der Knospenlage dachig. Stbgefässe 4-6; Fruchtknoten 2-6fächerig, mit 1eiigen Fächern, hängenden Eichen und fast sitzenden gelappten Narben. Beere mit steinharten eiweissreichen Samen. Keim gerade.

Ilex. K. 4-5zähnig, bleibend; Blkr. radförmig, 4-5theilig; Stbgef. 4-5; Narben $4-5$; Beeren kugelig.

\section{Ilex $L$. Stechpalme.}

581. I. Aquifolium $L$. Gemein e $\mathrm{St}$; ; Bl. eiförmig, dorniggezähnt, lederartig, glänzend; Blthen achselständig, fast doldig; Blkr. weiss; Beeren erbsengross, scharlachroth, \$ von $3-16^{\prime}$. An sehr alten Stämmen sind die Bl. ganzrandig und nur an der Spitze mit einem Dorn versehen.

In Wäldern und Gebüschen um Schönau und Neckarsteinach nicht selten: Vereinzelt bei Wilhelmsfeld und Ziegelhausen! Mai, Juni. 


\section{OLEACEAE. Lindl.}

Bäume od. Sträucher mit gegenständigen einfachen oder unpaarig gefiederten Blättern ohne Nebenblätter, meist mit traubenartigen Blthständen. Blthdecken vollständig od. fehlend. Blkrone regelmässig 4zählig, in der Knospe klappig. Blüthen meist zwitterig, selten eingeschlechtig oder vielehig. Staubgefüsse meist 2. Fruchtknoten 2fächerig; Fächer meist 2 eiig, Eichen hängend, Griffel 1. Frucht kapsel- oder beerenartig, selten flügelfruchtartig (bei Olea L. steinfruchtartig). Samen eiweisshaltig Keim gerade.

Ligustrum. K. 4zähnig mit 4theiligem Saum; Stbgef. 2; Beere 2 fächerig.

Syringa. K. 4zähnig; Blkr. trichterförmig mit 4theil. Saum: Stbgef. 2; Kapsel 2fächerig.

Fraxinus. K. u. Blkr. 3-4theilig od. fehlend; Stbgef. 2; Flügelfr. (Oft eingeschlechtig oder vielehig).

\section{4\%. Ligustrum $L$. Hartriegel.}

582. L. vulgare $L$. Gemeiner H.; Str. mit lanzettl, ganzrandigen, kahlen $\mathrm{Bl}$; gedrängten endständigen Rispen; Blkr. weiss; Beeren dunkelviolett.

In Wäldern, Gebüschen, an felsigen Abhängen, vorzüglich auf kalkhaltigem Boden häufig! Juli.

\section{Syringa $L$. Flieder.}

S. vulgaris L. Gemeiner F.; Str. mit herzeiförmigen ganzrandigen Bl.; reichblth, endständigen Rispen. Blkr. lila od. weiss.

Aus Persien stammend; in Zäunen, Waldgebüschen gleichsam verwildert. Mai.

\section{Fraxius $L$. Esche.}

583. F. excelsior $L$. Hohe E.; † von $40-100^{\prime}$; Bl. unprarig-gefiedert; Blttch. längl.-lanzettl., zugespitzt, gesägt; Blthen in kurzen, seitenständigen Rispen, yor den Blt. erscheinend; $K . u$. Blkr. häufig fehlend.

An Wegen, in feuchten Wäldern hie und da! April, Mai. (Off, : Cort. Fraxini). 


\section{ASCLEPIADEAE. $R$. Br.}

Kräuter oder Strüucher, meistens einen scharfen Milchsaft enthaltend, mit einfachen, gewöhnlich gegenständigen Blättern ohne Nebenblätter. Kelch 5theilig, bleibend; Blkr. 5spaltig, abfallend, in der Knospe dachig. Staubgefässe 5, mit meist ineinander verwachsenen Stbfiden. Antheren der Narbe anliegend. Blthstaub in bestimmt gestaltete wachsartige Massen verbunden und sich an die drüsigen Fortsätze der Narbe anhängend; Fruchtknoten mit 2 Griffeln und einer gemeinschaftlichen schildförmigen 5̌eckigen drüsigen Narbe. Balgkapseln 2. Samen zahlreich, mit spärlichem Eiweiss, dachziegelig geordnet, meist am Nabel mit einem Haarschopf. Keim gerade.

Cรnanchum. Blkr. radförmig, 5spaltig: Stbfäden in eine 5lappige Nebenkrone verwachsen, deren Lappen zwischen den Blbl. stehen; 10keulenfürmige Pollenmassen, Samen schopfig.

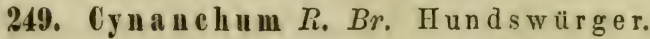

584. C. Vincetoxicum $R$. Br. Ge meiner H.; St. aufrecht, an der Spitze schwach gewunden; Bl. herzförmig-eirund, kahl; Blthen in achselst. Dolden; Nebenkr. nur bis $\frac{1}{3}$ fünflappig; Lappen dicklich, durch cine zwischengeschobene schmale Haut verbunden, 4. $1 \frac{1}{2}-2 \frac{11}{2}$. W. büschelig mit verlängerten Faserı. Blkr, weiss od. gelblich. (Asclepias Vincetoxicum L.).

An Abhängen, in Wäldern, auf Waldtriften der Gebirge und der Ebene, auf Kalk- und Sandboden stellentweise häufig, z. B. in Menge am Wege vom Schloss nach den Wolfsbrunnen! im Dreitrögethal! beim Haarlass! hie und da längs der Bergstrasse. Im Friedrichsfelder Walde! Juni-August. (Off.: Rad. Vincetoxici).

[C. laxum Bartl,; dem vorigen ähnlich; St. aufrecht, nicht gewunden, niedriger; Nebenkr. bis zur Mitte 5lappig; Lappen dünner, durch eine breite Hant verbunden. 4. 1-1 $\frac{1}{2}^{\prime}$. (W Wurde von dem verstorbenen Prof. G. W. Bischoff auf den Kalkhügeln des Haardtgebirges vor einigen Jahren erkannt und von der früher damit verwechselten vorigen Art unterschieden. Die angegebenen Charaktere haben sich bei im hiesigen bot. Garten cultivirten Exemplaren bisher bewährt. (Vgl, Jahresbericht d. Pollichia 1854). Verbreitg, noch 
weiter zu rerfolgen, aber im Gebiet der Flora noch nicht wahrgonommen. Sicheres Vorkommen bei Dürkheim : am Fusse des Schlammberges gegen die Kallstädter Ziegelhütte und auf den KalkhügeIn gegen Leistadt und Kallstadt! Juni, Juli.]

\section{APOCYNEAE. $R$. $B r$.}

Durch Milchsaft ausgezeichnete (meist tropische) Pflanzen, mit oft gegenständigen Blättern ohne Nebenblätter. Kelch 5theilig, Blkrone 5spaltig, in der Knospenlage gedreht, Stbgef. 5, frei, Antheren oft mit häutigem, verlängertem Anhängsel des Mittelbandes; Blüthenstaub körnig (nicht wachs= artig), Fruchtknoten 2, ein-oder zweifächerig, mit 1 oder meist 2 verbundenen Griffeln und einer gemeinschaftlichen Narbe. Frucht balgkapselartig oder beerenartig. Samen eiweisshaltig. Keim gerade.

Vinca. Blkr. trichter- oder tellerförmig. Antheren an der Spitze gebärtet, der Narbe anliegend; Narbe scheibenförmig mit Haarkranz; Balgkapsel mit schopflosen Samen.

250. Vinca $L$. Immergrün.

585. V. minor $L$. Kleineres I.; St. kriechend; Bl. gegenst. elliptisch-lanzettlich, lederartig, kahl, immer grün; Blth, einzeln, achselständig. 24 Blkr. hellblau; Stengel mit reichlichen Bastbündeln, daher ungewöhnlich zähe.

In Wäldern, Gebrischen hie und da, meist sehr gesellig. Stellenweise in Menge in den Gebirgswäldern vom Haarlass gegen Schönau! Schriesheim! Weinheim! Wiesloch! Schatthausen! In manchen Laubwäldern der Ebene gleichfalls nicht selten, z. B. bei Schwetzingen! Kirrlach! April, Mai. (Off.: Hb. Vincae pervincae).

\section{GENTIANEAE. Juss.}

Kräuter mit gegenständigen oder seltener abwechselnden Blättern ohne Nebenblätter. Kelch bleibend; Blkr. 4-8spaltig, meist verwelkend, bleibend, in der Knospe nach Rechts gedreht; Stbgef. von d. Zahl d. Blkrzipfel, meist 5; Fruchtknoten $1-2$ fächerig, mit 2 theilweise oder ganz ver- 
wachsenen Griffeln, mit 1-2 Narben. Frucht (bei unseren Arten) eine 2klappige, vielsamige Kapsel. Samenträger an den Rändern od, auf der Mitte der Klappen. Samen eiweisshaltig, mit geradem Keim. - Stengel und die immer ganzrandigen Blätter der einheimischen Arten sind kahl. Alle ausgezeichnet durch Bitterstoffe. Mehrere haben Vorliebe für Feuchtigkeit des Bodens oder gedeihen nur im Wasser. Einige sind kalkhold, die meisten zwar bodenvag, jedoch eine lockere humusreiche Unterlage verlangend.

a) Menyantheae. Fruchtknoten auf einer unterständigen Scheibo stehend oder von Drüsen umgeben. Stbgef. 5. Narbe 1.

Men y a nthes. K. 5theilig; Blkr. 5th., trichterförmig; Fruchtknoten am Grunde mit einer gewimperten Scheibe; Kapsel 1fächerig; Samenträger auf der Mitte der Klappen.

Limnanthemum. K. 5th.; Blkr. radförmig; Fruchtkn. am Grunde 5 Drüsen; Kapsel 1fächerig; Samentrïger am Rande der Klappen.

b) Gentianeae verae. Fruchtknoten ohne unterständige Scheibe.

Gentiana. K. 4-5theilig, seltener einseitig aufgeschlitzt; Blkr. cylindrisch oder glockig; Stbgef. meist 5; Antheren nach dem Verblühen gerade; Griffel sehr kurz; Narben 2 ; Kapsel 1 fächerig.

Chlora. K. 8theilig; Blkr. tellerförmig; Stbgef. 8; Griffel deutlich, mit 2 Narben; Antheren, Kapsel d. vor.

Erythraea. K. 5spaltig; Blkr. trichterförmig, 5spaltig; Stbgef. 5; Antheren nach dem Verblühen schraubenförmig gedreht; Griffel deutlich mit 2 Narben; Kapsel 1 fächerig.

\section{I. Menyanthes $L$. Fieberklee.}

586. M. trifoliata $L$. Dreiblättriger F.; Wstock kriechend; Bl. abwechselnd, grundst. langgestielt, mit sehr entwickelten Blattscheiden, 3zählig; Blättch. längl. verkehrt-eirund, glatt; Traube langgestielt, vielblüthig. 24. $\frac{1}{2}-2^{\prime}$. Blkr. weiss, etwas röthlich, innen mit zierlichem bärtigem Saume.

Auf feuchten Wiesen, in Sumpfgräben hie und da, z. B. Rohrhof! Brühl! Sandtorf! Auch bei Wilhelmsfeld. Mai.

[In der Ebene jenseits des Rheins, z. B. bei Speier! Maxdorf! verbreiteter als diesseits.] (Off.: IIb. Trifolii fibrini).

252. Lim anthem um Gmel. Teichblume.

587. L. nymphoides Vent. Seerosen-T.; St. langgestreckt, schwimmend; Bl. langgestielt, herzförmig-kreisrund, schwimmend, etwas lederartig; Blthstiele achselständig, einzeln oder doldig. 4 . 
Blkr. gelb, ansehnlich, mit gefranzten zarten Lappen. (Menyanthes nymph. L.)

In Teichen, Sumpfgräben, stehenden Gewässern, in der Nähe des Rheines hie und da. In Menge in den Neckarauer Sümpfen! bei Ketsch! Otterstadt u. s. w. Juli-Sept.

\section{Gentiana $L$. Enzian. \\ a) Schlund der Blkrone kahl.}

588. G. cruciata $L$. Kreuz-Enzian; St. aufsteigend; B1. kreuzweise gestellt, lanzettl., am Grunde scheidenartig verbunden; Blth. in achselst., gedrängten Köpfchen; Blkr. walzig-rührig, 4spaltig, blau. 2. $\frac{1}{2}-1$ '.

An Waldrändern, auf trockenen Waldtriften und sonnigen Hügeln hie und da, z. B. in der Hessel bei Wiesloch! bei Rauenberg! Teufelskopf bei Dielheim! Oberhof bei Schatthausen, am Fahrwege durch den Saalengrund (von Göler), Weinheim! Zwischen Friedrichsfeld und Schwetzingen wohl nur noch vereinzelt. Juli, August.

589. G. Pneumonanthe $L$. L ungen-E.; St. aufrecht; BI. sitzend, längl.-lineal, stumpf; Blth. end- und achselständig, einzeln oder gezweiet; Blkr. keulig-röhrig, 5spaltig, dunkelblau. 4. $\frac{1}{2}-2^{\prime}$. Niederbl. sehr klein; schuppenförmig.

Auf feuchten Wiesen der Rheinfläche, z. B. häufig zwischen Neckarau und dem Relaishause! beim Rohrhof! Waghäusel! Sandtorf! Juli-Sept.

[Ebenso verbreitet jenseits des Rhs., z. B. bei Maxdorf u.s. w.!]

[G. utriculosa L. S chla u chartiger E.; St. ästig; Bl. eiförmig od. länglich, stumpf; Wbl. rosettig; Kelch aufgeblasen, geflügelt-kantig, länglich-oval. ๑. 3-8". Blkr. himmelblau.

Auf feuchten Wiesen. N: V. in Rhb.: Maxdorf! Frankenthal! Dannstadt b. Speyer (Dr. Wals). Mai, Juni.

b) Schlund innen bärtig.

590. G. germanica Willd. Deutscher E.; St. ästig, vielblüthig; Bl. sitzend, eilanzettlich, spitz; Wbl. verkehrt-eiförmig, kurzgestielt; Blkr. keulig-röhrig, 5spaltig. ๑. 4-10". Blkr. blassviolett.

Auf Wiesen, Triften, an Waldrändern der Gebirge und der Ebene nicht selten. Sehr verbreitet zwischen Wiesloch! Dielheim! und Rauenberg! Schatthausen I auf dem Künigsstuhl! auch jenseits des Neckars auf der Engelswiese! und durch das Gebirge längs der Bergstrasse! In der Ebene zwischen Friedrichsfeld und dem Relaishause! Mannheim! August-October. 
c) Schlund innen kahl; Zipfel der Blkrone franzig-gewimpert.

591. G. ciliata $L$. Gew imperter E.; St. kantig, meist einfach, Bl. lineal-lanzettl.; Blth. achsel- und endständig; Blkr. 4spal. tig, blau. 24. $\frac{1}{2}-1^{\prime}$.

Auf sonnigen Hügeln, an Waldrändern, auf Waldtriften der Gebirge, kalkhold. Stellenweise verbreitet von Rauenberg bis Schatthausen! häufig zwischen Wiesloch und Nussloch! einzeln bis Leimen und Rohrbach! August-October.

\section{Chlora $L$. Bitterling.}

592. Ch. perfoliata $L$. Durchwachsener B.; bläulichgrün; St. einfach oder ästig; Stbl. 3eckig-eiförmig, mit ihrer ganzen Breite verwachsen; Blthen endständig; Kbl. pfriemlich, kürzer als d. Blkr,; Blbl. stumpf, gelb. ○. $\frac{1}{2}-1^{\prime}$.

Auf feuchten Wiesen der Rheinfläche, im Gebiet nur bei Neckarau! und am Rhein gegen Mannheim! Juni, Juli.

[Jenseits des Rheines mehr verbreitet, 2. B. in Menge bei Frankenthal! Maxdorf! Erpolsheim! Speier!]

593. Ch. serotina Koch. Später B.; der vorigen sehr ähnlich, vielleicht nur Yarietät derselben; Stbl, ei-lanzettlich, nur an der abgerundeten Basis verwachsen; Kbl. lanzettl.-pfriemlich, so lang als die Blkr.; Blbl. etwas zugespitzt, gelb. ๑. 4-10".

Auf feuchten Wiesen der Rheinfläche verbreiteter, als vorige, z. B. Neckarau! beim Relaishause! bei Seckenheim (Dr. Schimp.), hie und da längs des Rheines! häufig 2 wischen Ketsch und AltLussheim! August-October.

[Ebenfalls jenseits des Rheines nicht selten, z. B. zwischen Ludwigshafen und Mundenheim! Friesenheim! Frankenthal! Maxdorf 1]

205. Nrythrae Rich. T a u sendgüldenkraut,

594. E. Centaurium Pers. Gemeines T.; St. einfach, 4kantig; Bl. eirund-länglich, 3-4nervig; Wbl. rosettig, etwas spatelig; Trugdolde endständig, gedrängt, die gabelständigen Blthen fast sitzend; Blbl. rundl.-eiförmig, blassrosa. ๑. $\frac{1}{2}-1^{\prime}$.

Auf Triften, in lichten Wäldern, an Waldrändern häufig! Juli bis September. (Off.: IIb. et Flor. Centaurii minoris.

595. E. pulchella Fries. Niedliches T.; St. meist rom Grunde gabelig verzweigt, flïgelig-4kantig; Bl. eirund, 3-5nervig; Wbl. verkehrt-eiförmig, nicht rosettig; Trugdolde endständig, locker, die gabelst. Blth. deutlich gestielt; Bbl. eilanzettlich, rosa, selten weiss. ๑. 2-4". (E. ramosissima Pers.).

Auf feuchten Wiesen, besonders auf feuchten, lehmigen und 
kalkhaltigen Triften und Aeckern häufig! In der Nähe von H., z. B. am Neckarufer gegen Ziegelhausen! Juli-September.

\section{CONVOLVULACEAE. Juss.}

Meist windende, oft mit Milchsaft versehene Kräuter, mit abwechselnden ganzen oder gelappten Blättern ohne Nebenblätter, oder ganz ohne Blätter. Blüthen regelmässig. Kelch 5spaltig, bleibend; Blkrone regelmässig mit 5lappigem Saum und meist faltig zusammengedrehter Knospenlage. Stbgef. 5. Fruchtknoten meistens einer unterstïndigen Scheibe eingefügt, 2-4fächerig, selten 1fächerig, Fächer 1-2eiig.. Griffel 1-2. Kapsel 2-4fächerig mit unvollständigen Scheidewänden. Samen mit spärlichem Eiweiss, runzligen oder fehlenden Samenlappen. Keim gekrümmt.

a) Convolvuleae. BI. und Samenlappen vorhanden; Kapseln der Länge nach aufspringend.

Convolvulus. Blkr. trichterförmig-glockig, 5faltig; Griffel ungetheilt mit 2 Narben; Kapsel 1-4fächerig.

b) Cuscutineae. Bl. und Samenlappen fehlend; Keim spiralig, fadenförmig; Kapseln rundum aufspringend. Mittelst Saugwarzen schmarotzende Schlingkräuter.

Cuscuta. Blth, knäuelförmig; Blkr. glockig od. krugförmig, 4-5spaltig, unter der Anheftungsstelle der Stbgef. schuppenförmige Blättchen.

\section{Convolvulus $L$. Winde.}

596. C. sepium $L$. Z a un-W.; St. aufstrebend, windend; Bl. herz-pfeilfürmig; Blth. einzeln; Kelch von 2 grossen herzförmigen Deckbl. umgeben; Kapsel 1fächerig, unregelmässig aufspringend. 4. Blkr. ansehnlich weiss.

In Hecken, Gebüschen, besonders an Ufern häuffg! Juli-Sept.

597. C. arvensis $L$. Acker-W.; St. niederliegend, am Boden fortwindend; Bl. eirund- oder lanzettlich-pfeilförmig; Blth. einzeln oder paarweise; Deckbl. klein, lanzettlich, von der Blüthe entfernt; Kapsel 2fächerig, 2klappig aufspringend. 4. Blkr. rosa oder weiss. Die Breite der Bl. wechselt sehr; variirt kahl od, behaart.

An Wegen, auf Aeckern, besonders in Weinbergen sehr verbreitet! Mai-August. 
25\%. Cuscuta $L$. Fla chsseide.

598. C europaea $L$. Europä ische F.; St. fädlich, ästig, röthlich oder gelb; Blkrröhre walzig, von der Länge des Saums, mit aufrechten der Röhre anliegenden Schüppchen; Griffel von der Länge der gelblich-röthlichen Blkrone. ๑.

Auf Aeckern, in Gebüschen, besonders an Flussufern, auf Urtica, Saponaria, Tanacetum, Salix u. s. w. schmarotzend. Stellenweise sehr verbreitet, z. B. am Neckarufer bei H.! und z. B. bei Ladenburg in Vicia sativa grosse Verwüstungen anrichtend. Juli-Sept.

599. C. Epithymum $L$. Thymian-F.; St. ästig, haarfein, meist dichtverwebt, röthlich; Blkrröhre walzig, von der Länge des Saumes durch die zusammenneigenden Schüppchen geschlossen; Griffel länger als die Blkr. ๑. Blkr. weissröthlich,

Auf trockenen Wiesen, Triften, an Waldrändern, hauptsächlich auf Genista Arten, Calluna, Thymus schmarotzend, hie und da häufig, z. B. beim Relaishause! im Friedrichsfelder Walde! Schriesheim! oberhalb der Molkenkur und auf dem Heiligen Berge bei H.! Juni-August. $\left.{ }^{*}\right)$

\section{BORRAGINEAE. Juss. (Asperifoliae).}

Kräuter mit abwechselnden, einfachen, meist borstig-rauhhaarigen Blättern ohne Nebenbl., mit einseitigen, schneckenförmig eingerollten traaben- oder ährenförmigen Blüthenständen. K. und Blkrone 5spaltig od. 5theilig, meist regelmässig.

-) C. Epilinum Weihe von C. europaea besonders durch fast einfache Stengel, durch die kugelige Blkrröhre, welche zweimal so lang ist als der Saum, unterschieden, schmarotzt, besonders in feuchten Jahren häufig auf Linum usitatissimum L. Da aber die Flachs-Cultur im Gebiet der Flora sehr unbedeutend ist, so bleibt das Vorkommen dieser Art zweifelhaft. Die Pflanze findet sich zuweilen in den benachbarten Gebieten. - Auch die mit Luzerne- Kleesamen eingewanderte amerikanische, neuerdings in manchen Gegenden Deutschlands und auch jenseits des Rheines als lästiger $\mathrm{Pa}$ rasit wahrgenommene C. hassiaca Pfeiff. ist bisher im Gib. der Flora noch nicht beobachtet. Diese Art ist ausgezeichnet durch die büschelig gestielten, locker gestellten Blthen und durch glockige Blkrröhre. 
Blkrone oft im Schlunde mit verschiedenartigen Anhängseln (Decklilappen), Staubgef. 5. Fruchtknoten einer unterständigen Scheibe eingefügt, ungetheilt oder 4lappig mit 1 gemeinschaftlichen Griffel, bei der Reife in 4 einsamige Nüsschen zerfallend und von dem bleibenden Kelch eingeschlossen. Samen meist eiweisslos. Keim gerade. - Obwohl an Arten nicht reich, bilden die B. als meistens sehr gesellige Pflanzen und durch die Uebereinstimmung, welcise ihr Habitus zeigt, einen nicht unwesentlichen Theil unserer Krautvegetation. Die meisten lieben steinigen, sandigen Boden, manche gedeihen nur in feuchten Umgebungen, ohrie dadurch ihre bei uns immer rauhe Oberfläche zu verlieren. Viele sind ausgezeichnet durch Schleimgehalt, adstringirende Stoffe, theils im Kraut, besonders aber nebst rothen Farbstoffen in den Wurzeln, einige auch durch Ablagerung von kohlensaurem Kalk in den Nüsschen, z. B. Lithospermum officin.; purpurcoooerul. Die Blumenfarbe ist auffallend veränderlich, daher bei mehreren Arten Wechsel der Farbe während des Blühens.

Trib. 1. Heliotropeac. Fruchtknoten ungetheilt, erst bei der Reife sich in 4 an der Basis flache Nüsse spaltend.

Hel iotropium. Blkr. trichterförmig, ohne Deckklappen.

Trib. 2. Cynoglosseae. Nüsse 4, an den bleibenden Griffel angeheftet.

Echinospermum. Blkr. tellerförmig (mit Deckklappen), Nüsse $3 \mathrm{kantig}$, am Rande weichstachelig.

Cynoglossum. Blkr. trichterf. (mit Deckklappen), Nüsso oberseits abgeplattet, weichstachelig.

Trib. 3. Anchuseae. Nüsse 4, an der Basis mit einem gedunsenen, faltig gerieften Ringe versehen und innerhalb desselben ausgehöhlt; Griffel frei.

Borrago. Blkr. radfürmig, mit 5 kurzen, gekerbten Deckklappen.

Anchusa. Blkr. trichterfürmig mit gerader Röhre und 5 gewölbten Deckklappen.

Ly c opsis. Blkr. trichterförmig mit gekrümmter Röhre und 5 gewölbten Deckkl.

Symphytum. Blkr, walzig-glockig mit pfriemlichen zusammenneigenden Deckkl.

Trib. 4. Lithospermeae. Nissse 4, an der Basis nicht ausgehöhlt, sondern flach oder etwas convex; Griffel frei. 
Echium. Blkr. trichterf. mit schiefem, fast 2 lippigem Sa um. Deckklappen 0 .

Pulmonaria. Blkr. glockig-trichterf., regelmässig; Deckil. 0, statt derselben 5 Haarbüschel.

Lithospermum. Blkr. trichterf., regelmässig; Deckkl. 0; Schlund der Blkr. durch 5 Falten etwas verengert.

My osotis. Blkr. trichter- oder tellerf., regelmässig; Deckkl. 5, flachgewölbt, kahl.

258. Il el i otropium $L$. Sonnenwende.

600. H. europaeum $L$. Europä ische S.; graubehaart; Bl. ausgebreitet, etwas zottig; Bl. eiförmig, ganzrandig; Blth. in seitenständigen, meist gezweieten Achren; Fruchtkelche sternförmig ausgebreitet. $\odot \frac{1}{2}-\mathbf{1}^{\prime}$. Blkr. weiss.

Auf kalkhaltigen Hügeln, Sandfächen, Schutthaufen, in Weinbergen der Rheinflächo stellonweise, z. B. bei Alt-Lussheim! zwischen Plankstadt und Schwetzingen! am Rohrhofe und im Schwetzinger Schlossgarten (Schimp.). Juli-Sept.

[Jenseits des Rheines in der Nähe des Geb. ebenfalls nur stellenweise. In grösserer Verbreitung zunächst in Rhb. zwischen Dürkheim und Grünstadt! in Rhh, bei Oppenheim und Nierstein!]

\section{Echinospermum $L$. I gelnüsschen.}

601. E. Lappula Lehm. Gemeines I.; St. aufrecht, ästig; Bl. längl.-lanzettl., stumpf, graugrün; Trauben verlängert; Blth. klein; Fruchtstiele aufrecht; Nüsse am Rande mit 2 Reihen widerhakigen Stacheln. ๑. $\frac{1}{2}-1^{\prime}$. Blkr. hellblau. (Myosotis Lappula L.).

Auf Sandfeldern, an Ackerrändern, auf trockenen steinigen IÏ̈geln nicht häufig. Zwischen Friedrichsfeld und dem Relaishause im Nadelwalde hie und da! Häufiger zwischen dem Relaishause und Schwetzingen! bei Oftersheim, Walldorf, Hockenheim, Sandtorf! Juni, Juli. heim!]

[Weit verbreiteter auf Kalkhügeln und Weinbergen um Dürk-

\section{Cyuoglossum $L$. Hundszunge.}

602. C. officinale $L$. Heilkräft. II.; St, aufrecht, wie die Bl. dünngraufilzig; untere Bl. elliptisch, in den Bltstiel verlaufend, obere lanzettl, halbstengelumfassend; Trauben vielblüthig, deckblattlos; Nüsse gerandet. $\hat{\delta} \cdot \frac{1}{2}-3^{\prime}$. Blkr. braunroth.

An Wegen, Rainen, auf Triften häufig und stellenweise gesellig! Mai-Juli. (Off.: Rad. et hb. Cynoglossi.) 


\section{Borrago $L$. Borretsch.}

B. officinalis $L$. II eilkr. B., steifborstig; St. ästig, saftrcich; Bl. elliptisch, stumpf; Blth. langgestielt, nickend. ๑. 1-2'. Blkr. hellblau, selten weiss.

Im Orient einheimisch, häufig in Gärten kultivirt und hie und da auf Schutt, an Wegen verwildert. Juni-August.

261. Anchusa $L_{\text {: }} 0$ chsenzunge.

603. A. officinalis $L$. II eilk r. O., steifhaarig; St. aufrecht oder aufsteigend; Bl. lanzettl, wellig, die oberen eirund; Trauben vielblth.; Kbl, zugespitzt, abstehend behaart; Deckklappen sammetartig. 4. $1-2^{\prime}$. Blkr. blau, selten weiss.

An Wegen, Rainen, auf Sandfeldern nicht verbreitet. Zwischen Edingen, Seckingen und Mannheim hie und da! häuffg am neuen Kirchhofe bei Mannheim! Vereinzelt bei Rheinhausen. Mai-August. (Off. : Rad. et hb. Buglossi.)

\section{Lycopsis $L$. Krummals.}

604. L. arvensis L. A cker-K., steifhaarig; St. aufrecht; B1. lanzettl, buchtig-gezähnt; Trauben vielblth. $\odot \frac{1}{2}-1^{\prime}$. Blkr. hellblau. An Wegen, auf Aeckern, Sandfeldern häufig! Juli-September.

\section{Symphytum L. B einwell.}

605. S. officinale $L$. Heilkr. B.; Bl, rauhhaarig, herablaufend, untere eirund-lanzettförmig, in den Bltstiel verschmälert, obere lanzettl.; Trauben vielblüthig, deckblattlos; Deckklappen kürzer als der Blkrsaum; Antheren länger als die Stbfäden. 2. 1-3'. W. spindelförmig, ästig. - Variirt mit längerem oder kürzerem Griffel, mit violetten, rosenrothen oder weissen Blkronen.

Auf Wiesen, in feuchten Gebüschen, in Sümpfen allgemein verbreitet! Mai-Juli. (Off.: Racl. Consolidae majoris.)

606. S. bulbosum Schimp. Zwiebelig B.; Bl, rauhhaarig, länglich-eifürmig, obere halb herablaufend, untere in den Bltstiel verschmälert; Trauben armblüthig; Deckklappen länger als der Blkr.saum; Antheren von der Länge der Stbfäden. 24. 1-2'. Blkr. gelblich-weiss; Wzst. verlängert, runzelige, kugelige Knollen tragend.

In Weinbergen zwischen dem Dreitröge Thal und der ehemal. Krappfabrik bei H. in früheren Jahren in Mengo (Schimp., Bisch, etc.) vielleicht auch jetzt noch nicht völlig ausgerottet, aber jedenfalls sehr selten und vereinzelt. (Einziger Standort in Deutschland.) Die Pflanze findet sich in mehreren Gärten der Umgegend verwildert, u. A. ziemlich reichlich im Schwetzinger Schlossgarten! Mai, Juni. 


\section{Ne h ilm $L$. Natterkopf.}

607. E. vulgare $L$. Gemeiner N., borstig-steifhaariz; $\mathrm{TI}$. lanzettlich; Rispe vielblth.; Blkrrühre kürzer als der K. §. Blkr. blau oder röthlich.

An Wegen, auf Brachaeckern, Sandflächen häufig! Juni-Oktbr.

\section{PuImouaria $L$. Lungenkraut.}

608. P. officinalis $L$. Heilkr. L., borstig-rauhhaarig; Wbl. der blüthenlosen Triebe herzförmig, mit schmal geflügeltem Bltstiel, obere Bl. sitzend eirund-elliptisch; Blth. endständig. 4. 1'. Blkr. anfangs roth, dann violett.

In schattigen Laubwäldern und Gebüschen nicht verbreitet. In Menge in den Gebirgswäldern um Weinheim u. Nesterbach! weniger häufig bei Leutershausen! Schriesheim! In der Nähe von H. im Dreitröge Thal oberhalb des Lärchenbestandes! vereinzelt gegen Rohrbach! Nussloch! Schatthausen! In Wäldern der Ebcne b. Waghäusel u. Wiesenthal! April, Mai. (Off.: Hb.Pulmonariae maculosae.)

609. P. angustifolia $L$. Schmalbl. L., borstig-drüsig weichhaarig; Wbl. der blthlosen Triebe elliptisch-lanzettf, allmählig in den Bltstiel verschmälert; obcre Bl. lanzettl.; Blth. endständig. 4. 1'. Blkr. zuerst roth, dann blau.

In Wäldern, Gebüschen, auf Wald-Triften und -Wiesen häufiger als vorige. In grosser Menge am Geisberge bei H.! und durch das Gebirge bis Gaiberg, Schatthausen, Naischbach, Leimen, Dielheim stellenweise nicht selten! Auch bei Weinheim! Schriesheim! verbreitet. In Wäldern der Ebeno bei Wiesloch! Kïrlach! Waghäusel! April, Mai.

\section{Lith os permum $L$. Steinsame.}

610. L. arvense $L$. Acker-St., grauhaarig; St. oben ästig; Bl. lanzettl., stumpf; Nüsschen runzlich-rauh, bräunlich. ๑. $\frac{1}{2}-1^{\prime}$. Blkr. weiss.

Unter der Saat, auf Brachaeckern häufig! Mlai-Juli.

6ll. L. officinale $L$. H I ilkr. St. ; St. sehr ästig; Bl. breit lanzettl., spitz, scharfhaarig; Nüsschen glatt, weiss, glänzend. 4. $1-1 \frac{1^{\prime}}{2}$. Blkr. gelblich.

In feuchten Gebüschen, an Ufern, z. B. hie und da am Rheinufer bei Neckarau! beim Rohrhof! auf den Inseln bei Ketsch! In etwas feuchten Nadelwäldern, z. B. zwischen Friedrichsfeld und dem Relaishause! Vereinzelt aน steinigen Anhöhen zwischen Nussloch u. Wiesloch! Juni-August. 
612. L. purpureo-coeruleum $L$. Purpurblauer St.; St. aufrecht, schlank, oben ästig, mit ausläuferartigen, verlängerten, niederliegenden, nicht blühenden Trieben; BI. lanzettl., zugespitzt, rauhhaarig; Nüsse glatt. 4. 1-1 $\frac{1}{2}^{\prime}$. Blkr. ansehnlich, roth, später blau.

In lichten Wäldern, Gebuischen, selten. Am Rande von Kiefernwaldungen in der Nähe des Grenzhofes (Schimp.). In der näheren Lmgebung v. Schwetzingen allmählig ausgerottet (Schimp.) Mai,Juni.

[N. V. a. d. Geb. in B.: Bruchsal, auf dem Eichelberge und an der Ober-Grombacher Höhe! in Rhb.: Donnersberg! in Rhh. und an der hess. Bergstrasse fellend.]

\section{6\%. Iyosotis $L$. Vergissmeinnicht. \\ a) Kelche mit angedrückten, geraden Haaren.}

613. M. palustris With. Sumpf-V.; St. aufsteigend, kantig; Bl. länglich-lanzettl., spitz; Trauben mehr oder weniger gedrängt, reichblüthig; K. 5zähnig, bei der Fruchtreife offen; Griffel so lang als der Kelch. 24. $\frac{1}{2}-1 \frac{1}{2}^{\prime}$. Blkr. himmelblau, Lappen derselben leicht ausgerandet; Wzst. schief, kriechend.

In Gräben, an Ufern, auf feuchten Wieson sehr rerbreitet! Mai bis August.

614. Mi. caespitosa Schults. Rasenbildendes V.; St. aufrecht, fast stielrund; Bl. lineal-länglich, stumpflich; Trauben locker, sehr verlängert; K. 5spaltig, bei der Fruchtreife offen; Griffel sehr kurz. $\hat{\text { f. }} \frac{1}{2}-1^{\prime}$. Blkr. kleiner; Lappen ganz; W. absteigend, faserig.

In Torssïmpfen, in schattigen Waldsümpfen, auf nassen Bergwiesen nicht selten, z. B. in der Iirschgasse bei H.! im Mühlenthal bei Handschuchsheim! häufiger bei Brühl! Waghäusel! Sandtorf! Mai-Juli.

Ł) Kelche mit abstehenden Haaren, wovon die untersten hakenförmig.

615. M. sylvatica Hoffm. Wald-W.; St. aufrecht, kantig, wie die Bl, abstehend-rauhhaarig; Bl. länglich-lanzettl., kurz zugespitzt; Trauben locker; K. 5theilig, bei der Fruchtreife kaum zusammenneigend; Fruchtstiele abstehend, etwas länger als der K.; Blkrsaum flach, blau. $\frac{1}{2}-1_{\frac{1}{2}}^{\prime}$.

In schattigen, meist etwas feuchten Wäldern hie und da, z.B. zwischen Nussloch und dem Maischbacher Hof! Teufelskopf bei Dielheim! Gorxheimer Thal bei Weinheim! Käferthaler Wald (König). Mai-Juli.

616. M. intermedia $L k$. Mittleres V.; der vorigen ähnlich, aber mehr steifhaarig; Fruchtkelche fast völlig geschlossen; Fruchtsticle doppelt länger als der K.; Blkrsaum convex. ․․ $\frac{3}{4}-1^{\frac{1}{2}}$. Blkr. blau. 
Auf Aeckern, an Wegen, Waldrändern, in Gebüschen hïufg! Mai-August.

617. M. hispida Schlohtd. Steifha a riges V.; St. ästig, wie die Bl. abstehend-steifhaarig; Bl. länglich-lanzettl., etwas zugespitzt; Trauben verlängert, unbeblättert; Kelche 5spaltig, bei der Fruchtreifo offen; Fruchtstiele von der Länge der Kelche, wagerecht abstehend. ๑. 4-10". Blkr. sehr klein, blau. (M. collina Rchb.)

Auf trockenen Hügeln, auf sandigen Aeckern, an Rainen, Wegen hie und da, z. B. an den Felsen vor dem Haarlass! bei Schriesheim! im Birkenauer Thal bei Weinheim! Auf Sandflächen der Ebeno stellenweise, jedoch nicht allgemein, z. B. bei Schwetzingen! Hockenheim! Walldorf! Mai-August.

618. M. versicolor Per's. F a rbwechselndes V.; St. ästig, wie die Bl, abstehend-steifhaarig; Bl. länglich-lanzettl.; Trauben verlängèrt, unbeblättert; K. 5spaltig, bei der Fruchtreife offen; Fruchtstiele kürzer als d. K., aufrecht-abstchend. ๑. 6-8". Blkr. sehr klein, erst gelb, dann roth, zuletzt blau:

Auf grasreichen Triften. Sandfeldern, Hügeln, in trockenen Nadelwäldern nicht selten. In Menge $z$ wischen Friedriclsfeld und dem Relaishause! zwischen dem Rohrhof und Schwetzingen! bei Seckenheim! Alt-Lussheim! Sandtorf! Käferthal! Seltener auf den Felsen vor dem Haarlass! Mai-Juli.

619. M. stricta $L k$. Steifes V.; St. meist rasenförmig; BI eilänglich, stumpf, wie der St. dicht grauhaarig; Trauben gedrängt, unten beblättert; K. 5spaltig, bei der Fruchtreife fast geschlossen; Fruchtstiele sehr kurz, aufrecht. $\odot, 3-6^{\prime \prime}$. Blkr. sehr klein, blau.

Auf sandigen Aeckern, Haiden, auf den Sandflächen des Geb. meist schaarenweise! Mai-September.

\section{SOLANEAE Juss.}

Kräuter oder Sträucher mit meist abwechselnden Blättern ohne Nebenblätter. Kelch 5spaltig oder 5theilig, bleibend oder an der Basis sich ringsum ablösend. Blkr. mit 5theiligem, höchst selten etwas ungleichem Saum, abfallend, in der Knospenlage dachig oder gefaltet. Stbgef, 5, mit 2fïcherigen Antheren. Fruchtk. frei, 2-4fächerig, vieleiig, mit dicken, centralen Samenträgern. Griffel 1, mit einfacher Narbe. Frucht kapsel- oder beerenartig, 2-4fächerig, vielsamig. Samen eiweisshaltig. Keim (bei einheimischen Gat- 
tungen) ringfürmig oder spiralig gelirümmt. - Durch narkotisch wirkende Giftstoffe ausgezeichnet. Meist auffallend durch gesättigt grüne Oberfläche der krautigen Theile.

\section{a) Frucht beerenartig.}

L jeium. K. becherförmig, bleibend; Blkr. trichterförmig; Antheren in Längsspalten aufspringend.

Atropa. K. 5theilig, bleibend; Blkr. glockig, 5lappig; Antheren in Längsspalten aufspringend.

Solanum. K 5spaltig; Blkr. radförmig; Antheren zusammenneigend, an der Spitze mit 2 Poren aufspringend.

Physalis. K. 5spaltig, bleibend, nach der Blüthe blasenfürmig sich vergrössernd, die Becre cinschliessend; Blkr. fast trichterförmig; Antheren in Längsspalten aufspringend.

\section{b) Frucht kapselartig.}

H y os c y amus. K. krugfürmig, bleibend ; Blkr. ungleich-trichterförmig; Kapsel 2 fächerig, mit ringsum abspringendem Deckel.

Datura. K. röhrig, von der bleibenden Basis ringsum abspringend; Blkr. trichterförmig; Kapsel unvollkommen 4 fächerig, 4klappig.

\section{Lycium $L$. Bocks dorn.}

L. barbarum $L$. Gemeiner B.; St. mit herabgebogenen Zweigen; Bl. gestielt, eiförmig-länglich, ganzrandig, kahl; Blth. einzeln oder mehrere achselständig; Blkr. hellviolett; Stbgef. filzigzottig; Beeren elliptisch, roth.

Stammt aus der Berberei; wird in Gärten cultivirt und verwildert hie und da an Mauern, in Zäunen! Juni-September.

\section{Atropa $L$. Tollkirsche.}

620. A. Belladonna $L$. Gomoine T.; St. aufrecht, gabelästig; Bl. ciförmig, spitz, ganzrandig, fast kahl; Blthstiele achselständig 1-3, drüsig-behaart; Beeren kugelig, glänzend schwarz, vom bleibenden Kelch umgeben. 2. 2-4'. Blkr. braunroth. Sehr giftig!

In Waldgebüschen, lichten Wäldern, auf Steingeröll, besonders im Gebirge stellenweise. Oberhalb der Engelswiese! zwischen Ziegelhausen und Schönau! Auf dem heiligen Berge! bei der Molkenkur! hie und da auf dem Königsstuhl! in grosser Menge am Ende des Drachenhöhlen-Weges bei Neckargemünd! Längs der Bergstrasse nicht selten, besonders bei Weinheim! in der Hillenbach bei Handschuchsheim! Boi Rohrbach, Leimen, Schatthausen, Wiesloch nur selhr vereinzelt! Juni-August. (Off.: Rad. et hb. Belladonnae.) 


\section{Solanum $L$. Nachtschatten.}

621. S. nigrum $L$. Schwarzer N.; St. aufrecht, ästig, kantig; Bl. gestielt, eirund-keilförmig, ausgeschweift oder buchtig-gezähnt, selten fast ganzrandig; Blth. doldentr., locker; Fruchtstiele abwärtsgebogen; Beeren kugelig. $\odot \frac{1}{2}-2^{\prime}$. Blkr. weiss. Giftig!

Es finden sich 4 bemerkenswerthe Formen:

a) genuinum Aut.; St. höckerig, weichstachelig, zuweilen kantig-geflügelt, wie d. Bl. schwach behaart; Beeren schwarz.

$\beta$ ) lumile Bernh., kahl; Bl. fast ganzrandig; Beeren gelblich oder grün.

y) miniatum Bernh.; St. wie d. BI. abstehend-zottig; Beeren mennigroth.

ס) villosum L.; St. fast stielrund, wie die Bl. kurz-zottig; Beeren gelbbraun.

Auf Schutt, an Wegen, auf Aeckern, in Gärten Var, $\alpha$ sehr gemein in Weinbergen, Steinbrüchen; Var. $\beta$ hie und da b. Dossenheim! Nussloch! auf Sandflächen und in Kiesgruben Var. $\gamma, z$. B. Friedrichsfeld! Neckarau! Plankstadt! (Var. $\beta$ und $\gamma$ mit Uebergängen zu $\alpha$ ) Var. $\delta$ in Weinbergen bei Wiesloch! Auch bei Dossenheim und Schwetzingen (Döll). Juni-October. (Off.: Hb.Solaninigri.)

622. S. Dulcamara $L$. Bittersüss-N.; St. strauchartig, etras kletternd; Bl. eirund-herzförmig, spitz, ganzrandig; Blth. in fast blattgegenständigen Doldentrauben; Beere eilänglich, roth. t. $1-3$. Blkr. violett. Giftig!

In feuchten Gebüschen, besonders an Flussufern, an Waldrändern, Zäunen hie und da. Am Neckarufer $\mathbf{z}$ wischen Neuenheim und Ladenburg! und am Rheinufer stellenweise häufig! Auch bei Waghäusel! Kirchheim! in der Hillenbach bei Handschuchsheim! Friedrichsfeld! etc. oft in Menge! Juni-September. (Off.: Stipites Dulcamarae.

S. tuberosum $L$. Kart offel. Wzst. mit 1jährigen Knollen; Bl. unpaarig unterbrochen-gefiedert; Blth. doldentraubig; Beeren kugelig, grün. 4. Blth. violett oder weiss.

Aus Peru und Chili stammend; in zahlreichen Spielarten kultivirt. Juni-August.

270. Physalis $L$. Judenkirsche.

623. P. Alkekengi $L$. Gemeine J.; St. ästig; Bl. langgestielt, eirund, spitz, geschweift-gezähnt; Blth. achselständig, einzeln, nickend. 4. $\frac{1}{2}-2^{i}$. Kelch bei der Fruchtreife mennigroth; Blkr. weisslich-roth.

In Weinbergen, an Hecken, Waldrändern nicht häufig und meist einzeln, z. B. Nussloch! Wiesloch! Rheindamm zwischen Alt-Lussheim und Rheinhausen. (Bisch.) Juni-September. 


\section{2\%1. Il yoscyamus $L$. Bils en kraut.}

624. H. niger $I_{\text {. }}$ Schwarzes B., klebrig, zottig; St. aufrecht; Bl. halb stengelumfassend, eirund-länglich, buchtig - fiederspaltig; Blth. fast sitzend, eine einseitswendige Aehre bildend. ๑Blkr. gelblich, violett geadert; Samen nierenförmig, graugrün. Widerlicher Geruch. Giftig!

An Wegen, auf Schutt, Sandfächon hie und da, meist einzeln, in manchen Jahren ziemlich selten. Stellenweise am Neckar bei H.: bei der Molkenkur! Kirchheim! $Z$ wischen Friedrichsfeld, dem Relaishause und Schwetzingen! beim Rohrhof! Auffallend verbreitet zwischen Ladenburg u. Feudenheim! Juni-August. (Off, : Hb, et sem. Hyoscyami.

\section{2\%2. Dat Ira $L$. S techapfel.}

625. D. Stramonium $L$. Gemeiner St.; St. aufrecht, ästig; Bl. ei-länglich, tiefbuchtig gezähnt, kahl oder weichhaarig; Blth. einzeln, kurzgestielt, achselständig; Kelchbasis rundlich-4kantig; Kapseln aufrecht, dornig. ๑. $\frac{1}{2}-4^{\prime}$. Blkr. weiss. Samen nierenförmig, schwach-grubig, dunkelbraun. Sehr giftig!

Auf Schutt, Triften, Sandflächen, an Wegen hie und da, z. B. beim Relaishause! Schwetzingen! stellenweise an den Rheindämmen! häufig bei Feudenheim! Ladenburg! Zuweilen auch als Gartenflüchtling, z. B. bei H. am Neckar und in der Nähe des botanischen Gartens! Juni-September. (Off.: Hb. et sem. Stramonii.)

\section{Nicotiana $L$, Tabak.}

N. Tabacum $L$. ; drïsig-flaumhaarig; Bl. sitzend, länglich-lanzettlich oder elliptisch, zugespitzt, Hauptadern von der Mittelrippo unter einem spitzen Winkel ausgehend; Rispen gipfelständig, locker; Blkrröhre aufgeblasen-bauchig mit tief 5́spaltigem Saum. ๑. 3-4'. Blkr. rosa.

Wie die folgenden Arten aus Amerika stammend, und mit der nächsten Art eine im Floragebiet neuerdings sehr wichtige Culturpflanze! (Off.: Hb. Nicotianae.)

N. Latissima Mill.; der vorigen ähnlich; Bl. mehr eirund, Hauptadern von der Mittelrippe unter einem fast rechten Winkel ausgehend; Blkrsaum 5lappig. ๑.

Cultivirt. Juli-September.

N. rustica $L$.; schmierig-zottig; Bl. gestielt, eirund, stumpf Rispen gipfelständig, gedrungen; Blkrröhre verkehrt-eifộrmig, mit abgerundetem Saum, ๑. 2-3'. Blkr. grïngelb.

Cultivirt. Juli-September. 


\section{SCROPHULARINEAE Bartl.}

Krüuter, Sträucher oder Bäume mit meist gegenständigen, seltener abwechselnden Blättern ohne Nebenblätter. Blth. in einfachen Trauben oder Aehren, selten einzeln. K. frei, 4-5spaltig, bleibend. Blkr. 4-5gliederig, ungleich oder unregelmässig, meist 2lippig, oft rachenförmig, in der Knospenlage dachig. Stbgef. 5, ungleich, oder didynamisch, oder 2. Fruchtknoten frei, 2fächerig, mit 1 Griffel und 2lappiger oder einfacher Narbe. Kapsel 2 fücherig, vielsamig. Samen eiweisshaltig. Keim gerade oder etwas gekrümmt. - Der Mehrzahl nach durch Geselligkeit sehr auffallend, häufig den Vegetations-Charakter einzelner Gegenden wesentlich bedingend. Manche zeigen Vorliebe für warme, sonnige Standorte, mehrere gedeihen im Wasser oder sind von reichlicher Feuchtigkeit des Bodens abhängig. Einige zeichnen sich aus durch vorwaltenden Schleimgehalt (Verbascum), andere durch giftige Alkaloide (Digitalis) oder durch scharfe und bittere Stoffe. Fast alle sind gerbstoffhaltig. Die Rhinanthaoeen werden beim Trocknen blauschwarz.

Trib. 1. Verbasceae. Blkr. radförmig, ungleich oder 2lippig; Stbgef. didynam oder 5; Antheren 1fächerig, nierenförmig.

V erbas cum. Blkr. radförmig-ungleich; Stbgef. 5, ungleich.

S crophularia. Blkr. kugelig-2lippig; Stbgef. didynamisch, meist mit einem unfruchtbaren Stbgef, unter der Oberlippe.

Trib. 2. Antirrhineae. Blkr. unregelmässig oder ungleich; Stbgef. 2 oder didynamisch; Antheren 2fächerig, ohne Anhängsel.

L i n a ria. K. 5theilig; Blkr. rachenförmig, an der Basis gespornt; Stbgef. didynam.; Kapsel durch Löcher aufspringend.

Antirrhinum. Blkr. an der Basis höckerartig, übrigens wie vorige.

Gratiola. K. 5theilig; Blkr. röhrig, fast 2lippig; Stbgef. 4, jedoch nur 2 fruchtbar; Narbe 2lappig; Kapsel 2klappig.

Digitali s. K. 5theilig; Blkr. glockig, mit schiefabgestutztem Saum; Stbgef. didynam.; Kapsel 2klappig.

L indernia. K. 5theilig; Blkr. 2lippig; Stbgef. didynam.; Kapsel eilänglich, stumpf, 2klappig.

Veronica. K. 5theilig; Blkr. 4spaltig, radförmig-ungleich; Stbgef. 2 ;. Kapsel ausgerandet, 2klappig.

L i mos oll a. K. 5zähnig; Blkr. glockig, mit ungleichen Saumlappen; Stbgef, didynam, ; Kapsel rund, 2klappig. 
Trib. 3. Rhinanthaceae. Blkr. 2lippig, rachenförmig; Stbgef. didynam.; Antheren 2fächerig, an der Basis begrannt oder weichstachelig. (Dio meisten leben mehr oder weniger parasitisch).

Ped i c u l aris. K. aufgeblasen, 5zähnig; Oberlippe der Blkr. helmartig, zusammengedrïckt; Kapsel zusammengedrückt, geschnäbelt; Samen runzelig, flügellos.

M e l a m p y r um. K. röhrig, 4zähnig; Oberlippe d. Blkr. kurz zusammengedrückt; Kapsel der vorigen; Samen glatt, flügellos.

$\mathrm{R}$ hin an thus. K. aufgeblasen, 4zähnig; Oberlippo der Blkr. kurz kegelförmig; Kapsel stumpf; Samen mit Flügelrand.

Euphrasia. K. glockig oder röhrig, 4 spaltig oder zähnig; Oberlippe der Blkr. helmartig; Kapsel stumpf; Samen flügellos, mit Längsrippen.

\section{Verbascum $L$. Königskerze.}

a) Bl. herablaufend; Wolle der Stbfäden weiss.

626. V. Thapsus $L$. Woll kraut-K.; St. steif aufrecht, wie die BI. von gelblichen Haaren dünnfilzig-wollig; Bl. länglich-lanzettlich, die unteren langgestielt, die oberen lang herablaufend, seicht gekerbt; Blth. büschelig, in eine einfache dicht gedrängte Traube zusammengestellt; Blkrsaum convex; die 2 längeren Stbfäden kahl oder schwach behaart, $3-4$ mal länger als die Antheren. $\hat{\odot} 1-4^{\prime}$. Blkr. gelb, fast geruchlos. (V. Seltraderi Meyer.)

Auf trockenen Triften, an Waldrändern, auf Mauern, in Steinbrüchen hie und da, meist vereinzelt. Am Rheindamm zwischen Mannheim und Sandhofen! zwischen Ladenburg und Feudenheim! bei Nussloch! Wiesloch! Irandschuchshoim! Dossenheim! Auch selten am Neckar-Ufer! Juni-September.

627. V. thapsiforme Schrad. Wollkrautähnliche K; dem vorigen ähnlich; Bl. lang herablaufend, grob gekerbt, dichtfilzigwollig; Blthstand etwas lockerer; Blkrsaum flach; Blkr. etwas grösser, die 2 längeren Stbfäden nur 1 mal länger als d. länglichen Antheren. o. 2-6'. Blkr. gelb, wohlriechend.

An sonnigen Abhängen, auf trockenen Sandfeldern, am Rande von Nadelwäldern in der Ebene häufig, z. B. Friedrichsfeld! Walldorf! Am Rheindamm $z$ wischen Mannheim und Sandhofen!

628. V. phlomoides $L$. Windblumenähnliche K., steif aufrecht, dichtfllzig-wollig; Bl. elliptisch-länglich, kurz herablaufend, die unteren gestielt, die oberen stengelumfassend; aehrenf. Traube sehr locker; Blkrsaum flach; die 2 längeren Stbfäden 1-2mal länger als die sehr verlängerten Antheren. $\hat{\varsigma}$. $1-3^{\prime}$. Blkr. gelb, kleiner als bei den vorigen. 
Auf Sandflächen, Haiden, an Wegen, Flussufern nicht selten. Zwischen Friedrichsfeld und Schwetzingen mit dem vorigen. Ziemlich verbreitet bei Neu-Lussheim und an den Rheindämmen. Bei Ladenburg und Feudenheim! In der Hessel bei Wiesloch! Nussloch! Malsch! Juni-August. (Off.: Flores Verbasci [auch dio zwei vorigen Arten]).

b) Bl. nicht herablaufend; Wolle der Stbfäden weiss.

629. V. Lychnitis $L$. Lichtnelken-K.; St. ästig, kantig, aufrecht; Bl. oberseits fast kahl, unterseits staubfilzig, grau-weiss, untere elliptisch-länglich, in den Bltstiel verschmälert, obere eirund,

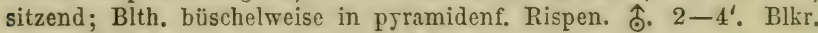
weiss oder seltener gelb, kleiner als bei d. vorigen.

Auf trockenen Hügeln, Sandfeldern, Steingeröll, an Wegen stellenweise häufig, z. B. auf den Vorbergen um H., besonders jenseits des Neckars gegen Ziegelhausen! Auch bei Nussloch! Wiesloch: Friedrichsfeld und gegen den Rhein oft recht gesellig! Juni-August.

c) BI. nicht herablaufend; Wolle der Stbfäden riolett.

630. V. nigrum $L$. Schwarze K.; St. einfach oder ästig, oben scharf-kantig; Bl. gekerbt, oberseits fast kahl, unterseits dïnn. fllzig, die unteren länglich-eiförmig, langgestielt, die oberen sitzend, eirund; Blth. büschelig in verlängerten lockeren Trauben. §. 2-3'. Blkr. gelb.

Auf Waldwiesen, in Gebüschen, an Ufern hio und da. Weinheim! Ladenburg! Feudenheim! Auf den Vorbergen der Bergstrasse und um H. stellenweise, z. B. auf dem heiligen Bergel beim Wolfsbrunnen! Spejerer Hof! An den Rheindämmen, z. B. bei Mannheim! zwischen Ketsch und Alt-Lussheim nicht selten! Juli-Scptember.

631. V. Blattaria $L$. Schabenkraut; St. aufrecht, fast einfach, oberwärts drüsig-behaart: Bl. kahl, untere in den Bltstiel verschmälert, eiförmig-länglich, buchtig; Traube endständig mit cin zelnen entfernten Blth. und drüsig-behaarter Axe. §. $1 \frac{1}{2}-2^{\prime}$. Blkr. gelb, selten weiss.

An steinigen Abhängen, Gräben, in feuchten Gebüschen stellenweise häufig, z. B. in der Ebene zwischen Leimen, St. Ilgen, Nussloch, Wiesloch! bei Ladenburg! Auf den Vorbergen bei Weinheim, z. B. im Birkenauer Thal! und zwischen Dossenheim und Handschuchsheim! Auch am Rheinufer, z. B. beim Rohrhofe! Neckarau! Mannheim!

Im Florageb. sind folgende hybride Mittelformen wahrgenommen:

V. nigro-Lychnitis Sohiede. St. oben scharfkantig; Bl. nicht herablaufend, oberseits fast kahl, unterseits dünnfilzig; untere in den 
Bltstiel verlaufend; Traube verlängert, einfach; Blkr. gelb; Wollo der Stbfäden purpurroth.

In Gesellschaft von $V$. nigrum und $V$. Lychnitis, im IIabitus dem ersten näher stehend. Auf dem heiligen Berge bei H.! zwischen Ladenburg und Feudenheim! Am Waldhofe bei Mannheim (Döll). Juli, August.

V. thapsiformi-Lychnitis Schiede (V ramigerum Schrad.). St. oben scharfkantig; Bl, halb herablaufend, untere gestielt, beiderseits weissgrau, dünnfilzig; Bltlastand rispig; Stbfäden alle weissbehaart.

In Gesellschaft zahlreicher V. Lychnitis und weniger kaum nachzumeisender $V$. thapsiforme. An Wegen, auf Steingeröll hinter dem Haarlass! An Abhängen zwischen dem Stift Neuburg u. Ziegelhausen! Juli, August.

V. Lychnitidi-phlomoides Bisch. St. stumpf-kantig; Bl, unterseits mit gelblichem Filze dicht bedeckt, oberseits dünnfilzig, untere clliptisch-länglich in den Bltstiel verschmälert, obere sitzend, sehr wenig herablaufend; Bltstd. einfach; Blkr. doppelt länger als d. K., hellgelb; Stbfäden weiss-wollig.

In Gesellschaft von wenigen $V$. Lychnitis und zahlreichen $V$. phlomoides und $V$. thapsiforme auf Sandflächen (auch im Sommer 1856) beim Relaishause! Juli, August.

iV. Lychnitidi-Blattaria Koch (nach d. Jahresbericht d. Pollichia 1849 bei Mechtersheim unfern Spejer vorkommend) ist für das Gebiet unserer Flora noch zu bestätigen].

\section{Scrophularia $L$. Braunwurz.}

632. S. nodosa $L$. Skrophelkraut; St. 4kantig, flügellos; Bl. eiförmig-länglich, doppelt gesägt, kahl; Rispe gipfelständig, gabeltheilig; Kzipfel stumpf, schmalhäutig berandet; unfruchtbare Stbgef. halbmondfürmig, schwach ausgerandet. 4. 2-3'. Blkr. grünlichbraun; Wzst. knollig.

An Gräben, Ufern, in Gebüschen, Wäldern allgemein verbreitet: Juni-August.

633. S. aquatica $L$. Wasser-B.; St. 4kantig-geflügelt; 131 . eiförmig-länglich, doppelt gesägt, kahl, in den geflügelten Bltstiel verlaufend; Rispe gipfelständig, gabeltheilig, gedrungen; Kzipfel stumpf, breithäutig berandet; unfruchtb. Stbgef. mehr oder weniger tief ausgerandet. 4. 2-4'. Blkr. grünlich-braun; Wzst. faserig. (S. Ehrhartii Stev.)

An und in Gräben, Bächen, in feuchten Gebüschen, Waldsïmpfen ebenfalls häufig, doch weniger verbreitet als vorige. Besonders vorherrschend an Bächen in den Waldthälern jenseits des $\mathrm{Ne-}$ ckars bei H.! Juli-September. 


\section{2\%5. L in aria Tournef. L e inkra ut. (Antirrhinum L.)}

๙) Bl. rundlich od. spiessförmig, alle gestielt.

634. L. Cymbalaria Mill. С ร mbel-L.; St. hängend oder kletternd, vielästig; Bl. herzförmig-rundlich, 5lappig, kahl; Blthen einzeln, achselständig. 4. Blkr. hellviolett, mit weissem Gaumen und 2 gelben Erhabenheiten.

An alten Mauern, in Felsenspalten, in der Nähe von $\mathrm{H}_{\text {, }}$, selbst innerhalb der Stadt sehr häufig! Sonst im Gebiete nur stellenweise, z. B. längs des Neckars b. Wieblingen! Ladenburg! Mannheim! Neckarsteinach! Auch in Handschuchsheim! Leimen! Mai-October.

[In den benachbarten Florengebieten zum Theil entweder selten, wie in Hessen, oder fehlend wie in Rhb.].

635. L. Elatine Mill. Spiessblättr. L.; niederliegend; BI. eiförmig, die oberen spiessförmig, wie die St. weichhaarig; Blth. einzeln, achselständig, langgestielt, kahl; Sporn der Blkr. gerade. ๑. Blkr. weisslich, Oberlippe violett, Unterlippe gelb.

Auf Aeckern, besonders auf Kalk- und Thonboden, seltener auf Sand, hie und da, z. B. zwischen Weinheim und Ladenburg! von St. Ilgen bis Rauenberg stellenweise! Schatthausen (an d. tiefen Gasse). Häufig zwischen Waghäusel und Wiesenthal! seltener $\mathrm{zw}$. Schwetzingen, Friedrichsfeld und Seckenheim! Juli-October.

636. L. spuria Mill. F als ches L.; niederliegend; Bl. rundlich-eiförmig, wie St. und Blthstiele zottig; Blthen einzeln, achselständig, langgestielt; Sporn der Blkr. bogig-gekrümmt. ๑. Blkr. der vor., etwas grösser.

Auf Aeckern, besonders auf Kalk - und Lehmboden, häufiger als vorige. Wiesloch! $z$ wischen Schatthausen, Baierthal $u$. Rauenberg! von Weinheim bis Ladenburg meist sehr verbreitet! Stellenweise bei Rohrbach! Wieblingen! Handschuchsheim! Friedrichsfeld und dem Relaishause! Auf der Rheinfläche bei Hockenheim! Alt-Lussheim! Rheinhausen hie und da! Juli-Oct.

b) Bl. lineal-lanzettlich, nur die unteren gestielt.

637. L. minor Desf. Kleineres L.; St. aufrecht, meist ästig, drüsig-behaart; Bl. gegenständig, lineal-lanzettlich, stumpf, Blthstiele achselst., einzeln, aufrecht, lockere Trauben bildend. ๑. 4-10". Blkr. klein, hellviolett, am Schlunde gelb.

Auf Aeckern, Sandflächen, an Wegen stellenweise häufig! Auch in der Nähe von H., selbst hie und da am Neckarufer nicht selten! Mai-August.

638. L. arvensis Desf. Acker-L.; St. aufrecht, meist ästig, 
wie d. Bl. kahl; Bl. lineal, die unteron 4-tändig, wirtelig; Blthen in gedrängten, später lockeren Trauben; K. und Blthenstiele drüsigbehaart. ○. $\frac{1}{3}-1^{\prime}$. Blkr. klein, hellblau.

Auf sandigen Aeckern, trockenen Hügeln hie und da, z. B. beim Rohrhof! bei Neu-Lussheim! Wiesenthal! Sandtorf! Käferthal! Juli-Sept.

639. L. vulgaris Mill. Ge meines L.; St. aufrecht od, aufsteigend, wie die Bl. kahl; Bl. lineal-lanzettlich, spitz, gedrängt; Trauben vielblüthig; Blthsticle drüsig-weichhaarig. 2. $1-1^{\frac{1}{2}}$.

An Wegen, auf Aeckern, Triften häufig! Juli-Sept. (Off.: Hb. Linariae).

\section{Antirinin m $L$. L öw enmaul.}

640. A. Orontium $L$. A cker-L.; St. einfach od. ästig, oberwärts drüsig; Bl. lineal-lanzettl., ganzrandig; Blthen achselständig, zerstreut; Kzipfel lanzettl., meist von der Länge der Blkr. ๑. $\frac{1}{2}-1^{\prime}$. Blkr. blassroth od. weiss, gestreift.

Auf Aeckern, Triften hie und da. Zwischen Wiesloch und Dielheim! bei Schatthausen (Lehrer Riegel), Weinheim! Dossenheim! ziemlich verbreitet. Seltener bei Rohrbach! bei ¿er Bergheimer Mühle! Wolfsbrunnen! Handschuchsheim! Friedrichsfeld! Juni-Aug.

641. A. majus $L$. Grosses L.; St. aufrecht, oberwärts nebst Blthstand drüsig-behaart; BI. lanzettl., kahl; Traube gedrängt; K.zipfel eiförmig, kurz. 2. 1-2'. Blkr. ansehnlich roth, seltener gelb od. weiss.

An alten Mauern, in Weinbergen, besonders in der Nähe von H. hie und da, wohl meist verwildert. Zuweilen, z. B. an Felsen zwischen H. und Schlierbach völlig eingebürgert! Juli-Sept.

\section{7\%. Gratiola $L$. Gnadenkraut.}

642. G. officinalis $L$. Heilkräftiges G.; kahl; Wstock kriechend; St. aufrecht, oben $4 \mathrm{kantig} ; \mathrm{Bl}$. gegenst., sitzend, lanzettlich, entferntgesägt; Blthen gestielt, einzeln, achselständig. 4. $4-8^{\prime \prime}$. Blkr. gelblich-weiss, am Saum etwas röthlich. Giftig!

Auf feuchten Triften, Wiesen der Rheinfläche hie und da. In Menge auf der Rheininsel bei Ketsch! und stellenweise am Rhein vom Rohrhofe bis Neckarau!

[Jenseits des Rheins, häufig in der Gegend von Speyer und Schifferstadt! auf den Wiesen bei Hanhofen!] Juni, Juli. (Off.: Hb. Gratiolae). 


\section{Lindernia $L$. L indernie.}

643. L. pyxidaria All. Europä ische L.; St. etwas niederliegend, meist rasenfürmig; Bl. länglich-eiförmig, ganzrandig, 3nervig, kahl, gegenständig; Blthen achselständig, einzeln, gestielt. $\odot .3-8^{\prime \prime}$. Etwas saftig, bräunlich-grün. Blkr. sehr hinfällig, nur Vormittags geöffnet, violett-rosa.

Auf feuchten, lehmigen, überschwemmt gewesenen Aeckern, in ausgetrockneten Sïmpfen. Bei Friedrichsfeld in der Richtung nach Schwetzingen, unfern des sog. rothen Loches in manchen Jahren, z. B. im Sommer 1856 in grosser Menge! Auch ausserdem noch hie und da im Friedrichsfelder Walde (Schimp.). Juli, August.

[N. V. a. d. Geb.: Carlsruhe (Düll); Entensee bei Offenbach (Schnttsp.).]

\section{Digitalis $L$. Fingerhut.}

644. D. purpurea $L$. Rother F.; St. einfach; Bl. ei-lanzettlich, gekerbt, unterseits wie St. u. Blthstiele grauflzig: Trauben verlängert; Kzipfel eirund, zugespitzt; Blkr. aussen kahl, purpurroth, innen behaart, gefleckt, selten weiss; Zipfel der Unterlippe kurz, abgerundet. $\hat{\odot} \cdot 2-3$ '. Giftig!

In den Gebirgswäldern um II., diesseits und jenseits des Neckars verbreitet! längs der Bergstrasse bis Weinheim! nnd durch den Odenwald sich erstreckend! Auf d. Königsstuhl oft schaarenweise und daselbst zuweilen weissblühend. Vorzugsweise auf Sand und Porphyr! Auf kalkhaltigem Boden sehr zurücktretend oder fehlend, und daher für unser Gebiet bei Angelloch und Wiesenbach bestimmte Grenzen des Vorkommens erreichend! Juni, Juli. (Off.: Hb. Digitalis).

[Jenseits des Rheins am Haardtgebirge, z. B. bei Neustadt sehr selten. (F. Scluultz).]

645. D. grandifiora Lrm. Grossbith. F.; St. aufrecht; Bl. längl.-lanzettlich, gesägt, unterseits weichhaarig; Traube verlängert einseitswendig; Kzipfel lanzettlich, spitz; Blkr. ansehnlich, aussen drüsenhaarig, gelb, innen braungeadert; Zipfel der Unterlippe dreieckig, stumpf od. zugespitzt. $41^{\frac{1}{2}-2^{\prime}}$. Giftig! (D. ambigua Murr.; D. lutea Poll. [non L.]).

In Gebirgswäldern zerstreuet und seltener als vorige. Hio und da auf dem Kïnigstuhl, besonders gegen Gaiberg und Neckargemünd: auch einzeln bis Rohrbach. An Weinbergsrainen unterhalb des Weges rom Riesenstein nach dem Speyrer Hof, daselbst gesellig! An der Hillenbach bei Handschuchsheim! Leutershausen! Wa- 
genberg bei Weinheim! Vereinzelt oberhalb des Philosophenteges gegen Wilhelmsfeld! Juni-August.

[N. V. a. d. Geb.: durch den Odenwald und längs der Pergstrasse bis Darmstadt. Am Haardtgebirge fehlend.]

250. Yeronica $L$. Ehrenpreis.

a) Trauben achselständig. (Kräuter 4.)

*) Kelche 4theilig.

646. V. scutellata $L$. Schildförm. E.; St. schwach, kriechend od. aufsteigend; Bl. lineal-lanzettlich, spitz, entferntgezähnt; Trauben wechselständig, locker; Blthstiele abstehend, später fast zurückgeschlagen; Kapsel stark zusammengedrückt. 4. $\frac{1}{2}-1 \frac{1}{2}$. Blkr. blasslila. - Die fast immer kahle Pflanze variirt selten:

ß) pubescens Koch; St., Blthstiele, Kelche und Kapseln behaart.

In Sümpfen, auf nassen Wiesen und Triften, an Gräben, Teichen der Ebene und der Vorgebirge hie und da, besonders gesellig in den Sümpfen der Rheinebene, z. B. im Friedrichsfelder Walde, beim Rohrhof! Waghäusel, woselbst auch zuweilen die Varietät. Juni-September.

647. V. Anagallis $L$. W as ser-E.; kahl; St. aufrecht, 6chwach $4 \mathrm{kantig,} \mathrm{ästig;} \mathrm{Bl.} \mathrm{sitzend,} \mathrm{eilanzettlich,} \mathrm{spitz,} \mathrm{gesägt;} \mathrm{Trauben} \mathrm{ge-}$ genst., vielblth, Kapseln rundlich, schwachausgerandet. 2. 1-2 $\frac{1}{2}$. Blkr. blassröthlich.

In Gräben, an Teichen, an feuchten sandigen Ufern, in Sümpfen häufig, besonders auf Lehm- und Kalkboden vorherrschend, daher in der Umgegend von Wiesloch, St. Ilgen und Ladenburg ziemlich allgemein! Juni-August.

648. V. Beccabunga $L$. B a ch bunge. Der vorigen ähnlich, kahl; St. niederliegend od. aufsteigend, stielrund; Bl. kurzgestielt, eiförmig-länglich, stumpf, entferntgesägt; Trauben gegenständig, locker; Kapsel rundlich, schwach ausgerandet. 24. 1-2'. Blkr. blau.

An und in Gräben, Sümpfen, an Bächen, Flussufern läufiger als vorige! Juni-August. (Off.: $I I b$. Beccabungae.)

649. V. Chamaedrys $L$. Gamander $-\mathrm{E}$; St. aufsteigend, zweireihig-behaart; Bl. fast sitzend, eiförmig, kerbig-gesägt, weichu haarig oder zottig; Traube reichblth., gegenständig oder einzeln; Blthstiele aufrecht, länger als die verkehrt-herzförmige, tiefausgerandete, gewimperte Kapsel. 24. $\frac{1}{2}-1^{\prime}$. Blkr. ansehnlich, hellblau.

In Wäldern, Gebüschen, auf Wiesen, an Wegen überall häuflg! April-Juni. 
650. V. montana $L$. B erg-E.; St. niederliegend, kriechend, allseitig weichhaarig; Bl. langgestielt, eiförmig, eingesehnitten-gesägt; Trauben armblüthig, gegenst. oder einzeln; Blthstiele abstehend, viel länger als die flache, herzförmige, nur am Rande gewimperte Kapsel. 24. $\frac{1}{2}-1 \frac{1}{2}^{\prime}$. Blkr. hellblau.

In schattigen Gebirgswäldern durch den Odenwald und längs der Bergstrasse zerstreuet, daher auch im Geb. der Flora hie und da, z. B in Menge am Ausgange des Hirschgassthales gegen den Philosophenweg, rechts! Auch in d. Nähe des Haarlass (Dr. Schimper). Im Gorxheimer Thal bei Weinheim! Teufelskopf bei Dielheim (Dr. Walz). Mai-Juli.

[Unterbrochenes Vorkommen durch B.! N. V. in Rhb.: Kaiserslautern ( $F$. Schultz), Donnersberg!]

651. V. officinalis $L$. A echter E.; St. kriechend, aufstei gend, wie die Bl. rauhhaarig; Bl. kurzgestielt, eiförmig-länglich, gesägt; Trauben gegenständig od. einzeln, vielblüthig, gedrungen; Blthstiele aufrecht, kürzer als die verkehrt-herzf., schwachausgerandeten Kapseln. 4. $\frac{1}{3}-\mathbf{1}^{\prime}$. Blkr. hellblau.

An Wegen, Waldrändern, auf Triften, IIaiden häufig! Juni bis August. (Off.: Hb. Veronicae).

*) Kelche 5theilig.

652. V. latifolia .L. Breitblättr. E.; St. aufrecht od. bogig aufsteigend, wie die Bl. mehr od. weniger behaart; Bl. sitzend, eiförmig-länglich, eingeschnitten-gesägt; Trauben gegenst. od. einzeln, reichblth.; Blthstiele aufrecht; Kapsel zusammengedrückt, tiefausgerandet. $\frac{1}{2}-1^{\prime}$. Blkr. blau. (V. Teucrium L.).

$\beta$ ) major; in allen Theilen grösser und kräftiger; $\mathrm{Bl}$. am Grunde herzf.-stengelumfassend.

Auf trockenen Triften, an sonnigen Rainen, Waldrändern nicht selten, z. B. Hessel bei Wiesloch! Maischbacher Hof! Leimen! Dielheim! auf sonnigen Hügeln zwischen Handschuchsheim und Weinheim! Haarlass! Philosophenweg! u. s. w. In der Ebene zwischen Friedrichsfeld und Schwetzingen! an den Rheindämmen bei Ketsch! Rheinhausen! u. s. w. ziemlich verbreitet. Var. $\beta$ etwas seltener, z. B. am Oelberge bei Schriesheim! zwischen Leimen und Nussloch! auf der Insel bei Ketsch! Juni, Juli.

653. V. prostrata $L$. Niedergestreckter E.; St. niederliegend-aufsteigend, wie die Bl. feinhaarig, röthlichgrau; Bl. kurzgestielt, lineal-lanzettl. oder elliptisch, kerbig-gesägt; Trauben gegenst., reichblth.; Blthstiele aufrecht; Kapsel verkehrt-eiförmig, schwach ausgerandet. 4 . $3-8^{\prime \prime}$. Blkr. hellviolett, kleiner als bei d. vor. (V. latifolia var. prostrata Döll.). 
Von der vorigen sicher verschieden. Aussen den angeführten Merkmalen auch dadurch besonders ausgezeichnet, dass die Pfl. mit der vorigen zuweilen an denselben Standorten wächst, aber ihre Blüthezeit völlig zurïckgelegt hat, wenn $V$. latifolia beginnt die Blüthen zu entfalten.

Auf Sandfeldern, in Nadelwäldern, auf trockenen, sandigen und kalkreichen Hügeln hie und da, z. B. beim Relaishause! stellenweise auf den Sandflächen zwischen Schwetzingen! Sandhausen! IIockenheim! Im Käferthaler Walde! Bei der Mannheimer Ziegelhütte! Bei Schatthausen (im sog. Vogelheerd)! April, Mai.

[Jenseits des Rheins auf den Kalkhügeln von Deidesheim bis Grünstadt, stellenweise z. B. bei Callstadt sehr gesellig und reichblühend!]

b) Traube endständig, gedrängt, verlängert; Röhre der Blkr. walzig. Kräuter 4.

654. V. longifolia $L$. L a ng blättr. E.; St. aufrecht, meist ästig; Bl.gestielt, gegenständig oder wirtelig, herzförmig-lanzettlich, langzugespitzt, scharfgesägt, behaart od. kahl; Kapsel rundlich-halbkugelig, schwachausgerandet. 4. 2-3'. Blkr. blau.

In feuchten Gebüschen, auf Wiesen an den Rheinufern, z. B. bei Ketsch! Zwischen Neu-Lussheim und Rheinhausen; zwischen Rohrhof und Relaishaus (Dr. Sclimp.). Juli, August. [Häufiger am jenseitigen Ufer.]

655. V. spicata $L$. A ehrenf. E.; St. aufsteigend, wie die Bl. kurzharig; Bl. gestielt, gegenst., eiförmig-lanzettl., kerbig-gesägt, an der Spitze ganzrandig: Kapseln rundlich-halbkugelig, schwach ausgerandet. 4 . $\frac{1}{2}-1^{\prime}$. Blkr. blau.

Auf trockenen IIügeln, an Riainen, auf trockenen Wiesen und Triften, in Nadelwäldern hie und da. In Menge beim Relaishause, gegen den Rohrhof! Zwischen Waghäusel und Wiesenthal! zwischen Käferthal und Sandtorf! Hie und da in der Hessel bei Wiesloch und gegen Rauenberg! Juli-September.

c) Trauben endständig, locker, vielblth. auf dem St. und den Aesten; Blkrröhre sehr kurz; Blätter allmählig in die Deckbl. übergehend.

*) Samen flach, schildförmig.

656. V. serpyllifolia $L$. Q u endelb I. E.; hellgrün, kahl; St. kriechend oder aufsteigend; Bl. eirund-länglich, schwachgekerbt, die unteren kreisrund, ganzrandig; Blthstiele kurz, aufrecht; Kapsel zusammengedrückt, rundlich-herzförmig, schwachausgerandet, 4 . $3-8^{\prime \prime}$. Blkr, blassblau. 
In feuchten Wäldern, auf feuchten Wiesen und Triften, in Siimpfen, Gräben iiberall verbreitet! April-Sept.

657. V. acinifolia $L$. Th hy mianblätr. E.; St. aufrecht oul. aufsteigend, meist sehr ästig; Bl. ciförmig, kerbig-gesägt, die oberen lanzettl., ganzrandig; Blthstiele absteliend, fast zweimal so lang als der K.; Kapsel zusammengedrüclit, fast kreisrund, tief ausgerandet. $\odot .2-4^{\prime \prime}$. Blkr, klein, dunkelblau.

Auf etwas lebmigen Aeckern zwischen Lcimen und Wiesloch. Mit Sicherheit an der Baiermühle oder Neumülle bei Leimen! April, Mai.

[Unterbrochenes York. durch B. (Döll.); fehlt in Rlıb, und im benachbart. Theile von Hessen.]

658. V. arvensis $L$. Feld-E.; St. meist ästig, aufrecht; Bl. lurzgestielt, herz-eiförmig, gekerbt, obere sitzend, lanzettl., ganzrandig; Blthstielo aufrecht, sehr kurz; Kapsel zusammengedrïckt, verkehrt-herzförmig. ๑. 3-6". 13lkr. blau.

Auf Aeckern, Triften, an Wegen häufig! März-Sept.

659. V. verna $L$. Frühlings-E.; drüsenhaarig; St. aufrecht, meist einfach, zart; Bl. fiedertheilig, die oberen lanzettlich, ganzrandig; Blthstiele sehr kurz, aufrecht; Kapsel zusammengedrücht verkehrt-herzf. ๑. 3-4". Blkr. klein, blau.

Auf Sandféldern, trockenen Hügeln hie und da, meist gesellig, z. B. auf den Felsen beim Haarlass! am Philosophenwege! im Ludwigsthal bei Schriesheim! auf Felsen im Birkenauer Thal bei Weinheim! Allgemeiner verbreitet auf den Sandflächen der Ebene, z. B. beim Relaishause! Sandhausen! Käferthal! Sandtorf! u. s. w. März bis Mai.

") Samen concav, bcckenförmig.

660. V. triphyllos L. Dreiblättr. E.; St. meist ästig, aufsteigend, oben drüsig behaart; Bl. fingerförmig, 3-5theilig, dio unteren eiförmig, gekerbt; Blthsticle länger als d. K., aufrecht; Kapsel verkehrt-herzf., etwas anschwellend. ๑. 3-6". Blkr. blau.

Auf Aeckern, Sandfeldern, Brachäckern häufg! März-Mai.

661. V. praecox $A l l$. Frühor E.; St. cinfach oder ästig, aufrecht, röthlich; BI. herz-ciförmig, gekerbt, stumpf; Blthstiele lünger als d. K., aufrecht; Kapsel verkehrt-herzf., anschwellend, am Rande etwas zusammengedrückt. ๑. 4-8". Blkr. blau.

Auf lehmigen und kalkigen, seltener auf feuchtsandigen Aeckern dor Ebene hio und da, z. B. bei Wieblingen! Edingen! zwischen Friedrichsfeld und dem Relaishause! bei Seckenheim! Mannheim! 
häufiger bei Ladenburg! Weinheim! Nussloch! Wiesloch! Dielheim! April, Mai.

๔) Blüthen einzeln, blattwinkelständig.

*) Fruchtstiele zurückgekrümmt.

662. V. agrestis $L$. A cker-E.; St. niederliegend; Bl. länglich-herz-eifürmig, kerbig-gesägt; Kzipfel elliptisch, stumpf; Kapsel anschwellend, spitz-ausgerandet, spärlich drüsenhaarig, Fächer 4-5samig; Stbgef. am Grunde der Blkrrühre befestigt. ๑. 4-8". Blkr. hellblau; Bl. hellgrün. ( $V$. didyma Ten.).

Auf Aeckern, Mauern, an Wegen überall verbreitet! März bis September.

663. V. polita Fries. Glänzender E.; St. niederliegend; Bl. rundlich-herz-eiförmig, kerbig-gesägt; Kzipfel eiförmig, spitz; Kapsel anschwellend, schwach ausgerandet, dichtbehaart, am Rande etwas drüsig, Fächer 5-10samig; Stbgef. am Grundo der Blkrröhro eingefügt. $\odot .4-8^{\prime \prime}$. Bl. glänzend grün; Blkr. hellblau.

Auf sandigen und kalkigen Aeckern hie und da, z. B. gegen Wieblingen! beim Grenzhofe, gegen Friedrichsfeld und Schwetzingen! Ziemlich verbreitet zwischen Alt-Wiesloch und Baierthal! April-September.

664. V. opaca Fries. Glanzloser E.; St. niederliegend, wio die Bl. zottig; Bl. rundl.-herzförmig, kerbig-gesägt; Kzipfel spatelförmig, stumpf; Kapsel anschwellend, spitz ausgerandet, krauszottig, etwas drüsig; Fächer 3-5samig; Stbgef. am Schlunde der Blkr eingefügt. ๑. 4-8". Blkr. blau.

Auf Aeckern zwischen Wiesloch und Rauenberg! Hinsichtlich der Verbreitung noch unsicher. März-Juni.

665. V. Buxbaumii Ten. Buxbaum's E.; St. niederliegend, meist weitverzweigt, wie die Bl. rauhhaarig; Bl. eiherzförmig, tiefkerbig-gesägt; Kzipfel eilanzettlich, bei der Fruchtreife wagerecht abstehend; Kapsel stumpf ausgerandet, erhaben-netzaderig; Lappen abstehend, etwas zusammengedrückt. ๑. 5-10". Blkr. ansehnlich, hellblau.

Auf Aeckern, in Weinbergen, besonders auf Lehmboden hio und da, z. B. hinter dem Haarlass und gegen Neuenheim! bei Dossenheim! Ladenburg! Leimen! Schwetzingen, Mannheim (Döll.). März-Juni.

666. V. hederaefolia $L$. Epheublättr. E.; St, niederliegend, ästig, behaart; Bl. langgestielt, herzförmig-rundlich, 3-5lappig; Kzipfel herzförmig; Kapsel kugelig-4lappig. ๑. Blkr. hellblau. 
A uf Aeckem, an Wegen, oft heerdenweise, überall verbreitet! März-Mai.

281. Ii mosella $L$. Schlammkraut.

667. L. aquatica $L$. Gemeines S.; St. sehr verkürzt, mit Ausläufern; Bl. langgestielt, lineal-spatelfürmig, kallı; Blthstiele achselständig, büschelig-gehäuft, 1blüthig. ๑. 1-2".' Blkr. sehr klein, röthlichweiss.

An überschwemmt gervesenen Plätzen, Teichrändern, in Sümpfen hie und da, meist sehr gesellig, z. B. in den Sümpfen des Friedrichsfelder Waldes! bei Brühl! Neckarau! Sandtorf! zwischen Kirchheim und St. Ilgen! Juli-September.

\section{Pedicularis $L$. I äusekraut.}

668. P. sylvatica $L$. W ald-L.; St. aufrecht, verkürzt, am Grunde schuppig, mit niederliegenden od. aufsteigenden Zweigen; Bl. fiedertheilig; Zipfel eingeschnitten-gezähnt; Traube locker; K. 5zähnig; Zähne blattartig. §. $4-6^{\prime \prime}$. Blkr. rosa.

Auf feuchten Wiesen der Ebene und der Gebirge nicht überall. Vorzugsweise häufig auf Waldwiesen jenseits des Neckars bei H., z. B. oberhalb der Hirschgasse! Engelswiese! Mühlenthal bei Handschuchsheim! Schönau! u, s. w. Längs der ganzen Bergstr. stellenweise! In den Sumpfgegenden der Ebene, z. B. beim Rohrhof! Neckarau! Waghäusel! jedoch weniger häufig als die folg. Mai, Juni.

669. P. palustris $L$. Sumpf-L.; St. steif aufrecht, ästig; Bl. gefiedert, mit fiederspaltigen Fiedern; Traube gedrängt, verlängert; K. 2lappig mit eingeschnitten gezähnten, krausen Lappen. ๙. $1^{\prime}$. Blkr, rosa.

Auf nassen Wiesen, in Sümpfen, an Flussufern häufig! Mai bis Juli.

\section{Me lamp y rum $L$. W a ch telweizen.}

670. M. cristatum $L$. Ka m m förmiger W.; St. meist sperrig-ästig: Bl. lineal-lanzettl., ganzrandig; Aehre sehr gedrängt, dichtdachig 4kantig; Deckbl. herzförmig, kammartig gezähnt, mit zurückgebogener Spitze. ๑. $\frac{1}{2} \multimap 1^{\prime}$. Blkr. weiss, an der Spitze gelb; Deckbl. purpurroth.

Auf Wiesen, in lichten Waldgebüschen der Rheinebene hie und $\mathrm{da}_{2}$ z. B. in grosser Menge auf der Rheininsel bei Ketschl weniger häufg bei Waghäusel! Rheinhausen! Sandtorf! Juni-August. 
[Jenseits des Rh. verbreiteter, z. B. stellenweise gesellig bei Speier! Mechtersheim! Maxdorf ! etc.]

671. M. arvense $L$. A cker-W.; St. meist ästig; Bl. lineallanzettl., fast ganzrandig; Aehre locker; Deckbl. eilanzettl., fiederiggespalten, rothgefärbt; Kelche flaumig-rauh, fast so lang als dio Blkrröhre. ๑. $1-1 \frac{1}{2}^{\prime}$. Blkr. rosa und gelb.

Auf Aeckern, vorzugsweise unter Sommergetreide, auf Kalkund Lehmboden. Verbreitet zwischen Nussloch! Wiesloch! Baierthal! Schatthausen! Weinheim! Ladenburg! Seckenheim! beim Relaishause! Vereinzelt bei Handschuchsheim! Wieblingen! u. s. w. Juni-August.

672. M. pratease $L$. Wiesen-W.; St. abstehend-ästig; B1. lineal-lanzettl.; Aehre locker, einseitswendig; Deckbl. spiessförmiggezähnt; Kelche kahl, 3mal kürzer als die gelbweissen Blkr. ๑. $\frac{1}{2}-1^{\prime}$.

In Wäldern, Waldgebüschen, auf Wiesen häufig! Juni-Sept.

\section{R h in anthus $L$. Hahnenk amm.}

673. Rh. minor Ehrh. Kleiner H.; St. meist einfach; Bl* lïngl.-lanzettl.; Aehre locker, einseitswendig; Deckbl. langzugespitzt, eingeschnitten-gezähnt, grün od. braun; Kelche kahl; Blkrröhre gerade, kürzer als d. K., Oberlippe mit 2 kurzen Zähnen; Griffel ein geschlossen; ๑. $\frac{1}{2}-1^{\prime}$. Blkr. gelb. (Rh. Cristagalli L.). Variirt:

$\beta$ ) angustifolius Koclı; zarter, etwas ästig; Bl. lineal-lanzettl.; Deckbl, tiefer eingeschnitten.

Auf Wiesen, Triften häufig, oft heerdenweise. Die Variet. im Gebirge, z. B. zwischen Schriesheim und Leutershausen; auf d. Teufelskopf bei Dielheim! Mai-Juli.

674. R. major Ehrh. Grosser H.; St. meist ästig; Bl. längl.lanzettlich; Aehre d. vor.; Deckbl. bleichgrün; Kelche kahl; Blkrrühre etwas gebogen, so lang als d. K., Oberlippe mit 2 längeren Zälınen; Griffel hervorragend. ๑. $1-2^{\prime}$. Blkr. gelb. (R. crista galli b. L.). Variirt:

B) hirsutus All. (R. Alectorolophus Poll.), mit zottig-rauhhaarigen Deckbl. $u$. Kelchen.

Auf Wiesen, Triften, in Sümpfen die Hauptart verbreitet. Die Variet. hie und da auf Wiesen, z. B. in Nenge vor Rohrbach! zwischen Handschuchsheim und Dossenheim! an Wegen und Rainen, z. B. im Dreitrögethal und beim Wolfsbrunnen bei H.! Zuweilen auch unter der Saat, z. B. bei Mannheim, unfern der Neckarbrücke! bei Rauenberg! Mai-Juli. 


\section{Eupluasia $L$. A ugentrost.}

675. E: officinalis $L$. Heilkräft. A.; Stı einfach od. ästig, wie die Bl. kurzhaarig od, zottig; Bl, eirund od. längl., scharfgesägt; Blthen in den Blattwinkeln gegenständig; Oberlippe der Blkr. 2lappig; unteres Antherenfach d, kürzeren Stbf. länger stachelspitzig als d. übrigen. ๑. Blkr. weiss, violettgestreift. Variirt:

a) pratensis Rchb.; drüsig abstehend-weichhaarig; St. ästig, Blkr. doppelt so gross wie $d . K$.

y) nemorosa Pers.; mehr oder weniger anliegend behaart, ohne Drüsen; St. mehr einfach; Blkr. bald grösser, bald kleiner.

Auf Haiden, in lichten Wäldern, Gebüschen Var. $\gamma$; auf Wiesen, Triften Var, $\alpha$ allgemein verbreitet! Juli-September. (Off.: Hb. Euphrasiae).

676. E. Odontites $L$. Rother A.; St. ästig, wie die Bl. kurzhaarig; Bl. lineal-lanzettl, entferntgesägt; Aehre locker, fast einseitswendig; Oberlippe der Blkr. ganz, stumpf; Antheren alle gleichmässig stachelspitzig, oben wollig, zusammenhängend. ๑. $\frac{1}{2}-1^{\prime}$. Blkr. roth.

Auf Aeckern, Triften, an Wegen, etwas Feuchtigkeit liebend, häufig! Juli-September.

677. E. Iutea $L$. Gelber A.; St. ästig, wie die Bl. feinbehaart; Bl. lanzettl.-lineal, entferntgesägt; Aehre gedrängt, fast einseitswendig; Blkr. bärtig-gewimpert; Antheren gleichmässig stachelspitzig, kahl. ๑. $\frac{1}{2}-1^{\prime}$. Blkr. gelb.

Auf trocknen kalkhaltigen od. sandigen Hügeln, Sandfeldern, in Nadelwäldern hie und da. In Menge in den Kiesgruben bei Schwetzingen! beim Relaishauso! bei Sandhausen! St. Ilgen! Wiesloch! einzeln bei Friedrichsfeld! Waghäusel! Alt-Lussheim! An felsigen Abhängen und auf sonnigen Hügeln bei Weinheim! Nesterbach! am Vitriolbergwerk bei Schriesheim! August-Oct.

(Euphrasia lutea L. lebt in der That zuweilen völlig parasitisch auf den Wurzeln von Tliymus Serpyllum. Ein ähnlicher wenigstens zufälliger Parasitismus zeigt sich auch bei $E$. Odontites, Melampyrum pratense und wohl noch bei mehreren Arten. Es gehören daher die Rhinanthaceen jedenfalls zu denjenigen Gerwächsen, welche hinsichtlich ihres Vorkommens von der Nähe anderer Pflanzen mehr oder weniger abhängig erscheinen.) 


\section{OROBANCHEAE. Juss.}

Chlorophylllose, auf den Wurzeln anderer Pflanzen parasitisch lebende Gewächse mit schuppenartigen Niederblättern, und :ahren- od. traubenförmigen Blthständen. Kelch 2 theilig oder 4-5spaltig, bleibend. Blkr rachenförmig. Stbgef. didynamisch mit 2fächerigen, an der Basis pfeilförmigen Antheren. Fruchtknoten 1fächerig mit 2-4 wandständigen Samenträgern. Griffel 1 mit kopfförmig-2lappiger Narbe; Kapsel 1fächerig, mit vielen sehr kleinen eiweisshaltigen Samen. Keim sehr. unscheinbar.

Orobanche. K. 4spalt. od. 2blättr.; Blkr. im verwelkten Zustande bleibend oder mit zurïckbleibender Basis rmgsum abspringend; St. an der Basis meist knollig verdickt.

Lathraea. Blkr. völlig abfallend; Fruchtknoten an der Basis mit einer Drüse; Wstock schuppig, sonst wie Orobanche.

\section{Orobanche $L$. S o m merwarz.}

a) K. 2blätterig, mit einem Deckblatte; St. einfach.

678. 0. procera Koch. Hoh er S.; Aehre dichtblth.; K. eiförmig-zugespitzt, mehrnervig, etwas kürzer als die Blkrröhre; Blkr. glockig, etwas gekrümmt, am Grunde kropfig; Lippen ungleich gezähnelt; Oberlippe ausgerandet mit gerade vorstehenden Lappen; Stbgef. im Grunde d. Blkr. eingefügt, an der Basis spärlich behaart, an der Spitze nebst Griffel etwas drüsig; Narbe schwach ausgerandet, bläulichroth od. bräunlich. 4. $\frac{1}{2}-2^{\prime}$. Blkr. bräunlich-gelb.

Auf Brachäckern, an Wegen, auf Cirsium arvense zw. Neckarau und Mannheim! Zwischen Schwetzingen und Plankstadt (Dr. Schimp.). Juli, August.

[Jenseits d. Rh. zwischen Ludwigshafen und Oppau ( $F_{0}$ Schultz).]

679. 0. Epithymum $D C$. Th y mian-S.; Aehre locker; K. eilanzettl., mehrnervig, etwas länger als d. Blkrröhre; Blkr. glockig, leicht gebogen, aussen drüsig-behaart; Lippen spitzgezähnelt, etwas krausrandig, Oberlippe schwach ausgerandet mit etwas aufstehenden Lappen; Mittelzipfel der Unterlippo grösser als d. seitlichen; Stbgef, etwas über dem Grunde d. Blkr, eingefügt, sonst wie vor.; Narbe kaum ausgerandet, dunkelroth. 4. 4-8". Blkr. gelbröthlich.

Auf trockenen Hügeln, Sandfeldern, Haiden, vorzugsweise auf Thymus Serpyllum. Häufg zwischen Schwetzingen und dem Re- 
laishause! bei Sandhausen! in der Hessel bei Wiesloch! Nesterbach bei Weinheim! Juni, Juli.

680. 0. Galil Duby. Labkraut-S.; Achre locker; K. lanzettl., mehrnervig, halb so lang als die Blkrröhre; Blkr. röhrigglockig, gebogen, aussen behaart; Lippen ungleich gezähnelt, Oberlippe kaum ausgerandet, vorgestreckt; Lappen der Unterlippe fast gleich; Stbgef. oberhalb der Blkrbasis eingefügt, dichtbehaart, wie d. Griffel drüsig behaart; Narbe tief ausgerandet, fast 2 lappig, dunkelroth. 4. $\frac{1}{2}-1^{\prime}$. Blkr. gelblich oder fleischroth, von nelkenartigem Geruch. (O. caryophyllacea Sm.).

Auf dürren Triften, sonnigen Hügeln auf Galium Mollugo und verum ziemlich häufig, z. B. Nussloch! Wiesloch! Schatthausen! zwischen St. Ilgen und Walldorf: auf dem Heiligen Berg bei H., zwischen Handschuchsheim und Dossenheim! längs der Bergstr. hiø und da bis Weinheim und Nesterbach! Juni, Juli.

681. 0. rubens Wallr. Röthlicher S.; Aehre locker; K. breit eiförmig-lanzettlich, mehrnervig, kürzer als die Blkrröhre; Blkr. röhrig-glockig, fast gerade, an der Spitze helmartig gebogen; Lappen ungleich gezähnt, krausrandig, nach aussen gebogen; Lippen der Unterlippe fast gleich; Stbgefässe oberhalb der Blkronbasis eingefügt, am Grunde behaart; Narbo kaum ausgerandet, gelb. $4 . \overline{3}-1 \frac{1}{4}^{\prime}$. Blkr. gelb, etwas bräunlich. Stengel meist auffallend dunkelroth. (O. Medicaginis Schultz).

Auf trockenen Hügeln, Triften auf Medicago falcata und sativa hie und da, z. B. zwischen Alt-Wiesloch und Baierthal! bei Nester. bach! Mannheim (Schimp.). Mai-Juli.

\section{b) Kelch verwachsenblättr., mit 3 Deckbl.}

682. 0. caerulea Fill. Himmelblauer S.; St. einfach ; Aehre locker, drüsig-behaart; Kzähne 5 lanzettl., kürzer als die gebogene Blkrröhre; Lappen der Blkr. spitz, flach; Antheren kahl od. am Grunde etwas behaart. 4. $\frac{3}{4}-1 \frac{1^{\prime}}{4}$. Blkr. hellblau.

Auf Triften, an Rainen, in Weinbergen, an lichten Waldstellen vorzugsweise auf Achillea Millefolium hie und da, z. B. oberhalb des Philosophenweges und in der Nähe der Hirschgasse bei H. Unterhalb der Ruine Windeck bei Weinheim! Zwischen Nesterbach und Sulzbach! Juni, Juli.

683. 0. arenaria Borkh. S a nd-S.; St. einfach; Aehre locker, drüsig-behaart; Kzähne 5, pfriemlich, kürzer als die fast gerade Blkrröhre; Lappen der Blkr. stumpf, am Rande zurückgeschlagen; Naht der Antheren wolligbehaart. $4 . \frac{1}{2}-1^{\prime}$. Blkr. hellblau.

Auf Sandflächen, Triften, Haiden auf Artemisia campestris. Häufig zwischon Walldorf! Sandhauson! und St. Ilgen! Beim Re- 
laishause! Zwischon Virnheim, Käferthal und Sandhofen (Schimp.). Juni, Juli.

[Auch jenseits des Rheins auf Sandflächen hio und da und daselbst auch auf Kalkboden zwischen Dürkheim und Grünstadt (F. Schult:).]

684. 0. ramosa $L$. Aestiger S.; St. ästig, selten einfach, behaart; Kzähne 4, eiförmig-3eckig, zugespitzt; Antheren kahl. $\odot$. 4-10". Blkr. kleiner als bei den übrigen Arten, hellblau oder gelblich.

Auf Hanf und Tabak in der Rheinebene hie und da rocht häufig, z. B. bei Schwetzingen! Ketsch! Waghäusel! Leimen! Sandhausen! Schatthausen! u. s. w. Juli-September.

\section{5\%. Lathraea $L$. S chuppenwurz.}

685. L. Squamaria $L$. Gemeine S.; Wstock schuppig, ästig, fleischig; Traube gedrängt, einseitswendig, nickend, wio die Blkr. fleischroth; Oberlippe helmförmig; Unterlippe 3lappig. 4. (Beim Trocknen schwarz werdend).

In feuchten Wäldern und Gebüschen auf Wurzeln von Buchen und Haselnüssen zum Theil in vermoderndem Laube versteckt. Mit Sicherheit gleich hinter dem Haarlass mit Arum maculatum! März, April.

[N. V. a. d. Geb.: Fürth im hess. Odenwalde; zwischen Felsen auf der Südseite der Melibocus-Spitze (Schnttsp.); in Rhb.: Donnersberg! Rheinwaldungen bei Roxheim (F. Schultz).]

\section{LABIATAE. Juss.}

Einjährige od. ausdauernde Kräuter, selten Halbsträucher mit fast immer 4kantigen Stengeln, gegenständigen oder quirligen Blättern ohne Nebenblätter. Blüthen achselständig, meist in Trugdolden, deren 2 gegenstïndige: sog. Scheinquirle bilden, welche mehr oder weniger zu Aehren oder Trauben gruppirt erscheinen. Blüthen unregelmässig, unterständig. Kelch meist bleibend, oft 2lippig od. röhrig, 5zähnig. Blkrone meist 2lippig, selten scheinbar 1lippig oder trichterförmig. Oberlippe meist 2spaltig, Unterlippe 3lappig. Stbgef. 2 oder öfter didynamisch. Fruchtknoten tief 4theilig, 4 eiig, auf einem kurzen, fleischigen Fruchtträger sitzend. Griffel 1 aus der Mitte der Fruchtkn, entspringend. Fruchtkn. bei der 
Reife vom bleibenden Kelch umschlossen in 4 einsamige Nüsschen zerfallend. Samen fast eiweisslos. Keim gerade. Die Labiatae secerniren in fast allen Theilen, besonders in Blättern und Blüthen ätherische Oele. Manche (Arzneipflanzen) enthalten ausserdem Bitterstoffe. Eigentliche Giftstoffe fehlen durchaus. Mehrere Arten sind sehr geneigt Spielarten zu bilden; Wechsel in Behaarung, Form der Blätter, Grösse der Blumenkronen ist fast bei allen mehr oder weniger nachzurweisen. Die Labiatae leben häufig gesellig, meist an sehr sonnigen, trockenen Standorten, gedeihen selten im dichten Schatten der Wälder, und nur zuweilen in feuchten oder gar sumpfigen, kühlen Umgebungen (z. B. Mentha, Scutellaria). Am reichlichsten finden sie sich in den Ebenen und an den Abhängen der Vorberge. In den höheren Gebirgen wird die Abnahme an Labiaten auch schon im Gebiete unserer Flora auffallend wahrgenommen.

1) Mit trichterförmigen 4-5spaltigen, ungleichen Blkr.

Mentha. K. 5zähnig; Blkr. 4spaltig; Stbgef. didynamisch.

Ly copus. K. 5zähnig; Blkr. 4spaltig; Stbgef. 2, zuweilen mit 2 Rudimenten.

2) Mit 2lippigen Blkronen.

a) Stbgef. 2, unter der Oberlippe gleichlaufend.

Salvia. K. 2lippig; Connectiv der Antheren wagebalkenartig verlängert mit 1 fruchtbaren Antherenfach.

b) Stbgef. didyn. von einander entfernt; d. untere Paar länger als d. obere; Antheren 2fächerig, die Fächer an das 3eckige Connectiv schief angewachsen.

a) Stbgef. an der Spitze auseinandertretend.

Origanum. K. röhrig, 5zähnig, im Schlunde wollig, Oberlippe d. Blkr. aufrecht, Unterlippe 3lappig.

Thymus. K. 2lippig, im Schlunde wollig; Blkr. wie vorige.

$\beta$ ) Stbgef. an der Spitze zusammenneigend.

Satureja. K. röhrig, 5zähnig; im Schlunde fast kahl; Blkr. wie Origanum.

Calamintha. K. 2lippig, im Schlunde behaart; Blkr. wie Origanum.

Cli in o po di u m. Wie vorige, aber die kopfig gedrängten Scheinquirle von zahlreichen, borstenförmigen Hüllbl. umgeben.

Melissa. K. 2lippig, Oberlippe flach abstehend; Oberlippe d. Blkr. concar; Unterlippe 3theilig. 
o) Sthgef. didynam., das obere Paar länger als das untere, alle unter der Oberlippe gleichlaufend; Antherenfächer durch ein schmales Connectiv zusammenhängend.

Nepeta. K. röhrig, 5zähnig; Mittellappen der Blkr.-Unterlippe verkehrt-herzförmig, flach; Antherenfächer geradlinig beisammenliegend.

Glechoma. K. röhrig, 5zähnig; Mittellappen d. Blkr.-Unterlippe verkehrt-herzförmig, flach; Antherenfächer gespreizt, kreuzweise gestellt.

d) Stbgef. didynam., d. untere Paar länger als d. obere, unter d. Oberlippe gleichlaufend; Antherenfäch. durch ein schmales Connectiv verbunden; K. röhrig oder glockig; Zähne des Fruchtkelches abstehend.

$\alpha$. Stbgef, nach dem Verblühen gerade.

") Blkrröhre innen mit einem Haarringe,") mit Ausnahme von Lamium amplexicaule.

Lamium. Oberlippe der Blkr. helmartig; Mittellappen der Unterlippe verkehrt-herzförmig; Seitenlappén sehr klein, zahnartig; Nüsschen 3 kantig-abgestutzt. Lappen.

Galeobdolon. Wie Lamium, aber Unterlippe mit 3 spitzen

Galeopsis. Oberlippe der Blkr. helmartig; Seitenlappen der Unterlippe mit 1 spitzen, hohlen Erhabenheit; Antheren der Queerenach a ufspringend.

Marrubium. Oberlippe gerade, flach; Mittellappen d. Unterlippe verkehrt-herzförmig; Nüsschen an der Spitzo 3kantig-gewölbt.

Ballota. Oberlippo schwach gewölbt; Unterlippo wie vor.; Nïsschen abgerundet, stumpf.

**) Blkrröhre innen ohne Haarring.

B et on ica. Oberlippe schwach gewölbt; Mittellappen d. Unterlippe länglich-stumpf; Nüsschen abgerundet, stumpf.

$\beta$. Stbgef. nach dem Verblühen auswärtsgebogen.

*) Blkrröhre innen mit Haarring.

Stachys. Oberlippe schwach gewölbt; Lappen der Unterlippo flach, stumpf; Nüsschen abgerundet.

L e on urus. Oberlippe fast flach; Lappen d. Unterlippo etwas umgerollt; Nüsschen 3eckig-abgestutzt.

-) Dieser Haarring findet sich an der Anheftungsstelle der Stb.gefässe oder tiefer im Grundo der Böhro. 


\section{") Blkrröhre innen ohne Haarring.}

Chaiturus. Oberlippe gewölbt; Lappen der Unterlippe flach, stumpf; Nüssch. 3eckig-abgestutzt.

e) Stbgef. und Antheren wie $d$; aber die Fruchtkelche zusammengedrückt und geschlossen; Oberlippe der Blkr. helmartig.

Prunella. Oberlippe des Kelches 3zähnig; Röhre der Blkr. mit Haarring; Stbfäden mit Zahnfortsatz.

Scutellaria. Oberlippe des Kelches ganzrandig, mit hohlem, bei der Fruchtreife abspringendem Anhängsel; Blkr. ohne Haarring; Stbfäden ohne Fortsatz.

f) Stbgef. didynam.; K. 5zähnig; Oberlippe der Blkr. sehr kurz, fast fehlend; Unterlippe verlängert.

Ajuga. K. eiförmig-glockig; Oberlippe der Blkr. ausgerandet; Unterlippe 3lappig, sehr viel grösser.

Teucrium. K. röhrig-glockig; Oberlippe d. Blkr. tief 2 theilig mit der 3theiligen Unterlippe gleichsam verbunden, so dass letztere 5lappig erscheint.

\section{II entha $L$. Münze.}

a) K. inwendig kahl.

686. M. rotundifolia $L$. Rundbl. M.; St. steif-aufrecht; Bl. sitzend, rundlich-eiförmig, kerbig-gesägt, runzelig, oben zottig, unten graufilzig; Scheinquirle in schmalen, linealisch-walzlichen Aehren; Deckbl. pfriemlich; Nüssch. glatt. 4. $\frac{1}{2}-1 \frac{1}{2}$. Blkr. klein, lila.

An Gräben, feuchten Waldrändern, Ufern hie und da, z. B. beim IIaarlass! im Dreitrïge Thal! Mühlenthal bei Handschuchsheim! stellenweise am Neckarufer, z. B. zwischen Neuenheim und dem Schwabenheimer IIof! Seltener bei Leimen! Nussloch! im Friedrichsfelder und Neckarauer Walde! Juli-September.

687. M. sylvestris $L$. Wilde M. (Pferdemünze); St. aufrecht; Bl. fast sitzend, eiförmig oder elliptisch-lanzettlich, ungleich gesägt; Scheinquirle in mehr oder weniger dichten länglichen Aehren; Deckbl. lanzettlich; Nüssch. warzig. 4. 1-3'. Blkr. hell violett od. lila. - Variirt in Behaarung, Grösse, Form, Einschneidung der BI. beträchtlich. Folgende Varietäten sind bei uns beachtenswerth.

a) vulgaris; Bl. beiderseits, besonders aber unterseits, mehr oder weniger grau-filzig; Aehre gedrängt, reichblüthig.

$\beta$ ) incana (M. incana Sm., mollissima Borkh.); Bl. beiderseits dicht weissfilzig, zuweilen unterseits fast wollig; Aehre gedrängt, reichblüthig. 
y) nemorosa; Bl. oberseits kahl oder fast kahl, unterseits dünn graufilzig (MI. nemorosa Willd.) oder dicht weissfilzig (M. candicans Crtz.). Erscheint mit sehr verlängerten Bl. (longifolia) od. auffallend breiten Bl. (latifolia).

ঠ) umbrosa; Bl. dünnhäutig, schlaff, oberseits fast kahl, unterseits feinhaarig; Aehren locker, armblüthig.

$\varepsilon)$ undulata; Bl. beiderseits dünn graufilzig, 2m Rande wollig, mehr oder weniger eingeschnitten-gesägt; Aehre gedrängt, reichblüthig.

$\eta)$ crispata; Bl. kahl, blasig-runzelig, eingeschnitten-gesägt; Aehre verlängert, locker.

In feuchten Gebüschen, Gräben, an Ufern. Var. $\alpha$ häufig! und zuweilen mit Var. $\beta$ am Neckar- und Rhein-Ufer! bei Waghäusel! an rauhen, steinigen Orten, z. B. bei Nussloch! im Birkenauer Thal bei Weinheim! sehr gesellig. Var. $\gamma$ an schattigen, feuchten Standorten, z. B. beim Haarlass! Neckargemünd! zwischen Ziegelhausen u. Schönau! Leimen! beim Naischbacher Hof! Var. $\delta$ in feuchten Waldgebüschen hinter dem Haarlass! Var. $\varepsilon$ an Zäunen, Wegen, z. B. in den Dörfern: St. Ilgen! Malsch! Malschenberg! Var. $\eta$ hio und da am Neckarufer verwildert, z. B, zwischen H. u. Neuenheim! Juli--September. (Off.: Hb. Menthae sylvestr.)

M. piperita $L$. Pfeffer-M.; St. aufrecht, wie die Bl. kahl; Bl. gestielt, eiförmig-länglich, spitz, ungleich gesägt; Scheinquirle in länglichen, walzlichen Aehren; Deckbl. lanzettl.; Nüssch. glatt. Variirt:

ß) Langii Koch; St., Bl, Kelche dichtgrau behaart. 4. $1-1 \frac{1}{2}$. Blkr. hellroth. Eigenthümlicher Geruch und Geschmack, auch bei der Varietät!

Dio Hauptart sehr selten und vereinzelt am Neckarufer verwildert Die Varietät am Neckarufer zwischen Neuenheim und H.! Ehemals auch unterhalb Neuenheim (Bisch.) August, September. (Off.: Hb. Menthae piperitae.)

688. M. aquatica $L$. (erweitert) Wasser-M.; St. aufrecht, mehr oder weniger behaart,") selten fast kahl; Bl. gestielt, eirundl. oder etwas herzförmig, in den Bltstiel verlaufend, gesägt, behaart oder kahl; Scheinquirle von einander entfernt oder sehr genähert; K. röhrig-trichterförmig, gefurcht, mit lanzettl., zugespitzten, stets vorgestreckten Zähnen; Nüssch. warzig oder giatt. 4. $\frac{1}{2}-2^{\prime}$. Blkr. rüthlich. - Variirt beträchtlich und zwar zunächst:

•) Die Haare sind bei allen Arten mehr oder weniger rückwärts gerichtet. 
«) aquatica genuina L.; Scheinquirlo dicht gedrängt, eine eiförmige, kopfartige Aehre bildend; Deckbl. kïrzer als d. Quirle, oft verschwindend-klein; Nüssch. warzig. Erscheint in 3 Formen:

1. vulgaris; Bl. meist eiförmig, wie die St. kurzhaarig. 2. hirsuta; Bl. mehr rundlich, wie die St. rauhhaarig, zuweilen weissgrau.

3. glabrata; fast ganz kahl, nur d. St. kurzhaarig; mit Oeldrüsen reichlich besetzt; Citronengeruch (M. citrata Ehrh.)

ß) sativa (MI. sativa L.); Scheinquirle kugelig, von einander entfernt; Deckbl. länger als d. Quirle; Nüssch. bald glatt, bald warzig. - Es finden sich folgende Formen:

1. comosa; mit durch mehr oder weniger entwickelte, jedoch stets deutliche Deckbl. begrenzten Blthständen.

In Behaarung, Blattform, Grösse aller Theile sehr veränderlich. Beachtenswerth sind:

b) latifolia; Bl. auffallend gross und breit; Blkr. ansehnlich, oft unfruchtbar.

c) hirsuta; durchaus rauhhaarig, bisweilen selbst zottig.

d) glabrata; fast ganz kahl; St. und K. röthlich (M. rubra $\mathrm{Sm}$.)

2. subspicata Pers.; unbegrenzte, d. h. durch Blth. u.verkümmerte Deckbl, abgeschlossene Blthstände; Nüssch. glatt. (Scheint eine hybride Mittelform (Mischling) zwischen Var. $\alpha$ und $\beta$ zu sein). (M. sativo-aquatica Bogenh.)

An Ufern, Gräben, in Sümpfen, auf nassen Wiesen verbreitet. Var. $\alpha$ 1) überall häufig! 2) hie und da am Neckarufer! häufiger am Rhein, z. B. bei Ketsch! Alt-Lussheim! Waghäusel! Sandtorf! 3) hie und da an schattigen Ufern, z. B. im Weidengebüsch bei Neuenheim! im Birkenauer Thal bei Weinheim! Var. $\beta$ 1) die gewöhnliche Form sehr verbreitet; $b$ ) hie und da am Neckarufer! an der Weschnitz bei Weinheim! c) auf feuchten Triften, z. B. bei Ladenburg! Waghäusel! auch am Neckarufer bei Neuenheim! Neckargemünd! d) in feuchten Gebüschen, selten am Rheinufer, z. B. Neckarau! 2) am Neckar, z. B. bei Neuenheim! auch einzeln beim Rohrhof! Juli-October. (Off.: Var. $\alpha$ Hb. Menth. aquat.)

689. $M$. arvensis $L$. Feld-M. St. niederliegend oder aufsteigend, wie die Bl. meist mehr oder weniger behaart; Bl. gestielt, eirund oder elliptisch, gesägt; Scheinquirle gesondert, halbkugelig, achselständig; Kröhre kurzglockig, steifhaarig, mit kurzen, dreieckiglanzettl, geraden Zähnen; Nüssch. kahl. 24. $\frac{1}{4}-1^{\prime}$. Blkr, röthlich. 
Variirt :

ß) villosa; St. und Bl. zottig.

$\gamma$ ) agrestis Sole; starkbehaart; Bl. rundlich-herzförmig.

J) parietariaefolia Rchb. (badensis Gmel.); St. schlank; Bl. langgestielt, elliptisch, beiderseits zugespitzt, nebst Blth.stielen fast kahl ( $M$. gentilis mancher Aut.)

ع) odorata; St. schlank; Bl. langgestielt, eirund-länglich, stumpflich, rauhhaarig, reichlich mit Drüsen versehen; Blthstiel fast kahl. Wohlriechend!

$\eta)$ procumbens Thuill.; niederliegend; B1. eirund-länglich, klein, wie dio Blthstiele schwach behaart.

ı) glabriuscula Meyer (M. gentilis Sm., non L, et Sole!) St. und Bl. fast kahl; Blthstiele völlig kahl; Bl. eirundlanzettlich.")

An Ufern, auf feuchten und trockenen Aeckern, Triften, an Waldrändern allgemein verbreitet! Var. $\beta$ und $\gamma$ häufig! Var. $\delta$ in feuchten Gebüschen, z. B. Waghäusel! Leimen! Ketsch! Var. $\varepsilon$ bisher nur in schattigen, feuchten Gebüschen am Ausgange der Hirschgasse! Var. $\eta$ auf feuchten Aeckern, z. B. bei Friedrichsfold! zwischen Ladenburg und Handschuchsheim! Var, $\iota$ an den Rheinufern selten, z. B, bei Neckarau! Mannheim. Juli-October.

b) Kelchschlund durch einen Haarring geschlossen.

690. M. Pulegium $L$. Poley-M.; St. aufsteigend, ästig; Bl. gestielt, elliptisch, stumpf, schwach gezähnt; Scheinquirle kugelig; K. 2lippig, die oberen Zähne zurïckgekrümmt. 4. 4-10". Blkr. blass-röthlich. (Pulegium vulgare Mill.)

An Ufern, sumpfigen, überschwemmt gewesenen Standorten, an Gräben nicht selten, meist gesellig. Häufig am Neckar zwischen dem Schwabenheimer Hof und Ladenburg! bei Neckarau! am Rhein bei Alt Lussheim! Ketsch! Rheinhausen! Am Kirchheimer See! Seltener bei St. Ilgen: Schwetzingen! Juli-September, (Off.: $H b$. Pulegii.)

Bastardformen sind bisher folgende beobachtet:

M. aquatica-sylvestris ( $M$. nepetoides Lej.). Bl. gestielt, eiförmig, gesägt, graugrün behaart; Scheinquirle $\mathrm{zu}$ dichten, längl.walzlichen Achren gedrängt; Kzähne lineal-borstlich, stets vorgestreckt; Blth, meist unfruchtbar. $1 \frac{1}{2}-2^{\prime}$.

") Die ächte $M$. gentilis L. habe ich in hiesiger Gegend noch nicht gesehen. Diese hat grosse Aehnlichkeit mit M. arvensis L., var. glabriuscula, aber die kahlen Bl. sind sehr kurzgestielt, mehr zugespitzt, scharf gesägt, unterseits reichlich drüsig; Kzähne lanzettlich, zugespitzt. 
Am Rande eines Waldgebüsches, am Neckarufer, oberhalb Ziegelhausen (Bisch.) August, September.

M. rotundifolia.sylvestris; Bl. sitzend, elliptisch, runzelig, unterseits graufilzig; Scheinquirle in länglichen, gedrängten Aehren; Nüssch. feinmarzig. Geruch der M. rotundifolia:

In Gesellschaft der 2 Stammpflanzen häufig am Neckarufer zwischen Ladenburg und Handschuchsheim, unfern des Schwabenheimer Hofes! August, September.

Bastardformen zwischen M. arvensis und aquatica habe ich bisher noch nicht mit Sicherheit nachweisen künnen. (Vgl. über Mentha: Wirtgen. Herbarium Mentharum rhenanarum. Coblenz 1854-55.)

\section{Lycopus $L$. Wolfsfuss.}

691. L. europaeus $L$. Europä is cher W.; St. steif-aufrecht; Bl. gestielt, eiförmig-länglich, mehr oder weniger tief gesägt oder fiederspaltig; Scheinquirle achselständig, vielblüthig; Rudimente der Stbfäden fädlich. 4. $\frac{1}{2}-1^{\prime}$. Blkr. klein, weiss.

An Gräben, Ufern, in feuchten Gebüschen, Sümpfen häufig, z. B. stellenweise in Menge am Neckarufer! In den Sumpfgegenden des Geb. oft heerdenweise! Juli, August.

\section{Salria $L$. Salbei.}

692. S. pratensis $L$. Wiesen-S.; St. aufrecht; Bl. herzfolänglich, unregelmässig doppelt gekerbt, runzelig, unterseits weichhaarig, untere gestielt, obere sitzend; Scheinquirle 6blüthig; Deckbl., K., Blkr. klebrig behaart. 4. $1-1_{\frac{1}{2}}{ }^{\prime}$. Blkr. blau, selten weiss oder rosa; Blkrröhre innen kahl.

Auf Wiesen, Waldtriften, an Rainen, Wegen häufig! Mai, Juni.

693. S. verticillata $L$. Quirlblühend. S.; St. aufrecht, wie die Bl. fast zottig; Bl. herz-deltaförmig, ausgeschweift-gezähnt; Scheinquirle reichblth., fast kugelrund. 4. $\frac{1}{2}-1^{\prime}$. Blkr. klein. blau, die Röhre innen mit 1 Haarring.

An Ackerrändern, Rainen, auf trockenen Triften selten, z. B. am Neckarufer bei Ladenburg. In der Kiesgrube bei Eppelheim, und neben dem Eisenbahndamm unfern Friedrichsfeld (Stud. Gysser), Weinheim $(F$. Schult $)$. Vielleicht auch jetzt noch hie und da bei Käferthal (Döll). Juli-September.

[Auch in den benachbarten Gebieten fehlend oder sehr zerstreut. N. V.: Darmstadt (Schnttsp.)] 


\section{9l. Origanum $L$. Dosten.}

694. 0. vulgare L. Gem. D. (wilder Majoran); St. aufsteigend, weichhaarig; Bl. eiförmig, spitz, fast ganzrandig, gewimpert; Blthäbren endständig in vierseitigen, gedrungenen Rispen, mit eiförmig-länglichen gefärbten Deckbl. 4. $\frac{1}{2}-1 \frac{1^{\prime}}{2}$. Blkr. roth, seltener weiss, meist vielehig.

An Rainen, Waldrändern, auf sonnigen Hügeln häufig! JuniSeptember. (Off.: $B b$. et flor. Origani vulg.)

\section{Thymus $L$. Thymian.}

695. T. Serpyllum $L$. Q u en de I-T.; St. niederliegend od. aufsteigend, ästig; Bl. elliptisch, eilängl, oder lineal, stumpf, ganzrandig, flach; Scheinquirle kopffürmig gedrängt. 2. Blkr. roth, selten weiss. - Variirt sehr in Behaarung, Breite der Bl. und der Grösse aller Theile, Beachtenswerth sind:

a) chamaedrys Koch; St. aufsteigend, 2reihig behaart; Bl. eirund-elliptisch, zottig, kurzhaarig oder fast kahl. An schattigen Standorten zuweilen bis $10^{\prime \prime}$ hoch, sehr breitblätterig.

$\beta$ ) angustifolius Koch; St. niederliegend, ringsum behaart; Bl. lineal, kahl, zottig oder kurzhaarig.

An Waldrändern, Wegen, auf Wiesen, Triften Var, $\alpha$ sehr verbreitet! Var. $\beta$ auf den Sandflächen d. Geb. häufig, oft sehr gesellig und veränderlich! Mai-Juli. (Off.: Hb. Serpylli.)

\section{Satureja $L$. Pfefferkraut.}

S. hortensis $L$. Garten-P.; St, aufrecht, ästig, fein drüsigbehaart; Bl. lineal-lanzettl., gewimpert, unterseits vertieft-punktirt; Bltstd, armblth. ๑. 1'. Blkr. lila.

Aus Süd-Europa stammend, in Gärtẹn cultivirt, hie und da verwildert! Juli-September. (Off.: Hb. Saturejae.)

\section{Calamintha Moench. Calamintha,}

696. C. Acinos Clairv. Feld-C.; St. aufrecht oder aufsteigend, meist ästig; Bl. eiförmig oder elliptisch, gesägt, meist grau behaart; Scheinquirle 6blth.; Blthstiele einfach; Fruchtkelche geschlossen. ๑. $\frac{1}{2}-1 \frac{1}{2}^{\prime}$. Blkr. hell violett oder weiss. (Thym. Acinos L.)

Auf trockenen Hügeln, Sandflächen, Brachaeckern, Mauern häufig! Eine weissblühende Form in Menge zwischen Friedrichsfeld und dem Relaishause! Juni-August. 
697. C. Officinalis Mnench. Gebräuchl. C.; St. aufrecht, üstig, wie die Bl: kurzhaarig; Bl. eiförmig, stumpf, gesägt; Scheinquirle trugdoldig, Blthstiele gabelspaltig, 3-5blth. 24. 1-2'. Blkr. purpurroth. (C. sylvatica Bromf., Melissa Calamintha L.)

An Waldrändern, in Gebüschen, besonders im Gebirge bei II., diesseits und jenseits des Neckars häufig! längs der Bergstrasse, z. B. bei Leutershausen! Weinheim! und durch den Odenwald verbreitet. Seltener bei Wiesloch! Auch in der Ebene nicht fehlend, z. B. im Friedrichsfelder Walde! bei Schwetzingen! Ketsch! zwischen Kirrlach und Waghäusel! Juli-September. [Fchlt in Rhb. (F.Sch.)]

\section{Clinopodium $L$. W irbeldost.}

698. C. vulgare L. Gem. W.; St. aufrecht, zottig; Bl, eifürmig, schwach gekerbt; Scheinquirle kopfförmig, vielblth; Hülle so lang als d. K. 2. 1-1 $\frac{1}{2}^{\prime}$. Blkr. roth.

In lichten Wäldern, Gebüschen, auf Wiesen häufig! Juli-Aug.

\section{Mllelissa $L$. Melisse.}

M. of ficinalis $L$. Heilkräft. M.; St. ästig, wie d. Bl. weichhaarig; Bl, eiförmig, spitz, kerbig-gesägt; Scheinquirle einseitswendig. 4. $1-1^{\prime}{ }^{\prime}$. Bl. weiss.

In Gärten cultivirt, hie und da verwildert, z. B. am NeckarUfer bei Neuenheim! Juli-September. (Off.: Hb. Melissae.)

\section{Nepeta $L$. Katzenminze.}

699. N. Cataria $L$. Gem. K.; St. ästig; Bl. gestielt, herzeifïrmig, spitz, tief gesägt, etwas runzelig, unterseits graufilzig; Trauben reichblüthig; K. eiförmig, etwas gekrümmt, pfriemlichstachelspitzig, gezähnt; Nüssch. kahl. 4. 1-2'. Blkr. röthlich-weiss. Meist von eigenthüml. starkem, selten citronenartigem Geruch.

An Wegen, auf Schutthaufen, Mauern, an Zäunen hie und da, z. B. beim Relaishause! Malsch! Malschenberg! Sandtorf! stellenweise am Neckarufer, z. B. unterhalb Neuenheim und in der Nähe von H.! Juli, August. (Off.: Hb. Nepetae.)

296. Glechoma $L$. Gundelrebe.

700. G. hederaceum L. Epheubl. G.; St. niederliegend, kriechend; Bl. gestielt, herz-nierentörmig, gekerbt, mehr od. weniger behaart; Scheinquirle 2-5blth., fast einseitswendig. 4. Variirt mit grüsseren und kleineren hellblauen Blkr.

In Gebüschen, Wäldern, an Wegen, auf Wiesen überall verbreitet! April-Juni. (Off.: Hb. Hederae terrestris.) 


\section{9\%. I amium $L$. Taubnessel.}

a) Blkrröhre gerade, innen olne Haarring; Antheren bärtig.

701. L. amplexicaule $L$. Stengelumfassende T.; St. niederliegend oder aufsteigend; Bl. nierenf,-rundl, eingeschnittengekerbt, die oberen stengelumfassend, die unteren gestielt; Scheinquirle reichblth.; Kzähne nach dem Verblühen zusammenneigend. ○. $\frac{1}{2}-1^{\prime}$. Blkr. purpurroth, mit kürzeren oder längeren Röhren, im Frühling meist nicht vollständig entwickelt.

Auf Aeckern, in Weinbergen, Gärten u. s. w. überall häufig! April-October.

b) Blkr. gekrümmt, innen mit einem Haarringe; Antheren bärtig.

702. L. purpureum $L$. Purpurrothe T.; St. aufsteigend oder etwas niederliegend; BI. gestielt, ei-herzförmig, gekerbt, weichhaarig, rurzelig; Scheinquirle gedrängt, armblth.; Blkrröhre schwach gekrïmmt. ๑. 4-8". Blkr. klein, purpurroth.

An Wegen, auf Aeckern, Culturland gemein! April-October.

703. L. maculatum $L$. Gefleckte T.; St. aufsteigend, wie die Bl. kurzhaarig; Bl. gestielt, herz-eiförmig, zugespitzt, doppelt sügezähnig; Scheinquirle von einander entfernt, reichblth.; Blkrröhro stark gekrümmt; Haarring gerade. 4. 1-2'. Blkr. ansehnlich, purpurroth, aussen weichhaarig. Blätter im Frühling meist weissgefleckt, später fast ganz grün.

In Wäldern, Gebüschen, auf Waldwiesen, an Gräben häufig! Mai-Juli.

704. L. album $L$. We isse T.; St. aufsteigend, wie die Bl. kurzhaarig; Bl. gestielt, herz-eifürmig, zugespitzt, grob gesägt; Scheinquirle ontfernt, reichblth.; Blkrröhre stark gekrümmt; Haarring schief. 24. 1-2'. Blkr. gelblich-weiss; Oberlippe aussen rauhhaarig.

Auf Wiesen, an Wegen, Zäunen, Waldrändern überall verbreitet! Mai-September. (Off.: Flor. Lrticae mortuae.)

\section{Ga le obd ol on Huds. Goldnessel.}

705. G. Iuteum Huds. Gel b e G.; St. am Grunde verzweigt, wie dio Bl. etwas rauhhaarig: Bl, gestielt, herz-eiförmig, ungleich kerbig-gesägt; Scheinquirlo meist 6blth.; Antheren kahl. 4. $\frac{1}{2}-1 \frac{1}{2}$. Blkr. ansehnlich, gelb. (Galeopsis Galeobdolon L.)

In schattigen, feuchten Wäldern, Gebüschen der Gebirge und der Ebene häuflg! April, Mai.

SCHMIDT, Flora v. H. 
399. Galeops is L. Hohlzahn.

a) St. unter den Gelenken nicht verdickt.

706. G. Ladanum $L$. A cker-H.; St. ästig; Bl. lineal oder länglich-lanzettl., gezähnt; Scheinquirle achselständig, 5-6blth.; Kzähne pfriemlich-stachelspitzig, kürzer als die Blkr.; Oberlippe der Blkr. schwach gezähnt. ๑. $\frac{1}{2}-1 \frac{1}{2}^{\prime}$. Blkr. bald grösser, bald kleiner, purpurroth. - Variirt sehr in Behaarung, bald graufilzig, bald fast kahl. Ausserdem:

a) latifolia Hoffm.; BI. länglich oder ei-lanzcttlich, meist weniger behaart.

B) angustifolia Ehrh.; Bl. lineal-lanzettl., oft filzig.

Auf Aeckern, in Weinbergen, auf Kalk- und Lehmboden hio and da, meist sehr gesellig, z. B. zwischen Wiesloch! Baierthal! Schatthausen! Malsch! bei Ladenburg! Handschuchsheim! Wieblingen! stets Var. $\alpha$ vorherrschend! Zuweilen auch Var. $\beta$ fast allein, z. B. an der Schlossterrasse und im Klingenthal bei H, ! beim Relaishausel Juli-September.

707. G. ochroleuca Lam. Gelblich-weisser II.; St. einfach oder ästig, wie die Bl. dicht weichhaarig; Bl. eirund oder eilanzettlich, gesägt; Scheinquirle achselständig, 2-6blth.; Kzähno lanzettl., kurzstachelsp., kürzer als d. Blkr.; Oberlippe der Blkr. eingeschnitten-gezähnt. ๑. 3-10". Blkr. ansehnlich, gelblich-weiss (G. grandiflora Roth., G. villosa Gmel.)

Auf sandigen Aeckern, Sandfeldern, an Wegen hie und da, z.B. bei Schönau! Wilhelmsfeld (Dierb.), beim Relaishause! Rohrhof! bei Seckenheim! Neckarau! Virnheim, Käferthal; häufig bei Sandtorf! Hockenheim! zwischen Waghäusel und Wiesenthal! Juli-Septbr.

b) St. unter den Gelenken angeschwollen, rückwärts-steifhaarig.

708. G. Tetrahit $L$. Gem. H.; St. ästig, wie die Bl. völlig steifhaarig; Bl. länglich-eirund, zugespitzt, gesägt; Scheinq. 6blth.; Kzähne pfriemlich-stachelspitzig, meist so lang wie die Blkrröhre; Mittellappen der Unterlippe länglich-4eckig, flach, kaum ausgerandet. ๑. 1-2 ${ }^{i}$. Blkr. blássroth. - Variirt:

$\beta$ ) bifida Bönngh.; Mittellappen der Unterlippe am Rande zurückgerollt, an der Spitze melir oder weniger ausgerandet.

An Wogen, auf Aeckern, Schutt die Hauptart verbreitet! Die Variet. hio und da zerstreut, an schattigen Waldrändern, auf feuchten, schattigen Aeckern, z. B. zwischen dem Schloss und der Molkenkur bei H.! im Gebirge zwischen Dossenheim und Schriesheim! JuliSeptember. 
709. G. pubescens Bess. Weichhaariger II.; St. ästig, wie die Bl. weichhaarig, nur unter den Knoten steifhaarig; Bl. eiförmig, fast herzf., zugespitzt; Scheinq. armblth.; Kzipfel pfriemlich, drüsig-gewimpert, kürzer als die Blkrrühre; Mittellappen der Unterlippe fein gekerbt. ๑. 1-2'. Blkr. klein, blassroth.

In lichten Wäldern, Gebüschen, Hecken bisher selten, hinsichtlich der Verbreitung noch unsicher. Sandtorf (Döll), Hockenheim (König). Juli-August.

[G. versicolor Curt, nach Dierb. p. 174 auf dem heiligen Berge vorkommend, wurde in neverer Zeit weder dort, noch sonst im Gebiet der Flora wahrgenommen.]

\section{II arubium $L$. Andorn.}

710. M. vulgare $L$. Weisser A.; St. ästig, weissflzig; Bl. eirund, gekerbt, runzelig, weiss-grau behaart; Scheinq. entfernt, fast kugelig, reichblth.; Kelche rauhhaarig, mit an der Spitze hakig-gekrümmten Zähnen. 4. $\frac{1}{2}-1 \frac{1}{2}^{\prime}$. Blkr. klein, weiss.

An Wegen, auf Schutt, Sandflächen, in Dörfern hie und da, z. B. auf den Sandfeldern zwischen Friedrichsfeld und dem Relaishause! beim Rohrhof! Ketsch! Rheinhausen! ziemlich häufg bei Feudenheim; Sandtorf! Juni-August. (Off. : Hb. Marrubii)

\section{Ballota $L$. Schwarzessel.}

7ll. B. nigra $L$. Gem. S.; St. ästig, wie die Bl. behaart; Bl. herz-eiförmig, gesägt; Scheinq. reichblth.; K. mit kürzeren oder längeren stachelspitzigen Zähnen. 4. 1-3'. Blkr, violett-roth, selten weiss. - Variirt in Behaarung, Grösse der Blätter und Länge der Kzähne.

An Wegen, Zäunen, Waldrändern, auf Schutt häuffg! JuniSeptember. (Off. : Hb. Ballotae)

\section{Betouica $L$. Betonie.}

712. B. officinalis $L$. Heilkr. B.; St. einfach, wie die Bl. meist rauhhaarig; Bl. eiförmig-länglich, mit herzf. Grunde, die unteren langgestielt; Scheinq. endständig, aehrenartig-gedrängt; K. meist rauhhaarig. 4. $1 \frac{1}{2}-2^{\prime}$. Blkr. roth. - Variirt:

$\beta$ ) glabrata; St. und K. kahl.

Auf Wiesen, an lichten Waldstellen, an sonnigen Abhängen d. Ebene und d. Gebirge nicht selten, besonders häufig längs der Bergstrasse! hie und da auch bei H., z. B. am Geisberge! im Dreitröge Thal! oberhalb des Philosophon-Weges! Auf den Wiesen der Ebene 
von Friedrichsfeld bis gegen den Rhein stellenweise sehr verbreitet! Die Var. selten: auf schattigen Bergwiesen hinter Schriesheim! Juli bis August. (Off.: Rad. et hb. Betonicae.)

\section{Stachys $L$. Ziest.}

a) Blth. roth.

713. St. germanica $L$. Deutscher Z.; St. steif aufrecht, dicht zottig; Bl. ei-herzförmig, gekerbt, weisswollig-filzig, d. oberen sitzend, länglich; Scheinq genähert, vielblth.; K. wollig, stachelspitzig gezähnt. 4. 1-1 $\frac{1}{2}^{\prime}$. Blkr, hellroth, klein.

Auf steinigen Triften, an Waldrändern, auf Mauern hie und da, z. B. einzeln zwischen Schwetzingen und dem Eiskeller; zwischen Neckarhausen und Seckenheim! häufiger beim Scharrhof, zwischen Sandhofen und Sandtorf! Nach Dierb. auf Weinbergshügeln um H., woselbst aber jetzt wohl fast ganz verschwunden! Juli, August.

714. St. sylvatica $L$. Wald-Z.; St. aufrecht, wie die Bl. rnuhhaarig; Bl. ei-herzf., zugespitzt, gesägt; Scheinq. 6blth., entfernt; Kzähne pfriemlich-stachelspitzig; Blkrröhre länger als der K. 4 . $1 \frac{1}{2}-2^{\prime}$. Fadenförmige Ausläufer treibend; Blkr. dunkelroth. - Stark und widrig riechend.

In feuchten Wäldern und Gebüschen, an Ufern häufig! Juni bis August.

715. St. palustris $L$. Sumpf-Z.; St. aufrecht, steifhaarig; Bl. herzf.-lanzettl., spitz, kerbig-gesägt, weichhaarig (oder kahl werdend), die oberen halb stengelumfassend; Scheinq. 6-12blth., genähert; Kzähne, Blkrröhre d. vor. 24. 1-2'. An der Spitze verdickte Ausläufer; Blkr. roth, gefleckt. - Findet sich sehr selten mit wirtelständigen Blăttern.

Auf feuchten Aeckern, Triften, an Gräben, Ufern, in Sümpfen und feuchten Gebüschen häufig! Juni-September.

Diese Art bildet mit St. sylvatioa eine hybride Pfl.: St. palustri-sylvatica Schiede (St. ambigua Sm.) BI. langgestielt, elliptischlanzettle, zugespitzt, feinhaarig; Scheinq. der sylvatica; Blkrröhre kürzer als d. K.; Blkr. etwas dunkler roth, als bei S. palustris. 1-2'.

In feuchten Gebüschen am Neckar oberhalb Ziegelhausen (Bisch.) Juni-August.

716. St. arvensis $L$. Acker-Z.; St. einfach oder ästig, abstehend-steifhaarig; Bl. gestielt, eirund, stumpf, gekerbt, schwach behaart; Scheinq. 6blth.; Kzähne lanzettl., stachelspitzig; Blkr. so lang als $\mathrm{d}$. Ko, roth. $\odot$. $\frac{1}{4}-\frac{1}{2}^{\prime}$.

Auf Aeckern, in Weinbergen, auf Lehm- und Sandboden hie und da, z, B. zwischen der Schauenburg bei Dossenheim und dem 
Oelberge! zwischen Weinheim und Grosssachsen! bei Friedrichsfeld Edingen! Wieblingen! Wiesloch! Schatthausen! Juli-September.

b) Blkr gelblich-weiss.

717. St. annua $L$. Einjähriger Z.; St. einfach oder ästig, oben weichhaarig; Bl. fast kahl, gestielt, die unteren eiförmig-länglich, kerbig-gesägt, die oberen lanzettl., fast ganzrandig; Scheinq. 3-6blth.; K. zottig, mit stachelspitzigen, weichhaarigen Zähnen. ๑. $\frac{1}{2}-\frac{3}{4}$.

Auf trockenen, sandigen und kalkhaltigen Aeckern und Triften häuffger als vorige, besonders in der Ebene zwischen Neckarau! Seckenheim! Friedrichsfeld! Schwetzingen! 'verbreitet. In grosser Menge zwischen Ladenburg und Handschuchsheim, besonders auf Feldern am Neckar! Häufig bei Wiesloch! Baierthal! Rauenberg! Juni-August.

718. St. recta $L$. Gerader Z.; St. aufsteigend, ästig, wie die Bl. rauhhaarig; Bl. gestielt, länglich-eirund oder lanzettl., kerbiggesägt, die oberen fast ganzrandig; Scheinq. 6-12blth.; K. rauh-

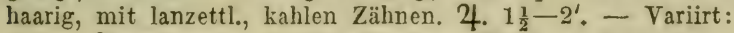

$\beta$ ) procumbens; niederliegend; Bl. lineal-länglich.

Auf sonnigen Hügeln, Bergwiesen, an Waldrändern, auf Kalkund Sandboden nicht selten! Die Var. in den Nadelwäldern bei Friedrichsfeld! Walldorf! Mai-August. (Off.: IIb. Sideritidis.)

\section{L e o u u us $L$. H erzgespann.}

719. L. Cardiaca L. Gem. H., dunkelgrün; St. ästig; Bl. gestielt, die unteren handförmig-5spaltig, eingeschnitten-gezähnt, die oberen 3lappig, am Grunde keilförmig, die vielblth. Scheinq. weit überragend; Kzähne begrannt, 4. 1-2'. Blkr. blassroth, aussen zottig.

An Wegen, in Hecken, auf Mauern, besonders in Dörfern, jedoch nicht häufig, z. B. zwischen Eppelheim nnd Plankstadt! beim Grenzhofe (Schimp.). Am Neckarufer bei Feudenheim! Seckenheim! Juli-September.

\section{Chaitulus Willd. Katschenschwanz.}

720. Ch. Marrubiastrum Rchb. Andornartig. Kz.; hellgrün; St. ästig; Bl. gestielt, weichhaarig, unterseits mit zahlreichen Drüsen besetzt., länglich-eirund, untere eingeschnitten-sägezähnig, obere nur schwach gezähnt, die vielblth. Scheinq. überragend; Kzähne strohgelb, stachelspitzig, lang begrannt. $\hat{\odot} \cdot 1 \frac{1}{2}-2^{\prime}$. Blkr. blassroth. (Leonurus Marrubiastrum L.)

An Zäunen, auf Triften, Schutthaufen sehr selten. Unfern des Seharrhofes zwischen Sandhofen und Sandtorf! Juli-September. 
[N. V. a. d. Geb.: In Hs. Leeheim (Schnttsp.) In Rhb. fehlend und in $\mathrm{B}$. ?]

\section{Prunella $L$. Brunelle.}

721. P. vulgaris $L$. Gem. B.; St. aufsteigend, wie die Bl. kurzhaarig; Bl. gestielt, länglich-eiförmig, ganzrandig oder buchtiggezähnt; Scheinq. mit eirunden, gewimperten Deckbl, aehrenartig; Blkr. kaum doppelt so lang, wie d. K. ; längere Stbfäden mit pfriemlichem Zahnfortsatz. 4. $\frac{1}{2}-1^{\prime}$. Blkr. blau.

B) laciniata; Bl. mehr od, weniger fiederspaltig! Blkr. weiss.

Auf Wiesen, an Waldrändern, Wegen die Hauptart häufig! Die Var, an grasreichen Anhöhen, auf Triften, z. B. am Neckar hinter Neuenheim! zwischen Nussloch und dem Maischbacher Hof! Juni bis September.

722. P. grandiflora Jacq. Grossblth. B.; St. aufsteigend, wie die Bl. rauhhaarig; Bl. gestielt, länglich-eiförmig, gezähnt oder etwas fiederspaltig; Scheinq. wie vor.; die längeren Stbfäden mit stumpfem, höckerartigem Fortsatz; Blkr. 3-4mal so lang wie d. K., dunkelviolett-roth. 4. 4-8".

Auf trockenen Wiesen und Triften, an Anhöhen nicht selten, z. B. hinter dem Haarlass! von Handschuchsheim längs der Bergstrasse bis Weinheim! häufig von Leimen bis Maischbach! Schatthausen! Dielheim! Malsch! Auch auf trockenen Wiesen d. Ebene, z. B. beim Relaishause! Juli, August.

\section{0\%. Scutellaria $L$. Helmkraut.}

723. S. galericulata $L$. Gem. H.; St. ästig, abwärts behaart; Bl. herzf.-lanzettl., gekerbt; Blth. achselständig, einseitswendig; K. meist kahl, viel kürzer als die violette Blkr. 4 . $\frac{1}{2}-1^{\prime}$.

An Ufern, in Gräben, feuchten Gebüschen hä̉ufig! Juli, Augst.

[S. hastifolia $L$. Spiessblättr. H.; St. aufwärts-behaart; Bl. längl.-lanzettl., ganzrandig, an der Basis fast spiessförmig; Blth. einseitswendig; K, drüsig, viel kürzer als d. violette Blkr. 4. $\frac{1}{4}-1^{\prime}$.

N. V. a. d. Geb. in Rhb. auf feuchten Wiesen bei Friesenheim rechts vom Wege der nach Oggersheim führt! In Rhh. von Oppenheim bis Mainz an den Rheinufern häufig. - Vielleicht im Geb. unserer Flora bisher nur übersehen?]

\section{A juga $L$. Günsel.}

a) Scheinq. vielblth. in endständigen Aehren.

724. A. reptans $L$. Kri $\theta$ chend. G., schwachbehaart; St. mit kriechenden Ausläufern, selten olıne dieselben; Bl. längl, verkehrt- 
eirund, schwach gekerbt; Aehre locker; Deckbl. eirund, ganzrandig oder ungleich gekerbt; Oberlippe der Blkr, tief ausgerandet. 4. $\frac{1}{2}^{\prime}$. Blkr. blau.

Mai, Juni.

An Waldrändern, Gräben, Wegen, auf Wiesen überall verbreitet!

725. A. genevensis $L$. Genfer-G., zottig; St. ohne Ausläufer; Bl. verkehrt-eifürmig-länglich, gekerbt; Aehre dicht; Deckbl. 3lappig; Oberlippe der Blkr. seicht ausgerandet. 4 . $\frac{1}{2}-1^{\prime}$. Blkr. blau. Erscheint zuweilen mit grösseren Blättern und höherem St. (A pyramidalis Dierb.?)

An grasreichen, sonnigen Anhöhen, Rainen, auf Sandfeldern, in Nadelwäldern hie und da. In der Nähe von H. selten, z. B. oberhalb des Philosophenweges! hinter dem Haarlass! häufiger längs d. Bergstrasse gegen Weinheim! allgemeiner verbreitet bei Leimen! Schatthausen! Wiesloch! und stellenweise in den Sandgegenden, z. B. bei Friedrichsfeld! Schwetzingen! Sandhausen! Mai, Juni.

[A. pyramidalis $L_{\text {. }}$, von Dierb. p. 166 aufgeführt, wächst nicht im Geb. der Flora, und wohl nicht näher als in Rhb. bei Kaiserslautern!]

b) Blth. eịnzeln, achselständig.

726. A. Chamaepitys Schreb. $\mathrm{Z} \Vdash \mathrm{er} \mathrm{g}-\mathrm{G}$, , niederliegend, ästig, zottig; Bl. 3spaltig, mit linealen Zipfeln. ๑. 2-4". Blkr. gelb. Riecht rosmarinartig. (Teucrium Chamaepitys L.)

Auf steinigen Aeckern und Triften, auf Kalk und kalkhaltigem Sande stellenweise, z. B. in Menge bei Rauenberg und Rodenberg! Baierthal! seltener $\mathrm{zwischen}$ Alt-Wiesloch und Dielheim! bei Oberhof, unfern Schatthausen (v. Göler), häufig bei Nesterbach! vereinzelt bei Eppelheim! Plankstadt, Schwetzingen. Juni-September, (Off.: Hb. Chamaepitys.)

\section{Tенсгі ит $L$. G a mander.}

a) K. 2lippig; Oberlippe eiförmig, ungetheilt; Unterlippe 4zähnig.

727. T. Scorodonia $L$. Salbeiblättr. G., weichhaarig; Bl. gestielt, herzf,-eirund, kerbig-gesägt, runzelig; Blth. in verlängerten, einseitswendigen Trauben. 4. 1'. Blkr. gelblich.

An Waldrändern, Gräben, Hecken, auf Waldtriften der Gebirge und der Ebenen häufig, oft heerdenweise! Juli-September.

b) K. 5zähnig, fast gleiohmässig.

728. T. Botrys $L$. Trauben-G., etwas drüsig-behaart; Bl. gestielt, doppelt fiederspaltig; Scheinq. 2-6blth.; K. etwas aufgeblasen, ○. 3-10". Blkr. röthlich. 
In Weinbergon, an steinigen, kalkhaltigen, sonnigen Anhühen hic und da, z. B. häufig hinter Rauenberg! bei Nesterbach! seltener in Eingange des Birkenauer Thales bei Weinheim! am Galmeybergwerk bei Wiesloch! auch einzeln an den Rheindämmon bei Mannheim (Döll). Juni-August.

729. T. Scordium L. Knoblau ch-G.; St. aufsteigend, zottig, mit kriechenden Ausläufern; Bl. sitzend, längl. lanzettl., kerbig-gesägt, kurzhaarig; Scheinq. 2-4blth. 2. $\frac{1}{2}-\frac{3}{4}$. Blkr. purpurroth. Riocht knoblauchartig.

Auf sumpigen Wiesen selten. Zwischen St. Ilgen und Kirchhoim. Juli-September.

[N. V. a. d. Geb. in Rhb, zwischen Friesenheim und Oppau! Erpolsheim! Speier (F.Sch.). B: Carlsruhe (Döll). Hs : zwischen Darmstadt und Mainz (Schnttsp.).] (Off.: Hb. Scordii.)

730. T. Chamaedrys $L$. Edler G.; St. aufsteigend, fast 2zeilig zottig; Bl. kurzgestielt, eiförmig-keilig, tief gekerbt, kahl, oberseits glänzend; Scheinq. 2-6blth., in endständigen Trauben. 4. $\frac{1}{2}-1^{\prime}$. Blkr. rosa.

An sonnigen Abhängen, auf trockenen, steinigen, kalkhaltigen Hügeln, auf Granitfelsen stellenweise, z. B. an den Abhängen vor dem Haarlass! und gegen Ziegelhausen! Längs der Bergstrasse hic und da, z. B. bei Dossenheim! im Ludwigsthal bei Schriesheim! Leutershausen! Weinheim! Nesterbach! Zwischen Dielheim! Rauenberg! Malsch! ziemlich verbreitet! Seltener b. Maischbach! an den Weinbergen zwischen H. und Rohrbach! Juli-September. (Off.: Hb. Chamaedryos.)

\section{VERBENACEAE Juss.}

Krïuter mit gegenständigen Blättern ohne Nebenblïtter. K. röhrig, bleibend. Blkr. röhrig, mit ungleichem, 4-5spaltigem Saum. Stbgef. didynamisch oder, indem die 2 oberen unfruchtbar bleiben, diandrisch. Fruchtknoten 2-4fücherig, mit gipfelständigem Griffel. Frucht meist steinfruchtartig, oft bei der Reife in 4 Nüsschen zerfallend. Samen eiweisslos. Keim gerade.

Verbena. K. 5spaltig; Blkr. trichterfürmig, ungleich 5lappig; Stbgef, didynam,; Frucht in 4 Nüsschen zerfallond. 
Lentibularieae.

\section{Verbena $L$. Eisenkraut.}

731. V. officinalis $L$. Gebräuchl. E. ; St. 4 kantig; Bl. eiförmig-länglich, 3lappig oder etwas eingeschnitten; schärflich; Blth. in verlängerten Aehren. 2 $\frac{1}{2}-1 \frac{1}{2}^{\prime}$. Blkr. klein. röthlich-violett.

An Wegen, Ufern, auf Triften häufig, oft sehr gesellig! Juni bis September.

\section{LENTIBULARIEAE Rich.}

Wasser- oder Sumpfpflanzen mit einfachen oder vielfach zertheilten Blättern. K. 2lippig, bleibend. Blkr. 2lippig. Unterlippe am Grunde gespornt. Stlogef. 2, mit 1fächerigen Antheren. Fruchtknoten 1fächerig aus 2 Fruchtblättern gebildet, mit freiem, kugeligem, mittelpunktstindigem Samentrïger, zahlreichen Eichen, 1 Griffel, mit 2lappiger Narbe. Kapsel 2 klappig oder unregelmässig aufspringend. Samen eiweisslos. Keim aufrecht.

Pinguicula. K. 5spaltig; Blkr. rachenförmig, offen; Kapsel 2klappig, aufspringend.

Utricularia. K. 2blättr.; Blkr. rachenfürmig, geschlossen (maskirt); Kapsel unregelmässig aufspringend.

\section{Pinguicula $L$. Fet tkraut.}

732. P. vulgaris $L$. Gem. F.; Bl. grundständig, rosettig, eirund, etwas fleischig, drüsig-schleimig, hellgrün: Schaft 1blth.; Sporn pfriemlich, kïrzer als die Blkr. 4. 2-3". Blkr, violett.

In Torfsümpfen, auf nassen, moorigen Wiesen nur bei Waghäusel und Neu-Lussheim, daselbst aber häufig! Mai, Juni.

[N. V. a. d. Geb. in Hs. zwischen Kranichstein und Messel, unfern Darmstadt (Schnttsp.); in Rhb. fehlend; in B. im Oberlande vorbreitet $(D \ddot{l} l l)$.]

\section{Ctricularia $L$. W asserschlauch.}

733. U. vulgaris $L$. Gem. W.; Bl. untergetaucht, nach allen Seiten abstehend, fiederspaltig-vieltheilig, mit haarfeinen gezähnten Zipfoln; Schaft 4-6blth., aus dem Wasser sich erhebend; Sporn kegelfürmig; Oberlippe von der Länge des Gaumens; Fruchtstiel gerade. 4. Blkr. ansehnlich, gelb oder rothgelb. 
In Gräben, Sümpfen, Teichen, besonders in tiefen Moorgräben der Rheinfläche häufig! seltener zwischen St. Ilgen und Kirchheim! zwischen Weinheim und Ladenburg! Juni-August.

734. U. minor $L$. KleinerW., kleiner u. zarter; Bl, untergetaucht, gablig-vieltheilig, mit borstlichen, zahnlosen Zipfeln; Schaft 3-4blth., kurz auftauchend; Sporn sehr kurz; Oberlippe von der Länge des Gaumens; Fruchtstiel zurückgebogen. \%. Blkr. klein, blassgelb.

In den Torfsümpfen und Moorgräben bei Waghäusel! Sandtorf! bei Roth (Lehrer Riegel). Juni-August.

(Die deutschen Arten dieser Gattung entwickeln an den Blattflächen blasenartige Schläuche, welche vor der Blüthezeit mit Luft angefüllt sind und daher die am Grunde des Gewässers vegetirende Pflanze an die Oberfläche zu steigen veranlassen. Später platzen die Schläuche und die Pflanze sinkt wieder auf den Grund zurück.)

\section{PRIMULACEAE Vent.}

Kräuter mit meist gegenständigen, oft nur grundstïndigen Blättern ohne Nebenblätter, mit regelmässigen Blüthen. K. u. Blkr. 4-5(-7)gliederig, (bei Glaux Blkr. o). Stbgef. 4 bis 5 , selten 7 , den Blumenblättern gegenüberstehend, selten noch ausserdem mit unfruchtbaren Stbgef. Fruchtknoten frei (boi Samolus halb mit dem Kelch verwachsen), 1fächerig, mit freiem, centralem Samenträger, vielen Eichen, 1 Griffel und kopfiger Narbe. Kapsel an der Spitze mit Klappen oder Zähnen, selten in der Mitte ringsum aufspringend. Samen eiweisshaltig, meist schildförmig. Keim gerade, meist wagerecht, seltener (bei Hottonia, Samolus) aufrecht. Dio im Habitus sehr verschiedenen Arten dieser Familie sind fast alle durch Geselligkeit ausgezeichnet, bedürfen meistens einen etwas feuchten Boden oder sind geradezu Wasserpflanzen; einige sind salzliebend. Obwohl mehrere Arten die Flora des Frühlings eröffnen, und schon mit der zweiten Hälfte des Frühlings ihre Blüthezeit beendet haben, beginnt die Blüthe der meisten hier aufgeführten Arten erst zu Ende des Frühlings oder später. Eigenthümliche scharfe, brechenerregende Stoffe sind für manche Primulaceae bezeichnend.

L y s i machia. K. 5theilig; Blkr. radförmig; Stbgef. 5 ; Kapsel 5klappig. 
An a gallis. K. 5th.; Blkr. radf.; Stbgef. 5; Kapsel ringsum aufspringend.

Cont unculus. K. 4th.; Blkr. glockig-kugelig, schr klein ; Stbgef, 4 ; Kaps. ringsum aufspringend.

Androsace. K. 6zähnig od. spalt.; Blkr. teller- oder trichterf.; Röhre eiförmig, am Schlunde verengert; Stbgef. 5; Kaps. 5kl.

Primula. K. 5spalt.; Blkr. trichterf., Röhre walzig: Stbgef. 5; Kaps. 5kl.

Hottonia. K. 5theil; Blkr. tellerf, , Röhre walzig; Stbgef. 5 ; Kaps. $5 \mathrm{kl}$.

S a molu s. K. 5spalt., halb mit d. Fruchtknoten verwachsen; Blkr. glockig; Stbgef. 10, wovon 5 unfruchtbar; Kaps. 5kl.

Gla ux. K. 5spalt., gefärbt; Blkr. 0; Stbgef. 5; Kaps. 5kl.

\section{Iysimachia $L$. L y simachie.}

735. L. vulgaris $L$. Gem. L.; St, aufrecht, wie d. Bl. etwas weichhaarig, selten kahl; Bl. gegenst. od. wirtelig, kurzgestielt, eif.längl.; Blth. in gipfelst. Rispen; Kzipfel lanzettl.; Stbgef. bis zur Mitte verwachsen。 4. 1-3'. Blkr. goldgelb.

In Gebüschen, Wäldern, an Ufern, auf feuchten Wiesen häufig. Mai-Juli.

736. L. nemorum $L$. H a in-L.; St. niederliegend, kriechend, kahl; Bl. gegenst., eiförmig, spitz, am Rande fein gewimpert; Blthstiele fadenförmig, einzeln, achselst., 1blth.; Kzipfel lineal; Stbfäden frei. 4. 4-6". Blkr. hellgelb.

In feuchten Wäldern, an schattigen Bächen, Quellen hie und da. Hirschgasse! am Wege nach der Engelswiese! von dort durch das Gebirge gegen Ziegelhausen und Schönau stellenweise in Menge! Häufig auch bei Maischbach! Leimen! Dielheim! Gaiberg! Schriesheim! Weinheim! Seltener im Friedrichsfelder Walde. Mai, Juni.

737. L. Nummularia $L$. Pfennig-L.; St. niederliegend; kriechend; Bl. herzförmig-eirund, kahl; Blthstiele achselst., einzeln, 1blth.; Kzipfel herzf.-lanzettl.; Stbf. frei. 4. Blkr. citronengelb; Bl. dunkelpunktirt.

An Gräben, in feuchten Wäldern, auf feuchten Wiesen und Triften allgemein verbreitet! Juni-August.

\section{An agallis $L$. Gauchheil.}

738. A. arvensis $L$. A cker-G.; St. niederliegend oder aufsteigend, ausgebreitet; Bl. sitzend, eiförmig; Blthstiele achselständig, 1blth.; Blbl. etwas länger als d. K, am Rande fein gekerbt, mehr 
oder weniger drüsig. ๑. Bl. unterseits dunkel punktirt. - Giftig. Es lassen sich 3 Varietäten unterscheiden:

a) vulgaris; Blkr. roth, fast immer am Rande mit Drüsenhaaren.

ß) carnea; Blkr. fleischroth od. Weiss, ebenfalls drüsig.

$\gamma)$ coerulea; Blkr. blau, meist drüsenlos, seltener mit einzelnen Drüsenhaaren.

Auf Aeckern, Triften, an cultivirten Orten. Var. $\alpha$ besonders auf Sandboden! Var. $\gamma$ vorzugsweise auf Lehm- und Kalkboden häufig! Var. $\beta$ ziemlich selten, z. B. bei Ladenburg! Alt-Wiesloch! Juni-September.

\section{Centunculus $L$. Kle inling.}

739. C. minimus $L$. Kleinster Kl.; niederliegend od. aufsteigend, meist ästig; Bl. eirund, ganzrandig; Blthen einzeln, achselständig, sitzend; Kzipfel lineal, länger als die kugelige Kapsel. ๑. 1-4". Blkr. hellröthlich.

Auf feuchten, sandigen und lehmigen Aeckern und Triften hio und da, z. B. bei Friedrichsfeld in der Nähe des rothen Loches! Brühl! Neu-Lussheim! Sandtorf! Auch bei H. am Wege vom Dreitrögethal nach dem Speyrer Hof! Juli; August.

\section{[Aindrosace $L$. Mannschild.]}

[A. maxima L. Grösster M.; Bl. grundst., rosettig, lanzettl.elliptisch, gezähnt; Schaft behaart mit endständiger armblth. Dolde; K. länger als die Blkr, nach der Blüthe vergrössert. ๑. 2-4". Blkr. klein, weissröthlich.

Auf lehmigen und kalkhaltigen Aeckern. N. V. a. d. Geb. in Rhb. einzeln bei Oggersheim! häufiger bei Ruchheim! Fussgönnheim! Ellerstadt! April, Mai.]

\section{Primula $L$ : Primel, Schlüsselblume.}

740. P. elatior Jacq. Hohe P.; St. sehr verkürzt; BI. grundst., eirund-längl., wellig-gekerbt, runzelig, unterseits kurzhaarig; Schaft verlängert; Blthen doldig; K. scharfkantig, röhrig, wenig abstehend mit langzugespitzten Zähnen; Blkrsaum flach. 4. $\frac{3}{4}-1^{\prime}$. Blkr. schwefelgelb, geruchlos. ( $P$. veris $\beta$ elatior $\left.\mathrm{L}_{\text {. }}\right)$.

In schattigen, feuchten Wäldern, auf Waldwiesen, in Gebüschen häufig! März, April.

741. P. officinalis Jaoq. Gebräuchl. P.; der vorigen ähn- 
lich; BI. unterseits weichhaarig; K, glockig-erweitert, mit kurzzugespitzten Zähnen; Blkrsaum concar zusammenneigend. 4. $\frac{1}{4}-3^{3}$. Blkr. kleiner, citronengelb mit 5 safrangelben Flecken.

In lichten Wäldern, auf trockenen Wiesen, Triften und Haiden häufig, meist geselliger als vorige. April, Nai. (Off.: Flores Primulae veris.).

\section{1\%. Il ottonia $L$. Hottonie.}

742. H. palustris L. Sumpf-H.; St. mit den rosettigen, kammartig gefiederten Bl. untergetaucht; Schaft auftauchend mit endst. quirliger Traube. 4. Blkr. hellrosa, Schlund gelb.

In Gräben, Sümpfen, Teichen der Rheinebene häufig, z. B. beim Rohrhof! Neckarau! zwischen Kirchheim und St. Ilgen! Leimen! besonders häufig bei Waghäusel! Mai, Juni.

\section{Sa molus $L$. Samolus.}

743. S. Valerandi $L$. Salz-S.; hellgrün, kahl; St. aufrecht, etwas ästig; Bl. verkehrteirund-spatelig, ganzrandig, die unteren rosettig; Blthen in verlängerten Trauben. 4. $\frac{1}{2}-1^{1}$. Blkr. weiss.

In Sümpfen, Gräben, auf feuchten Wiesen meist auf etwas salzhaltigem Boden selten. Zwischen St. Ilgen und Leimen; einzeln bei Waghäusel! Juni-Sept.

[Jenseits des Rh. viel häufiger, z. B. in Menge in d. Sümpfen bei Oggersheim! bei Maxdorf! Lambsheim! bei den Dürkheimer Salinen!]

\section{[Glaux $L . M i l c h k r a u t$.}

[G. maritima L. Küsten-M.; niederliegend, etwas fleischig, kahl; Bl. sitzend, lanzettl., ganzrandig, meist gegenst., gedrängt, Blth. achselst., sitzend, einzeln, fleischroth. 2-5".

N. V. a. d. Geb.: in Rhb. an den Salinen von Dürkheim! Juni, Juli.]

\section{GLOBUlarinEAE. De Cand.}

Ausdauernde Kräuter od. Halbsträucher mit abwechselnden Blättern ohne Nebenblätter, von einer gemeinschaftlichen Hülle umgebenen und mit Spreublättchen versehenen kugeligen Blüthenständen. Kelch 5spaltig, röhrig, bleibend; Blkr. unregelmässig, fast 2lippig, 5spaltig; Stbgef. 4 mit den Blumenblät- 
tern abwechselnd. Fruchtknoten frei, 1fächerig, 1eiig, mit hängendem Eichen, 1 Griffel und meist 2spaltiger Narbe. Frucht eine schlauchartige Nuss. Samen eiweisshaltig. Keim gerade. - Charakter der einzigen Gattung Globularia mit dem Familien-Charakter übereinstimmend.

\section{Hobularia $L$. Kugelblume.}

744. G. vulgaris $L . G \in \mathrm{m}$. K.; St. aufrecht, einfach, beblättert; Wbl. rosettig, verkehrteirund-spatelig, an der Spitze ausgerandet oder gezähnt, kahl; Blthk. endständig, kugelig; Hüllbl. lanzettl., stachelspitzig. 4. 5-10". Blkr. hellblau.

Auf trockenen sonnigen Hügeln (auf Syenit) bei Nesterbach in grosser Menge! seltener zwischen Nesterbach und Weinheim! Mai.

[N. V. a. d. Geb.: In Rhb. auf Kalkhügeln zwischen Deidesheim! Dürkheim! Grünstadt häufig! In Hs. und $\mathrm{B}$. in d. Nähe d. Geb: fehlend.]

\section{PLUMBAGINEAE. Juss.}

Ausdauernde Kräuter mit meist grundständigen, rosettigen, den Stengel scheidig umfassenden Blättern ohne Nebenblätter. K. röhrig, 5zähnig, gefaltet, bleibend. Blkr. regelmässig, in der Knospenlage gedreht. Stbgef. '5, den Blumenblättern gegenüberstehend, in der Knospenlage gerade; Fruchtknoten 1 fächerig, mit 1 hängenden Eichen. Griffel 5. Kapsel 1samig, 5klappig, oder am Grunde unregelmässig aufspringend. Samen eiweisshaltig. Keim gerade.

Armeria. K. trockenhäutig; Blkr. 5theilig; Kapsel am Grunde aufspringend; Blthstand kopfförmig mit Hüllblttch, im Knospenzustande von einer scheideartigen, später zurückgeschlagenen Hülle umgeben; Blthboden spreublätterig; Griffel unten mit Sammelhaaren versehen.

\section{Armeria Willd. Grasnelke.}

745. A. vulgaris Willd. Gem. G.; BI. grundst., rosettig, schmal lineal, ganzrandig, 1nervig; Schaft 1köpfig, fast kahl, üussere Hblttch. langzugespitzt, innere stumpf oder stachelspitzig. 4 . $\frac{1}{2}-1^{\prime}$. Blkr. rosa. (Statice elongata Hffm.). 
Auf Sandfeldern, Haiden, sandigen Hügeln nicht häufig, z. B. zwischen dem Relaishause und Seckenheim! stellenweise zwischen Heddesheim und Virnheim! bei Sandtorf! Mai-Sept.

[N. V. a. d. Geb.: In Hs, von Sanddorf und Lambertheim gegen Darmstadt stellenweise! in Rhb. sehr selten: auf Sandhügeln zwischen Grethen und Seebach, unfern Dürkheim! In B. in d. Näho des Geb. fehlend!]

\section{PLANTAGINEAE. Juss.}

Kräuter oder Halbsträucher, mit einfachen, seltener fiederspaltigen Blättern ohne Nebenblätter. Blüthen regelmässig, (bei d. Gattg. unserer Flora) zwitterig; K. 4spaltig, bleibend, seltener 3lappig; Blkr. 4spaltig, trockenhäutig, bleibend; Stbgef. 4, mit den Blbl. wechselnd, in der Knospe einwärtsgeschlagen. Antheren beweglich. Fruchtknoten 1 fïcherig oder durch einen centralen geflügelten Samenträger. scheinbar 2-4fächerig. Fächer 1-mehreiig. Griffel 1. Frucht: ringsum aufspringende Kapsel oder Nuss. Same eiweisshaltig mit wagerechtem Keim.

PI a n t a g 0. Blthst. ährenf.; Blbl. 4, trockenhäutig, zurückgeschlagen; Kapsel ringsum, aufspringend, 2-4fächerig.

\section{I. Plantago $L$. Wegerich.}

a) St. verkürzt, mit grundständigen Blättern und verlängertem Blüthenschaft.

746. P. major $L_{\text {。 }}$ Gros ser W.; Bl. gestielt, eiförmig, 5-9nervig; Schaft stielrund; Aehre verlängert, walzenf.; Deckbl. eirund, stumpfgekielt, am Rande häutig. 4. Blkr. hellbraun. $\frac{1}{2}-1^{\prime}$. Variirt in der Grösse aller Theile, und findet sich besonders auf feuchten Aeckern bisweilen auffallend zwergartig.

An Wegen, auf Brachäckern, Triften überall verbreitet. Juli bis October. (Off.: Fol. Plantaginis).

747. P. media $L$. Mittl. W.; Bl. gestielt, elliptisch, schwach gezähnt, Fnervig; Schaft stielrund; Aehre walzenf., gedrungen; Deckbl. eiförmig, spitz, am Rande häutig. 4 . $\frac{1}{2}-1^{\prime}$. Blkr. wejsslich. Auf Wiesen, Triften, an Wegen häufig! Mai-Juli.

748. P. lanceolata $L$. L a $\mathrm{z} \in \mathrm{ttl}$. W.; Bl, gestielt, lanzettlich, schwach gezähnt, 5nervig, kahl oder behaart; Schaft gefurcht; 
Aehre eiförmig, gedrungen; Deckbl. eiförmig, spitz, am Rande häutig. 4. $\frac{3}{4}-1^{\prime}$. Blkr. weisslich.

An Wegen, auf Wiesen, in trockenen Wäldern überall verbreitet. April-September.

b) St. beblättert, ästig.

749. P. arenaria $W$. et $K$. S and-W. ; graubehaart; Bl. Iineal, ganzrandig oder etwas gezähnt; Aehre eiförmig, gedrungen. ๑. $\frac{1}{2}-1^{\prime}$. Blth. gelbgrün.

Auf Sandfeldern der Ebene, an sandigen Ufern, z. B. in Menge beim Relaishause! seltener beim Rohrhof! Schwetzingen (z. B. in der Nähe der Kiesgruben!), zwischen Feudenheim und Käferthal! am. Rheinufer zwischen Mannheim und Sandhofen! Juli-Sept.

[Auch jenseits des Rheins, z. B. boi Speier! Schifferstadt! Maxdorf! u, s. w. nicht selten.]

\section{Subclass. 4.}

\section{HONOCHLAMIIDEAE. (Apetalae Juss.)}

Blüthendecken meist einfach, aus einem sog. Perigon bestehend. Dasselbe ist häufig sehr unscheinbar, kelchähnlich, zuweilen blumenkronartig gefärbt. Selten fehlt das Perigon und die Blüthe ist blumenlos. (In wenigen Familien finden sich als Anomalie Gattungen mit doppelten Blüthendecken [Juglandeae, Euphorbiaceae]). Pflanzen zur Monnecia oder Dioecia gehörig, werden in dieser Abtheilung hịufiger wahrgenommen.

\section{AMARANTACEAE. Juss.}

Kräuter mit abwechselnden Blättern, ohne Nebenblätter und Blattscheiden. Blüthen zwitterig oder einhäusig, zuweilen vielehig. Perigon unterständig, 3-5theilig, trockenhäutig, bleibend. Staubgefässe 3-5, unterständig. Fruchtknoten frei, 1fächerig, mit 1-mehreren Eichen und 1-3 Grifieln. Frucht nussartig, meist 1samig oder kapselartig, ringsum 
aufspringend. Samen linsenfürmig, mit mehligem Eiweiss und ringförmigem Keim.

A marantus. Blthen monoec. od. polygam., mit 2 kleinen Deckbl.; Perigon 3-5theilig; Stbgef. 3-5; Griff. 0; Narb. 3 . Kapsel oder Nuss.

Polycnemum. Blthen triandr., mit 2 kleinen Deckbl.; Perigon 5theil.; Griff. kurz mit 2 Narben. Nuss.

\section{Amarantus L. Amarant.}

a) Kapsel ringsum aufspringend.

750. A. retroflexus $L$. Z ur ü ckgekrümmter A.; rauhhaarig; St. aufrecht; Bl. längl.-eirund, stumpflich; Blthen achselständig, rispenartig geknäuelt; Deckbl, stachelspitzig, noch einmal so lang als d. grünliche Perigon. ๑. $\frac{1}{2}-2^{\prime}$.

An Wegen, auf Sandfeldern, an Zäunen ziemlich häufig, besonders in den Dörfern der Rheinfläche, z. B. Friedrichsfeld! Hockenhejm! Waghäusel! Neckarau! u. s. w., vereinzelt auch am Neckar von Neuenheim bis Ladenburg! Weniger verbreitet bei Wiesloch! Rauenberg! Juli-October.

\section{b) Nuss.}

751. A. Blitum $L$. Gemeiner A.; kahl; St. niederliegend ol. aufsteigend; Bl. eirund-rautenförmig, stumpf, ausgerandet; Blthen achsel- und endständig, knäuelartig-rispig; Deckbl. länger als das

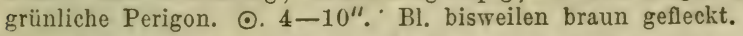

An Wegen, auf Schutt, Triften, in Gärten allgemein verbreitet. Juli-Oktober.

\section{Polycnemum $L$. Knorpelkraut.}

752. P. arvense $L$. Acker-K.; St. niederliegend, ausgebreitet ästig; Bl. 3kantig, pfriemlich-stachelspitzig, fast nadelartig; Blth. achselständig, sitzend, klein, meist einzeln; Deckbl. häutig, so lang als d. grünliche Perigon; Samen klein, punktirt. ๑. 2-3". Variirt :

B) majus A. Braun; in allen Theilen kräftiger; St. mehr aufsteigend, stärker; Bl. starrer; Deckbl. länger; Samen grösser. 4-8".

Auf Sandnächen, sandigen und kalkhaltigen Aeckern, dürren Triften, in Weinbergen hie und da, meist gesellig. Die Hauptart z. B. bei Friedrichsfeld zwischen Schwetzingen und Hockenheim! bei Waghäusel und Wiesenthal! zwischen Schatthausen und 
Baierthal! Die Varietät seltener, z. B. beim Relaishause! in der Eppelheimer Kiesgrube! zwischen Rauenberg und Rodenberg! bei Schriesheim (Döll). Juli-October.

[Auch in den benachbarten Florengebieten nicht selten. Die Var. in ungewöhnlich grosser Form auf kalkhaltigen Aeckern bei Leistadt in Rhb.!]

\section{LXXVI.- CHENOPODEAE. Vent.}

Ausdauernde od. (bei uns fast immer) einjährige Kräuter mit meist abwechselnden Blättern ohne Nebenblätter, unscheinbaren, zwitterigen oder vielehigen, seltener eingeschlechtigen Blüthen, welche bald achselständig einzeln, bald, und zwar hä口figer, knäuelartig, trugdoldig oder rispig gruppirt sind. Perigon unscheinbar, 2-5theilig, unterständig, selten fehlend, zuweilen mit der Frucht auswachsend, fleischig werdend und eine falsche Beere darstellend. Staubgefässe dem Grunde des Perigon's eingefügt, meist 5, seltener weniger; Antheren 2 fächerig, der Länge nach aufspringend; Fruchtknoten 1fiicherig, 1eiig, mit halbgekrümmtem aufrechtem Eichen. Narluen fädlich 2, selten mehrere. Frucht meistens eine Schlauchnuss, sehr häufig von dem bleibenden Perigon umgeben. Samen meist eiweisshaltig mit ringförmigem oder spiralig gekrümmtem Keim. - Die grösstentheils mehr oder weniger saftreichen Chenopodeae sind durch ihr häufiges meist geselliges Vorkommen, besonders in der Nähe menschlicher Wohnungen ausgezeichnet. Die meișten lieben Kali-, Natron - oder Ammoniakhaltige Bodenarten, einige sind an Salzgehalt des Bodens gebunden und enthalten als sog. Halophyten Natronsalze. Im Gebiet der Flora haben die Chenopodeae jedoch vorherrschend den Sandsteppen-Charalkter und sind stellenweise auf den Sandfächen wesentliche Bestandtheile der Vegetation. Die Halophyten-Bildung findet sowohl im Gebiet der Flora, als auch an den benachbarten Salinen von Dürkheim nur Andeutungen (Salsola Kali, Chenopodium glaucum, Atriplex latifolia $\beta$ salina). Die Blüthezeit fast aller Chenopodeae ist die zweite Hälfte des Sommers und der Herbst (meist bis zum Eintritt der Nachtfröste). Frucht und Samen sind aber für die Bestimmung der Gattungen und Arten durchaus nothwendig, woshalb 
diese Pflanzen auch für das Studium die cigentlicho Herbstfiora bilden.

a) Spirolobeae C. A. Meyer; Keim spiralig, mit sehr geringem oder fehlendem Eiweiss. Blüthen zwitterig.

Salsola. Perigonzipfel 5, bei der Reifo auf dem Rücken queergeflügelt; Staubgef. 5 ; Narben 2; Schlauchnuss zusammengedrückt, von dem bleibenden Perigon umhüllt.

b) Cyclolobeae C. A. Meyer; Keim ringfürmig, das reichlicho mehlige Eiweiss umgebend.

๙) Blüthen zwitterig.

Corispernum. Perigon fehlend od. durch Schüppchen ersetzt; Stbgef. 1-5; Narben 2; Nuss zusammengedrückt.

K ochia. Perig. 5spaltig, mit flügelförmigen Anhängseln; Stbgef. 5; Narb. 2; Schlauchnuss mit wagerechtem Samen.

Chenopodi um. Perig. 5spaltig od. theilig, bleibend; Perigonzipfel gelielt; Stbgef. 5, am Grunde des Perig. eingefügt; Narb. 2; Schlauchnuss mit magerechtem od. aufrechtem Samen.

Beta. Perig. 5spaltig, bleibend, fleischig und erhärtend; Stbgef. 5 cinem drüsigen Ringe eingefügt; Narben 2 ; Nuss mit wagerechtem Samen; Blüthen mit einander verwachsend.

$\beta$ ) Blüthen eingeschlechtig.

Spinacia. Dioecisch. Frucht mit dem erhärtenden $2-3 z$ ähnigen Perigon verwachsen. Männl. Perigon 4-5blättr.; Stbgef. 4-5.

Atriplex. Monoecisch oder polygamisch; Stbgef. 3-5; Schlauchnuss der weibl. Blthen seitlich flach zusammengedrückt, der Zwitterblth. niedergedrückt; weibl. Perig. 2tbeilig oder spaltig, die Frucht bedeckend.

\section{Salsola $L$. Salzkraut.}

753. S. Kali $L$. Gemeines S.; graugrün, saftreich; St. niederliegend oder aufrecht, meist ästig; Bl. pfriemlich, nadelartig, steif; Blthen achselst., sitzend, klein; Perig. bei der Fruchtreife knorpelig. $\odot . \frac{1}{4}-1^{\prime}$.

Auf den Sandfeldern der Rheinfläche ziemlich verbreitet, z. B. in grosser Menge bei Schwetzingen! Friedrichsfeld! beim Relaishause! zwischen Wallstadt und Feudenheim! und weiter gegen Virnheim! Käferthal und Sandtorf! Seltener bei Sandhausen! Walldorf! Juli bis October.

\section{2.. Corispermum $L$. W anzensame.}

754. C. Marschallil Stev.; graugrün; St. ästig; Bl, lanzettl., 
zugespitzt, Inervig; Blth, einzeln, achselst, von eiförmigen, stachelspitzigen Deckbl. umgeben; Perigon fehlend; Stbgef, meist 1-2; Nüsse fast kreisrund, geflügelt, glatt. $\frac{1}{2}-1_{\frac{1}{2}}^{\prime}$.

In Taurien, an den Ufern des Dnjepers einheimisch, seit den russischen Feldzügen (1814) bei Schwetzingen auftretend, und besonders in den Kiesgruben daselbst und in deren Umgebung noch jetzt alljährlich vorhanden, auch in neuester Zeit bis Oftersheim verbreitet! August-October.

\section{Kochia Roth. Kochie.}

755. K. arenaria Roth. S a nd-K.; grauhaarig; St. aufrecht oder niederliegend, meist ausgebreitet ästig; Bl. fadenförmig-pfriemlich; Blthen achselständig, sitzend, etwas knäuelartig, grünlich; Anhängsel des Fruchtperigons fast rautenförmig sternartig ausgebreitet. ○. $\frac{1}{2}-1 \frac{1}{2}^{\prime}$.

Auf den Sandflächen um Schretzingen, besonders in den Kiesgruben! häufig beim Relaishause! seltener beim Rohrhofe! Friedrichs. feld! zwischen St. Ilgen und Walldorf! Juli-October.

[N. V. a. d. Geb.: Sandfelder in Rhl. bis gegen Bingen! In Rhb. fehlend. B.: in d. Nähe d. Geb. fehlend.]

\section{2\%. Chenopodium $L$. Gänsefuss. *)}

a) Samen meist aufrecht; Stbgef. 1-5, oft 2 oder 4.

- 756. Ch. bonus Henricus $L$. Guter Heinrich; St. einfach, aufrecht; Bl. dreieckig-spiessförmig, ganzrandig; Blth. knäuelartig in end - und achselst. blattlosen Aehren; Samen stets aufrecht, stumpfrandig, glänzend. 4. 1'. (Blitum bonus Henricus MI.).

An Wegen, Zäunen, auf Schutt überall verbreitet. Mai-Sept.

757. Ch. rubrum $L$. Rother G.; St. aufrecht; Bl, rautenförmig, buchtig-gezähnt od. etwas lappig, glänzend; Blthen knäuelartig in aufrechten beblätterten achsel - und endständigen Aehren; Samen theils aufrecht, theils wagerecht, glänzend, stumpfrandig, sehr fein punktirt. $\odot .1-1 \frac{1}{2}^{\prime}$. St. häufig roth angelaufen. Die seitenständigen Blüthen eines jeden Knäuels haben meist 1-2 Staubgef., nur die endst. deren 5. (Blitum rubrum Rchb.).

An Wegen, Rainen, auf Triften, Mauern, in Dörfern häufig! Juli-September.

758. Ch. glancum L. M e ergrüner G.; St. niederliegend oder aufrecht, dichtbeblättert; Bl. fleischig, eiförmig-längl., stumpf,

-) Fast bei allen Arten sind St. und BI. äusserst saftreich. 
buchtig-gezähnt, unterseits graugrün bereift; Aehren kurz, knäuelartig, fast blattlos; Samen theils aufrecht, theils wagerecht, glatt. ๑. $\frac{1}{4}-\mathbf{1}^{\prime}$. (Blitum glauoum Koch).

An Ufern, auf feuchten sandigen Triften, in Sümpfen, Dörfern hie und da, meist gesellig, z. B. häufig längs des Neckars von Neuenheim bis Ladenburg! bei Waghäusel! Sandtorf! Schwetzingen! St. Ilgen! in etwas feuchten Dörfern, z. B. Neckarau! Feudenheim! Ketsch etc. eine der gemeinsten Pflanzen! Juli-September.

b) Samen stets wagerecht; Stbgef. meist 5.

a) Bl. gezähnt od. lappig.

759. Ch. hybridum $L$. B a stard-G.; St. aufrecht, ästig; BI. langgestielt, herzförmig, tiefbuchtig, gezähnt, langzugespitzt, hellgrün, oberseits glänzend; Blthknäueln in abstehenden Rispen; Samen grubig punktirt. $\odot .1-3^{\prime}$. Perig. dunkelgrün, weissberandet; Bl. widerlich betäubend riechend. Giftig. Verwechslg. der Bl, mit Datura Stramonium.

Auf Schutt, Aeckern, an Wegen, Zäunen häufig! Juli-Sept.

760. Ch. urbicum $L$. Dorf-G.; St. aufrecht; Bl. 3eckig, buchtig gezähnt, am Grunde in den Blattstiel zusammengezogen; Blthknäuele in einfachen, steif aufrechten, blattlosen Aehren; Samen stumpfrandig, glatt (od. sehr fein punktirt). ๑. 1-3'. Blth. grünlich.

An Wegen, in Dürfern, auf Triften nicht häufig, z. B. beim Grenzhof! Brühl; auch einzeln auf der Insel bei der Bergheimer Mühle bei H.! Juli-Sept.

761. Ch. murale $L$. Ma uer-G.; St. aufrecht, sperrig ästig; B1. eirund-rautenförmig, ungleich spitziggezähnt, oberseits glänzend; Blthknäuele in abstehenden Rispen; Samen gokielt, berandet, glanzlos. ๑. $\frac{1}{2}-2^{\prime}$. Blth. grünlich.

An Wegen, Gräben, auf Schutt, Mauern hie und da, in manchen Gegenden besonders häufig, z. B. bei Rauenberg! Malsch! Juli-October.

762. Ch. album $L$. Melde; St, aufrecht; Bl. eirund-rautenf., mehr oder weniger buchtiggezähnt, die oboren lineal, ganzrandig; Blthknäuele fast blattlos; Samen glatt, glänzend; Blth, grünlich. ๑. $4^{\prime \prime}-1 \frac{1}{2}^{\prime}$. Variirt:
๔) album; weissbereift; Blthknäuele ährenförmig. Ch. al- bum L.).
$\beta)$ viride; grün, unbereift; Blthknäuele in Trugdolden. (Ch. viride L.).

An Wegen, auf Schutt, Aeckern, an Ufern allgemein verbreitet und oft sehr gesellig! Juli-November. 
763. Ch. opulifolium Schrad. Sch neeballb lättr. G.; getrübtgraugrün; St. aufrecht ; Bl. rautenf.-rundlich, stumpf, 3lappig, buchtig-gezähnt, die oberen elliptisch; Rispen kurz; Samen glatt, glänzend. ๑. 1-2'. Blth. grünlich; Bl. otwas dümnhäutig, daher loicht welkend.

An Wegen, Rainen, auf Mauern, an Zäunen, auf unbebauten Triften hie und da, jedoch keineswegs überall, z. B. einzeln am Neckar bei H.! Häufiger zwischen Ladenburg und Feudenheim! beim Grenzhofe! bei Schwetzingen! Ketsch! Waghäusel! hie und da zwischen Mannheim und Sandhofen! Juni-September.

[Zeigt weiter abwärts am Rhein stellenweise ein sehr allgemeines Vorkommen, z. B. bei Oppenheim in Rhh.!]

764. Ch. ficifolium $L$. Feigenblättr. G.; Stı aufrecht, untere Bl. 3lappig mit vorgezogenem länglichem, stumpfen, fast ganzrandigen Mittellappen, die oberen lineal-lanzettl., ganzrandig; Blthrispen fast blattlos; Samen feingrubig punktirt, glänzend. ๑. $\frac{1}{2}-1 \frac{1}{2}^{\prime}$. (Hat grosse Aehnlichkeit mit Ch. album).

An Wegen, Dämmen, auf Schutt, Aeckern der Rheinfläche, besonders auf Lehmboden, jedoch nur stellenweise, z. B. zwischen Neckarau und Mannheim! bei Alt-Lussheim! Schwetzingen (Schimp.). Juli-September.

[Jenseits des Rheins in d. Nähe d. Geb., z. B. bei Ludwigshafen, am Rande von Saatfeldern neben der Fahrstrasse nach Mundenheim! bei Friesenheim!]

765. Ch. polyspermum $L$. Viels a miger G.; St. meist niederliegend; Bl. eiförmig stumpf oder zugespitzt, ganzrandig, kahl; Trauben blattlos; Samen glänzend fein punktirt. ๑. $\frac{1}{2}-1 \frac{1}{2}^{\prime}$. Variirt:

$\alpha$ ) cymosum; Trauben trugdoldig; Bl. stumpf.

$\beta$ ) spicatum; Trauben ährenf., verlängert; Bl. spitz. (Ch aoutifolium Kit.).

Auf Aeckern, besonders auf Lehmboden, Triften, an Gräben, Ufern häufig. Var, $\beta$ etwas seltener, z. B. zwischen Brühl und Schwetzingen! Juli-October,

766. Ch. Vulvaria $L$. U ebelriechender G.; St. niederliegend, ästig; Bl. ei-rautenförmig, meist ganzrandig, staubartig weissgrau; Blthknäuele in blattlosen kurzen Rispen; Samen glänzend, fein punktirt. ๑. $\frac{1}{2}-1^{\prime}$. Uebelriechend! (Ch. olidum Curt.).

An Wegen, Zäunen, Mauern, auf Triften häufig, jedoch nicht überall. Verbreitet z. B. bei Neuenheim! und jenseits des Neckars gegen Ziegelhausen! Stellenweise in grosser Menge, z. B. Friedrichsfeld! Waghäusel! Wiesloch! Juni-Sept. (Off. : Hb. Vulvariac). 
B. vulgaris L. Gem. M.; kahl; St. aufrecht, gefurcht; Bl. herzeifürmig, glänzend; Blthknäuele in verlängerten beblätterten Aehren, ๑-令. $2 \div 4^{\prime}$.

Die Variet. rapacen Koch (Runkelrübe) mit rübenf., fleischiger, zuckerhaltiger Wurzel, häufig im Grossen gebaut. Juli-Sept.

\section{Spinacia Tournef. Spinat.}

Sp. oleracea L. Gebräuchl. Sp.; St. aufrecht; Bl. cilängl. oder spiessförmig; Blth. geknäuelt, achselständig. ๑.

Stammt aus dem Orient, wird cultivirt, verwildert bisweilen. Juli, August.

\section{Atriplex $L$. Melde.}

a) Polygamisch. Weibl. Perigon 2theilig.

A. hortensis L. Garten-M.; St. kantig, kahl; Bl. herzf.-dreieckig, gezähnt, grün od. blutroth; Fruchtperigon rundlich, zugespitzt, netzaderig, ganzrandig. ๑. 2-3'.

Aus dem Orient stammend. Verwildert hie und da! Juli bis September.

b) Meist monoecisch. Weibl. Perig. 2theilig od. nur gespalten;

Aehren knäuelartig, end- und achselständig.

767. A. oblongifolia W. et $K$. Länglichblättr. M.; St. und $\mathrm{Zweige}$ aufrecht; Bl. graugrün, untere ei-lanzettl., fast spiessförmig, gezähnt, obere längl.-lineal, ganzrandig; weibl. Aehre locker; Fruchtperigon eirund-rautenförmig, ganzrandig, glatt. ๑. 1-3'. (A. tatarica L.).

An Dämmen, Wegen, auf Triften, trockenen Hügeln der Rheinfläche. Im Gebiet der Flora sehr selten, z. B. am Rheindammo bei Mannheim! [Jenseits des Rheins verbreiteter. Durch allgemeines Vorkommen besonders ausgezeichnet auf den Kalkhügeln bei Dürkheim und Callstadt!] August-October.

768. A. angustifolia Sm. Schmalblättr. M.; St. aufrecht od. niederliegend, ästig, untere Zweige sperrig abstehend; Bl. kurzgestielt, grün, untere rautenförmig-lanzettl., buchtiggezähnt, obere lineal; weibl. Aehre locker; Fruchtperigon spiessf.-rautenförmig, glatt oder weichstachelig. $\frac{1}{2}-3^{\prime}$. (A. patula L.).

An Wegen, Zäunen, auf Aeckern, Schutt, in Gärten allgemein vorbreitet, Juli-October. 
769. A. Iatifolia Wahlbg. Breitblättr. M.; St. aufrecht od. niederliegend, ästig, untere Zweige sperrig abstehend; Bl. länger gestielt, grün, untero 3eckig-spiessförmig, gezähnt, obere lanzettl., ganzrandig, weibl. Aehre locker; Fruchtperigon 3eckig, glatt oder weichstachelig. $\hat{\delta} \cdot \frac{1}{2}-3^{\prime}$. (A. patula Sm.).

Auf fouchten Triften, an Teichrändern, Flussufern, Gräben seltener als vorige. Hie und da am Neckarufer, sowohl bei H., als weiter abwärts gegen Ladenburg! Feudenheim! Auch in den Sumpfgegenden, besonders bei Brühl! Waghäusel! Neckarau! ziemlich verbreitet. Juli-October.

[Variirt $\beta$ salina; die ganze Pflanze, besonders die Bl. blaugrau feinschuppig. Auf Salzboden, z, B. in Rhb, an den Salinen bei Dürkheim! ]

\section{POLYGONEAE. Juss.}

Kräuter mit knotig gegliederten Stengeln, abwechselnden oder wirteligen Blättern, deren Grund jederzeil ausgezeichnet ist durch eine mehr oder weniger verlängerte geschlossene Blattscheide (Tute, ochrea). Blth. achselst. od. endst,, meist zwitterig, seltener 1geschlechtig. Perigon unterständig, meist gefärbt, 3-6theilig, bleibend; Stbgef. im Grunde des Perigons 4-10. Fruchtknoten 1fächerig, 1eiig; Griffel oder Narben 1-3; Frucht nussartig, zusammengedrückt od. 3 kantig. Samen mit mehligem Eiweiss und geradem oder gekrümmtem Keim. - Diese Pflanzen bilden insofern einen nicht unwesentlichen Bestandtheil der Vegetation, als die meisten Arten auffallend gesellig, mehrere zugleich fast allgemein vorkommen. Unsere Arten sind grösstentheils bodenvag, doch zeigen sie fast alle eine Vorliebe für feuchte Standorte. Der Reichthum an Stärkemehl in den Samen, der Gohalt an Oxalsäure und Kali in den Blättern, an Gerbsäure in den Wurzeln macht mehrere einheimische und im Grossen kultivirte Arten für die Anwendung bemerkenswerth.

Polygonum. Perig. 3-5spaltig, fast gleichförmig; Stbgef. 5-8; Narben kopfig; Nüsschen 3kantig oder linsenförmig.

Rumex. Perig. 6blätterig, die 3 inneren Zipfel grösser, die Frucht als sog. Klappen bedeckend; Stbgef. 6; Narben pinselförmig; Nüsschen 3kantig. 


\section{Polygonum L. Knöterig.}

a) St. einfach, mit einer endständigen Aehre od. ährenf. Traubo.

770. P. Bistorta $L$. Wi esen-K.; Bl. langgestielt, längl.herzförmig, wellig, unterseits graugrün, mit geflügeltem Blattstiel. 4. 1-2'. Blth. rosa, meist octandr; Wstock 1-2mal, gebogen, innen röthlich.

Auf fouchten Wiesen hie und da, meist gesellig, z. B. bei Schönau! Schriesheim! Wilhelmsfeid ! Handschuchsheim! Weinheim! Mai, Juni. (Off.: Rad. Bistortae).

b) St. verzweigt, an den Zweigen mit gipfelständigen Aehren; Nüsse flach od. undeutlich 3 kantig.

771. P. amphibium $L$. Ortwe chselnder K.; Wstock kriechend; Bl. längl.-lanzettl.; Aehren gedrungen, walzenförmig. 4. Blth. roth, meist pentandr. Variirt:

a) natans; St. im Wasser gestreckt; Bl. langgestielt, schwimmend, oberseits glänzend, kahl.

B) tervestre; St. aufrecht od. aufsteigend; Bl. kurzgestielt, schmäler, steifhaarig, glanzlos. $1-1_{\frac{1}{2}^{\prime}}$.

Var. $\alpha$ in stehenden und fliessenden Gewässern, z, B. im Neckar hio und da! im Kirchheimer See! in Sümpfen bei Ladenburg! Neckarau! Var. $\beta$ auf nassen sandigen Triften, an Flussufern, Teichen, in Sümpfon nicht häufig, z. B. am Neckarufer! zwischen Schlierbach und Neckargemünd! bei Neuenheim! Ladenburg! selten beim Rohrhof! Waghäusel! stellenweise verbreitet am Rheinufer.

772. P. lapathifolium $L$. A mp ferblättr. K.; St. aufsteigend oder niederliegend, an den Knoten meist sehr rerdickt; Bl. eiförmig oder lanzettl., kahl oder unterseits graufilzig; Blattscheiden kahl, an der Spitze feingewimpert; Aehren walzenförmig, kurzgestielt; Stiele und Perigonzipfel drüsig-rauh. 4. 1-2'. Blth. hellrosa oder grüngelb, meist hexandr.; Bl. bisweilen gefleckt. Variirt im Habitus, in der Breite und Behaarung der Bl. nach localen Verhältnissen.

Auf Aeckern, an Ufern, Gräben, Wegen, sowohl auf trockenem, als feuchtem Boden häufig! In Torfmooren oft ein wesentlicher und vorherrschender Bestandtheil der Vegetation! Juli-Sept.

773. P. Persicaria $L$. Pfirsichblättrig. K.; St. autsteigend oder niederliegend; Bl. länglich-lanzettl. kahl; Blattscheiden behaart, meist langgewimpert; Aehren walzenförmig, gedrungen, kurzgestielt; Stiele und Perigonzipfel drüsenlos. 2. $\frac{1}{2}-1^{\prime}$. Blth. rosa, meist hexandr.; Bl. bisweilen gefleckt. 
An Wegen, auf Aeckern, Triften allgemein verbreitet! Juli bis September.

774. P. mite Schrank. Milder K.; St. aufrecht, schlank; Bl. lanzettl., kahl; Blattscheiden langgewimpert; Aehren linealisch, locker, aufrecht oder etwas überhängend; Stiele und Perigonzipfel drüsenlos. $\odot$. 1-2'. Blth. grünlich-weiss, meist hexandr. - Dem folgenden sehr ähnlich, aber sogleich durch den Mangel des pfefferartigen Geschmackes sich unterscheidend. Vielleicht eine hybride Mittelform zwischen P. Persicaria und P. Hydropiper?

An Ufern, Gräben, auf feuchten Triften, an sumpfigen Waldrändern nicht selten, besonders häufig längs des Neckars! Verbreitet auch beim Rohrhof! im Friedrichsfelder Walde! bei Sandtorf! Juli, August.

775. P. Hydropiper $L$. W a s s erp feffer; St. aufrecht, schlank; Bl. lanzettl., etwas wellig, kahl; Blattscheiden kurzgewimpert; Aehren linealisch, locker, überhängend; Perigonzipfel schwach drüsig punktirt. ๑. 1-2'. Blth. grünlich-roth, meist hexandr. - Das ganze Kraut schmeckt brennend scharf, pfefferartig.

An Gräben, auf feuchten Triften, Wiesen, an Wegen allgemein verbreitet. Juli-October.

776. P. minus IIuds. Kleiner K.; hellgrün, kahl; St. zart, niederliegend oder aufsteigend; Bl. lineal-lanzettl ; Scheiden langgewimpert; Achren linealisch, locker, aufrecht; Perigonzipfel drïsenJos. ๑. $\frac{1}{2}-1^{\prime}$. Blth. hellrosa, pentandr. - Ohne scharfen Geschmack.

Auf feuchten Haiden, schattigen feuchten Triften, in Torfsümpfen, an Ufern hie und da, z. B. bei Waghäusel! Sandtorf! Brühl! stellenweise am Neckar, z. B. bei Neuenheirn! oberhalb Ziegelhausen! Juli-October.

c) Blth. blattwinkelständig, büschelig.

777. P. aviculare $L$. Vogel-K.; St. meist niederliegend, ästig; Bl. elliptisch-lanzettlich, am Rande rauh; Scheiden zerschlitzt, silberweiss glänzend; Blth. einzeln oder $\mathrm{zu} 2-3$. ๑. $\frac{1}{3}-1_{\frac{1}{2}}^{\prime}$. Blth. grünlich-roth, octandr.

An Wegen, auf Wiesen, Aeckern, Triften überall verbreitet. Juli-October.

778. P. dumetorum $L$. Hecken-K.; St. rechtswindend, rund, gestreift; Bl. herzfürmig 3eckjg, zugespitzt; Blthbüschel meist traubig, die 3 äusseren Zipfel des Fruchtperigons geflügelt. $\odot$. Blth. grünlich-weiss; Nüssch, schwach glänzend.

In IIecken, Gebüschen, an Flussufern, feuchten Waldrändern nicht überall, aber stellenweise häufg, z, B. boim Haarlass! Ziegel- 
hausen! Dreitröge Thal bei H.! Friedrichsfelder Wald! Schwetzingen! am Rheinufer, z. B. bei Ketsch! zwischen dem Rohrhofe und dem Relaishause! Juli-September.

779. P. Convolvulus $L$. Winden-K.; St. windend oder niederliegend, ïstig, kautig-gefurcht; Bl. herz-pfeilförmig; Blthbüschel traubig; Zipfel des Fruchtperigons nicht geflügelt. ๑. $\frac{1}{2}-3^{\prime}$. Blth. grünlich-wreiss; Nüssch, glanzlos.

Auf Aeckern, an Wegen, auf Schutt häufig! Juli-September.

d) Blth. end- und achselständig, in rispenfürmigen Trauben.

P. Fagopyrum $L$. Buchweizen, II aidekorn; St. aufrecht; Bl. herz-pfeilförmig; Nüssch. 3kantig, an den Kanten ganzrandig. ๑. 1-2'. Blth. hellroth. (Fagopyrum esculentum Moench.)

Aus dem Orient stammend, auf Sand- und Haideboden der Ebene nur selten, häufiger in den Gebirgsgegenden des Odenwaldes im Grossen gebaut. Juli, August.

P. tataricum L. Dem vorigen ähnl,; Blthstd. lockerer; Nüssch. 3kantig, an den Kanten buchtig-gezähnt. ๑. 1-2'. Blth. grünlich, kleiner.

Aus Sibirien und der Tartarei stammend, mit d, vorigen cultivirt. Juli, August.

\section{Rumex $L$. A mpter.}

a) Blth. meist zwitterig, quirlfürmig-traubig; Bl. am Grundo abgerundet oder herzförmig, nicht spiessförmig; Klappen entweder alle oder theilweise mit einer mehr oder wcniger drüsigen Anschwellung (Schwiele).

780. R. maritimus $I_{\text {. }}$ Strand-A.; St. ästig; Bl. lanzettl.lineal; Blthquirle genähert, beblättert; Klappen der Fruchtperigone rautenförmig, kurz zugespitzt, alle schwielig, am Rando mit $2-3$ Zähnen, die eben so lang als die Klappen sind. ๑. 1-1 $1_{\frac{1}{2}}{ }^{\prime}$. Blthst. goldgelb, auch das Kraut gelblich.

In Sümpfen, an Flussufern, Gräben in der Nähø des Rheines, hio und da, z. B. bei Neckarau! Sandhofen! Mannheim! Ketsch! Alt-Lussheim! selten am Rheinufer! vereinzelt zwischen Kirchleim und St. Ilgen! Juli-September.

781. R. palustris Sm. Sumpf-A.; dem vorigen ähnlich; St. schlanker, mehr abstehend-rerzweigt; Bl. verlängert-lanzettlich; Quirle mehr entfernt; Klappen eirund-länglich, lang zugespitzt; Zähne der Klappen kürzer als die letzteren. $\hat{\odot} \cdot 1 \frac{1}{2}-3^{\prime}$. Die ganzo Pflanzo ist grünlich oder wenig gelb.

In Sümpfen, in feuchten Gebüschen, an Flussufern sehr vereinzelt und selton, z. B. am Rheinufer zwischon Neckarau u. Mannheim._(Yerbreitung noch weiter zu verfolgen!) Juli-September. 
782. R. conglomeratus Murr. Geknäuelter A.; St. abstehend-ästig; untere Bl. herzförmig od. eilänglich, obere schmäler; Blthquirle entfernt, beblättert, die oberen blattlos; Klappen lineallänglich, stumpf, ganzrandig, alle schwielentragend. 4. 1-2'. Blth. klein, grünlich.

An Wegen, auf Triften, Wiesen überall häufig. Juli-September.

783. R. sanguineus $L$. Blut rother A.; St. schlank, mit aufrechten $\mathrm{Z}$ weigen; untere $\mathrm{Bl}$. langgestielt, herzförmig-länglich, obere lanzettlich; Blthquirle entfernt, fast blattlos; Klappen lineal-länglich, ganzrandig, stumpf, nur eine derselben schwielentragend. 4. 2-3'. Blth. klein, grïnlich oder roth; St. und Blattadern zuweilen blutroth, häufiger aber grün. (R. nemorosus Schrad.)

In schattigen, feuchten Wäldern, in feuchten Gebüschen auch in der Nälie von H. häufig! Juli-September-

784. R. obtusifolius $L$. Stum p fblättr. A.; St. ästig, untere BI. eirund-herzförmig, stumpf oder kurz zugespitzt, obere lan zettlich; Blthquirle entfernt, fast unbeblättert; Klappen länglich3kantig, lang zugespitzt, am Rande unten mit 3-5 ungleichen Zähnen, alle oder $1-2$ schwielentragend. 4. 2-4'.

Auf feuchten Wiesen, in Gebüschen, an Zäunen häufig, z. B. am Neckarufer bei Wieblingen! Schlierbach! auf der Insel bei der Bergheimer Mühle! bei Ziegelhausen! Schönau! Rohrbach! Leimen! beim Maischbacher Hof! u. s. w. Juni-August. (Off.: Rad. Lapathi acuti.)

785. R. crispus $\boldsymbol{L}$. Krauser A.; St. wenig ästig, fast einfach; Bl. am Rande wellig-kraus, die unteren herzf.-längl., obere lanzettl.; Blthquirle sehr gedrängt, fast unbeblättert; Klappen herzfürmig-rundlich, stumpf, ganzrandig oder etwas gezähnelt, alle oder nur eine schwielentragend. 4. $2-3^{\prime}$. Blth. blassröthlich, grösser als bei den vorigen.

An Wegen, auf Wiescn und Triften überall häuff. JuliSeptember.

Die beiden letztgenannten Arten erzeugen eine hybride Mittelform:

R. pratensis $M$. et $K$; im Habitus der ersteren näher stehend; BI. länglich oder längl.-lanzettl., nicht kraus; Klappen herzf.-längl,, eingeschnitten gezähnt, an der Spitze stumpf, ganzrandig, alle oder nur eine schwielentragend. $2-4^{\prime}$.

Auf Wiesen und Triften in Begleitung der vorigen Arten, z. B. auf der Insel bei der Bergheimer Mühle! im Gorxheimer Thal boi Weinheim! bei Schwetzingen (Dr. Schimp.) Juli-September.

786. R. Hydrolapathum Huds. Rieson-A.; St. ästig; Bl. grob und ungleich gekerbt, etwas wellig, in den oberseits fast flachen Blattstiel verlaufend; Blthquirle sehr gedrängt, die oberen blatt- 
los; Klappen eiförmig-3eckig, spitz, ganzrandig oder unten gezähnelt, alle schwielentragend. 24. 5-6'. Blattflächen $1 \frac{1}{2}-2^{\prime}$ lang. (R. acutus Ehrh.; R. maximus Gmel.)

An Ufern, in Gräben, Torfsïmpfen hie und da. Stellenweise am Neckar, z. B. zwischen Neuenheim und Ladenburg! häufiger bei Waghäusel! Sandtorf! beim Rohrhof! Juli-September.

787. R. aquaticus $L$. Wasser-A.; St. ästig; untere Bl. herzförmig-länglich, spitz, in den rinnenförmigon Blattstiel verlaufend; Blthquirle sehr gedrängt, blattlos, cine grosso dichte lappige Rispo bildend; Klappen eirund-horzförmig, fast ganzrandig, schwielenlos. 4. $3-4^{\prime}$.

An Gräben und Uforn, auf nassen Wiesen ziemlich selten, meist vereinzelt, z. B. bei Ziegelhausen! auf der Insel bei der Bergheimer Mühle und gegen Wieblingen! bei Neckarau! Juli-September.

b) Blth. dioecisch oder polygamisch; Bl. spiess- oder pfeiltörmig.

788. R. Acetosa $L$. Sa ueramp fer; aufrecht; Bl. pfeil- oder spiessförmig, obere stengelumfassend; Quirle reichblth., die 3 inneren Perigonklappen rundl.-herzf., am Grunde mit herabhängender Schuppe, die 3 üusseren zurückgeschlagen, alle schwielentragend. 4. $1-1 \frac{1}{2}^{\prime}$.

Auf Wiesen, in lichten Wäldern, an Wogen häufig. Mai-August. (Off.: $H b$ Acetosae.)

789. R. scutatus L. Schildblättr. A.; graugrün, glatt; St. aufsteigend, langgestielt, rundl.-spiessf.; Quirle armblth., innere Klappen rundlich-herzf., äussere anliegend, alle schwielenlos. 4. $\frac{1}{2}-1 \frac{1}{2}^{\prime}$.

An Felsen und alten Mauern hie und da um H., auf Weinbergsmauern im Dreitrögo Thal! unterhalb der Engelswiese! in der Nähe der Hirschgasse! zwischen H. und Neuenheim! Juni-August.

790. R. Acetosella $L$. Kleiner Sauer a mpfer; aufrecht; BI. spiessf.-lanzettl. oder lineal., innere Klappen rundlich-herzförmig, schwielenlos, äussere aufrecht, anliegend. 24. $\frac{1}{2} \rightarrow 1^{\prime}$.

Auf Sandfeldern, trockenen Hügeln und Triften häufig und oft sehr gesellig. Mai-Juli.

\section{THYMELEAE Juss.}

Kräuter oder Sträucher mit abwechselnden oder wirteligen ganzrandigen Blättern ohne Nebenblätter, auffallend verschieden im Habitus. Blth. regelmässig, meist zwitterig. Perigon. unterständig, röhrig, gefärbt, $4-5$ spaltig, in der 
Knospenlage dachig; Stbgef. dem Perigon eingefügt, $4-8$, selten 10. Antheren 2fächerig, der Länge nach aufspringend. Fruchtknoten frei, 1fächerig, mit einem hängenden Eichen. Grifel 1 mit einfacher Narbe. Frucht eine einsamige Nuss oder Beere. Samen eiweisslos oder mit spärlichem Eiweiss. Keim gerade.

Daphne. Perigon 4spaltig, abfallend; Beere; Stbgef. 8.

Passerina. Perigon 4spaltig, bleibend; Nuss; Stbgef. 8.

\section{I. Daphue $L$. Seidelbast.}

791. D. Mezereum L. Gem. S.; Strauch mit büscheligen, keilig-lanzetti., kahlen, hellgrünen Blättern; Blth, an den Seiten der Zweige zahlreich, büschelig, sitzend, weichhaarig, fleischroth, wohlriechend, vor den Blättern erscheinend; Beeren ziegelroth. - 1-4 Samen und die mit reichlichem Bast versehene und daher selrr zähe Rinde sind scharf und giftig!

In etwas feuchten Gebirgswäldern, auf Waldtriften, kalkhold. In grosser Menge bei Weinheim, besonders zwischen W. u. Nesterbach! im Gorxheimer Thal! stellenweise auch bei Leutershausen! Schriesheim, auf dem heiligen Berge bei H.! zwischen Ziegelhausen und Schönau! - Bei Wiesloch! Naischbach nicht verbreitet, auch bei Schatthausen nur stellenweise, z. B. im Saalengrund bei Oberhof (v. Göler) (Off.: Cort. Mezerei.)

[D. Gneorum L. Ni ed erli eg. S.; Strauch niederliegend, dicht beblättert; Bl. lineal-keilig, kurzstachelspitzig, kahl, immergrün; Blth. endständ., büschelig, weichhaarig, rosa, wohlriechend, später als die $\mathrm{Bl}$. sich entwickelnd.

Auf Haiden, trockenen Wiesen. N. V. a. d. Geb. bei IIanhofen, unfern Speier (Dr. Wals.) Mai, Juni.]

\section{Passerina $L$. S patzenzunge.}

792. P. annua Wickstr. Einjährige S.; St. aufrecht, ruthenfürmig, einfach oder verzweigt, wie die Bl. kahl; Bl. lineal, spitz, aufrecht-abstehend; Blth. achselständig, einzeln oder gehäuft; Perigon klein, grünlich, nach dem Verblühen zusammenneigend, am Grunde mit 2 Deckblättchen. ๑. $\frac{1}{2}-1 \frac{1}{2}^{\prime}$.

Auf trockenen, kalkhaltigen Acckern stellenweise, z. B. am sogenannten Schlangengrunde zwischen Alt-Wiesloch und Baierthal! auf den Anhöhen hinter Rauenberg und Rodenberg! zwischen Nesterbach und Sulzbach bei Weinheim! in der Eppelheimer Kiesgrube (Dr. Schimp.) August-October. 


\section{SANTALACEAE R.Br.}

Strïucher oder Kräuter mit ganzrandigen, nebenblattlosen Blättern. Blth. meist zwitterig, regelmässig. Perigon 3-5theilig, in der Knospenlage klappig, oberstïndig, mit dem Fruchtknoten verwachsen. Stbgef, von der Zahl der Perigonglieder, am Schlunde eingefügt. Fruchtknoten unterständig, 1fächerig, mit 2-4 hängenden, nack ten*) Eichen. Griffel 1, mit einfacher Narbe. Frucht nuss- oder steinfruchtartig, 1samig. Samen eiweisshaltig. Keim gerade. 5 ; Nuss.

Thesium. Perigon röhrig-glockig, 4-5theilig; Stbgef. meist

\section{The sium Leinblatt.}

793. Th. montanum Ehrh. Berg-L.; St. aufsteigend, ruthenförmig; Bl. lanzettlich, lang zugespitzt, 3-5nervig, kahl, etrras blaugriin; Rispen verlängert-pyramidenförmig, jede Blüthe am Grunde mit 3 Deckblttch.; Perigon nach dem Verblühen völlig eingerollt; Frucht kugelig. 4. $1-2^{\prime}$. Perigon grün, inwendig weiss. - Wzst. ohne Ausläufer.

An trockenen, bowaldeten Abhängen hie und da, z. B. häufig am Geisberge bei H.I zwischen Dossenheim und dem Oelberge bei Schriesheim! auf dem Wagenberge bei Weinheim! bei Birkenau u. Nesterbach! Juni, Juli.

Diese Art, wie wahrscheinlich alle Arten leben auf den Wurzeln anderer Pflanzen parasitisch. Die Nährpflanzen sind verschiedenartig: für diese Art u. A.: Hypericum perforatum, Geranium sanguineum, Thymus Serpyllum.

794. Th. intermedium Schrad. Mittleres L.; dem vorigen schr ähnlich, aber niedriger, in allen Theilen kleiner; Bl. lineal-lanzettlich, spitz, schwach 3nervig; Rispe kürzer; Frucht eirund-länglich. 4. $\frac{1}{2}-1^{\prime}$. Wzst. mit Ausläufern. (T/h linophyllum L)

Auf trockenen Hügeln, Triften, an bewaldeten Ab̉hängen nicht häufig, z. B. zwischen Schriesheim und Leutershausen! bei Weinheim! in der Hessel bei Wiesloch! Mai-Juli.

") Ein nacktes Eichen (Ovulum nudum), welches in seinem ursprünglichen. Zustande verharrt und keine Eihäute bildet, ist eine Eigenthümlichkeit dieser und der folg. Familie. 
[Jenseits des Rheines, am Haardtgebirge sehr verbreitet, z. B. häufig bei Dürkheim! Callstadt!]

[Th. alpinum $L$.; St. aufsteigend; BI. linenl, 1nervig; Traube fast einseitswendig; Perigon nur an der Spitze eingerollt, röhrig, voln der Länge der kugeligen Nuss. 4. $\frac{1}{2}-1^{\prime}$.

N. V. a. d. Geb.: Haardtgebirge, z. B. an steinigen Ablängen am Fusse des Schlammberges bei Dürkheim! Juni, Juli.]

\section{LORANTHACEAE Juss.}

Auf Bäumen parasitisch lebende (grösstentheils tropische) Strïucher, mit meist gegenständigen, häufig lederartigen Blättern ohne Nebenblätter, mit monoecischen oder dioecischen Blüthen. Männl. Blth.: K. röhrig, 4spaltig. Blkr. 0. Antheren ohne Stbgef. den Kelchlappen angewachsen, mehrfächerig. Weibl. Blth.: K. mit dem Fruchtknoten verwachsen, 4zähnig; Blbl. 4, am Rande der Kelchröhre; Griffel 1; Fruchtknoten 1fächerig, mit $1-2$ hängenden, nackten Eichen. Frucht beerenartig, mit gummiähnlichem, klebrigem Brei. Samen eiweisshaltig.

Vi iscum. Meișt dioecisch; Kelchbl. der männl. Blth. 4, lederartig, in der Knospe klappig, jeder Kelchlappen mit einer sitzenden mehrfächerigen Anthere; weibl. Blth. mit unscheinbarem Kelchsaum und 4 Blbl.; Griffel sehr kurz; Narbe fast sitzend.

\section{Viscum $L$. Mistel.}

795. V. album L. Gem. M.; wiederholt-gabelästig, grünlichgelb; Bl. gegenständig, lederartig, immergrün, länglich, ganzrandig; Blth. gelblich, endständig, knäuelartig; Frucht weiss. ち. $\frac{1}{2}-2^{\prime}$.

Meist auf Aepfel- und Birnenbäumen, selten auf Pappeln, Wallnussbäumen, auch auf Kiefern schmarotzend. Hie und da häufig genug, z. B. zwischen Schriesheim und Handschuchsheim! zwischen Schwetzingen und Plankstadt! Ziegelhausen! Wolfsbrunnen! etc. Im Friedrichsfelder Walde auf Kiefern nicht nur in den Kronen, sondern zuweilen in geringer Höhe auch an den Stämmen der Bäume! März, April. (Off.: Stipites Visoi.) 


\section{ARISTOLOCIIEAE Juss.}

Kräuter oder rankende Strïucher mit meist sehr entwickelten Wurzelstücken, alswechselnden Blättern ohne Nebenbliitter. Perigon oberstïndig, meist gefiirbt, 3-6lappig od. zungenförmig, in der. Kinospe klappig. Stbgef. 6-12, frei oiler gynandrisch. Fruchtlinoten mehrfächerig, vieleig, mit mehrstrahiiger Narbe, Frucht eine meist vielsamige, 6fiicherige Kapsel oder Beere. Samen mit reichlichem Eiweiss u. senr kleinem Keim.

Aristolochia. Perigon rölhig-zungenförmig, am Grunde bauchig; Antheren 6, ohne Stbf. mit dem Griffel verwachsen; Kapsel 6fächerig, 6klappig.

Asarum. Perigon glockig, 3klappig; Stbgef, 12, frei ; Kapsel 6fächerig, unregelmässig zerreissend.

\section{Aristolochia $L$. Osterluzei.}

796. A. Clematitis $L$. Gem. O.; Wzst. kriechend; St. aufreclit, wie die Bl. kahl, matt glänzend; Bl. rundlich-tiefherzförmig, sehr fein gesügt; Blth. achselständig, einzeln oder büschelig. భ. $2-3^{\prime}$. Perigon gelblich.

In Weinbergen, an Ackerrändern, Zäunen, auf Triften hie und da. In Menge bei Malsch! Malschenberg! Rauenberg! Rodenberg! seltener bei Nussloch! am Kirchlheimer See! stellenweise in Weinbergen zwischen H, und Rohrbach! Mai-Juli. (Off.: Rad, et $h b$. Aristol. vulgar.

\section{A s a rum $L$. Haseíwurz.}

797. A. europaeum $L$. Eu ropäis cher H.; Wzst. wagerechtkriechend; St. niederliegend; Bl. langgestielt, nierenförmig, glänzend, (zierlich netzaderig), schwach behaart; Perigon kurzgestielt, achselstïndig, einzeln, aussen etwas zottig, rothbraun. 4. 2-4". Wzst. eigenthümlich kampferartig riechend.

In schattigen Laubräldern, in Gebüschen, besonders in Haselnussgebüschen, auf Lehm- und Kalkboden stellenweise häufig, meist gesellig, z. B. hinter dem Haarlass! zwisehen Ziegelhausen u. Schönau! bei Schriesheim! Leutershausen! Weinheim! seltener bei Leimen! Nussloch! häufiger beim Maischbacher Hof! in den Gebirgswäldern um Dielheim! April, Mai. [Jenseits des Rheines in der Näho d. Geb, und selbst am Iraardtgebirge viel seltener.] (Off.: Rad. Asciri.) 


\section{EUPHORBIACEAE Juss.}

Die im Gebiet der Flora einheimischen Arten dieser (vorzugsweisen tropischen) formenreichen, weiten, aber wesentlich sehr natürlichen Familie sind Kräuter, deren Habitus viel Uebereinstimmendes zeigt, mit meist abwechselnden Blättern ohne Nebenblätter, fast immer durch reichlichen, weissen, scharfen und zuweilen giftig wirkenden Milchsaft ausgezeichnet. Blüthen monoecisch oder dioecisch, meist sehr unvollständig, die männl. und weibl. Blüthen oft von einer gemeinschaftlichen becherartigen Hülle umgeben, welche einem Perigon gleicht. Blüthendecke zuweilen doppelt, häufiger aber einfach, meist sehr unscheinbar oder fehlend. Stbgef. 1-viele, mitunter monadelphisch. Antheren 2 fächerig, der Länge nach aufspringend. Fruchtknoten sitzend, seltener gestielt, meist 3 fächerig, seltener mehrfächerig. Fächer mit 1-2 hängenden Eichen. Griffel meist 3, frei od. verwachsen. Frucht in den meisten Fällen eine 3fächerige Kapsel, deren Fächer bei d. Reife von einer Mittelsäule sich trennen. Samen eiweissreich, mit sehr entwickeltem Nabelwulst und geradem Keim. - Mehrere Arten der Gattung Euphorbia sind auf den Kies- und Sandfächen unserer Ebenen so gesellig, andere wenigstens stellenweise so häufig auftretend, dass d. Gattung ihres öfteren Vorkommens wegen, zu den bekanntesten Repräsentanten der Flora gezählt werden kann, auch hiø u. da durch die Uebereinstimmung ihrer reichlichen gelben Blüthenstände den landsehaftlichen Charakter wesentlich bedingen hilft.

Euphorbia. Blth. monoecisch; eine einzige centrale weibliche Blüthe, von zahlreichen männl. Blüthen umgeben; jede Blüthe mit 1 Stbgef, und von einem fadenförmigen Deckblatt (welches jedoch zuweilen verkümmert) unterstützt, das Ganze von einer glockigen Becherhülle umfasst. Diese 3-4lappig, am Rande der Lappen mit elliptischen oder halbmondförmigen Drüsen; Kapsel überhängend, 3fächerig, 3samig.

Mercurialis. Blth. dioecisch; Perigon 3-4theilig; Stbgef.blth. mit 8-12 Stbgef, in unterbrochenen Aehren; Kapsel 2fächerig, 2samig. 


\section{3\%. Euphorbia $L$. Wolfsmileh.}

a) Drüsen am Rande der Becherhülle elliptisch, gelblich (bei $E_{*}$ dulcis purpurroth).

$\alpha$. Kapseln glatt; Samen netzig-grubig.

798. E. helioscopia $L$. Sonnenwende-W.; St. aufrecht; Bl. verkehrt-eifürmig, gesägt; Dolde 5strahlig; Strahlen 3theilig u. gabelig. ๑. $3-10^{\prime}$ '

Auf Aeckern, in Gärten, an Wegen überall verbreitet. JuniOktober.

$\beta$ : Kapseln warzig; Samen glatt.

799. E. platyphyllos L. Breitblättr. W.; St. aufrecht, wie die Bl. meist weichhaarig, seltener zottig; Bl. keilig-lanzettl., fein gesägt, spitz, die unteren stumpf; Dolde 5strahlig; Strahlen 3theilig und gabelig; Warzen der Kapseln halbkugelig; Samen rundlich. ๑, $\frac{1}{2}-1 \frac{1}{2}^{\prime}$.

Auf etwas feuchten Aeckern, besonders auf Kalk- und Lehmboden, an Wegen hie und da. Häufig zwischen H. und Schwetzingen! Handschuchsheim! Neckarau; stellenweise an den Rheinufern! Bei Ladenburg! Rauenberg! Waghäusel oft sehr vorherrschendI Juni-September.

800. E. stricta $L$. Steife W.; St. steif aufrecht, der vorigen ähnlich, aber zarter; $\mathrm{Bl}$. zahlreicher und kleiner, meist kahl; Dolde der vorigen; Warzen der Kapseln walzlich verlängert; Samen ciförmig. $\odot \cdot \frac{1}{2}-1 \frac{1}{2}^{\prime}$. Das ganze Kraut riecht eigenthümlich betäubend. (E. dubia Dierb.)

In Waldgebüschen, lichten Wäldern hie und da, meist gesellig, z. B. im Thale der Hirschgasse: hinter d. Haarlass! gegen Wilhelmsfeld! Stellenweise häufig im Friedrichsfelder Walde! beim Relaishause! Neckarau! auf der Rheininsel bei Ketsch! Juni-August.

801. E. dulcis Jacq. Süsse W.; Wzst. kriechend; St. aufrecht; Bl. lïnglich-lanzettl., stumpf oder zugespitzt, ganzrandig oder fein gesägt, unterseits graugrün; Dolde $3-5$ strahlig; Strahlen 2spaltig; Deckbl. der Strahlen 3eckig-eiförmig; Warzen der Kapseln ungleich, rundlich, dunkelpurpur; Kapseln meist weichhaarig, selten kahl; Drüsen der Becherhülle meist purpurroth oder etwas gelb. 2. 1'. Milchsaft milde, gering.

In schattigen Laubwäldern der Gebirge nicht selten, z. B. in Menge hinter dem Haarlass! längs der Bergstrasse, besonders bei Weinheim häufig! Diesseits des Neckars seltener, z. B, einzeln im Dreitröge Thal! Auch im Gaiberger Waldel bei Schatthausen! Leimen! beim Maischbacher Hof! April-Juni. [Jenseits des Rheines, in der Nähe des Gpbiotes fehlond.] 
802. E. palustris $L$. Sumpf-W.; St. aufrecht, ästig; BI. sitzend, lanzettl., stumpf, ganzrandig oder fein gesägt, kahl; Doldo vielstrahlig; Strahlen wiederholt 3spaltig; Deckbl. verkehrt eirundlänglich; Warzen der Kapseln kurz elliptisch. 24. 2-3'. Nach der Blüthezeit treiben blüthenlose $\mathrm{Zwcige}$ aus den oberen Blattwinkeln.

An Flussufern, auf feuchten Wiesen, in Sümpfen der Rheinfläche stellenweise nicht selten, z. B. beim Rolirhofe! beim Relaishause! bei Alt-Lussheim! Ketsch! Neckarau! Sandtorf! zwischen St. Ilgen und Kirchheim! einzeln auch am Neckarufer zwischen II. u. Ziegelhausen! Mai, Juni. [Auch in der Nähe des Gebiets jenseits des Rheines bei Oggersheim!]

$\gamma$. Kapseln glatt, oder rauh punktirt; Samen glatt.

803. E. Gerardiana Jacq. Gerards-W.; St. aufrecht, dicht beblättert; Bl. lineal oder lineal-lanzettl., spitz, ganzrandig, kahl, blaugrün; Deckb!. 3eckig-eirund, stachelspitzig; Dolde vielstrahlig; Strahlen wiederholt gabelig. 4. $\frac{1}{2}-1 \frac{1}{2}^{\prime}$. (E. linariaefolia Dierb.)

Auf den Sandflächen der Ebene meist sehr verbreitet u. häufig gesellig! Auch auf kalkhaltigen oder lehmigen Irïgeln und Triften zwischen Nussloch und dem Maischbacher Hofe, bei Wiesloch, Rauenberg, Malsch nicht selten! Woniger verbreitet bei Ladenburg! Woinheim! Mai-August.

b) Drüsen am Rande der Becherhülle halbmondförmig oder 2hörnig, gelblich.

$\alpha$. Samen glatt.

804. E. Cyparrissias $L$. Cуpressen-W.; St. aufrecht, ästig, dicht beblättert; Bl. schmal lineal, die oberen fast borstenfürmig, ganzrandig, kahl; Dolde vielstrahlig; Strahlen wiederholt gabelig; Deckbl. 3eckig-eiförmig, stachelspitzig; Kapsel fein punktirt raul. $41^{\prime}$. Wzst. kriechend. - (Die Unterseite der Blätter ist nicht selten mit einem Pilz (Aecidium Euphorbicae Pers.) besetzt, wodurch Verkrüppelung und Unfruchtbarkeit der Pflanze bewirkt wird.)

Auf Sandfeldern, an Wegen, auf trockenen Triften, Haiden, an Waldrändern häufig! Mai-Juli.

805. E. Esula $L$. Scharfo W.; St. aufrecht; Bl. lineal.-lanzettlich, die unteren etwas keilförmig, die der unfruchtbaren Sommer-Triebe fast spatelförmig, alle ganzrandig, kahl, nur am Rande rauh; Dolde u. Kapsel d. vorigen. 4. 1-2'.

Auf etwas feuchten, sandigen und lehmigen Triften, Aeckern, in Gebüschen, besonders am Rheinufer hie und da, z. B. beim Relaishause!. Rohrhof! zwischen Mannheim u. Sandhofen! b. Neckarau! Ketsch! Rheinhausen! einzeln auch am Neckar bei Ladenburg! und 
an der Weschnitz bei Weinheim! Mai-Juli. [Jenseits des Rheines in der Nühe des Gebietes verbreitet bei Friesenheim u, Oggersheim!]

\section{$\beta$. Samen runzlig-grubig.}

806. E. Peplus $L$. Gem. W.; kahl, grasgrün; St. einfach od. istig; Bl. gestielt, verkehrt-eiförmig, die unteren tast kreisrund; Dolde 3strahlig, wiederholt gabelig; Kapseln auf dem Rücken flügeliggekielt; Samen netzartig-runzelig. ๑. 4-8".

An Wegen, auf Aeckern, in Gärten allgemein verkreitet! Juni bis Oktober.

807. E. exigua $L$. Kleine W.; kahl; St. einfach oder ausgcbreitet ästig; Bl. lineal-spitz; Dolde 3-4strahlig, wiederholt gabelig; Kapseln glatt; Samen queer-runzelig. ๑. 3-8",

Auf Aeckern und Triften, besonders auf Kalk- und Lehmboden läufig! Juni-September.

[E. falcata $L$. Sichelf. W.; St. aufrecht, einfach oder ästig, kahl, graugrün; Bl. lanzettl., spitz, untere spatelfürmig, stumpf od. stachelspitzig; Dolde 3-5̌strahlig, wiederholt gabelig; Kapseln glatt; Samen 4reihig-queergrubig, ค. $3-6^{\prime \prime}$.

N. I. a. d. Geb. in Rhb.: auf kalkhaltigen und lehmigen Acckern zwischen Ludwigshafen und Oggersheim! Frankenthal! Maxdorf! A ugust-Oktober.]

\section{Hercurialis $L$. Bingelkraut.}

808. M. perennis $L$. Ausdau erndes B.; St. einfach, stielrund, wie die Bl. fein behaart; Bl. gegenst., eiförmig-längl., mit kurzen Nebenbl.; weibl. Blth. langgestielt. 4. $\frac{1}{2}-1^{\prime}$. Blth, grïnlich. Nicht milchend. Beim Trocknen blau werdend.

In schattigen, etwas feuchten Wäldern, in. Waldgebüschen nicht selten, z. B. beim Haarlass! bei Ziegelhausen! Schönau! Wilhelmsfeld! im Carmeliterwäldchen und auf dem Friesenberge bei H.! hïufig bei Schriesheim und Weinheim! seltener zwischen Leimen $u$. Maischbach! bei Dielheim! Auch in der Ebene zwischen Waghäusel und Kirrlach: April, Mai.

809. ㄱ. annua $L$. Einjähriges B.; St. ästig, 4 kantig, wie die eilanzettl. Bl. kahl; weibl. Blth, fast sitzend. ○. $\frac{1}{2}-1^{\prime}$. Blth. grünlich. Nicht milchend.

Auf Aeckern, in Weinbergen, an Wegen, auf Schutt sehr bäufg. Juni-November. 


\section{URTICEAE Juss.}

Kräuter, Sträucher oder Bäume mit gegenständigen orler abwechselnden scharfen oder rauhhaarigen Blättern, abfallenden oder bleibenden Nebenblättern. Blth. monoécisch oder dioecisch. Perigon meist sehr unscheinbar, unterstïndig, der männl. Blth. 3-5theilig, der weibl. 2-5theilig orler ungetheilt. Stbgef. von der Zahl der Perigon-Theile, oft das Rudiment eines Fruchtknotens umgebend. Fruchtknoten 1-2fächerig, 1eig, mit 1 oder fehlendem Griffel, aufrechtem oder hängendem Eichen. Frucht nussartig. Samen eiweisshaltig oder eiweisslos, mit geradem oder gekrümmtem Keim.

a) Urticaceae; Kräuter; Stbgef. in der Knospe eingebogen, elastisch aufspringend; Samen mit Eiweiss; Keim gerade.

Urtica. Monoec. oder dioec.; männl. Perigon gleichmässig 4theilig, weibl. Perigon ungleichmässig 4theilig; Stbgef.4; Griffel 0; Narbe pinselig.

Parietaria. Polygam.; Perig. 4-5theilig, gleichmässig; Stbgef. 4-5; Griffel fadenförmig, mit kopfartiger, pinseliger Narbe.

b) Cannabineae; Kräuter; Stbgef. in der Knospe gerade; Samen eiweisslos; Keim spiralig oder gekrümt.

Cannabis. Dioec.; männl. Blth. in Trauben; Perig. 5theilig; Stbgel. 5; weibl. Blth. 1-2, achselständig; Perig. zungenfürmig, die Nuss ganz einhüllend.

Humulus. Dioec.; männl. Blth. wie vorige, weibl. Blth. in Kätzchen vereinigt; Perig. schuppenf., die Nuss theilweise einhüllend.

c) Moreae; Bäume oder Sträucher, Milchsaft enthaltend;

Stbgef, in der Knospe eingebogen; Samen eiweisshaltig; Keim gekrümmt.

Morus. Blth. monoec. oder dioec. in dichten, fast kugeligen Aehren; Perig. 4blätterig; Stbgef. 4; Fruchtknoten 2fächerig; Nuss von dem saftigen Perig. umgeben, eine falsche Beere darstellend.

\section{Urtica $L$. Brennnessel.}

810. U. arens $L$. Klein $\theta$ B.; Bl. elliptisch-eirund, spitz, eingeschnitten-gezähnt; Blth. monoec. in achselständigen kurzen Rispen. ๑. Blth. wie die der folg. Art klein, grünlich; St. u. Bl. wio bei der folg. Art mit Brennhaaren versehen. $\frac{1}{2}-1$ '. 
Auf Schutt, an Wegen, auf Aeckorn überall sehr häufig! Juli bis October.

81l. U. dioica $L$. Grosse B.; Bl. länglich-herzförmig, zugespitzt, grob gesägt; Blth. dioec. in achselständigen verlängerten Rispen. 4. 1-3'.

An Wegen, in Gebüschen, in lichten Wäldern, auf Schutt allgemein verbreitet. Juli-October.

\section{Parietaria $L$. Wandkraut.}

812. P. erecta $M$. et $K$. A ufrechtes W.; St. aufrecht, einfach; Bl. elliptisch, lang zugespitzt, ganzrandig, unterseits kurzhaarig; Blth. in achselständigen, kugeligen, reichblth., kurz gestielten Knäueln; Perig. der Zwitterblth. nach dem Verblühen glockig. 4 . $1-1 \frac{1}{2}^{\prime}$. Blth. grünlich. ( $P$. officinalis L.)

An Mauern, auf Schutt selten. Heidelberger Schloss, z. B.. am Otto-Heinrichs-Bau! Juli-October.

[Auch in d. Nähe d. Geb. nur vereinzelt. N. V. a. d. Geb. in Hs.: Darmstadt (Sohnttsp.); in Rhb.: Deidesheim $\left.\left(F_{0} S c h.\right)\right]$

813. P. diffusa $M$. et $K$. Aus $g$ ebreitetes $W_{0}$; St. niederliegend, ausgebreitet ästig; Bl. elliptisch-eirund, stumpflich, ganzrandig, unterseits kurzhaarig, oberseits stark glänzend; Blth. fast sitzend, achselständig, knäuelförmig; Perig. der Zwitterblth. nach dem Verblühen röhrig, verlängert. 4 . $\frac{1}{2}-1^{\prime}$. ( $P$ officinalis $L$. var.)

An Mauern und Felsen nur im Neckarthal, besonders bei H.! nicht selten am Wege gegen Neuenheim! am Haarlass! bei Ziegelhausen! auch weiter abwärts am Neckar bis zum Ilvesheimer Schlösschen und der Ueberfahrtsstelle bei Seckenheim (Döll) Mai-Oktober.

[N. V. nördl. v. Ilvesheim: Frankfurt a/M. u. Mainz (Schnttsp.) In Rhb, und B. (in der Nähe des Geb.) fehlend.]

\section{Cannabis $L$. Hanf.}

C. sativa $L$. Gebräuchl. H. ; St. aufrecht; Bl. fingerförmigzusammengesetzt, scharf sägezähnig, scharfhaarig; männl. Blth. traubig verlängert, weibl. Blth, zu 2, achselständig und sitzend. ○. 2'. Blkr. grünlich.

Stammt aus Indien und Persien, wird häufig gebaut und verwildert hie und da. Juli-September. (Off.: Semen Cannabis.)

\section{II umuIus $L$. Hopfen.}

814. H. Lupulus $L$. Gem. H.; St. rechtswindend; Bl. 3-5lappig, grob gesägt, scharf; Fruchtaehro eiförmig, mit trockonbäutig. 
Deckblättern, deren Grund (nach Innen) mit goldgelbon, rundlichen Drïsen (Lupulin absondernd). 2. Blth. grïn.

In Hecken, Gebüschen, Wäldern nicht selten; die wcibl. Pf. häufg cultivirt. Juli-September. (Off.: Strobuli Lupuli.)

II orus Tournef. Ma ulbeerbaum.

M. alba $L$. Weisser M.; Bl. herz-eifürmig, ungetheilt oiler lappig, kahl oder schwach behaart; weibl. Aehren gestielt; Perig. am Rande kahl; Narben kahl. †. Fruchtachre weiss.

Aus Asien stammend; der Seidenzucht wegen angebaut. Mrai.

M. nigra $L$. Schwarzer M.; Bl. d. vorigen, aber unterseits fast filzig-behaart; weibl. Aehren fast sitzend; Perig. am liande, nebst Narben rauhhaarig. ந. Fruchtaehren schwarz-roth.

Aus Asien stammend. Cultivirt. Mai. (Off.: Mori nigrae.)

\section{ULMACEAE. Endl.}

Bäume oder Sträucher mit abwechselnden, zweizeiligen Blättern und hinfälligen Nebenllättern. Blth (bei Ulmus) zwitterig. Perigon unterständig, glockig, 4-5-, selten Stheilig. Stbgef. von der Zahl der Perigon-Glieder, in der Knospe aufrecht. Fruchtknoten frei, 1-2fächerig, mit 2 hängenden Eichen und 2 fadenförmigen Griffeln. Frucht nussartig, geflügelt. Samen eiweisslos. Keim gerade.

U lmu s. Perig. glockig, meist 5̌theilig; Stbgef. 5; Flügelfrucht rundlich, zusammengedrückt.

\section{U I m us $L$. Ulme (Rüster).}

815. U. campestris $L$. Fold-U.; Bl, eirund-länglich, doppelt gesägt, am Grunde ungleich, scharfhaarig; Blth. büschelig, fast sitzend; Früchte kahl. † von $40-60^{\prime}$. Blth. grünlich-roth, vor lintfaltung der Bl. erscheinend. - Variirt mit starker Entwickelung von Kork an den Zweigen:

B) suberosa Ehrh.; meist strauchartig; etwas verkrüppolt.

In Wäldern, Dörfern, an Wegen häufig. Var. seltener, z. B. bei Weinheim! beim Relaishause! April. (Off.: Cort. Ulmi interior.)

816. U. effusa Willd. Stiel-U.; Bl. d. vorigen, mehr oval; Blth. langgestielt, hängend; Früchte am Rande zottig gewimpert. ち von $20-50^{\prime}$. Blth. grünlich.

In Waldgebüschen, an Wegen, besonders im Gebirge, aber scl. tener als vor. April, 


\section{JUGLANDEAE $D$.C.}

(Nur mit Berïcksichtigung der Gattung Juglans.)

Bïume mit alwechselnden, gefiederten, aromatischen, nicht punktirten Blättern, nhne Nebenblïtter, grünlichen, unscheinbaren monoecischen Blüthen. Männl. Blth.: hängende, cylinderische Kätzchen; Perigon 2-6theilig, mit Deckblättchen verwachsen; Stbgef. zahlreich. Weibl. Blth. einzeln oder wenige an den Enden der Zweige. Kelch 4zähnig, mit flem Fruchtknoten verwachsend. Blkr. 4 blätterig, abfallend. Fruchtknoten 1fächerig, 1eiig, mit aufrechtem Eichen, lappiger Narle. Steinfrucht mit 2klappigem Stein, eiweisslosem Samen, mit buchtig-faltigen, fleischigen Samenlappen.

\section{Juglans $L$. Wallnussbaum.}

J. regia $L$. Gem. W.; Bl. unpaarig-gefiedert; Blttch. eirund, gesägt, kahl; Steinfrüchto kugelig, kahl, fleischig. 方 von $40-70^{\prime}$. Narkrühre der Zweige fächerartig!

Cultivirt; aus Persien stammend. Mai. (Off.: Tnt. et Cort. nucum Juglandis.)

\section{CUPULIFERAE Rich.}

Büume oder Sträucher mit abwechselnden Blättern und linfälligen Nebenblïttern. Blth. monoecisch. MIännl. Blth. in Kätzchen; Perigun 3-6spaltig oder seltener fast ganz rerkümmert; Stbgef. 5-viele. Weibl. Blth. einzeln oder ährig verbunden, von dachziegeligen, mehr oder weniger verwachsenen Deckblättern umgeben, welche bei der Fruchtreife eine sog. Becherhülle (cupula) bilden; weibl. Perị. dem Truchtknoten angewachsen, schr unscheinbar, meist ein gezähnter Saum. Fruchtknoten 2-6fächerig. Fïcher 1-2eiig. Eichen hängend. Grifel 2-6, liurz, mit einfachen nder lappigen Narben. Frucht eine lederartige oder holzige 
Nuss, entweder theilweise oder gänzlich von der Becherhülle umgeben, 1fächerig, 1samig. Samen eiweisslos mit geradem Keim.

a) Männl. Blth. mit Perig.; Stbf. ungetheilt; Antheren ohne Haarbüschel.

F a gus. Männl. Kätzchen hängend, fast kugelig, deckblattlos; Perig. glockig; Stbgef. 10-15; Weibl. Blth. paarweise in verlängerten Aehren; Fruchtknoten 3fächerig; Nüsse 1-2, 3kantig, von der endlich 4klappig aufspringenden Hülle vollständig eingeschlossen. - Keimblätter bei der Keimung oberirdisch.

C a s t a n ea. Männl. Kätzchen verlängert, mit knäuelartigen Blth.; Perig. 5-6theilig; Stbgef. 10-20; weibl. Blth. in achselständigen Köpfchen; Fruchtk. 6fächerig; Nüsse 1-3, von der endlich aufspringenden Hülle vollständig eingeschlossen, - Keimblätter bei d. Keimung unterirdisch.

Quercus. Männl. Kätzchen verlängert, mit einzelnen, deckblattlosen Blth.; Perig. 5-9theilig; Stbgef. 5-9; weibl. Blth, einzeln, von dachigen Deckbl, umgeben, welche später zur Becherhülle auswachsen; Fruchtknoten 3fächerig; Nüsse eirund, nur am Grundo von der lederartigen Hülle umgeben.

b) Männl. Blth. ohne Perig.; Stbfäden gespalten; Antherenfächer getrennt, auf jeder Antherenhälfte ein Haarbüschel.

Cor jlus. Männl. Kätzchen walzenfürmig; Stbgef. 8, von 2-3 Deckbl. umgeben: weibl. Blth. 1-2, an der Spitze einer Knospe; Fruchtknoten 2fächerig, mit 2 fädlichen rothen Narben; Nuss oval, am Grunde von einer blattartigen, zerschlitzten Hülle umgeben.

Carpinus. Männl. Kätzchen walzenförmig; Stbgef. zahlreich, von 1 Deckbl, umgeben; weibl. Kätzchen paarweise mit hinfälligen Deckbl; Nuss oval, kantig-gestreift, von einer 3lappigen Hülle umgeben.

\section{F a gus $L$. B u c h e.}

817. F. sylvatica $L$. Wald-B.; Bl. elliptisch, ganzrandig, am Rande gewimpert; männl. Kätzchen langgestielt, hängend; weibl. Blth. kurz gestielt, aufrecht. $\hbar$ bis 100 !

In Wäldern, besonders im Gebirge häufig. Mai.

\section{Castanea Tournef. Kastanie.}

C. vulgaris Tournef. Bl. länglich-lanzettl., zugespitzt, gesägt, meist kahl, etwas lederartig. $\hbar$ von $30-40^{\prime}$. (C vesca Gaertn.. Fagus Castonea L.) 
Häufig cultivirt und in den Gebirgswäldern um H. nicht selten gleichsam verwildert. Juni, Juli.

\section{Quereus $L$. Eiche.}

818. Q. pedunculata Ehrh. Stiel-E.; Bl. sehr kurz gestiolt, länglich, tief buchtig gelappt, kahl; weibl. Blth. und Früchte mehr oder weniger langgestielt. $\hbar$ von $100-130^{\prime}$. (Q. Robur L.)

In Wäldern allgemein verbreitet. Mai.

819. a. sessiliflora $S m$. Stiello s e E.: Bl. länger gestielt, verkehrt-eiförmig, buchtig, 'kahl; weibl. Blth. nnd Früchte sitzend oder sehr kurz gestielt. $\hbar$ selten über $80^{\prime}$.

Mit der vorigen in Wäldern, Gebüschen häufig. Blüht 8-14. Tage später. (Off.: Cort. Quercus.)

\section{Corylus Tournef. Haselnuss.}

820. C. Avellana $L$. Ge m. H.; Bl, rundlich-herzförmig, doppelt gesägt, kurz zugespitzt, rauhhaarig; Becherhülle glockig, mit zerrissen-gezähntem Saum. - Strauch von $6-12^{\prime}$. Die purpurrothen Narben der Fruchtknoten meist etwas früher aus den Knospen aufbrechend als die Antheren.

In Wäldern, Gebüschen, Zäunen häufig. Februar-April.

\section{Carpinus $L$. Ha inbuche.}

821. C. Betulus $L$. Weiss b u che; Bl. eirund-länglich, spitz, doppelt gesägt, faltig; 3lappige Becherhülle mit verlängertem Mittellappen. Ђ. $20-40^{\prime}$.

In Wäldern, Gebüschen fast überall sehr verbreitet. Mai.

\section{BETULINEAE Rich.}

Bäume oder Sträucher mit abwechselnden einfachen Blättern und hinfälligen Nebenblättern. Blth. monoecisch, in Kätzchen mit schuppenförmigen, von kleineren Deckblättchen begleiteten Deckblättern. Perigon 4theilig, schuppenartig oder fehlend. Stbgef. 4 (eigentlich 2, indem die Stbfäden, wie bei den verwandten Gattungen Corylus und Carpinus gespalten, die Antherenfächer getrennt sind). Fruchtknoten 1-2fächerig, 1-2eiig, mit 2 Narben. Nuss 1 samig. Samen eiweisslos. Keim gerade. Die Blüthen erscheinen vor oder mit der Entwickelung der Blätter. 
Betula. Männl. Kätzchen hängend, mit schildfürmigen Deckblättern, jedes Deckbl. mit 2 kleineren Deckblttch. und 3 I3lth.; Perig. schuppenartig, am Grunde mit 4 Stbfiden (und also 12 Stb.fïden an jedem Declibl.); Antheren getrennt, 1fächerig; weibl. Kätzchen mit 3lappigen, dachigen, abfallenden Deckbl.; Fruchtknoten 3 unter jedem Deckbl.; Narben 2, farenförmig; Nuss geflïgelt.

A lnus. Männl. Kätzchen hängend, mit schildförmigen Deckbl., jedes Deckbl. mit 5 kleinen Deckblttch. und 1-3 Blth:; Perig. 4theilig; Stbfäden 4, mit getrennten 2fächerigen Antheren; weibl. Kätzchen mit dachigen, rerholzenden, bleibenden Deckbl. (endlich zapfenähnlich); Fruchtlnoten 2 unter jedem Deckbl.; Narben 2 fadenförmig; Nuss geflïgclt oder ungeflïgelt; Laublinospen gestielt!

\section{1\%. Betula $L$. B irke.}

822. B. alba $L$. 'W eiss c B.; Bl. rautenfürmig-dreieckig, lang zugespitzt, doppelt gesügt, kahl; weibl. Kätzch. lang gestielt, hängend; seitliche Deckblttch. der Deckbl. zurückgekrümmt; FlügeI länger und breiter als die eigentliche Nuss. \$ ron $10-50^{\prime}$. Zweige hängend; Korkschicht der Iinde abbliitternd, weiss. (B. odorata Bechist.) - Variirt selten:

\section{B) laciniata Wahlbg.; Bl, zerschlitzt.}

In Wäldern, an Wegen allgemein verhreitet. Dic Var, auf dem Noore bei Sandtorf (Döll). April, Mai.

823. B. pulescens Lirh. Weichhaarige B.; BI. rauteneiförmig, zugespitzt, doppelt gesägt, weichhaarig, allmählig zwar fast kahl werdend, aber stets unterseits an den Nervenwinkeln reichhaarig-bärtig bleibend; weibl. Kätzch. der vorigen; seitliche Deckblttch. der Deckbl. abstchend; Flïgel von der Länge und Breite der Nuss. - Meist strauchartig mit aufrechten Zweigen.

In Torfsümpfen vereinzelt: Waghäuscl! Sandtorf! (Döll). April bis Mai.

\section{Alnus Tournef. Erle.}

824. A. incana $D C$. Weissgraue E.; Bl. eiförmig, kurz zugespitzt, doppelt gesägt, unterseits graugrün, weichhaarig; weibl. Kätzchen sitzend oder kurz gestielt; Nïssch. schmal geflügelt. †. $10-20^{\prime}$. Rinde grau, glatt.

In feúchten Wäldern, an Ufern, Bächen hie und da, z. B. im Friedrichsfelder Walde! beim Relaishause, Rohrhofe, Ketsch! Auch am Fusse des Gebirges zwischen Rohrbach und Leimen! bei Weinheim ! U. s. w. März, April. 
825. A. glutinosa Gicern. Gem. E.; Bl, rundlich, an dor Spitze abgestutzt oiler buchtig ausgerandet, ausgeschweift-gezihhnt, interseits liahl, grïn, in der Jugend, wie auch an den Zweigen klebrig: weibl. Küitzchen lang gestielt; Nüsse ungenlügolt. ț. 10-60'. Rinde bräunlich; rissig.

In feuchten Waldgebüschen, an Ufern, in Sümpfen allgemein verbreitet. Februar-April.

\section{SALICINEAE Rich.}

Bitume oder Strïucher mit einfachen, meist abrivechselnden Blïttern und hinfilligen Nebenblittern. Blth. kïtzchenartig, dioecisch, in den Achseln dachziegclig gestellter meist zottiger oder gewimperter l)eckblitter. Perigon vüllig fehlend, meistens durch 1-2 driisenïhnliche Stiele oder durch eine napflürmige, Ilonigsaft alssonilernde Scheibe vertreten. Stbgef. 2-24, frei oder mehr oler weniger mit einander verwachsen. Fruchtknoten frei, 1fächerig, mit 1 Griffel und 2, zuweilen (Populus) eigentliümlich verzweigten Narben. Kapsel 2klappis, vielsamig. Samen aufrecht, von einer seidenartigen Wolle (welche aus der auswachsenden Nabelschnur entstanden) umgeben, ohne Eiweiss. Keim gerade.

Salix. Deckbl. der Kätzchen ungetheilt; Stbgef. in jeder Blütho 2-5; Fruchtknoten am Grunde mit 1-2 Drüsen.

Populus. Deckbl. der Kätzchen eingeschnitten; Stbgef. 8viele, wie die Fruchtknoten am Grundo mit becherförmiger Scheibe.

\section{Salix $L$. W eide:}

a) Fragilis Koch; Kätzchen auf boblätterten Stielen, mit den

Bl. sich entwickelnd; Deckbl. d. weibl. Kätzchen gelbgrün, vor der Reife abfallend; Aeste leicht abbrechend.

826. S. alba $L$. We is se W.; Bl. schmal lanzettl, zugespitzt,

*) Um die Salices zu bestimmen, sind nicht allein die Frühlingszustände nöthig, welche allordings die wichtigen 'Verhältnisse der Blüthen und Fruchtstände im Verlauf von nur wenigen Wochen zeigen, sondern man bedarf auch der späteren Entwickelung, um die Blätter in ihrer vollen Ausbildung zu prüfen. Diese, 'wie auch die eigenthümliche Form der Nebenblätter pflegen gegen Ende Juli und im August an den sog. Sommertrieben am deutlichsten erkannt zu werden. 
gesägt, beiderseits weissseidenhaarig; Nebenbl. lanzettl.; Stbgef. 2; Kapseln ei-lanzettl., stumpf, kahl, fast sitzend; Griffel und Perigondrüse kurz. $\hbar$ von $10-50^{\prime}$. - Variirt:

ß) coerulea; Bl. blaugrün, fast völlig kahl werdend.

$\gamma$ ) vitellina; Zweige dottergelb.

An Wegen, Ufern, in Dörfern häufig; die Var. etwas seltener, Var. $\beta$ hie und da am Rhein, z. B. beim Relaishause! April, Mai.

827. S. fragilis $L$. Bruch-W.; Bl. lanzettl., lang zugespitzt, kahl (in der Jugend seidenhaarig), drüsig-gesägt; Nebenbl. nierenf.; Stbgef. 2; Kapseln*) ei-lanzettl., kahl, lang gestielt; Stiel 2-3mal lïnger als die Perigondrüse. ఫे ron $10-30^{\prime}$. - Variirt:

ß) Iusseliana; Bl. fein seidenhaarig, erst spät oder gar nicht kahl werdend; Nebentl, eifürmig-länglich, spitz.

An Ufern, auf feuchten Wiesen, in Sümpfen hie und da am Rhein, z. B. zwischen Mannheim und Sandhofen! auch am Teckar bei Feudenheim (Döll). Die Var. an Neckar zwischen Ladenburg und Neuenheim! am Rhein beim Relaishause! Uebrigens hinsichtlich der Verbreitung noch zu verfolgen. April, Mai. (Off.: Cort.Salicis.)

b) Amygdalineae Koch; Kätzchen auf beblätterten Stielen, mit den Bl. sich entwickelnd; Deckbl. gelblich-grïn, bis zur. Fruchtzeit bleibend.

828. S. amygdalina $L$. Mandelblättr. W.; Bl. lanzettl oder elliptisch, zugespitzt, drüsig-gesägt, kahl, oberseits glänzend, unterseits grün oder bläulich; Nebenbl. halb herzf.; Deckbl. kahl oder etwas gewimpert; Stbgef. 3; Griffel sehr kurz; Kapseli eilänglich, kahl, lang gestielt; Stiele 3mal länger als die Perigondrüse. Strauch 4-8'. (S. triandra L.). - Variirt:

$\alpha)$ conoolor Koch; Bl. beiderseits grün.

ß) discolor Koch; Bl. unterseits blaugrün.

An Ufern, in feuchten Gebüschen, Sümpten der Ebene und der Gebirge häufig. Var. $\beta$ im Gebirge zwischen $H$. and Weinheim stellenweise nicht selten. Var. $\alpha$ am Rhein und Neckarufer allgemein verbreitet! April, Mai.

829. S. hippophaëfolia Thuill. Sanddornblättr. W.; Bl. lanzettlich, zugespitzt, fein drüsig-gesägt, weichhaarig, später kahl werdend; Nebenbl. halb herzförmig; Deckbl. filzig, an der Spitze bärtig; Stbgef. 2; Griffel verlängert; Kapseln eilänglich, fast kahl,

-) Die Gestalt der Kapsel ist zu beachten, bevor durch vollständige Reife das Aufspringen erfolgt. 
gestielt; Stiel kaum länger als die Perigondrüse. Strauch 5-10'. Nur weibl. Exemplare beobachtet,

An Ufern, z.B. am Neckar zwischen H. und Schlierbach : gegen Neckargemünd! bei der Bergheimer Nühle! Wieblingen! Am Phein bei Mannheim! [besunders jenseits des Rheines bei Ludwigshafen!) April, Mai.

S. babylonica $I_{\text {. }}$ 'Trauer-W.; Zweige hängend; Bl. schmal lanzettl., zugespitzt, fein gesägt, kahl, unterseits grau-grün; Nebenbl. schief lanzettl.; Deckbl. lineal-lanzettl., schwach behaart; Kapseln fast sitzend, eiförmig, kahl. Ђ.. Es finden sich nur weibl. Exempl. Aus dem Orient stammend. Häufig angepflanzt. April, Mai.

c) Purpureae Koch; Kätzchen vor den Blättem sich entwickelnd, sitzend; Deckbl. an der Spitze schwarzrandig; Antheren purpurroth, nach dem Verblühen sch๘ärzlich; Kapseln sitzend oder sehr kurz gestielt.

830. S. purpurea $L$. Purpurrothe W.; Bl. lanzettl., spitz, oben etwas breiter, fein gesägt, unterseits oder beiderseits bläulichgrün; Stbgef. 2, bis an die Spitzo rerwachsen; Kapseln eiförmig, sitzend, seidenhaarig; Griffel kurz, mit eiförmigen Narben. Strauch 4-10'; Nebenbl.s. hinfällig oder fehlend; Zweige und Bl. häufig gegeust. (S. monandra Hoffm.) - Variirt:

ק) Lambertiana Sm.; niedrig, ausgebreitet; Bl. eirund-lanzettlich; Kätzchen gedrungen.

y) Helix L.; schlanker, aufrecht; Bl. schmal lanzettl.; Kätzchen länger.

An Flussufern, Bächen, in feuchten Gebüschen häufig. Var. $\beta$ auf der Insel bei der Bergheimer Mühle und bei Neuenheim in Menge! Var. $\gamma$ am Neckar- und Rheinufer verbreitet! April, Mai. (Off.: Cort. Salicis.)

831. S. rubra Huds. Rothe W.; Bl. schmal lanzettl., spitz, etwas drüsig-gesägt, unterseits seidenhaarig, oft aber fast kahl werdend; Nebenbl. lineal; Stbgef. 2, bis zur Hälfte verwachsen; Kapseln eiförmig, sitzend, seidenhaarig, grau; Griffel verlängert; mit fadenförmigen, sperrigen, rothen Narben. Strauch $4-12^{\prime}$.

An Flussufern, in feuchten Gebüschen moist vereinzelt. Hie und da am Neckar bei H. und Neuenheim! häufiger am Rhein zwischen Neckarau und Mannheim! beim Rohrhof! Ketsch! (Off.: Cort. Salicis.)

d) Pruinosae Koch; Kätzchen vor den Bl. sich entwickelnd, sitzend; Deckbl. an der Spitzo gefärbt; Antheren nach dem Verblühen gelb; Kapseln sitzend oder kurz gestielt; innere Rinde gelblich.

832. S, daphnoides Vill. Lorbeer-W.; Bl, länglich-lan- 
zettlich, drüsig-gesägt, zottig, kahl werdend; Nebenbl, halb licrzf.; Stlogef. 2; Kiapseln sitzend, ei-kegelig, kahl; Griffel rerlïngeri; Narben länglich. 支 ron $6-16^{\prime}$. Zweige blïulich bereift.

Am Rheinufer bei Mannheim (J)üll). März, April.

c) Timinales Koch; Kätzchen vor den Bl. sich entwickelnd, sitzend; Deckbl. an der Spitze gefärbt; Antheren nach dem Verblïhen gelb; Kapseln sitzend oder kurz gestielt; Innere Rinde grün.

833. S. viminalis $I_{\text {. }}$ Korbwcide; Bl. schmal lanzettlich, zugespitzt, fast ganzrandig, unterseits seidenhaarig, silberglänzent, oberseits kahl; Nebenbl. lineal, hinfällig; Kapseln kegrelig, filzig; Perigondrüse liürzer als der Iruchtlknoten; Griffel so lang wie die fiidlichen ungetheilten Narhen; Declibl. kurz seidenhaarig. Strauch 5-16', mit langen, ruthenfürmigen, biegsamen, glatten Zweigen.

An Flussufern, Bächen, in Sümpfen allgemein verbreitet. April.

834. S. Smithiana Willl. B1. eifürmig-lanzettl., ganzrandig oder fein gesiigt, unterseits filzig-seidenhaarig, glänzend; Nebenbl. nieren-herzfürmig, zugespitzt; Kapseln kegelig, filzig; Perigondrüso der vorigen; Griffel länger oder kürzer; Narben getheilt oder ungetheilt; Deckbl. zottig-seidenhaarig. Strauch 6-12'. - Variirt:

B) acuminata; Bl. elliptisch, zugespitzt, unterseits filzig, nicht glänzend. ( $S$, acuminata $\operatorname{Sim}$. ?)

An Ufern und in feuchten Gebüschen vereinzelt. IIinsichtlich der Verbreitung genauer zu verfolgen. Hauptart am Neckar zwischen Schlierbach und Nechargemünd! Variet. im Neckarauer Walde (Schimp.), am Fusse des Gebirges zwisehen Rohrbach und Leimen (Döll). April.

f) Capreac Foch; Iï̈tzchen kurz gestielt, vor den Bl. sich entwickelnd; Deckbl. an der Spitze gefärbt; Antheren nach dem Verblühen gelb; Kapseln gestielt:

835. S. cinerea $L$. Graue W.; Jïngere Zweige u. Inospen graufilzig; Bl. elliptisch oder lanzettl.-rerkehrt-eiförmig, spitz, ganz-randig oder wellig-gesägt, oberseits weichhaarig, unterseits graugrünfilzig; Nebenbl. nierenf.; Deckbl. zottig, an der Spitze braunschwarz; Kapseln eilanzettl., filzig, mit kurzem Griffel und gespaltenen Narben; Kapselstielchen $4 \mathrm{mal}$ so lang als die Perigondrüse. Strauch 6-12'. - Variirt:

B) aquatica $\mathrm{Sm}$. ; Bl. rundlich-eiförmig, fast stumpf.

An Wegen, Ufern, in feuchten Gebüschen, auf Wiesen stellen-: weise häufig, jedoch nicht so allgemein verbreitet wie die folgende. März, April. 
836. S. Caprea $L$. Sahlweide; Knospen kahl; jüngere Zweige meist kahl oder spärlich behaart; Bl. rundlich oder elliptisch, zugespitzt, an der Spitze zurïckgebogen, wellig-gekerbt, oberseits meist kahl, unterseits graufilzig; Nebenbl. nierenförmig; Deckbl. an der Spitze braun-schwarz; Kapseln ei-pfriemlich, filzig, mit kurzem Griffel u. gespaltenen Narben; Kapselstielo 4-6mal so lang als die Perigondrüse. †. $15-20^{\prime}$.

An Wegen, in Gebüschen, lichten Wäldern, auch im Gebirge häufig, an sumpflgen Stellen zuweilen kleine Bestände bildend. März, April.

837. S. aurita $L$. Salbei-W.; Knospen kahl, röthlich, jüngere Zweige fast kahl; Bl. verkehrt-eifürmig, am Grunde keilig, kurz zugespitzt, kaum zurückgebogen, etwas gesägt, unterseits runzelig, blaugrün filzig; Nebenbl. nierenf.; Deckbl. zottig, an der Spitze braunroth; Kapseln lanzettl., fllzig; Griffel sehr kurz, Narben ausgerandet; Kapselstiel 3-4mal länger als die Perigondrüse. Strauch 2-8'. - Variirt mit kleineren und grösseren Bl.

Auf feuchten Wiesen, in Sümpfen, an Waldrändern der Geb. und der Ebene nicht selten. Die kleinbl. Form vorherrschend; die grossbl. Form in lichten, feuchten Waldgebüschen, z. B. bei Waghäusel! Neckarau! April.

838. S. nigricans Fries. Schwarzwerdende W.; Zweige und Knospen weiss-grau behaart; BI. längl. oder eiförmig, spitz, wellig-gesägt, oben kahl, unten dünn grauhaarig, endlich kahl werdend; Nebenbl, halb herzförmig; Kapseln eirund-pfriemlich, lang gestielt; Stiel $2-3 \mathrm{mal}$ so lang als die Perigondrüse; Griffel sehr lang; Narben 2spaltig. Strauch 8-12'. Bl. beim Trocknen schwarz werdend.

In Gebüschen am Rheinufer bis Mannheim! Im Geb. d. Flora nur sporadisch und ohne sicheren Standort. [Jenseits des Rheines bei Ludwigshafen!] April, Mai.

839. S. repens $L$. Kriechende W.; Bl. eiförmig oder lanzcttl., spitz, am Rande umgebogen, ganzrandig oder entfernt drüsiggezähnt, unterseits grau seidenhaarig; Nebenbl. lanzettl.; Kapseln eifürmig-lanzettl., meist filzig, kurz gestielt; Stiel 2-3mal länger als die Perigondrüse; Griffel kurz; Narben gespalten. Strauch 1-3', niederliegend oder aufsteigend; Bl. in Form und Behaarung sehr veränderlich.

B) argentea; Bl. breit-oval, beiderseits weissgrau-seidenhaarig.

Auf sandigen Haiden, in Torfmooren, in lichten Nadelwäldem selten, z. B. bei Sandtorf! Waghäusel! April, Mai.

SCHMiDT, Flora $\mathrm{r} . \mathrm{H}$. 
[Hz̈ufger jenseits des Rheines, z. B. bei Maxdorf! Speyer (auf d. Ganerben) F. Sch.]

(Diese Art erzeugt mit S. aurita zuweilen die Bastardfnem:

S. ambigua Ehrh.; Bl. elliptisch oder eirund, zurückgekrümmt, unterseits runzelig-aderig, zottig-seidenhaarig; Nebenbl. halb eiförmig, spitz; Kapsel eirund-lanzettlich, filzig, lang gestielt; Griffel kurz; Narben gespalton. - Im Habitus der S. aurita näher stehend. Stets in Gesellschaft der beiden Stammarten. Hinsichtlich des Vorkommens im Geb. d. Flora (bei Waghäusel? Sandtorf?) zweifelhaft.

\section{Populus $L$. Pappel.}

a) Knospen nicht klebrig; Deckbl. mehr oder weniger gewimpert; Stbgef. 8.

840. P. alba $L$. Silber-P.; Zweige und Knospen weissfilzig; Bl. herzförmig-rundlich, ausgeschweift gezähnt, unterseits weissfilzig, die jüngeren gelappt; Deckbl. der weibl. Kätzchen elliptisch, gekerbt, fein gewimpert. . $40-60^{\prime}$.

In feuchten Wäldern am Rheinufer, z. B. bei Ketsch! Wághäusel! Neckarau! beim Rohrhof! März, April.

P. canescens $S m$. Weissgraue P.; Zweige und Knospen graufilzig; Bl. eirundlich, ausgeschweift gezähnt, unterseits meist graufilzig, seltener kahl, dio jüngeren nicht gelappt; Deckbl. tief geschlitzt, gewimpert. \$ $40-60$ '.

Cultivirt. März, April.

841. P. tremula $L$. Zitter-P.; Zweige und Knospen kahl; Bl. fast kreisrund, ungleich buchtig-gezähnt, beiderseits fast kahl; Blattstiele stark zusammengedrückt; Deckbl. handförmig-zerschlitzt, gewimpert. Meist strauchartig bis $12^{\prime}$. - Variirt seltener mit in der Jugend etwas behaarten Zweigen und

$\beta$ ) sericea Döll; Bl. beiderseits seidenartig-filzig.

In Wäldern, Gebüschen, an Ufern häufig. März-April.

b) Knospen klebrig; Deckbl. nicht gewimpert; Stbgef. 12-30.

842. P. nigra $L$. Schwarz-P.; Zweige abstehend, wie dio Knospen kahl; Bl. dreieckig-eiförmig, zugespitzt, gesägt, kahl. † bis $50^{\prime}$.

An Wegen, Ufern, in Dörforn hie und da. März, April.

P. pyramidalis Rozier. Italien is che P.; Zweige anliegend, pyramidenförmig, wie die Knospen kahl; Bl. rautenförmig, zugesp., drüsig-gesägt, kahl. $\hbar$ bis $100^{\prime}$. - Im Gebiete der Flora sind nur mïnnl. Exemplare beobachtet. (P. dilatata Ait.)

Wahrschoinlich aus Persien stammond, häufig cultivirt. April. (Off.: Gemmae Populi.) 


\section{Class. II. \\ G Y II N O S P E B II A E.}

(Nacktsamige Pflanzen.)

Pflanzen ohne Pistille und daher ohne wahre Früchte. Samenknospen (Eichen) völlig nackt, d. h. nicht eingeschlossen in Fruchtknoten, entweder ganz frei an der Spitze einer Blïthenaxe oder öfter am Grunde blattartiger Schuppen, welche sich zu Zapfen oder falschen Beeren vereinigen. Der Blüthenstaub gelangt unmittelbar (d. h. ohne Mitwirkung eines der Narbe ähnlichen Organs) zu den Samenknospen. Keimblätter oft mehr als 2.

\section{CONIFERAE Juss.}

Bäume oder Sträucher mit verzweigten Stämmen, meist nadelförmigen, bald einzeInen, bald büscheligen Blättern. Blüthen monoecisch oder dioecisch, ohne Perigon. MIünnl. Blth. kätzchenartig gruppirt, aus 1-mehreren, oft monadelphischen Staubgef. bestehend. Antheren 2-mehrfächerig, meist an der Spitze von dem schuppen- oder schildförmigen Mittelbande (Connectiv) üherragt. Weib). Blth. (nämlich die nackten Samenknospen) meist am Grundle von dachziegeligen Deckschuppen umgeben, welche bei der Reife saftig odler holzig werden, und sich zu Zapfen oder Scheinbeeren vereinigen. (Seltener, z. B. bei der nicht einheimischen Taxus stehen die Samenknospen ganz frei, einzeln, endständig auf schuppigem - oder scheibenartigem Samentrïger). Samen meist trockenschaalig, zuweilen von flügelartigem oder saftigem Anhange umgeben, eiweisshaltig, mit 2 oder mehreren Keimblättern. - Die Coniferen (Nadelhülzer) secerniren Harz in allen Organen. Das Holz, welches aus 
sog. getüpfelten Holzzellen besteht, ist ausgezeichnet durch den fast gänzlichen Mangel aller Gefässe, indem nur in der Markscheide einige Spiralgefässe sich finden.

Juniperus. Dioecisch; Antheren 3-7fächerig, mit schildförmiger Ausbreitung des Staubfaden-Mittelbandes (Connectiv); Samen zu 3 in scheinbeerartigen Fruchtständen (Beerenzapfen); Samenlappen 2.

Pin us. Monoecisch; Antheren 2fächerig, mit schuppenförmiger Ausbreitung des Staubfaden-Mittelbandes; Samenschuppen zu holzigen Zapfen verwachsend, jede Schuppe am Grunde mit 2 geflügelten Samen; Samenlappen viele.

\section{5l. Juniperus $L$. W a chholder.}

843. J. communis $L$. Gem. W.; Nadeln 3ständig, lineal, pfriemlich, stechend, immergrün; männl. Kätzchen klein, achselständig; Beerenzapfen kugelig, aufrecht, im zweiten Jahre reifend, dann blauschwarz bereift. $\$ 2-4^{\prime}$.

In trockenen Wäldern, auf Haiden, Sandđächen, sonnigen Hügeln, sowohl der Ebene als der Gebirge häufig! April, Mai. (Off.: Lignum et Bacc. Juniperi.)

\section{P inus $L_{\text {. }}$ T a nne.}

a) Nadeln büschelig; immergrün; samentragende Deckschuppen an der Spitze verdickt, bleibend, am Grunde innen ausgehöhlt; Flügel der Samen abfallend; männl. Kätzchen gipfelst.; Antheren der Länge nach aufspringend.

844. P. sylvestrís $L$. Kiefer, Föhre; Nadeln gezweiet, starr, graugrün, oberseits rinnig; Zapfen eiförmig-kegelig, abwärts gekrümmt. $\hbar$ v. $50-80^{\prime}$, mit braunrother, abblätternder Stammrinde.

Auf Sandboden der Ebene stellenweise gesellig, im Gebirge hio und da, oft nur einzeln. Mai. Samenreife im Herbst des 2. Jahres. (Off.: Turiones Pini, Resina Pini etc)

P. Strobus $L$. Weymuthkiefer; Nadeln zu 5, 3kantig, lang, biegsam, hellgrün; Zapfen walzig, sehr locker (jedoch bei uns meist nicht zur Ausbildung kommend). $\hbar$ von $10-40$.

Aus Nordamerika stammend, hie und da cultivirt. Mai, Juni.

b) Nadeln büschelig, einjährig, samentragende Deckschuppen an

d. Spitze verdünnt, bleibend, am Grunde innen ausgehöhlt ; Flügel der Samen bleibend; männl. Kätzchen gipfelständig auf verkürzten Aestchen; Antheren der Länge nach aufspringend.

P. Larix $L$. Lärche; Nadeln zahlreich, fast flach, biegsam, 
hellgrün; männl. Kätzchen kurz, aus becherförmigen Scheiden hervortretend; Zapfen eiförmig, aufrecht, anfangs purpurroth. \$ von $20-60^{\prime}$.

Cultivirt; hie und da, besonders in Gebirgswäldern verwildert und stellenweise kleine Bestände bildend. April, Mai. Samenreife im Herbst des 1. Jahres. (Off.: Terebinthina laricina.) *

c) Nadeln einzeln, immergrün; samentragende Deckschuppen an der Spitze verdünnt, am Grunde innen ausgehöhlt, abfallend; Flügel der Samen bleibend; männl. Kätzchen achselständig, einzeln; Antheren der Länge nach aufspringend.

845. P. Abies Duroi. Edeltanne, Weisstanne; Nadeln 2zeilig, flach, ausgerandet, unterseits mit 2 weissen, vertieften Längslinien; Zapfen walzig, aufrecht, mit ganzrandigen, stumpfen Deckschuppen. \$ ron $80-150^{\prime}$. (P. Picea L., Abies pectinata DC.)

In den Gebirgswäldern, besonders längs der Bergstrasse hio und da. Mai. Samenreife im Herbst des 1. Jahres.

d) Nadeln einzeln, immergrün; samentragende Deckschuppen an der Spitze verdünnt, am Grunde nicht ausgehöhlt, abfallend; Flügel der Samen bleibend; männl. Kätzchen achselständig einzeln; Antheren der Queere nach aufspringend.

846. P. Picea Duroi. Roth-Schwarztanne, Fichte; Nadeln fast 4kantig zusammengedrückt, stachelspitzig; Zapfen walzig, hängend, mit an der Spitze unregelmässig-gezähnten Deckschuppen. ந von 70-120'. (P. Abies L., Abies excelsa DC.)

In Gebirgswaldungen hie und da. Mai. Samenreife im Herbst des 1. Jahres. (Off.: Terebinthina oommunis.) 


\section{Series II.}

\section{MONOCOTYLEDONEAE.}

\section{(Einkeimblätterige Pflanzen.)}

Stengel mit zerstreut stehenden Gefässbündeln, ohne scharfe Sonderung von Rinde, Holz und Mark, ohne Markstrahlen. Blätter mit wenigen Ausnahmen parallel- oder bogig-geadert. Blüthentheile mit vorherrschender Dreizahl. Keim mit einem scheidenartigen Keimblatte (selten keimblattlos). - Die einheimischen Arten sind Kräuter mit meist einfachen, am Grunde scheidenförmigen Blättern. Die Blthdecken sind zwar häuflg vollständig ausgebildet, aber meist perigonartig, sehr selten durch Farbe und Textur gleichsam in Kelch und Blumenkrone gesondert, oft aber auch sehr verkümmert oder fehlend.

\section{HYDROCHARIDEAE D.C.}

Wasserpflanzen mit meist schwimmenden Blättern, dioecischen, von einer $1-2$ blätterigen Scheide während der Knospung eingeschlossenen, regelmässigen, oberständigen Blüthen. Kelch 3 blätterig, grün. Blkr. 3blätterig, weiss. Stbgef. 3viele, epigynisch. Fruchtknoten 1-mehrfächerig, vieleiig, mit wandständigen Samenträgern und 3-6 Griffeln. Frucht kapselartig, etwas saftig, vielsamig. Samen eiweisslos, mit geradem Keim.

Hydrocharis. Scheide 2blätterig; männl. Blth.: Stbgef. 9 , mit 3 unfruchtbaren Nebenstaubf.; weibl. Blth.: Griffel 6, 2spaltig, mit 6 unfruchtb. Nebenstaubf.; Kapsel 6fächerig. 


\section{3ǎ3. Mydrocharis $L$. Frosehhiss.}

847. H. Morsus ranae $L$. Ge m. F.; St. schwimmend, verlängert, mit fadenfürmigen Ausläufern; Bl. gestielt, herzförmig-kreisrund, ganzrandig, etwas lederartig, schwimmend, unterseits röthlich, oberseits grün; Blth. achselständig, lang gestielt. 2. Blkr. weiss.

In Gräben, Sümpfen der Ebene, besonders in der Nähe des Rheines häufg, z. B. bei Neckarau! Ketsch! Sandtorf! Waghäusel! u. s. w. Juli, August.

\section{ALISIIACEAE Juss.}

Sumpfpflanzen mit blattlosem Schaft, scheidenförmigen Blättern, quirlständigen zwitterigen oder monoecischen Blüthen. Kelch und Blkr. 3gliederig, unterständig. Stbgef. 6 zahlreich, hypogynisch. Fruchtknoten 3 oder Wiederholung von 3 , einfächerig, mehr oder weniger mit einander verwachsen, jeder mit 1 Griffel, 1-2eiig. Früchte nussartig, kreisförmig gestellt. Samen eiweisslos, mit gekrümmtem Keim.

Alisma. Zwitterig; Stbgef. 6; Nüssch. um eine centrale Achse sitzend.

Sagittaria. Monoecisch; Stbgef, zahlreich; Nüsschen auf kugeligem Fruchtboden.

\section{Alisma $L$. Froschlöffel.}

848. A. Plantago L. Gem. F.; Bl. grundständig, kahhl, eirund oder eirund-länglich, spitz, lang gestielt; Schaft aufrecht; Blth. in quirligen Trauben; Nüssch. zusammengedrückt, abgestumpft, 12rippig. 4. $\frac{1}{2}-3^{\prime}$. Blkr. weiss oder rosa. - Variirt:

B) lanceolatum; Bl. schmal lanzettlich.

v) graminifolium; Bl, schwimmend, lineal-lanzettlich, mit sehr verlängerten Stielen.

In Gräben, Teichen, Sümpfen, an Dfern häufig! Var. $\beta$ an ausgetrockneten Sümpfen: am Neckarufer mit Uebergängen zur Hauptform. Var. $\gamma$ in stehenden tieferen Gewässern, in Torfsümpfen, z. B. bei Sandtorf! Neckarau! Juni-September. 


\section{Sagittaria $L$. P feilkraut.}

849. S. sagittaefolia L. Gem. P.; St. verkürzt; 13I. grundständig, lang gestielt, pfeilförmig, die untergetauchten lanzettlich; Schaft mit gipfelst., quirlig-traubigen Blüthen, die oberen weiblich, die unteren männlich. Blkr. weiss, mit violettem Grunde; St. mit langen weissen Ausläufern.

In Gräben, Flüssen, Sümpfen, theils im Wasser und dann mit schwimmenden Blättern, theils im Schlamm mehr od. weniger ausserhalb des Wassers mit aufgetauchten Blättern, hie und da häufig, z. B. in dor Nähe des Rheines, bei Neckarau! Sandtorf! Ketsch! Waghäusel! seltener im Neckar, z. B. beim Haarlass! unterhalb der Bergheimer Mühle! bei Ladenburg! Juni-August.

\section{BUTOMEAE Rich.}

Sumpf- oder Wasserpflanzen mit grundständigen Blättern. Blüthen regelmässig, zwitterig. Perigon unterständig, 6theilig. Stbgef. hypogyn. Fruchtknoten $3-6-$ mehrere, 1fächerig. Eichen zahlreich, an einem netzförmig-iistigen, die innere Fläche ganz einnehmenden Samenträger. Früchtchen balgkapselartig, kreisförmig gestellt, vielsamig. Samen eiweisslos, mit geradem oder gekrümmtem Keim.

Butomus. Stbgef. meist 9; Balgkapseln 6, am Grunde verbunden.

356. Butomus $L$. Wasserviole.

850. B. umbellatus $L . G e m . W . ; B l$ grundst., lineal, schilfartig, unten 3kantig, kürzer als der doldentragende Schaft, 4. Blth. rosa; Wzst. horizontal, fleischig. $1 \frac{1}{2}-2 \frac{1}{2}^{\prime}$.

An Ufern, in Sümpfen, Gräben hie und da, z. B. am Neckarufer stellenweise: Schlierbach! Neuenheim! unterhalb der Bergheimer Mühle! Ladenburg! ziemlich verbreitet zwischen Kirchheim und St. Ilgen! bei Roth! in den Sümpfen der Rheinfläche! Juni-August.

\section{JUNCAGINEAE Rich.}

Sumpfpflanzen mit schmalen linealischen Blättern. Blüthen regelmässig, zwitterig. Perigon unterständig, 6gliederig, 
krautartig. Stbgef. 1-6, hypogynisch. Frachtknoten $3-5$, kapselartig, mehr oder weniger verwachsen, mit eben so vielen meist sitzenden Narben und aufrechten Eichen. Früchtchen $3-6$, kapselartig, nur am Grunde oder völlig mit einander verwachsen, bei der vollständigen Reife sich aber trennend, Samen eiweisslos, mit geradem Keim.

Scheuchzeria. Perig. bleibend; Stbgef. 6; Fruchtknoten 3-6, am Grunde zusammengewachsen; Narben sitzend, weichhaarig; Kapseln aufgeblasen, abstehend.

Triglochin. Perig. abfallend; Stbgef. 6; Fruchtknoton 3-6, der ganzen Länge nach durch einen centralen Fruchtträger zusammengehalten, zuletzt vom Grunde aus sich lösend; Narben sitzend, fiederig; Kapseln 3kantig.

Scheuchzeria $L$. S che uchzerie.

S. palustris $L$. Sumpf-S.; St. aufrecht, armblätterig; Bl. meist grundständig, schmal lineal, steif, etwas fleischig; Traube armblüthig; Früchtch. aufgeblasen. 4. 3-8". Blth. gelb-grünlich.

Auf sumpfigen Torfwiesen bei Waghäusel (König), aber wahrscheinlich jetzt durch den Torfstich verschwunden, daher für diø Flora vorläufig unsicher.

[Würde der einzige Standort im Geb. und in der Nähe desselben sein. N. V. nach F. Schultz: Kaiserslautern.]

\section{5\%. Triglochin $L$. D reiz a ck.}

851. T. palustre L. Sumpf-D.; Bl. grundständig, schmal lineal, pfriemlich; Blth. in fadenförmigen, endständigen Aehren, Früchte linealisch, aus 3 Kapseln bestehend, an die Spindel angedrückt. 4. 1'. Blth. röthlich-grün.

Auf nassen Wiesen, in Torfsümpfen hie und da, meist gesellig, z. B. bei Waghäusel! Sandtorf! St. Ilgen! Roth! Juni-August.

[T. maritimum $L . ;$ dem vorigen ähnlich, in allen Theilen etwas grösser; Früchte eiförmig, aus 6 Kapseln bestehend, abstehend. 4. $1 \frac{1}{2}^{1}$.

[N. V. a. d. Geb.: z. B. in Rhb. mit d. vorigen an den Salinen bei Dürkheim: Juni-August.]

\section{POTAMEAE Juss.}

Untergetauchte oder schwimmende Wasserpflanzen mit kleinen, unscheinbaren, in Aehren gestellten, zwitterigen oder 
monoecischen Blth. Perigon fehlentl. Stbgef. $1-4$ bodenständig. Antheren 2fächerig, meist von einer perigonähnlichen Ausbreitung des Mittelbandes überragt. Fruchtknoten meist 4, eineiig, mit sitzenden Narben. Früchte steinfruchtartig. Samen eiweisslos, mit hakenförmig gekrümmtem oder spiraligem Keim.

Potamogeton. Blth. zwitterig; Stbgef. 4; Antheren-Mrittelband beträchtlich erweitêrt und fast ganz von den Fächern abgelöst; Fruchtknoten 4; Keim gekrümmt.

Zannichellia. Blth. monoec.; männl.: Stbgef. 1, mit schmalem, d. Antherenfächer verbindendem Mittelbande; weibl.: Fruchtknoten 4, von einer zarten Deckblattbildung umschlossen.

\section{Potam ogetou $L$. La i chkraut.}

1. B1, abwechselnd (die oberen zuweilen gegenst.); Nebenbl, frei.

a) Bl. eirund oder lanzettlich.

852. P. natans $L$. Schwimmendes L.; St. meist einfach; Bl. lang gestielt, glattrandig, die oberen schwimmend, eilänglich, lederartig, die untergetauchten lanzettl.; Aehren walzig, an langen, gleichmässig dicken Stielen; Früchte zusammengedrückt, mehr oder weniger stumpfrandig. - Variirt:

$\beta$ ) fuitans Roth; St. fluthend, auch die schwimmenden Bl. lïnglich-lanzettlich; Früchtch. etwas scharfkantig berandet.

In stehenden und fliessenden Gewässern nicht selten. Var. $\beta$ nur in rasch fliessenden Flüssen oder Bächen, z. B. häufig am Neckar zwischen $\mathrm{H}$. und der Bergheimer Mühle! auch zwischen $\mathrm{H}$. und Ziegelhausen, aber weniger häufig! Juni-August.

853. P. plantaginea Ducros. St. meist ästig, kriechend; Bl. gestielt, dünnhäutig, zierlich netzaderig, glattrandig, schwimmende eirund oder elliptisch, untergetauchte spatelf.-lanzettl.; Aehren walzig, auf gleichmässig dicken Stielen; Früchtch. zusammengedrüekt, stumpfrandig (kleiner als bei d.vorigen.) 4 . Bl. bräunlich-grün, meist sehr hinfällig. (P. coloratus Hornem, P. Hornemanni Meyer).

In den Torggräben bei Waghäusel gesellig, sowohl im Graben neben der Chaussee nach Neu-Lussheim, als auch weiter im Moor gegen Rheinhausen! [Einziges Vorkommen im Gebiet und in der Nähe desselben. N. V.: Flora von Mainz (Schnttsp.)]. Juni, Juli.

854. P. Iucens $L$. Spiegelndes L.; St. ästig; Bl. alle untergetaucht, gestielt, häutig durchscheinend, stark glänzend, eiförmig, melir od. weniger stachelspitzig, fein gesägt od. ganzrandig; Neben- 
blätter geflïgelt; Achren gedrängt, reichblüthig, auf verlängerten, oben verdickton Stiolen; Früchtchon zusammengedrückt, stumpfrandig. 4.

In Sumpfgräben, Teichen, auch in langsam fliessenden Gewässern hie und da, oft sehr gesellig, z. B. bei Neckarau! Sandtorf! Waghäusel! Brühl! überhaupt in der Nähe des Rheines. [Auch jenseits des Rheines hie und da in grosser Menge, z. B. bei Ludwigshafen! Oggersheim!] Juni, Juli.

855. P. rufescens Schrad. Rötbl. L.; St. fast einfach; Bl. untergetaucht, sitzend oder in den kurzen Blattstiel verschmälert, verlängert-lanzettlich, stumpf, glattrandig, moist etwas lederartig; Nebenbl. ungeflügelt; Aehren walzig, auf gleichmässig dicken Stielen; Früchtchen eiförmig-zusammengedrückt, scharfrandig. 2. Blätter bräunlich-grün.

In Torfgräben bei Sandtorf (Schimp.), als einziger Standort im Gebiet [jedoch auf der Rheinfläche stellenweise in Rhb. und Hs. Juli, August.

856. P. perfoliata $L$. Durch wa chsenes L. ; St. ästig, stielrund; BI. alle untergetaucht, eiförmig-rundlich, stumpf, am Grunde herzförmig-stengelumfassend; Aehren walzig, auf kurzen, gleichmässig dicken Stielen; Früichtchen rundlich-zusammengedrückt, kurz geschnäbelt. 4.

In stehenden und fliessenden Gewässern häufig, meist gesellig. In der Nähe von H., z. B. am Neckar unterhalb der Bergheimer Mühle in grosser Menge! Mai-Juli.

857. P. crispa $L$. K rauses L.; St. ästig, zusammengedrückt; Bl. alle untergetaucht, durchscheinend, etwas steif, halb stengelumfassend, länglich, kurz zugespitzt, am Rande wellig-kraus, fein gesägt; Aehren locker, armblïthig, auf kurzen, gleichmässig dicken Stielen; Früchtchen zusammengedrückt, geschnäbelt. 4.

In Sümpfen, Torfgräben, Teichen nicht selten, z. B. im Kirchheimer See! beim Rohrhof! in Menge bei Neckarau! Waghäusel! Sandtorf! Juni, Juli.

b) Bl. lineal, grasartig, am Grunde durch die verwachsenen Nebenblätter den Stengel scheidig umfassend.

858. P. pectinata $L$. Fadenblätt. L.; St. fadenförmig, ästig, zusammengedrückt; Bl. alle untergetaucht, häutig, schmal lineal, zugespitzt, 1nervig; Aehre locker, fädlich, gestielt; Früchtch. zusammengedrückt, rundlich, an den Seiten mit 2 Streifen. 4 . ( $P$. marinum Gmel.)

In stehenden und fliessenden Gewässern hie und da, aber wenig blühend. An den schlammigen Neckarufern unterhalb Neuenheim und boim Haarlass! bei Neckarau! Waghäusel ( $F$. sch.) Juli, Aug. 
c) Bl. lineal, grasartig; Nebenbl, frei.

859. P. pusilla $L$. Kleines L.; St. ästig, ausgebreitet, fast stielrund; Bl. alle untergetaucht, sitzend, dünnhäutig, schmal lineal, zugespitzt, 3-5nervig; Aehre armblüthig, langgestielt; Früchtchen zusammengedrückt, stumpf gekielt, kurz geschnäbelt. 4. - Variirt:

$\beta$ ) tenuissima M. et $\mathrm{K}$; $\mathrm{Bl}$. sehr fein, haarförmig, meist 1nervig.

In stehenden und langsam fliessenden Gewässern nicht selten, meist sehr gesollig, z. B. bei Waghäusel! Roth! Sandtorfl am Wolfsbrunnen bei H. (Döll). Die Var. beim Relaishause (Döll). Juli, August.

d) Bl, verschieden gestaltet; Nebenbl. frei.

860. P. graminea $L$. Grasblättr. L.; St. ästig; untergetauchte Bl. dünnhäutig, linien-lanzettfürmig, sitzend, am Rande schärffich, die oberen schwimmend, lanzettl. oder elliptisch, lang gestielt, lederartig; Aehren walzig, auf etwas verdickten Stielen; Früchte rundlich, etwas zusammengedrückt, stumpf gekielt, kurz geschnäbelt. 4. (P. heterophyllus Schreb.). - Variirt:

a) graminifolia Fries; Bl. alle untergetaucht, lanzettlichlineal, an beiden Enden verschmälert.

$\beta$ ) heterophylla Fries; untergetauchte BI. linienförmig, starr, etwas zurückgekrümmt, schwimmende lang gestielt, länglich-lanzettl. oder elliptisch, etwas krausrandig.

In stehenden und langsam fliessenden Gewässern in der Nähe des Rheines stellenweise, in unserm Gebiet aber noch weiter zu verfolgen. Var. $\alpha$ und $\beta$ bei Rheinhausen, unfern Alt-Lussheim. Var. $\beta$ in Wasserlöchern des Käferthaler Waldes ( $D$ öll). Juli, August.

2. BI. alle gegenständig; Nebenbl. fehlend.

861. P. densa $L$. Dichtblättr. L.; St. kurz, wenig ästig; Bl. alle untergetaucht, durchscheinend häutig, halb stengelumfassend, eilanzettl., gedrängt; Aehre kurz gestielt, achselständig, armblüthig, später zurückgebogen; Früchtchen rundlich zusammengedrückt, geschnäbelt. 4.

In stehenden Gewässern, besonders in den Sümpfen längs des Rheines. Hinsichtlich der Verbreitung noch unsicher. Am Relaishause (Döll). Juli, August.

\section{Zannichellia $L$. Zannichellia.}

862. Z. palustris $L$. S umpf-Z.; untergetaucht; St. fädlich ästig, kriechend; Bl. lineal-pfriemlich, gegenständig; Blth. achselständig, sitzend, sehr klein, über dem Wasser blühend; Früchtchen kurz gestielt, länglich, mit kurzem Griffel. 4. 
In stehenden und langsam fliessenden Gewässern, besonders in Sümpfen in der Nähe des Rheines hio und da, aber am diesseitigen Ufer, wie es scheint, seltener, z. B. zwischen Ketsch und Rheinhausen. [Jenseits des Rheines zuweilen häufig, z. B. in Sümpfen bei Oggersheim! bei Roxheim!] Juli, August.

\section{NAJADEAE $L k$.}

(Mit Berücksichtigung der nur allein vorkommenden Gattung Najas.)

Untergetauchte Wasserpflanzen. Blth. monoec. od. dioec., achselst., ohne Perig., von einer scheidenartigen Hülle umgeben, welche beim Aufblühen zerreisst. Antheren fast sitzend, 4fächerig. Fruchtknoten 1fächerig, 1eiig, mit $2-3$ Narben. Früchte nussartig, von der bleibenden scheidenartigen Umhüllung eingeschlossen. Samen eiwcisslos, mit geradem Keim.

\section{Najas $L$. Najade.}

863. N. major Roth. Grosse N.; St. ästig; Bl. fast gegenständig, lineal, ausgeschweift stachelspitzig gezähnt; Blattscheiden ganzrandig; Blth. dioecisch. $\odot$.

In stehenden und fliessenden Gewässern, z. B. in Sumpfgräben bei Neckarau, besonders gegen Mannheim! Juli-September. [In den Altwassern des Rheines von Mundenheim bis Worms stellenweiso häufig, z. B. in grosser Menge bei Roxheim!]

864. N. minor All. Kleine N.; St. ästig; Bl. lineal fädlich, stachelspitzig gezähnt, zurückgebogen; Blattscheiden wimperartig gezähnelt; Blth. monoecisch. $\odot$.

In stehenden und langsam fliessenden Gewässern, mit d. vorigen bei Neckarau. Juli-September. [Wie die vorige im Alt-Rhein zwischen Ludwigshafen und Worms, besonders bei Friesenheim und Roxheim []

\section{LEMNACEAE $L k$.}

Sehr kleine schwimmende Wasserpflanzen mit platten, blattähnlichen Stengeln. Diese aus 2-mehreren sehr verkürzten Gliedern zusammengesetzt, aus deren Rändern die 
Blüthen hervorgehen. Aus den Stengelgliedern éntwickeln sich nach Unten Wurzelfasern, deren Ende mit einer verlängerten schwammigen Wurzelhaube versehen ist. Blüthen unscheinbar, von einer unregelmässigen, dünnhäutigen Scheide umgeben, zwitterig, olıne Perigon. Staubgef. 2, mit 2fücherigen Antheren. Fruchtknoten 1-mehreiig, mit kurzem oder fehlendem Griffel und unregelmässig gezähnelter Narbe. Früchtchen nussartig, meist 1samig. Samen mit geringem Eiweiss und geradem Keim.*)

361. Le mua $L$. Wr a s sęr linse (einzige Gattung).

a) Fruchtknoten 1eiig; Staubfälen fadenfürmig.

865. L. minor $L$. Kl leine W.; Stengelglieder verkehrt eifürmig, beiderseits fast flach, stiellos; Wurzeln einzeln. ๑. Antheren gelb.

In stehenden, Ġewässern, Teichen, Gräben, auf dem Wasser schwimmend, sehr verbreitet, aber selten bluhend! Mai-August.

866. L. trisulca $L$. Gekreuzte W.; Stengelglieder lanzettl., an der Spitze ausgeschweift gezähnt, kreuzweise gestellt, am Grunde gestielt; Wurzeln einzeln. ๑.

In stehenden Gewässern untergetaucht, schr hättfig, aber sehr selten blühend. Juni-August.

\section{b) Fruchtknoten 2-mehreiig.}

867. L. gibba L. IIöckerige W.; Stengelglieder rundlichverkehrteiförmig, unterseits deutlich schwammig-convex, sehr kurz gestielt (fast stiellos); Stbfäden in der Mitte breiter; Wurzeln einzeln. ๑. (Telmatophace gibba Schleid.)

In stehenden Gewässern, auf dem Wasser schwimmend hie und da, z. B. beim Rohrhof! in den Sümpfen des Friedrichsfelder Waldes! bei Neckarau! in Sümpfen des Mühlenthales bei Handschuchsheim! Blüht ebenfalls selten von Juni-August.

868. L. polyrrhiza $\boldsymbol{L}$. Vielwurzelige W.; Stengelglieder rundlich-verkehrteifürmig, beiderseits fast flach, stiellos; Stbfäden am Grunde verdünnt; Wurzeln büschelig. ๑. (Spirodela polyrrhiza Schld.)

In stehenden Gewässern häufig, theils einzeln, theils gesellig, auf dem Wasser schwimmend, blüht sehr selten. Mai-Juli.

") L. minor und yibba sind anatomisch durch den Mangel der Gefässbündel ausgezeichnet. Bei L. trisulca und polyrrhiza lassen sich Spiralgefässo nachweisen. 
Typhaceae.

303

\section{TYPHACEAE Juss.}

Ausdauernde Wasserpflanzen mit linealen ganzrandigen Blättern und sehr entwickelten Blattscheiden. Blüthen eingeschlechtig, monocc., in kolben- oder kopfförmigen Aehren, die oberen männlich, die unteren weiblich. Perigon sehr unentwickelt, aus mehreren unterständigen Fäden od. Schuppen bestehend. Stbgef. einfach oder 2-3spaltig, an jeder Spitze eine 2fächerige Anthere tragend. Fruchtknoten frei, 1eiig. Eichen hängend. Griffel 1, mit verlängerter, zungenförmiger Narbe. Frucht nussartig, von einer schlauchartigen Hülle umschlossen. Samen eiweisshaltig. Keim gerade.

T урhа. Kolben verlängert; Perig. borstenförmig; Stbgef. 1, mit 2-3 Antheren; Fruchtknoten auf stielartig verlängertem Fruchtboden; Fruchthülle bei der Reifo zerreissend.

Sparganium. Köpfchen zahlreich, kugelig; Perig. schuppig; Stbgef. 3; Fruchtknoten sitzend; Fruchthülle bei der Reife nicht zerreissend.

\section{Typha $L$. Rohrkolben.}

869. T. latifolia L. Breitblättr. R.; St. breit linealisch, flach, schilfartig, länger als der Blüthenschaft; Kolben endständig, männl. und weibl. Blüthen einander genähert. 4. 3-4'. Weibl. Kolben braun.

In Sümpfen, an Flussufern, Teichen, hie und da, besonders in der Nähe des Rheines. Juli, August.

870. T. angustifolia $L$. Schmalb I. R.; Bl. schmal lineal, unten rinnenförmig, länger als der Schaft; Kolben endständig, etwas von einander entfernt. 4. 3-4'. Weibl. Kolben braun.

In Sümpfen, Torfgräben, Teichen hio u. da, seltener als vorige, z. B. beim Rohrhof! zwischen Kirchheim und St. Ilgen! bei Waghäusel! Sandtorf! Juni-August.

\section{S p a r g a n ium L. I gelkolben.}

871. S. ramosum Huds. A estiger I.; St. aufrecht; Bl. schmal lineal, am Grunde 3kantig, rinnig; Blthstand ästig; männl. Köpfch. $3-6$, viel kleiner als die weibl.; Narben lineal. 4. $1 \frac{1}{2}-2^{\prime} . \quad\left(S_{0}\right.$ erectum a $\mathrm{L}_{\text {. }}$ )

In Gräben, Sümpfen, an Flussufern, besonders in den Sumpfgegenden des Geb, verbreitet. Juni-August. 
872. S. simplex Huds. Einfacher I.; St. aufrecht, einfach; Bl. schmal lineal, am Grunde 3kantig, flach oder schwach gekielt; männl. Köpfchen 3-4, wenig kleiner als die weibl,; Narben lineal. 4. $1-1 \frac{1}{2}^{\prime}$. (S. erectum $\beta$ L.)

Mit dem vorigen stellenweise, zuweilen vorherrschend, im Ganzen aber seltener, z. B. bei Ketsch! Neckarau! zwischen Kirchheim und St. Ilgen; u. s. w. Juni-August.

873. S. minimum $C$. Bauhin. Kleinster I.; St. einfach, aufrecht; Bl. schlaff, linienförmig, flach, schwimmend oder niederliegend; Küpfchen sehr klein, meist nur $1-3$ weibl, und 1 männl.; Narben eiförmig-länglich. 4. 5-10". (S. natans $\beta$ minimum L., S. natans Aut. (non L.)

In Torfsümpfen, moorigen Gräben bei Sandtorf (Schimp.) Juli August.

[N. V. a. d. Geb.: Rhb.: Maxdorf, Kaiserslautern (F. Sch.); Hs.: Darmstadt (Schnttsp.)]

\section{AROIDEAE Juss.}

Ausdauernde Kräuter mit meist fleischigem Wurzelstock, sehr entwickelten Blattscheiden u. einfachem Blüthenschaft. Blthstand endständig, meist von einer ansehnlichen Scheide umgeben. Blüthen klein, auf Kolben vereinigt, entweder monoec. ohne Perigon, mit einzelnen Stbgef. und Fruchtknoten, oder zwitterig mit 3-5theiligem unscheinbarem Perigon, 6 Stbgef. und 1 Fruchtlinoten. Fruchtknoten frei, 1-mehrfächerig, 1-mehreiig, mit 1 Narbe. Frucht beerenarti,g saftig oder trocken, 1-mehrsamig. Samen eiweisshaltig, mit geradem Keim.

Arum. Monoec.; ohne Perigon; Kolben an der Spitze nackt, von einer tutenförmigen Scheide umgeben; Fruchtknoten am Grunde des Kolbens, die einzelnen Antheren ohne Staubfäden oberhalb der Fruchtknoten; Beeren 1samig, saftig.

A c orus. Zwitterig; Perigon unterständig, 6blätterig; Kolben ganz mit Blüthen bedeckt, mit sch»rertfürmiger Scheide; Stbgef. 6; Beeren trocken, mehrsamig.

\section{A r II I. A r 0 n.}

874. A. maculatum $L$. Gefleckter A.; Bl. grundständig, lang gestielt, spiess-pfeilförmig, kahl, glänzend, gefleckt oder un- 
gefleckt; Kolben 2-3mal kürzer als der Scliaft; Blthscheide den Kiolben überragend. 4. Wzst. knollig, eifürmig (giftig); Beeren dunkelroth. - Gefässbündel der Bl. verzweigt, als Anomalie des Monoc. 'Tspus.

In feuchten Laubwäldern, Gebüschen, besonders in der Nähe von H., z. B. Haarlass! Carmeliterwäldchen! häufig. Bei Weinheim! Leutershausen! Nissloch! Dielheim verbreitet. Auch in der Ebene zwischen Friedrichsfeld $u$. Waghäusel stellenweise nicht selten! Mai. (Off.: Rad. Ari.)

\section{A corus $L$. K a lmus.}

875. A. Calamus $L$. Gem. K.; B1. schwertförmig; Schaft blattartig, 2schneidig-zusammengedrüelt, an der inneren Seite rinnig, den walzenfürmigen Kolben überragend, 4. 2-4'. Wzst. wagerechtkriechend, geringelt, aromatisch; Blth. grünlich-gelb.

In Gräben, Teichen selten: Waghäusel! Vereinzelt in Sümpfen hci IIandschuchsheim, woselbst aber allmählig ausgerottet! JuniAugust.

[In den Alt-Wassern des Rheines ausserhalb d. Geb. stellenweise.] (Off.: Rad. Calami aromatici.)

\section{ORCHIDEAE Juss.}

Ausdauernde Krïuter mit bei uns sehr einfachen, ganzrandigen, kahlen, meist glänzenden Blättern, mit sehr entwickelten, scheidenförmigen Niederblättern, (sehr selten ohne Laubblïtter), hïufig am Grunde der Stengel mit sog. Scheinknollen. Blüthen unregelmässig. Perigon oberstïndig, 6 ğlielerig; in 2 Kreisen, meist gefürbt, 2lippig, die 3 Glieder les äusseren und die 2 seitlichen Glieder des inneren Kreises weniger abweichend gebildet, oft mehr oder weniger helmartig zusammenneigend, das dritte Glied des inneren Kreises dagegen stets sehr unregelmässig, die sog. Lippe (labellum) darstellend und oft gespornt. (Durch eine eigenthümliche Drehung des Fruchtknotens wird dieses innere Glied nach Aussen gekehrt). Stbgef. normal 3, wovon aber nur 1 oder selten (bei Cypripedium) 2 sich ausbilden, diese dem Grifiel dicht unter der Narbe aufgewachsen und 
mit demselben das sog. Befruchtungssiiulchen bildend ( $G y$ nandria). Antheren sitzend, meist 2fächerig, bald endständig, deutlich, bald mehr verdeckt durch die Ausbreitungen der Narbe. Die Pollen-Masse jedes Faches zusammenhängend, oft eigenthümlich gestielt und in klebrige Drüsen endigend. Diese Drüsen sind bisweilen in eine häutige Faite (Beutelchen), vom Narbenrande herrührend, eingeschlossen). Narbe zuweilen mit schnabelartigem Fortsatz. Fruchtknoten 1 fächerig, mit wandständigen Samentrïgern und vielen Eichen. Kapsel 1fächerig, 3klappig. Samen sehr klein, zahlreich, eiweisslos. Keim ohne deutlichen Samenlappen. - Die Repräsentanten dieser Familie, welche in allen Höhen und an den verschiedenartigsten Standorten unseres Gebietes angetroffen werden, flnden sich der Mehrzahl nach auf den kalkhaltigen Hügeln zwischen Nussloch und Wiesloch und sind dort stellenweise durch geselliges Vorkommen auffallend. Einige sind an Feuchtigkeit des Bodens gebunden. Manche der aufgeführten Arten wachsen aber, wie kaum andere Pflanzen der Flora, sehr vereinzelt. Gar oft ist auch dio Entwickelung von den Witterungsverhältnissen abhängig, indem es Jabrgänge giebt, welche die Blüthe mancher Arten wenig oder gar nicht zur Ausbildung bringen. - Die Scheinknollen (hauptsïchlich der Orchis-Arten) enthalten viel Schleim und Stärke.

A) Eine einzige vüllig angewachsene 2fächerige Anthere; Pollenmasse elastisch zusammenhüngend, gestielt; Fruchtknoten mehr oder weniger (bei Oplurys sehr wenig) gedreht.

\section{a) Lippe gespornt.}

1) Drüsen-der Pollenstiele mit einem Beutelchen.

O rchis. Perig. rachenfürmig, 3-5 Zipfel helmartig; Lippe abstehend, 3lappig oder spaltig; die 2 Drüsen der Pollenmassen getrennt, in einem 2fächerigen Beutelchen befestigt; Narbe geschnäbelt.

An a camptis. Wie vorige, aber Drüsen der Pollenmassen vereinigt, in einem 1fächerigen Beuftelchen befestigt.

Himantoglossum. Wie Anacamptis, aber dio 3spaltigo Lippe spiralig gedreht, mit langem, linealem Mittellappen.

2) Drüsen der Pollenstiele nackt, d. h. ohne Beutelchen.

Gymnadenia. Lippe rundlich, 3lappig, abstehend; Sporn fädlich; Narbe gıschnäbelt. 
Coeloglossum. Lippe lineal, 3zähnig, herabhängend; Sporn liurz; Narbe stumpf gekielt.

Platanthera. Lippe lineal, ungetheilt, abwärtsgebogen oder abstehend; Sporn fädlich, verlängert; Antherenfächer deutlich getrennt; Narbe oline Schnäbelchen und Kiel.

b) Lippe spornlos.

1) Drüsen d. kurzen Pollenstiele nackt.

Herminium. Perigon glockig; Lippe aufrecht, 3lappig; Schnäbelchen fehlt.

2) Drüsen der Pollenstiele mit Beutelchen.

Aceras. Perigon helmartig; Lippe hängend; Stiele d. beiden Pollenmassen mit gemeinschaftlicher Drüse und cinfächerigem Beutelchen; Narbo geschnäbelt.

Ophrys. Perigon ausgebreitet; Lippe abstehend oder gebogen; Sitielo der Pollenmassen mit 2 Drüsen und 2fächerigem Beutelchen; Narbe ohne Schnäbelchen.

B) Eine einzige 2fächerige, freie, nicht fest gewachsene Anthere; Pollenmassen meist kïrnig und ohne Stielchen.

a) Lippe spornlos, durch queerfürmige Einschnürung 2gliederig.

Cephalanthera. Lippe 3lappig, wie der ganze Perigon aufrecht; Fruchtkmoten sitzend, etwas gedreht; Befruchtungssäulchen verlängert; Narbe ungeschnäbelt.

Epipactis. Perigon glockig, der untere Theil der Lippe hohl, nach oben etwas zusammengeschnürt; Fruchtknoten gestielt, d. Stiel etwas gedreht; Befruchtungssäulchen kurz; Narbe geschnäbelt.

b) Lippe spornlos, nicht gegliedert.

Listera. Perigon helmartig; Lippe niedergebogen, 2lappig; Befruchtungssäulchen sehr kurz; Narbe nach hinten mit einem etwas gebogenen Fortsatz geschnäbelt.

Neottia. Perigon glockig-helmartig; Lippe niedergebogen, 2lappig; Befruchtungssäulchen etwas verlängert; Narbe kurz geschnäbelt, ohne gebogenen Fortsatz. (Chlorophylllos).

Spiranthes. Perigon helmartig; die seitlichen Zipfel abstehend; Lippe am Grunde rinnig, vorn etwas zurückgekrümmt und gekerbt; Befruchtungssäulchen kurz; Narbe mit 2spaltigem Schnabelfortsatz.

C) Eine einzige freie, 2fächerige Anthere; Pollen zu wachsartig zusammenbängenden Massen verbunden ohne Stielch.;

Fruchtknoten gestielt.

Sturmia. Perigon ausgebreitet; Zipfel lineal; Lippe aufrecht, 
rimnenförmig, spornlos; Befruchtungssäulchen verlängert, vorn ausgebuchtet.

D) Die mittlere Anthere blumenblattartig, unfruchtbar, die 2 seitlichen Antheren fruchtbar.

Cyprip edium. Perigon abstehend; Lippe bauchig aufgeblasen; Befruchtungssäule 3spaltig; die seitlichen Fortsätze derselben die fruchtbaren Antheren tragend.

\section{Orchis $L$. S t end elwurz.}

a) Knollen ungetheilt.

๔. Lippe 3lappig; Lappen breit und kurz; Deckbl. 1nervig (nur die unteren bei $O$. Morio 3nervig).

876. 0. Morio L. Salep-St.; Bl. länglich-lanzettlich; Aehre locker, armblüthig; Mittellappen der Lippe abgestutzt-ausgerandet; Sporn walzig, so lang wie der Fruchtknoten; Helmzipfel stumpf, alle zusammengeneigt, grün gestreift. 4. 5-10". Kn. kugelig; Plth. purpurn, selten gelblich-weiss.

Auf Wiesen, Triften, an Waldrändern oft gesellig, besonders auf Bergwiesen längs der Bergstrasse und in der Nähe von II., z. B. im Thale der Hirschgasse häufig! Mai. (Off.: Rad. Salep.)

877. 0. mascula $I_{\text {. }}$ Männl. St.; Bl, länglich-lanzottlich; Aehre locker, reichblüthig; Mittellappen der Lippe ausgerandet, länger als die seitlichen Lappen; Sporn walzlich, meist aufsteigend, von der Länge des Fruchtknotens; Helmzipfel spitz, die 2 seitlichen zurïckgeschlagen. 4. $1-1 \frac{1}{2}$. Kn. länglich; Blth, äunkel purpurn.

Auf Waldwiesen, an Waldründern, in lichten Gebüschen der Gebirge und Hügel hie und da, z. B. in der Nähe der Molkenkur bei $H . !$ an den Abhängen des Königsstulles gegen Gaiberg! im Gemeindewald bei Schatthausen! Vereinzelt auch hinter dem Haarlass! gegen Schönau: Am Oelberge bei Schriesheim und im Mühlenthale bei Handschuchsheim (Stud. Gysser), zwischen Leutershausen und Weinheim! Mai, Juni. (Off.: Rad, Salep.)

(Das Vorkommen von O. pallens L. im Geb. der Flora ist unsicher.)

$\beta$. Lippe 3theilig; Mittellappen ausgebreitet, 2spaltig und oft in der Mitte mit einem Zälhnchen; Deckbl. 1nervig.

878. 0. ustulata $L$. Angebrannter St.; Bl. lanzettlich, spitz; Aehre gedrängt, reichblüthig, meist kurz; Mittellappen d. Lippe keilig-lineal; Seitenlappen länglich-lineal; Sporn 3mal kürzer als d. Fruchtk.; Deckbl. halb so lang als d. Fruchtk.; IIelmzipfel eiförmig, stumpf. 4. 4-10". Kin. länglich; Blth. klein, braunpurpur; Lippe weiss, purpurroth punktirt. 
Auf lelimigen und kalkhaltigen Wiesen und Triften, hesonders auf Bergwiesen, z. B. häufig nächst der Hirschgasse bei H.! längs der Bergstrasse, z. B. im Mühlenthale und am Steinberge b. Fandschuchsheim! bei Leutershausen! Weinheim! In der Ebene zwischen Neckarau und dem Relaishause vereinzelt! Mai. (Off.: Rad. Salep.)

879. 0. militaris $L$. Helm-St.; Bl. länglich; Aehre gedrängt, reichblüthig; Mittellappen lineal, länger als d. linealen Seitenlappen; Sporn halb so lang, Deckbl, viel kürzer als d. Fruchtknoten; Helm-

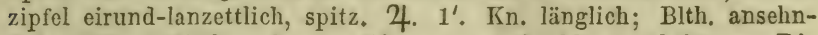
lich; Helm röthlich-aschgrau; Lippe rosa, dunkler punktirt. - Die Pfl. besitzt getrocknet den Geruch von Anthoxanth. odoratum.

Auf Wiesen, an Waldrändern, in Gebüschen, an bewaldeten Abhängen, besonders auf Kalk und Lüss nicht selten, oft gesellig, z. B. zwischen Leimen, Nussloch und dem Maischbacher Hof! im Vogelheerd bei Schatthausen! bei Weinheim! am Oelberge b. Schriesheim! am Steinberge und in der Hillenbach bei Handschuchsheim! einzeln auch hinter dem Haarlass! Stellenweise auf den Wiesen der Rheinebene, z. B. beim Relaishause! Mai, Juni. (Off.: Rad. Salep.)

880. O. fusca Jacq. Braune St.; Bl. eirund-länglich; Aehre reichblth., gedrängt; Nittellappen verkehrt-eirund, länger als dio linealischen Seitenlappen; Sporn halb so lang, Deckbl. viel kürzer

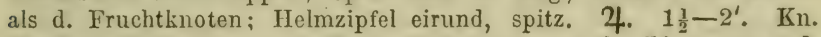
länglich; Blth. ansehnlich; IIelm dunkel purpurroth; Lippe rosa od. weiss, dunkler punktirt. (O. militaris $\beta$ L.)

An bewaldeten Bergabhängen, in lichten Gebirgswäldern auf Kalkboden hie und da, z. B. in grosser Menge zwischen Nussloch und dem Maischbacher Hof 1 vereinzelt in der Hessel bei Wiesloch! im sog. Forlenwalde bei Schatthausen; am Teufelskopf b. Dielheim! Häufig bei Leutershausen und.Schriesheim, besonders beim Vitriolbergwerk (Stud. Gysser), seltener bei Weinheim! Mai.

$\gamma$. Lippe 3spaltig; Mittellappen schmal, ungetheilt od. ausgerandot Deckbl. 1nervig, ron der Länge des Fruchtknotens.

881. 0. coriophora $L$. Wanzen-St.; Bl. lineal-lanzettlich; Achre reichblth, locker; Lippe abwärtsgebogen, Zipfel eiförmig-lineal, der mittlere etwas länger; Sporn kegelförmig, bogig absteigend, kürzer als der Fruchtknoten; Helnzipfel spitz, alle zusammengeneigt. 4. $1^{\prime}$. Kn. kugelig; Blth. getrübt roth, von wanzenartigem Geruch.

Auf feuchten Wiesen der Ebene und der Gebirge hie und da, z. B. Engelswicse bei II.I Birkenauer Thal bei Weinheim! zwischen Leimen und St. Ilgen (Lehrer Riegel), bei Alt Wiesloch! Nussloch! beim Maischbacher Hof! Auch stellenweise auf den Wiesen bei Neckarau! Waghäusel: Mai, Juni. 
ઈ. Lippe 3lappig, nach den Seiten zurückgeschlagen; Dockbl. mit $3-5$ netzartig verbundenen Nerven.

882. 0. palustris Jacq. S u mp f-St.; Bl. lineal-lanzettlich; Achre locker; Lippe schwach 3lappig; Seitenlappen abgerundet, länger als der ausgerandete Mittellappen, Sporn halb so lang als der Fruchtknoten; Helmzipfel stumpf, die 2 äusseren Zipfel zurückgeschlagen. 4. 1-1 $\frac{1}{2}^{\prime}$. Kn. länglich; Blth. purpurroth (der 0 . mascula ähnlich). (O. laxiflora Lam.)

Auf feuchten, torfhaltigen Wiesen bei Waghäusel! Juni, Juli.

[Stellenweise in B. bis Bruchsal (Döll), jenseits des Rheines b. Speyer, Maxdorf, Erpolsheim etc. $(F$. Sch.). N. V. diesseits d. Rheines nördl. v. Waghäusel, in Hs, zwischen Dornheim und Griesheim. (Schnttsp.)]

b) Knollen handfürmig getheilt oder gelappt, zuweilen nur an der Spitze gezähnt; Deckbl. 3-mehrnervig.

883. 0. sambucina $L$. Hollunder-St.; Bl. lanzettl.; Aehro gedrängt, reichblth.; Lippe schwach 3lappig; Sporn kegelig, stumpf, abwärtsgebogen, so lang als der Fruchtknoten; Helmzipfel lanzettl., die seitlichen etwas abstehend. 24. 6-9". Kn. länglich, an d. Spitze meist kurz 2-3lappig; Blth. gelblichweiss, ähnlich wie die Blth. von Samb: nigra riechend.

An bewaldeten Bergabhängen, am Rande trockener Nadelwalwaldungen selten und vereinzelt. Verbreitung näher zu verfolgen. In der Ebene bei Walldorf, beim Relaishause, am Rande des Käforthaler Waldes (Döll). April, Mai.

[N. V. a. d. Geb. in Rhb.: Neustadt (F.Sch.)]

884. 0. maculata $L$. Gefleckter St.; St. nicht hohl; Bl. abstehend, länglich-lanzettl., gefleckt; Aehre locker; Lippe 3lapnig; Zipfel flach, abgerundet; Sporn kegelförmig, kürzer als der Fruchtknoten; die unteren Deckbl. länger, die mittleren so lang als die Blth.; Helmzipfel abstehend. 4. 1'. Kn. 3-4lappig oder spaltig; Blth. hellroth oder weisslich, mit dunkleren Zeichnungen.

Auf feuchten Wiesen, in Wäldern der Gebirge und d. Ebenc, besonders in der Nähe von H., diesseits und jenseits des Neckars häufig! Juni, Juli. (Off.: Rad. Salep.)

885. 0. latifolia $L$. Breitblättr. St.; St. hohl, 4-6blätterig; Bl. abstehend, eilänglich, stumpf, meist geflecht; Aehre gedrängt; Lippe 3lappig, seitliche Zipfel zurückgeschlagen, kürzer als der mittlere; Sporn kegelförmig, kürzer als d. Fruchtknoten; Deckhl. von der Länge der Blth.; Helmzipfel abstehend. 2. 1'. Kn. 2-4lappig oder spaltig; Blth. hellroth, mit dunkleren Zeichnungen. Salep.)

Auf Wiesen, Triften, an Waldrändern häufig! Mai. (Off.: Rad. 
886. 0. incarnata $L$. Fleischrothe St.; St. hohl, 4-6blitterig; Bl. aufrecht, lineal-lanzettl., an der Spitze kappenartig zusammengezogen, spitz, meist ungefleckt; Achre sehr gedrängt; Lippe und Sporn der vorigen; Deckbl. länger als die Blth.; IIelmzipfel abstehend. 4. 1'. Blth. fleischroth; Kn. 2-4spaltig. ( 0 . angus if folia W. et $\mathrm{Gr}_{\text {.) }}$

Auf feuchten oder sumpfigen torfhaltigen Wiesen, z. B. bei Waghäusel! Sandtorf! Roth! im Mühlenthale bei Handschuchsheim! Juni. (Blüht 3-4 Wocken später als die vorige.)

\section{6\%. Anacamptis Pich. Anacamptis.}

887. A. pyramidalis Rich. Pyramidenf. A.; Bl. linealIanzettI.; Aehre reichblüthig, pyramidal;. Lippe 3lappig, am Grunde jederseits mit einem Anhängsel; Sporn fadenförmig, gebogen, länger als der Fruchtknoten; Perigonzipfel helmartig, die seitlichen Zipfel abstehend. 4. $1-1 \frac{1}{2}$. Kn. kugelig-eifürmig; Blth. purpurroth, wohlriechend. (Orchis pyramidalis L.)

An waldigen Bergablängen, kalkhold, hie und da. Zwischen Niussloch und dem Maischbacher Hof! Am Teufelskopf bei Diellnim! vereinzelt auch zwischen Wiesloch und Baierthal! An der Grenze des Geb, bei Hemsbach an der Bergstrasse (Döll). Mai, Juni.

[N. V. a. d. Geb. in B.: Eichelberg bei Bruchsal, Weingarten; in Rhb.: bei Mechtersheim, unfern Speyer! bei Dannstadt, gegen Schifferstadt (Dr. Walz).]

368. Il imantoglossum Spr. Rollzunge.

888. H. hircinum Spr. Bocks-R.; Bl. länglich-lanzețtlich; Achre verlängert, locker; Lippe 3theilig; Zipfel linealisch, d. mittlere sehr lang, etras gedreht, die seitenständigen kürzer, wellig-kraus; Sporn sehr kurz. 4. $1-12{ }_{2}^{\prime}$. Kn. ungetheilt, länglich; Blth. grünlich-weiss; Lippen roth punktirt, von unangenehmem Geruch. (Orchis hircina $\mathbf{L}$.)

Auf sonnigen Irügeln, an Waldrändern, auf Kalkboden, selten und meist einzoln, z. B. in der Hessel bei Wiesloch! beim Maischbacher IIof! bei Nussloch! An der Burg Windeck bei Weinheim! unterhalb der Strahlenburg bei Schriesheim. [Auch in der Nähe des Gel. auf d. Starkenburg bei Heppenheim an d. Bergstr. (Schnttsp.)] Mai, Juni.

369. Hym nadenia $R . B r$. Nacktdrüse.

889. G. conopsea $R$. Br. Mü $\mathrm{cken-N}$; Bl. lineal, rinnenförnig; Aehre verlängert, reichblüthig; Lippo 3spaltig; Zipfel fast 
gleich lang, stumpf; Sporn gebogen, fadenförmig, zwcimal so lang als der Frucktlinoten. 2. 1-1 $\frac{1^{\prime}}{}$. Kn. handförmig-getheilt; Blth. hellpurpurn, selten weiss, wohlriechend.

Auf Wiesen, sonnigen Waldtriften der Gebirge und d. Ebene hie und da, z. B. zwischen Nussloch und Maischbach! im Vogelheerd bei Schatthausen! unfern Roth (Lehrer Riegel), bei Weinheim! am südwestl. Abhange des Steinberges bei Handschuchsheim (Stud. Gysser). Juni, Juli.

\section{[Coeloglossum Hartm. Hohlzunge.]}

[C. Viride Hartm. Grüne H.; BI. eirund-länglich, stumpf; Achre locker; Lippe 3zähnig; mittl. Zipfel sehr kurz, seitl. lineal; Sporn kurz, sackförmig; Perig.-Helm zugespitzt. 4. $3-8^{\prime \prime}$. Kn. handförmig getheilt; Blth. grünlich. (Habenaria viridis R.Br.)

N. V. a. d. Geb. auf Wiesen in Rhb., z. B. Maxdorf! Lambsheim! Hanhofẹn bei Speyer etc. Mai, Juni.]

370. Platanthera Pich. Breitkölbchen.

890. P. bifolia Rich. Zweiblüttr. B.; zwei fast gegenst,, eirund-längliche Bl.; Aehre verlängert, locker; Lippe lineal, ganz; Sporn fadenförmig, gekrümmt, zweimal so lang als der Fruchtknoten; Antherenfächer parallel verlaufend, die sehr concave Narbe fast verdeckend. 4. 1-1 $\frac{1}{2}^{\prime}$. Kn. länglich; Blth, weiss, wohlriechend.

In lichten Laub- und Nadelwäldern, auf Waldwiesen der Gebirge und der Ebene, besonders auf Sandboden nicht selten, z. B. zwischen Ziegelhausen und Schönau! bei der Molkenkur und am Königsstuhl bei H.! im Gaiberger Walde! in Kastanienwäldern am nord-westl. Abhange des Heiligen Berges bei Handschuchsheim! bei Schriesheim! Auch in Nadelwäldern bei Friedrichsfeld! u. in Waldgebüschen bei Kirrlach und Waghäusel etc.! Mai, Juni.

891. P. chlorantha Cust. Gelbgrünes B.; der vorigen ähnlich, meist etwas kräftiger; Aehre reichblüthiger; Blth. etwas grösser; Sporn keulig-fadenförmig, $1 \frac{1}{2}$ mal so lang als der Fruchtknoten; Antherenfächer nach unten auseinander weichend, die wenig ausgehöhlte Narbe nicht verdeckend. 4. $1 \frac{1^{\prime}}{2}$. Blth. weiss-grünlich, fast geruchlos. (P. montana Rchb. fll.)

In lichten Gebirgswäldern, auf Bergwieson, besonders auf Kalkund Lehmboden hie und da, zuweilen gesellig, z. B. Leimen! Nussloch! Maischbach! Wiesloch! im Vogelheerd bei Schatthausen! zwischen Weinheim und Leutershausen! einzeln hinter dem Haarlass! Juni. 


\section{3\%ั. Hl crm in im $R . B r$. Herminie.}

892. H. Monorchis R. Bir. Einknollige II,; Bl. linglichlanzettlich; Aehre rerlängert, linealisch, locker; Blth. nickend, allo Perigonzipfel rorgestreckt; Lippe 3lappig, mittl. Lappen länger als die linealen scitlichen. 2. Blassgrün. 5-10". Blth. grünlich-gelb, wohlriechend. (Wälırend d. Blüthezeit nur ein kugeliger Knollen. Im August treten aus dem Grunde des Schaftes einige Ausläufer, ron welchen einer oder mehrere an der Spitze knollenartig anschwellen und die Knollen für die nïchstjührigen Blthstengel liefern.)

Auf Waldtriften, an grasreichen Rainen, Abhängen, auf feuchten. Wiesen, besonders auf Kalk und Löss stellenweise, z, B. in Mengo am Teufelskopf bei Dielheim! bei Baierthal: Maischbach! Nussloch Schatthausen! Auf dem Wagenberge und im Gorxheimer Thale bei Weinheim! auch gegen Leutershausen nicht selten! Vereinzelt am Oelberge bei Schriesheim! Juni, Juli.

\section{Aceras $R$.Br. Spornlose.}

893. A. anthropophora $R$. Br. Menschentragende Sp.; B1. länglich-lanzettl., stumpf; Aelire verlängert, locker; Lippe abwärts hängend, lineal-fadenfürmig, verlängert, übrige Perigonbl. helmartig. 4. $\frac{1}{2}-1^{\prime}$. Blth. grünlich-roth; Lippe bräunlich; Kn. elliptisch.

Bisher nur im sog. Vogelheerd (einem feuchten Nadelwalde) bei Schatthausen, daselbst nicht häufig! (Der Standort wurde mir von Herrn v. Göler gezeigt und scheint bis 1854 unbeachtet geblieben zu sein. (Mai, Juni. [In der Näho des Geb. fehlend, nächstes sporadisches Vorkommen bei Pforzheim $(I \ddot{\prime l l l})$.]

\section{Ophrys $L$. Ragwurz.}

894. 0. muscifera Ifuds. Fliegentragende R.; Bl. lanzettl.; Achre locker, armblth.; Lippe fast flach, länglich, 3spaltig, sammetartig, braunroth, in der Mitte mit einem kahlen, bläulichen, fast 4eckigen Fleck; Mittellappen verlängert, 2spaltig; äussere Porigonzipfel längl,-eifürmig, kahl, grün, innere schmal lineal, umgerollt, sammetartig; Anthere stumpf, ohne Anhängsel. 4. $\frac{1}{2}-1 \frac{1}{2}$. Kn. kugelig. (O. myodes Jacq.).

Auf sonnigen IIügeln und Triften, auf trocknen Wiesen hio und da, z. B. in Menge bei Nussloch! zwischen Nussloch und Wiesloch! beim Maischbacher IIof! Baierthal! Oberhof bei Schatthausen! vereinzelt bei Leimen! Dossonheim! häufiger bei Weinheim und Leutershausen! Mai, Juni. 
895. 0. arachnites IIost. Spinnenähnliche R.; BI. länglich; Aehre locker, armblüthig; Lippe rundlich, ungetheilt, gewölbt, am Rande flach, sammetartig, rothibraun, gelb gezeichnet, vorn mit aufwärtsgerichtetem kahlem Anhängsel; äussere Perigonzipfel elliptisch, innere lineal, sammetartig behaart; Anthere mit kurzem, hakenartigem Fortsatz. 4. 3-10". Kn. kugelig. Perig. rosa od. weiss, etwas grünlich.

Auf trocknen, sonnigen, kalkhaltigen IIügeln und Triften selten, z. B. zwischen Nussloch und dem Maischbacher Hof (von $\mathbb{N}$. kommend, gleich rechts auf Triften)! Zwischen Baierthal und Wiesloch ebenfalls nur vereinzelt! Mai, Juni.

896. 0. apifera Ifuds. Bienentragende R.; der vorigen ähnlich; Lippe 3spaltig, sehr gewölbt, oberseits sammetartig, dunkelbraun, mit kahlen gelben Linien gezeichnet, Seitenzipfel abstehend, kurz, zottig, Mittelzipfel grüsser, etras 3lappig, zurïckgekrümmt, in der Mitte mit kahlem gekrümmtem Anhängsel; äussere Perigonzipfel länglich, innere lineal, zottig; Antheren mit verlängertem Fortsatz. 4. $\frac{3}{4}-1^{\prime}$. Kin. kugelig; Perig. röthlich woiss, etwas grün.

Auf sonnigen, kalkhaltigen Hügeln, trocknen Wiesen gewiss schr selten und sporadisch. Wiesloch, Maischbacher Hor (F. Sch. Döll.). [A. d. Geb. in Menge auf Wiesen in d. Gegend von Speyer, z. B. bei Hanhofen! bei Dannstadt (Dr. Wals). Juni.

\section{3\%4. Cephalanthera Rich. Cephalanthere.}

897. C. pallens Rich. Breitblätt erige C.; Bl. eiförmig oder eilanzettl.; Deckbl. länger als d. kahle Fruchtknoten; Achre locker; Indglied der Lippe herzeirund; IIelmzipfel stumpf. 4. 1-1 $\frac{1}{2}^{\prime}$. W. faserig (wie bei d. folg. Arten). Blth. gelblich weiss. (C. grandiflora Bab. Serapias grandiflora L.).

In Wäldern, auf Waldtriften, besonders auf Kalkboden hie und da. In Menge hinter dem IIaarlass! nächst der Hillenbach bei Handschuchsheim! seltener bei Leutershausen und Weinheim! In den Gebirgswäldern zwischen Leimen und Wiesiocl, besonders bcim Maischbacher Hof und bei Schatthausen ziemlich verbreitet! Mai, Juni.

898. C. ensifolia Rich. Schwertblätterig. C.; Bl. lineallanzettl., zugespitzt; Deckl. viel kïrzer als d. kahle Fruchtknoten; Aehre locker; Endglied d. Lippe eirund; IIelmzipfel spitz. 4. 1'. Blth. weiss. (C. Xiphnyhyllum Rchb.; Serapias ensifolia Murr.).

In Laubwäldern, ebenfalls auf kalkhaltigem Boden mit d. vorigen, aber weniger gesellig. Verbreitet zwischen Nussloch und dem MIaischbacher Hof! Schatthausen! Leimen! einzeln bei Rohrbach und 
hinter dem IIaarlass! Zwischen Irandschuchsheim und Dossenhcim! boi Weinheim häufiger als vorige!- Mai, Juni.

899. C. rubra Rich. Rothe C.; Bl. längl,-lineal; Deckbl. länger als d. weichhaarige Fruchthnoten; Aehre locker; Endglied d. Lippe eirund; Helmzipfel spitz. 4. $1-1_{2}^{\prime 1}$. Blth. hellroth. (Sierclpias rubra L.).

In lichten Wälilern, besonders Nadelwäldern d. Gebirge und der Ebene hie und da, z. B. in Menge in d. Ifessel bei Wiesloch! solten in Nadelwäldern bei Walldorf! zwischen Nussloch und dem Maischbacher Hof! im Vogelheerd bei Schatthausen! im Wäldchen nächst der IIillenbach bei IFandschuchsheim (Stud. Gysser); stellenweise in den Friedrichsfelder Nadelwäldern! im Käferthaler Walde, (Schimp.) Juni, Juli.

\section{Wpipactis Rich. Sumpfwurzel.}

900. E. latifolia $A l l$. Breitbl. S.; Bl. eiförmig, spitz; Traube meist einseitswendig, reichblth; Blth. nickend; Endglied d. Lippe zugespitzt, flach, beiderseits mit einem glatten Höcker. 4. 1-2'. W. faserig (wie bei d. folg. Arten). Blth. grünlich rothbraun, zuweilen weisslichgrün.

In feuchten Wäldern und Gebüschen der Gebirge u. d. Ebene, z. B. in der Näho ron II., besonders jenseits des Neckars! häufig bei Neckarsteinach! am Künigstuhl! im Gaiberger Walde, bis Schatthausen und Wiesloch! Seltener bei Schriesheim und Weinheim! Im Friedrichsfelder und Neckaraucr Walde! bei Kirrlach! Waghäusel, auch in den fruchten Gebüschen längs des Rheins, z. B. beim Relaishause ! Ketsch verbreitet! Juli, August.

901. E. atrorubens Schull. S chwarzrothe S.; Bl. eiförmiglängl., spitz; Traube einseitswendig, reichblth.; Blth. nickend; Endglied d. Lippe zugespitzt, am Grunde oberseits faltig-kraus. 4. $1-11^{\prime}$. Bl. dunkelgrün, unterseits rothbraun; Blth. dunkelroth, kleiner als bei der vorigen. (E. rubiginosa Koch).

In trockenen Nadelwäldern der Ebene verbreitet, z. B. in Menge bei Friedrichsfeld! Schwetzingen! Oftersheim! Sandhausen! Auch im sog. Vogelheerd bei Schatthausen! Juni, Juli.

902. E. palustris Crenl . Aechto S.; Bl. längl.-lanzettl; Traubo einseitswendig, armblth.; Blth. nickend; Endglied d. Lippe kreisrundlich, stumpf, am Grundo höckerartig gekerbt. 4. 1'. Lippe weiss, übrige Perigonglieder rüthlich. (Serapias palustris Scop.).

Auf feuchten Wiesen, in Sümpfen der Ebene stellenweise, z. B, 
heim Johrhof! auf der Insel hei Ketsch! Waghäusel! Sanütorf! Roth (Lelirer Riegel), Birkenau, unfern Weinheim! Juni, Juli.

Jenseits des Rheins, besonders in der Näho des Gebietes noch verbreiteter, z. B. bei Maxdorf! Forst! Manhofen! u. s. w.]

\section{3\%. Listera $R$. Br. Z w e iblatt.}

903. L. ovata $R$. Br. Eiförmiges Z.; St. in der Mitte mit 2 eiförmigen, fast gegenst. Bl.; Traube reichblth., verlängert; Lippo lineal-gespalten. 24 $1 \longmapsto 1 \frac{1}{2}^{\prime}$. (Ophrys ovata L.; Neottia latifolia Rich.).

Auf Wiesen, in feuchten Laubwäldern der Gebirge u. d. Ebene durch das Geb. verbreitet, in der Näho von II., z. B. Wolfsschlucht! Schlierbach! Handschuchsheim! Rohrbach! u. s. w. Mai, Juni.

\section{3\%. Neottia $L$. Nestwurz.}

904. N. Nidus avis $L$. Vogelnest; chlorophylllos; St. mit Schuppen besetzt, wio die ganze Pflanze hellbraun; Traube dichtblth.; Lippe verkehrt-herzförmig. 4. $1-1^{\frac{1}{2}}$. Wfasern kurz, fleischig, nestartig verwickelt. (Ophrys Nid. avis L.).

In schattigen, etwas feuchten Laubwäldern, besonders in der Nähe älterer Buchenstämme nicht selten, z. B. in Menge zwischen Nussloch und dem Maischbacher Hof! im Vogelheerd bei Schatthausen! vereinzelt bei Leimen! Rohrbach, hinter dem Haarlass! Sehr zerstreuet im Gebirge zwischen Schriesheim und Schönau! häufiger bei Weinheim! In den ausgedehnteren Laubwaldungen der Ebene hie und da, z. B. zwischen Waghäusel und Kirrlach! Mai, Juni.

\section{Spiranthes Rich. Schraubenblume.}

905. S. autumnalis Rich. IIerbst-S.; Bl. grundst., rosettig, längl.-lanzettlich; Schaft seitenständig, mit scheidenförmigen Bl.; Aehre spiralig gedreht, reichblth. 4. 4-8". Kin. eilänglich; Blth. klein, weisslich. (Ophrys spiralis L.).

Auf etwas feuchten Bergwiesen nicht häufig. An don Abhängen nächst der Hirschgasse und auf der Engelswiese bei II.! bei Wcinheim (Döll.). August, September.

[N. V. a. d. Geb.: in B.: Durlach (D̈̈̈l.), in IIs.: Darmstadt (Sclenttsp.), in Rhb.: Kaiserslautern $(I$. Sch..).]

\section{Sturmia Rchb. Sturmie.}

906. S. Loeselii Rchb. Lös ol's St.; St. 3kantig; Bl. längl.c.lliptisch, gelblich-grün; Traube armblth.; Lippe verkehrt-ciförmig, 
stumpf, feingekerbt. 4. 2-6". St. am Grunde knollig rerdickt; Blth. grünlich gelb. (Liparis Loesel. Rich.; Hulaxis Lreeselii $\mathrm{SW}_{\mathrm{W}}$ ).

In Torfsümpfen bei Waghäusel! häufiger und zwar stellenweise in umfangreichen Colonien bei Sandtorf I Juni.

11. V. a. d. Geb.: Rhb.: MIaudach (Düll.), Rhh.: Eich, unfern Eberstadt (Sclinttsp.).]

\section{Cypripedium $L$. Frauenschuh.}

907. C. Calceolus L. Europ ä ischer F.; St. beblittert, meist 1blüthig; Bl. elliptisch, spitz; Lippe bauchig, etwas zusammengedrückt, schuhähnlich, hängend, kürzer als dio helmartigen üusseren Perigonzipfel. 24. 1-1 $1 \frac{1}{2}^{1}$. W. faserig; Lippe gelb, übrige Perigontheile purpurbraun.

In lichten Waldgebüschen bei Balsenbach unfern IIemsbach (Döll.). Juni.

[Verbreitung ron hier sporadisch t durch den Odenwald ins Mainthal bei Wertheim, Schweinfurt u. s. w.; Würtemberg.]

\section{IRIDEAE Juss.}

Kräuter mit fleischigen Wurzelstöcken od. Zwiebelknollen, schwertfürmigen Blättern und von meist trockenhäutigen Scheiden umgebenen regelmässigen oder unregelmässigen Blüthen. Perigon oberständig, gefärbt. 6gliederig, die 3 inneren Glieder meist verschieden von den äusseren. Staubgefïsse 3, dem Grunde der ïusseren Perigonglieder eingefügt. Antheren auswärts aufspringend. Fruchtknoten 3 fächerig, mit centralem Samenträger, vieleiigen Füchern, 1 Griffel und 3 meist blumenblattartigen Narben. Kapsel 3fächerig, 3klappig̣, Samen ciweisshaltig mit geradem Keim.

Iris. Perigon 6theilig, röhrig, die 3 inneren Zipfel aufrecht, die äusseren zurückgebogen. Narben blumenblattartig, 2lippig.

Gladiolus. Perig. 6theil., unregelmässig, fast 2lippig; Narben oben blattartig ausgebreitet.

\section{Ir is $L$. Schwertlilie.}

a) Perigonblätter kahl.

908. I. Pseudacorus L. Wass er-S.; St. etwas zusammengedriickt, viclblütlig, so lang als d. lineal-lanzettl. Bl,; äusserc Pe- 
rigontheile cifürmig, allmählig verschmälert, innero Perigontheile schmal lineal, kïrzer als d. Narben. 4. $3^{\prime}$. Blth. gelb. Wstock horizontal, schwammig, innen röthlich.

In Gräben, an Ufern, in Sümpfen häufig, weniger an Neckar als am Rhein verbreitet. In der Nähe von II., besonders bei IIandschuchsheim und Kirchheim in grüsserer Menge! Mai, Juni.

909. I. sibirica $L$. Sibirische S.; St. sticlrund, meist 2-3blüthig, länger als die linealen spitzen Bl.; äussere Perigontheile verkehrt-eirund, innere länglich, länger als d. Narben. 4. $1 \frac{1}{2}-2 \frac{1}{2}^{\prime}$. Wstock kurz, dünn. Blth. hellblau.

Auf feuchten Wiesen der Rheinfläche hie und da, z. B. beim Rohrhof I Relaishause! auf der Insel bei Fetsch: einzeln bei Waghäusel! Juni.

b) Aeussere Perigontheile mit einem Längsstreifen dichter Haare.

I. germanica L. Deutsche S.; St. stielrund, mehrblth., länger als die lineal-lanzettl. Bl.; Blthscheiden an d. Spitze bis zur Mitte trockenhäutig; Perigontheile verkehrt-eifürmig, stumps, d. inneren plötzlich in den Nagel zusammengezogen; Stbfäden so lang als die Antheren. 24. 2-3'. Blth. violett, mit gelblichweissen und brïunlichen Adern, fast geruchlos; Wstock knollig.

Auf einer alten Mauer unterhalb der Engelswiese und in Wein-

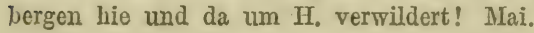

\section{[Gladiolus $L$. Siegwurz.]}

G. palustris Gaud. S u mpf-S.; Bl. lineal-schwertförmig; Achre einseitswendig 4-6blth.; Kapsel verkehrt-eiförmig, 6furchig, an d. Spitze abgerundet; Faserhaut d. Zwiebelknollen netzartig gewebt. 4. 1-1 $\frac{1}{2}^{i}$. BIth. purpurroth. (G. Bouchéanus Schlchtd.).

Auf feuchten Wiesen. N. V. a. d. Geb. in Iihb.: zwischen Tussgünnheim und Wachenheim, besonders auf d. sog. Bischofswiesen bei Forst! bei Dannstadt, unfern Schifferstadt (Dr. Wal ), seltener zwischen Maxdorf und Eppstein (F. Schult:).]

\section{AMIARYLLIDEAE $R$. $B r$.}

Die einheimischen Arten sind lirautartige Zwiebelpflanzen mit grundstïndigen, von Scheiden begleiteten Bliittern, seitenstïndigem Schaft und von einer häutigen Scheile umschlossenen Blüthen. Perigon oberstïndig 6theilig, blumen- 
artig. Staubgef. meist 6 mit einwärts aufspringenden Antheren. Grifiel 1. Fruchtknoten 3fïcherig, mehreiig. Kapsel 3klappig, mehrsamig. Samen eiweisshaltig mit geradem Keim.

L өu ојum. Perig. glockig, 6theilig; Zipfel alle gleich; Stbgef. 6.

Galanthus. Perig. glockig, 6theilig, die 3 äusseren Zipfel abstehend, die 3 inneren becherartig kleiner; Stbgef. 6.

\section{Lе исој ит $L$. Knotenblume.}

910. L. vernum L. Frühlings-K.; Bl. lineal, hellgrün; Schaft 1blth.; Perig. weiss mit grünen Spitzen, 4. $\frac{1}{2}-1^{\prime}$.

Auf Waldwiesen, in lichten Wäldern bei Weinheim (T)ierl.). März, April. häufig.]

[N. V. a. d. Geb.: im hessischen Odenwalde, wo stellenwciso

Galauthus $L$. Schneeglö ckchen.

G. nivalis $\mathrm{L}$. Gemeines S.; Bl. linenl, blaugrün; Schaft 1blth; Perig. weiss, die inneren Zipfel grün gezeichnet. 4. 1 - 31 . bis April.

In Grasgärten, auch auf Wiesen; aber nur verwildert. Februar

\section{ASPARAGEAE Juss.}

Die einheimischen Arten sind Krïuter mit kriechende॥ wagerechten Wurzelstücken, ganzrandigen, einfachen od. sehr verkümmerten Blïttern, regelmïssigen, in den Zahlenverhiiltnissen oft schwankenden Blüthen. Perigon unterständig, grün oder gefirit, 4-6-, seltener Stheilig od. spaltig. Staubgefiisse ron derselben Zahl, dem Perigon od. dem Fruchtboilen eingefügt. Antheren nach Innen aufspringend. Fruchtknoten frei, meist 3fächerig, selten 2-mehrfächerig. Fächer 1 -vieleiig. Griffel 1-mehrere, frei orler verbunden. Frucht beerenartig, mehrsamig. Samen eiweisshaltig mit kleinem Keim.

A sparagus. Perig. trichterI.-glockig, 6theilig; Stbgef. fo. Giriff. 1. Beere 3fächcrig. (Zuweilen dioecisch.) 
Convallaria. Perig. glockig od. rührig, Czähnig od. spaltig. Stbgef. 6; Griff. 1, einfach; Becre 3fächerig.

Majanthem um. Perig. Atheilig mit ausgebreiteten Zipfuln; Stlugnf. 4; Griff. 1, an iler Spitze 2spaltig: Beere 2färherier.

Paris. Perig. bleibend, meist Stheilig; Stbgef. S (selten if od. i1)); Antheren mit selır verlängertem Mittelbande. Griffel 4; Beere 4fächerig.

\section{Asparagus $L$. Spargel.}

911. A. officinalis $L$. Gebräuchlicher S.; St. aufrecht. ¿istig, liahl; Bl. zu unscheinbaren Schuppen verkümmert, aus deren. Achseln Büschel kleiner, nadelfürmiger, blattloser Zweige entspringen; Blth. häufig đlioecisch, gestielt, meist paarweise; Blthstielchen in der Mitte gegliedert. 24. 2-4'. Blth. grünlich; Beeren scharlachroth.

Auf Sandflächen, in feuchten Narlelwäldern, auf Wiesen, an Ufern häufig, z. B. beim Relaishause! Rohrhof! Neckarau! Ketsch! hie und da im Friedrichsfelder Walde! auf Sandtriften bei Mannheim! Sandhofen! St. Ilgen! Am Neckarufer zuweilen gesellig, z. B. bei Feudenheim! Ladenburg! seltener bei Neuenheim! Juni, Juli. (Off.: Rad. Asparagi).

\section{Conrallaria $L$. Ma iblume.}

a) Perig. röhrig; Blüthen achsclst, einzeln od. zu 2-5, einseitswendig. Wstock kurz, gegliedert.

912. C. Polygonatum L. Sal omon s siegel; St. kantig; Bl. wechselständig, 2zeilig, stengelumfassend, eirund-längl., kahl, unterscits graugrün; Blth, einzeln; Stbf. kahl. 24. $\frac{1}{2}-1 \frac{1}{2}^{\prime}$. Perig. ctwas bauchig, weiss; mit grünen Spitzen; Becren schwarzblau.

Auf Felsen, Kalkhügeln, sandigen Haiden, in Nadelwäldern nicht läufig, z. B. auf bewaldeten Felsen ror dem IIaarlass! zwischen Nussloch und dem Naischbacher Mofl in d. Heśsel bei Wiesloch! bei Nesterbach und Weinheim! zwischen Friedrichsfeld und dem Relaishause! im Käferthaler Walde. (An schr trockenen Standorten, z. B. in Nadelwäldern u. a. d. Geb, auf den Kalkhügeln bei Dürkheim bleibt d. Pfl. zwergartig und ist oft 1blüthig).

913. C. multiflora L. Vielb lü th i g e M.; St. sticlrund; Bl. wechselst., 2zeilig, stongelumfassend, eilänglich, kahl; Blthstiele 2-5blth.; Stbf. behaart. 4. 1-2'. Perig. schmalröhrig, weiss mit grünen Spitzen; Beeren schwarzblau.

In schattigen Laubwäldern der Gebirge und der Ebene ziemlich rorbreitet, jedoch nicht überall. Häufig bei Leimen! Nussloch! Maischbach! im Gaiberger Walde! im Mauerer-Walde bei Schatthau- 
sen! bei Dielheim! Auch in der Nähe von H., besonders jenseits des Neckars, z. B. Küblers Wiese! Heiligen Berg. - In Wäldern der Ebene, z. B. zwischen Schwetzingen und Ketsch! bei Kirrlach! im Neckarauer Walde! Mai, Juni.

(Das von Dierb. p. 96 angegebene Vorkommen von C.latifolia Murr. ist jedenfalls irrthümlich.)

b) Perig. glockig; Blth. traubig mit schuppenförmigen Deckbl.; Wzst, verlängert, dünn.

914. C. majalis $L$. M a iblume; Bl. grundständig, langgestielt, elliptisch; Schaft halbstielrund; Traube einseitswendig. 4. $6-10^{\prime \prime}$. Blth. weiss, wohlriechend; Beeren roth.

In schattigen Laubwäldern, auf Waldwiesen häufig. Mai. (Off.: Flor. Liliorum Convallium.

\section{II ajanthemum Wigg. Schattenblume.}

915. M. bifolium $D C$. $\mathrm{Z}_{w}$ eibl. $\mathrm{Sch}$; St. aus kriechendem Wstock aufsteigend, 2 gestielte, herzförmige Bl.; Traube endständig. 4. 3-6". Blth. klein, weiss, wohlriechend; Beeren roth.

In schattigen Laubwäldern stellenweise häufig, besonders im Gebirge zwischen Leimen, Maischbach und Dielheim! am Geisberge und in d. Wolfsschlucht bei $\mathrm{H}$.! seltener bei Weinheim! $\mathrm{zwischen}$ Dossenheim und Schriesheim! bei Handschuchsheim! In den Wäldern der Ebene hie und da, in Menge z. B. zwischen Waghäusel und Kirrlach! Mai, Juni.

\section{Paris $L$. Einbere.}

916. P. quadrifolia $L$. Vierbl. E.; St. aus kriechendem Wstock aufsteigend, an d. Spitze meist 4blätterig; Bl. quirlig, elliptisch; Blthen einzeln, gipfelst., gestielt, äussere Perigonglieder breiter als d. inneren. 2. $1^{\prime}$. Blth. grün; Beeren schwarzblau. (Die Beeren schmecken widerlich, sollen jedoch nicht eigentlich giftig sein.) Gefässbündelverlauf in den Blättern verzweigt, als Anomalie des Monocot.-Typus! Staubgef. bleibend! - Zuweilen enthält d. Blattquirl $3-5-6$ Blätter, und dem entsprechend ist auch die Zahl der Blüthentheile vermindert. oder vermehrt.

In schattigen Laubwäldern, feuchten Waldgebüschen durch d. Geb. verbreitet. In der Nähe von $H$. nur stellenweise, z. B. hinter d. Haarlass! unterhalb d. Engelswiese! im Eingange des Dreitrögethales oberhalb des Lärchenbestandes! Viel häuflger und oft sehr gesellig zwischen Leimen und Wiesloch! bei Weinheim! im Neckarauer Walde! bei Kirrlach u. s. w. Mai, Juni. 


\section{LILIACEAE $D C$.}

Kräuter mit ganzrandigen, oft sehr einfachen Blittern und bei den einheimischen Arten fast immer mit am Grunde der Stengel durch fleischige Niederblätter gebildete Zwiebeln. Blüthen meist regelmässig. Perigon unterständig, blumenartig, 6gliederig. Staubgefässe 6 dem Perigon oder dem Fruchtboden eingefügt; Antheren nach Innen aufspringend. Fruchtknoten 3fächerig, Fächer 2-vieleiig, Griffel 1 mit $1-3$ Narben. Kapsel $3 \mathrm{klappig}$, vielsamig, Scheidewände in der Mitte der Klappen; Samen eiweisshaltig. Keim gerade.

a) Perig. 6blätterig oder tief 6theilig.

Tulipa. Perig. glockig, ohne Honigbehälter; Antheren an ihrem Grunde mit dem Stbf. verbunden; Narbe sitzend, 3lappig.

Fritillaria. Perig. glockig, am Grunde mit einer Honiggrube, Narbe 3theilig.

Lilium. Perig. glockig trichterf.; Perigtheile mit honigführender Längsrinne; Antheren aufliegend *); Griffel keulenförmig ; Narbo 3lappig.

Anthericum. Perig. ausgebreitet, ohne Honigbehälter; Blthstiele mit Gelenkknoten; Antheren aufliegend; ") Narbe stumpf.

Ornithogalum. Perig, ausgebreitet od, glockig, ohne Ifonigbeh.; Blthstiele ungegliedert; Antheren aufliegend; Narbe stumpf.

Gagea. Perig. ausgebreitet, ohne Honigbeh. (gelb); Antheren an ihrem Grunde mit d. Stbf. verbunden; Narbe 3kantig.

Scilla. Perig. fast glockig, olne Honigbeh. (blau); Antheren aufliegend; Narbe stumpf.

Allium. Perig. glockig od, ausgebreitet, ohne Honigbeh.; Antheren aufliegend; Narbe stumpf; Blüthenstand von einer Scheide während d. Knospung umschlossen.

b) Perig. 6zähnig.

Muscari. Perig. kugelig-eiförmig od. walzlich; Stbgef. dem Perigon eingefügt.

\section{8\%. Tulipa $L$. Tulpe.}

917. T. sylvestris $L$. Wilde T.; Bl. lineal-lanzettl.; Schaft kahl 1blth.; innere Perigonglieder u. Stbgef, am Grunde bärtig. 4. 1'. $Z$ w. eiförmig; Perig. gelb.

") d. ho in der Mitte befestigt. 
In Weinbergen bei H., in der Nähe des Dreitrögethales und oberhalb der früheren Krappfabrik! Am Philosophenwege, nahe bei Neuenheim (Stud. Gysscr). Auch häufig an der Grenze des Geb. b. Berghausen unfern Speier (Dr. Walz). April, Mai.

\section{[Hritillaria $L$. Schachblume.]}

[F. Meleagris L, Gemoine Sch.; Schaft 1-2blth; Bl. lineallanzettl., rinnig; Perig. glockig, röthlich, schachbrettartig gefleckt, selten wciss. 4. 1'.

N. V. a. d. Geb, in Rhb, auf Wiesen bei Wachenheim (Dr. Koch)! April.]

\section{Lilium L. Lilie.}

918. L. Martagon $I$. Türkenbund-L.; St. beblättert; B1. quirlig od. wechselst., elliptisch-lanzettl, zugespitzt; Traube locker; 13lth. nickend; Perigonglieder zurückgerollt. 4. 1-2'. Perig. violett-fleischroth, braungefleckt. Zw. schuppig, goldgelb.

In schattigen Gebirgswäldern nicht häufig, z. B. Beiermühle bei Leimen! hie und da zwischen Leimen, Nussloch und NIaischbach 1 Zwischen Schriesheim und Leutershausen (Schimp.). Juni, Juli.

[In d. Nähe des Geb. fehlend, N. V.: Taunus; Oberhessen (Schnttsp.), Donnersberg (F. Sch.).

\section{A in the ricum $L$. Graslilie.}

919. A. Liliago $L_{\text {. }}$ Gemeine G.; Bl, grundst, lineal, etwas rinnig, graugrün; Schaft aufrecht; Traube fast einfach; Griffel etwas gebogen. 4. I $-2^{\prime}$. St. (wie d. folgende Art) am Grunde wenig verdickt, keine $Z$ wiebelbildung. Wstock kurz; Perig. weiss.

Auf sonnigen, trockenon Hügeln, in Nadelwäldern, auf trockenen Wiesen hie und da (Kalk- und Sandboden). In Menge bei Friedrichsfeld! beim Relaishauso! auf den Sandfächen gegen Seckenheim und Käferthal! beim Naischbacher Hof! bei Nussloch! Leimen! häufig bei Weinheim! am Oelberge bei Schriesheim! an d. Itillenbach bei IIandschuchsheim! vereinzelt beim Haarlass! Mai, Juni.

920. A. ramosum $L$. A estige G.; dem vorigen ähnlich, in allen Theilen etwas kleiner und schwächer; B1. kürzer; Blthstand rispig; Griffel fast gerade. 4. $1-1 \frac{1}{2}^{\prime}$. Perig. weiss, sehr hinfällig.

An ähnlichen Standorten wie die vorige, stellenweiso verbreiteter, z. B. in der Gegend von Wiesloch und Nussloch! Mit der 
vorigen längs der Bergstr.! beim Haarlass! Auch an grasreichen Rainen und trockenen Hügeln der Ebene von Mannheim und Friedrichsfeld bis Waghäusel, Ketsch nicht selten!

\section{Oruithogalum $L$. Milchstern.}

921. 0. umbellatum $L$. D ol den tra u b g er M.; Bl. grundst., schmal lineal, rinnig; Blth. doldentraubig; Deckbl. kürzer als d. Blthstiele; Fruchtstiele weit abstehend; Stbfäden pfriemlich, einfach. 4. $6-10^{\prime \prime}$. Perig. weiss, aussen grün. $Z_{w}$. (wie b. d. folg.) schaalig.

Auf Aeckern und Triften hio und da, z. B. Ladenburg! Weinheim! Schwetzingen! Eppelheim! zwischen Wiesloch und Dielheim! häufig in Weinbergen, z. B. oberhalb Handschuchsheim und Neuenheim! Philosophenweg! gegen Ziegelhausen etc. April, Mai.

922. O. nutans $L$. Nickender M.; Bl. grundst. lineal, rinnig; Traube fast einseitswendig; Blth. nickend; Deckbl. von der Länge der Blüthenstiele; Stbfäden an der Spitze 3zähnig. 4. 1'. Perig. weiss, aussen grün.

In Gebüschen, Weinbergen, Grasgärten hie und da, z. B. bei H. im Carmeliterwäldchen und in d. Umgebung des Schlosses! bei Handschuchsheim! Ursprünglich höchst wahrscheinlich verwildert, jetzt gleichsam eingebürgert. April, Mai.

391. Gagea Salisb. Gelbstern.

923. G. Iutea $R$. et Sch. WaId-G.; Zw. einzeln, aufrecht, mit 1 grundst. lineal-lanzettl. rinnigem Bl.; Schaft kürzer als d. Bl.; Doldentraube 2-6blth, am Grunde mit 2 Deckbl; Blthstiele kahl; Perigbl. längl.-stumpf, grünlich gelb. 4. 4-8".

Auf Waldwiesen, in schattigen Wäldern, Gebüschen, Hecken hie und da. In Menge in den Thälern bei Weinheim! zwischen Leutershausen und Schriesheim! seltener auf d. Teufelskopf bei Dielheim! bei Wiesloch! auf Wiesen dicht vor Rohrbach! Zwischen Waghäusel und Kirrlach! April, Mai.

924. G. arvensis R. et Sch. Feld-G.; Zw. 2, aufrecht mit gemeinsamer Umhüllung, mit 2 linealen fadenförmigen, zurückgebogenen Bl.; Schaft kürzer als d. Bl.; Doldentraube 3-8blth, am Grunde mit 2 Deckbl.; Blthstiele kurzzottig; Perigonbl. lanzettl., zugespitzt, gelb. 4. 3-5"; graugrün.

Auf Aeckern, in Weinbergen auf sandigem od. lehmigem Boden häufig! April, Mai.

[Q. saxatilis Koch. Felsen-G.; ZW. wio d. vorige, mit 2 
fadenförmigen zurïckgebogenen 11.; Schaft kürzer als d. Bl.; 1-2blth, mit 2 Deckbl.; Blthst. zottig; Perigonbl. längl.-lanzettl., stumpf, gelb. 4. 1-3".

N. V. a. d. Geb.: Rhb.: Kalkhügel bei Callstadt! März.|

925. G. pratensis $R$, et Sch. Wiesen-G. Zw. 3 getremnt wagerecht, verlängert (von keiner gemeinsamen IHïllo umschlossen), mit 1 lineal-lanzettl., spitzem, gelieltem Bl.; Schaft kürzer als dio Bl. 2-4blth, mit 2 Deckbl.; Blthst. kahl; Perigonbl. lineal-lanzottl., gelbgrün. 24. 4-6". (G. stenopetala Rchb.).

Auf Aeckern, Sandfeldern, lehmigen Triften hio und da, z. B. zwischen dem Relaishause und Schwetzingen! bei Eppelheim! Ladenburg! Käferthal! März, April.

\section{Scilla $L$. Meerzwiebol.}

926. S. bifolia $L . Z$ weibl. M.; Schaft stielrund, aufrecht, mit 2-3 hellgrünen, lineal-lanzettl., rinnenförmigen, stumpfen Bl.; Traube armblth, aufrecht, meist deckblattlos; Perigonbl. ausgebreitet, längl., hellblau (selten weiss). 24. 4-6". 'Zw. eirund.

In Wäldern, Gebüschen, auf Waldwiesen nur stellenweise, z. B. in Menge im Carmeliter-Wäldchen bei H.! bei Neckarsteinach! seltener zwischen dem Stift Neuburg und Ziegelhausen! Häufig im Neckarauer Walde! bei Weinheim (Döll.). März, April.

\section{Alli IIm L. Lauch.}

a) Staubfäden alle einfach, pfriemlich.

927. A. ursinum $L$. Bärenla u ch; Schaft 3kantig; BI. grundst., langgestielt, elliptisch-lanzettl.; Dolde locker, fast flach, nur kapseltragend, mit 2-3spaltiger Scheide; Perigonbl. sternförmig ausgebreitet, lanzettl., spitz, weiss. 4. 6-10". Zw. dünn, spindelförmig. - Widerlich riechend.

In schattigen etwas feuchten Laubwäldern häufig, z. B. in grosser Menge hinter dem Haarlass! bei Leimen! im Schwetzinger Schlossgarten! bei Ketsch! Waghäusel u. s. w. Mai.

928. A. acutangulum Schrad. Scharfkantigor L.; Schaft oben scharfkantig; Bl. grundst., schmal lineal, flach, stumpf; Dolde gewölbt, reichblth, nur kapseltragend, mit 2-3spaltiger Scheide; Perigon becherförmig; Zipfel lineal-längl., spitz, rosa (selten weiss); Stbgef. von d. Länge des Perig. 4. 1'. Wstock wagrecht, kaum zwiebelig verdickt.

Auf feuchten Wiesen der Rheinfläche verbreitet, stellenweise sehr gesellig, z. B. zwischen Neckarau und dem Rohrhof! b. Kotsch! 
Lussheim! Waghäusel! Auch zwischen St. Ilgen und Sandhauson! zwischen Handschuchsheim und Dossenheim! Juni-August.

929. A. oleraceum $L$. Gem üs e-L.; Schaft stielrund, bis zur Mitto beblättert; Bl. lineal, rinnig, gegen die Spitze flach; Dolde ausser wenigen langgestielten Blth. zahlreiche Brutzwiebeln tragend; Blthscheide 2theilig, d. eine Theil sehr verlängert; Perigbl. längl., spitz, grünlich od. röthlich; Stbgef. fast so lang wie d. Perig. 4. 1-2'. Zw. kugelig-eiförmig.

In Gebiischen, Weinbergen, auf somnigen IIügoln, Triften hie und da, z. B. beim Relaishause! bei Neckarau! Schwetzingen! häufig zwischen Rauenberg und Malsch! Juni-August.

930. A. carinatum $L$. Gekielter L.; Schaft stielrund, his zur Nitte beblättert; BI. lineal, flach, am Grunde gekielt; Dolde d. vor. Art; Stbgef. länger als d. Perig.; Perigbl. längl., stumpf, roth. 4. $1-1 \frac{1}{2}^{\prime}$. Z $\mathrm{Zw}$. kugelig-eiförmig.

Nur an der Grenze d. Geb. am Rheindamm zwischen Ketsch und Philippsburg (Döll.). Juni, Juli.

[Scheint mit dem Rhein aus den Alpen herabgeschwemmt zu sein.]

b) Die inneren 3 Staubfädon 3spitzig, die mittlere Spitze die Anthere tragend.

931. A. Scorodoprasum $L$. Sand-L.; Schaft bis zur Mitte beblättert; Bl. flach, breit lineal, am Rande rauh; Dolde liugelig, schwärzlich-riolett, Brutzwiebeln tragend, die wenigen Blthen meist verdrängt; Blthscheide 2-3theilig; Stbgef. kürzer als d. Perig. 4. $1 \frac{1}{2}-2^{\prime}$. Z w. mit wenigen Brutzw.; Blth. purpurn. (A. arenarium Sm.)

In Gebüschen, Zïunen, an Gräben, Waldrändern stellenweise, bei Handschuchsheim, z. B. im Mühlenthal und an der Chaussee nach Dossenheim! Zwischen Rohrbach und Leimen! bei Brühl! Schwetzingen, Neckarau, Mannheim. Juni, Juli.

932. A. vineale $L$. We inbergs-L.; Schaft bis zur Mitto beblättert; Bl. stielrund, hohl, etwas rinnig; Dolde kugelig, grünliche Brutzwiebeln tragend, die wenigen Blthen meist verdrängt; Blthscheide einfach linealisch, verlängert; Stbgef. länger als d.Perig. 4. 1-2'. Zw. mit mehreren Brutzw.; BIth. hellroth.

Auf sandigen Aockern, Sandfeldern, in Weinbergen, an Rainen ziemlich verbreitet, z. B. am Philosophenwego bei II.! an den Felsen vor dem Haarlass! zwischen IIandschuchsheim und Ladenburg! $\mathrm{zwischen} \mathrm{Friedrichsfeld} \mathrm{und} \mathrm{dem} \mathrm{Relaishause!} \mathrm{bei} \mathrm{Wiesloch!} \mathrm{Juni}$ bis August.

933. A. sphaerocephalum $L$. IK ugelküpfiger L.; Schaft 
bis zur Mitte beblättert; B1. halbstielrund, rinnig;") Dolde kugelig, reichblth., nur kapseltragend; Blthscheido einfach, kurz; Perigonbl. aussen glatt, kürzer als Stbf. und Griffel. 24. 1-1 $\frac{1}{2}^{\prime}$. Zw. mit mehreren grösseren, meist 3kantigen Brutzw.; Blth, purpurroth.

Auf Sandflächen, trockenen Hügeln, in Weinbergen nicht selten, z. B. bei Sandhausen! zwischen Friedrichsfeld und dem Relaishause! häufiger beim Rohrhof! Schwetzingen! Oftersheim! und auf den Sandflächen d. Geb. stellenweise. Auch bei II. in Weinbergen bei der früheren Krappfabrik ( $D \ddot{\prime l l l}$ ). Juni, Juli.

934. A. rotundum $L$. Rundköpfiger L.; Schaft bis zur Mitte beblättert; Bl. lineal, flach; Dolde fast kugelig, reichblth, nur kapseltragend, mit einfacher, kurzer Blthscheide; Perigonbl, aussen rauh, so lang wio d. Stbf. u. Griffel. 4. 1-2'. Zw. mit zahlreichen kleinen gestielten Brutzw.; Blth. purpurroth.

In Weinbergen, an Rainen, auf Mauern, Sandfeldern hie und da, z. B. häufig am Philosophenwege und am Wege nach dem Haarlass bei H.I in den Weinbergen zwischen Handschuchsheim und Dossenheim! Auf den Sandflächen bei Schwetzingen! Hockenheim, Sandhausen, daselbst jedoch viel seltener als d. vorigo Art! Juni, Juli,

\section{II us cari Tournef. B is amhyacinthe.}

935. M. comosum Mill. Schopfö̈rmige B.; BI. lineal, rinnig, kürzer als d. Schaft; Blüthen in verlängerten Trauben, kantig-walzenförmig, untere wagrecht abstehend, fruchtbar, obere schopfförmig, gedrängt, aufrecht, geschlechtslos. 4. 1-1 $\frac{1}{2}^{\prime}$. Blth. hellblau. $Z_{w}$. eiförmig (wie bei d. folg.).

Auf sandigen Aeckern, in Weinbergen hie und da, z. B. häufig bei Hockenheim! Reilingen! Alt- und Neu-Lussheim! seltener bei Schwetzingen! Brühl! beim Relaishause! zwischen Wiesloch und Rauenberg! Stellenweise auch zwischen Schriesheim und Ladonburg! bei Handschuchsheim und Edingen (Stud. Gysser). Juni.

936. M. racemosum Mill. Traubige B.; Bl. schmal lineal, rinnig, zurückgekrümmt, zur Blüthezeit an den Spitzen schon absterbend; Traube kurz gedrängt; Blthen nickend, eiförmig, die oberen aufrecht, geschlechtslos. 4. 5-8". Blth. dunkelblau, bereift, wohlriechend.

Auf sandigen und lehmigen Aeckern, Triften, in Weinbergen stellenwcise, z. B: ziemlich häufg bei Ladenburg! und von dort

-) Zur Blüthezeit sind die Bl. bei dieser Art und den verwandten Arten meist verdorrt. 
vereinzolt bis Handschuchsheim und Neuenheim! Auch bei Leimen? Wiesloch. April, Mai.

937. M. botryoides Mill. St e if blätt. B.; dem vorigen ähnlich; dio Bl. kürzer, aufrecht-abstehend, breiter, flachrinnig, zur Blüthezeit an den Spitzen noch nicht absterbend; Traube gedrängt; Blth. nickend, elliptisch-kugelig, die oberen aufrecht, geschlechtslos. 4. 4-6". Blth. dunkelblau, bereift, fast geruchlos.

Auf Sandfeldern, an Rainen stellenweise, seltener als d. vorigen, z. B. auf dem Sande bei der Mannheimer Spiegelfabrik mit Carex supina! beim Relaishause! in d. Gegend von Käferthal u. Schwotzingen (Döll.). April, Mai.

\section{COLCHICACEAE De Cand.}

Kräuter mit zuweilen knolligen Wurzelstöcken od. Zwiebelknollen, einfachen Blättern und regelmässigen Blüthen. Perigon gefärbt, 6blätterig oder 6theilig, unterständig. Staubgef. 6 dem Fruchtboden oder (bei den Gattungen der Flora) dem Perigon eingefügt. Fruchtknoten frei, 3fächerig, mit 1-3 Griffeln und randständigen Samenträgern. Frucht balgkapselartig mit vielen eiweissreichen Samen.

To fieldia. Perig. 6blätterig, Perigbl. kurzbenagelt; Griffel 3 kurz, mit kopfförmigen Narben; Balgk. 3kantig.

Colchicum. Perig. 6spaltig, trichterförmig, mit langer Röhre, Griffel 3 mit sehr verlängerten Narben; Balgkaps. aufgeblasen.

\section{Tofieldia Huds. T ofieldie.}

938. T. calyculata Wahlbg. Kelchblüthige T.; kahl; St. aufrecht, armblätterig; Bl.meist grundständig, lineal, grasartig, spitz; Aehre endständig, meist verlängert; Blüthen von 3 kleinen kelchartig verwachsenen Deckblättchen unterstützt. 4. $\frac{1}{2}-1 \frac{1}{2}^{\prime}$. W. faserig; Blth. gelb.

Auf etwas torfhaltigen Wiesen, an bewaldeten Abhängen, Waldrändern hie und da, z. B. häufig am Teufelskopf bei Dielheim! beim Maischbacher Hof! im Oberhofer Walde bei Schatthausen! Seltener bei Weinheim, z. B. am Wagenberg! bei Lüzelsachsen (Dierb.). Juni, Juli.

[Auch in d. Näho d. Geb. in B. u. Hs. verbreitet, selten in Rhb, z. B. auf Wiesen bei Hanhofen unfern Speyer!] 


\section{Colchicum $L$. Zeitlose.}

939. C. auctumnale $L$. Horbst-Z.; Bl. grundst., breitlanzettl., spitz, glänzend, im Frühling sich entwickelnd; Blthen einzeln od. 2-3 auf kurzem Schaft, innere Perigonzipfel schmäler als die äusseren. 4. Zwknollen eirund; Perig. fleischroth, im Aug. und Sept. erscheinend; Früchte den Winter über unterirdisch, entwickeln sich im Frühling des folg. Jahres mit d. Bl.

Auf feuchten Wiesen allgemein verbreitet. (Off.: Rad, et sem. Colohioi).

\section{JUNCACEAE Bartl.}

Ausdauernde oder einjährige Kräuter mit grasähnlichen Stengeln (Halmen), einfachen stielrunden oder flachen, mit Scheiden versehenen Blättern, doldentraubigen od. ährenartigen Blüthenständen. Blüthen regelmässig, zwitterig. Perig. unterständig, 6 gliederig, bleibend, mehr oder weniger trockenhäutig, und meist von $2-3$ trockenhäutigen Deckblättchen unterstützt. Staubgefässe 6 , selten 3 , im Grunde des Perigons eingefügt. Fruchtknoten 3 fächerig, vieleiig oder 1 fächerig 3 eiig. Griffel 1 mit 3 meist fädlichen Narben. Kapsel 3klappig. Samen eiweisshaltig. Durch Geselligkeit ausgezeichnet. Die Juncus.-Arten nassen, sumpfigen Boden, Luzula-Arten Waldboden liebend. Das reichliche Vorhandensein der Juncaceae schliesst gewöhnlich die übrige Vegetation aus und ist immer ein Zeichen grosser Unfruchtbarkeit des Bodens.

Luzula. Kapsel Ifächerig, ohne Scheidewand, 3samig; Stbgefässe 6.

Jun cus. Kapsel 3fächerig, mit mittelständiger Scheidewand, vielsamig; Stbgef. meist 6 , seltener 3 od. 4-5.

\section{9\%. Luzula De Cand. Ha insimse.}

(Die Arten haben alle einen einfachen, beblätterten Stengel, flache, grasartige, mehr oder weniger behaarte Bl. und kleine unscheinbare Blüthen.)

a) Blthstand doldentraubig.

940. L. pilosa Willd. Behaarte H.; Bl. lanzettl.-lineal, zottig gewimpert; Doldentr. einfach mit 1-3blüthigen, nach dem Verblühen zurückgebogenen Aesten; Perigonzipfel spitz, etwas kür- 
zer als die Kapsel; Samen rnit sichelfürmigem Anhängsel. - Lockere Rasen bildend, ohne Auslïufer; Perig. u. Kapsel braun. $\frac{1}{2}-1^{\prime}$. (L. vernalis DC.).

In schattigen Laubwäldern, auf Waldwiesen häufig. April, Mai.

(L. Forsteri DC., wclcho sich durch dic stets aufrechten Verzweigungen des Blüthenstandes, durch gerade stumpfo Anhängsel iler Samen, hellbraune Kapseln, auch durch schmälere Bl. unterscheidet, ist bisher im Geb. der Flora noch nicht nachgewiesen. Es wird dies aber vielleicht in der Wieslocher Gegend, etwa in den Gebirgswäldern zwischen Rauonberg und Malsch, um so mehr möglich sein, als dio Pflanze schon in nicht grosser Entfernung in den Bergwäldern zwischen Bruchsal und Grombach verbreitet ist. Mai, Juni.)

941. L. maxima $D C$. Grösste II.; Dl. breit lineal-lanzettl., langgewimpert; Doldentraube mehrfach zusammengesetzt, länger als d. unterste Deckbl.; Verzweigungen an den Enden meist 3blth.; Perigzipfel stachelspitzig, von der Länge der Kapsel ; Samen ohne Anhängsel. 24. 1-2'. Perig. dunkelhraun. - Lockere Rasen bildend, ohne Ausläufer.

In Gebirgswäldern häufig, besonders bei II. diesseits und jenseits des Neckars sehr verbreitet! Mai, Juni.

942. L. albida $D C$. Weissliche II.; Bl. schmal lineal, gewimpert; Doldentraubo mehrfach zusammengesetzt, kürzer als das unterste Deckbl,; Bith. an den Enden der Zweige büschelig; Perig.zipfel stachelspitzig, lïnger als die Kapsel; Samen mit kurzem Anhängsel. 4. 1-1 $\frac{1}{2}^{\prime}$. Perigon gelblich-weiss. - Variirt:

$\beta$ ) rubella Hoppe; Perigon röthlich-braun.

In Wäldern der Gebirge und der Ebene häufig! Die Var. z, B.: auf dem Oelberge bei Schriesheim! Juni-August.

b) Blthstand aus mehr oder weniger gedrängten Aehrchen bestehend; Samen mit einem kegelfürmigen Anhängsel.

943. L. multiflora $L \epsilon j$. Vielb Ith. II.; Bl. lineal, am Rande gewimpert, zuletzt kahl werdend; Aehrchen ciförmig, 5-9, d. endständige fast sitzend, die seitenständigen lang gestielt, aufrecht; Perigonzipfel spitz, länger als d. Kapsel; Antheren nach der Blüthe 2-3mal so lang als d. Stbfäden. 4, $\frac{3}{4}-1^{t}$. Olne Ausläufer. Pcrigon gelbbraun. - Variirt:

B) pallesecns; schlanker; Achrchen 3-4, strohgelb.

Auf Waldtriften, Haiden, in trockenen Wäldern häufig, besonders im Gebirge. In der Nähe von H. diesseits und jenseits des 
Neckars, z. B. hinter dem IIaarlass! am Geisberge! liings der Bergstrasso ziemlich verbreitet, scheint seltener in der Wieslocher Gegend. Dio Var. entsteht an sehr schattigen Standorten, z. B. hinter dem Iraarlass! im Dreitrüge Thal bei H.! im Mühlenthale b. IIandschuchsheim! April, Mai.

944. L. campestris I) $C$. Gem. II. ; Bl. lineal, am Rande gowimpert, zuletzt kahl werdend; Achrchen eiförmig, $3-5$ mehr oder weniger gedrängt, die seitlichen gestielt, etwas nickend; Perigonzipfol spitz, länger als d. Irapsel; Antheren nach der Blüthe etwa 4 mal so lang als d. Staubf. 24. 3-6". Auslïufer kurz, bogenförmig. Perigon braun.

bis Mai.

Auf Wiesen, Triften, an Waldrüneern überall häufig. März

\section{Jun us $L$. Binse (Simse).}

a) Halm aufrecht, blattlos, am Grunde mit Scheiden; Blthstand endständig, büschelig oder gelinäuelt, von dem pfriemlichen

Declibl. zur Seite gedrängt, daher scheinbar seitlich.

945. J. conglomeratus $L$. Geknäuelto B.; Halme aufrecht, fein gestreift, hellgrïn, mit ununterbrochenem Mark; Blthstani knäuclartig oder etwas büschelig; das Deckbl. vielmal kürzer als der Ilalm; Perigonzipfel so lang wie die 3liantige gestutzte, oben etwas rertiefte, fein zugespitzte Kapsel; Griffel kurz; Stbgef. 3. 4. 1-2'. Perigon hellgrün; Wzst. liricchend; Blttscheiden gelbbraun.

Auf feuchten Triften, in Sïmpfen, Gräben sehr verbreitet. Juni bis August.

946. J. effusus $I$. Flatter-B.; dem vorigen ähnlich, aber IIalme fast glatt; Blthstand meist ausgebreitet, seltener etwas geknäuelt; Perigonzipfel so lang wie dio 3kantige gestutzte, rertiefte, nicht zugespitzte Krapsel; Griffel kurz; Stbgef. 3. 4. 1-2'. Perig. hellgrün.

Auf feuchten und sumpfigen Triften, in feuchten Wäldern, an Uferm überall verbreitet. Juni-August.

947. J. glaucus Elirh. Blaugrüne B.; Halme aufrecht, tief gestreift, blaugrün, mit fächerartig unterbrochenem Nark; Blthstand büscholig, verzweigt; die Deckbl. vicl kürzer als der Halm; Perig.zipfel lanzettl., zugespitzt, von der Länge der elliptischen kurz-

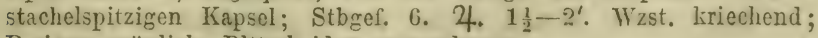
Perigon grünlich; Blttscheiden purpurbraun.

Auf feuchten Triften, besonders an Ufern und auf Sumpfwiesen häufig. Juni-August. 
b) Halme mit mehr oder wenigen stielrunden, durch Queerwände fächerigen Blättern; Blthstand aus endständigen

Köpfchen oder büscheligen Rispen bestehend.

948. J. obtusifiorus Ehrh. Stumpfblth. B.; Halmo aufrecht, stielrund, meist 2blätterig; Rispe wiederholt zusammengesetzt, sperrig-ästig; Perigonzipfel gleich lang, länglich-lineal, stumpf, so lang wie die 3kantige, spitze, hellbraune Kapsel; Stbgef. 6. 2. $2-3^{\prime}$. Wzst. kriechend; Blth. blassgelb.

Auf nassen Wiesen, in Torísümpfen, Gräben hie und da, z. B. häufig bei Brühl! Waghäusel! Sandtorf! zwischen St. Ilgen und Kirchheim! zwischen Handschuchsheim und Ladenburg! JuniAugust.

949. J. sylvaticus Reich. Wald-B.; Halme aufrecht, etwas zusammengedrückt, 3-4blätterig; Rispe mehrfach zusammengesetzt, verlängert, abstehend-ästig; Perigonzipfel lanzettlich, zugespitzt, die inneren länger als die äusseren, alle kürzer als die 3kantige, lang zugespitzte hellbraune Kapsel; Stbgef. 6. 4. 11 $\frac{1}{2}-2^{\prime}$. Wzst. kurz kriechend; Blth. braun. ( $J$. acutiflorus Ehrh.)

Auf sumpfigen Waldwiesen, in feuchten Gebüschen, an Ufern stellenweise häufig, z. B. auf den nassen Bergwiesen bei H.: Engelswiese! beim Stift Neuburg! im Mühlenthal bei Handschuchsheim! Auch in den Sumpfgegenden am Rheine, z. B. bei Ketsch! Waghäusel! beim Rohrhof! Juni--August.

[J. atratus Krocker. Schwarzbraune B,; dem vorigen ähnlich; Halme mehr aufsteigend; Perigonzipfel glänzend schwarzbraun, fast gleich gross, so lang als die kurz zugespitzte Kapsel. 4. 2-3'. Blth. etwas grösser als bei der vorigen.

N. V. a. d. Geb.: in Rhb. zwischen Schifferstadt und Mutterstadt auf einer sumpigen Wiese nahe der Eisenbahn, und einige 100 Schritte vom Walde (Dr. Walz). Juni-August.]

950. J. lamprocarpus Ehrh. Glanzfrüchtige B.; Halme aufrecht oder aufsteigend, beblättert, wie d. Bl. stielrund zusammengedrückt; Bl. mit äusserlich sehr wahrnehmbaren Queerscheidewänden; Rispe mehrfach zusammengesetzt, abstehend ästig; Perig.zipfel gleich lang, stachelspitzig, die äusseren spitz, die inneren stumpf, alle kürzer als die 3kantige stachelspitzige, glänzend braune Kapsel; Stbgef, 6. 2. 1-2'. Blth. grünlich braun; Wzst. kurz kriechend.

Auf feuchten Wiesen, Triften, in Sümpfen allgemein verbreitet. Juni-August.

951. J. alpinus Vill. Alp en-B.; Halm aufrecht, meist 2blätterig, wie die Bl. etwas zusammengedrückt; Rispo aufrecht-ästig; 
Perigonzipfel gleich lang, abgerundet, innere stumpf, äussere unter der Spitzo kurz stachelspitzig, kürzer als die 3kantige, stachelspitzige glänzend braune Kapsel; Stbgef. 6. 4. 1-1 $\frac{1}{2}^{\prime}$. Blth. schwarzbraun; Wzst. kurz kriechend.

Auf nassen Triften, in Torfsümpfen der Rheinfläche hie und da, z. B. zwischen dem Rohrhof und Brühl! bei Waghäusel! bei Sandtorf? Juli, August.

[J. supinus Moench. Sump f-B.; Halme aufrecht oder niederliegend, zuweilen kriechend, fadenförmig; Bl, borstlich, schmalrinnig; Rispe einfach verlängert, mit wenigen entfernten Knäueln; Perig.zipfel lanzettl., kürzer als die stumpf 3 kantige stachelspitzige Kapsel; Stbgef. meist 3. 4-10". Bith. grünlich-braun.

Vorkommen im Gebiet der Flora unsicher. Vielleicht b. Sandtorf? An entsprechenden torfhaltig-sandigen Stellen jenseits des Rheines bei Maxdorf und Speyer. Juni-August.]

952. J. capitatus Weig. Kop fförmige B.; Halm am Grunde beblättert; Bl. borstlich-rinnenförmig; Blthköpfchen kugelig, endständig, einzeln oder $1-2$ seitenständige; Perigonzipfel lanzettlich, fein zugespitzt, länger als die Kapsel; Stbgef. 3. ๑. 2-4". Blth. grün-bräunlich. (J. ericelorum Poll.)

Auf feuchten Sandflächen, sandigen Triften und Haiden selten. Zwischen Schünau uud Neckarsteinach (Dierb.)

[N. V. a. d. Geb.: zwischen Maxdorf und Dürkheim! Spejer ( $F$ Schultz). In IIs.: in der Gegend von Darmstadt verbreitet (Schnttsp.). Juni-August.

c) IIalme etwas zusammongedrückt; Blätter rinnig oder flach; Blüthenstand doldentraubig.

953. J. compressus Jarq. Z us a m meng edrückte B.; Halm armblätterig; Bl. schmal lineal, rinnig; Doldentraube mehrfach zusammengesetzt, aufrecht, locker; Perigonzipfel elliptisch, stumpf, kürzer als die rundlich-ovale, kurz stachelspitzige Kapsel; Stbgef. 6. 4. 3-1'. Blth. hellbraun; Antheren fast von der Länge der Staubfäden. (J. bulbosus L.)

Auf feuchten Wiesen, Triften, an Wegen allgemein verbreitet und oft sehr gesellig. Juni-August.

[J. Gerardi Lois. Ifalm und Bl. der vorigen; Doldentraube weniger locker; Perigonzipfel elliptisch, fast so lang als die rundlichlängliche, deutlich stachelspitzige Kapsel; Stbgef. 6. 4. ${ }^{3}-1^{\prime}$. Blth. dunkıer braun; Antheren verlüngert, wenigstens $2 \mathrm{mal}$ so lang als die Staubräden.

Salzboden liebend. N. V. a. d. Geb.: Salinen bei Dürkheim Juni-August.] 
954. J. Tenageia Eh\%. Sand-B.; IIalme armblätterig; BI. rimnig-borstlich; Doldentraube ausgebreitet, abstehend gabelartigverzweigt; Perigonzipfel ei-lanzettlich, spitz, so lang als die 'rundliche, stumpfe IKapsel. ๑. $3-8^{\prime \prime}$. Blth. grünlich-braun. - Variirt:

$\beta$ ) spluaerocarpus Gren. et Ciodr.; Doldentraube aufrecht verzweigt; Perigonbl. etwas länger als dic Kiapsel.

Auf feuchten, sandigen Triften u. Sandfeldern selten, hinsichtlich der Verbreitung unsicher. Vielleicht bei Sandtorf? Mit Sicherheit nur zwischen dem Relaishauso und dem Altwasser des Rheines (Döll): Juli-September.

[Jenseits des Rheines und in der Nähe des Geb. bei Speyer, Ellerstadt, Maxdorf ( $F$. Schult $\approx$ ).]

955. J. bufonius $L$. Kröten-B.; IIalm beblïttert; BI. borstlich-rinnig; Doldentraube locker, aufrecht gabelartig-verzwcigt; Perigonbl. lanzettlich, zugespitzt, lïnger als die lïngliche, stumpfe Kapsel; Stbgef. 6. ๑. 3-10". Blth, wie die ganze Pllanzo weisslich-grün.

Auf feuchten Triften, Wiesen, Aeckern, an Wegen überall sehr verbreitet. Juni-August.

\section{CYPERACEAE Jus.}

Einjährige oder häufiger ausdauernde grasïhnliche Krïuter: mit oft kriechenden Wurzelstücken, meist 3 kantigen, linotenlosen IIalmen, oft sehr scharfrandigen Blättern und völlig geschlossenen Blattscheiden. Blth. ziemlich unvollständig, zwitterig oder monoecisch, seltener dioecisch, von 1-2 spelzenartigen Deckschuppen umgeben, zunïchst zu aehrenartigen Blüthenständen (Aehrchen) rereinigt. Perig. oft völlig fehlend oder aus 2-mehreren Schuppen oder Borsten gebildet, oder auch aus 2 Schuppen bestehend, welche schlauchartig den Fruchtlinoten innig umschliessen und mit demselben verwachsen. Sthgef. meist 3 , seltener 2, mit aufrecht am Staubf. angewachsenen an der Spitze und am Grunde a b g erund et en An theren. Fruchtlinoten oberständig; mit 1 Griffel und $2-3$ Narben. Frucht nussartig (caryopsis), 3 kantig oder zusammengedrückt. Samen eiweisshaltig. Keim sehr klein, an Grunde des reichlichen mehligen Eiweisses eingeschlossen. - Die Cyperaceae (Halbgräser) licben 
vorzugsweise Sumpfboden, einige wachsen sogar im Wasser, wenigo zichen den dürrsten Sandboden vor; sie treten meist gesellig und nicht selten verhecrond für-die übrige Vegetation auf.

(i) Cypereae. Blth. zwitterig; Deckschuppen 2zeilig.

Cy p erus. Aehrchen vielblüthig, zusammengedrückt, in Trugdolden oder Knäueln; Perigon fehlt; Stbgef. 2-3; Griffel mit 3 Narben.

Schoenus. Aehrchen 3-6blüthig, in endständigen Köpfchen; Perigon aus 1-6 Borsten; Stbgef. 3; Griffel mit 3 Narben.

b) Scirpeac. Blth. zwitterig; Deckschuppen allseitig dachziegelig.

$\alpha$. Untere Decksch, kleiner als die oberen, unfruchtbar.

Cla dium. Aehrchen in zusammengesetzten Trugdolden ; Perig. fehlt; Stbgef. 2; Griffel am Grunde verdickt, vüllig abfallend.

Rhynchospora. Aehrchen in endständigen Knäueln; Perig. Gborstig; Griffel am Grunde abgliedernd, d, Basis bis zur Fruchtreifo bleibend; Narben 2.

$\beta$ ) Untere Deckschuppen grösser als die oberen, gewöhnlich alle fruchtbar.

Heleocharis. Aehrchen einfach, endständig; Perigon 3-6borstig; Stbgef. 3; Griffel mit dem Fruchtknoten durch ein knotenartiges Gelenk verbunden, Griffelbasis erhärtend und bleibend; Narben $2-3$.

Scirpus. Aehrchen einzeln oder mehrfach verbunden: Perig. borstig oder fehlend; Stbgef. 3; Griffel nicht gelenkartig mit dem Fruchtknoten verbunden, Griffelbasis abfallend oder bleibend; Narben $2-3$.

Eriophorum. Aehrchen (bei unseren Arten) doldentraubigbüschelig; Perigon-Borsten zahlreich, nach der Blüthe zu langen, wollenartigen Fasern auswachsend; Stbgef. 3.

c) Cariceae. Blth. meist monoecisch, entweder in einem Aehrchen oder in getrennten Aehrchen, seltener dioecisch; Deckschuppen allseitig dachig.

Carex. Aehrchen mehrblüthig; Stbgef. 3; Fruchtknoten von einem häutigen, flaschenartigen, oft geschnäbelten Schlauch umgeben, welcher als sog. Fruchts chla uch völlig mit der Frucht verwächst; Narben 2-3, aus der Mündung des Schlauches hervorstehend.

\section{Cyperus $L$. Cyperngras.}

956. C. flavescens $L$. Gelblichos C.; Halm stumpf 3kantig; B1. Ilach, lang zugespitzt; Doldentraube kopfartig zusammengesetzt; 
Aehrchen länglich-lineal; Deckschuppen stumpf, scharf gekielt; Narben 2 ; Nüsschen zusammengedrückt, kreisrund. ๑. 2-6". Aehrchen grünlich-gelb.

Auf feuchten lehmigen oder sandigen Triften, sumpfigen Wiesen stellenweise, z. B. in der Nähe von H. in der Hirschgasse (am Wege links, an einer sumpfigen Stelle, aber nicht häufig)! hio und da in. den Sümpfen des Friedrichsfelder Waldes! beim Relaishause! bei Neckarau! sehr vereinzelt beim Rohrhof! August-October.

957. G. fuscus $L$. Braunes C.; Halm scharf 3 kantig; Bl. flach zugespitzt; Doldentraube meist mehrfach zusammengesetzt; Aehrchen lineal; Deckschuppen spitz, scharf gekielt; Nüsschen scharf 3kantig; Narben 3. ๑. 4-10". Achrchen schwarzbraun oder seltener grünlich.

Auf nassen Triften, feuchten Sümpfen, in Torfsümpfen häufiger als vorige, z. B.: Waghäusel! Rohrhof! Neckarau! Relaishaus! Friedrichsfeld! Bei H. zuweilen vereinzelt am Neckarufer! auch in der Hirschgasse! Juli-October.

400. Seloeu us Vahl. Knopfgrás.

958. Sch. nigricans $L$. Schwärzliches K.; rasenbildend; Halme stielrund, am Grunde von schwarzbraunen Scheiden umgeben; Bl. fadenförmig, fast so lang als der Halm; Blthköpfchen endstänrl., eiförmig, mit 5-10 schwarzbraunen Aelrchen; Perigonborsten 1-6, sehr kurz, bisweilen fehlend. 4. $1^{\prime}$.

Auf Torfwiesen bei Waghäusel stellenweise gesellig! [Nördlichstes Vorkommen in B., scheint bei Sandtorf zu fehlen, obwohl vorkommend auf torfhaltigen Wiesen jenseits des Rheines zwischen Frankenthal und Dürkheim!] Mai, Juni.

\section{Cl all ium P. Brown. Su m p fgras.}

959. C. Mariscus $R . B r . G \in \mathrm{m} . \mathrm{S}$; ; IJalm fast stielrund, steif aufrecht; Bl. starr, am Kiel und an den Rändern scharf gesägt; Aehrchen kopfartig-gedrängt in wiederholt zusammengesetzten Rispen. 4. 2-3'. Wzst. kriechend; Aehrchen rothbraun. (C. germanicum Schrader.)

Auf torfhaltigen Sumpfwiesen bei Waghäusel hie und da; stellenweise, z. B. in der Nähe der Lussheimer Chaussee, gesellig! Juni bis August.

[N. V.: in B. im Oberlande (Döll), in Rhb. und Hs. fehlend.] 
402. Rhyuch ospor a Vahl. Schnabelsame.

960. R. alba Tahl. Woisser S.; Halm aufrecht, 3kantig; Bl. lineal, flach; Aehrchen kopfförmig gedrängt, endständig, fast so lang wie die äusseren Deckbl.; Perigonborsten von der Länge des Nüsschens. 4. $\frac{1}{2}-1^{\prime}$. Aelirchen weiss; Stbgef. 2 ; ohne Ausläufer. (Schoenus albus L.)

Bisher nur an der Grenze des Geb. oberhalb Sulzbach, unweit Weinheim (Dierb.) Juli, August.

[N. V. a. d. Geb.: Im hess. Odenwald b. Ober-Mossau (Schnttsp.) In Rhb.: Kaiserslautern ( $F$. Schultz).]

961. R. fusca $R$. et $S c h$. Brauner S.; Halm aufrecht, 3kantig; Bl. fadenförmig; Aehrch. kopfförmig gedrängt, endständig, kürzer als die äusseren Deckbl.; Perigonborsten länger als die Nüsschen. 4. 5-10". Aehrchen braun; Stbgef. 3; Ausläufer kriechend. (Schoenus fuscus $\mathrm{L}$.) August.

Auf torfhaltigen Wiesen bei Schönau (Dierb, Düll). Juli-

[Höchst wahrscheinlich auf den höheren Bergen des Odenwaldes nachzuweisen. N. V.: Frankfurt a/M.; Kaiserslautern.]

403. Il ele o char is $R . B r$. S a m p f b inse.

962. H. palustris $R . B r$. Gem. S.; Halm aufrecht, etwas zusammengedrückt, bläulich-grün, glanzlos, am Grunde von $2-3 \mathrm{ab}-$ gestutzten Scheiden umgeben; Aehre endständig, länglich-lanzettlich, am Grunde von 2 abgerundeten Deckschuppen umfasst; Perigon 4 borstig, so lang als das stumpflantige, glänzende Nüsschen. 4. $1-2^{\prime}$. Wzst. kriechend; Aehre gelbbraun. (Scirpus palustris L.)

An Ufern, auf nassen Wiesen und Triften überall häufg. Juni, Juli.

963. H. uniglumis $L k$. Ein spelzige S.; Halm aufrecht, stielrund, glänzend, grasgrün, am Grunde von $2-3$ abgestutzten Scheiden umgeben; Aehre länglich-lanzettl., am Grunde ron der untersten Deckschuppe ganz umfasst; Perigon 4borstig, so lang als das stumpfkantige, glänzende Nüsschen. 4. $\frac{1}{2}-1 \frac{1}{2}^{\prime}$. Wzst. kriechend; Aehre gelbbraun. (Scirpus uniglumis II. et $\bar{K}$.)

Auf sumpfigen Wiesen, in Sümpfen, an Ufern stellenweise häufg, z. B. in Menge auf den Wiesen zwischen Gaiberg und Sehatthausen! an Sumptstellen $z$ wischen Dielheim und Rauenberg! Am Neckar bei Neuenheim! Bergheimer Müble u. s. w. Auch hie und da am Rheinufer. Mai- Juli.

964. H. acicularis R. Br. Nadelförmige S.; zwergartig, hellgrün; Halme meist zahlreich, büschelig, fadenförmig, zart, stielSCHMIDT, Flora v. H。 
rund; Achre endständig, eirund; Deckschuppen stumpf; Narben 3; Nüsschen länglich, zusammengedrückt, fein gerippt, queerstreifig. ๑. $2-3^{\prime \prime}$. Aehren klein, grünlich.

An Ufern, auf feuchten, sandigen Triften hie und da. In Menge am Neckar bei Ladenburg und Neckarhausen! seltener b. Schwabenheimer Hof Neuenheim! gegen Ziegelhausen! Auch bei Neckarau! und stellenweise in der Näho des Rheines. Juni-August.

\section{Seirpus $L$. Binse.}

a) Aehre einzeln, endständig; Perigon borstig; Narben 3 (Baeothryon Nees).

965. S. paucifiorus Lightf. A rmblth. B.; Halm stielrund, gestreift, am Grunde mit wenigen Scheiden; Aehre elliptisch, am Grunde von der rundlichen Deckschuppe umfasst; Perigonborsten widerhakig; Nüsschen stumpf 3kantig, stachelspitzig. 4. 3-10" Aehre braun. Schwache Rasen bildend. (Sc. Baeothryon Ehrh.) - Im Gebiete der Flora nur auf torfhaltigen Wiesen bei Waghäusel! Juni, Juli.

[Auf Torfwiesen der Rheinfläche übrigens verbreitet, in Rhb.: von Speyer-Dürkheim-Frankenthal $(F$. Schulti), in B.: bei Neudorf $(D \ddot{\partial} l l)$, zwischen Waghäusel und Graben, daselbst eine gewisse Verbreitungsgrenze erreichend.

b) Aehren endständig, meist büschelig, geknäuelt, von d. obersten Deckbl. zur Seite gedrängt, daher scheinbar seitenständig; Perig. fehlend; Narben 3; Halme nur am Grunde schwach beblättert.

-) Deckschuppen der Aehre längsrippig, stachelspitzig, nicht ausgerandet. (Isolepis Nees.)

966. S. setaceus $L$. Borsten-B.; Halme fadenförmig, aufrecht oder aufsteigend, stielrund, büschelig; Bl. sehr kurz, borstlich; das unterste Deckbl, die Aehrchen 2-4mal überragend, viel kürzer als der Halm; Aehrchen 2-3, eiförmig, klein; Nüsschen stumpf 3kantig, längsrippig, stachelspitzig. ๑. $3-6^{\prime \prime}$.

Auf feuchten Triften, in Sümpfen, an Gräben hio u. da, z. B. bei H. in der Hirschgasse mit Cyperus flavescens! beim Bierhälter Hof (Dierb.), in Sümpfen des Friedrichsfelder Waldes! beim Relaishause! Neckarau! Waghäusel. Juli, August.

967. S. supinus $L$. Niederliegende B.; Halme büschelig, fadenförmig, stielrund, ausgebreitet, niederliegend oder aufsteigend; Bl. sehr kurz, borstlich; das unterste Deckbl. viel länger als die Aehrchen, von der Länge des Halmes; Aehrchen 3-6, etwas grösser als bei d. vorigen; Nüsschen stumpf $3 \mathrm{kantig}$, queerrunzelig, stachelspitzig. $\odot .4-6^{\prime \prime}$. 
Auf feuchten lehmigen oder sandigen Triften, in Sümpfen, hinsichtlich der Verbreitung noch unsicher. Bisher nur in der Gegend von Friedrichsfeld, in der Nähe des sog. rothen Loches (Döll). Juli, August.

*) Deckschuppen der Aehre queerrunzelig, ausgerandet, stachelspitzig, mit einem trockenhäutigen Rande; Perigonborsten widerhakig.

968. S. lacustris $L$. Teich-B. ; Halme stielrund, aufrecht, grasgrün, am Grunde von wenigen scheidenförmigen Blättern umgeben; Aehren büschelig-rispig; Deckschuppen glatt, rostbraun, am Rande gewimpert; Narben 3; Nüsschen verkehrt eiförmig, stumpf 3kantig. 24. 3-6'. Wzst. kriechend.

An Flussufern, Teichen, in Sümpfen häufg, besonders am Neckar ziemlich verbreitet. Juni, Juli.

969. S. Tabernaemontani Gmel. Tabernaemontan's B.; Halme stielrund, aufrecht, fein gestreift, blaugrün, am Grunde von wenigen scheidenförmigen Blättern umgeben; Aehren büschelig-rispig; Deckschuppen bräunlich, durch rothbraune Wärzchen rauh, am Rande gewimpert; Narben 2; Nüsschen zusammengedrückt, verkehrt eiförmig. 4. 2-3'. Wzst. kriechend. (Sc. glaucus Sm.)

In Sümpfen, auf torfhaltigen Wiesen, in Gräben auf der Rheinfläche stellenweise häufig, z. B. bei Waghäusel. In der Nähe des Rheines oft heerdenweise, z. B. jenseits des Rheines in den Oggersheimer Sümpfen! Juni, Juli.

970. S. Duvalii Hoppe. Dem S.lacustris sehr ähnlich; Halme grasgrün, unten stielrund, in der Mitte stumpf 3kantig, 2 Seiten etwas gewölbt, die dritte flach; Aehren büschelig rispig oder knäuelartig gedrängt; Deckschuppen wie bei S. lacustris; Narben 2 ; Nüsschen verkehrt eiförmig, zusammengedrückt. 4. $1-1^{\frac{1}{2}}$.

An und in Sümpfen in der Nähe des Rheines, z. B. zwischen Waghäusel und Alt-Lussheim. Jenseits des Rheines nicht selten (F. Schultz), diesseits weiter zu verfolgen! Juli, August.

c) Blthstand deutlich endständig, zusammengesetzt, von flachen Deckbl. umgeben; Perigonborsten widerhakig; Narben 3.

971. S. sylvaticus $L$. Halm stumpf 3kantig, beblättert; Bl. lineal-lanzettl.; Rispe doldentraubig, mehrfach zusammengesetzt; Aehrchen eiförmig; Deckschuppen stumpf, kurz stachelspitzig, grau-

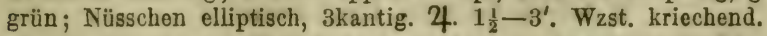

An sumpfigen Waldstellen, auf nassen Wiesen, in Gebüschen häufig, z. B. in der Nähe v. H. hinter dem Haarlass! Handschuchsheim! hio und da am Neckarufer! u. s. w. Juni-August. 
972. S. maritimus $L$. Meerstrands-B.; Halm scharf 3kantig, beblättert; Bl. lineal-lanzettl., verlängert; Doldentraube weniger zusammengesetzt, oft geknäuelt; Achrchen elliptisch, spitz, rothbraun; Deckschuppen stachelspitzig, 2spaltig; Nüsschen rundlich, etwas zusammengedrückt, kurz zugespitzt. 24.1-4'. Wzst. kriechend, mit knolligen Verdickungen.

An Ufern, Gräben häufig, z. B. am Neckarufer sebr verbreitet! Juli-September.

\section{Vriop horum $L$. W ollgras.}

973. E. angustifolium Roth. Schmalb l. W.; Halm aufrecht, fast stielrund, glatt; Bl. schmal lineal, rinnig; Stiele der anfangs aufrechten, endlich hängenden Aehren glatt; Wollenbüschel d. reifen Aehren elliptisch, abgerundet. 4. $1-1_{2}^{\frac{1}{2}}$. (E. polystachyum $\alpha$ L.)

Auf sumpfigen Wiesen der Ebenen und der Gebirge nicht überall, z. B. bei Schönau! Wilhelmsfeld! Schriesheim! ziemlich verbreitet bei Gaiberg und Bammenthal! Waghäusel! April, Mai. Reife der Wolle: Juni.

974. E. Iatifolium Hoppe. Breitbl. W.; Halm aufrecht, stumpfkantig, glatt; BI. lanzettl.-lineal, fast flach; Stiele d. endlich hängenden Aehren rückwärts schärflich; Wollenbüschel eirund, abgestutzt (feiner als bei dem vorigen). 24. 1-1 $\frac{1}{2}^{\prime}$. (E. polystaohyum $\beta$ L.)

Auf torfhaltigen und feuchten Wiesen der Ebenen und der Gebirge verbreiteter als voriges, z. B. in der Nähe von H. auf der Engelswiese! häufig zwischen Handschuchsheim und Dossenheim und stellenweise längs der Bergstrasse! In den Torfsümpfen des Geb.! April, Mai. Reife der Wolle: Juni.

975. E. gracile Koch. Schlankes W.; Halm aufrecht, dünn, stumpfkantig, glatt; BI. schmal, rinnig, 3kantig; Stiele der stets fast aufrechten Aehren filzig-rauh; Wollenbüschel kürzer u. dünner als bei dem rorigen. 4. ${ }_{4}^{3}-1^{\prime}$. (E triquetrum Hoppe.)

In Torfsümpfen selten. Waghäusel! Sandtorf (Schimp.). Mai, Juni. [Auch in der Nähe des Geb. nur sehr stellenweise. N. V. in Rhb.: Studernheim, Maxdorf ( $F$. Schultz).]

\section{Carex $L$. Segge.*)}

A) Aehre einzeln, endständig.

a) Aehren dioecisch, kurz; Narben 2,

976. C. dioica $L$. $\mathrm{Z}_{\mathrm{w}}$ i h äusige $\mathrm{S} . ;$ Halme einzeln, wie d.

) Für Diejenigen, welche noch keine Carex-Arten hestimmt 
B1. glatt; B1. lineal; Fruchtschl, gedrängt, eiförmig, spitz, aufrecht abstehend oder wagerecht, braun. 4. $5-6^{\prime \prime}$. Wzst. kriechend.

Auf torfhaltigen und sumpfigen Wiesen selten, z. B. bei Waghäusel! Sandtorf! zwischen St. Ilgen und Leimen (Schimp.) April, Mai. [In der Nähe d. Geb. fehlend.]

977. C. Davalliana Sm. Davall'sche S.; rasenbildend; IIalme und lineale Bl. rauh; Fruchtschl. gedrängt, lanzettlich, zugespitzt, gerippt, wagerecht oder abwärts gerichtet, schwärzlich. 4 . $5-10^{\prime \prime}$. Wzst. faserig.

Auf torfhaltigen Wiesen, in Torfsümpfen hie und da, z. B. im Torfstich bei Brühl! Waghäusel, Sandtorf! zwischen Ladenburg und Schriesheim (Bisch.), bei Wiesloch (Dierb). April, Mai. [Auf der Rheinfläche auch in der Nähe des Geb. stellenweise verbreitet.]

b) Aehren oben männlich, unten weiblich, locker.

978. C. pulicaris $L$. Flolt-S.; Halme und lineale Bl. kahl; Fruchtschl. länglich, beiderseits zugespitzt, abstehend, abwärts gerichtet, glänzend, braun ; Narben2 ; Deckschuppen hinfällig. 4. 6-10" .

Auf sumpflgen Torfwiesen bei Waghäusel nur noch vereinzelt. Mai-Juni. [N. V. a. d. Geb. in IIs. : Neunkircher Höhe im Odenwald (Sclunttsp.), in B. und Rhb. in der Nähø des Geb. fehlend.]

[C. pauciflora Light. A rmblth. S.; hauptsächlich verschieden durch armblüthige Aehren (4-5weibl., 1-2männl.) und durch lanzettlich-pfriemliche, stielrunde, zurückgebogene, blassgelbe Fruchtschl. mit 3 Narben, früher ebenfalls in den Torfsümpfen bei Waghäusel (Sohimp., Düll), scheint daselbst jetzt verschwunden, und ist auch in der Nähe des Geb. nicht nachgewiesen.]

B) Aehre aus mehreren Aehrchen zusammengesetzt.

a) Aehre einfach oder rispenförmig zusammengesetzt; Aehrch. an der Spitze männlich, unten weiblich; Narben 2; Rasenbildend, ohne kriechend. Wzst.; Bl. lineal,

979. C. valpina $L$. Fuchs-S.; Halm scharf 3 kantig mit concaven Flächen; Aehre walzenförmig, meist gedrungen, am Grunde etwas rispig; Fruchtschl. eirund-zugespitzt, flach-convex, sperrig-abstehend, deutlich nervig, in einen platten, kurz gespaltenen, foin

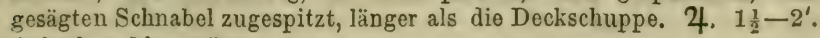
Aehrchen blassgriin.

haben, bemerke ich, dass ein einigermassen ausgebildeter $\mathrm{Zu}$ stand der Fruchtschläuche durchaus nothwendig ist, nur darf die Reife nicht allzuweit vorgeschritten sein, weil die Früchte alsdann bei der geringsten Berührung abfallen. 
In fouchten, lichten Wäldern, auf Wiesen, an Gräben, in Sümpfon häufig. In der Nähe von II, z. B. in Menge am Neckarufer! im Mühlenthal bei Handschuchsheim! u. s. w. Mai, Juni.

980. C. muricata $L$. Weichstachelige S.; Halme stumpf 3kantig, mit ebenen Flächen; Aehre walzenförmig, am Grunde unterbrochen; Fruchtschl. d. vorigen, wagerecht-abstehend, schwachnervig oder nervenlos. 4. 1-2'. Aehrchen grünbraun.

Auf Wiesen, Triften, an Wegen häufig. - Variirt:

$\beta$ ) divulsa Good; Halme schlank; Aehre sehr verlängert; Aehrchen alle mehr oder weniger von einander entfernt, blassgrün; Früchte weniger abstehend, kleiner. 2-3'.

In Laubwäldern, auf Waldtriften der Gebirge und $d$. Ebene hie und da, z. B. hinter dem Haarlass! in Gebüschen neben der Engelswiese! beim Maischbacher Hof! bei Weinheim!

y) virens Koch; Halme weniger schlank; Aehre meist kurz; Aehrchen mehr oder weniger entfernt, die oberen genähert, bald klein, bald grösser, bleichgrün, zuweilen fast gelblichweiss. $1-2^{\prime}$.

In feuchten Waldgebüschen hie und da, z. B. zwischen Waghäusel und Lussheim! Mai, Juni.

981. C. teretiuscala Good; Stielrundl. S.; Halme schlank, rundlich-3kantig, mit gewölbten Flächen, etwas scharf; Bl. schmal lineal, etwas rinnig; Aehre eiförmig-länglich; Aehrchen sehr gedrungen; Fruchtschl. aufrecht, eiförmig-länglich, glatt, beiderseits convex, nach Aussen mit 2 schwachen Längsrippen, plötzlich in einen kurzgespaltenen Schnabel zugespitzt. 4. 1-1 $\frac{1}{2}^{\prime}$. A ehrchen u. Frucht dunkelbraun.

Auf torfhaltigen Wiesen, in Torfsümpfen selten, z. B. bei Waghäusell (mit der folg. ähnlichen Art und mit C. Pseudo-Cyperus) bei Sandtorf (Schimp.). Mai, Juni. [N. V. a. d. Geb. in Rhb.: Speyer, Germersheim ( $F$ Schultz), in B.: Welsch-Neureuth (Döll).]

982. C. paniculata $L$. Rispige S.; Halme scharf 3 kantig; Bl. breit lineal, flach; Aehre fast abstehend, rispig, pyramidal; Früchte aufrecht, eirund, zusammengedrückt $3 \mathrm{kantig}$, etwas gestreift, in einen kurz gespaltenen, fein gesägten Schnabel zugespitzt. $4.2-3^{\prime}$. Aehrchen grünbraun.

In Sümpfen, auf feuchten Wiesen der Eberèe häufig und meist gesellig, z. B. bei Waghäusel! Brühl! Neckarau! Sandtorf! zwischen Gaiberg und Schatthausen! Mai, Juni.

*) Wenn die Blätter nicht besonders hervorgehoben, so sind sie zur Unterscheidung der Arten weniger geeignet. 
983. C. paradoxa Willd. Selts a mo S.; Halme scharf 3 kantig; Bl. schmal lineal, flach; Aehre zusammengezogen rispig, schmal; Fruchtschl. aufrecht, eirund, beiderseits convex, nervig-gestreift, in einen kurz gespaltenen, fein gesägten Schnabel zugespitzt. 4. 1-2'. Aehrchen hellbraun; Basis der Halme mit den Resten der Blätter und Scheiden schopfartig bekleidet.

Auf torfhaltigen Wiesen bei Waghäusel ( $F$. Schultz, Döll). Mai, Juni. [Auch stellenweise in der Nähe des Geb. in Hs. (Schnttsp.), in Rhb. bei Forst, Friedelsheim, Deidesheim (F. Soh.).]

b) Mittlere Achrchen männlich, das obere und die unteren weiblich; Wzst. kriechend.

984. C. intermedia Good. Mittelmännige S.; Halm scharf 3 kantig; Aehre gedrungen, länglich ; Fruchtschl. eiförmig, flach-convex, vielnervig, schmal berandet, in einen kurz gespaltenen, scharfrandigen Schnabel zugespitzt, etwas länger als dio Deckschuppen. 4 . $1-1_{\frac{1}{2}}$. A Aelirchen braungelb. (C. disticha Huds.)

Auf feuchten Wiesen, an Ufern, besonders der Ebene, auch in der Nähe von H., z. B. bei Handschuchsheim, Rohrbach u. s. w. häufig! Mai-Juli.

c) Aehrchen am Grunde männlich, an d. Spitze weiblich.

•) Dichte hellgrüne Rasen bildend; Wzst. nicht kriechend.

985. C. remota $L$. Entferntaehrige S.; Halme schlank, überhängend, von der Länge der schmal linealen Bl,; Aehrchen lanzettlich oder eirund, 4-10, meist weit von einander entfernt, dio untersten von ihrem verlängerten Deckbl. weit überragt; Fruchtschl. aufrecht, eiförmig, flach-convex, mit kurz gespaltenem Schnabel, länger als die Deckschuppen. 4. 1-2'. Aehrchen hellgrün.

In schattigen, feuchten Laubwäldern d. Gebirge und d. Ebenen meist gesellig. In der Nähe von H., z. B. in der Hirschgasse! am Wege nach der Engelswiese! hinter dem Haarlass! im Klingenthal! Auch stellenweise zwischen Ziegelhausen und Schönau! bei Handschuchsheim! Weinheim! Leimen! im Gaiberger Walde! am Teufelskopf bei Dielheim! In feuchten Gebüschen bei Waghäusel und Kirrlach! Mai, Juni.

986. C. stellulata Good. Sternförmige S.; Halm steif aufrecht, fast glatt; Aehrchen 3-5, fast kugelig, wenig von einander entfernt; Fruchtschl. sternförmig abstehend, eiförmig, flachconvex, feingestreift, deutlich berandet, mit kurzgespaltenem Schnabel, länger als die Deckschuppen. 4. $\frac{3}{4}-1^{\prime}$. Aehrch. grïnlich gelb.

Auf feuchten Waldwiesen, Torfwiesen hie und da, z. B. Engelswiese bei H.! im Mühlenthal bei Handschuchsheim! im Birkenauer Thal bei Weinheim! bei Waghäusel! Mai, Juni. 
987. C. elongata $L$. Verlängerte S.; Halme schlank, scharf $3 \mathrm{kantig}$, länger als d. Bl.; Aehrchen 6-10 länglich, locker, genähert; Fruchtschl. aufrecht abstehend, eilanzettl., flach-convex, nervig-gestreift, schwach berandet, mit sehr kurz gespaltenem Schnabel, länger als die Deckschuppen. 24. $1 \frac{1}{2}-2^{\prime}$. Aehrch. gelblich oder hellbraun.

Auf feuchten Wiesen, in Waldgebüschen stellenweise, z. B. im Mühlenthal bei Handschuchsheim! auf den Wiesen gegen Dossenheim! zwischen Schriesheim und Ladenburg! bei Waghäusel! Mai, Juni.

988. C. leporina $L$. II a s e n-S.; Halme steif aufrecht, stumpfkantig, oben rauh; Aehrchen 3-6 rundlich-elliptisch, genähert; Fruchtschl. aufrecht, eiförm., flach-convex, nervig gestreift, mit schmalem, oben fein gesägtem Rande und kurzgespaltenem Schnabel von der Länge der Deckschuppen. 4. 1-1 $\frac{1}{2}^{\prime}$. Aehrch. gelbbraun. (C. ovalis Good.).

Auf Wiesen, Triften, an Wegen der Ebene und der Gebirge häufig. Juni, Juli. Variirt:

ß) argyroglochin Wahlbg. Aehrch. etwas lockerer und kleiner, weiss od. bleich grün.

In feuchten schattigen Gebüschen im Gebirge am Wege von der Hirschgasse nach der Engelswiese!

*) Wstock kriechend.

989. C. Schreberi Schrank. Schreber's S.; Halm stumpfkantig, oben rauh, etwas länger als d. kurzen $\mathrm{Bl}$; ; Aehrchen 3-6 aufrecht, gerade, längl.-lanzettl., meist etwas gebüschelt; Fruchtschl. eiförmig-länglich, flachconvex, gestreift, schmal geflügelt, feingesägt, mit gespaltenem Schnabel von der Länge der Deckschuppen. 4. $\frac{1}{2}-1 \frac{1}{2}$. Aehrch. röthlichbraun.

Auf sandigen Triften, an Rainen, trockenen, sonnigen Hügeln hie und da, z. B. am Philosophenwege! an d. Strasse nach Neuenheim ! auf den Felsen vor dem Haarlass! im Birkenauer Thal bei Weinheim! beim Maischbacher Hof I zwischen Friedrichsfeld und Schwetzingen! Käferthaler Wald: auf dem Sande bei der Mannheimer Ziegelhütte und am Rhein gegen Sandhofen! Waghäusel (Döll.). April, Mai. *)

") C. ligerica Gay. scheint, nach Ansicht getrockneter Exemplare nicht wesentlich verschieden von $C$. Schreberi. Vergl. jedoch: Döll., Flora des Grossh. Baden p. 253 und das daselbst angegebene Vorkommen am Rande der Torfwiesen zwischen Waghäusel und Lussheim. 
990. C. brizoides $L$. Zittergras artige S.; Malme schlank, stumpfkantig, oben raul, meist kürzer als d. Bl.; Aehrch. 2-5, etwas gekrümmt, lanzettl., genähert; Fruchtschl. lanzettl, flach-convex, schmalgeflügelt, feingesägt, mit sehr kurzgespaltenem Schnabel, längor als die Deckschuppen. 24. $1-1 \frac{1}{2}^{\prime}$. Aehrch. strohgelb.

In schattigen, etwas feuchten Laubwäldern zwischen Ziegelhausen, Schönau, Heddesbach stellenweise nicht selten! Auch einzeln im Gebirge gegen Wilhelmsfeld! Im Friedrichsfelder Walde beim rothen Loch (Döll.). Mai, Juni.

C) Gipfelähre männlich, die unteren Aeliren weiblich (bei $C$. Buxbaumii die Gipfelähre unten männlich, oben weiblich.

a) Narben 2 ; Schnabel der kahlen Fruchtschläuche kurz, abgerundet, grundst. Declsbl. d. Aehren verlängert, blattartig, am Grunde geöhrt, stumpf.

991. C. stricta Good. Steif a ufrechte S.; rasenbildend; Halme scharfkantig, steifaufrecht; Bl. blaugrün mit netzigfaserigen Scheiden; Aelrchen sitzend oder kurzgestielt, aufrecht, walzenfürmig, kurz oder verlängert, männl. meist 1, weibl. 3-4. Fruchtschl. elliptisch, flach, 3- inervig, gedrängt, von der Länge der lanzettlichen Deckschuppen. 4. 1-3'. W. ohne Ausläufer. Deckschuppen schwarzbraun, mit grünem Kiel.

In Torfsümpfen, auf nassen Wiesen, an Sumpfgräben der Ebene hie und da, z. B. bei Waghäusel! Sandtorf! Brühl! beim Rohrhof! einzeln bei Handschuchsheim (Bisch.).

992. C. Vulgaris Fries. Gemeine S.; Halme steif, etwas gebogen, oben schärflich; Bl, bläulich grün mit nicht netzig faserigen Scheiden; männliche Aehrchen 1-2, weibl. 2-3 länglichwalzenförmig, aufrecht; Fruchtschläuche meist gedrängt, rundlichelliptisch, flach-convex, schwach nervig, länger als d. Deckschuppen. 4. $\frac{1}{2}-1^{\prime}$. Wstock mit Ausläufern. Deckschuppen meist schwärzlich ; Fruchtschl. grïn od. etwas braun. (C. caespitosa Good.).

Auf nassen Wiesen, in Torfsümpfen sehr verbreitet, auch in der Nähe von H. häufig, z. B, auf der Engelswiese! bei Handschuchsheim. April, Mai.

993. C. acuta $L$. Scharfe S. ; Halm scharfkantig, oben sehr rauh; Bl. grün mit nicht netzigfaserigen Scheiden, männl. Aehrch.3, weibl. 3-4, verlängert walzenförmig, die unteren gestielt, etwas nickend; Fruchtschl. länglich, beiderseits gewölbt, schwachnervig, ziemlich locker, von der Länge der länglichen Deckschuppen. 4 . $1 \frac{1}{2}-2^{\prime}$. Wstock mit Ausläufern; Fruchtschl, blassgrün; Decksch, schwärzlich mit grünem Kiel, 
Auf feuchten Wiesen, an Ufern, in Stimpfen häufig. In der Nähe von H. z. B. in der Hirschgasse! am Neckarufer hio und da! bei Handschuchsheim! verbreiteter auf den Wiesen der Rheinfläche! Mai, Juni.

b) Narben 3; Schnabel der kahlen Fruchtschläuche kurz od. fehlend.

[C. Buxbaumii Wahlbg.; Halme scharfkantig, wie d. Bl. steif aufrecht, blaugrün, mit netzig-faserigen Scheiden; Aehren 3-4, walzlich, die oberste unten männlich, oben weiblich; Fruchtschl. elliptisch, 3kantig, beiderseits convex, kurzgeschnäbelt, etwas kürzer als d. Deckschuppen. 4. 1-1 $\frac{1}{2}^{\prime}$. Wstock mit Ausläufern; Deckbl. am Grunde der Aehren blattartig geöhrt. Fruchtschl, grün; Deckschuppen rothbraun, - grüngekielt.

Auf sumpfigen Wiesen. N. V. a. d. Geb. in Rhb.: zwischen Ludwigshafen und Oggersheim! Maxdorf, Ellerstadt, Speyer ( $F$. Schultz). Mai, Juni.

994. C. supina Wahlbg. Niedrige S.; Halm aufsteigend, oben rauh; Bl. lineal-borstlich, männl. Aehren 1, weibl. 1-2 kugelig, sitzend; Fruchtschl. elliptisch, 3kantig, mit kurzem, trockenhäutigem, 2lappigem Schnabel. 4. 5-8". Wstock kriechend; Aehren hellbraun; Deckbl. am Grunde der Aehren kurz, häutig.

An trockenen, sandigen Rainen, auf trockenen Hügeln, in Nadelwäldern selten, z. B. auf dem Sande bei der Mannheimer Rheinziegellü̈tte in trocknen Gebüschen in Menge! zwischen Friedrichsfeld und dem Relaishause (Döll., Bischoff). Mai.

[In B. nicht weiter verbreitet. N. V. in Rhb.: am Battenberge zwischen Dürkheim-Grünstadt ( $F$. Schultz), in Hs. : Flora von Mainz (Sohnttsp.).

995. C. panicea $L$. Hirsenfrüchtige S.; Halm glatt; Bl. bläulichgrün, kahl, männl. Aehren 1-2, weibl. 1-3, gestielt, entfernt, aufrecht, walzig, locker; Fruchtschl. kugelig-eiförmig, kurzgeschnäbelt, länger als die eiförmigen röthlichbraunen Deckschuppen. 4. 1'. Wstock mit Ausl,; Deckbl, der Aehren scheidig-blattartig; Fruchtschl: gelbgrün.

Auf Wiesen, feuchten Triften, in Gebüschen häufig. Mai.

996. C. pallescens $L$. Bleiche S.; blassgrün; Halme oben rauh; Bl. unterseits, nebst Scheiden etwas behaart, männl. Aehren 1, weibl. 2-3 genähert, blassgrün, eiförmig, gedrungen, die unterste etwas nickend; Fruchtschl. länglich-elliptisch, stumpf, ungeschnäbelt, etwas länger als die Deckschuppen. 2. $1-1 \frac{1}{2}^{\prime}$. Deckbl. d. Aehren scheidig-blattartig.

An Waldrändern, auf Waldwiesen, in Gebüschen der Gebirge 
und der Ebene, besonders in der Näho von II. diesseits und jenseits des Neckars häuffg! Mai.

997. G. strigosa Huds. Schlankährige S.; Halm glatt, wie die sehr verlängerten $\mathrm{Bl}$. hellgrün, männl. Aehren 1, weibl. 3-5, entfernt, schlank, verlängert lineal, hängend, locker; Fruchtschl. länglich $3 \mathrm{kantig}$, oben schief gestutzt, grün, länger als die zugespitzten, weissberandeten Deckschuppen. 24. $1 \frac{1}{2}-2^{\prime}$. Wstock mit kurzen Ausläufern. Deckbl. der Achren scheidig-blattartig. (C. leptostachys Ehrh.).

In schattigen feuchten Waldgebüschen hie und da, z. B. in der Hirschgasse mit der folgenden Art! hinter dem Haarlass! bei Leimen! im Birkenauer Thal bei Weinheim! (an beiden Standorten mit Equisetum Telmateia Ehrh.). Zwischen dem Bierhelder Hof und Rohrbach (Bisch.).

[Fehlt jenseits d. Rh. im Haardtgeb. und in d. Nähe des Geb. In Hs., besonders an der Bergstrasse die Verbreitung wohl noch nicht hinlänglich verfolgt.]

998. C. maxima Scop. Grösste S.; umfangreiche Rasen bildend ; Halm oben rauh; Bl. breitlanzettl, unterseits blaugrün, männl. Aehren 1, weibl. 3-6, entfernt, verlängert-walzenförmig, dichtblüthig, hängend, untere langgestielt ; Fruchtschl. elliptisch, 3kantig, kurzgeschnäbelt, grün, länger als die stachelspitzigen Deckschuppen. 4. 2-4'. Ohne Ausl. Deckbl. d. Aehren scheidig-blattartig. (C. pendula Huds.).

In feuchten, besonders quellenreichen Waldgebüschen der Gebirge nicht selten, z. B. in der Hirschgasse! in Waldbächen am Wege nach der Engelswiese! hinter dem Haarlass! bei der sog. Brunnenstube! Zwischen Handschuchsheim und Schriesheim stellenweise, zuweilen, z. B. oberhalb Dossenhoim ganz häufig! Im Birkenauer Thal bei Weinheim! Zwischen Leimen und Nussloch. Mai, Juni. [Wie die vorige, diesseits $d$. Rh., auch in der Nähe d. Geb. stellenweise, aber jenseits d. Rh. zunächst fehlend.]

c) Narben 3; Schnabel der mehr oder weniger behaarten Fruchtschläuche kurz und stumpf, oder fehlend.

") Deckbl. d. Aehren scheidenförmig.

999. C. humilis Leyss. Niedrige S.; Halme von den sehr verlängerten, linealen, rinnigen $\mathrm{Bl}$. verhüllt, männl. Aehren 1, weibl. 2-4, armbliithig, von den trockenhäutigen, weissen Scheiden fast eingeschlossen; Fruchtschl. verkehrt-eifürmig , 3kantig, hurzhaarig, sehr kurz geschnäbelt. 4. 2-5". Bl, nach der Blüthezeit dichte Rasen bildend. ( $C$. clandestina Good.).

In trockenen Nadelwäldern, auf trockenen Sand - und Kalkhü- 
geln. Im Käferthaler Nadelwalde (Schimp.), auch jetzt noch stellenweise in Menge (Stud. Gysser). März-Mai.

Callstadt !]

[N. V. a. d. Geb. in Rhb.: Kalkhiigel zwischen Dürkheim und

1000. C. digitata $L$. Ge fingerte S.; rasenbildend, Halme etwas gebogen, schwach, glatt, männl. Aehren 1, weibl. 2-3, entfernt, gestielt, lineal, locker, die Stiele von trockenhäutigen Scheiden umschlossen; Fruchtschl. verkehrt-eiförmig, 3kantig, kurzgeschnäbelt, flaumig-kurzhaarig, so lang wie die abgestutzten gelbbraunen Deckschuppen. 24. $\frac{1}{2}-1^{\prime}$. Truchtschl. gelblich: Halme seitlich entspringend, am Grunde mit gelbbraunen Scheiden.

In schattigen Wäldern, an Waldrändern, besonders auf Kalkund Lehmboden, im Gebirge verbreitet, z. B. diesseits und jenseits des Neckars b. H.! längs der Bergstrasse! Gaiberger Wald! zwischen Leimen und Wiesloch! In Wäldern der Ebene etwas seltener, aber meist gesellig, z. B. zwischen Walldorf und Roth! Kirrlach! Waghäusel! April, Mai.

100l. C. ornithopoda Willd. Vogolfuss-S.; der vorigen ähnlich, aber kleiner; Bl. kürzer; Halme mehr gebogen, abstehend; Achren gedrängt, kürzer; Fruchtschläuche länger als die gelblichen Deckschuppen. 24. 5-7".

An lichten Waldstellen, auf grasreichen sonnigen Hügeln, besonders auf Kalk und Löss im Gebirge, auch auf den Sandflächen der Ebene etwas seltener als vorige. Haarlass! Mühlenthal bis Handschuhsheim! oberhalb Dossenheim! Weinheim! Sehr häufig an den sonnigen Anhöhen bei Leimen! Maischbach! Dielheim! Rauenberg und Wiesloch! Auf den Sandflächen bei Sandhausen! Mai, Juni. Blüht $2 \multimap 3$ Wochen später als vorige.

*) Deckbl. der Aehren blattartig, am Grunde scheidenförmig oder scheidenlos.

1002. C. glauca Scop. Bl a u grüne S.; Halm glatt, wio die Bl. blaugrün, männl. Aehren 1-2, weibl. 1-3, entfernt, walzenförmig, dichtblüthig, langgestielt, hängend; Fruchtschl. elliptisch, sehr kurz geschnäbelt, schärflich-rauh, gelblich, von der Länge der länglich-linealen, braunen Deckschuppen. 24. $\frac{1}{2}-1_{\frac{1}{2}}^{\prime}$. Wstock mit Ausl.; Deckbl. der Aehren scheidenlos.

Auf Wiesen, an Wegen, Ufern, auf feuchten Waldtriften häufig! Mai, Juni.

1003. G. tomentosa L. Filzfrüchtige S.; Halm steif aufrecht, scharfkantig, oben rauh, männl. Aehren 1, weibl. 1-2, fast Gitzend, walzenförmig, stumpf, mit wagerecht abstehenden scheiden- 
losen Deckbl.; Fruchtschl. gedrängt, kugelig-verkehrteiförmig, weissgraufilzig-kurzhaarig, kurzgeschnäbelt, länger als die eirunden spitzen, braunen Deckschuppen. 24 3 -1'. Wstock mit Ausläufern.

Auf feuchten, besonders lehmigen Triften, an Waldrändern selten, z. I. im Walde zwischen Ketsch und IIockenheim! beim Relaishause und im Neckarauer Waldo (Düll.). [Uebrigens in der Näho des Geb. stellenweise verbreitet, ఒ. B. häufig in len Oggersheimer Lehmgruben!] April, Mai.

1004. C. pilulifera $I_{\text {. }}$. Pill ontragende S.; rasenbildend; Halm etwas niedergebogen, länger als d. Bl.; männl. Achren 1, weibl. 2-3, genähert, sitzend, fast kugelig, armblüthig, am Grundo mit kurzem, lineal-pfriemlichem, scheidenlosem Deckbl.; Fruchtschl. kugelig 3kantig, flaumig, kurzzugespitzt, von der Länge der elliptischen, stachelspitzigen, rothbraunen Deckschuppon. 4. $\frac{1}{2}-1$ '. Ohne Ausl.

In lichten Wäldern, auf Waldtriften hie und da, z. B. am Königstuhl, im Walde gegen Gaiberg 1 zwischen Handschuchsheim und der Glashütte! Mai, Juni.

1005. C. montana $L$. Berg-S.; rasenbildend; Halme etwas niederliegend, wie die schmal linealen, weichen Bl. hellgrün; männl. Aehren 1, weibl. 1-2 eirund, genähert, sitzend, mit kurzen, trockenhäutigen, stachelspitzigen Deckbl.; Fruchtschl. 3kantig-elliptisch, kurzgeschnäbelt, kurzhaarig, etwas länger als dic schwarzbraunen Deckschuppen. 24. $\frac{1}{2}-1^{\prime}$. Ohne Ausläufer. (C. collinr Willd.).

An Waldrändern, auf grasreichen trockenen Hügeln, Waldtriften besonders auf Kalk und Löss im Gebirge verbreitet, z. B. hinter dem Haarlass! am Gaisberge! längs der Bergstrasse! Leimen! Nussloch, Wiesloch u. s. w. April, Mai.

1006. C. ericetorum Poll. Haide-S.; Halm aufrecht glatt; Bl steif, langzugespitzt, männl. Aehren 1, weibl. 1-2, locker, länglich, sitzend, mit kurzen, trockenhäutigen, meist rothbraunen, am Grundo scheidigen Deckbl.; Fruchtschl, verkebrt-eiförmig, stumpf 3kantig, kurzgeschnäbelt, flaumig-weissgrau, fast von der Länge der stumpfen, wimperig-gezähnelten, dunkelbraunen, weissberandeten Deckschuppen. 4. $\frac{1}{2}-1^{\prime}$. Ausläufer kurz; männl. Aehre keulenförmig, durch die weissberandeten Deckschuppen zierlich. (C. ciliata Willd.).

Auf Sandflächen, IIaiden, in Nadelwäldern hie und da, z. B. bei Sandhausen! zwischen Friedrichsfeld und dem Relaishause! beim Rohrhofe! im Käferthaler Waldo! Auf Hügeln bei Nussloch (Döll.). April, Mai.

1007. C. praecox Jucq. Frühe S.; Halm aufrecht, glatt, länger als die etwas steifen Bl,; männl. Aehren 1, weibl. 2-3, gea 
nähert, eirund-länglich, die unterste kurzgestielt, mit kurzen, am Grunde scheidenfürmigen Deckbl.; Fruchtschl. verkehrt-eiförmig, stumpf 3kantig, kurzgeschnäbelt, flaumig, kürzer als die eirunden, stachelspitzigen, hellbraunen Deckschuppen mit schwach vortretender grüner Mittelrippe. 24. $\frac{1}{3}-1^{\prime}$. Mit kurzen Ausläufern.

Auf trockenen Wiesen und Triften, Sandflächen, an Waldrändern der Gebirge und der Ebenen überall häufig! März, Mai.

1008. C. polyrrhiza Wallr. Vielwurzelige S.; rasenbildend; Halme aufrecht, glatt, am Grunde von zahlreichen theilweise abgestorbenen und faserigen älteren Blättern umgeben; Aehren und Deckbl. d. vorigen; Fruchtschl. stärker behaart; Deckschuppen dunkler braun mit stark vortretenden grünen Mittelrippen. 2. 1-1 $\frac{1}{2}$. Ohne Ausläufer. (C. umbrosa Hoppe; C. longifolia Host.).

In schattigen Wäldern, auf feuchten Waldtriften, besonders im Gebirge hie und da, z. B. hinter dem Haarlass! am Oelberge bei Schriesheim! bei Weinheim, besonders in Gorxheimer Thal! Gaiberger Wald! Nussloch! Maischbacher Hof! Mai.

d) Narben 3; Schnabel der kahlen Fruchtschläuche verlängert, deutlich 2zähnig. - Wstock ohne Ausläufer.

1009. C. sylvatica Huds. Wald-S.; hellgrüne Rasen bildend; Halm glatt, etwas überhängend, etwas kürzer als die ziemlich scharfen Bl.; männl. Aehren 1, wcibl. 2-5 schmal walzenförmig, locker, langgestielt, hängend, entfernt stehend; Deckbl. am Grunde scheidig; Fruchtschl. $3 \mathrm{kantig}$, elliptisch, glatt, langgeschnäbelt, die grünlich häutigen Deckschuppen kaum überragend. $1 \frac{1}{2}-2^{\prime}$. (C. Drymeja Ehrh.).

In Wäldern und Gebüschen der Ebenen und der Gebirge häuffg, besonders in der Nähe von $H$. jenseits des Neckars verbreitet, z. B. Haarlass! Hirschgasse! Handschuchsheim! längs der Bergstrasse und gegen Schönau! Leimen! Nussloch! In feuchten Wäldern d. Ebene oft gesellig, z. B. hie und da im Friedrichsfelder Walde! bei Walldorf! Neckarau! Waghäusel! Mai, Juni.

1010. C. distans $L$. Entferntaehrige S.; Halm glatt, länger als die blaugrünen Bl.; männl. Aehren 1, weibl. 2-3, aufrecht, meist weit von einander entfernt, eiförmig-länglich, gedrungen, die unterste länger gestielt; Deckbl. aufrecht, mit verlängerter Scheide; Fruchtschl. anliegend, stumpf $3 \mathrm{kantig}$, grün, deutlich längsnervig, mit geradem, zweispaltigem, am Rande fein gesägtem Schnabel, länger als die stumpfen oder zugespitzton Deckschuppen, 24. 1-2'.

Auf feuchten Wiesen, sumpfigen Triften hio und da, z. B. auf der Wiese vor dem Maischbacher Hof! boi Ketsch (Bisch.), Waghäusell Mai. 
1011. C. Hornschuchiana Hoppe. Hornschuchs-S.; der vorigen ähnlich; Halm oben rauh; weibl. Aehren kürzer, mehr genähert; Fruchtschl, abstehend mit etwas gebogenem Schnabel, länger als die zugespitzten, rothbraunen, am Rande trockenhäutigen Deckschuppen. 4. 1-1 $\frac{1}{2}^{\prime}$. (C. fulva Good.)

Auf feuchten Wiesen selten, hinsichtlich der Verbreitung zweifelhaft. Waghäusel (Döll). Mai.

1012. C. flava $L$. Hellg elbe S.; rasenbildend; Halme glatt oder schärflich, wie die ganze Pflanze gelblich-grün; männl. Aehre 1, weibl. 2-3 genähert, fast kugelig-eiförmig; Deckbl. mit kurzer Scheide; Fruchtschl, eirund, aufgeblasen, gestreift, sperrig-abstehend, mit zurückgebogenem, fein gesägtem, zweizähnigem Schnabel, länger als die rundlichen, gelbbraunen Deckschuppen. 4. $\frac{1}{2}-\mathbf{1}^{\prime}$.

Auf torfhaltigen, feuchten Wiesen und Triften hie und da, z. B. Engelswieso! zwischen Ziegelhausen und Schönau! beim Maischbacher Hof! Verbreiteter bei Sandtorf! Waghäusel! Mai, Juni.

1013. C. Oederi Ehrh. Oeder's S.; der vorigen ähnlich; Aehren kleiner, gedrängter; Fruchtschl. kleiner, mit geradem Schnabel, länger als die rundlichen, grünlich-gelben Decksch. 4. 2-6".

Auf feuchten, sandigen Triften der Ebene, in Sümpfen häufig, z. B. bei St. Ilgen und Leimen! Roth! Brühl! Waghäusel! Sandtorf! u. s. w. Mai, Juni.

1014. C. Pseudo.Cyperus $L$. Cypergras-S.; gelblich-grün; IIalm scharfkantig; männl. Aeliren 1, weibl. 4-6, genähert, langgestielt, hängend, walzenförmig, gedrungen; Deckbl. sehr verlängert, kurzscheidig; Fruchtschl. cirund-lanzettlich, aufgeblasen, nervig gestreift, glänzend, mit langem, 2zähnigem Schnabel, von der Länge der pfriemlichen Deckschuppen. 4. 1-2'.

Auf sumpflgen Torfwiesen, in torfhaltigen Gräben bei Sandtorft Waghäusel! Neckaraı (Bisch.). Juni, Juli.

e) Narben 3; Schnabel der kahlen Fruchtschläuche mit 2 auseinandertretenden Zähnon; Deckbl. der Aehren scheidenlos (bei

C. riparia zuweilen mit Scheiden); Wzst, mit Ausläufern.

1015. C. ampullacea Good. FI as chen-S.; Halm stumpfkantig, glatt; Bl. rinnig, bläulich-grün; männl. Aehren 1-3, weibl. $2-3$, entfernt, gestielt, walzenförmig, dichtblüthig; Fruchtschl, abstehend, fast kugelig, aufgeblasen, gestreift, lang geschnäbelt, grün glänzend, wenig länger als die länglichen, spitzen Deckschuppen. 4. 1-2. - Variirt:

ß) pendula; weibl. Achren verlängert, locker, lang gestielt, hängend. 
Auf sumpfigen Wiesen, in Torfsïmpfen stellenweise, z. B. bei Handschuchsheim in den halb verschïttoten Sumpfgräben! b. Sancltorf (woselbst auch die Var.)! Waghäusel! Brühl! Mai, Juni.

1016. C. vesicaria $I$. B lason-S.; der vorigen ählich, aber verschieden durch den scharfkantigen, oben rauhen Halm, flache, hellgrüne Bl., kürzere und dickere weibl. Aehren, durch weniger abstehende, kegelig-eiförmige, gelbgrüne Fruchtschl. 4. 1-2'.

Auf reuchten Wiesen, in Sümpfen, an Ufern häufiger als vorige, z. B. am Neckar unterhalb der Bergheimer Mühle! bei Handschuchsheim! zwischen Kirchheim und St. Ilgen und in den Sümpfen der Ebene! Mai, Juni.

1017. C. paludosa rood. Sump f-S.: Halm steif aufrecht, scharfkantig, oben rauh; 13. flach, lang zugespitzt, bläulich-grün, mit netzfaserigen Scheiden; männl. Aehren 2-3, weibl. 2-3, aufrecht, walzenfürmig, dichtblüthig; Fruchtschl. eifürnig, fast 3kantig, nervig-gestreift, kurz geschnäbelt, von der Lünge der lanzettlichen, schwarzbraunen Deckschuppen. 2. 1-2'.

Auf feuchten Wiesen, an Ufern, in Sümpfen und Gräben häufig; în den Sumpfgegenden sehr verbreitet und gesellig! Mai-Juli.

1018. C. riparia Curt. Ufer-S.; Halm steif aufrecht, scharf kantig, rauh; Bl. flach, verlängert, zugespitzt; Scheiden nicht netzfaserig; männl. Aehren 3-5, weibl. 3-4, walzenförmig, aufrecht, dichtblüthig; Fruchtschl. elliptisch-kegelförmig, beiderseits convex, vielnervig, kürzer als dis lang zugespitzten, braungrünen Decksch. 4. 2-4'. Deckbl. der untersten Aehre oft mit beträchtlicher Scheide.

In und an Sumpfgräben, Teichen, an Ufern hie und da, z. B. zwischen St. Ilgen und Walldorf! bei Roth! Reilingen! zwischen Neckarau und dem Rohrhof! bei Handschuchsheim (Döll). Auch ganz in der Näho des Geb. in Gräben unweit Ludwigshafen, gegen Oggersheim! und wahrscheinlich auch diesseits des Rheines gegen Sandhofen stellenweise. Mai, Juni.

f) Narben 3 ; Schnabel d. behaarten Fruchtschl. mit auseinander weichenden Zähnen; Wzst. kriechend.

1019. C. filiformis $L$. Fadenförmige S.; Halm oben schärflich; Bl. fadenförmig, rinnig, kahl; männl. Aehren 1-2, weibl. 2-3, aufrecht, fast sitzend, längl. oder eiförmig, dichtblüthig; das unterste Deckbl. mit kurzer Scheide; Fruchtschl. elliptisch, convex, nervig-gestreift, grauwollig-behaart, kurz geschnäbelt, von der Längø der lanzettlichen, braunen, weissberandeten Decksch. 4. 1-3'.

In Torfsümpfen bei Sandtorf (Schimp.). Mai, Juni. [N. V. a. d. Geb. in B,: Sinsheim (Düll), in Rhb.: Speyer ( $F$, Schultz).] 
1020. C. hirta $L$. K urzharigo S.; IIalm glatt oder oben schärflich; Bl. flach, nebst Scheiden kurzhaarig; männl. Aehren 2, weibl. 2-3, länglich-walzenförmig, aufrecht, das unterste Deckbl. mit langer Scheide; Truchtschl. eiförmig-länglich, convex, nervig, graukurzhaarig, etwas länger als die lanzettl., stachelspitzigen Deckschuppen. 24. $\frac{1}{2}-1 \frac{1}{2}^{\prime}$. Fruchtschl, und weirs berandete Deckschuppen gelblich-grün. - Variirt an schattigen Standorten mit mehr oder weniger kahlen $\mathrm{Bl}$. und Scheiden.

Auf feuchten Triften, Sandnächen, auf Wiesen, an Cfern überall häuflg und meist sehr gesellig. Mai-Juli.

\section{GRAMINEAE Juss.}

Kriäuter mit röhrigem, lnotig-gegliedertem, stielrundem oder zusammengedrüktem Stengel (Halm). Blätter lineal, mit gespaltenen Scheiden, deren innere Haut meist als Blatthä utchen am Grunde der Blattflïche vortritt. Blth. meist zwitterig, seltener eingeschlechtig, in sog. Aeh rchen vereinigt und diese wiederum zu Rispen oder aehrenförmigen Blüthenständen gruppirt. Achrchen 1-2-vielblüthig, zunïchst gebildet aus dachigen, häutigen Deckschuppen (Spelzen, paleae), von welchen 2 zu einer Blüthe gehören.*) Jedes Aehrchen wird am Grunde von meist 2 (seltener 1), den Spelzen ähnlichen Deckschuppen (Balgklappen, glumae) umgeben, wclche letztere als Aehrchendeckblätter keine Blüthe direct unschliessen.**) (In sehr seltenen Fällen fehlt d. Balg). Blüthendecke entweder ganz fehlend oder nur durch 2-3 klcine Schüppchen (Perigonschuppen) am Grunde d. Frucht-

*) Man unterscheidet untere (äusscre) und obere (innere) Spelzen. Die letzteren sind etwas höher eingefügt, meist zarter und kleiner. Die Spelzen (besonders die unteren) sind häufig begrannt. Als Granne betrachtet man einen frei werdenden erhärteten Nerv, welcher entweder vom Grunde oder vom Rücken (aus d. Mitte) oder von d. Spitze d. Spelzen ausgeht.

") Auch hier unterscheidet man obere und untere Balgklappen. Begrannt sind diese viel seltener.

SCHMIDT, Flora v. H. 
knotens angedeutet.") Stbgef. meist 3, seltener 2-6. Antheren in der Mitte mit dem Staubfaden verbunden, an beiden Enden ausgeschnitten. Fruchtlinoten oberstindig: 1eiig, mit 2 (seltener 1) Griffel und fadenförmigen oder federartigen Narben. Frucht nussartig (caryopsis), frei oder mit Spelzen und Balg verwachsen, meist sehr dünnhïutig und den Samen innig umschliessend. Keim ausserhalb des grossen, mehligen Eiweisses an dessen Grunde liegend. Die Gramineae, welche durch ihr häufig sehr geselliges Vorkommen in Zahl der Individuen von keiner anderen Pflanzenfamilio des Geb. äbertroffen werden, sind auch an Arten, nächst d. Composit. am reichlichsten vertreten. Von den 94 Arten sind 17 als wesentliche Bestandtheile unserer Wiesen zu betrachten, ausserdem besitzen 8 ein ganz allgemeines Vorkommen, 12 treten als oft lästige AckerUnkräuter und 11 als eigentliche Waldgräser auf. Ausserdem sind einige häufig vorkommende Arten von sumpfigem oder wasserreichem Boden abhängig, andere erscheinen sandstet. Die übrigen zeigen ein zerstreutes, oft einzelnes -Vorkommen.

\section{Blüthen eingeschlechtig}

(männl. und weibl. Blüthen in verschiedenen Aehrchen).

1. Olyreae. Aehrch. monoec, männl. und weibl. Aehrch. einander unälnnlich.

$\mathrm{Z}$ e a. Männl. Aehrch. endständig, in Rispen, 2blüthig, weibl. achselständig, von Scheiden umschlossen, 2blüthig; Grifiel sehr lang, hängend; Trïchte rundlich-nierenfürmig, kolbenartig gruppirt.

II. Blüthen zwitterig oder vielehig.

(d. h. Aehrch, enthalten im letzteren Falle sowohl Zwitter-, als männl., zuweilen aber auch geschlechtslose Blth.

A. Rispengräser. Aehrch. mehr oder weniger gestielt, in eine Rispe oder in mehrere gipfelst. Aehren zusammengestellt.

") Die Perigonschüppchen sind für die Charaktore der Grasgattungen zwar zuweilen nicht unwesentlich, da aber hier überhaupt nur die wichtigsten Merkmalo der Gattungen hervorgehoben werden, so sind sio bei der Aufzählung der Gattungen weggelassen. Es finden sich meist 2 Schüppchen; in einzelnen Gattungen sind sio ziemlich deutlich (Bromus, Glyceria, Avena), meist ganzrandig, zuweilen auch gesägrt oder gezähnt (Aira, Avena, Loocleria). Bei stipa sind deren 3. 
2. Andropogoncae. Aehrch, rom Rücken her zusammengedrückt, 1blüthig, mit spelzigem Ansatz einer zweiten Blth.; untere Balgklappe grösser als die obere.

Andropogon. Achrch. lineal in fingerartig gestellte Aehren, gezweiet, das eine sitzend, zwitterig, das andere gestielt, männl.

3. Panicete. Aehrch, vom Rücken her zusammengedrückt, 1blth., zuweilen mit cinom 1spelzigen Ansatz zu einer zweiten Blth., welcher einer äritten Balgklappe ähnlich sieht; untere Balgkl. kleiner, oft sehr klein, zuweilen fchlend; Griff, lang; Narb. fädlich.

Panicum. Achrch. 1blth., nebst ciner leeren dritten Spelze, wodurch der Balo scheinbar 3klappig ist; Spelzen knorpelig.

Setaria. Aehrch, wio bei Panicum, aber von ciner borstenfürmigen Ilülle umgeben, stets in achrenfürmigen Rispen.

4. Phalaroideae. Aehrch, ron den Seiten zusammengedrückt, 1blth., mit 1-2 unteren lecren Spelzen; (iriff. lang; Narb. federig.

Phalaris. Anhrch. ausser d. fruchtb. Blth. mit 1-2 kleinen, grannenlosen, leeren Spclzen, fruchtbaro Spelzen kürzer als die fast gleichlangen, kielig-zusammengeḑrückten Balgklappen.

Anthoxanthum. Aehrch. mit 2 lecren, begrannten Spelzen, welche die kürzeren fruchtbaren, unbegrannten Sp. umgeben; Balgklappen von ungleicher Länge; Stbgef. 2.

5. Alopecuroillcae. Achrch, von den Seiten zusammengedrückt, 1blth., zureilen mit einer oberen lecren Spelze; Balg 2klappig; Griffel lang, mit fädlichen, bchaarten Narben, an der Spitze der

Spelzen vortretend; Rispen aehrenförmig.

Alopecurus. Balgkl. gekielt, unten verwachsen; Spelze 1, schlauchförmig, mit rückenständiger Granne.

Phleum. Balgkl, gekielt, unten frei; Spelzen 2, begrannt od. unbegrannt.

Chamagrostis. Balgki. kiellos, unten frei; Spelzen 2 unbegrannt, wimperig-behaart.

6. Chlorideae. Aehrch, von den Seiten zusammengedrückt, 1mehrblüthig, an der unteren Seito einer Spindel einseitig sitzend; Griffel lang; Narben federig.

Csnodon. Aehren fingerartig gestellt; Aehrch 1blth., mit Ansatz zu unvollständigen Blth.; Spelzen und Balg gekielt.

7. Oryzeae. Aehrch. von den Seiten zusammengedrückt, 1blth., allseitswendig; Balgkl. sehr klein oder fehlend; Griffel kurz; Narben federig.

Leorsia. Balg fehlend; Spelzen grannenlos, dünnhäutig; Narben an der Mitto der Spelzen vortretend. (Stbgef. bei manchen Arten 6, bei unserer Art aber nur 3.) 
8. Agrostideae. Aehrch. von den Seiten zusammengedrückt, 1blth., (bei Calamagrostis zuweilen mit Ansatz zu einer oberen Blth.); Balg 2klappig; Griffel kurz; Narben federig, an der Basis der Spelzen vortretend.

Agrostis. Balg länger als die Spelzen, untere Balgkl, grüsser als die obere; Spelzen am Grunde mit sehr kurzen Haarbüscheln. Apéra. Wie vorige, aber untere Balgkl. kleiner als d. obere.

Cal amagrostis. Wie Agrostis, aber dio Spelzen am Grunde ron langen Haaren umgeben; Rispe länglich.

Ps amma. Wio Calamagrostis, aber die untere Balgkl. etwas kürzer als $d$. obere.

9. Stipaceae. Aehrch, stielrund, oder rom Rücken wenig zusammengedrückt, 1blth.; Narben federig, an den Seiten d. Spelzen vortretend; Frucht in die erhärteten Spelzen eingeschlossen.

Milium. Spelzen grannenlos; Rispe locker.

Stip a. Untere Spelze walzig-zusammengerollt, in eine gedrehte, sehr lange Granne ausgehend; Rispe etwas zusammengezogen.

10. Arundinaceae. Aehrch. von den Seiten zusammengedrückt, mehrblth.; Narben fädlich, an der Mitte d. Spclzen vortretend.

Phragmites. Aehrch. 4-7blth; untere Blth. männl., kahl, die übrigen $\mathrm{zwitterig,} \mathrm{von} \mathrm{langen} \mathrm{IIaaren} \mathrm{umgeben.}$

11. Avenaceae. Aehrch. von den Seiten etwas zusammengedrückt, 2-mehrblth.; Balg 2klappig, gross, das Aehrchen fast ganz einschliessend; Narben federig, an d. Basis d. Spelzen vortretend.

Koeleria. Aehrch. fast 3blth.; Balgkl. gekielt-zusammengedrückt; untere Spelze an der Spitze stachelspitzig oder kurz begrannt; Rispe aehrenförmig.

Aira. Aehrch. 2blth., mit Ansatz zu einer dritten Blth; Balgklappen gekielt; untere Spelze abgestutzt, 4zähnig, auf dem Rücken mit einer geknieten oder geraden Granne.

Coryne phorus. Aehrch. 2blth.; Balgkl. gekiclt, untere Spelze mit einer rückenständigen, in der Mitte geknieten, daselbst behaarten, an der Spitze keulenförmigen Granne.

$\mathrm{Holeus.} \mathrm{Aehrch.} \mathrm{2blth.:} \mathrm{untere} \mathrm{Blth.} \mathrm{zwitterig,} \mathrm{unbegrannt,}$ obere männl., mit gebogener, eingeschlossener oder freier Granne.

Arrhenatherum. Aehrch. 2blth.; untere Blth. männl., mit starker geknieter Granne, obere zwitterig, unbegrannt.

Avena. Aehrch. 2-mehrblth.; untere Spelze an der Spitze 2spaltig, mit einer rückenständigen, gewundenen, geknieten Granne.

Triodia. Aehrch. 2-mehrblth.; untere Spelze an der Spitzo 3zähnig; Balgkl. bauchig. 
M elica. Aehrch. meist 2blth., mit einem keulenförmigen Ansatz zu Blüthenrudimenten; Balgkl. u. Spelzen gewölbt, grannenlos.

12. Festuoacede. Aehrch, von den Soiten zusammengedrückt oder stielrund, 2-vielblth., mit oft verkümmerter endständiger Blth.; Balgkl. 2, kürzer als die $\Lambda$ ehrchen; Narbon federig, an der Basis der Spelzen vortretend.

Briza. Spelzen 2zeilig-dichtdachig, grannenlos, untere Spelze stumpf, aufgeblasen, am Grunde etwas herzförmig; Aehrch. oval, in lockerer, zitternder Rispe.

Poa. Untera Spelze 5-7nervig, eirund oder lanzettl., auf dem Rücken zusammengedrückt-gekielt, grannenlos, mit d. Gelenken der Spindel abfallend; Rispe locker.

Eragrostis. Wio vorige, aber Balg und untere Spelze abfallend, obere Spelzo nebst d. Spindelchen bleibend.

Glyceria. Untere Spelze 5-7nervig, länglich, stumpf, auf dem Rücken halbwalzlich, einwärts fast bauchig, grannenlos; Spindel der Rispe 3seitig; Caryopse mit tiefer Furche; Aehrch. reichblth.

Catabrosa. Wie vorige, aber untere Spelze deutlich 3nervig; Spindel der Rispe sticlrund; Caryopse ohne Furche; Aehrchen armblüthig.

Sclerochloa. Spelzen gekielt, unbegrannt, untere Spelze schwach 5nervig, dünnhäutig; Rispe aehrenförmig, einseitig; Spindel zusammengedrïckt, starr.

Molinia. Untero Spelze eiförmig-lanzettl. (kegelfürmig), zugespitzt, auf dem Rücken lalbwalzlich, begrannt oder unbegrannt; Aehrch. locker.

Dactylis. Spelzen zusammengedrückt-gekielt mit gebogener Spitze, untere Spelze ungleichseitig, an der ungetheilten oder 2 spalt. Spitze stachelspitzig oder kurz begrannt; Rispe geknäuelt.

Cynosurus. Spelzen auf dem Rücken abgerundet; jedes Aehrch. am Grunde mit einer 2zeilig-gefiederten Hülle gestüzt; Rispe aehrenförmig, einseitig.

Festuca. Spelzen lanzettl. oder lanzettl, -pfriemlich, auf dem Rücken abgerundet, untere Spelze 3-5nervig, begrannt od. grannenlos, obere am Rande sehr fein gewimpert; Griffel und Narben auf der Spitze des Fruchtknotens; Rispo mehr oder weniger 1seitig, Spindel 3kantig.

Brachypodium. Obere Spelze am Rando kammförmig-gowimpert; Aehrch. sehr kurz gestielt; Achre 2zeilig, Spindel 4kantig (sonst wie Festuca).

Bromus. Spelzen lanzettl, oder ei-lanzettl., begrannt oder unbegrannt; Griffel oder Narbe vorn unterhalb d. Spitzo d. Fruchtknotens entspringend; lispo moist allsoitig; Spindel stielrundlich. 
B. A ehrongräsor. Aehrch, auf den Zühnon oder in den Aushöhlungen einer Spindel sitzend, eine einzelno gipfelständige Aehre bildend, (Die seitenständigen Aehrchen bei Hordeum oft gestielt.

13. Hordeacece. Aehrch. 1-vielblth.; Narben 2, federig, an der Basis der Spelzen vortretend.

a) Aehrchen einzeln.

Triticum. Aelrch. 4-5blth.; Balgklappen 2, eiförmig oiler lanzettlich, gekielt; untere Spelzen begrannt oder unbegrannt.

Secale. Aehrch. 2blth. mit Rudiment zu einer dritten Blth.; Balgklappen 2, pfriemlich, gekielt, untere Spelzen begrannt.

Lolium. Aehrch. vielblth.; Balg. 1klappig, nur bei den endständ. Aehrch. 2klappig, untere Spelzen begrannt od, unbegrannt.

b) Aehrchen zu 2-3 auf jedem Gelenk der Spindel.

II ordeum. Achrch. 1blth, die seitenst. Aehrch, oft unfruchtbar oder männlich, kurz gestielt.

Elymus. Aehrch, vielblth., alle zwitterig.

14. Nurdoideae. Aehrch. 1blth.; Narbe 1, fädlich, aus d. Spitzo der Spelzen hervortretend.

Nardus. Balg fehlend, oder nur durch eine zalınartige $\Lambda \mathrm{n}$ deutung vorhanden; Spelzen 2, pfriemlich; Aehre einseitig.

\section{He a $L$. Ma is,}

Z. Mais $L$. Gem. MI.; weibl. Kolben achselst., ron Scheiden umhüllt ; Griffel sehr lang, hängend; männl. R.") gipfelst., ausgebreitet. ๑. $3-6^{\prime}$.

Aus Südamerika stammend, häufig gebaut. August, Septbr.

\section{0\%. And ropogon $L$. Bartgras.}

1021. A. Ischaemum $L$. Gem. B.; IIalmo büschelig, aufsteigend; Bl. lineal-rimnig, etwas steif, meergrün; Aehren flngerartig gestellt, 5-10; untere Balgkl. des zwitterigen Aelrchens am Grunde seidenhaarig, des männl. kahl. 4. 1--1!2. Achrchen etwas violett.

Auf sandigen Flächen, trockenen, sandigen und kalkhaltigen Hügeln, an Rainen hie und da, z. B. in Menge an den Felsen vor dem Haarlass! seltner beim Relaishauso und gegen Neckarau! an der Chausseo zwischen Schwetzingen und Brïhl! Juli-September.

-) R, bedeutet Rispe. 


\section{Panicum $L$. Fénich.}

a) Digitaria. Aehrch, in mehreren oinfachen, einseitswondigen, fast fingerförmigon Aehren; geschlechtslose Blth. mit einer lanzettl. Spelze; untere Balgkl. klein oder fehlend.

1022. P. sanguinale L. Blut-F.; aufsteigend; Bl. u. Scheiden wimperartig behaart; Aehren 4-5, Spindel derselben plattgedrückt, wellig; Aehrchen längl.-lanzettl.; Spelze der geschlechtslosen Blth. nur am Rande weichhaarig.") ๑. $1-1 \frac{1}{2}^{\prime}$. Aehrch. griin oder purpurn. - Variirt:

B) ciliare Döll. Spelze der geschlechtslosen Blth. auf dem Kiele und am Rande mehr oder weniger steifharig gewimpert. ( $P$. ciliare Retz.)

An Wegen, Rainen, auf Sandflächen und Aeckern dio Hauptform häufig, z. B. in der Nähe ron H. an der Strasse nach Neuenheim! bei Dossenheim! u. s. w. Die Var. auf sandigen Aeckern der Rheinfläche hio u. da, z. B. Schwetzingen! Ketsch! zwischen Seckenheim und Mannheim! August, September.

1023. P. glabrum Gaud. Kahler F.; niederliegend; BI. u. Scheiden kahl; Aehren meist 3, deren plattgedrückte Spindel kaum wellig; Aehrchon ellipsoidisch, weichhaarig, auf den Nerven meist kahl. ๑. $\frac{1}{2}-1^{\prime}$. Aehrch. grün oder etwas röthlich,

Auf sandigen Aeckern, an Wegen häufig, z. B, in der Nähe v. II. am Philosophenwege! beim Speyrer Hof! Handschuchsheim! in grosser Mengo stellenweise zwischen Friedrichsfold und Hockenheim! Waghäusel! Wiesenthal! August-October.

7) Milium; Rispo ausgebreitet, überhängend; Aehrchen langgestielt.

P. miliaceum L. Hirse; Halmo aufrecht, kahl; Bl. u. Scheiden rauhhaarig; Aehrch. elliptisch, spitz, blassgrün. ○. $1 \frac{1}{2}-2^{\prime}$.

Aus Ostindien stammend. Auf sandigen Acckern hie und da cultivirt, bisweilen verwildert. Juli, August.

c) Echinochloa; einseitswendige Rispe mit kurzen dachziegeligen

Verzweigungen; Balgklappen begrannt oder stachelspitzig.

1024. P. Crusgalli $L_{\text {. }} \mathrm{H}$ a hn $\theta \mathrm{n} \mathrm{fuss}-\mathrm{F}$.; Halm aufrecht od.

*) Die 2 Spelzklappen der Zwitterblth. umgeben, dell Fruchtknoten innig, die Spelzklappo der geschlechtslosen Blth. ist frei und von den 3 Blättchen, welcho die Zwitterblth. ungeben, die innere, die 2 äusseren stellen den Balg dar. (Die unterste Balgkl. wird sehr leicht übersehen, fehlt aber auch bistreilen völlig.) 
niederliegend, wic d. Bl. kahl; R. fast walzenförmig; Aelırchenstielo steifhaarig. $\odot \frac{1}{4}-2^{\prime}$. Variirt mit mehr oder weniger begrannten grünen oder violetten $\Lambda$ chrchen. (Oplismenus Crus galli Kth.).

Auf feuchten sandigen und lehmigen $\Lambda$ eckern, Triften, auf Mauern, an Gräben häufig, hesonders vorherrschend zwischen Ladenburg und Feudenheim! bei Schwetzingen! Alt-Lussheim u. s. w.: Juli-October.

\section{Setaria Beauv. Borstengras.}

1025. S. verticillata Beauv, Qu irliges B.; Halm aufrecht; ährenförmige R, verlängert, locker, am Grunde oft unterbrochen; Hüllborsten durch rückwärts gekehrte Zähnchen rauh, hellgrün; Spelzen der $\mathrm{Zwitterblth.} \mathrm{fast} \mathrm{glatt.} \mathrm{\odot .} \mathrm{1-2'.} \mathrm{(Panicum} \mathrm{verticillatum} \mathrm{L.).}$

Auf Aeckern und Sandfächen hie und da, z. B. im Eingange des Dreitrügethales bei H. (auf Aeckern links!), zwischen dem Rohrhofe und Schwetzingen: bei Mannheim, an der Strasse nach Schwetzingen $(D \dot{d} l l$.$) . Juli-September.$

1026. S. viridis Benuv. Grünes B.; Halm aufrecht; ährenf. R. gedrungen, walzlich; IIüllborsten von aufrechten Zähnchen scharf; Spelzen der Z Zwitterblth. fast glatt. ๑. $\frac{1}{2}-1^{\prime}$. Borsten und Blätter blassgrün. (Panicum viride L.). bis October.

Auf Aeckern, Sandfeldern, an Wegen, Mauern häuffg! Juli

1027. S. glauca Beauv. Meergrünes B.; Halm aufrecht; ährenf. R. gedrungen, walzlich; Hüllborsten von aufrechten Zähnchen scharf; Spelzen der Zwitterblth. deutlich queerrunzelig. $\odot$. $\frac{1}{2}-1^{\prime}$. Bl. blaugrïn; Borsten gelb. (Panicum glaucum L.).

Auf Sandflächen, Aeckern, an Wegen, besonders der Ebeno häufig! auch in d. Nähe von H. nicht fehlend, z. B. am Philosophenwege! oberhalh Handschuchsheim gegen Dossenhcim! Juli bis September,

\section{Phalaris $L$. Glanzgras.}

1028. P. arundinacea $L$. Rohrartiges G.; Ilalm aufrecht; Bl. lineal-lanzettl. mit sehr entwickelten Blatthüutchen; R, pyramidenfürmig mit gebüschelten grünen od, violetten Aehrchen; Balgkl. gekielt, ungeflügelt.' 2. 2-4'.

Auf nassen Wiesen, an Ufern häufig, z. B. arn Neckar b. II. allgemein verbreitet. Juni-August. 


\section{I. Authoxanthum $L$. Ruchgras.}

1029. A. odoratum $L$. Wohlriochendes R.; Halme büschelig, aufrecht, mit kurzen Bl.; R. ährenförmig, länglich, locker, die Spelzen der rudimentären Blthen angedrückt behaart. 24. 1- $1^{\prime}{ }^{\prime}$. Diandrisch! Enthält Cumarin, daher besonders die unteren Theilo der Pflanze und im getrockneten Zustando wohlriechend. - Gutes Wiescngras!

Auf Wiesen, in Wäldern, an Wegen allgemein verbreitet. Mai bis Juli.

412. A l p pecurus $L$. Fuchsschwanz.

1030. A. pratensis $L$. Wiesen-F.; Halmo aufrecht, glatt; R. ährenf., walzenf., stumpf, mit $5-7$ ährigen Aesten; Balgklappen spitz, bis zur Mitte verwachsen, weichhaarig-gevrimpert; Granne 2 mal so lang wie d. Aehrchen, am Grunde der Spelze entspringend. 4. 2-3'. Gutes Wiesengras.

Auf Wiesen, Grasplätzen allgemein verbreitet. Mai-Sept.

1031. A. agrestis $L$. Acker $-\mathrm{F}$; Halme aufrecht, oben etwas schärflich; R. ährenf., walzenf, , schlank mit 1-2ährigen Aesten; Balgklappen bis zur Mitte verwachsen, scharfkielig, kahl, nur am Rande etwas gewimpert; Granne wie vorige, aber etwas gekniet. ๑. $1-2^{\prime}$.

Auf lehmigen Aeckern, Triften, an Wegen häufig, in der Näho von II., z. B. zwischen Neuenheim und Handschuchsheim verbreitet! Mai-Juli.

1032. A. geniculatus $L$. Geknieter F.; Halme niederliegend, aufsteigend, an den Knoten gekniet, kahl, nebst Bl. bläulichgrün; R. ährenf., walzenf., mit 2-8ährigen Aesten; Balgklappen nur am Grunde verwachsen mit gewimpertem Kiele; Granne der Spelze gekniet, fast am Grunde des Rückens entspringend. ๑. 1'. Antheren lineal, gelblich-braun.

An Flussufern, in Sümpfen, an Gräben hie und da, z. B. am Neckar bei der Bergheimer Mühle! gegen Ziegelhausen und Schlierbach! bei St. Ilgen! Kirchheim! Wiesloch! beim Rohrhof! im Friedrichsfelder Walde! Mai-August.

1033. A. fulvus Sm. Rothgelber F.; dem vorigen sehr ähnlich, an den Knoten weniger gekniet, hauptsächlich zu unterscheiden durch die gerade kürzere, fast in der Mitte des Rückens entspringende Granne, und durch die kürzeren rothgelben Antheren. ๑. $1-2^{\prime}$. 
An den Rändern stehender Gewässcr, in schlammigell Sumpfgräben stellenweise, z. B. am Weiher hinter dem Stift Neuburg! zwischon Handschuchsheim und Ladenburg! Waghäusel! Rohrhof! Juni-August.

\section{Phleum $L$. Lieschgras.}

1034. P. pratense $L$. Wiesen $L$. ; Halm aufsteigend, einfach; R. ährenf., walzenf. stumpf; Balgkl. länglich, queerabgeschnitten, begrannt, am Kiele steifhaarig gervimpert. 2. $1 \frac{1}{2}-2^{\prime}$. Hellgrün. Gutes Wiesengras! Variirt:

ß) nodosum; Halme am Grunde knollig rerdickt. $\frac{1}{2}-1^{\prime}$, R. kürzer, wie d, ganze Gras graugrün. ( $P$. nodosum L.).

Auf Wiesen, Triften, an Waldrändern häufig. Die Variet. auf Sandflächen, in Nadelwäldern, z, B. zrischen Friedrichsfeld und dem Relaishause! Juli-September.

(Diese Art wird von Anfängern leicht mit Alopecurus pratensis verwechselt, unterscheidet sich aber sogleich, olne Berücksichtigung des Gattungscharakters, durch die queerabgeschnittenen Balghlappen.)

1035. P. asperum Till. Rauhes L.; Halme aufrecht, meist biischelig; R. ährenf., walzlich, stumpf; Balgkl. keilförmig, an der Spitze schief abgeschnitten, stachelspitzig, aufgeblasen, rauh, ๑. $\frac{1}{4}-3^{3}$, graugrün.

Auf lehmigen und kalkhaltigen Aeckern nicht häufig, z. B. Wiesloch! Dielheim! Baierthal! Rauenberg! Ladenburg (Bischoff, Schwetzingen und vereinzelt beim Relaishause (Schimp.). Juli, Aug.

[Fehlt in der Nähe des Geb. in Rhb. u. Hs.]

1036. P. phalaroides Koel. Glanzgrasartiges L.; Halme aufrecht, schlank, kleine bläulichgrïne Rasen bildend; R. ährenf., walzig, stumpf; Balgkl, lineal-länglich, schief abgeschnitten, stachelspitzig, am Kielo gewimpert, rauh. 4. $\frac{3}{4}-1 \frac{1}{2}$. (P. Bochmeri Wib.). Variirt:

B) viviparum; Aehrchen knospenartig auswachsend.

(In diesem Zustande hat das Gras täuschende Aehnlichkeit mit der südeuropäischen Phalaris paradoxa L.).

Auf trockenen Hügeln, an Abhängen, auf Sandfeldern hio und da, meist gesellig, z. B. auf den Hügeln vor dem Haarlass! bei Schriesheim! Weinheim! Leimen! Wiesloch! beim Maischbacher IIof! bei Raucnberg; Auf den Sandflächen der Ebene verbreitet. Die Varietät auf dem Sande bei der Mannheimer Rheinziegelhütte in Menge! Juni, Juli, 


\section{Chamagrost is Borkh. Zwerggras.}

1037. Ch. minima Borkh. Kleinstes Z.; IIalme aufrecht, fadenfürmig, zahlreich, büschelig (fast polsterartig); Aehren einseitswendig, lineal, violett oder grïnlich. ๑. 1-3". (Mibora verna Adans; Sturmia minima Hoppe).

Auf feuchten sandigen Aeckern und Sandflächen der Ebeno hie und da häufig, z. B. zwischen dem Relaishause und Schwetzingen! bei Oftersheim (daselbst in einzelnen Weinbergen!) beim Rohrhofe! bei Hockenheim! Käferthal, besonders in der Nähe des Nadelwaldes! Seltener bei der Mannheimer Ziegelhütte und gegen Sandhofen! März, April.

\section{4l5. Cynodou Per's. Hundszahn.}

1038. C. Dactylon Pers. Gemeiner II.; graugrün; IIalme niederliegend, verzweigt, mit sehr verlängerten, kriechenden Nebenhalmen; Bl. kurz, unterseits behaart; Aehren 3-5; Spelzen am Kiel und an den Rändern gewimpert. 4. $\frac{1}{2}-1^{\prime}$. Aehren meist violett.

An grasreichen Abhängen, auf sonnigen trockenen Hügeln, an Wegen hie und da, meist gesellig, z. B. am Neckar hinter Neuenheim! am Philosophenwege! an der Strasse von Neuenheim-Ziegelhausen! Seltener beim Relaishause! bei Mannheim! Schretzingen! Juli-October.

\section{Leersia Soland. Leersie.}

1039. L. oryzoides $S w$. Reisähnliche L.; hellgrün; Halme aufsteigend, schlank; Bl. rauh; R. ausgebreitet, locker, meist nur theilweise aus den oberen Blattscheiden hervortretend; Aehrchen fast oval, triandrisch, gewimpert (leicht abfallend). 24. 2-3'.

An Sumpfgräben, Fluss - und Teichufern nicht häufig. Zwischen Brühl und dem Rohrhofe (Schimp.), am Neckarufer bei Feudenheim (Bischoff). Im Schwetzinger Schlossgarten; bei Ketsch (Döll.). August-October.

\section{1\%. Agrostis $L$. Windhalm.}

a) Blätter alle flach; obere Spelze völlig apusgebildet.

1040. A. alba Selvad. We isser W.; IIalme aufsteigend od. etwas niederliegend, nebst den Scheiden glatt; Blatthäutchen länglich, R. längl.-kegelförmig mit rauhen Verzweigungen, nach der Blüthe zusammengezogen, 4, Achrch, grünlich oder röthlich, - Variirt mit 
kürzeren oder längeren Ausläufern, mit begrannten oder häufiger unbegrannten Spelzen, 24. 1-3'. (A. stolonifera $\beta$ L.).

An Wegen, auf Triften, Wiesen, in Wäldern üborall verbreitet! Juni, Juli.

1041. A. vulgaris With. Gemeiner W.; Halme aufrecht od. aufsteigend, nebst den Scheiden glatt; Blatthäutchen sehr kurz, gestutzt; R. eiförmig-länglich, mit etwas schärflichen Verzweigungen, nach der Blüthezeit abstehend-ausgebreitet. 4. $\frac{1}{2}-2^{\prime}$. Achrchen meist unbegrannt, violett. Ausläufer kurz oder verkümmert.

An Wegen, auf Triften und Sandflächen häufig. Juni, Juli.

b) Blätter zusammengefaltet-borstig, die obere Spelze fehlend oder sehr klein.

1042. A. canina L. Hunds-W.; Halmo aufsteigend oder aufrecht; Bl. borstig od. d. unteren theilweise flach; Blatthäutchen länglich, stumpf, eiförmig-länglich, mit rauhen, nach der Blüthezeit zusammengezogenen Verzweigungen; Aehrchen mit verlängerter, geknieter Granne, violott oder hellgrün. 24. 1-2'. (Trichodium caninum Schrad.).

Auf sumpfigen Wiesen und Torfmooren hio und da, z. B. beim Rohrhof! bei Waghäusel! Sandtorf (Schimp.), beim Bierhälter Hof bei H. (Dierb.). Juli, August.

\section{A péra Adans. Wind falne.}

1043. A. Spica venti Adans. Geme ine W.; Halm aufrecht; $\mathrm{Bl}$. flach mit längl.-zugespitzten Blatthäutchen; $\mathrm{R}$. länglich ausgebreitet, nacl dem Verblühen zusammengezogen; Aehrchen lang begrannt, grün oder bräunlich. ๑. 1-3'. (Agrostis Spica venti L.).

Auf Aeckern, an Wegen allgemein verbreitet, oft als GetreideUnkraut sehr lästig. Juni, Juli.

\section{Calamagrostis Roth. Reithgras.}

a) Aehrchen ohne Ansatz zu einer zweiten Blüthe.

1044. C. lanceolata Roth. Lanzettl. R.; Halm aufrecht; BI. rauh, abstehend; Balgkl. schmal-lanzettl., zugespitzt, Haaro länger als die Spelzen; Granne endständig, gerade, sehr kurz, aus der kurzgespaltenen Spelze hervortretend. 4. 2-4'. Aehrch, grünlich-violett, später hellbraun. (Arundo Calamagrostis L.).

Auf sumpfigen Wiesen. Bisher nur in einem tast trockengelegten Sumpfe bei Handschuchsheim, woselbst früher häufiger (Dierb., Bisch., A. Braun), jetzt nur noch sehr voroinzelt. Juni, Juli, 
[N. V. a. d. Geb. in IIs.: 2wischen Leeheim und Griesheim (Schnttsp.), in Rhb,: bei Oggersheim und Maxdorf (F. Schult:).

1045. C. littorea $D C$. Ufer R.; der vorigen ähnlich, blïulichgrün, ausgebreitet, etwas nickend; Balgkl. und IIaare wie vor.; Granne endständig, gerade, aus der kurzgespaltenen Spelze hervortretend, diese weit überragend. 4. 3-4". Achrchen hellviolett. (Arundo littorea Schrad.; A. effusa Gmel.).

Auf feuchtem Kiessande und in Weidengebüschen am Rheinufer, z. B. auf der Insel bei Ketsch! zwischen Ketsch u. Neckarau! ziemlich häufig zwischen Mannheim und Sandhofen! Juli, August.

1046. C. epigejos Roth. Gomo in es R.; IIalm aufrecht, wie die etwas steifen Bl. graugrün; R. aufrecht, ausgebreitet-lappig; Balgkl. lanzettl.-pfriemlich, Ilaare linger als die Spelzen; Granne rückenständig, gerade. 24. 2-4'. IR. meist violettgrün, seltener bläulich. (C'. glauca Reichb.; Arundo Épigeios L.).

In lichten Wäldern, auf Sandä̈chen, an Ufern hie und da, stellenweise auch im Gebirge, z. B. Königstuhl! Haarlass! oberhalb des Wolfsbrunnens! zwischen Dossenheim und Schriesheim! am Rheinufer ziemlich verbreitet; auch am Rande der Nadelwälder in der. Ebene nicht selten! Juli, August.

b) Ansatz zu einer zweiten Blüthe aus einem behaarten Stielchen bestehond.

1047. C. arundinacea Roth. Wa ld-1i,; hellgrün; Bl. etwas bläulich; R. aufrecht, schmal; Balgklappen lanzettl, zugespitzt, Haare 4mal kürzer als d. Spelzen; Granne rückenständig, gekniet, die Spelzen weit überragend. 4. 2-4'. (Agrostis arundinacea L.; Arundo sylvatioa Schrad.; Deyeuxia sylvatica Kth.).

An bewaldeten Anhöhen, in Gebirgswäldern hie und da, z. B. b. H. im Dreitrögethal, daselbst im Lärchenbestande, am Fusse der nürdl. Bergseite! auch oberhalb des Speyrer Hofes und am Künigstuhl! Stellenweise bis Nussloch (I)̈̈ll.) und zwischen Rauenberg und Malsch! Jenseits des Neckars im Walde hinter dem Haarlass (Bisch.). Längs der Bergstr.? Juli, August.

\section{P s amma $R$. et $S c h$. S andgras.}

1048. P. arenaria R. et Sch. A echtes S.; Halm steif aufrecht, kahl; $\mathrm{Bl}$. eingerollt; $\mathrm{R}$. ährenf., walzenf., strohgelb; Balgklappen lanzettl., spitz; Haare 3mal kürzer ås d. Spelzen. 4. 2-3', Wstock kriechend. (Ammophila arenaria Lk.; Arundo arenaria L.).

Auf Sandfeldern, am Rande der Föhrenwaldungen b. Friedrichs- 
feld, gegen Mannheim, unfern der Eisenbahn, daselbst häufig (Schimp.). Juli, August.

[N. V. a. d. Geb.: Darmstadt.]

\section{Stipa $L$. Pfriemengras.}

1049. St. pennata $L$. Federartiges P.; IIalme büschelig; Bl. borstenförmig; R. am Grunde von Blattscheiden eingeschlossen; Granne sehr lang, gekniet, gefiedert. 4. 112-2'.

Auf trockenen Sandfeldern, Irïgeln, am Rande von Nadelwäldern. Z Zwischen Friedrichsfeld und dem Relaishause $\left(\frac{1}{4}\right.$ Stunde von ersterem Ort) in Menge! Juni, Juli.

[N. V. a. d. Geb. in Rhb.: Ilügcl zwisehen Dürkheim und Terxheim: in Hs.: Bickenbacher Tamne (Sclnutsp.), in B. in der Nähe des Geb. fehlend (Düll.).]

1050. St. capillata $L$. II a arartiges P.; Halme buischelig; Bl. rinnig-fadenförmig; R. am Grunde eingeschlossen; Granne sehr lang, hin und hergebogen, kahl. 4. $\frac{1}{2}-2^{\prime}$.

Auf trockenon Hügeln, Sandflächen cbenfalls nicht verbreitet; z. B. auf dem Sando bei dem Mamnheimer neuen Kirchhofo; beim Relaishause (Schimp.), einzoln am liando des Käferthaler Waldes (Döll.). Juli, August.

N. V. a. d. Geb.: in Rhb. mit d. vorigen auf Hügeln zwischen Dürkheim und Leistadt! in IIs. zwischen Darmstadt-Mrainz (Schnttsp.),

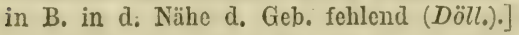

\section{Hilium $L$. Flat tergras.}

1051. M. effusum $L$. A u sgebreitetes F.; hellgrün; IIalme einzeln, kahl; Bl. flach; $R$. ausgebroitet locker; Aehrchen eiförmig. 4. $2-3^{\prime}$.

In schattigen Wäldern, Gebüschen der Ebene und der Gebirge häufig, z. B. b. II. hinter dem IIaarlass! im Dreitrügethal! u. s. w. Mai, Juni.

\section{Phigmites Trin. Rohr.}

1052. Ph. communis Trin. Gemeines R.; Halm steif; Bl. sehr verlängert, anselinlich, graugrïn; R. weitschwoifig, pyramidenfürmig, endlich etwas einseitig überhängend, rothbraun. 4. 4-8'. (Arundo Phragmites L.).

An Ufern, in Gräben und Sümpfen allgemein verbreitet. Juli bis September. 


\section{Koeleria Pers. Koelerie.}

1053. K. cristata Pers. I a $\mathrm{mm}$ förmigo K.; rasenbildend, hellgrün; Bl. kurz, flach, etwas weichhaarig; R. ährenf. lappig, am Grunde unterbrochen, untere Spelze zugespitzt, begramnt oder unbegrannt. $4.1-\mathbf{1}^{\frac{1}{2}}$. (Aira cristata $\mathrm{L}$.). Variirt:

ß) glcuca; bläulichgrün ; Bl. steifer, rinnig, kahl, untere Spolze stumpr, begrannt oder unbegrannt. (K, glauca DC.; Aira glauca L.).

Auf Wiesen, Triften, in trockenen lichten Wäldern, an Wegen dio Hauptform häufig. Die Variet. in Nadelwäldern und auf Sandflächen der Ebene stellenweise schr verbreitet, z. B. zwischen Friedrichsfeld, dem Relaishause, Schwetzingen und Hockenheim! zwischen Käferthal und Sandtorf! bei Sandhausen! Juni, Juli.

\section{1\%. Aira $L$. Schmiele.}

1054. A. caespitosa $L$. Tas an-S.; rasenbildend; Halme aufrecht, glatt; Bl. flach, hellgrün, oberseits scharf; R. ansehnlich, pyramidenf., ausgebreitet, mit rauhen Aesten; Granme fast gerade, haum länger als dio Spelze. 24. 2-4'. Aehrchen mit fadenförmigem, dichtbehaartem Ansatz zu einer dritten Blüthe. Aehrch. glänzend, grünlich violett. Gutes Wiesengras. (Desohampsia caespitosa Beauv.). Variirt:

ß) pallida Koch; Aehrchon grünlichgelb.

$\gamma$ ) setifolia Bisch.; Halme meist niedriger, schief aufsteigend $1-2^{\prime}$; Blätter borstenfürmig cingerollt, blaugrün.

Auf Wiesen, an Flussufern, in feuchten Gebüschen, in Sümpfen die Hauptform häufig, z. B. in der Näho von Handschuchsheim! in Torfsümpfen, z. B. bei Sandtorf heerdenweise! Var. $\beta$ in feuchten Wäldern der Gebirge und Ebenen, z. B. am Oelberge bei Schriesheim! beim Relaishause! im Neckarauer Walde! Var. $\gamma$ auf trockenen Wiesen und Triften, z. B. zwischen dem Relaishause und dem Rohrhof, beim rothen Loch unweit Friedrichsfeld (Düll.), früher auch bei H. am Eingange des Hafens vor d. Mannheimer Thor (Bisch.). - In der Nähe d. Geb. bei Ludwigshafen, zu beiden Seiten der Fahrstrasse nach Mundenheim häufig und daselbst auch mit Uebergängen zur gewöhnlichen Form! Juni-August.

1055. A. flexuosa $L$. Geschlängelte S.; rasenbildend; Halme glatt, aufrecht; Bl. borstig, sehr schmal; R. abstehend, etwas überhängend; Verzweigungen hin und hergebogen, schärflich; Granne

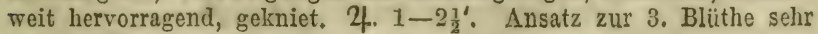
klein; Aehrchen glänzend, gelbgrün. 
Auf Waldwiesen, an Waldrändern, auf Iraiden, in Nadelwäldern der Gebirge und der Ebenen hänfig. Juni-August.

126. Coryue porus Beauv. Keulengranne.

1056. C. canescens Beauv. G raue K.; graugrün, rasenbildend; Halme büschelig; Bl. borstenfürmig, starr, mit verlängerten Blatthäutchen; R, abstehend, vor und nach der Blüthe zusammengezogen. 24. $\frac{1}{2}-1^{\prime}$. Aehrch. röthlich grau. (Aira canescens L.).

Auf Sandflächen, trockenen sandigen Hügeln, besonders in den Sandgegenden der Ebene sehr verbreitet und zuweilen einzige Spur der Vegetation. Juni-August.

\section{Holcus $L$. Honiggras.}

1057. H. lanatus $L$. Wolliges II.; Ialme büschelig; B1. und Scheiden weichhaarig-zottig; R. abstehend; Granne kurz, im Aehrch. verborgen, zurückgekrümmt. 4. 1-2'. W. faserig; Aehrch. rosa. Gutes Wiesengras.

Auf Wiesen, an Wegen, auf Waldtriften überall verbreitet. Juni-August.

1058. H. mollis $L$. Woiches II.; dem vorigen ahnlich, die oberen Bl. und Scheiden meist kahl, die unteren kurzweichhaarig; R. mehr zusammengezogen; Granno weit vortretend, gekniet. 4 . $1-3^{\prime}$. Wstock kriechend; Aehrch. grünlichgelb od. blassviolett.

In lichten Wäldern, auf Waldwiesen hie und da, seltener als d. vor., z. B. hinter dem Haarlass! in d. Waldgebüschen bei der Engelswiese! zwischen Ziegelhausen und Schönau! im Mühlenthale bei IIandschuchsheim! Woinheim! Maischbacher Hof! Juni, Juli.

\section{A r r he in therum Beauv. Glat thafer.}

1059. A. elatius $M$. ct $\pi$. Hoher G. (französisches Raygras); Halme aufrecht, kahl; Bl. nlach, scharfrandig; R. verlängert, locker, ausgebreitet. 4. 2-3i. Aehrch. glänzend, weisslichgrün. Gutes Wiesengras. (Avena elatior L.; Arrhenalh. avenaceum Beauv.).

Auf Wiesen, an Waldrändern, W'egen allgemein verbreitet. Juni-August.

\section{A reua $L$. Hafer.}

(l) Aehrchen nach dem Verblühen hängend; Balgklappen 5-9nervig; Fruchtknoten an der Spitze behaart.

A. sativa L. Gemeiner H.; Rispe gleichmässig ausgebreitet; 
Aehrch. 2blüthig, kahl, Spelzen an der Spitze 2spaltig und gezähnelt, die der unteren Blüthe vom Rücken begrannt. ๑.

Gebaut; hio und da verwildert.

A. orientalis Schrad. Türkischer H.; der vorigen sehr ähnlich, aber d. R. einseitswendig zusammengezogen. ๑.

Ebenfalls gebaut, aber selten. Juli.

1060. A. fatua $L$. Flug h a fer; R. gleichmässig ausgebreitet; Aehrch. 2-3blth., Spindel derselben rauhhaarig; Spelzen an der Spitze 2zähnig-gespalten, vom Rücken begrannt, vom Grunde bis zur Mitte gelbbraun borstig behaart. ๑. 2'.

Unter dem Getreide, auf Brachäckern hie und da, besonders auf Lehmboden, z. B. bei Ladenburg und Wiesloch nicht selten! Juli, August.

b) Aehrchen nach der Blüthezeit aufrecht; Balgklappen 1-3nervig; Fruchtknoten an der Spitze behaart.

1061. A. pubescens $L$. Weichha ariger H.; Halme aufsteigend, graugrün; Bl. flach, d. unteren nebst den Scheiden zottig; R. wonig ausgebreitet, locker; Aehrch. 2-3blth., begrannt, Granne fast gerade; Balgklappen und Spelzen trockenhäutig weiss berandet. 4. $1 \frac{1}{2}-3^{\prime}$.

Auf trockenen Wiesen, Sandflächen, Hügeln, an Rainen hie und da, z. B. Haarlass! Handschuchsheim! längs der Bergstrasse! Rohrbach; Leimen! Wiesloch! Häufig an den Rheindämmen und auf den Wiesen zwischen Rohrhof und Neckarau! Juni, Juli.

1062. A. pratensis $L$. Wiesen-H.; der vorigen ähnlich; Bl. schmal lineal, meist etwas zusammengefaltet, oberseits rauh, übrigens wio die Scheiden kahl; R, zusammengezogen, locker; Aehrch. 4-5blüthig, begrannt, Granne rechtwinkelig abstehend; Balgkl. und Spelzen trockenhäutig weissberandet. 4. $1 \frac{1}{2}-2^{\prime}$.

Auf trockenen Wiesen, Triften, Hügeln, an Waldrändern seltener als vorige, z. B. am Oelberge bei Schriesheim! in d. Hessel bei Wiesloch! zwischen Dielheim! Rauenberg! und Rodenberg! Baierthal, Waghäusel, Käferthaler Wald, Sandtorf (Döll.). Juli bis August.

c) Aehrchen nach dem Verblühen aufrecht; Balgklappen 1-3nervig; Fruchtknoten kahl; Granne aus oder oberhalb der Mitte der Spelzen entspringend.

1063. A. flavescens $L$. Gelblicher H.; Halm aufrecht, nebst Scheiden glatt; Bl. flach, oberseits feinhaarig; R. reichblüthig, 
wenig ausgebreitet; Achrchen 3blüthig, klein, gelblich, begrannt, mit behaarter Achse; Spelzen trockenhäutig berandet. 2. 1-2'. Gutes Wiesengras. (Trisetum flavescens Beauv.).

Auf Wiesen, an Wegen und Waldrändern allgemein verbreitet. Juni, Juli.

d) Aehrchen nach dem Verblühen aufrecht; Balgkl. 1-3nervig; Fruchtknoten kahl; Granne unterhalb der Mitte der Spelzen entspringend.

1064. A. caryophyllea Wigg. Nelkenhafer; Halme aufrecht, glatt; Bl. zusammengerollt-borstig; R. elliptisch, ausgebreitet, locker; Aehrchen 2blüthig, untere Spelze an der Spitze haarspitzig gespalten. ๑. 2-5". R. weissgrau. (Aira caryophyllea L.).

Auf Sandfeldern, trockenen sandigen Hügeln, Haiden, in $\mathrm{Na-}$ delwäldern hie und da häufig, z. B. in d. Nähe von H. beim Riesenstein! Philosophenweg! Ziegelhausen! Sandflächen der Ebene! Mai, Juni.

[A. praecox Beauv. Früher H.; der vorigen ähnlich; Halme meist büschelig; $R$. länglich-zusammengezogen, etwas gedrungen, grünlichweiss, ○. 2-5". (Aira praecox L.).

Auf sandigen Aeckern, Sandflächen im Geb. d. Flora ohne sicheren Standort. Vielleicht bei Sandtorf? beim Relaishause? -

N. V. a. d. Geb. Rhb.: Seebach bei Dürkheim! in B.: Carlsruhe (Döll.), in Hs.: Kranichstein (Schnttsp.). April, Maai.]

\section{Triodia $R . B r$. Dreizahn.}

1065. Tr. decumbens Bcuuv. Nied erlieg ender D.; rasenbildend; Halme niederliegend oder aufsteigend; Bl. und Scheiden behaart; R. locker, zusammengezogen, die unteren Aeste 2-3, die oberen 1 eilängliche, weissgrüne, glänzende Aehrchen tragend. 4. $\frac{1}{2}-1^{\prime}$. (Festuca deoumbens L.; Danthonia decumbens DC.).

Auf trockenen Wiesen und Triften, in trockenen Wäldern, auf Sandflächen, in d. Nähe von H. ziemlich verbreitet, z. B. Engelswiese! oberhalb des Philosophenweges! Geisberg! Mühlenthal bei Handschuchsheim! in den Sandgegenden der Ebene zuweilen sehr gesellig, z. B. zwischen Friedrichsfeld und dem Relaishause! beim Rohrhof! bei Sandhausen und Walldorf! Juni, Juli.

\section{II elica $L$. Perlgras.}

1066. M. uniflora Retz. Einblüthiges P.; Halm aufsteigend; Bl. 1lach, feinhaarig, mit röhrigem, zugespitztem Blatthäut- 
chen; R. locker mit aufrecht abstehenden rauhen Aesten; Aehrchen aufrecht, 1blüthig, kahl, röthlich. 4. 1'.

In schattigen Wäldern hie und da, z. B. Haarlass! Hillenbach bei Handschuchsheim! Schriesheim! Weinheim! Gaiberg! Maischbach! zwischen Waghäusel und Kirrlach! im Neckarauer Walde! Mai, Juni.

1067. M. nutans $L$. Nickendos P.; Halm aufsteigend; Bl. flach, rauh, mit sehr kurzem Blatthäutchen; R. einfach, fast traubig, einseitswendig; Aehrchen nickend, 2blüthig, kahl, röthlich. 4. 1'.

In schattigen Wäldern allgemeiner verbreitet als vorige, oft mit derselben, z. B. beim Ilaarlass! Häufig zwischen Leimen und Nussloch ! bei Weinheim! u. s. w. Mai, Juni.

[1I. ciliata L. Gow impertes P.; Halm aufrecht; Bl. schmal lineal, behaart, mit verlängertem Blatthäutchen; R. ährenf.; Aehrch. 2blüthig, untere Spelze am Rande zottig gewimpert. 4. 1-2'.

Auf trockenen Kalkhügeln, an Felsen. N. V. a. d. Geb.: zwischen Dürkheim und Leistadt häufig! Juni, Juli.]

\section{Briza $L$. Zittergras.}

1068. B. media $L$. Gemeines Z.; Halm aufrecht, glatt; R. etwas ausgebreitet; Aehrchen herz-eiförmig 5-9blüthig, nickend, glänzend; Aehrchenstiele sehr fein. 4. 1'. Gutes Wiesengras.

Auf Wiesen allgemein verbreitet. MIai-Juli.

\section{Lragrost is Beaur. Li e besgras.}

1069. E. poaeoides Beauv. Rispengrasartiges L.; bläulichgrün; Halme aufsteigend büschelig; Bl. lineal, meist kahl; Blattläutchen sehr kurz mit wimperartigem Haarkranz; R. locker; Aelreh. lineal-lanzettl., kurzgestielt, 8-16blüthig, rothbraun, untere Spelzen stumpf. ๑. $\frac{1}{2}-1 \frac{1}{2}^{\prime}$. (Poa Eragrostis L.).

Auf sandigen Aeckern, Triften und Kiesflächen selten, z. B. beim Relaishause (Bisch.), Sehwetzingen, z. B. beim Eiskeller und einzeln bei den Kiesgruben! Mannheim (Döll.). Juli-September.

[Fehit in der Nähe d. Geb.]

1070. E. megastachya $L k$. Grossähriges L.; dem vorigen :̈hnlich, melir niederliegend u. ausgebreitet; Blatthäutchen langgewimpert ; R. steif, gedrungen; A ehrch. lineal-lanzettl, kurzgestielt, 15-20bliithig, untere Spelzen stumpf, ausgerandet, stachelspitzig. ๑. $\frac{1}{2}-2^{\prime}$. Aehrch. grüsser als bei rorig., blaugrünglänzend. (Briza Eragrostis L.).

Auf Sandfeldern, Maisäckern, an Wegen selten, z. B. bei 
Schwetzingen (auf Aeckern gegen Friedrichsfeld)! beim Rohrhof (Bisch.), bei Walldorf (Bisch., Döll.). Juli-September.

[Auch in der Nähe des Gebietes, z. B. in Rhb. zwischen Neuhofen und Waldsee, unfern Schifferstadt (F. Sch.); in IIs.: Pfungstadt (Schnttsp.).]

\section{Poa $L$. Rispengras.}

a) Wurzel faserig; Ausläufer fehlen. (Bl. bei allen Arten flach, lineal).

107I. P. annua $L$. E in jähriges Rs.; hellgrüne Rasen bildend; Halme aufsteigend oder niederliegend, glatt, etwas zusammengedrückt; R. fast einseitswendig, locker, abstehend; Aehrchen länglich-eiförmig, 3-7blüthig; Spelzen kahl. ๑. $\frac{1}{2}$ '.

An Wegen, auf Triften, Culturland überall verbreitet und fast das ganze Jahr blühend.

1072. P. bulbosa $L$. $\mathrm{Z}$ wiebeliges Rs.; blaugrüne Rasen bildend; Halme am Grunde mehr oder weniger zwiebelig verdickt, aufrecht, glatt; Blatthäutchen länglich; R. eiförmig, gedrängt, wenig ausgebreitet; Aehrchen 4-6blüthig; Spelzen weichhaarig od. kahl. 4. $\frac{1}{2}-1^{\prime}$. Variirt:

$\beta$ ) vivipaia; Aehrch. mit $Z$ wiebelknospen, welche den Fruchtknoten ersetzen.

Auf dürren Sandflächen, trockenen Hügeln der Ebene hie und da, z. B. zwischen Schwetzingen und Hockenheim! bei Sandhausen und Walldorf! bei der Mannheimer Rheinziegelhütte! Käferthal! selten bei Friedrichsfeld! beim Relaishause! An allen Standorten flndet sich fast nur die Varietät. [Sehr verbreitet auch auf den Kalkhügeln und auf Weinbergsmauern um Dürkheim!] Mai, Juni.

1073. P. trivialis $L$. Gemeines Rs.; Halm meist einzeln, aufsteigend, nebst den etwas zusammengedrückten Scheiden rauk (sehr selten glatt); Blatthäutchen lineal, spitz; R. abstehend, Aeste rauh, die unteren 5ständig; Aebrch. eiförmig, 3blüthig; Spelzen deutlich 5nervig, fast kahl. 4. 2'. Gutes Wiesengras!

Auf feuchten Wiesen und Triften, an Wegen und Gräben sehr verbroitet. Juni-August.

b) Wurzelstock mit kurzen Ausläufern.

1074. P. nemoralis $L$. $\mathrm{H}$ a in-Rs.; schwachrasig; Halm aufrecht, fast stielrund; Scheiden kürzer als die Halmglieder; Blatthäutchen sehr kurz, fast schwindend; R. etwas einseitswendig mit rauhen 2-5ständigen Aesten; Aehrch, länglich, 2-5blth.; Spelzen schwach 5nervig, auf dem Kiele und an den Rändern flaumhaarig. 4. $\frac{1}{2}-3^{\prime}$. Die sehr veränderliche Art variirt bei uns wie folgt: 
«) vulgäris Gaud.; grasgrün; HaIm schlank, glatt; R. schmal; Aehrch. 2-3bith, an sehr schattigen Standorten auch 1blüthig.

ß) firmula Gaud.; grasgrün; Halm steif aufrecht, glatt; $R$. pyramidal, sehr ausgebreitet; Aehrch. 3-5blth.

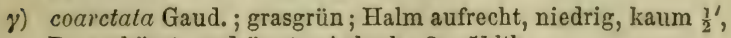
R. verkürzt, gedrängt; Aehrch. 3-5blth.

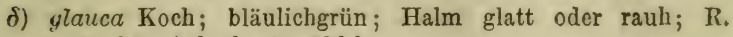
aufrecht; Aehrch. 2-5blth.

In Wäldern, Gebüschen, auf Waldwiesen und Triften. Var. $\alpha$ sehr verbreitet; Var. $\beta$ besonders in feuchteren Waldgebüschen der Ebene, z. B. häufig bei Waghäusel und Kirrlach! beim Rohrhof! Ketsch! Var. $\gamma$ an felsigen, trockenen aber schattigen Standorten, z. B. in der Nähe von $H$. an d. Felsen gegen Schlierbach! am Schloss! Var. $\delta$ auf Sandflächen bei Friedrichsfeld, Schwetzingen. Juni-August.

1075. P. fertilis Host. Fruchtbares Rs.; dem vorigen ähnlich, aber verschieden durch das verlängerte spitze Blatthäutchen; R. mehr gleichseitig ausgebreitet, Aeste rauh, die unteren meist 5ständig; Aehrch. und Spelzen der vorigen. 4. 1-2'. Variirt mit kahlen und schärflichen Halmen.

Auf feuchten Wiesen und Triften, an Ufern stellenweise häufig, z. B. am Neckarufer bei Neuenheim! Bergheimer Mühle u. s. w. Auch am Rhein in feuchten Gebüschen oft verbreitet. Juni-Aug.

c) Wurzelstock mit weithinkriechenden Ausläufern.

1076. P. pratensis $L$. Wiesen-Rs.; Halm aufrecht, wie d. Scheiden stielrund, kahl ; Blatthäutchen kurz, abgestutzt; R. ausgebreitet, Aeste rauh, untere meist 5ständig; Aehrch. eiförmig 3-5blüth.; Spelzen deutlich 5nervig, auf dem Kiele und am Rando flaumig. 2. $\frac{1}{2}-2^{\prime}$. Gutes Wiesengras! Variirt:

$\beta$ ) latifolia; ( $P$. humilis Ehrh.) $5-8^{\prime \prime}$, bläulichgrün; $\mathrm{Bl}$. kürzer und breiter als bei der gewöhnlichen Form.

$\gamma)$ angustifolia; meist $\mathbf{1}^{\frac{1}{2}}{ }^{\prime}$, etwas graugrün; Bl. verlängert, sehr schmal.

Auf Wiesen, Grasplätzen, an Wegen dio Hauptform überall. Var. $\beta$ auf trockenen Sandfeldern beim Relaishause! bei Friedrichsfeld! Sandhausen ! zwischen Mannheim und Sandtorf! Var. $\gamma$ auf feuchten, sandigen od. lehmigen Triften, trockenen Hügeln hio und da, z. B. bei Schriesheim! beim Rohrhof! bei Virnheim (Schimp.). Mai-Juli. 
1077. P. compressa $I_{\text {. }}$ Zus a m men gedrücktes Rs.; bläulich-grün; Halm aufsteigend, fast zweischneidig-zusammengedrückt; Blatthäutchen kurz; R. gedrungen, fast einseitswendig; Aehrch. eiförmig-längl. 5-9blüthig; Spelzen nur am Grunde etwas flaumig. 4. $\frac{1}{2}-1 \frac{1}{2}^{\prime}$. Variirt mit kürzeren oder längeren Rispen.

Auf Mauern, Dächern, an Wegen, in Weinbergen häufig; in d. Nähe von H., z. B. bei Neuenheim! Wieblingen sehr verbreitet. Juni, Juli.

43. Glyceri a $R$. Br. Süssgras.

1078. G. spectabilis $M$. et $K$. Ansehnl. S.; Halm steic aufrecht; R. gleichseitig ausgebreitet, sehr ästig; Aehrch. länglich, zusammengedrüclit; Spelzen stumpf, deutlich 7nervig. 4. 4-6: (Poa aquatica L.).

An Flussufern, Gräben, in Sümpfen häuflg. Juli-Sept.

1079. G. fluitans $R$. Br. F I u thendes S.; IIalm aufsteigend, schwach; Bl. in der Jugend gefaltet, später mehr oder weniger flach; R. einseitswendig verlängert, locker; Aehrch. walzenförmig, untere Spelzen länglich-lanzettl., mohr oder weniger zugespitzt, deutlich 7nervig. 4. 2-4'. Spelzen trockenhäutig weissberandet. Variirt:

$\beta$ ) obtusiflora Sond. (G. plicata Fries) untere Spelzen oval, stumpf, feingekerbt.

In Sümpfen, Gräben, an Ufern häufig, zuweilen in fliessenden Gewässern fluthend. Die Variet. seltener, bisher nur bei Waghäusel! und in der Nähe des Geb. am Rhein bei Ludwigshafen! Juni bis September:

[G. distans Wahlbg. A bstehendes S.; bläulich-grün; Halm aufrecht; R. ausgebreitet-abstehend, die Aeste bei der Fruchtreifo zurückgeschlagen; Aehrch. lineal; Spelzen stumpf, undeutlich 5nervig. 2. 1-2'. (Poa distans L.).

Auf feuchten Wiesen und Triften, an Gräben, vorzugsweise auf Salzboden, z. B. häufig an den Dürkheimer Salinen! Juni, Juli.]

\section{Catabrosa Beauv. Quellgras.}

1080. C. aquatica Presl. Wasser-Q.; Halm aufsteigend, mit kriechenden Ausläufern; R. ausgebreitet, abstehend ästig; Aehrchen lineal; Spelzen deutlich 7nervig. 4. 1-2'. R. meist violett gefärbt. (Aira aquatica L.; Glyceria airoides Rchb.).

An und in Gräben, an Ufern, in Sümpfen besonders der Ebene stellenweise häufig, z. B. vorherrschend bei Waghäusel! Neckarau! Mai-Juli. 


\section{3\%. Sclerochloa Becuv. Hartgras.}

1081. S. dura Beauv. Eigentl. H.; bläulich-grïn; Halme büschelig, kurz, niederliegend, glatt, mit deutlich gekielten Blattscheiden; R. länglich-eirund, einseitswendig mit zusammengedrückter, starrer Spindel, Aehrchen länglich, 5blth. auf sehr kurzen, dicken Blüthensticlchen. ๑. 4-6". Spelzklappen weissberandet. (Poa dura Scop.; Cynosurus durus L.).

Auf etwas feuchten, lehmigen Triften, an Wegen selten, $Z_{\text {wi- }}$ schen Sandtorf und Lambertheim, in der Nähe des letztoren Ortes und sehr nahe der Grenze des Grossherzogth. Baden! - Nach Düll auch bei Mannheim, jenseits des Neckars, in der Nähe der Brücke. Mai, Juni.

[N. V. in Rlib. zwischen Oggersheim und den Thongruben, in ler Nähe der letzteren (Bisch.); in Hs.: Worms, und durch Rh5. verbreitet.]

\section{Molinia Mroench. Molinie.}

1082. M. coerulea $M$. et $K$. Bla u $\mathrm{M}$.; rasenbildend, hellgrün; Halme steif aufrecht, glatt, mit sehr verlängerten $\mathrm{Z}$ wischengliedern (daher fast knotenlos); Bl. etwas eingerollt, mit gewrimperten Blatthäutchen; R. verlängert, steif; Aehrch. 3-4hlth. 4. Halm am Grunde mit knollenartigen Anschwellungen. - Erscheint in 2 Formen:

a) pratensis Schlechtd.; Halm 1-2'. R. zusammengezogen, dunkelviolett.

ß) sylvatica Schld.; Halm $4-6^{\prime}$; R. ausgebreitet abstehend, grünlich-violett.

Auf feuchten Wiesen, Haiden der Ebene und der Gebirge ist $\alpha$ verbreitet, z. B. bei St. Ilgen! Wiesloch! Waghäusel! u. s. w.; $\beta$ in Wäldern, besonders im Gebirge oft sehr häufig, z. B. bei H. diesseits und jenseits des Neckars wesentlicher Bestandtheil der Vegetation! Auch in den Wäldern der Ebene bei Friedrichsfeld! Kirrlach! Wiesloch häufig! Juli-September.

\section{Dactylis $L$. Knäuelgras.}

1083. D. glomerata $L$. Gem. K; rasenbildend, hellgrün od. etwas bläulich-grün; Bl. flach; R. pyramidenförmig, zusammengezogen, fast einseitswendig; Aehrch. dichtbüschelig geknäuelt, untere Spelzen 5nervig. 4. 1-3i. bis Juli.

Auf Wiesen, an Wegen, Waldrändern überall verbreitet. MIai 


\section{Cynosurus $L$. Kammgras.}

1084. C. cristatus $L$. Gem. K. ; Halme steif aufrecht; BI. schmal-lineal, flach; R. aehrenförmig, einseitswendig; Spelzen der unfruchtbaren Aehrch. kammförmig-2zeilig, hellgrün. 4. 1-2'. Gutes Wiesengras!

Auf Wiesen, an Wegen, Waldrändern häuffg! Juni, Juli.

\section{I. Iestuea $L$. S $\mathrm{chw}$ ingel.}

a) Vulpia Gmel.; R. fast aehrenf.; Zweige der R. am Grunde der Aehrch. mehr oder weniger verdickt; Spelzen langbegrannt; Blätter borstenförmig, mit 2lappigem Blatthäutchen. - ๑. -

Die 2 vorkommenden Arten sind monandrisch.

1085. F. Pseudo-Myuros Soy-Will. Rispenart. S.; blassgrün-gelblich; Halme büschelig; die oberen Blattscheiden den Halm bis zur Basis der R. bedeckend; R. einseitswendig, etwas zusammengezogen, ästig-verlängert, schlank, an der Spitze etwas nickend; Aehrch. 4-5blth.; obero Balgkl, 2-3mal länger als die untere; Granne länger als die Spelzen. ๑. $\frac{1}{2}-1 \frac{1}{2}^{\prime}$. ( $F$. Myuros Ehrh.)

Auf Sandfeldern, an Wegen, in Nadelwäldern nicht selten, z. B. bei H. diesseits, seltener jenseits des Neckars! Dreitröge Thal! Riesenstein! am oberen Wege nach dem Wolfsbrunnen! Philosophen Weg! häufig in den Nadelwäldern bei Friedrichsfeld! Sandhausen! Käferthal! auf den Sandnächen zwischen Feudenheim u. Virnheim! Juni-August.

1086. F. sciuroides Roth. A ehrenart. S.; der vorigen ähnlich, aber verschieden durch die viel kürzeren Blattscheiden, welche den oberen Theil des Halmes nicht bedecken; R. aufrecht, steifer, weniger ästig. $\odot . ~ \frac{1}{2}-1^{\prime}$. (F. bromoides Smith.)

Auf Sandtriften, trockenen Hügeln, in Nadelwäldern zuweilen mit der vorigen, hie und da häufig, z. B. jenseits des Neckars an den Sandstein-Abhängen zwischen der Stiftsmühle und Ziegelhausen! oberhalb Dossenheim! bei Schwetzingen, Oftersheim, Hockenheim Juni-August.

b) Festueae genuinae; Zweige der mehr oder weniger ausgebreiteten R. fadenförmig; Spelzen begrannt oder unbegrannt; Bl. borstenförmig oder sehr schmal gefaltet mit 2lappigem (20ehrigem) Blatthäutchen. 4.

1087. F. ovina $L$. Schaf-S.; dichtrasig; Halme aufrecht, alle Bl. borstenförmig; R. locker, zusammengezogen, wenig abstehend; Aehrch. 4-8blth.; Spelzen lanzettlich, schwachnervig, begrannt oder unbegrannt. 4. $\frac{1}{2}-\mathbf{1}^{\frac{1}{2}}$, - Variirt: 
B) vulgaris Koch; $\mathrm{Bl}$. sehr dünn, meistens grïn, seltener blaugrün; R. schmal; Spelzen begrannt oder unbegrannt.

$\gamma$ ) glauca; blaugrün oder grau; Halm kaum $\frac{1}{2}^{\prime} ; \mathrm{Bl}$. etwas starr, rauh; Aehrchen etwas grösser; Spelzen begrannt.

ঠ) duriuscula L.; in allen Theilen grösser und stärker, daher auch die grünlichen oder bläulichen Blätter etwas steifer und dicker.

Auf trockenen Wiesen. Triften, an Wegen, in Wäldern die Hauptform überall verbreitet! auch Var. $\beta$ auf Sandflächen, in Nadelwäldern der Ebene und der Gebirge nicht selten. Var. $\gamma$ nur auf den Sandflächen des Geb., besonders beim Relaishause! Sandhausen! Käferthal! Sandhofen! Var. $\delta$ in trockenen Gebüschen, an Waldrändern, etwas seltener, z. B. im Dreitröge Thal bei H.l am Oelberge bei Schriesheim! Juni-August.

1088. F. heterophylla Lam. Verschiedenblättrige S.; dichtrasig; grundst. Bl. borstenförmig, schlaff; Halmbl, flach; R. locker, etwas abstehend und überhängend; Aehrch.4-5blth.; Spelzen lanzettl., kurz begrannt. 24. $1 \frac{1}{2}-2^{\prime}$. W. faserig.

Auf Waldwiesen, in Wäldern der Gebirge und der Ebene nicht häufig, z. B. an d. Hillenbach b. Handschuchsheim! auch einzeln gegen Schriesheim! Waghäusel, Kirrlach, Oftersheim, Sandhausen (Döll). Juni, Juli.

1089. F. rubra $L$, Rother S.; Wzst. kriechend; IIalmo aufsteigend, meist einzeln; grundst. Bl. borstenförmig; Halmbl. fiach; R. steif aufrecht; A ehrch. 4-5blth., meist kahl, hellgrün (zuweilen etwas röthlich); Spelzen lanzettl., begrannt. $4 \cdot \frac{3}{4}-1 \frac{1}{2}^{\prime}$. - Variirt selten mit mehr oder weniger behaarten Aehrchen.

Auf sandigen Triften, an Abhängen, in lichten Wäldern, an Wegen häufig, von den 2 vorhergehenden Arten leicht durch den kriechenden Wzst. zu unterscheiden! Juni, Juli.

c) Zweige der R. fadenförmig; Bl. alle flach mit länglichem od. kurzem, etwas abgestutztem, nicht 2lappigem Blatthäutch. 4 .

$\alpha$. Fruchtknoten an der Spitze behaart.

1090. F. sylvatica Vill. Wald-S.; rasenbildend; Halme aufrecht, etwas schärflich; Bl. oberseits bläulichgrün, scharfrandig, mit längl. stumpfen Blatthäutchen; R. aufrecht, ausgebreitet, sehr ästig; Aehrch. länglich, 3-5blth., hellgrün; Spelzen lanzettl., spitz, unbegrannt. 24. 2-3'. W. faserig. ( $F$. calamaria Sm., Poa sylvatica Poll.)

In schattigen Gebirgswäldern selten, z. B. bei H. zwischen der Molkenkur und dem Schlosse! Glashütte (Dierb.), zwischen Dossenheim und Schrresheim (Döll), Oelberg bei Schriesheim? Juni-Au- 
gust. (Hinsichtlich der Verbreitung zwischen H. u. Nussloch, Rauenberg etc. noch $\mathrm{zu}$ verfolgen.)

[N. V. a. d. Geb, in IIss. : Bergstr. bei Zwingenberg und Auerbach (Schnttsp.).]

\section{$\beta$. Fruchtknoten kahl.}

1091. F. elatior $L$. Hoher S.; Halme aufrecht, wio die schmal-linealen Bl. glatt; Blatthäutchen kurz, gestutzt; R. locker, efwas zusammengezogen; Aeste rauh, gezweiet, der eine kürzer, 1 aehrig, der andere 3-4aehrig; Aehrch. länglich, lineal, 5-10blth., untere Spelzen spitz, kurz begrannt oder grannenlos. 4. 1-2'. Aehrch. etwas lila; W. faserig. (F. pratensis Huds.) Gutes Wiesengras!

Auf Wiesen, Triften, an Wegen überall verbreitet. JuniSeptember.

1092. F. loliacea Huds. Lolchartiger S.; der vorigen ähnlich, aber Aehrch. einzeln, 2zeilig gestellt, etwas entfernt, stets sehr kurz gestielt oder fast sitzend, unbegrannt, hellgrün. 24. 2-3'. Aehrch. bald grösser, bald kleiner, bald mehr stielrund, bald auffallend zusammengedrückt. - Blth. bleiben unfruchtbar; die Fruchtknoten meist etwas verkümmert.

Auf feuchten Wiesen in Gesellschaft von $F$. elatior L. und Lolium perenne L., vielleicht eine hybride Form dieser beiden Arten, ziemlich häufig im Mühlenthale bei Handschuchsheim! bei Rolrbach! auf der Wiese am Neckar unterhalb der Bergheimer Mühle! am Fusse des Geisberges, unterhalb der Wolfsschlucht! Mai-Juli.

1093. T. arundinacea Sclireb. Rohrartiger S.; Halme aufsteigend, kräftig, kahl; Bl. oberseits schärflich; Blatthäutchen sehr kurz, abgestutzt; R. ausgebreitet, ansehnlich, etwas überhängend, mit stets meliraehrigen Aesten; Aehrch. ei-lanzettl.; untere Spelzen lanzettl., begrannt oder unbegrannt. 24. 2-4'. Aehrch. grün-riolett. ( $F$ elatior $\mathrm{Sm}$. )

An Ufern, auf feuchten Wiesen und Triften, in Weidengebüschen hie und da, z. B. am Neckar bei H. unterhalb der Bergheimer Mühle und auf der benachbarten Insel! auch bei Ladenburg! am Rhein zwischen Brühl und Neckarau (Döll). Juni, Juli.

1094. F. gigantea Vill. Riesen-S.; Halme aufsteigend, kahl; Bl. oberseits scharf; Blatthäutchen kurz, abgestutzt; R. sehr ausgebreitet, schlaff, überhängend; Aehrch. lanzettl., 5 -8blth.; untere Spelze mit langer, dünner, hin- und hergebogener Granne. $\mathcal{4}$. $2-4^{\prime}$. A ehrch. hellgrün. (Bromus giganteus L.)

In Wäldern, Gebüschen, an Waldrändern der Gebirge und der Ebenen häufig, besonders bei $\mathrm{H}$. diesseits und jenseits des Neckars! Im Friedrichsfelder Walde! Juni-August. 


\section{I rac hypodium Beauv. Zwenké.}

1095. B. pinnatum Beauv. Ge fi ed er te Z .; hellgrün; Wrst. kriochend; IIalm aufrecht; Bl. steif, kurz, flach; Aelre aufrecht, 2zeilig; Aehrch, zahlreich, fast sitzend, entfernt, Spelzen kurz bo . grannt. 4. 2-3'. (Bromus pinnatus L.)

Auf trockenen Anhöhen, an Rainen, in Gebüschen, an Waldrändern, besonders auf Kalk- und Lelımboden, z. B. Haarlass! Philosophen Weg! oberhalb Dossenheim! gegen Rohrbach! und besonders häufig zwischen Leimen, Nussloch und Wiesloch! Juni, Juli.

1096. B. sylvaticum $R$. et Sch. Wald-Z.; dunkelgrün; W. faserig; Halme aufrecht; Bl. schlaff, verlängert, flach, behaart; Aehre 2zeilig, hängend; Aehrch. zahlreich, fast sitzend, entfernt; Spelzen lang begrannt. 24. 2-3'. (Bromus pinnatus $\beta$ L., Bromus sylvatic. Poll., Triticum sylvatic. Moench.)

In lichten Wäldern, Gebüschen häufig, z. B. Haarlass! Dreitrögø Thal! u. s. w. Juni-August.

\section{Bromus $L$. Trespe.}

a) Aehrch. nach der Blth. an der Spitze schmäler, untere Balgklappe 3-5nervig, obere 7 -9nervig; obere Spelzklappen am Rande borstig-gewimpert.

1097. B. secalinus L. Roggen-T.; Halme aufrecht; Bl. behaart; Scheiden meist kahl; R. aufrecht, abstehend, nach der Blüthe überhängend; Aehrch, eiförmig-länglich, 6-8blth.; Spelzen. breit elliptisch, bei der Fruchtreife von einander weichend und an den Rändern eingebogen, untere Spelzen kurz begrannt od. stachelspitzig, selten wehrlos. $\hat{\wp}$. $1-3^{t}$. Aehrch. dunkelgrün, kahl oder etwas rauh. ( $\mathrm{Br}$. segetalis Braun et Düll.) - Variirt:

$\beta$ ) grossus; Aehrch. auffallend gross, 10-16blth.; Spelzen bei der Fruchtreife weiter abstehend, kahl oder rauh, meist begrannt.

$\gamma)$ velutinus (Br.velutinus Schrad.); Aehrch. ebenfalls gross, kurzhaarig-sammetartig, begrannt; untere Blattscheiden weichhaarig.

Auf Aeckern, besonders im Wintergetreide, und auf Brachaeckern, an Wegen die Iauptform häuff. Var. $\beta$ vereinzelt hie und da, z. B. im Dreitröge Thal bei H.! bei Wiesloch! und ziemlich verbreitet bei Rauenberg! Var. $\gamma$ seltener, z. B. auf trockenen Aeckern zwischen Alt-Wiesloch und Dielheim! Juni-August.

1098. B. racemosus $L$. Tra ub en-Tr.; hellgrün; Halme aufrecht; BI. und Sclieiden mehr oder weniger behaart; R. aufrecht, 
wenig überhängend, nach der Blüthe zusammengezogen; Aehrch. eiförmig-länglich, zugespitzt, kahl, 5-9blth.; Spelzen an den Seiten abgerundet, sich deckend, untere Spelzen begrannt; Grannen gerade, von der Länge der Spelzen. §. 1-1 ${ }^{\prime \prime}{ }^{\prime}$. Aehrch. dunkelgrün. (B. raccmosus $\beta$ pratensis Döll.) - Variirt:

B) commutalus (B. commutatus Schrad.); Halmo schlanker, $1 \frac{1}{2}-2 \frac{1}{2}^{\prime}$, deutlich a fsteigend, unten reichlich behaart; R. mehr überhängend; Aehrch. lanzettl., zugespitzt; Spelzen an den Seiten einen stumpfen Winkel bildend. - Uebergänge sind unverkennbar, besonders ist die Abrundung der Spelzen sehr wechselnd. Die ausgeprägtesten Formen von commutatus, die alsdann auch durch schlankeren Habitus auffallend waren, fand ich auf Esparsett- und Luzernerkleefeldern, wo sich die Pflanze ziemlich frei entwickeln konnte, so z. B. in Menge bei Schatthausen! bei Baierthal! Dielheim! einzeln bei Alt-Lussheim! [Auch jenseits des Rheines hie und da nicht selten, z. B. bei Maxdorf! zwischen Ellerstadt und Dürkheim! bei Callstadt l]

Dis Hauptform (racemosus) auf Wiesen, an Wegen häufig. Juni, Juli.

1099. B. mollis $L$. Weiche T.; hellgrün oder grau; Halme aufrecht; Bl. und Scheiden weichhaarig; R. aufrecht, nach dem Verblühen zusammengezogen; Aehrch. eiförmig-elliptisch, stumpf oder wenig spitzlich, weichhaarig, Spelzen an den Rändern abgerundet, bei der Reife sich deckend, untere Spelzen begrannt; Grannen gerade, von der Länge der Spelzen. $\hat{\text {. }} \frac{1}{2}-1 \frac{1}{2}^{\prime}$. (Auf sehr dürrem Boden in Zwergform von 3-4", mit 1-2 Aehrch.) — Variirt:

$\beta$ ) glabratus; Aehrch. kahl oder etwas schärflich.

Auf Wiesen, Triften, an Wegen die Hauptform überall sehr häufig. Die Var. auf feuchten Triften hie und da, gewöhnlich mit Uebergängen zur Hauptform, z.B. beim Rohrhof! Juni, Juli.

1100. B. patulus $M$. et $K$. A bstehende T.; hellgrün; Halme aufsteigend, unten knieförmig gebogen; Bl. und Scheiden weichhaarig oder etwas zottig; R. aufrecht, locker, nach dem Verblühen etwas einseitig überhängend; Aehrch. elliptisch-lanzettlich, kahl; Spelzen an den Rändern einen stumpfen Winkel bildend, schmal weissberandet, etwas von einander entfernt; Granno (wenigstens im trockenen Zustande) abstehend, nach Aussen gebogen und etwas gedreht. ๑. $1-1_{\frac{1}{2}}^{\prime}$.

Auf Aeckern, trockenen Hïgeln und Triften bisher im Gebiet nur sehr selten: Friedrichsfeld (Döll). [Jenseits des Rheines häufiger, 
z. B. verbreitet auf den IYügeln bei Callstadt! zwischen Herxheim und Leistadt! bei Deidesheim.] Juni, Juli.

1101. B. arvensis $L$. Feld-T.; Halme aufrecht; Bl. und Scheiden weichhaarig; R. aufrecht, ausgebreitet, bei der Reife etwas nickend; Aehrch. lanzettlich, lineal, kahl; Spelzen an den Rändern einen stumpfen Winkel bildend, sich deckend; Grannen gerade vorgestreckt, im trockenen Zustando nur sehr wenig gebogen. $\odot$. 1$\mathbf{1}_{\frac{1}{2}}{ }^{\prime}$. Aehrch. grün, zuweilen purpurroth gefärbt. (Diese Art kann im blühenden Zustande d. A ehreh. leicht mit der vorigen Art und mit B. racemosus verwechselt werden, wird sich aber jederzeit von den vorigen durch die gleicho Längo der oberen und unteren Spelzen unterscheiden.

Auf Aeckern, an Wegen, Rainen stellenweise sehr häufig, z. B. bei Alt-Wiesloch! Baierthal! Rauenberg! Ladenburg! Schwetzingen! auch hie u. da in der Nähe von H.! Juni-August.

b) Aehrch. an der Spitze schmäler; untere Balgklappen 1nervig, obere 3nervig; obere Spelzkl. am Rande sehr kurz behaart.

1102. B. asper Murr. Rauhe T.; Halm aufrecht, besonders oberwärts rauh; Bl. verlängert breitlineal, wie die unteren Scheiden rauhhaarig; R. verlängert, locker, überhängend; Aehrch. lineal-lanzettlich, zusammengedrückt, rauh, lang zugespitzt, 7-9blth.; untere Spelzen 2zähnig zugespitzt, mit gerader Granne. 4. 3-5'.

In feuchten/Wäldern d. Gebirge häufig, z. B. in d. Nähe v. H.: Geisberg! Dreitröge Thal! Handschuchsheim! etc., seltener in Wäldern der Ebene, z. B.: Friedrichsfelder Wald! Mai-Juli.

1103. B. erectus Huds. Aufrechte T.; blassgrün; Halme aufsteigend, kahl; Bl. schmal lineal, etwas rinnig, behaart; untere Scheiden weichhaarig; R. steif aufrecht, zusammengezogen; Aehrch. lineal-lanzettlich, zusammengedrückt, kahl; untere Spelzen an der Spitze gespalten, doppelt so lang als die Granne. 24. 1-2 $\frac{1}{2}^{\prime}$. W. faserig, ohne Ausläufer; Aehrch. gelblichgrün; Antheren schwefelgelb oder goldgelb. - Variirt etwas in Behaarung, doch sind die unteren Blattscheiden nie völlig kahl, wie bei der folgenden Art.

Auf trockenen Triften und Wiesen, an Abhängen, Rainen vorzugsweise auf Kalkboden nicht selten und zuweilen heerdenweise, z. B. Stift Neuburg! Philosophen Weg! Haarlass! bei Dossenheim! Weinheim! Wiesloch! Schatthausen! Dielheim! Stellenweise auch bei Friedrichsfeld! Schwetzingen! an den Rheindämmen bei Ketsch! Mannheim! Juni, Juli.

1104. B. inermis Leyss. Wehrlos e T.; dem vorigen ähnlich; Wrst. kriechend; Bl. breiter, flach, wie d. Scheiden kahl; R. steif aufrecht, zusammengezogen, mehr gedrängt; Aehrch, lineal-lanzettlich, 
weniger zusammengedrückt; untere Spelzen gespalten, abgerundet, stachelspitzig oder sehr kurz begrannt. 4. 1-2'. Aehrch. grünlichgelb; Antheren goldgelb.

An Ackerrändern, Wegen, auf Triften hie und da, z. B. bei der Bergheimer Mühle! zwischen dem Haarlass und Ziegelhausen! an den Chausseegräben zwischen Rohrbach und Leimen! Auch bei Wiesloch, Schwetzingen, beim Rohrhof, Waghäusel! Juni, Juli.

c) Aelırch. zusammengedrückt, an der Spitze beträchtlich breiter; untere Balgklappen 1nervig, obere 3nervig; obere Spelzklappen borstig gewimpert.

1105. B. sterilis $L$. Unfruchtbare T.; hellgrün; Halm kahl; BI. und Scheiden weichhaarig oder kahl; R. sehr locker, mit verlängerten, überhängenden, sehr scharfen Aesten; Aehrch. 5-9blüthig; Spelzen lineal-pfriemlich, scharf; Grannen gerade, länger als die Spelzen. ๑. 1-2'. Aehrch. grün, zuweilen bei der Reife violett gefärbt.

An Wegen, auf unfruchtbaren Triften, Mauern sehr verbreitet. Mai-August.

1106. B. tectorum $L$. D a ch-T.; graugrün; Halm oberwärts, wie die Bl. und Scheiden weichharig; R. gedrïngt, einseitswendig, mit überhängenden weichhaarigen Aesten; Aehrch. 3-9blth.; Spelzen lanzettl.-pfriemlich, meist weichhaarig; Grannen gerade, von der Länge der Spelzen. ๑. $\frac{1}{3}-1^{\prime}$. In allen Theilen zarter und kleiner als die vorige Art.

Auf Sandflächen der Ebene meist sehr gesellig, jedoch auch in der Nähe von H. auf Mauern, Dächern, an Wegen verbreitet, z. B. bei Neuenheim! Wieblingen! am Haarlass! u. s. w. Mai-Juli.

\section{Triticum $L$. Weizen.}

a) Aehrch. mehr oder weniger bauchig-gedunsen; Balgklappen eirund, abgestutzt.

T. vulgare Vill. Gem. W.; Aehre 4seitig, mit zäher Spindel; Balgkl. knorpelig, gleichhälftig, nur an der Spitze (und zwar meist mit einem sichtbaren Eindruck) zusammengedrückt-gekielt, stachelspitzig oder begrannt; Frucht bei der Reife aus den Spelzen herausfallend. $\odot$ und $\hat{\odot}$.

Als Sommer- und Wintergetreide hie und da, jedoch im Ganzen viel seltener als folg. Art gebaut. Juni. Juli.

T. Spelta L. Spelz; Aehre fast 4seitig, mit zerbrechlicher Spindel; Balgkl. knorpelig, ungleichhälftig, mit zahnartig vorragendem 
Kiel, stachelspitzig, selten begrannt; Frucht bei der Reife ron den Spelzen

Als Wintergetreide häufg gebaut. Juni.

T. monococcum L. Eink orn; Aehre von der Seite zusammengedrückt; Aehrch. meist 3blth., nur die unterste Blth. fruchtbar; Balgkl. schief abgestutzt, an der Spitze mit 3 spitzen geraden Zühnen; Frucht ron den Spelzen eingeschlossen. $\hat{\odot}$.

Als Wintergetreido seltener, bezonders auf sandigem Boden gebaut. Juni, Juli.

b) Aehrch, nicht bauchig-gedunsen, daher verlängert, mehrblth.;

Balgkl. lanzettl.; Frucht von den Spelzen innig umschlossen.

1107. T. repens L. Quecke; Wzst. kriechend; Bl. flach; Halme aufrecht, kahl; Bl. oberseits rauh; Achre 2zeilig, aufrecht; Aehrch. 5blth, mit scharfer (und zuweilen weichhaariger) Spindel; Balgkl. lanzettl. 4. 1-3'. (Agropyrum repens Beauv.) - Es finden sich folgende Formen:

«) vulgare; grasgrün; Spelzen stumpf od. kurz stachelspitzig.

$\beta$ ) aristatum; grasgrün; Spelzen und zuweilen auch Balgkl. mit geraden Grannen, deren Länge variirt.

$\gamma)$ glaucum; blaugrün; Bl. steifer, meist etwas eingerollt; Spelzen unbegrannt oder seltener begrannt.

An Wegen, Zäunen, auf Wiesen und Triften die Form $\alpha$ allgemein verbreitet. Var. $\beta$ hie und da, besonders auf Lehm- und Kalkboden, z. B. Philosophen Weg! Mühlenthal bei Ifandschuchsheim! Leimen! Wiesloch! u. s. w. Var. $\gamma$ auf den Sandflächen d. Ebene, in Nadelwäldern nicht häufig, z. B. beim Relaishause! Friedrichsfeld! Walldorf! auch an sandigen Ufern des Rheines, z. B. Ketsch! beim Rohrhof! Juni-August. (Ofr.: Rad. Graminis.)

1108. T. caninum Schreb. II und s-W.: Wrst. nicht kriechend; IIalm kahl; Bl. beiderseits rauh; Aehre 2zeilig, verlängert, etwas überhängend; Aehrch. 4-5blth., mit zottiger Spindel; Balgkl. lanzettlich; Spolzen langbegrannt. 24. 2-3'. (Agropyrum caninum Beauv., Elymus caninus L.)

In Wäldern und feuchten Gebüschen nicht verbreitet, z. B. stellenweise am Königsstuhl und gegen Rohrbach! bei Schriesheim! Juni-August.

\section{Secale $L$. Roggen.}

S. cereale L. Ge m. R.; Aehro dicht dachig, mit zäher Spindel; Balgkl. kürzer als die Aehrch.; untere Spelzen mit gewimpertem Kiele und verlängerter rauher Granne. $\hat{\odot}$.

Als Wintergetreide gebaut. Mai, Juni. 


\section{Lolíum $L$. Lolch.}

I109. L. perenne $L$. A usdauernder L. (englisches Raygras); dichtrasig; Halme aufsteigend, glatt; Bl. bei der Entwickelung einfach gefaltet; Aehrch. reichblth., zusammengedrückt, länger als d. Balgkl.; äussere Spelzen lanzettlich, stumpf oder kurz stachelspitzig. 4. 1-2'. Gutes Wiesengras!

Auf Wiesen, Grasplätzen, an Wegen überall. Juni-August.

L. multiflorum Lam. It a li en isches Raggras; unterscheidet sich besonders durch die bei der Entwickelung umeinander gerollten $\mathrm{Bl}$, und durch gewühnlich lang begrannte Aehrchen. 4. $2-3^{\prime}$. (L. italicum A.Br.).

Hie und da cultivirt und zuweilen verwildernd, z. B. (1856) häufig im Mühlenthale bei Handschuchsheim! Juni-August.

1110. L. Linicola Sond. Lein-L.; Halme einfach, aufrecht, glatt, oberwärts schärflich; Aehrch.4-8blth., eiförmig, wenig länger als d. Balgkl.; äussere Spelzen grannenlos oder kurz begrannt. $\odot$. $1-1_{\frac{1}{2}}$. (L. arvense Schrad.)

Nur auf Leinaeckern. Da in hiesiger Gegend sehr wenig Lein gebaut wird, so findet sich dieses, wie die übrigen denselben begleitenden Unkräuter sehr selten. Zwischen Schönau und Wilhelmsfeld (Bisch., Döll). Juni, Juli. [Jenseits des Rheines bei Grethen, unfern Dürkheim in Menge (Dr. Koch).]

1111. L. temulentum $L$. T a u mel-L.; Halme steif aufrecht, fast einfach, etwas bläulichgrün; Aehrch. 6-8blth., elliptisch, etwas abstehend, von der Länge der Balgkl.; äussere Spelzen länger oder kürzer begrannt. $\odot .1 \frac{1}{2}-3^{\prime}$. Giftig! - Es finden sich 2 Formen:

a) macrochaeton A.Br.; Grannen fast gerade, länger als d. Spelzen.

$\beta$ ) leptochaeton A.Br.; Grannen sehr kurz, etwas hin- und hergebogen.

Unter Sommergetreide stellenweise nicht selten, besonders $\alpha$ in d. Ebenen ziemlich verbreitet. Var. $\beta$ auf kalkigen und lehmigen Aeckern weniger häufig, z. B.: Ladenburg; Baierthal! Alt-Wiesloch! Juni-August.

446. Elymus $L$. Haargràs.

1112. E. arenarius $L . \mathrm{S}$ and-H. (Sandhafer); graugrün; Wzst. kriechend; Halm steif aufrecht; Bl.starr, eingerollt, wie d. Scheiden 
kahl; Aehren steif; Aehrch. meist 3blth., weichhaarig, grannenlos; Balgklappen auf dem Kiele gewimpert, meist von der Länge des Aehrchens. 4. 3-4'.

Auf Sandflächen bei Schwetzingen sehr vereinzelt und selten (Dr. Schimp.) [Fehlt in der Nähe des Geb. völlig. N. V.: Mainz. Juni, Juli.

\section{4\%. II ordeum $L$. Gerste:}

a) Blth. alle zwitterig oder dio seitenständigen des Aohrchens männl. und grannenlos; Spindel der Aehre bei der Reife nicht

in Glieder zerfallend.

II vulgare L. Gem. G.; Aelirch. alle zwitterig, sehr lang begrannt; Fruchtähre 6reihig, 2 Reihen mehr hervortretend. $\hat{\odot}$.

Als Wintergetreide gebaut. Mai, Juni.

II distichum $\mathrm{L}$. $\mathrm{Z}$ weizeilig $\theta$ G.; Aehre zusammengedrückt; die mittleren Aehrch. zwitterig, lang begrannt, die seitenständigen männlich, lineal, unbegrannt. $\odot$.

Als Sommergetreide gebaut, häufiger als vorige Art. Juni, Juli.

b) Seitenständige Aehrchen männlich oder geschlechtslos, alle Aehrch. begrannt; Spindel der Aehre bei der Reife in Glieder zerfallend.

1113. H. murinum $L$, Mäuse-G.; Halme büschelig, aufsteigend; Aehre walzenförmig; Balgkl. des Zwitter-Aehrch. lineal-lanzettlich, gervimpert, d. kurzgestielten Seitenährchen borstenförmig, rauh; Grannen sehr lang. $\odot . \frac{1}{2}-1 \frac{1}{2}^{\prime}$.

An Wegen, auf Mauern, Schutt überall häufig. Juni-Septbr.

[H. secalinum Schreb. Roggenähnliche G.; Halm aufrecht; Aehre walzenförmig; Balgkl. aller Aehrchen borstenförmig, rauh; Grannen kürzer als bei der vorigen Art. 4. $1 \frac{1}{2}-2^{\prime}$. H. pratense Huds., H. nodosum Bbrst.)

N. V. a. d. Geb. auf Wiesen bei Dürkheim (Bisch.), b. Speyer. Juni, Juli.]

\section{Naydus $L$. Nardengras.}

1114. N. stricta $L$. Steifes N.; dichtrasig, graugrün; Bl. borstenartig, eingerollt, wie die Halme steif; Aehre verlängert, zierlich, einseitig, locker; Aehrch. pfriemlich, stahlblau, äussere Spelzen lang begrannt. 4 . $\frac{1}{2}-1^{\prime}$.

Auf trockenen Haiden, Torfwieson selten, z. B. zwischen dem SCHMIDT, Flora v. H. 
Baierhofo und Altnoudorf, gegen Ileiligkreuzsteinach (Dicrb.), auf moorigen Bergwiesen zwischen Dosscnheim und dem Oelbergo bei Schriesheim! Mai-Juli.

[In B. n. V.: Ettlingen (Düll). In Hs.: durch den Odenwald verbreitet. In Rhb. bei Speyer, Musbach ( $F$ Schultz), allgemein bei Kaiserslautern!] 


\section{BEGISTER \\ der Ordnungën, Familien und Gattungen.}

(Dio beigefügte Zahl zeigt die Seitenzahl an.)

Acer 58.

Aceras 313.

Acerineae 58.

Achillea 164.

Acorus 305.

Actaea 10.

Adonis 5.

Adoxa 137.

Aegopodium 126.

Aethusa 129.

Agrimonia 95 .

Agrostemma 43.

Agrostis 363 .

Aira 367.

Ajuga 246.

Alchemilla 98.

Alisma 295.

Alismaceae 295.

Allium 325.

Alnus 284.

Alopecurus 361.

Alsine 45 .

Alsinear 44.

Althaea 54.

Alyssum 25.

Amarantaceae 256.

Amarantus 257.

Amaryllideao 318.
Ambrosiaceae 187.

Ampelideae 60.

Amygdaleae 85.

Amygdalus 85.

Anacamptis 311.

Anagallis 251.

Anchusa 207.

Andropogon 358.

Androsace 252.

Anemone 4.

Anethum 132.

Angelica 130.

Angiospermae 2.

Anthemis 165.

Anthericum 323.

Anthoxanthum 361.

Anthriscus 134.

Anthyllis 72 .

Antirrhinum 219.

Apera 364.

Apium 125.

Apocyneae 199.

Aquifoliaceae 196.

Aquilegia 10.

Arabis 19.

Araliaceae 136.

Aretostaphylos 193.

Arenaria 45. 
Aristolochia 273.

Aristolochiea 273.

Armeria 254.

Arnica 160.

Arnoseris 175 .

Aroideae 304.

Arrhenatherum 368.

Artemisia 167.

Arum 304.

Asarum 273.

Asclepiadeae 198.

Asparageae 319.

Asparagus 320.

Asperula 140.

Aster 155.

Astragalus 78 .

Atriplex 263.

Atropa 211.

Avena 368.

Ballota 243.

Balsamineae 64.

Barbarea 18.

Bellis 157.

Berberideae 11.

Berberis 11.

Berula 128.

Beta 263.

Betonica 243.

Betula 284.

Betulineae 283.

Bidens 163.

Borragineae 204.

Borrago 207.

Brachypodium 379.

Brassica 23.

Briza 371.

Bromus 379.

Bryonia 111.

Bupleurum 128.

Butomeae 296.

Butomus 296.

Calamagrostis 364.

Calamintha 239.
Calendula 168.

Callitriche 107.

Callitrichineae 107.

Calluna 194.

Caltha 9.

Caljciflorae 66.

Camelina 26.

Campanula 189.

Campanulaceae 188.

Cannabis 279.

Caprifoliaceae 137.

Capsella 28.

Cardamine 19.

Carduus 173.

Carex 340.

Carlina 175.

Carpinus 283.

Carum 126.

Castanea 282.

Catabrosa 374.

Caucalis 133.

Celastrineae 66 .

Centaurea 168.

Centunculus 252 .

Cephalanthera 314.

Cerastium 50.

Ceratophylleae 108.

Ceratophyllum 108.

Chaerophyllum 135.

Chaiturus 245.

Chamagrostis 363 .

Cheiranthus 18.

Chelidonium 13.

Chenopodeae 258.

Chenopodium 260.

Chlora 202.

Chondrilla 179.

Chrysanthemum 166.

Chrysosplenium 118.

Chrysocoma 155.

Cichorium 175.

Cicuta 125.

Cineraria 161. 
Circaea 105.

Cirsium 171.

Cistineae 31.

Cladium 336.

Clematis 4.

Clinopodium 240.

Cnidium 130.

Cochlearia 26.

Coeloglossum 312.

Colchicaceae 328.

Colchicum 329.

Comarum 90.

Compositae 148.

Coniferae 291.

Conium 135.

Convallaria 320.

Convolvulaceae 203.

Convolvulus 203.

Coriandrum 136.

Corispermum 259.

Corneae 136.

Cornus 137.

Corolliflorae 196.

Coronilla 78.

Corydalis 14.

Corylus 283.

Corynephorus 368.

Crassulaceao 114.

Crataegus 100.

Crepis 181.

Cruciferae 15.

Cucubalus 42.

Cucumis 111.

Cucurbita 111.

Cucurbitaceae 110.

Cupuliferae 281.

Cuscuta 204.

Cydonia 101.

Cynanchum 198.

Cynodon 363.

Cynoglossum 206.

Cynosurus 376.

Cyperaceao 334.
Cyperus 335.

Cypripedium 317.

Cytisus 71.

Dactylis 375 .

Danthonia 370.

Daphne 270.

Datura 213.

Daucus 133.

Delphinium 10.

Dentaria 20.

Dianthus 40.

Dictamnus 66 .

Digitalis 220.

Diplotaxis 25.

Dipsaceae 146.

Dipsacus 146.

Doronicum 160.

Draba 26.

Drosera 36.

Droseraceao 36.

Echinospermum 206.

Echium 208.

Elatineas 51.

Elatine 52.

Elymus 385.

Epilobium 102.

Epipactis 315.

Eragrostis 371.

Ericeae 192.

Erigeron 156.

Eriophorum 340 .

Erodium 63.

Erucastrum 25.

Ervum 82.

Eryngium 125.

Erysimum 23.

Erythraea 202.

Esculus 59.

Eupatorium 154.

Euphorbia 275.

Euphorbiaceae 274.

Euphrasia 228.

Eronymus 67. 
Tagus 282.

Falcaria 126.

Farsetia 26.

Festuca 376.

Filago 159.

Fragaria 89.

Fraxinus 197.

Fritillaria 323.

Fumaria 14.

Fumariaceae 14.

Gagea 324.

Galanthus 319.

Galeobdolon 241.

Galeopsis 242.

Galinsogea 163.

Galium 141.

Genista 71.

Gentianeae 199.

Gentiana 201.

Geraniaceae 60.

Geranium 61.

Geum 89.

Gladiolus 318.

Glaux 253.

Glechoma 240.

Globularia 254.

Globularieae 253.

Glyceria 374.

Gnaphalium 159.

Gramineae 353.

Gratiola 219.

Grossularieae 116.

Gymnadenia 311.

Gymnospermae 291.

Gypsophila 40.

Habenaria 312.

Halorageae 105.

Hedera 136.

Heleocharis 237.

Helianthemum 31 .

Helichrysum 160.

Heliotropium 206.

Helleborus 10.
Helosciadium 126.

Heracleum 132.

Herminium 313.

Herniaria 113.

Hieracium 183.

Himantoglossum 311.

Hippocastaneae 59.

Hippocrepis 79.

Hippuridea 106.

Hippuris 106.

IIolcus 168.

Holosteum 47.

Hordeum 385.

Hottonia 253.

Humulus 279.

Hutchinsia 28.

Hydrocharidea 294.

Hydrocharis 295.

Hydrocotylo 124.

Hyoscyamus 213.

Hypecoum 13.

Hypericum 56.

Hypericineae 56.

Hypochoeris 178.

Jasione 188.

Iberis 29 .

Ilex 196.

Impatiens 64.

Inula 157.

Irideae 317.

Iris 317.

Isatis 29.

Isnardia 105.

Juglandere 281.

Juglans 281.

Juncaceae 329.

Juncagineae 296.

Juncus 331.

Juniperus 292.

Jurinea 170.

Knautia 147.

Kochia 260.

Koeleria 367. 
Labiata 231:

Lactuca 179.

Lamium 241.

Lappa 171.

Lapsana 175.

Lathraea 231.

Lathyrus 82.

Leersia 363.

Lemna 302.

Lemnaceae 301.

Lentibulariea 0249.

Leontodon 176.

Leonurus 245.

Lepidium 27.

Lepigonum 47.

Loucojum 319.

Ligustrum 197.

Liliacea 322.

Lilium 323.

Limnanthemum 200.

Limosella 226.

Linaria 218.

Lindernia 220.

Lineae 52.

Linum 52.

Listera 316.

Lithospermum 208.

Lolium 348.

Lonicera 139.

Loranthaceae 272.

Lotus 72 .

Luzula 329.

Lychnis 43.

Lycium 211.

Lycopsis 207.

Lycopus 238.

Lysimachia 251.

Lythrariae 108.

Lythrum 109.

Majanthemum 321.

Malachium 51.

Malva 54 .

Malvaceav 53.
Marrubium 243.

Matricaria 165.

Medicago 73.

Melampyrum 226.

Melica 370.

Melilotus 74 .

Melissa 240.

Mentha 234.

Menyanthes 200 .

Mercurialis 277.

Mespilus 100.

Milium 366.

Moehringia 46 .

Molinia 375 .

Monochlamydeae 256.

Monotropa 195.

Monotropeae 195.

Montia 112.

Morus 280.

Muscari 327.

Myagrum 30.

Myosotis 209.

Myosurus 9.

Myricaria 110.

Myriophyllum 106.

Najadea 301.

Najas 301.

Nardus 385.

Nasturtium 21.

Neottia 316.

Nopeta 240.

Neslia 30.

Nicotiana 213.

Nigella 10.

Nuphar 12.

Nymphaea 12.

Nymphaeacea 11.

Oenanthe 128.

Oenothera 104.

Oleaceae 197.

Onagrarieae 101.

Onobrychis 79 .

Ononis 72. 
Onopordon 174.

Ophrys 313.

Orchideae 305.

Orchis 308.

Origanum 239.

Orlaya 132.

Ornithogalum 324.

Ornithopus 79.

Orobanche 229.

Orobancheae 229.

Orobus 84.

Oxalideae 64.

Oxalis 65.

Panicum 359.

Papaver 13.

Papaveraceae 12.

Papilionaceae 68.

Parietaria 279.

Paris 321.

Parnassia 37.

Parnassineae 37.

Paronychieae 112.

Passerina 270.

Pastinaca 132.

Pedicularis 226.

Peplis 109.

Persica 85.

Petasites 155.

Petroselinum 125.

Peucedanum 130.

Phalaris 360 .

Phaseolus 84 .

Phleum 362.

Phragmites 366 .

Physalis 212.

Phyteuma 189.

Picris 175.

Pimpinella 127.

Pinguicuia 249.

Pinus 292.

Pisum 82.

Plantagineae 255.

Plantago 255.
Platanthera 312. Plumbaginea 254.

Poa 372.

Podospermum 177.

Polycarpum 113.

Polycnemum 257.

Polygala 38.

Polygaleae 37.

Polygonea 264.

Polygonum 265.

Pomaceae 99.

Populus 290.

Portulaca 112.

Portulaceae 111.

Potameae 297.

Potamogeton 298.

Potentilla 90.

Poterium 99.

Prenanthes 181.

Primula 252.

Primulaceae 250.

Prunella 246.

Prunus 85.

Psamma 365.

Pulicaria 158.

Pulmonaria 208.

Pyrola 194.

Pyrus 100.

Quercus 283.

Radiola 53.

Ranunculaceae 2.

Ranunculus 6 .

Raphanus 30.

Rapistrum 30.

Reseda 36.

Resedaceae 35.

Rhamnus 67.

Rhamneae 67.

Rhinanthus 227 .

Rhynchospora 337.

Ribes 117.

Robinia 78.

Rosa 95. 
Rosacore 87.

Rubia 143.

Rubus 92.

Rumex 267.

Rutaceae 65.

Sagina 48.

Sagittaria 296.

Salicineae 285.

Salix 285.

Salsola 259.

Salvia 238.

Sambucus 138.

Samolus 253.

Sanguisorba 98.

Sanguisorbeae 97.

Sanicula 124.

Santalaceao 271.

Saponaria 40.

Sarothamnus 71.

Satureja 239.

Saxifraga 118.

Saxifrageae 117.

Scabiosa 147.

Scandix 134.

Scheuchzeria 297.

Schoenus 336.

Scilla 325 .

Scirpus 338.

Sclerantheao 113.

Scleranthus 114.

Sclerochloa 375.

Scorzonera 177.

Scrophularia 217.

Scrophularineae 214.

Scutellaria 246.

Decale 383.

Sedum 114.

Selinum 130.

Sempervivum 116.

Senebiera 29.

Senocio 161.'

Serratula 170.

Sesoli 129.
Setaria 360.

Sherardia 140.

Silaus 130.

Sileno 42.

Silenear 39.

Silybum 174.

Sinapis 24.

Sisymbrium 22.

Sium 127.

Solaneae 210.

Solanum 212.

Solidago 157.

Sonchus 180.

Sorbus 101.

Sparganium 303.

Specularia 191.

Spergula 48.

Spinacia 263.

Spiraer 88.

Spiranthes 316.

Stachys 244.

Stellaria 46.

Stellatao 139.

Stenactis 156.

Stipa 366.

Sturmia 316.

Succisa 148.

Symphytum 207.

Syringa 197.

Tamariscineae 110.

Tanacetum 167.

Taraxacum 178.

Teesdalia 29.

Tetragonolobus 73.

Teucrium 247,

Thalamiflorae 2.

Thalictrum 4.

Thesium 271.

Thlaspi 28.

Thrincia 176.

Thymeleae 269.

Thymus 239.

Tilia 55. 
Tiliacea 55.

Tofieldia 328.

Torilis 133.

Tragopogon 176.

Trapa 105.

Trifolium 75 .

Triglochin 297.

Trinia 125.

Triodia 370 .

Triticum 382.

Tulipa 322.

Turgenia 133.

Turritis 22.

Tussilago 154.

Typha 303.

Typhaceae 303.

Dimus 280.

Ulmaceae 280.

Umbelliferae 119.

Urtica 278.
Urticeas 278.

Utricularia 249.

Vaccinium 193.

Valeriana 145.

Valerianeao 144.

Valerianella 144.

Verbascum 215.

Verbena 249.

Verbenaceae 248.

Veronica 221.

Viburnum 138.

Vicia 79.

Vinca 199.

Viola 32.

Violarieae 31.

Viscum 272.

Vitis 60 .

Xanthium 187.

Zanichellia 300 .

Zea 358. 


\section{Druckfehler und Verbesserungen.}

Seite 2 Zeile 2 von oben lies und statt oder.

- 14 nach Fumariacea fehlt der Autor: Do Cand.

- 15 nach Cruciferao - _ - Juss.

- 25 Zeilo 17 von unten lies Mannheim statt Weinheim.

- 31 - 4 von oben lies $5 \mathrm{Klbl}$. statt 4.

- 39 nach Sileneae fehlt der Autor: De Oand.

- 44 nach Alsinea - - - De Cand.

- 55 Zeilo 9 ron unten ist nach "blaugrün" der Punkt zu streichen.

- 58 - 6 - oben ist nach "Seltener" das Komma zu streichen.

- $67-5$ - oben lies Blkr, statt Bl.

- 73 - 19 - oben fehlt vor ,länglich" d. Wort Blättchen.

- $91-10$ - oben lies $3-6^{\prime \prime}$ statt $3-6^{\prime}$.

- 106 - 15 - oben lies M. spicatum L. statt verticillatum.

- $112-10$ - unten lies Stbgef. 4-5 statt 4.

- $188-18$ - oben lies Sammelhaare statt Sammethaare.

- 271 - 12 - oben setze nach "Thesium" das fehlendo I.

- $303-19$ - unten lies Bl. statt St.

- $335-16$ - oben fehlt: Stbgef. 2-3. 




\section{In meinem Verlage sind ferner erschienen:}

Leonhard, K. C. V., Handbuch der Orglitognosie. Für akademisehe Vorlesungen und zum Selbststudium. Mit 7 Kupfertaf. 2. vermehrte und verbess. Aufl, gr. 8. 1826.6 Rthlr. oder 10 fi, 48 kr.

- - Agenda geognostica, Hülfsbuch für reisende Gebirgsforscher und Leitfaden zu Vorträgen über angewandte Geognosie. Mit eingedruckten Steindrucktafeln. 2. verb. u. verm. Auff. 8. geb. Weisses Druckpapier 2 Rthlr. oder $3 \mathrm{fl}$. $36 \mathrm{kr}$. Velinpapier 2 Rthlr. $20 \mathrm{Ngr}$. oder $4 \mathrm{fl}, 48 \mathrm{kr}$.

- - Beiträge zur Geologie der Gegend um Heidelberg. Mit zwei color. Steindrucktafeln. gr. 8. geh. 10 Ngr. oder $36 \mathrm{kr}$.

Leonhard, Gust., Handwörterbuch der topographischen Mineralogie. breit 8. cart. 2 Rthlr. 20 Ngr. oder 4 fl. $40 \mathrm{kr}$.

Erhard, G., der Tabak mit besonderer Rücksicht auf die für Kultur und IIandel wichtigen Arten, nebst deren Varietäten botanisch und landwirthschaftlich bearbeitet. gr. 8. geh. $7 \mathrm{Ngr}$. oder $27 \mathrm{kT}$.

ఛ. Riedheim, G. Th. Freih, naturhistorische Beschreibung des hessen-darmstädtischeu Odenwaldes, nebst seinen westlichen Yor. bergen. Mit einem Kärtchen, 8. geh. 15 Ngr. oder 54 kr.

Heidelberg, März 1857 .

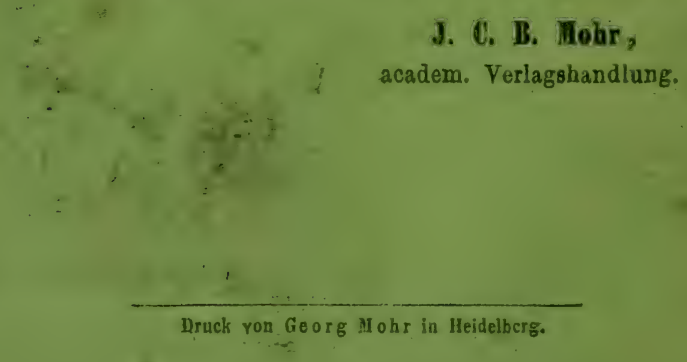








\section{QK314.S243}

QK314.S243 Ant/Flora von Heidelberg

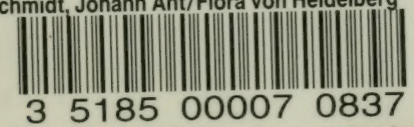




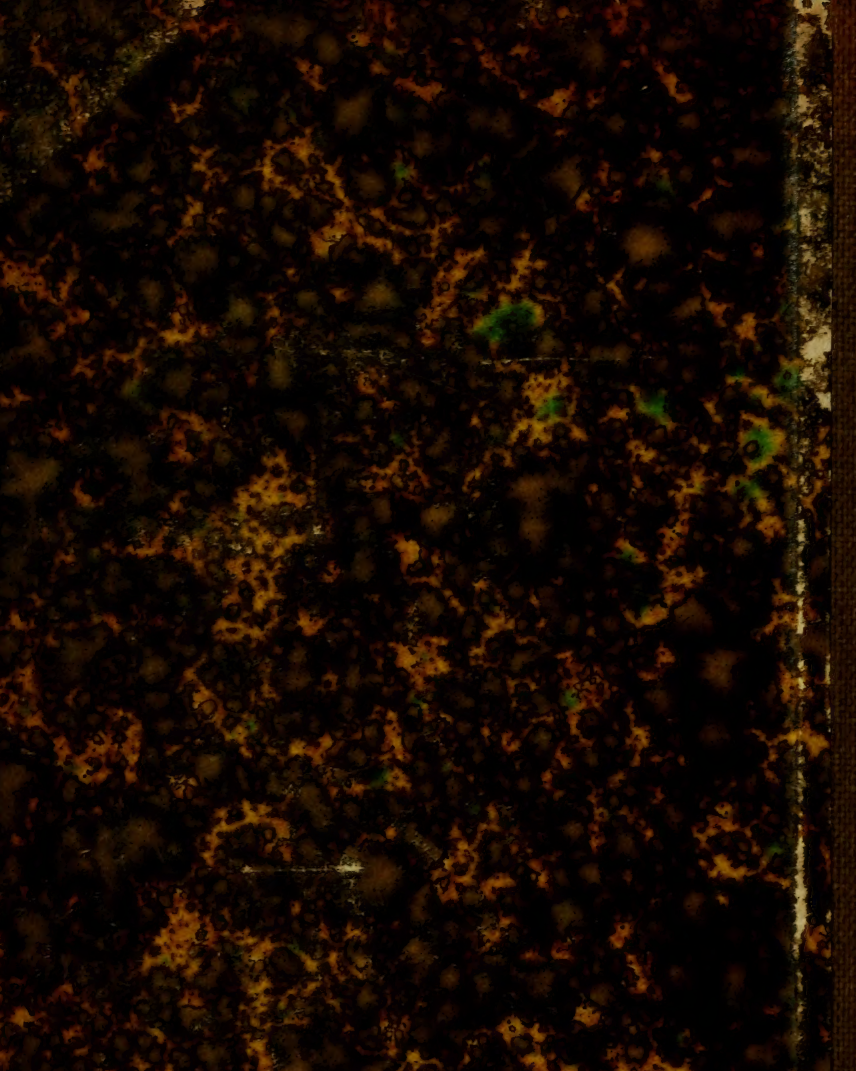

